\title{
FINAL DECISION
}

\section{MONTANA WILDERNESS INVENTORY}

\section{Miles City and Lewistown Bureau of Land Management Districts}

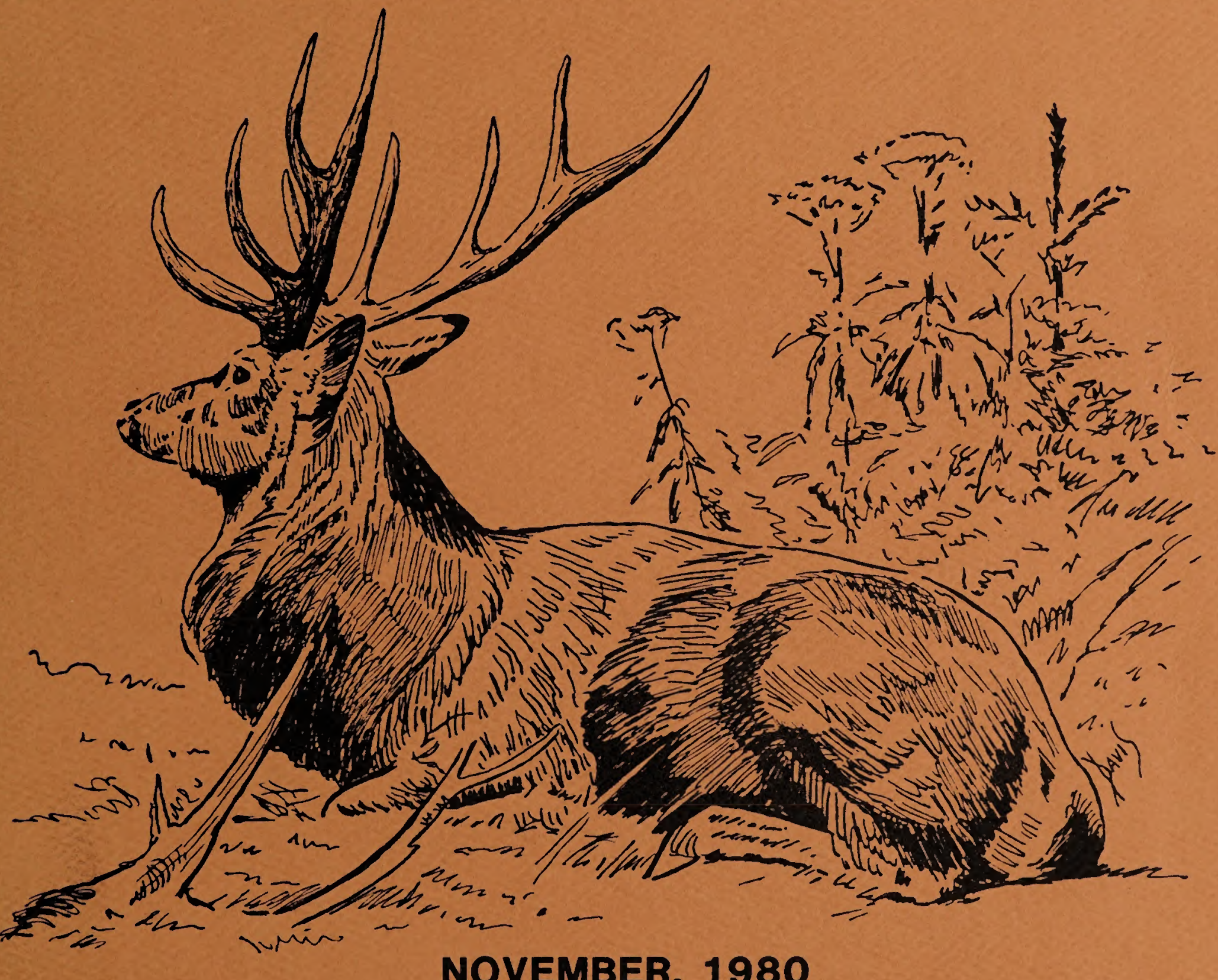

\section{NOVEMBER, 1980}

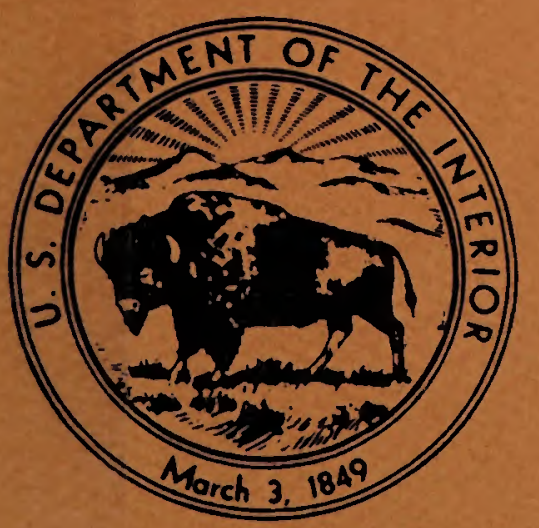

United States Department of the Interior

Bureau of Land Management

Montana State Office

222 North 32nd Street

P.0. Box 30157

Billings, Mt. 59107

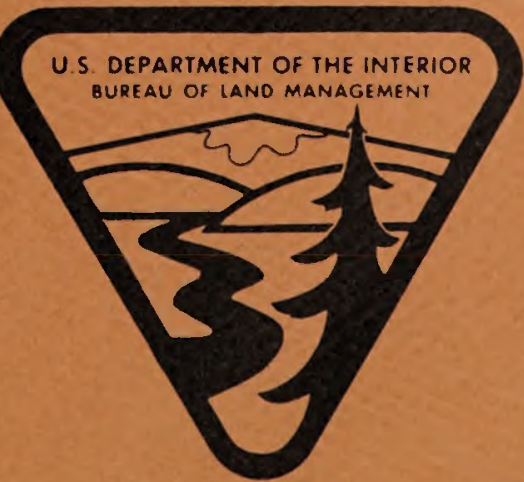


As the Nation's principal conservation agency, the Department of the Interior has responsibility for most of our nationally owned public lands and natural resources. This includes fostering the wisest use of our land and water resources, protecting our fish and wildlife, preserving the environmental and cultural values of our national parks and historical places, and providing for the enjoyment of life through outdoor recreation. The Department assesses our energy and mineral resources and works to assure that their development is in the best interests of all our people. The Department also has a major responsibility for American Indian reservation communities and for people who live in Island Territories under U.S. administration.

\author{
BLM Library \\ Denver Federal Center \\ Bldg. 50, OC-521 \\ P.O. Box 25047 \\ Denver, CO 80225
}




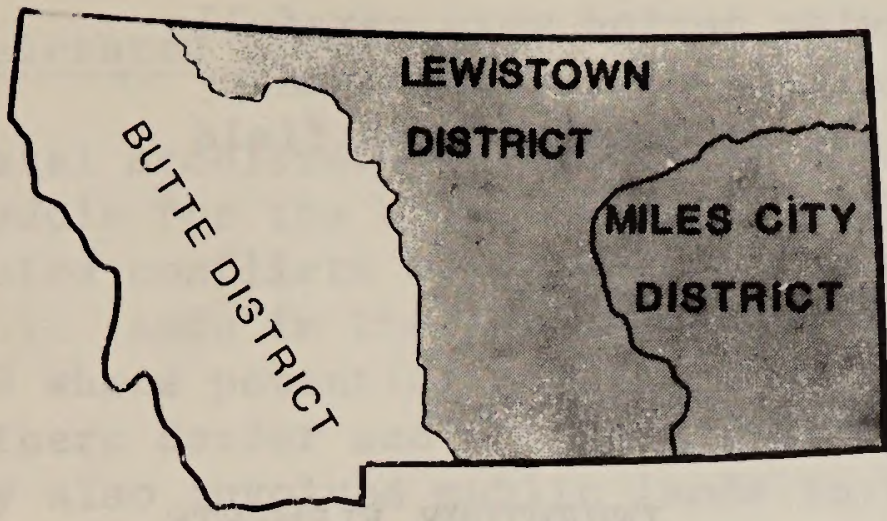

\section{Area Of Concern Discussed}

In This Document

\section{Introduction}

This document announces the final inventory decision for Bureau of Land Management lands under wilderness review in the Lewistown and Miles City, Montana BLM Districts.

A wilderness review of the BLM administered public lands was mandated with the passage of the Federal Land Policy and Management Act of 1976. Section 603 of that Act directed the BLM to inventory all public lands and public land islands under its jurisdiction for the presence of wilderness characteristics as specified in Section 2(c) of the 1964 Wilderness Act. These are areas of federal land which "(1) generally appears to have been affected primarily by the forces of nature, with the imprint of man's work substantially unnoticeable; (2) has outstanding opportunities for solitude or a primitive and unconfined type of recreation; (3) has at least five thousand acres of land or is of sufficient size as to make practicable its preservation and use in an unimpaired condition; and (4) may also contain ecological, geological, or other features of scientific, educational, scenic or historical value."

The inventory in Montana was begun in November 1978. The inventory phase was divided into two portions, the "initial" and "intensive" inventories.

The initial phase consisted of an examination of BLM road inventories and other office data. A proposed decision was publicly announced and upon completion of a 90 day public comment period, the final initial inventory decision resulted in approximately five million acres in the Lewistown and Miles City Districts being dropped from further wilderness consideration. The remaining 1.8 million acres of BLM administered land in these districts was carried into the "intensive inventory". These lands were field inventoried, resulting in a recommendation that 23 units totaling 392,306 acres in the Lewistown District and 12 units totaling 82,688 acres in the Miles City District become wilderness study areas. Another 903,639 acres (58 units) in the Lewistown District and 453,030 acres ( 45 units) in the Miles City District were proposed to drop from further wilderness consideration. This proposal was publicly announced in late March 1980 and was followed by a 150 day public comment period from March 30 to August 30, 1980. 
The comments received during the public review period were carefully examined and considered using a content analysis process. Manmade impacts that were reported and not previously documented were field checked before a final decision was reached.

\section{MONTANA BLM WILDERNESS INVENTORY}

\section{Miles City and Lewistown Districts}

\section{EFFECTIVE DATES}

INVENTORY ELEMENTS

November 1978
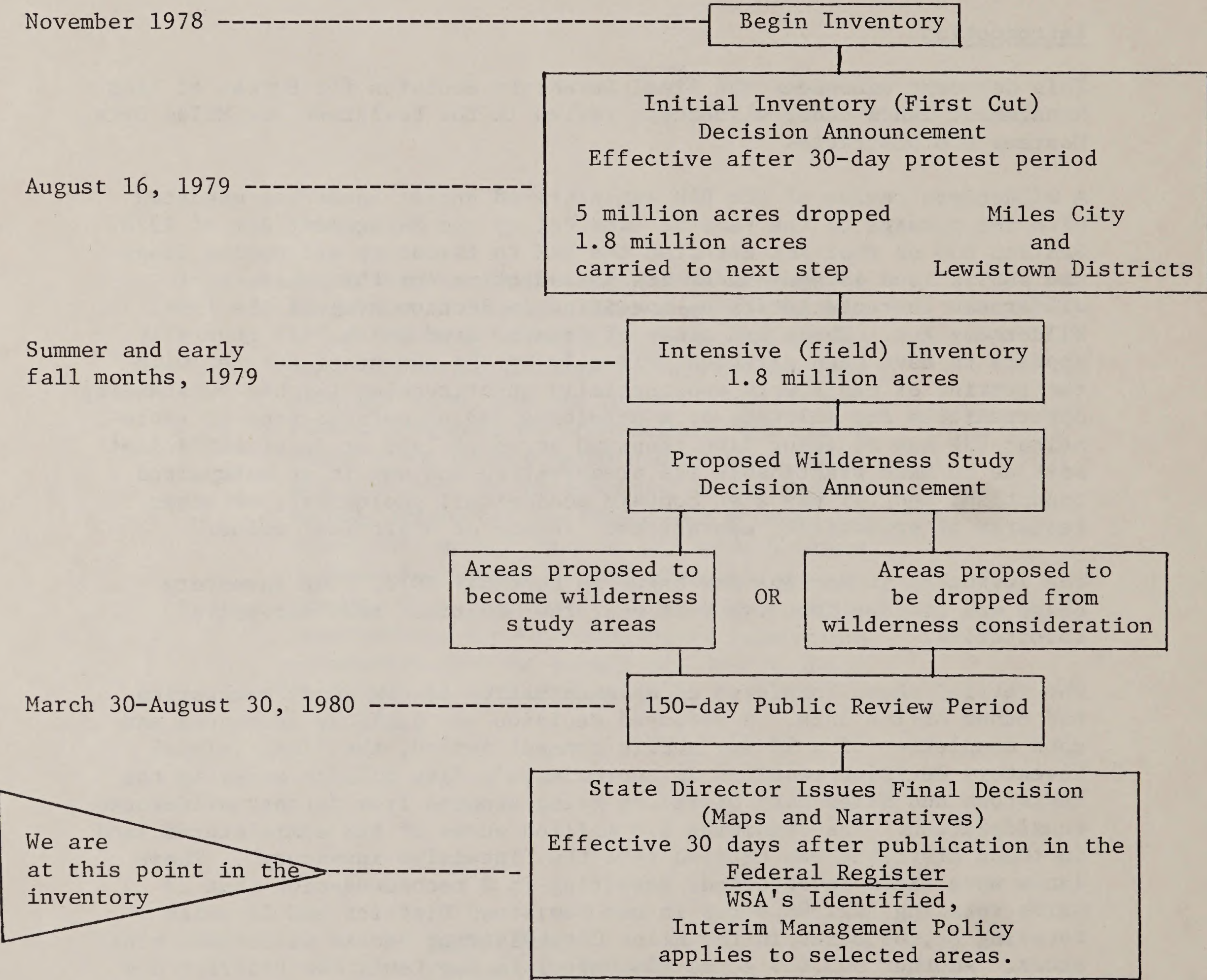
Accelerated Inventories

Several accelerated inventories were completed ahead of the general schedule for the Miles City and Lewistown Districts because of energyrelated conflicts or potential for conflict. Two inventories involving public lands in the Lewistown and Miles City Districts were conducted in 1979 where potential conflicts existed along the proposed routes of the Northern Border and Northern Tier Pipelines. The Northern Tier inventory also involved public lands in the Butte BLM District. These inventories resulted in the formal designation of three wilderness study areas (WSAs). The Wales Creek WSA - Unit MT-074-150 (11,580 acres) and the Terry Badlands WSA - Unit MT-024-684 (44,515 acres) were formally designated as a result of the Northern Tier inventory. The Wales Creek Unit is located in the Butte District near Missoula while the Terry Badlands Unit is located near Terry in the Miles City District. (See large $1 / 500,000$ scale map for locations.)

The Northern Border accelerated inventory resulted in the designation of one wilderness study area. The Bitter Creek Unit MT-064-356 (59,112 acres) is located near Glasgow, Montana.

The wilderness inventory for the Butte District was accelerated because of potential energy exploration and development conflicts. The Butte District lies within the Rocky Mountain Overthrust Belt - a "geologically disturbed" zone with potential for oil and gas discoveries. The final inventory decision was publicly announced in March 1980. The Overthrust Belt inventory resulted in 21 units consisting of 132,822 acres being designated wilderness study areas.

North Dakota - South Dakota Inventory

The Montana State BLM Office is also responsible for the management of BLM lands in North and South Dakota. All of the 68,102 acres of public land in North Dakota and all but 4,600 acres of the 276,297 acres managed by BLM in South Dakota were dropped from wilderness consideration during the initial inventory.

The remaining 4,600 acres in South Dakota (Miles City District) are being dropped by this decision.

\section{Instant Study Areas}

The public lands which were managed as outstanding natural areas or primitive areas prior to the passage of the Federal Land Policy and Management Act in October 1976 have been classified as "instant study areas." These lands are being inventoried and studied for their wilderness potential on a separate schedule. There are four such areas in Montana. They are the Humbug Spires, Bear Trap Canyon and Centennial Mountains Instant Study Areas in the Butte District and Square Butte Instant Study Area in the Lewistown District. 
This decision is based upon field investigations, public comments and guidelines provided in the Wilderness Inventory Handbook (dated September 27, 1978). Detailed instructions were also provided BLM wilderness inventory personnel in Organic Act Directive No. 78-61, with changes 1, 2 and 3 and Instruction Memorandum 80-236. All of the printed or typewritten materials referenced are available upon request from any Montana BLM office.

Numerous form letters were received which addressed the wilderness characteristics of inventory units. Identical form letters were treated as a single comment by a number of individuals. This is reflected in the public comment summaries.

\section{Summary of Final Intensive Inventory Decision}

\section{MILES CITY DISTRICT}

Big Dry Resource Area

Unit Name/No.

Yellowstone Island 610

Yellowstone Island 611

Yellowstone Is land 612

Cheyenne Island 613

Yellows tone Is 1 and 614

Yellowstone Island 615

Seven Sisters 616

Missouri River Island 617

East Bridge Coulee 632

Billy Creek 633

Cabin South 634

Timber Creek 635

Lone Tree-Ash 642

Sand Arroyo 643

Jack Creek 645

McGuire Creek 646

Germaine Coulee 648

S. Fork Little Squaw Creek 649

Jack Lane Coulee 650

Lodgepole Creek 652

North Squaw Creek 653

Squaw Creek 654

Seven Blackfoot 657

Maloney Hill 661

Crooked Creek 662

Woody Flat 665

Cairn Butte 671

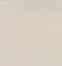

Acreage Designated For WSA Status
Acreage

Not Designated

For WSA Status

5
4
2
$132 *$
$31 *$
$147 *$
$83 *$
617
7,300
7,030
6,500
19,040
6,990
9,720
13,440
5,065
16,400
8,540
7,580
6,840
7,070
$123 *$
17,120
6,530
9,800
5,270
$19,677 * \quad$


Bridge Coulee 675

Newhouse Coulee 676

Musselshell Breaks 677

5,650

Lisk-Cherry 679

8,050

9,000

6,150

7,130

Brakett Creek 685

5,100

Stellar Creek 691

160

Subtotal:

$\overline{36,857}(4)$

$\overline{188,919}(31)$

$\underline{\text { Powder }}$ River Resource Area

Unit Name/No.

Zook Creek 701

Buffalo Creek 702

Buck Creek 703

Rough Creek 704

Dry Creek 709

Spring Creek 710

Lone Tree 711

Corral Creek 712

Muskrat 714

Deadhorse Badlands 715

Prairie Dog 716

Beaver Dam 717

Indian Creek 718

Ow1 Creek 719

Fence Creek 721

Cottonwood 723

Dixon-Deep 728

Willow Creek 729

Whitetail 730

Crow 732

Deadman Creek 733

Whitetail Creek 734

Tongue R. Breaks Contiguity 736

Subtotal:

TOTAL (A11 States):
Acreage Designated For WSA Status

$$
\begin{aligned}
& 8,440 * \\
& 5,650 *
\end{aligned}
$$

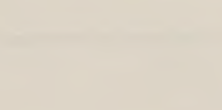$$
x^{2}
$$

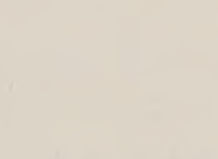

$1,484 \%$

$\overline{15,574 *(3)}$

$52,431 *(7)$

$494,841 *(54)$

* Change from Proposed Intensive Inventory Decision

() Units 
Billings Resource Area

Unit Name/No.

Acreage

Acreage

Designated For Not Designated

WSA Status For WSA Status

Deer Mountain 201

Bear Creek 204

Burnt Timber Cyn. 205

Bighorn Tack-On 207

Pryor Mountain 206

Yellowstone Is1. 210

Twin Coulee 212

Dry Creek 200

$\begin{array}{cc} & 6,970 \\ \text { MT } & 8,950 \\ \text { WY } & 550 \\ \text { MT } & 10,438 * \\ \text { WY } & 120\end{array}$

MT 4, 470\%

WY 80

MT $12,575 *$

$1,140 *$

WY 4,352

6,870

5,860

Subtota1:

$\overline{28,347}(3)$

$\overline{34,330}(5)$

Judith Resource Area

Unit Name/No.

Big Snowy Tack-Ons 211/217

Middle Fork Judith Tack-On 216

Cottonwood/W. Cottonwood 221/222

Blood Creek 223

Dovetail Creek 224

Arrow Creek 225

Arme 11 's Creek 227

Fargo Coulee 228

Carter Coulee 229

Two Calf Creek 231

Reed Coulee 232

Drag Creek 233

W. Crooked Creek 236

Horse Camp Trail 237

Chain Buttes 238

Fort Musselshe11 Tack-On "A" 240

Missouri River Is 1.243

Dog Creek South 244

Chimney Bend 245

Woodhawk 246

Woodhawk Creek 247
Acreage

Designated For

WSA Status

$8,500 *$

$5,230 *$

$13,730(2)$
Acreage

Not Designated

For WSA Status

1,725

145

12,650

20,100

24,380

9,100

$18,750 *$

5,000

5,760

$6,500 *$

$10,430 *$

16,500

10,700

11,200

7,200

1,200

917

$6,520 *$

$16,700 *$

$17,000 *$

5,820

Subtotal:

$\overline{208,297}(21)$ 
Havre Resource Area

Acreage Designated For WSA Status

Unit Name/No.

The Wall 249

Stafford 250

Cummings Bench 251

Black E1k Coulee 252

Ervin Ridge 253

Sand Creek 254

Bullwacker 255

Cow Creek 256

Timber Ridge 258

Wild Horse Lake 261

Woody Island Coulee 264

Subtota1:

$\begin{array}{cc}12,200 * \\ 4,700 * & 2,477 * \\ & 6,280 \\ & 9,700 \\ 12,000 * & 10,527 * \\ & 12,087 \\ & 40,851 \\ 36,200 * & 34,913 * \\ & 8,000 \\ & 11,453 \\ & 23,035\end{array}$

$\overline{52,900}(3)$
Acreage Not Designated For WSA Status

$\overline{171,523}(8)$

Phillips Resource Area

Antelope Creek 266

Cyprian Creek 268

Beauchamp Creek 274

Indian Lake 275

Box Elder Creek 277

Burnt Lodge/Sage Creek 278

Dry Fork Creek 280

Third Creek 282

Little Rockies 286

Flat Creek 290

Beaver Creek 297

Black Coulee 303

Lamere Coulee 304

Frenchman Creek W. 320

E. Beauchamp Tack-On 365

$$
9,400 *
$$

$12,100 *$

6,900

30,400

20,600

$15,500 *$

$15,000 *$

$51,460 *$

16,000

31,860

6,900

29,760

19,700

8,360

37,100

13,700

Beauchamp Tack-On 366

Subtotal: 


$\begin{array}{ccc} & \text { Acreage } & \text { Acreage } \\ & \text { Designated For } & \text { Not Designated } \\ \text { Unit Name/No. } & \text { WSA Status } & \text { For WSA Status }\end{array}$

Square Creek 323

Carpenter Creek 326

Wagon Coulee Tack-On 325

Duck Creek 328

Gumbo Plateau 329

Caravan 330

South Fork Willow Creek 331

Marsh Hawk Hills 336

Grant Coulee 337

Pearson Coulee 338

Hurricane 340

Coyote Creek 342

Moss Coulee 343

Sage Hen 346

Seventh Parallel 347

North Fork Brazil Creek 348

S. Fork Antelope Creek 350

Antelope Creek 352

Willow Creek 357

Crow Creek 358

Frenchman Creek-East 359

E. Fork Crow Creek 360

Little Flat 361

Subtota1

GRAND TOTAL

$$
\begin{gathered}
10,800 * \\
10,000 \\
560 \\
6,400 \\
18,200 \\
5,580 * \\
10,840 \\
78,340 * \\
66,980 \\
23,840 \\
6,680 \\
22,430 \\
20,160 \\
7,540 \\
6,660 \\
7,960 \\
6,160 \\
15,840 \\
39,040 \\
7,054 * \\
49,094 * \\
24,940 \\
13,940 \\
\hline 459,038(23)
\end{gathered}
$$

$119,377(10)$

$1,177,168(71)$

* Change from Proposed Intensive Inventory Decision

() Units

\section{What This Decision Means}

The inventory units designated wilderness study areas as a result of this decision will be retained for further study through BLM's land use planning system. All resource values present in specific units will be analyzed and any conflicts with wilderness designation will be addressed in suitability reports to be prepared for Congressional consideration. 
Suitability reports will be prepared for all areas designated as wilderness study areas. Reports which address the minerals potential will be prepared by the U.S. Geological Survey and Bureau of Mines for all areas found to be suitable for wilderness designation. Environmental statements will also be prepared by the BLM for all areas.

All wilderness study areas will be managed under the BLM Wilderness Interim Management Policy until such time as Congress acts upon specific Bureau proposals. Both suitable and unsuitable wilderness recommendations must be considered and acted upon by Congress before these lands either become designated wilderness or are dropped from consideration.

Wilderness study areas will be studied as quickly as Bureau scheduling and financial constraints permit. Public involvement will again be solicited during the study phase.

\title{
Individual's Right of Protest - Appeal
}

Any person who disagrees with this decision and has information which may influence the decision may file a protest with:

\author{
State Director (931) \\ Bureau of Land Management \\ P. 0. Box 30157 \\ 222 North 32nd Street \\ Billings, Montana 59107
}

Protests must be filed with the Montana State Director by 4:30 p.m., December 31 , 1980. No specific forms need be used in filing a protest; however, protests must be identified as follows:

"PROTEST TO MONTANA STATE DIRECTOR'S FINAL WILDERNESS INVENTORY DECISION"

Protests should address specific inventory unit(s) and must include a clear and concise statement of reasons for the protest, including any supporting documents available. Should any protests be filed on any inventory units, the State Director will consider such protests and issue a written decision. If a particular decision remains unchanged, the individual filing the protest has the right of appeal to the Interior Board of Land Appeals under the provisions of the Code of Federal Regulations 43, Part 4.

This decision will become effective at 4:30 p.m., December 31, 1980, (close of protest period) for all inventory units on which no protest was filed. A Federal Register and media notice, as well as a mailing to all individuals on the Montana BLM wilderness mailing list, will be made announcing this fact after the close of the protest period. 
The tables which follow are a compilation of previously announced decisions, interstate units and instant study area acreage status. They are provided in order to help you better understand the entire BLM wilderness review program. 


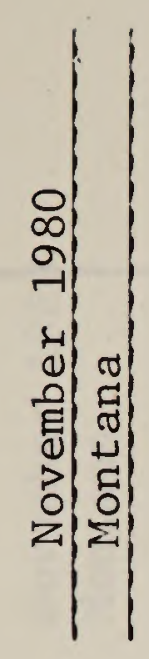

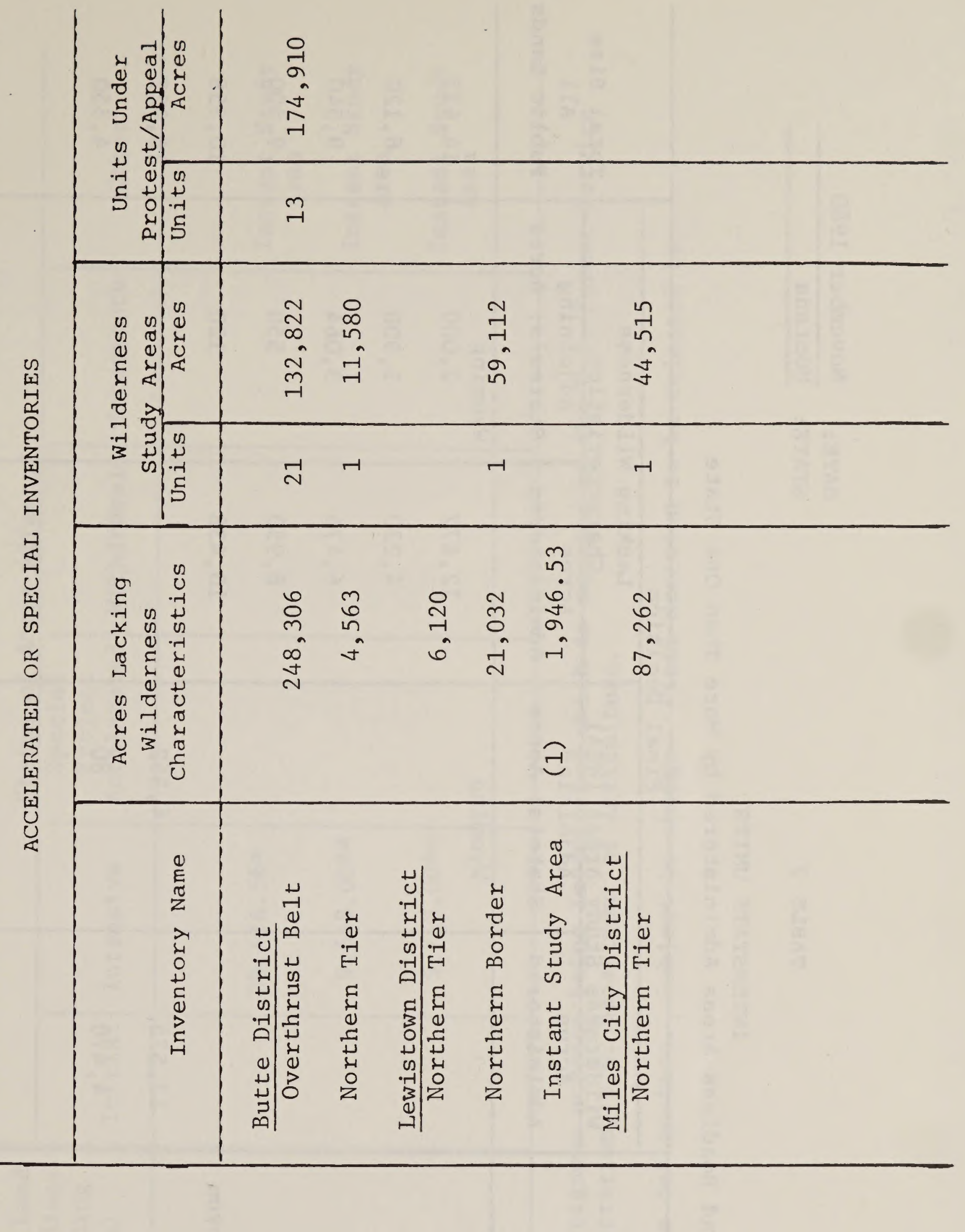

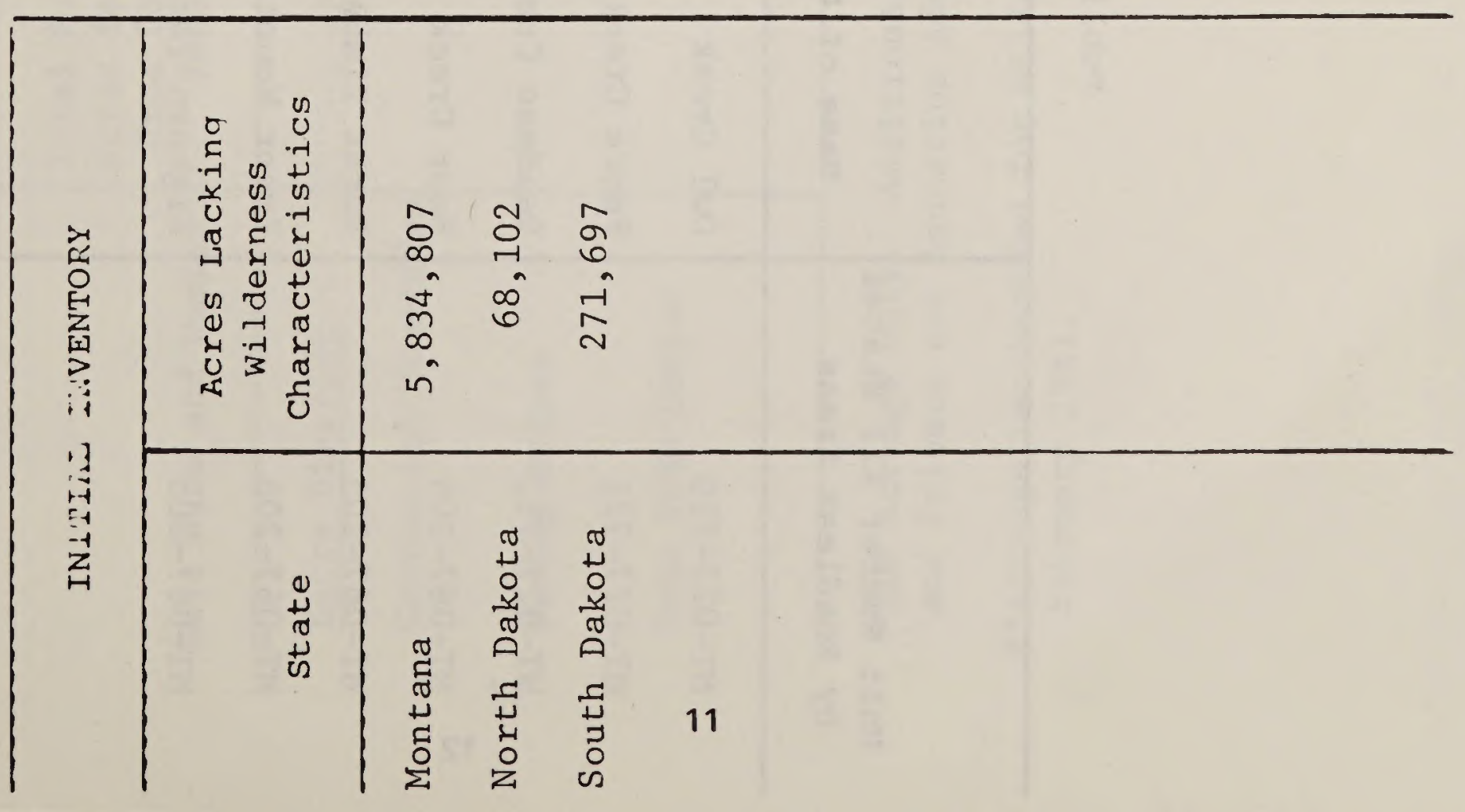




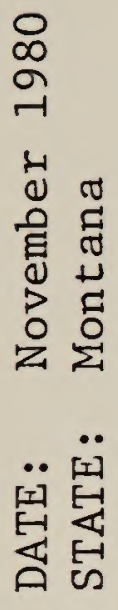

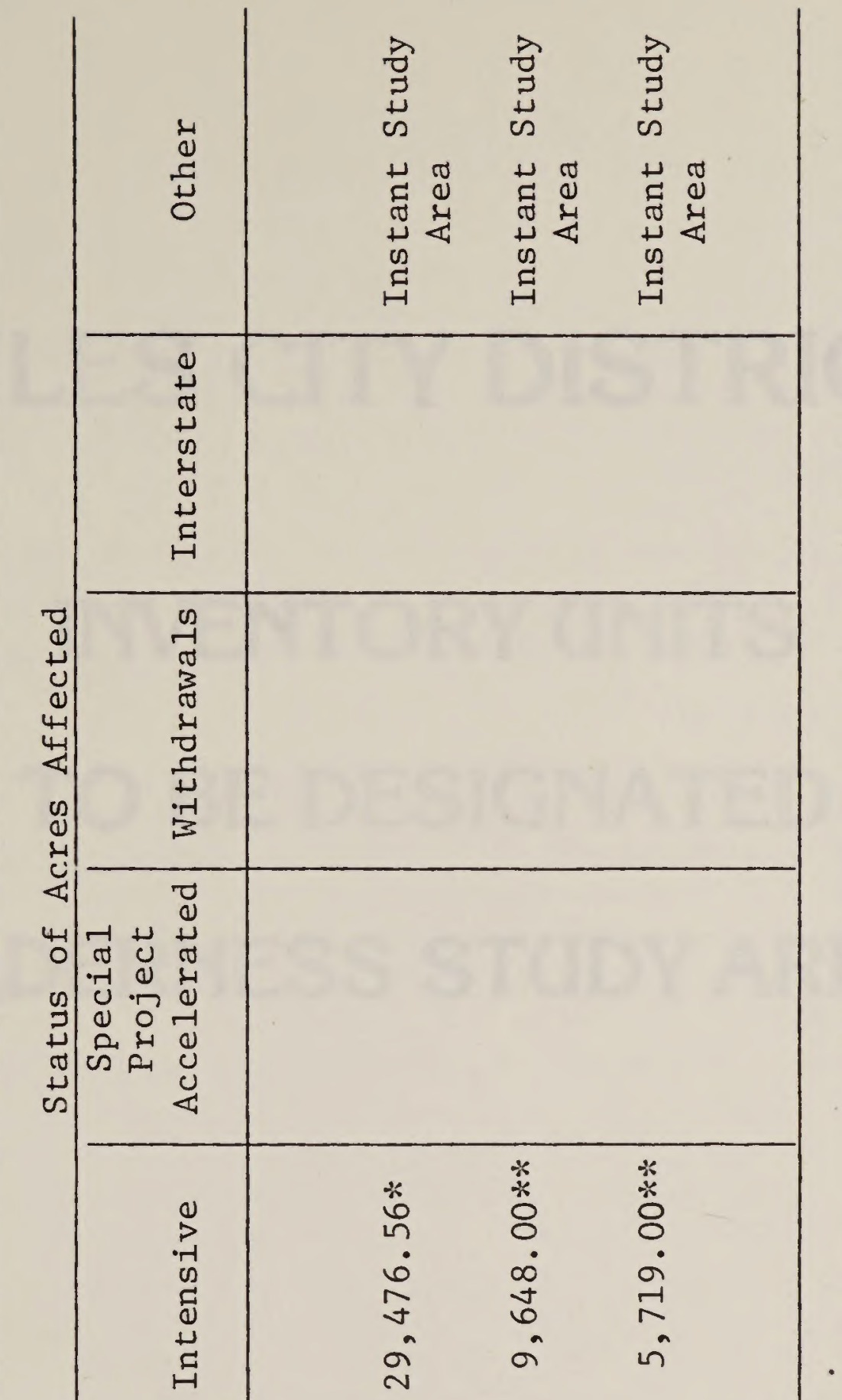

ن

$\begin{array}{ll}0 & 0 \\ 0 & 0 \\ 0 & 0 \\ 0 & 0 \\ \text { li } & 0 \\ 0 & 0 \\ 0 & 0 \\ 0 & 0\end{array}$

䒠

스우

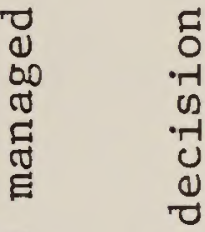

on

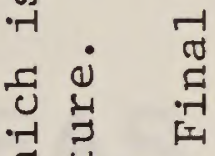

索

वृ 0 व

-

这

ت

व० 0

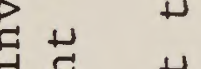

(1)

告热

वे

$\infty$

i ए

हैं

๑ ह

ว. 0 ०

盛

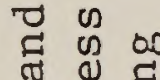

거

บ ్ํㄱ

-1 0 가국

व

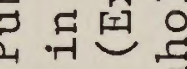

न

岁蓬

반

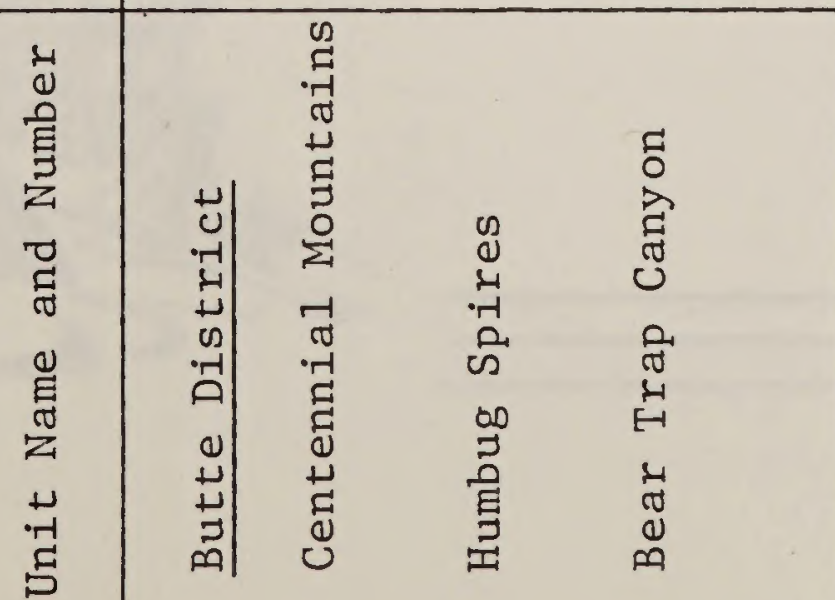

त क o

है.

要突 娄

䓃

- 5

放望

४

. 茎 导

ते च

०

0 00 U

बै

讪

$\sum 0$ 造

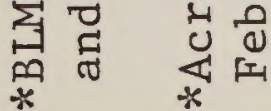





\title{
MILES CITY DISTRICT
}

\author{
INVENTORY UNITS
}

TO BE DESIGNATED

WILDERNESS STUDY AREAS

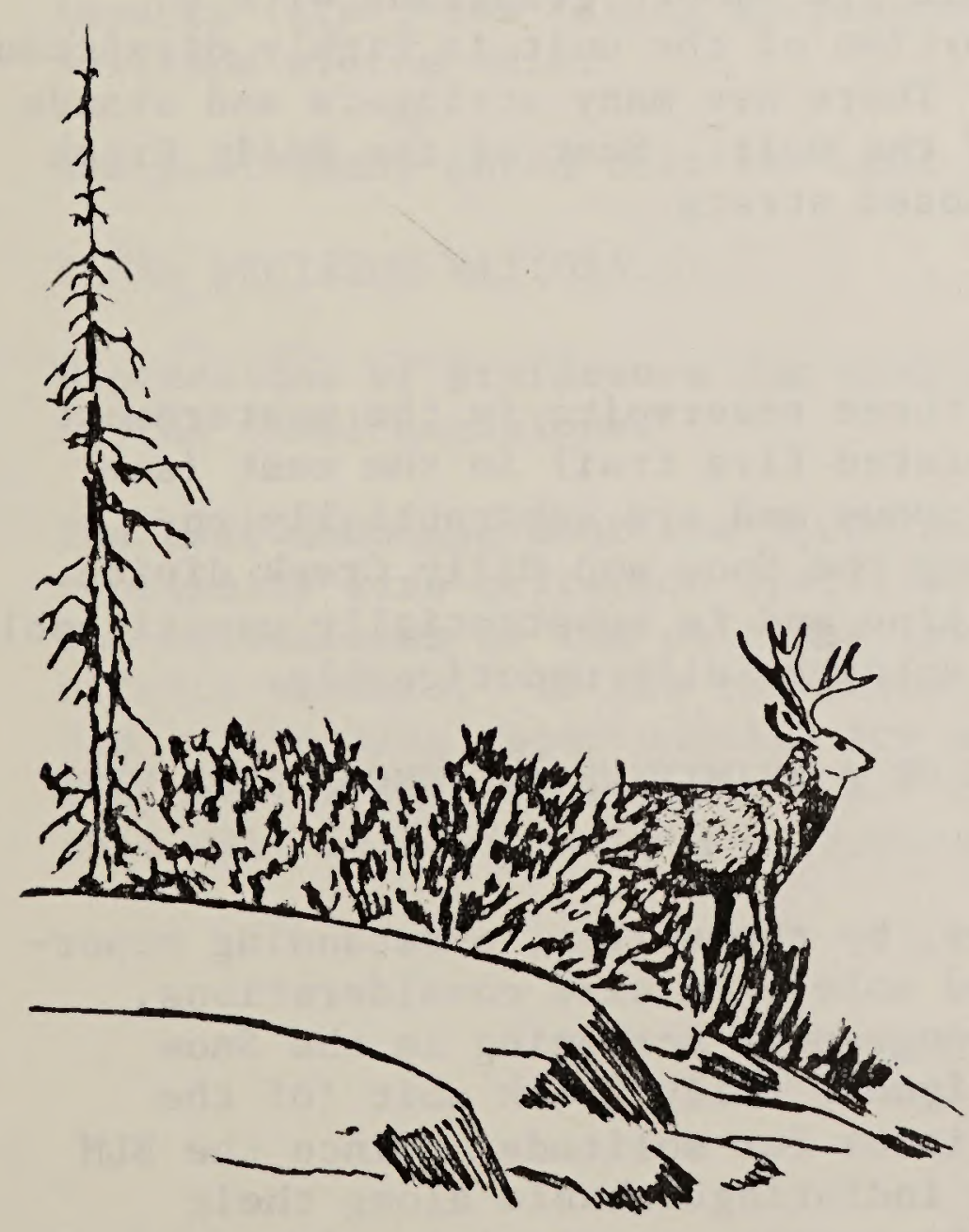




\section{NARRATIVE SUMMARY \\ WILDERNESS INTENSIVE INVENTORY}

UNIT NO: MT-024-633

NAME OF AREA: Billy Creek

\section{SUMMARY OF RECOMMENDATION}

Al1 4 roadless areas of the unit are recommended for WSA status, because they meet the size, naturalness, and outstanding opportunities for solitude and primitive recreation criteria.

\section{SIZE AND UNIT DESCRIPTION}

The acreage of the unit remains the same after intensive inventory as it was in the initial inventory $(3,480)$. The unit is contiguous to the U.S. Fish and Wildlife Service Billy Creek unit along 5 miles of common boundary. The Billy Creek unit has been recommended by the F\&WS for wilderness consideration. The BLM unit is fragmented into 4 roadless areas by roads (see map) of $1800,400,1200$, and 80 acres (from west to east). The unit is 14 miles north-northwest of Brusett.

The unit contains much of the headwaters of the Billy Creek drainage. Billy Creek flows north through the F\&WS Billy Creek Unit and into Fort Peck Reservoir. Approximately 400 acres in several portions on the south edge of the unit are in the Snow Creek drainage. The topography of the Snow Creek portions of the unit are smooth grassland with a southern aspect. The Billy Creek portion of the unit is highly dissected and drops off steeply to the north. There are many stringers and stands of pine covering about 30 percent of the unit. Most of the Billy Creek side of the unit is grassland or exposed strata.

\section{NATURALNESS}

Developments in the unit consist of three reservoirs in the westernmost roadless area and a partially revegetated fire trail in the east (see map). The reservoirs are not conspicuous and are substantially unnoticeable. The fire trail runs along the Snow and Billy Creek divide. It is screened by narrow fingers of pine and is substantially unnoticeable. These developments are cumulatively substantially unnoticeable.

\section{OUTSTANDING OPPORTUNITY FOR SOLITUDE OR A PRIMITIVE AND UNCONFINED TYPE} OF RECREATION

No one of the four roadless areas has, by themselves, outstanding opportunities for solitude. This is based solely on size considerations. There is very good vegetative and topographic screening in the Snow Creek portion of the unit. The contiguous Billy Creek unit (of the F\&WS) does have outstanding opportunities for solitude. Since the BLM and F\&WS units are physiographically indistinguishable along their common boundary, the BLM unit has outstanding opportunities for solitude in conjunction with the F\&WS unit. 
The roadless areas of the unit do not have outstanding opportunities for primitive recreation. This is due primarily to considerations of size. A visitor involved in hunting, hiking or horseback riding would probably use the BLM unit in conjunction with the F\&WS unit. Since the F\&WS unit has outstanding opportunities for primitive recreation and is physiographically indistinguishable from the BLM unit along their boundary, the BLM unit has outstanding opportunities for primitive recreation in conjunction with the F\&WS unit.

\section{SUPPLEMENTAL VALUES}

There are no known supplemental values in the unit.

\section{FINAL DECISION ANALYSIS}

\section{SUMMARY OF PUBLIC COMMENT:}

There were expressions of preference both for and against the unit becoming a WSA.

Several comments reaffirmed the existence of 4 roads in the unit, which fragment it into 4 roadless areas. Some individuals noted that the unit is very narrow and that the contiguous USF and WS lands should not be a factor in whether the unit is a WSA. A comment was made that the unit did not meet the 5,000 acre criterion. Another individual stated that the unit provided good mule deer habitat. Several comments noted offsite impacts (i.e., low flying airplanes, tractors, etc.) which affect the solitude of the unit.

One individual noted that the unit provided good grazing for cattle.

\section{FINAL DECISION RATIONALE:}

Expressions of preference for grazing or the other uses are not a factor in the final decisions.

The unit does not meet the 5,000 acre size criterion, but does meet the contiguity size criterion specified in the "Wilderness Inventory Handbook." The naturalness of the unit was reassessed considering both onsite and offsite impacts. It has the characteristics of naturalness. The unit has outstanding opportunities for solitude and primitive recreation in conjunction with contiguous U.S. Fish and Wildlife Service lands. The unit will be designated a wilderness study area. 

R. $34 E$
R. $35 \mathrm{E}$.

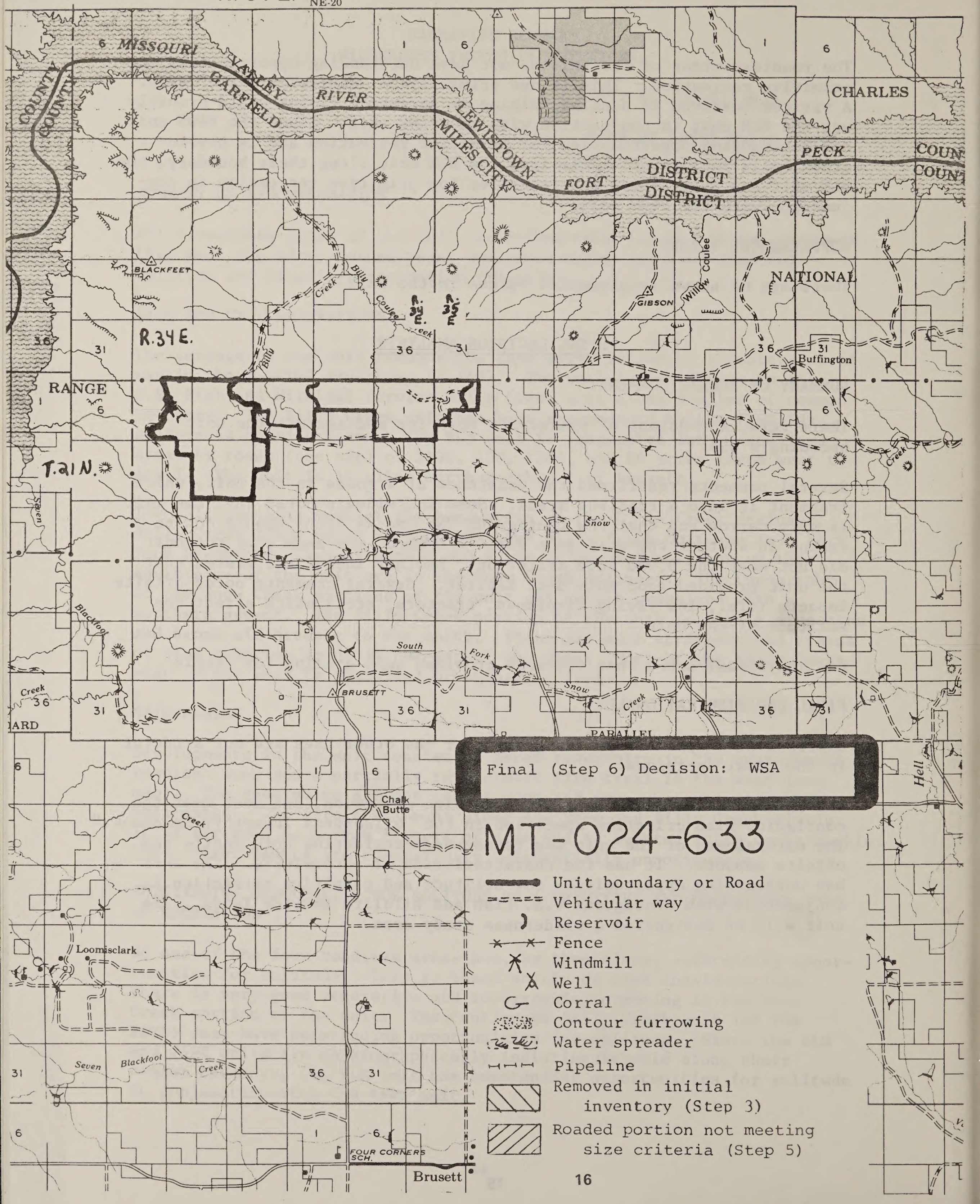




\section{NARRATIVE SUMMARY \\ WILDERNESS INTENSIVE INVENTORY \\ UNIT NO. : MT-027-657 \\ UNIT NAME: Seven Blackfoot}

\section{SUMMARY OF DECISION}

The unit is composed of three roadless areas. They are recommended for WSA status because they meet the size, naturalness, solitude and primitive recreation criteria.

\section{SIZE AND UNIT DESCRIPTION}

The acreage of the proposed intensive inventory unit was 19,800. Roads were identified during proposed and final intensive inventories which fragment the unit into 3 roadless areas. The northwest portion (labeled A) is 3,965 acres. The northeast portion (labeled B) is 4,843 acres. The southern portion (labeled C) is 10,992 acres. There is a 360 -acre parcel of private land which is connected to private land by these roads. There is also a Montana State section (640 acres) surrounded by public land of the unit. Two parcels of U.S. Fish and Wildlife Service (hereafter, USF\&WL) land contiguous to this unit have been recommended for Wilderness. West seven Blackfoot $(6,456$ acres) is contiguous to portion $A$ of this unit along 3.75 miles of USF\&WL and BLM boundary. East Seven Blackfoot $(11,744$ acres) is contiguous to portion $B$ of this unit along 5 miles of USF\&WL and BLM boundary. Portion $C$ of the unit meets the 5,000 acre size criterion. Portions $A$ and $B$ are contiguous to USF\&WL land formerly determined to have wilderness or potential wilderness values and so meet the size characteristic. This unit is 30 miles northwest of Jordan, Montana.

Almost the entire unit is in seven Blackfoot drainage. Seven Blackfoot Creek flows north through the unit onto USF\&WL lands and into Fort Peck Reservoir. North and South Sawmill and Big Coulee Creeks are major tributaries on the west of seven Blackfoot. Many other unnamed tributaries create heavily dissected terrain in the unit. Approximately 200 acres in five small portions lay east of the seven Blackfoot drainage. The boundaries of the unit do not correspond closely to the boundaries of the drainage. However, the unit boundary does generally correspond to a "rim" around the edge of the unit. The terrain around the boundary is generally smooth with little dissection. Within the unit, particuarly along the east boundary, the terrain drops rapidly to the creek bottom. Those tributaries in the west and north have rolling meadows interspersed with ponderosa pine. On the east and south, where the dissection is more severe, the meadows and pine stands are smaller. The pine generally exist in stands up to 60 acres in size, which are located on north slopes. There are also juniper and douglas fir in the stands. Approximately $40 \%$ of the unit has tree cover. 


\section{NATURALNESS}

Developments are scattered throughout the unit. Vehicle ways penetrate into the unit numerous places on the periphery. Generally, these terminate at reservoirs or spring developments (see map). Twelve reservoirs, some of which are silted in, are in the unit. There are approximately eight miles of fence in the unit, the major portion of which is along the west side of Seven Blackfoot Creek. Some posts and poles have been cut in the unit, particularly in the southeast. These signs of man are screened by topography or trees. No one of these developments is substantially noticeable nor are they cumulatively substantially noticeable. There are reports of old cabins on public land in the unit.

Offsite impacts include ranch-related developments and activity on the periphery of the unit. The impact of these is not significant because of their frequency and magnitude and furthermore, they are generally above the rim that contains the unit. There are some developments on the surrounding state or private lands and the USF\&WL lands to the north. Motorboats also use Fort Peck Reservoir several miles to the north. Their impact is not significant.

\section{OUTSTANDING OPPORTUNITY FOR SOLITUDE OR A PRIMITIVE AND UNCONFINED RECREATION ANALYSIS}

The unit is contiguous to USF\&WL lands which have outstanding opportunities for solitude and have been recommended to Congress for consideraation for designation as Wilderness. The USF\&WL and BLM lands are topographically and vegetatively indistinguishable along the common boundary. Therefore, portions of this unit have outstanding opportunities for solitude in conjunction with the USF\&WL lands to the north. They both have vast amounts of vegetative and topographic screening.

Portion $C$ of the unit itself has outstanding opportunities for solitude. This unit has vast amounts of topographic screening. This topographic screening is enhanced by considerable amounts of vegetative screening (in the form of trees). A dominant characteristic of the unit that enhances solitude is that most of the unit is below the "rim" which approximately coincides with the boundary. The configuration of Portion $C$ is somewhat gerrymandered by inholdings. The topographic and vegetative screening and the configuration and size are sufficient to provide outstanding opportunities for solitude in portion $C$. There are 3 peninsulas (labeled $D, E$ and $F$ ) on the east side of portion $B$ of the unit, which are in the Snow Creek drainage. They do not share the outstanding opportunities for solitude with the unit. Their acreages are 16,89 and 18, respectively, and total 123 acres.

Portion $A$ and $B$ of the unit, except for the aforementioned 123 acres, have outstanding opportunities for primitive and unconfined recreation in conjunction with contiguous USF\&WL land. The rationale is similar to that for solitude. Portion $C$ of the unit has outstanding opportunities for primitive recreation. This is due to the diversity of activities which include hiking, backpacking, horseback riding and hunting. 


\section{SUPPLEMENTAL VALUES}

The unit has one recorded archaeological site which has minor significance. The unit has scenic values. The existence of douglas fir in the unit is not unique, but is very unusual for this region. It may be of ecological or scientific value. There are no other known supplemental values.

\section{FINAL DECISION ANALYSIS}

SUMMARY OF PUBLIC COMMENTS:

Preferences were expressed both for and against WSA status.

The status of roads in the unit was commented upon. Developments noted in the proposed intensive inventory were thought to be substantially noticeable. Offsite impacts were felt by some to affect the opportunities for solitude. The lack of drinking water and weather conditions were thought to degrade the opportunities for primitive recreation.

Wilderness study related comments included the status of access to state, private and USF\&WL lands. There were comments that WSA status would preclude the use of the unit by the elderly and handicapped. Others commented that WSA or wilderness status would have detrimental effects on ranch operations. Concern was also expressed about existing oil and gas leases.

FINAL DECISION RATIONALE:

Comments were analyzed for specific comments related to on the ground impacts.

The status of roads in the unit was reexamined and changes made where appropriate. Both onsite and offsite impacts were reexamined. The entire unit was found to possess the characteristic of naturalness.

of this 19,800 acre unit, 19,667 have the characteristic of outstanding opportunities for solitude and primitive recreation. Portions $A$ and $B$ have these characteristics in conjunction with USF\&WL lands. Portion C exhibits the characteristic independent of the adjacent federal lands.

Three portions of the unit, totaling 19,667 acres, have the characteristic of size, naturalness and outstanding opportunities for solitude and primitive recreation. They will become WSAs. The remaining 123 acres do not have the outstanding opportunities for solitude or primitive recreation characteristic. This portion of the unit will be dropped from wilderness consideration. 


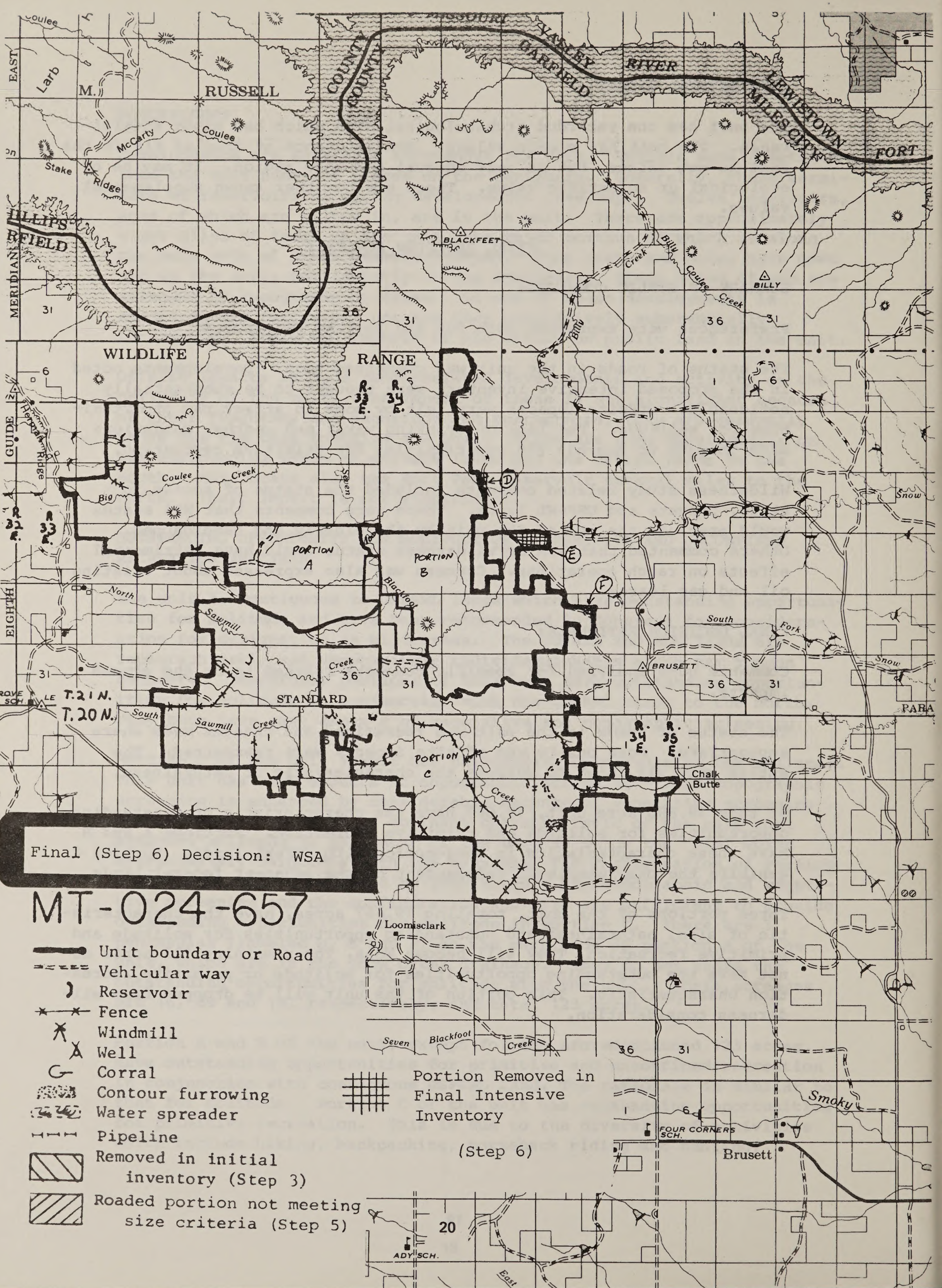




\section{NARRATIVE SUMMARY \\ WILDERNESS INTENSIVE INVENTORY}

UNIT NO.: $\underline{\text { MT }-024-675}$

UNIT NAME: Bridge Coulee

\section{SUMMARY OF RECOMMENDATION}

The unit is recommended for WSA status, because it meets size, naturalness and outstanding opportunities for solitude criteria.

\section{SIZE AND UNIT DESCRIPTION}

The unit is 5,650 acres in size. It is bounded by roads on the south, most of the north, and parts of the east and west. The remaining boundaries are formed by private or state lands. The unit is approximately 15 miles north of Mosby, Montana.

The drainage pattern is to the west into the Musselshell River, which is out of the unit. The general character of this unit is one of open, grassy benches separated by deep canyons and gullies. The entire unit, with the exception of portions of the southeastern part of the unit, consists of deeply dissected terrain. The many canyons, found throughout the unit, are several hundred feet deep with very steep walls which rise nearly straight from the floor of the canyon. Uniquely shaped sandstone formations are common in both the sides of the canyons and atop the ridges and buttes. Moderately dense stands of junipers and ponderosa pines grow on the steep hillsides, along the ridgetops and in the bottoms of the canyons and coulees. Cottonwoods are found in the bottoms of the more shallow coulees. Approximately thirty percent of the entire unit is covered by individual or small stands of trees. The southeastern portion of the unit is generally composed of gently rolling grasslands with a few gumbo domes topped with sandstone outcroppings. Extensive stands of ponderosa pines are commonly found in the low lying areas of this portion of the unit. The ridges and benches which separate the deep canyons consist for the most part of open rolling terrain. Although ponderosa pines and junipers are found in the grassy benches, they are more common along the ridgetops which separate the canyons.

\section{NATURALNESS}

The manmade developments within the unit consist of two vehicle ways and reservoirs along the eastern boundary. A vehicle way is located on the ridgetop which separates the two tributaries of Bridge Coulee. Due to the nature of the way and the fact that it is well screened by stands of trees, the impact of this vehicle way upon the naturalness of the unit is very low. The other vehicle way is in the northeast corner of the unit and is approximately .25 miles long. It is very faint and goes to 
two reservoirs. The impact of the four reservoirs (see map) is also low because they are well screened by the surrounding topography and tree cover. They are virtually unnoticeable from most points within the unit. The individual and cumulative impacts of these developments are substantially unnoticeable.

\section{OUTSTANDING OPPORTUNITY FOR SOLITUDE OR A PRIMITIVE AND UNCONFINED TYPE} OF RECREATION

The extremely dissected nature of this unit and the high degree of tree cover contribute to outstanding opportunities for solitude. Due to the extremely rugged topography found throughout the unit, the opportunities for solitude are very high. Several different groups could be in the unit at one time and not be aware of each other because of the maze of canyons and the high degree of vegetative screening afforded by the many stands of ponderosa and juniper trees. The boundaries of the unit on the north, south and much of the east correspond to ridges in the unit. So, although this is a small unit, the combination of size, vegetative and topographic screening, and configuration provide outstanding opportunities for solitude.

The many deep canyons, unique sandstone formations, and large stands of trees contribute to the opportunities for primitive recreation in this unit. The canyons and buttes provide opportunities for hiking, rock collecting, and nature photography. The deep canyons and steep hillsides create scenic vistas when viewed from the ridges. Due to the dissected topography throughout most of the unit, horseback riding would be best suited in the more open areas of the southeastern portion of the unit. Vegetation type and animal sign indicate that deer and grouse are present within the unit, thus providing opportunities for hunting. No single one of these opportunities nor the diversity of them is outstanding.

\section{SUPPLEMENTAL VALUES}

This unit does not contain known supplemental values.

\section{FINAL DECISION ANALYSIS}

\section{SUMMARY OF PUBLIC COMMENTS}

There were expressions of preference both for and against the unit becoming a WSA.

One individual stated that there are additional impacts in the unit associated with post and pole cutting in 1959 and a fire in 1973. It was noted that offsite impacts in the form of farming and ranching activities occur west of the unit. Roads which are in near proximity or form the boundary of the unit were noted and that sights and sounds from these affect the solitude and the naturalness of the unit. It was felt 
that the removal of vegetative screening by the 1973 fire reduced the opportunities for solitude in the unit. The narrow portion of the unit in Section 15, Township 17 North, Range 30 East, was noted. The vegetative and topographic screening was thought to be less than stated in the narrative summary.

A wilderness study phase consideration noted was the potential for cedar posts and logging.

\section{FINAL DECISION RATIONALE}

The boundaries of the unit were reexamined and not changed. Both onsite and offsite impacts were reexamined. They are substantially unnoticeable, or not significant, respectively. The unit has the characteristic of naturalness. The narrow portion of the unit is within a drainage which is a natural part of the area. As such, no boundary change is warranted. While the 1973 fire did burn through approximately 20 percent of the unit, the vegetative and topographic screening are still sufficient for a unit of this size to provide outstanding opportunities for solitude.

The unit has the characteristics of size, naturalness and outstanding opportunities for solitude. It will be studied further for wilderness. 
R. $29 \mathrm{E}$

UTM ZONI T 18 N ZONE 13

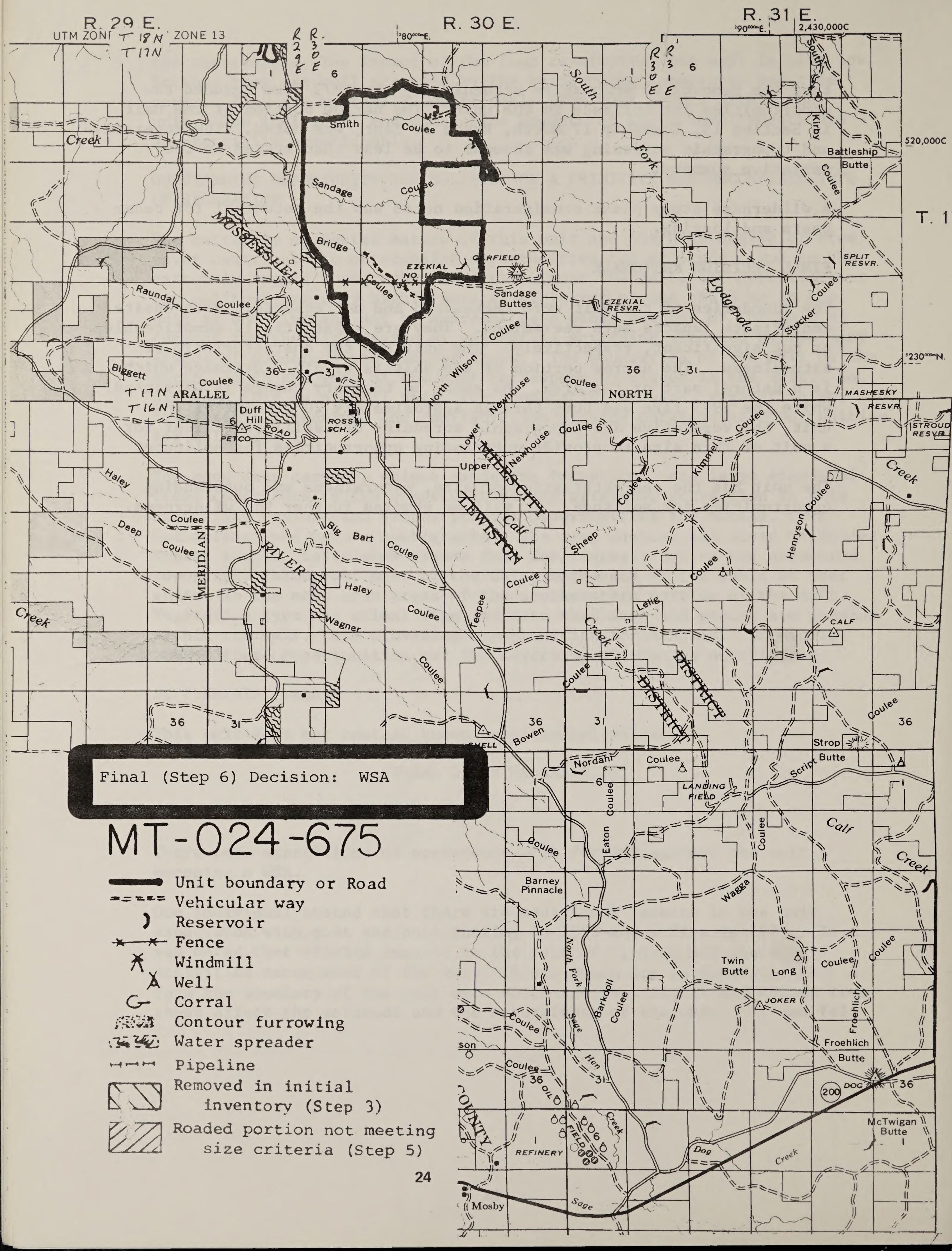




\section{NARRATIVE SUMMARY \\ WILDERNESS INTENSIVE INVENTORY}

UNIT NO.: MT-024-677

UNIT NAME: Musselshell Breaks

\section{SUMMARY OF RECOMMENDATION}

The unit is recommended for WSA status, because it meets the size, naturalness and outstanding opportunity for solitude criteria.

\section{SIZE AND UNIT DESCRIPTION}

Unit 677 as it exists now is 8,050 acres in size. In the final initial inventory, 150 acres on the west side of the Musselshell were removed. The unit is bordered on the west by private land, and north, south and east by roads except for small portions of private land. The unit is 8 miles north of Mosby, MT.

This unit is diverse topography. Three intermittent coulees (Haley, Wagner, and Williams) drain west out of the unit. These, and unnamed other tributaries of the Musselshell, form heavily dissected topography. This dissection is dominant in the north of the unit and moderates toward the south. The knifelike ridges in the north have scattered trees on their north slopes with the remainder of the vegetation being grasses and pricklypear cactus. Towards the south, the ridges are broader with lusher grass and small stands of ponderosa pine. There is an elevation gradient apparent for the ponderosa pine. They are denser in the coulee headwaters (at the higher elevations) toward the east and particularly the southeast of the unit.

\section{NATURALNESS}

Developments in the unit are exclusively range-oriented (see map). There is a fence along much of the ridge south of Haley Coulee. There are several vehicle ways, most of which are faint. These developments are individually and cumulatively substantially unnoticeable. The vehicular way in Sections 33, 34 and 35, T. 16 N., R. 30 E., M.P.M., is substantially unnoticeable from most points within the unit. However, for the westernmost 0.2 miles in Section 34 and the remainder in Section 33 along and in the vicinity of the vehicle way, there is recent and extensive surface disturbance. This blading is conspicuous from everywhere in the unnamed coulee and on some points along ridgetops in the vicinity. Altogether it is conspicuous from about 600 acres with the unit. From the remainder of the unit, it is unnoticeable. This work of man is substantially unnoticeable when viewed from the context of the whole unit. 
There are outstanding opportunities for solitude within this unit. Theabundance of trees, particularly in the central and southern portions provide excellent vegetative screening. Topographic screening is provided by the numerous coulees and ridges, particularly in the northern portion of the unit. Furthermore, the variations in topographic and vegetative screening generally compliment each other. Where the topography is less dissected, there are more trees. There are two narrow "necks" of land associated with this unit which will be study phase considerations. One of these (in Section 1, T. 15 N., R. 30 E.) is approximately 180 acres and is connected to the remainder of the unit by a .3 mile strip. This portion of the unit has some trees in the southwest corner. The other is the 560 acres within Section 12, T. 15 N., R. 30 E., and Sections 7 and 18, T. 15 N., R. 31 E., M.P.M. It contains the mainstem of William's Coulee and is partially screened by small stands of ponderosa pine in the bottom. Neither of these portions of the unit exhibit outstanding opportunities for solitude in the unit. Screening, size, and the configuration of the unit in combination provide outstanding opportunities for solitude in this unit.

This unit does not have outstanding recreational opportunities. Hiking is possible on ridgetops and in drainages with pleasant, but not outstanding scenery throughout. Horseback riding would be difficult in the coulees, but feasible on the ridges. Opportunities for hunting deer are not excellent.

\section{SUPPLEMENTAL VALUES}

The unit does not have any known supplemental values. 


\section{FINAL DECISION ANALYSIS}

SUMMARY OF PUBLIC COMMENTS

There were preferences expressed both for and against WSA status.

Several comments suggested that the way through the center of the unit was a road due to recent blading. The existence of a second road was noted. The commenter noted that some post and poles had been cut.

FINAL DECISION RATIONALE

Expressions simply for or against wilderness study designation were not a factor in this final decision. The vehicle way through the center of the unit does not meet the road definition, because the only blading occured (in 1979) after the passage of the Federal Land Policy and Management Act. It will revert to a substantially unnoticeable level through natural revegetation. The other road noted forms the south boundary. The unit has the characteristics of size, naturalness, and outstanding opportunities for solitude. The unit will be further studied for possible wilderness designation. 


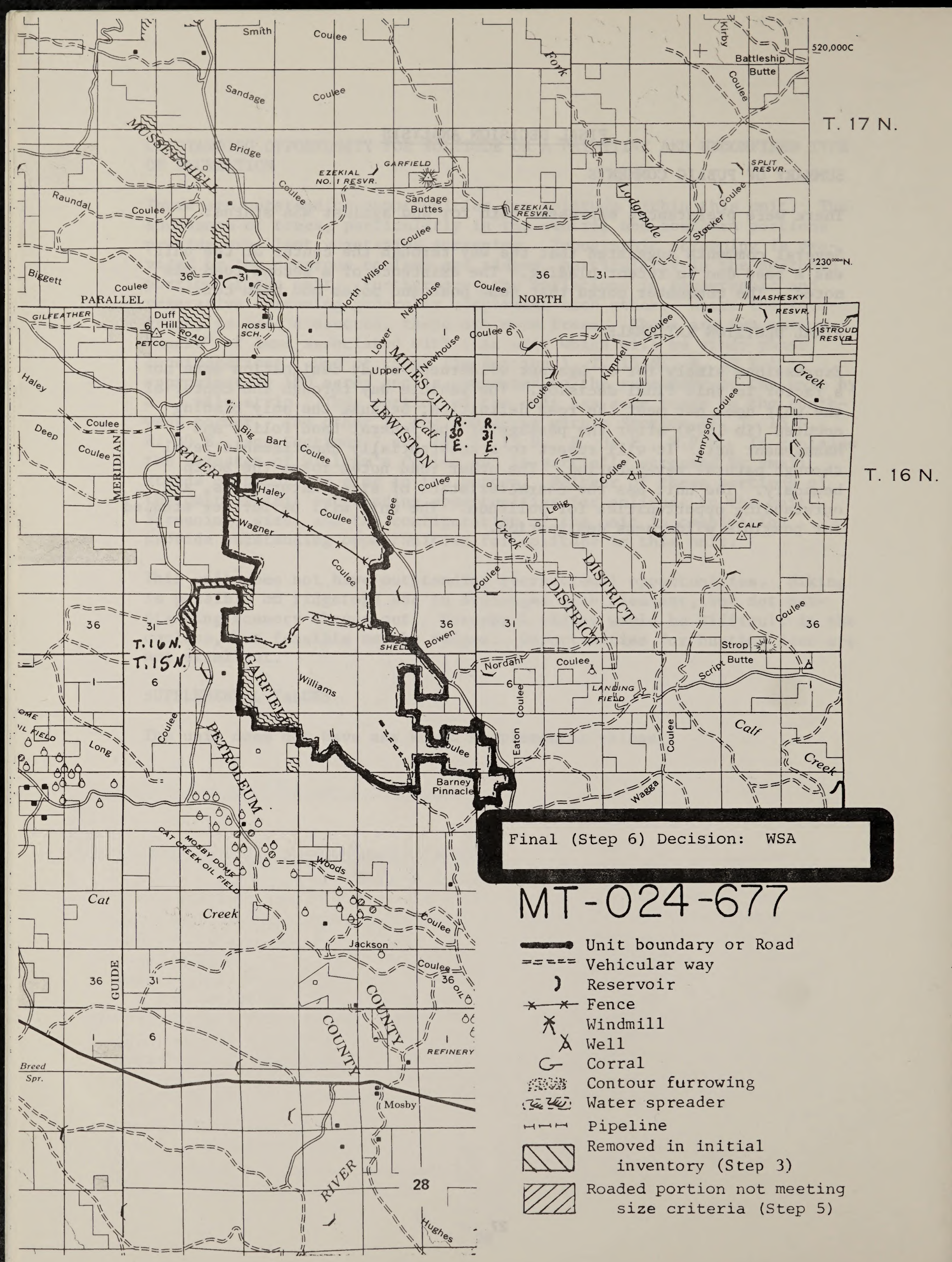


UNIT NO.: $\quad$ MT-027-701

UNIT NAME: Zook Creek

\section{SUMMARY OF DECISION}

Eighty-four hundred forty acres of the unit are recommended for WSA status because they meet the size, naturalness, solitude and primitive recreation criteria. Another 1,280 acres that were in the proposed intensive inventory are dropped in this (final) decision.

\section{SIZE AND UNIT DESCRIPTION}

The Zook Creek Unit is located 26 miles southwest of Ashland, Montana. The acreage of the proposed WSA was 9,720. However, it has been determined that what was previously described as a way along Whitten Creek meets the road definition. This fragments the unit into 998 and 8,732 acre roadless units. The smaller portion meets none of the size criterion. (Also, a boundary modification was made under the solitude characteristic. See the map and the solitude section of this narrative summary.)

The Zook Creek Unit consists of rugged breaks with elevations ranging from 3,200 feet in the east to 4,100 feet in the west. The higher western portion of the unit is covered with dense stands of ponderosa pine. The eastern part of the unit is covered with sagebrush and grasses, with juniper and ponderosa pine trees scattered throughout. The northern slopes of the majority of breaks in the unit are also covered with stands of ponderosa pine. Deciduous trees, including cottonwoods, line the creeks draining eastward out of the unit. Trees cover about $40 \%$ of the unit.

Zook and Whitten Creeks drain the southern half of the unit. This area is characterized by high bluffs of red and white sandstone. The ridges between these creeks are extremely rugged and are composed of loose, rocky soil cut by frequent side drainages.

\section{NATURALNESS}

The vast majority of the zook Creek Unit appears natural. There are several minor developments, but even these have their impacts lessened by the vegetative and topographic screening. A majority of these developments are along the edges of the unit. There are three miles of vehicle ways in the unit. A faint vehicle way enters the unit in T.6S., R.42E., section 2 and ends at a windmill. A vehicle way in sections 4 and 5 of T.6S., R.42E. is very hard to find and no longer appears to be used. Another vehicle way in T.5S., R.42E., section 28 goes to a windmill in section 29. 
A new reservoir was constructed during 1979 at the site of an older reservoir in T.5S., R.42E., section 30. The old reservoir is silted in and the area is heavily vegetated. The replacement reservoir impacts the immediate area of this rough drainage, but the site should substantially recover in one or two years. A vehicle way extends for one mile into the unit to this reservoir site. This was improved for construction of the original reservoir. The vehicle way looks heavily used now because of heavy machinery passing through. This impact should al so be considerably lessened in one or two years.

There are six other small reservoirs and four developed springs in the unit along with 8.5 miles of fence. The impacts of these improvements are insignificant, especially with the vegetative and topographic cover.

Offsite impacts include the east and west side Tongue River roads and traffic thereon. Also, ranch facilities exist and activities occur adjacent to the unit. Some of these impacts can be seen from some ridges in the unit while looking east or north. However, their magnitude is not significant.

\section{OUTSTANDING OPPORTUNITY FOR SOLITUDE OR A PRIMITIVE AND UNCONFINED TYPE OF RECREATION}

The Zook Creek Unit contains outstanding opportunities for solitude. The extremely rugged terrain of these breaks provides significant topographic screening. The stands of ponderosa pine trees provide vegetative cover in much of the unit. Several creeks with 400 to 500-foot divides would separate visitors from each other without tending to funnel them into the same part of the unit. A 269-acre portion of the unit just east of the Whitten creek road forms a peninsula. This portion is separated from the remaining 8,440 acres of the unit by a ridge between two tributaries of Whitten Creek. This finger of roadless land extends outside the bulk of the unit and does not share the outstanding opportunities for solitude exhibited by the remainder of the unit.

This unit contains outstanding opportunities for primitive recreation due to outstanding hiking and backpacking potential and because of a variety of other potential activities. The rough terrain, scenery and trees for shelter all contribute to opportunities for backpacking and related activities such as sightseeing and photography. Snowshoeing and cross country skiing could be enjoyed in the zook Creek Unit. Hunting, especially for deer, is an activity presently occurring on this roadless area. The rationale for the boundary change discussed under solitude also applies under the primitive recreation characteristics.

\section{SUPPLEMENTAL VALUES}

The vistas afforded in this area provide scenic values. From the tops of ridges, one can see the Tongue River valley and rugged breaks along it. To the south, the Bighorn Mountains of Wyoming stand out on the horizon. No other supplemental values were noted and there are no recorded archaeological sites for this unit. 


\section{FINAL DECISION ANALYSIS}

SUMMARY OF PUBLIC COMMENTS:

Preferences for and against WSA status were received as comments.

Most of the ways in the unit were considered by some of the commenters to be roads. Some additional developments were mentioned. Numerous commenters felt that offsite impacts affected solitude. One comment noted that the solitude provided by the unit had value for sacred traditional rites and that the unit contained sites of cultural and scientific value. Commenters noted that there was no water for recreational use, that the unit was not well suited for snowmobiling, snowshoeing or cross country skiing and that there was good hunting and primitive recreation opportunities in the unit. Another comment noted that clinker was common in the region.

Study phase considerations included coal and timber values of the unit and the effect of WSA status on agricultural activities. Also noted were effects of WSA status on coal values outside the unit. It was noted that the access to the area might change with WSA or wilderness status. One individual felt that wilderness would restrict the use by older people and would benefit fewer people than present management.

\section{FINAL DECISION RATIONALE:}

The road status of the unit was reassessed and it was determined that the Whitten creek route met the road definition. The boundary was modified to reflect this decision. Naturalness was reassessed based on all impacts within the unit and offsite impacts. The unit has the characteristic of naturalness. Many people felt offsite impacts affected solitude. These were considered under naturalness, as specified in the "Wilderness Inventory Handbook". Cultural values associated with the unit are a supplemental characteristic. Both opportunities for solitude and primitive recreation were reassessed and, except for 269 acres, were felt to be outstanding.

of the 9,720-acre intensive inventory unit, 8,440 acres meet the size, naturalness, outstanding opportunities for solitude and primitive recreation criteria. This portion of the unit will become a WSA. The remaining 1,280 acres do not meet the size or outstanding opportunities for solitude or primitive recreation criteria. The 1,280 acres will be dropped from further wilderness consideration. 


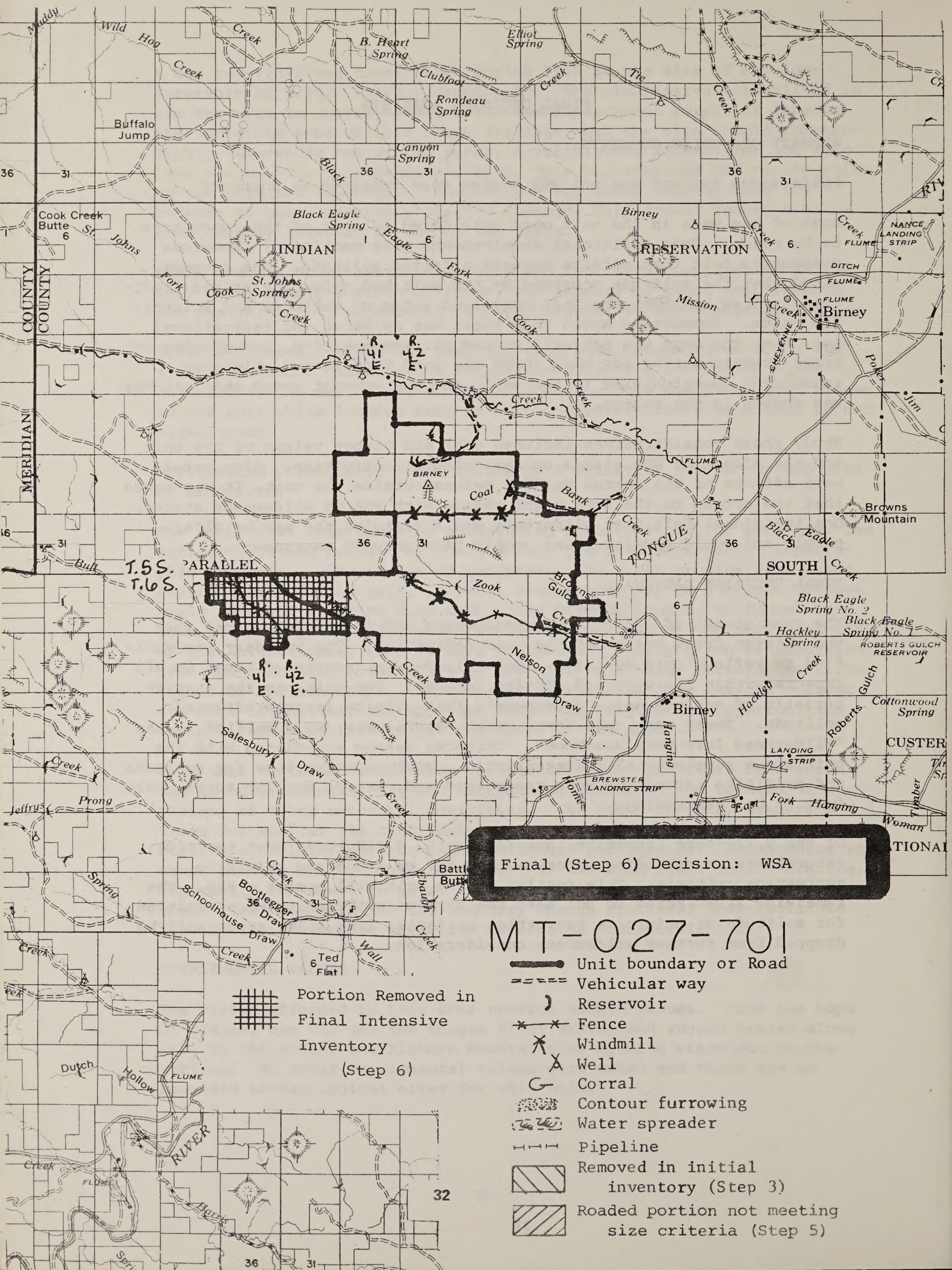


NARRATIVE SUMMARY

WILDERNESS INTENSIVE INVENTORY

UNIT NO.: $\quad$ MT-027-702

UNIT NAME: Buffalo Creek

SUMMARY OF DECISION

A 5,650-acre portion of the 7,940-acre unit intensively inventoried is recommended for WSA status because it meets the size, naturalness, and solitude criteria.

\section{SIZE AND UNIT DESCRIPTION}

The unit is located 35 miles southwest of Broadus and is entirely within Montana. The size of the initial inventory unit was 8,310 acres. A road was found in the unit which completely cut out one 370-acre segment. The smaller piece was dropped from intensive inventory by the State Director in August 1979. The size of the intensive inventory unit is 7,940 acres.

Three roads within the intensive inventory unit necessitate acreage reductions. The Buffalo Creek road passes through public land in section 26, T.8S., R.48E., fragmenting 17 acres off. The east side of Tongue River road passes through section 4, T.9S., R.48E., fragmenting 10 acres off. A road also runs from section 9, T.9S., R.48E. southeast to section 14, T.9S., R.48E. This creates a 2,263-acre fragment southwest of it and a larger roadless area northeast of it. None of these three fragments (totaling 2,290 acres) meet any of the size criteria. The remaining 5,650 acres does meet the 5,000 acre or larger size criterion. A .2 mile segment of road also goes to the windmill in section 12 , T.9S., R. 48E.

The Buffalo Creek Inventory Unit contains some of the best breaks to be found along the Powder River. Many of the Powder River breaks on public land are evidently too rugged to have been extensively developed and this area is no exception. The overall impression of this unit is one of relatively untouched country, although there are some minor impacts caused by man's activities.

The Buffalo Creek Unit consists of a north-south trending ridge about 4,100 feet in elevation. Several rugged drainages run off the ridge to the Powder River on the west and Buffalo Creek on the east. These canyons drop about 600 feet from the rim to the valleys on the boundaries of the unit. Over $50 \%$ of the unit is covered with ponderosa pine with open areas of grass on the ridge tops. In many areas, the rock near the canyon tops along the $\mathrm{rim}$ is a bright red rock locally known as scoria. 
Almost all of the human improvements occur on the ridge tops, especially in the southern portion of the unit. There are about seven miles of fence in the unit. The most obvious section of fence appears to be that which runs north along the highest ridge from the southeast corner of section 24, T.9S., R.48E. The pipeline and associated stockwater tanks are the next most obvious signs of man, although the pipeline itself is almost invisible. It was installed three years ago. The only evidence of the pipeline are the metal tanks and the pipeline drains. Two very small reservoirs are along the east boundary of the unit and would have very little impact even a short distance away. A windmill is located in the northeast part of T.9S., R.48E., section 12. A vehicle way exists in section 35, T.8S., R.48E., and sections 2 and 11 of T.9S., R.48E. This was improved long ago, is not maintained (it is not passable in many spots), and is not used. There are several springs in the unit.

Offsite impacts include oil pads on the south boundary, low-flying USAF jets, and roads adjacent to the boundary. Portions of those roads are visible from a few ridges in the unit. Offsite impacts are not significant due to their low frequency or the small magnitude of their impact. There is a grazing AMP on this unit and most of this roadless area has rest-rotation grazing practices with the western half of this unit presently not grazed.

In summary, most of the unit contains no evidence of man's influence and those imprints of man that are here do not have a substantial impact on the apparent naturalness of the area.

\section{OUTSTANDING OPPORTUNITY FOR SOLITUDE OR A PRIMITIVE AND UNCONFINED RECREATION ANALYSIS}

The Buffalo Creek Unit offers outstanding opportunities for solitude because of the rugged terrain and widespread cover of trees combined with its relatively large size. The best opportunities for solitude occur in the many canyons developing off the main ridge in this unit. Most of these canyons have numerous side drainages and are heavily vegetated with ponderosa pine, especially the northern slopes. The ridges in the unit would offer lesser opportunities for solitude because they are narrow in most places and generally flat with only a grassy cover. This could pose a problem for visitors being shielded from each other. Many visitors might tend to hike the easiest terrain, the ridges. The 5,650 -acre portion of Buffalo Creek Unit provides outstanding opportunities for solitude.

Hunting is the only known recreational use within the unit presently. This area is popular with deer hunters. The rugged canyons running off the main ridge would make interesting places to explore on foot. There are a few sandstone walls in the lower reaches of some canyons that contrast with green vegetation of the unit. There are also sandstone overhangs and a water seep from another sandstone formation, but this water may be seasonal or nonexistent most years. There is good potential for 
horse travel, especially along the open ridge. Horse travel in other portions of the unit would be difficult. The unit does not have outstanding opportunities for primitive recreation, because the opportunity for no single activity is outstanding and the diversity of activities is not such as to provide outstanding opportunities for solitude.

\section{SUPPLEMENTAL VALUES}

No special supplemental values were noted in the Buffalo Creek Unit. However, the Reynold's Battlefield site is located on the west bank of the Powder River just opposite the northwestern part of this unit. This 1876 battle was a prelude to Custer's Last Stand. This site is eligible for National Historic site status and is in the process of being recommended for it.

\section{FINAL DECISION ANALYSIS}

PUBLIC COMMENT SUMMARY:

Preferences were expressed for and against WSA status.

A number of comments related to roads in the intensive inventory unit. Other comments concerned the impacts of offsite impacts on solitude. Other individuals thought that the unit had outstanding opportunities for solitude and met the naturalness characteristic. The opportunities for primitive recreation were thought to be diminished by the presence of rattlesnakes and the lack of water.

Study phase considerations mentioned included the effect of WSA status on fire control activities, the impact of increased visitor use on naturalness, and the relationship between coal developments to the west and WSA or wilderness status.

\section{FINAL DECISION RATIONALE:}

The road status was reexamined and boundary changes were made where appropriate (see narrative and map). Offsite impacts were reconsidered under naturalness and found not to be significant. The 5,650 roadless acres of the unit were reassessed for solitude. It has outstanding opportunities for solitude due to topographic and vegetative screening.

The 5,650 acres of the unit will be studied further for potential wilderness designation.

The three roadless portions totalling 2,290 acres do not meet any of the size criteria. They will be dropped from further wilderness consideration. 


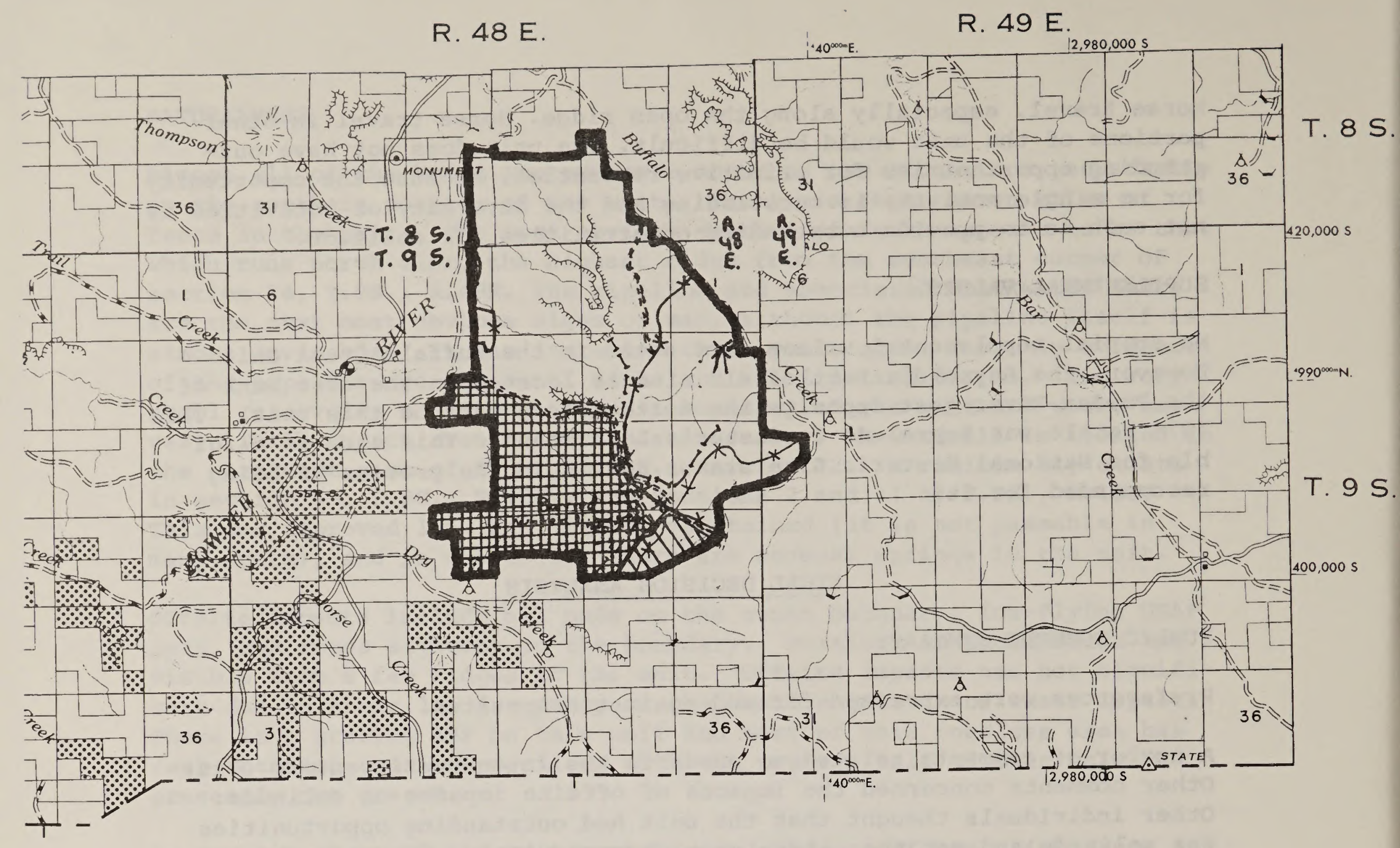

Final (Step 6) Decision: WSA

\# Portion Removed in Final Intensive Inventory (Step 6)

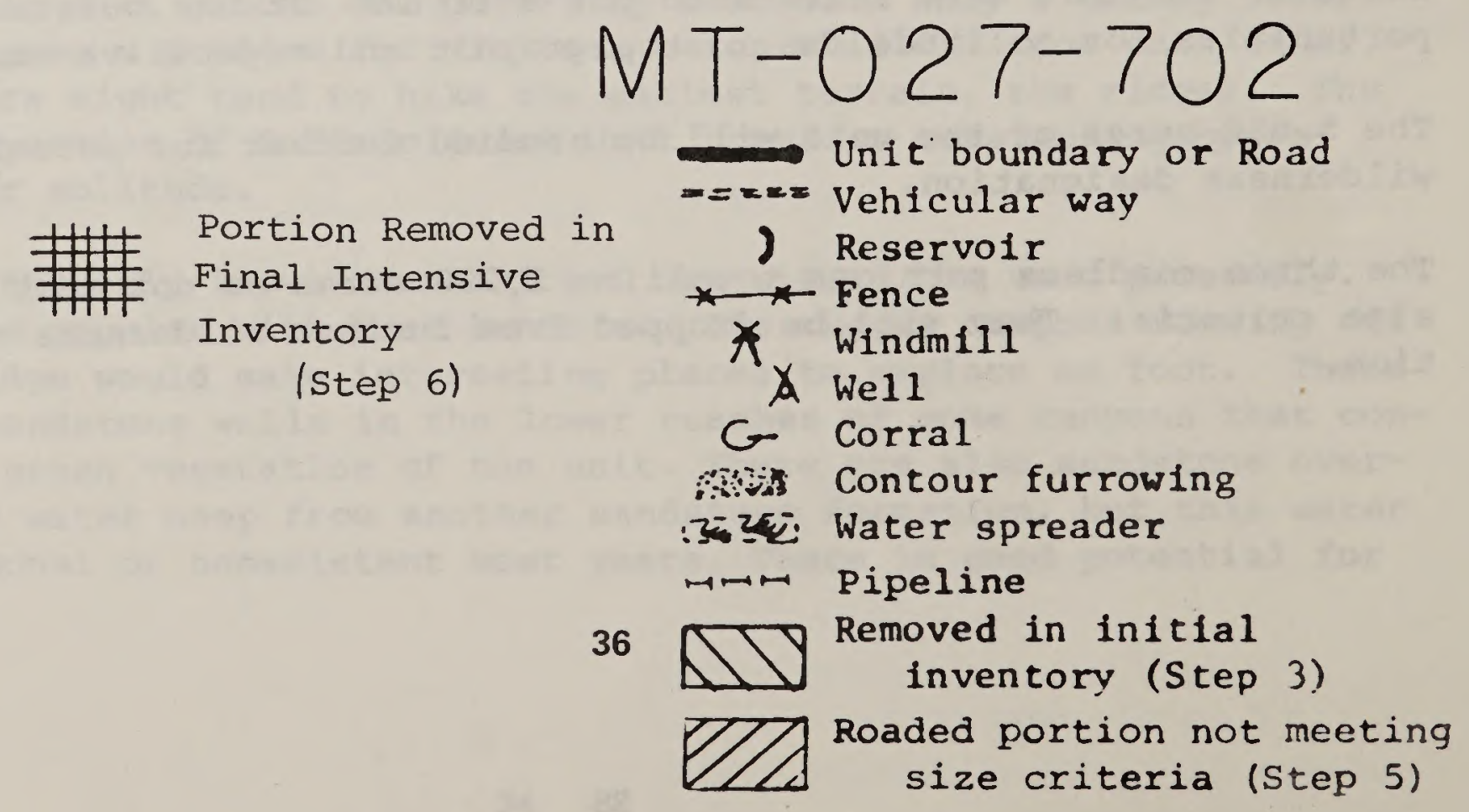


UNIT NO.: $\quad$ MT-027-736

UNIT NAME: Tongue River Breaks

\section{SUMMARY OF DECISION}

A portion of the unit is recommended for WSA status because it meets the size, naturalness, solitude and primitive recreation criteria.

\section{SIZE AND UNIT DESCRIPTION}

The south portion (labeled "3") of this unit is 3 miles northwest of Birney, Montana and the northern portions (labeled " 1 " and "2") are 9 miles northeast of Birney. These three portions are contiguous with the U.S. Forest Service (hereafter USFS) proposed Tongue River Breaks wilderness. The size of the initial unit was 2,004 acres. Three boundary changes in the proposed intensive inventory decision removed 239 acres from further wilderness consideration (see Naturalness and Solitude narratives). What was described in the proposed intensive inventory decision as a way up Gate creek is a deadend road to within $1 / 8$ mile of the USFS boundary (see map). Other boundary changes from the step 5 decision are discussed under naturalness.

The three portions of this unit are contiguous with the proposed USFS Tongue River Breaks Wilderness. It is impossible to distinguish topographically between public land and the USFS land along their 5.25 miles of common boundary. The western portion of the Tongue River Breaks contains very rugged topography with 500 to 600 -foot deep drainages. This area is drained northwest to the Tongue River. This river has formed a flat valley one to two miles wide. The public land contiguity unit is a transition zone between the wide alluvial plain and the forested breaks. Portion 1 of the unit contains some flat grasslands on the west, level but dissected topography and some breaks on the east. Portion 2 of the unit contains dissected topography and some flat grassland in the north. The topography of both portions 1 and 2 against the USFS land consists of 200-foot breaks dotted by ponderosa pine and juniper trees. Portion 3 of the unit is primarily moderate breaks with elevations varying up to 500 feet. Scattered juniper trees cover the breaks while some dense stands of ponderosa pines grow on the north slopes of the higher elevations.

\section{NATURALNESS}

The unit appears relatively natural. However, there are two developments that require boundary modifications. A powerline crosses the northwest corner of T.5S., R.43E., section 2 (portion 1). Removing the public land containing this powerline and northwest of it drops 15 acres from further wilderness consideration (see map for boundary modification "A"). This portion of the unit also contains two small fenced exclosures. There are also many uncased drill holes in this portion of the unit, but they are barely discernible. 
There are no developments in portion 2 of the unit.

Portion 3 of the unit has one small reservoir in the southwest corner of Section 5 of T.6S., R.42E. The major impact of this portion, however, is a small borrow pit and bladed way to it. This development is located in the northwest corner of T.6S., R.42E., Section 5. This portion of the unit is being dropped from further consideration and will eliminate 20 acres (see map for boundary modification "B").

A fence runs along the entire USFS boundary. However, it is unobtrusive due to the broken terrain and forest cover. The on-site developments, except the powerline and scoria pit, are neither individually nor cumulatively substantially noticeable.

Some offsite impacts have been determined to be significant which result in boundary change " $D$ " (see map). The alluvial flats of portions 1 and 2 are significantly impacted by traffic on the east side Tongue River road as well as other offsite activities and developments on the flats. In contrast, the breaks topography is not significantly impacted by activity or development on the alluvial flats. The basis of this boundary modification is the identification of alluvial flats and their proximity and relationship to the road. A crucial point is that the "zone of influence" of the east side Tongue River road would not extend into the breaks, even if the road were nearer to them. The resulting boundary modification removed 241 acres in portion 1 and the east half of portion 2. This includes those alluvial flats from which the offsite impacts of the east side Tongue River road are so apparent as to be significant. The boundary in portion 1 has been drawn on legal boundaries except for NE NE SW1/4, Section 2, T.5S., R.43E., where it is on the Gate creek road. The 20 acres of alluvial flats in portion 2 are the E $1 / 2$ of NE NE, Section 10, T.5S., R.43E. Removing the e alluvial flats effectively removes all 40 acres of portion 2, because the west half is then not contiguous to USFS or BLM lands.

\section{OUTSTANDING OPPORTUNITY FOR SOLITUDE OR A PRIMITIVE AND UNCONFINED RECREATION ANALYSIS}

None of the three portions of the unit, by themselves, has outstanding opportunities for solitude. They are each simply too small in spite of topographic and vegetative screening. However, each of the three portions of the unit has outstanding opportunities for solitude when viewed in conjunction with the USFS lands. Generally, if any portion of an inventory unit exhibits outstanding opportunities for solitude (or primitive recreation), the remainder of the unit which meets the naturalness criterion will be brought forward as a proposed Wilderness Study Area. An exception is relevant for portion 3 of this unit in sections 29 and 30, T.5S., R.43E. This 204-acre "peninsula" does not possess any opportunities for solitude (or primitive recreation), nor does it enhance any opportunities for solitude (or primitive recreation) of contiguous public lands. On this basis, this narrow neck of land will be dropped from further consideration (see map for boundary modification "C"). 
None of the three portions of the unit, by themselves, has outstanding opportunities for primitive recreation. However, they do meet this criterion in conjunction with the USFS Tongue River Breaks, which has outstanding opportunities for primitive recreation. The "peninsula" discussed under solitude does not contain any outstanding opportunities for primitive recreation nor does it enhance those of contiguous public lands. It is connected to the remainder of portion 3 by a 377-foot wide strip (see boundary modification "C"). The potential recreation activities of this unit and USFS land, which cumulatively are outstanding, include hunting, hiking, backpacking, bird watching, photography of flora and fauna, and perhaps winter sports.

\section{SUPPLEMENTAL VALUES}

There are no archaeological sites known or recorded for this unit. No other supplemental values were found during intensive inventory.

\section{FINAL DECISION ANALYSIS}

SUMMARY OF PUBLIC COMMENTS:

Preferences were expressed both for and against WSA status.

Comments were made that there is a road up Gate creek and that the unit did not meet the 5,000 acre size criterion.

Many commenters mentioned offsite impacts which included the east side Tongue River road, the powerline, and ranch development and activities on adjoining private land. Also mentioned as a potential offsite impact was the proposed MONTCO coal mine. Many commenters felt that the unit had outstanding opportunities for solitude and primitive recreation in conjunction with the USFS Tongue River Breaks. Others stated that the unit did not contain these characteristics or that the alluvial flats did not. Comments on supplemental values stated that the unit had none or that it did have scenic, ecological and geological values.

Study phase considerations noted both offsite and onsite coal potential and their economic implications. It was also noted that the unit contained oil and gas leases. Comments were made that the unit was fragile and should be preserved or that the unit had unusual landforms.

FINAL DECISION RATIONALE :

Expressions simply for or against wilderness study designation, study phase concerns and possible future offsite developments are not a basis for this final decision.

Comments concerning road status were reviewed and boundary changes made where appropriate. The unit meets the size characteristic due to the contiguity criterion. This unit will be further studied for wilderness potential. 
The onsite impacts were reviewed and, except for the powerline and gravel pit, are individually and cumulatively substantially unnoticeable. Thirty-five acres were dropped on the basis of the gravel pit and powerline corridor.

Offsite impacts were reassessed and 281 acres have been dropped on that basis.

The outstanding solitude or primitive recreation characteristic was reexamined. The 204 acres dropped in the proposed intensive inventory decision on this basis was appropriate. The remaining acreage has, in conjunction with USFS lands, that characteristic.

The 1,484 acres of the unit have size and naturalness characteristics and, in conjunction with USFS lands, have outstanding opportunities for solitude and primitive and unconfined recreation. That 1,484 acres is a WSA. The remaining 520 acres are not a WSA.

40 


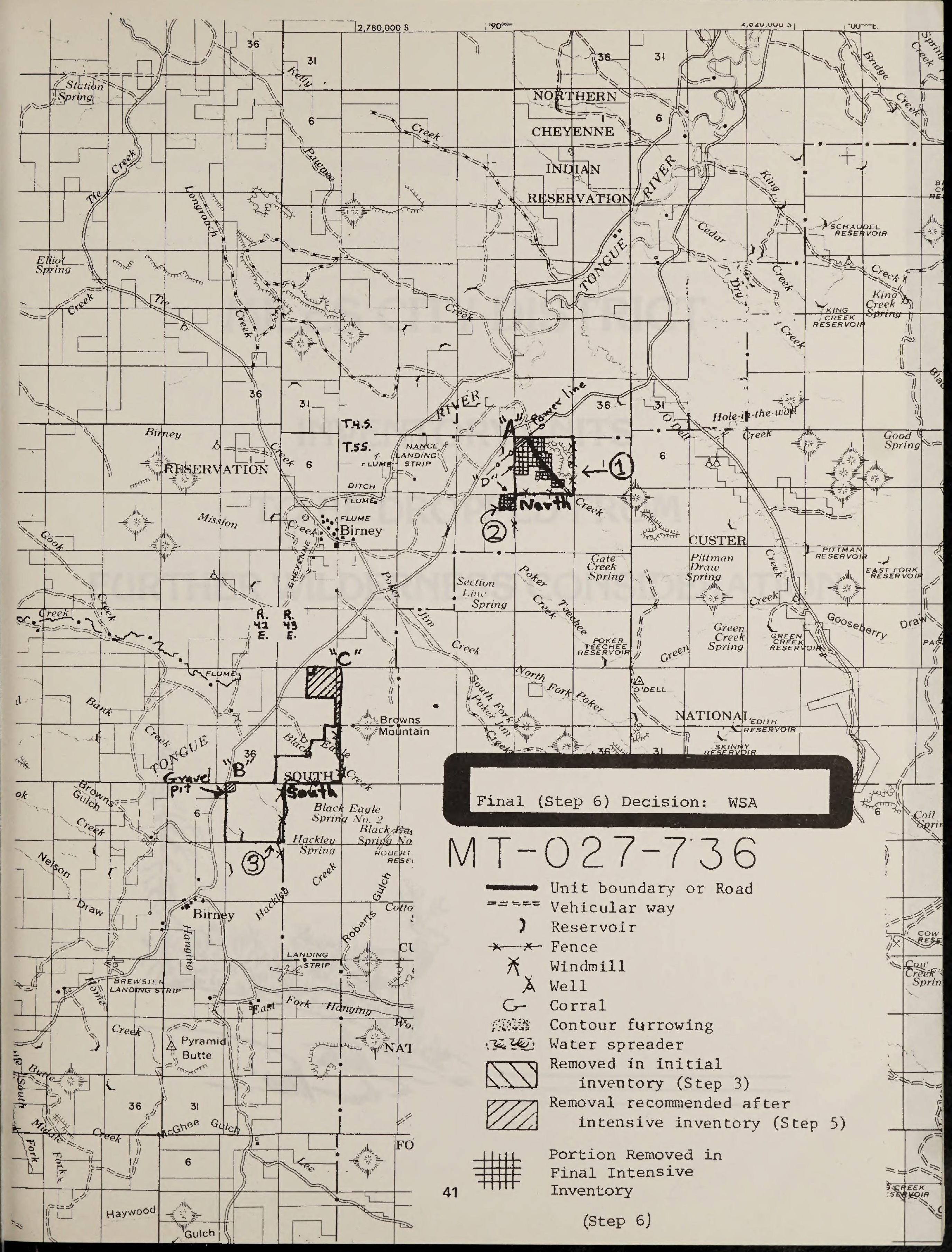





\title{
MILES CITY DISTRICT
}

\author{
INVENTORY UNITS
}

TO BE DROPPED FROM

\section{FURTHER WILDERNESS CONSIDERATION}

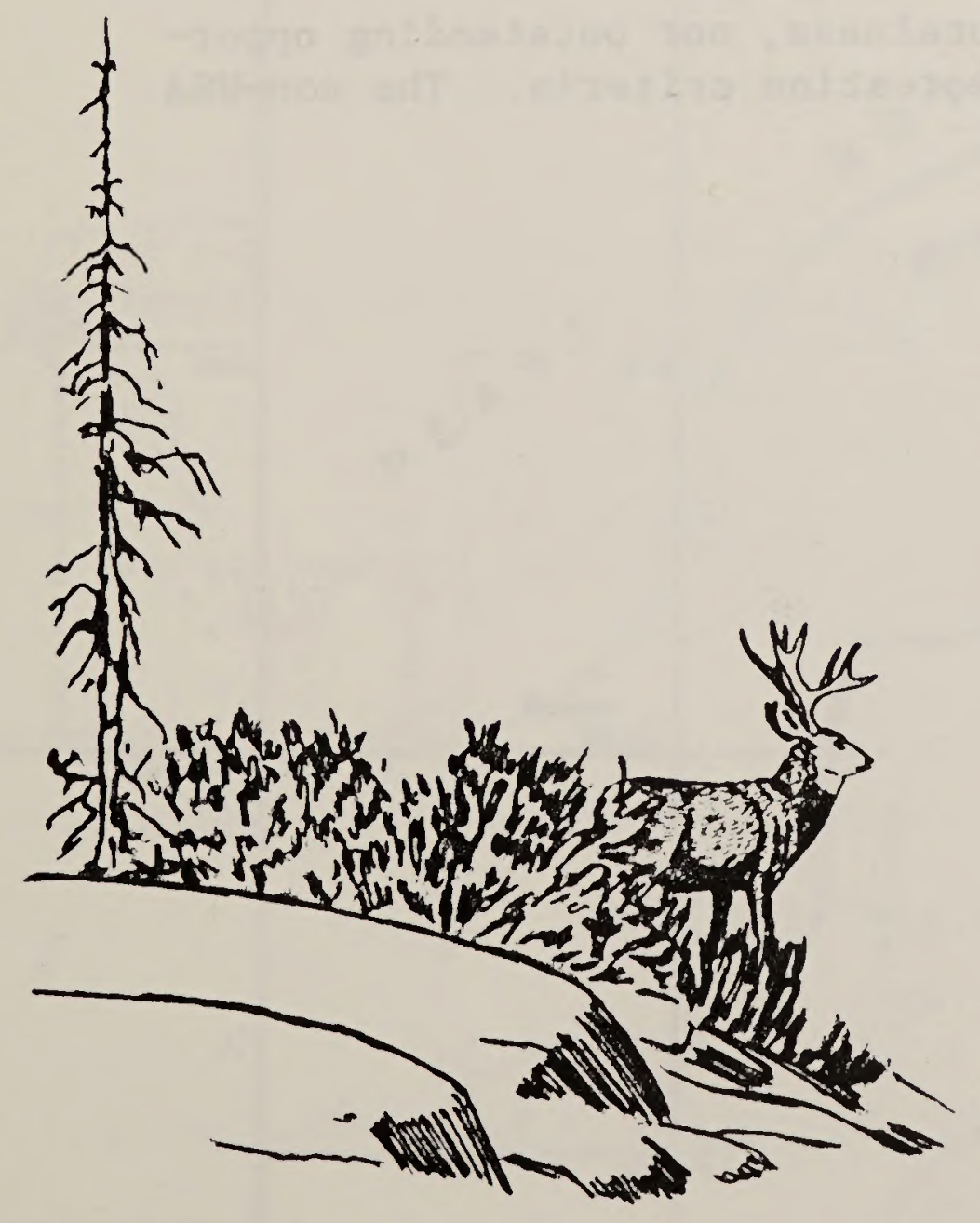




\author{
UNIT NO.: $\quad$ MT- $24-610$ \\ INIT NAME: Yellowstone Island
}

STIMMARY OF RECOMMENDATION

The unit is not recommended for WSA status.

SIZE \& ITNIT DESCRIPTION

The island no longer exists. The river has changed since the United States Geoloqical Survey Map (1960) and extensivelv since the mapping of the Master Title plat. The location of the island is now occupied by the main channel of the Yellowstone River.

\title{
FINAL DECISION ANALYSIS
}

SUMMARY OF PUBLIC COMMENTS:

The only comments received supported the Intensive Inventory finding. FINAL DECISION AND RATIONALE:

The unit does not meet the size, naturalness, nor outstanding opportunities for solitude or primitive recreation criteria. The non-WSA recommendation is unchanged. 
Final (Step 6) Decision: Not WSA

MT-024-610

- Master Title Plat Boundary

Inventory Boundary (N ONE)

Scale: $25 / 8 \%$ mile

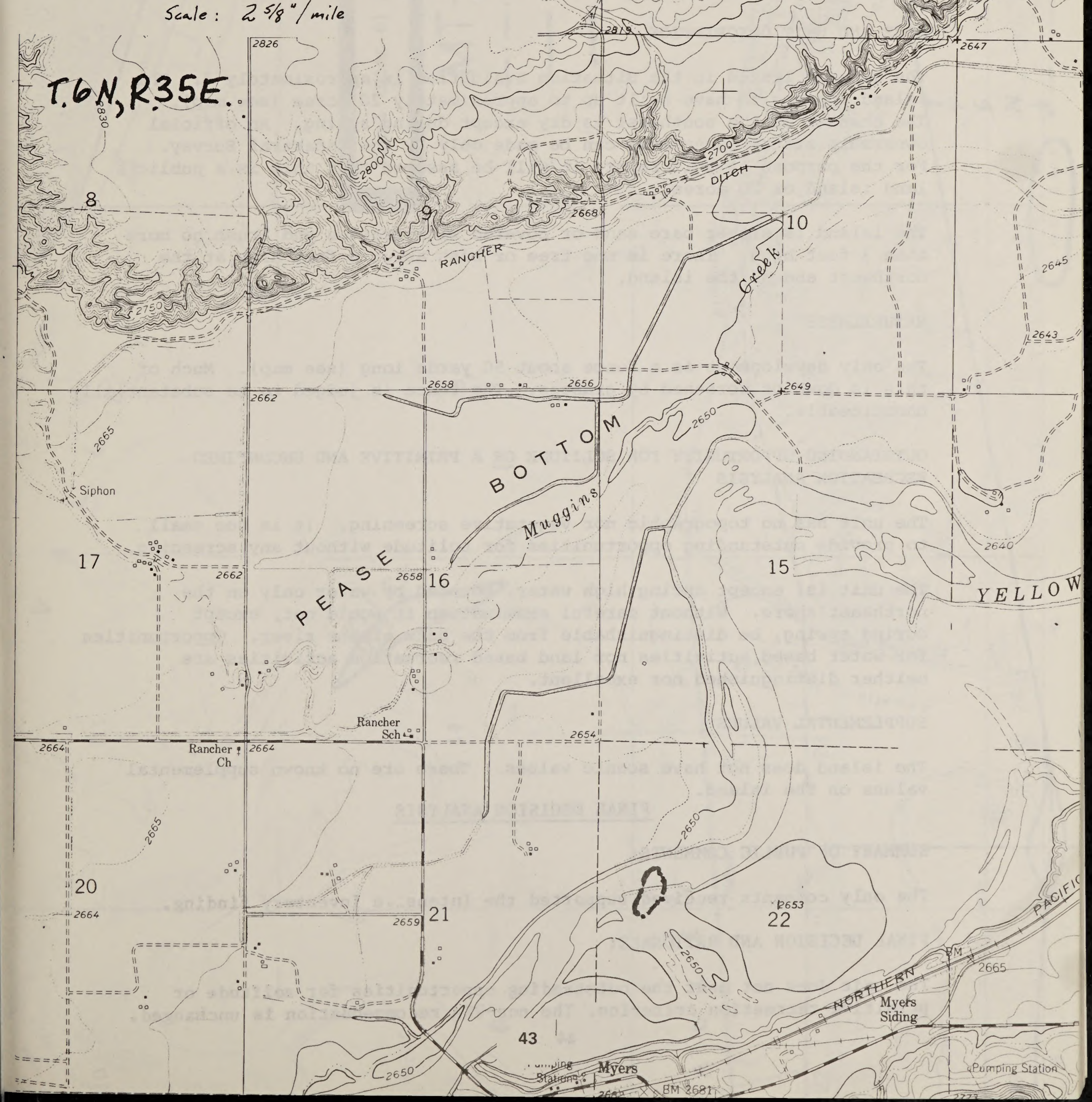


SUMMARY OF DECISION

The unit is not recommended for WSA status.

\section{SIZE AND UNIT DESCRIPTION}

The acreage listed in the Situation Evaluation is approximately 4. The island appears to have built up to approximately 20 acres (see map). The channel on the southwest is dry except during spring. An official ownership status assessment can be made only by the Cadastral survey. For the purpose of this report it will be assumed that this is a public land island of 20 acres.

The island is either bare sand or covered with grasses and brush no more than 3 feet high. There is one tree or bush about 8 feet high at the northwest end of the island.

\section{NATURALNESS}

The only development is a fence about 50 yards long (see map). Much of this is down or screened by grasses. The fence is judged to be substantially unnoticeable.

OUTSTANDING OPPORTUNITY FOR SOLITUDE OR A PRIMITIVE AND UNCONFINED RECREATION ANALYSIS

The unit has no topographic nor vegetative screening. It is too small to provide outstanding opportunities for solitude without any screening.

The unit is, except during high water, bounded by water only on the northeast shore. Without careful examination it would not, except during spring, be distinguishable from the bank of the river. Opportunities for water based activities nor land based recreation activities are neither distinguished nor excellent.

SUPPLEMENTAL VALUES

The island does not have scenic values. There are no known supplemental values on the island.

\section{FINAL DECISION ANALYSIS}

SUMMARY OF PUBLIC COMMENTS :

The only comments received supported the Intens_ve Inventory finding.

FINAL DECISION AND RATIONALE:

The unit does not meet the outstanding opportunities for solitude or primitive recreation criterion. The non-WSA recommendation is unchanged. 


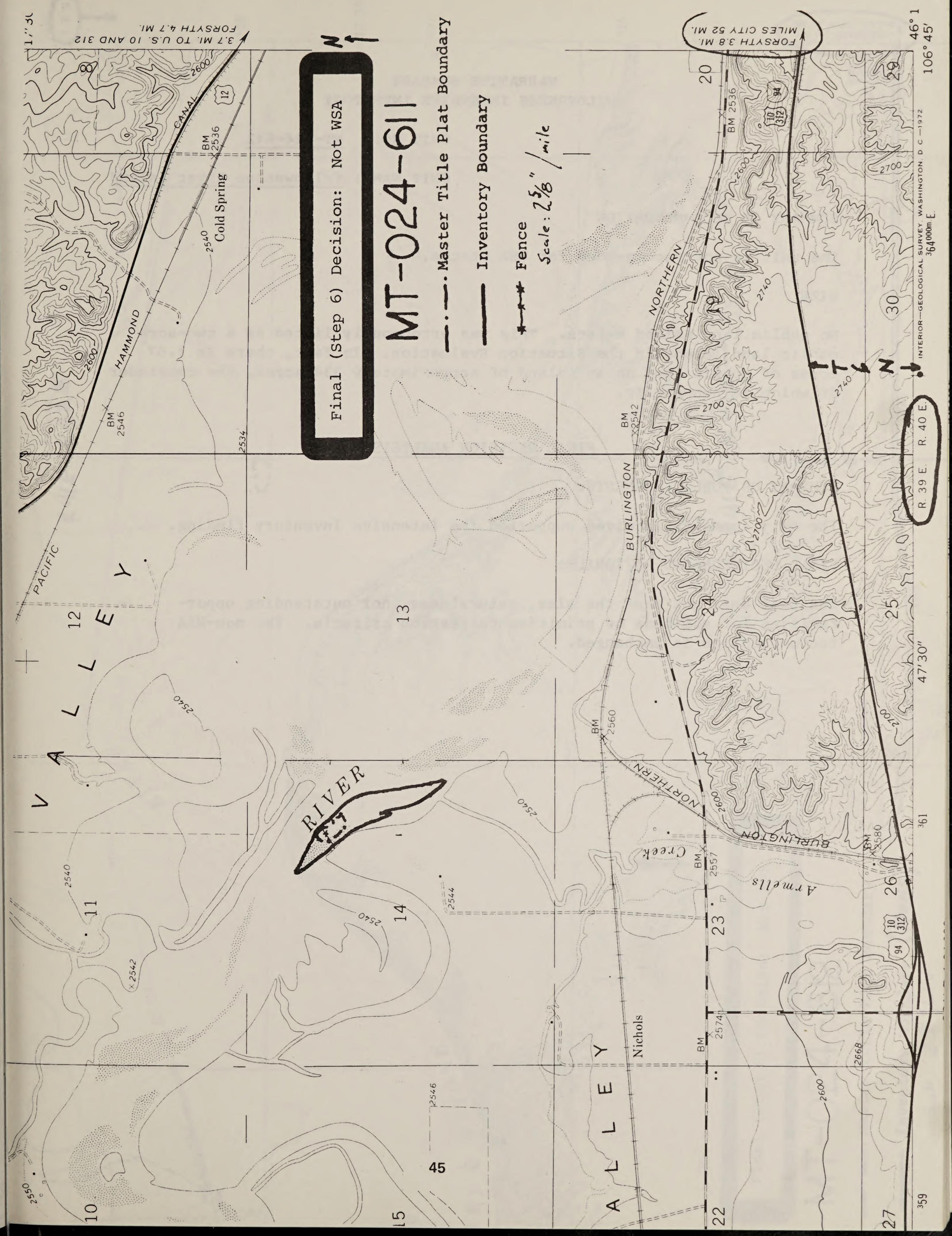


NARRATIVE SUMMARY

WILDERNESS INTENSIVE INVFNTORY

UNIT NO.: $\quad$ MT-024-612

INIT NAME: Yellowstone River Island

SUMMARY OF RECOMMENDATION

The unit is not recommended for WSA status.

SIZF

No public land island exists. This was erroneously listed as a two-acre Dublic land island in the situation Evaluation. In fact, there is 1.67 acres of public land on an island of approximately 334 acres, the remainder of which is non-public.

\section{FINAL DECISION ANALYSIS}

SUMMARY OF PUBLIC COMMENTS:

The only comments received supported the Intensive Inventory finding. FINAL DECISION AND RATIONALE:

The unit does not meet the size, naturalness, nor outstanding opportunities for solitude or primitive recreation criteria. The non-WSA recommendation is unchanged. 


\title{
NARRATIVE SUMMARY \\ WILDERNESS INTENSIVE INVENTORY
}

\author{
UNIT NO.: MT-024-613 \\ UNIT NAME: Yellowstone Island \\ -Cheyenne Islands
}

\section{SUMMARY OF DECISION}

The unit is not recommended for WSA status although it meets the size and primitive recreation criteria.

\section{SIZE}

The sizes of the islands, on the basis of the Montana Plat, are 31.57 and 100.35 acres. During high water additional channels are flooded which create additional islands from the two on the map.

The islands are elevated as much as 8 feet above the river. They are covered with grasses and brush as well as trees despite a fire in 1976. There are rows of cottonwood along the southern shores and heavier stands of shrubs and trees along the northern end of the islands.

\section{NATURALNESS}

There are few impacts of man on the island. Some fire rings of recent origin exist. Some old rock paths exist -- the only remnants of a Boy Scout camp that was abandoned at least three decades ago. A major, but not apparent, impact is a bladed channel through the lower island. This was done in 1967 for erosion control. It is indistinguishable from other channels in the islands. Ongoing vegetative research studies coordinated by the Fort Keogh Livestock and Range Research Station involve no impacts. On the basis of onsite impacts, the islands appear natural.

Offsite developments on the south shore of the river include the Burlington Northern Railroad and a pumping station. They are as close as 100 feet and no further than $3 / 4$ mile from any point on the islands. Their visual impact is much less at the north end of the islands. Impacts of sound from the developments are larger than the impacts of the sights. The sounds from the coal train alone pass with an average frequency of one per hour. The pumping plant operates intermittently. There is riprap along the south bank of the river which averages less than 200 feet from the south shore of the island. Finally, boat traffic is increasing dramatically along this stretch of the Yellowstone. These offsite impacts cumulatively are sufficient to judge that the islands do not meet the naturalness characteristics. Impacts from train traffic alone are sufficient to warrant the same conclusion. 


\section{OUTSTANDING OPPORTUNITY FOR SOLITUDE OR A PRIMITIVE AND UNCONFINED RECREATION ANALYSIS}

The island has some vegetative screening at the north end. There is no topographic screening except for old channels on the islands. The screening is not sufficient to provide outstanding opportunities for solitude on islands of this size.

The islands can be used for overnight camping during river floats, rock and agate collecting, white-tailed deer hunting and fishing. The diversity of these opportunities is excellent or outstanding.

SUPPLEMENTAL VALUES

A withdrawal application for the establishment of these islands as a natural area is pending (M 17858). Undisturbed cottonwood stands on public land are unusual in eastern Montana. The islands provide excellent riparian habitat for plant and animal species. The islands have ecological and scientific supplemental values.

\section{FINAL DECISION ANALYSIS}

\section{SUMMARY OF PUBLIC COMMENTS}

Comments were received expressing preferences both for and against WSA status.

Inventory consideration brought to the Bureau's attention included the channelization, Boy Scout camp, riprap and research activities. The impact of train traffic was considered by several respondents to be a significant offsite impact. Ecological values of the island were also mentioned.

Comments relevant in Phase II were also received. They included concerns about possible Class I air status and potential effects on development of the surrounding area.

\section{FINAL DECISION AND RATIONALE}

The proposed WSA recommendation is reversed. The unit is not a WSA as it does not meet the naturalness characteristic. This is due to the magnitude and frequency of the offsite impacts of train traffic. Also, on the basis of the withdrawal application, the islands may not meet the public land definition for wilderness review. However, since the island is not being selected as a WSA, the point is moot. 


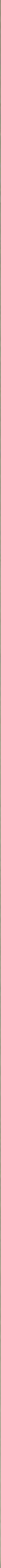




\title{
WILDERNESS INTENSIVE INVENTORY
}

\author{
UNIT NO.: $\quad$ MT-024-614 \\ UNIT NAME: Yellowstone Island
}

SUMMARY OF DECISION

The unit is not recommended for WSA status although it meets the size and primitive recreation criteria.

SIZE AND UNIT DESCRIPTION

The acreage of the island is 31 acres. The island is 3 miles west of Terry, Montana. The channel on either side of the river is approximately .25 miles wide.

The island lies mid-channel in the Yellowstone River. It is low with a small rise running $1 / 4$ the length of the island on which grow approximately a dozen trees.

\section{NATURALNESS}

There are no developments on the island.

On the south bank of the river are two railroads and a pumping station. They are as close as $1 / 8$ mile from the island and on the bank approximately 40 feet above the island. Coal trains alone pass with an average frequency of one per hour. This offsite impact is sufficient to judge that the island does not meet the naturalness characteristic.

OUTSTANDING OPPORTUNITY FOR SOLITUDE OR A PRIMITIVE AND UNCONFINED RECREATION ANALYSIS

The stringer of trees does not provide screening nor does the topography of the island. The size of the island is simply not sufficient to provide outstanding opportunities for solitude.

The island provides opportunities for rock collecting, fishing, and perhaps camping while river tripping. None of these opportunities is outstanding. However, the diversity of these uses does provide outstanding opportunities for primitive recreation.

SUPPLEMENTAL VALUES

The unit does not have scenic values. It has no known other supplemental values. 


\section{FINAL DECISION ANALYSIS}

SUMMARY OF PUBLIC COMMENTS

Comments were received expressing preferences both for and against WSA status.

Some comments considered passing trains to be a significant offsite impact. Possible ecological values were also mentioned.

Comments relevant to Phase II were also received. They included concerns about possible Class I air status and potential effects on development of the surrounding area.

FINAL DECISION AND RATIONALE

The proposed WSA recommendation is reversed. The unit is not a WSA at it does not meet the naturalness characteristic. This is due to the magnitude and frequency of the offsite impacts of train traffic. 
MT-024-614

-. Master Title Plat Boundary

Inventory Boundary

$$
\text { Scale : } 25 \% " / \text { mile }
$$

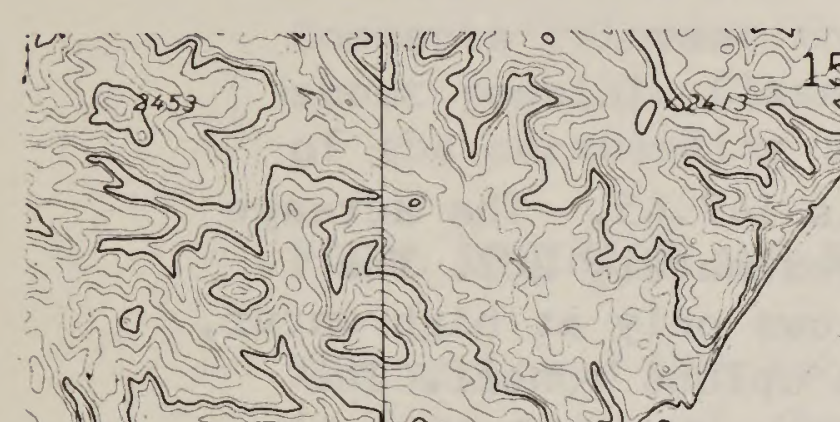

M 5 - 3

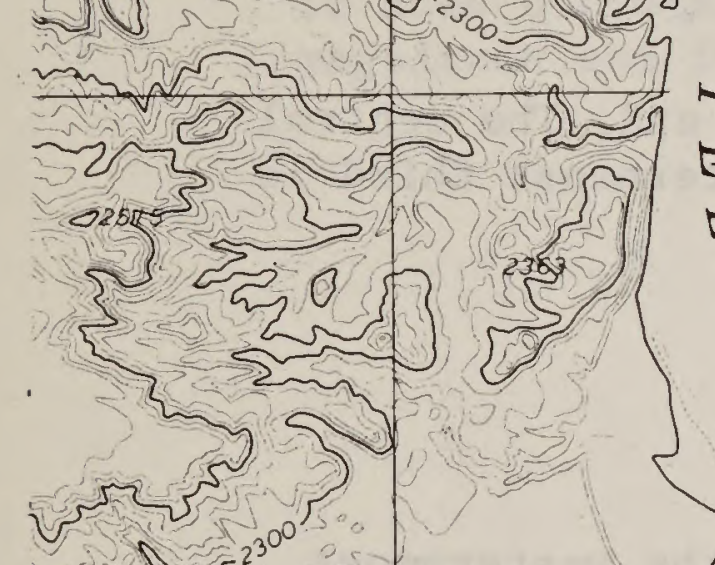

15

14

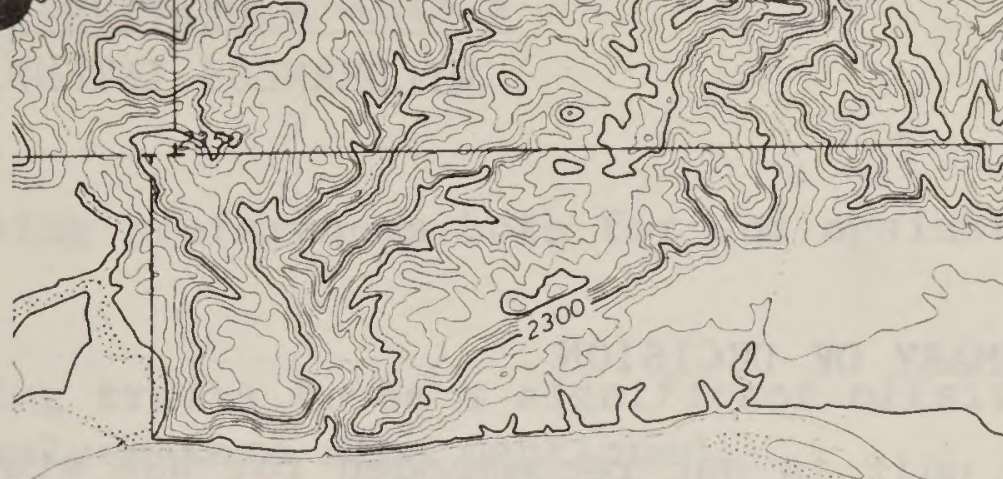




\section{NARRATIVE SUMMARY \\ WILDERNESS INTENSIVE INVENTORY \\ UNIT NO.: $\quad$ MT-024-615 \\ UNIT NAME: Yellowstone Island}

\section{SUMMARY OF DECISION}

The unit is not recommended for WSA status although it meets the size and primitive recreation criteria.

\section{SIZE AND UNIT DESCRIPTION}

The acreage of the island in Master Title Plats is 147.45. The acreage computed from U.S. Geological Survey maps is approximately 202. The channel of the Yellowstone south of the island flows only at high water, although there is some water in that channel from upland runoff. The island is two miles east of Fallon, Montana.

The island has heavy stands of cottonwood at the east end. The central portion is mixed wild rose and cottonwood and the westernmost third is open gravels.

\section{NATURALNESS}

There are no developments on the island.

Offsite developments, which have visual imapcts from the westernmost portion of the island, include a pumping station (north) across the river. A railroad is $1 / 2$ mile south of the island is an offsite source of sound. Coal trains alone pass with an average frequency of one per hour. This offsite impact is sufficient to judge that the island does not meet the naturalness characteristic.

OUTSTANDING OPPORTUNITY FOR SOLITUDE OR A PRIMITIVE AND UNCONFINED RECREATION ANALYSIS

The easternmost portion of the island has heavy vegetative screening with both cottonwoods and tall shrubs. This screening provides exceptional opportunities for solitude for an island of this size. However, the opportunities for solitude are not outstanding.

The island provides opportunities for fishing, white-tail deer hunting, bird watching and riverside camping. While none of these are excellent individually, through their diversity, they do provide outstanding opportunities for primitive recreation.

\section{SUPPLEMENTAL VALUES}

The unit has no supplemental values. Cottonwood stands on public land are fairly unusual. However, these have been grazed and so are not considered a supplemental value. 


\section{FINAL DECISION ANALYSIS}

SUMMARY OF PUBLIC COMMENTS

Comments were received expressing preferences both for and against WSA status.

Some comments considered passing trains to be a significant offsite impact. Possible ecological values were also mentioned.

Comments relevant to Phase II were also received. They included concerns about possible Class I air status and potential effects on development of the surrounding area.

FINAL DECISION AND RATIONALE

The proposed WSA recommendation is reversed. The unit is not a WSA as it does not meet the naturalness characteristic. This is due to the magnitude and frequency of the offsite impacts of train traffic. 


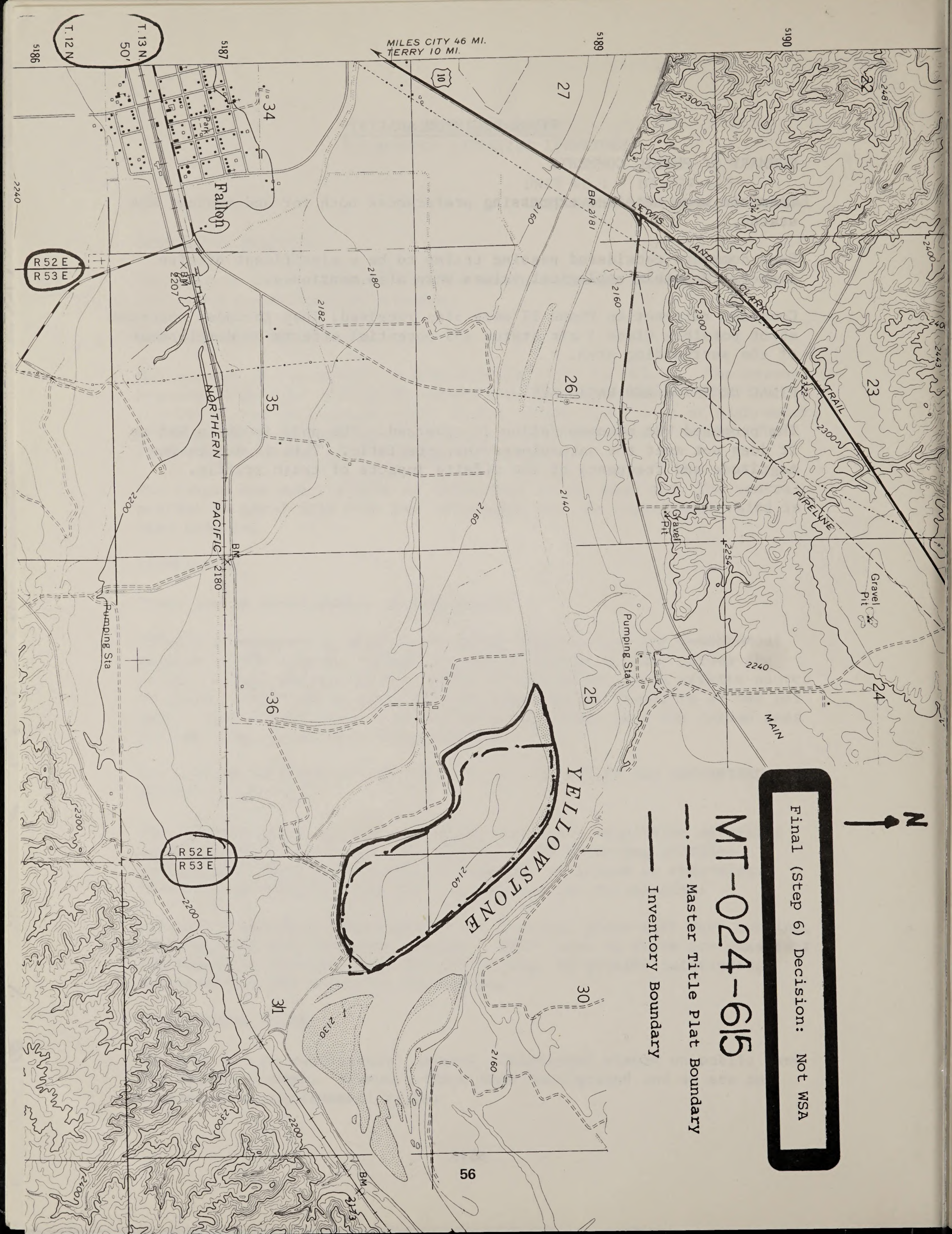


UNIT: MT-024-616

UNIT NAME: Yellowstone Island (Seven Sisters)

\section{SUMMARY OF DECISION}

The unit is not recommended for WSA status although is meets the size and outstanding opportunities for primitive recreation criteria.

\section{SIZE AND UNIT DESCRIPTION}

The acreage of the island is 82.71. It is bounded by the major channel of the Yellowstone on the east, a smaller channel on the west and a seasonal channel on the north. The island has been withdrawn under M 044785 .

The island is clustered in a group of islands. The low terrain of this island is covered with low brush.

\section{NATURALNESS}

There are no developments on the island.

Offsite impacts on the north shore of the Yellowstone include the Burlington Northern Railroad, several houses, and Highway 10. Coal trains pass with an average frequency of one per hour. The terrain between the railroad and the island is unscreened.

OUTSTANDING OPPORTUNITY FOR SOLITUDE OR A PRIMITIVE AND UNCONFINED RECREATION ANALYSIS

The island is fairly flat and has low vegetative screening. However, the screening is not dense enough nor the size of the island large enough to provide outstanding opportunities for solitude.

The island provides opportunities for fishing, hunting white-tail deer, and perhaps river-float camping. None of these opportunities is outstanding. However, the diversity of these opportunities provides outstanding opportunities for primitive recreation.

SUPPLEMENTAL VALUES

The unit does not have scenic values. It has no known other supplemental values.

\section{FINAL DECISION ANALYSIS}

SUMMARY OF PUBLIC COMMENTS

Comments were received expressing preferences both for and against WSA status. 
Some comments considered passing trains to be a significant offsite impact. Possible ecological values were also mentioned.

FINAL DECISION AND RATIONALE

The proposed WSA recommendation is reversed. The unit is not a WSA as it does not meet the naturalness characteristic. This is due to the magnitude and frequency of the offsite impacts of train traffic. 


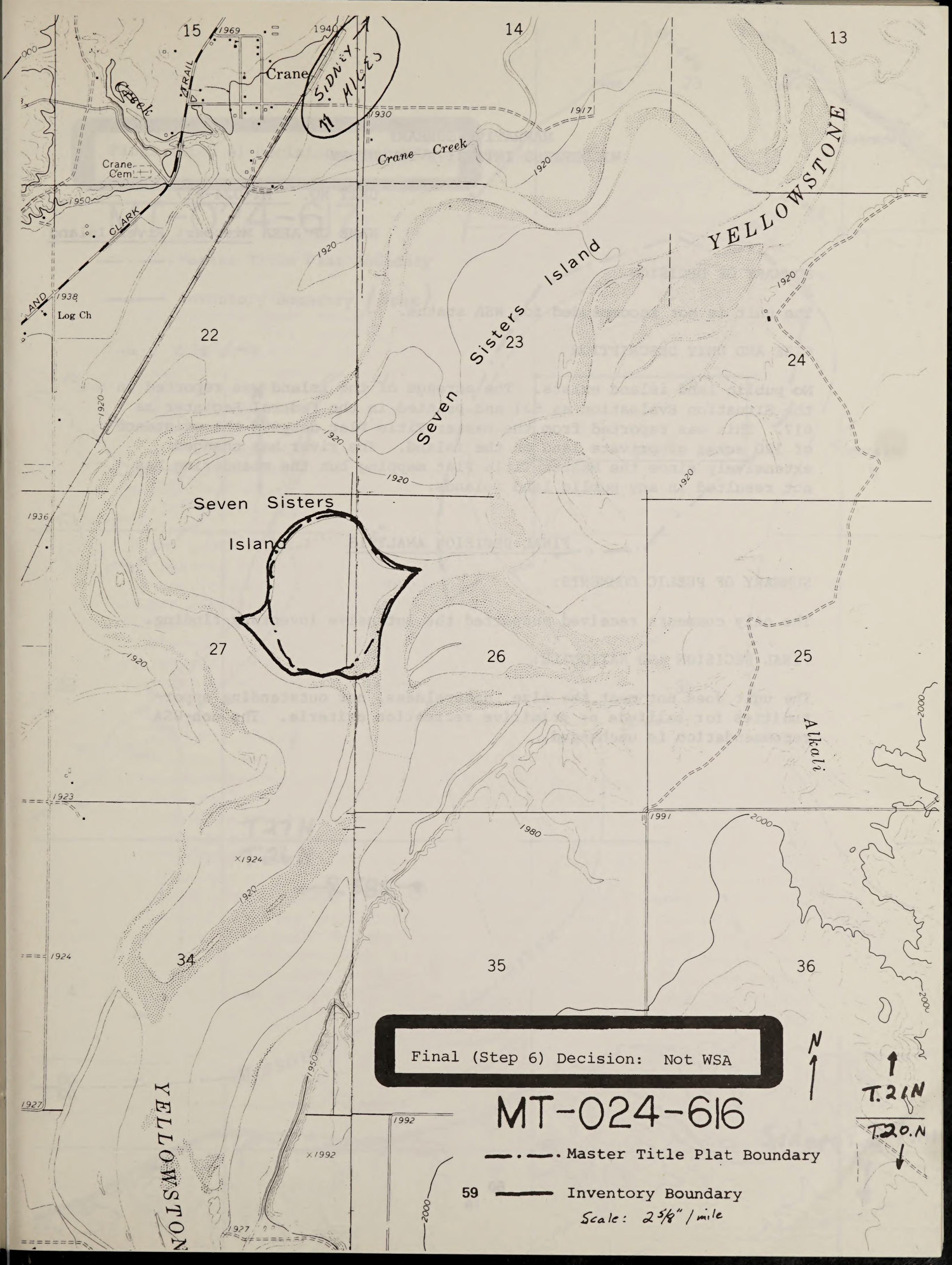


UNIT NO. $\mathrm{MT}-024-617$

NAME OF AREA Missouri River Island

SUMMARY OF DECISION

The unit is not recommended for WSA status.

SIZE AND UNIT DESCRIPTION

No public land island exists. The acreage of the island was reported in the Situation Evaluation as 621 and printed in the Federal Register as 617. This was reported from the Master Title Plat despite the existence of 120 acres of private land on the island. The river has changed extensively since the Master Title Plat mapping but the meandering has not resulted in any public land islands.

\section{FINAL DECISION ANALYSIS}

SUMMARY OF PUBLIC COMMENTS :

The only comments received supported the Intensive Inventory finding. FINAL DECISION AND RATIONALE:

The unit does not meet the size, naturalness, nor outstanding opportunities for solitude or primitive recreation criteria. The non-wSA recommendation is unchanged. 
Final (Step 6) Decision: Not WSA

\section{MT-024-617}

-. Master Title Plat Boundary

- Inventory Boundary (None)

\section{Scake: $2 \mathrm{~s} / 8^{\prime \prime} /$ mile}

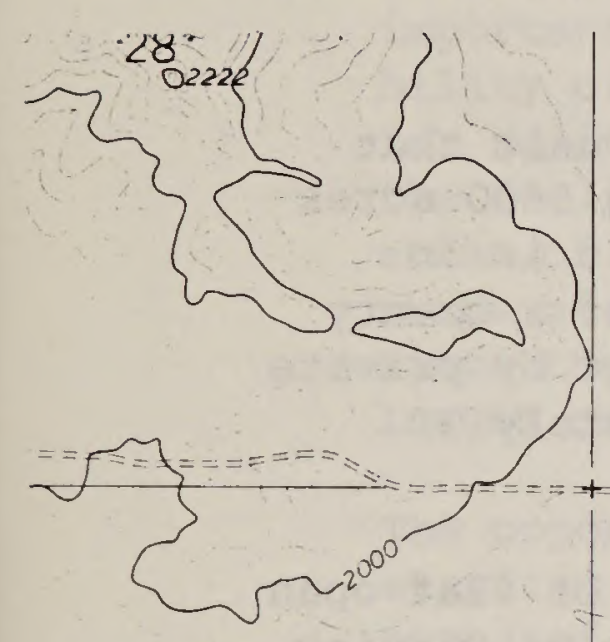

33
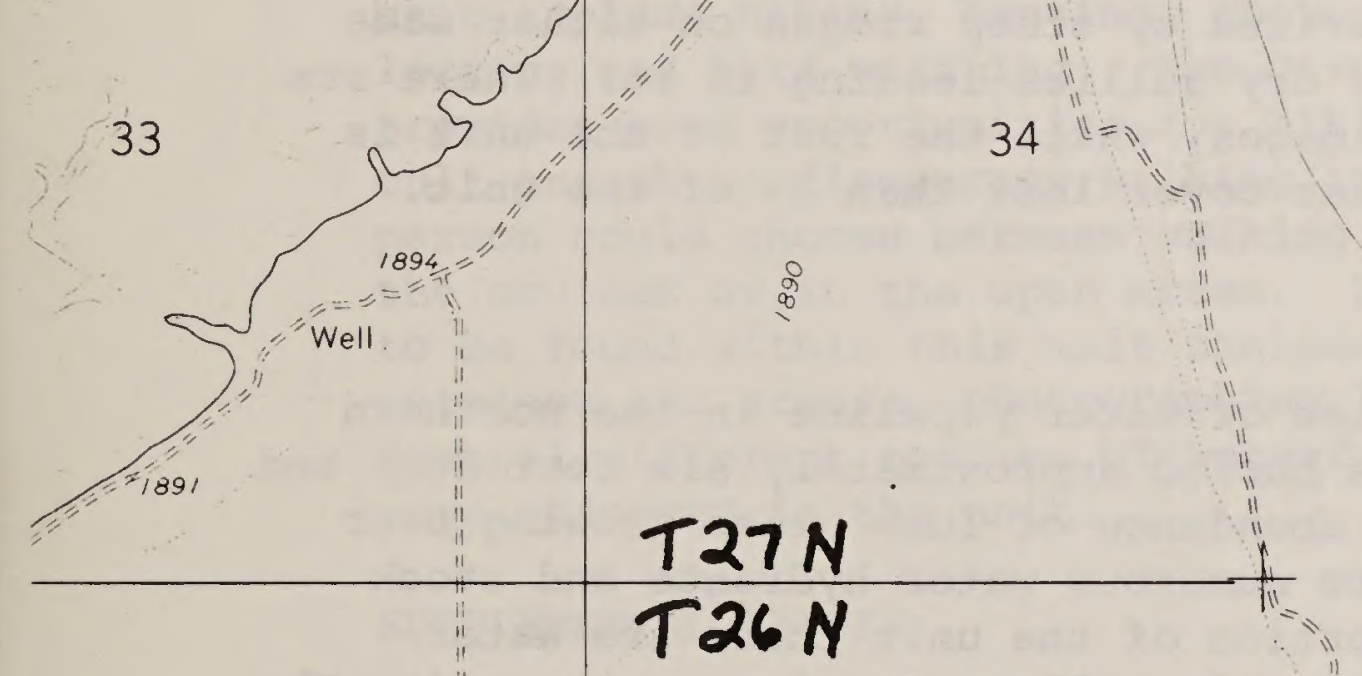

$T 26 N$

-R S8E $\rightarrow$

4. 
NARRATIVE SUMMARY

WILDERNESS INTENSIVE INVENTORY

UNIT NO: $\quad$ MT-024-632

UNIT NAME: East Bridge Coulee

\section{SUMMARY OF RECOMMENDATION}

The unit is not recommended for WSA status although it meets the size and outstanding opportunities for solitude criteria.

\section{SIZE \& UNIT DESCRIPTION}

There is a road running through the southern portion of the unit that cuts approximately 700 acres from the original unit, leaving 6600 acres (see map). It receives regular use and maintenance. The unit is in Garfield County, Montana. The unit is bounded on the west of a county road, on the north by state and private land, and on the east by private land and U.S. Fish and Wildlife land. The unit is approximately 32 miles northeast of Jordan, MT.

This unit is somewhat broken in topography with large areas of flat open short-grass prairie interspersed with gumbo knobs and ridges of varying sizes. The unit is bisected by Bridge Coulee, which runs from northwest to southeast through the unit draining into Big Dry Creek, which is off the unit. The coulee is characterized by steep ridges on either side with numerous small drainages and dry gullies leading to it. There are junipers growing along these drainages, while the rest of the unit is generally without trees. The trees cover less than $2 \%$ of the unit.

\section{NATURALNESS}

There are approximately three miles of water pipeline in the northern portion of the unit. The pipe is buried approximately six feet deep and is visible on the surface by the abundance of lush grass growing over it. Accompanying the pipeline are numerous water hydrants and stock water tanks. In the northeast portion of the unit there are water spreaders. There are approximately 11 small reservoirs on the unit. The impact of the water spreaders and reservoirs is substantially noticeable. Some receive more livestock use than others, and one or two are completely dry. Numerous vehicular ways, some of which have been improved, run through the unit. Many of them lead to reservoirs and all are used. Fences run throughout the unit as well. On the whole, these impacts combine to have a significant effect on the naturalness of the unit, due to their extent and distribution. 
OUTSTANDING OPPORTUNITY FOR SOLITUDE OR A PRIMITIVE AND UNCONFINED TYPE OF RECREATION

Unit $632^{\prime}$ does possess outstanding opportunities for solitude. Those features within the unit which contribute to the opportunities for solitude include many coulees and gumbo buttes, areas of open space and the configuration of the unit. The moderate dissection of the coulees make it possible for several people to be in the area at one time and yet still be unaware of each other. In a similar fashion the gumbo buttes and the juniper trees in the southern portion of the unit also serve as a natural means to physically and visually separate people. Another important element of solitude, contained within this unit is the availability of areas of open space. Areas such as these provide opportunities for solitude because of the opportunities for widespread dispersal and the feelings of solitude that are inspired by open vistas. The configuration of the unit corresponds well to the drainage patterns. The shape of the unit is conducive to promoting feelings of solitude since there is no portion of the unit that is constricted in either length or width.

The opportunities for primitive and unconfined recreation are not outstanding in Unit 632. Although opportunities for several different types of primitive recreation do exist on this Unit, these opportunities are not excellent. No combination of these opportunities are excellent. Those recreational activities for which there are opportunities on this unit include hiking, hunting, photography, horseback riding, rock collecting and bird watching. The diversity of terrain types in this unit provides good opportunities for hiking. While the terrain is not difficult enough to discourage walking it is still diverse enough that a person could choose between walking along the ridge tops, the bottoms of the coulees or in the open areas. The other recreational opportunities to be found within this unit include hunting for mule deer, pronghorn antelope and grouse, photographing landscapes, wildlife and wildflowers. Several different species of waterfowl, passerines, and some raptors were observed in the unit.

\section{SUPPLEMENTAL VALUES}

There are no known supplemental values in the unit. 
SUMMARY OF PUBLIC COMMENTS:

Several comments noted the contiguity of this unit to USF \& WL land. Other comments received supported the Intensive Inventory finding.

FINAL DECISION AND RATIONALE:

The contiguous USF \& WL lands do not affect the naturalness of this unit. The unit does not meet the naturalness criterion. The non-WSA recommendation is unchanged. 


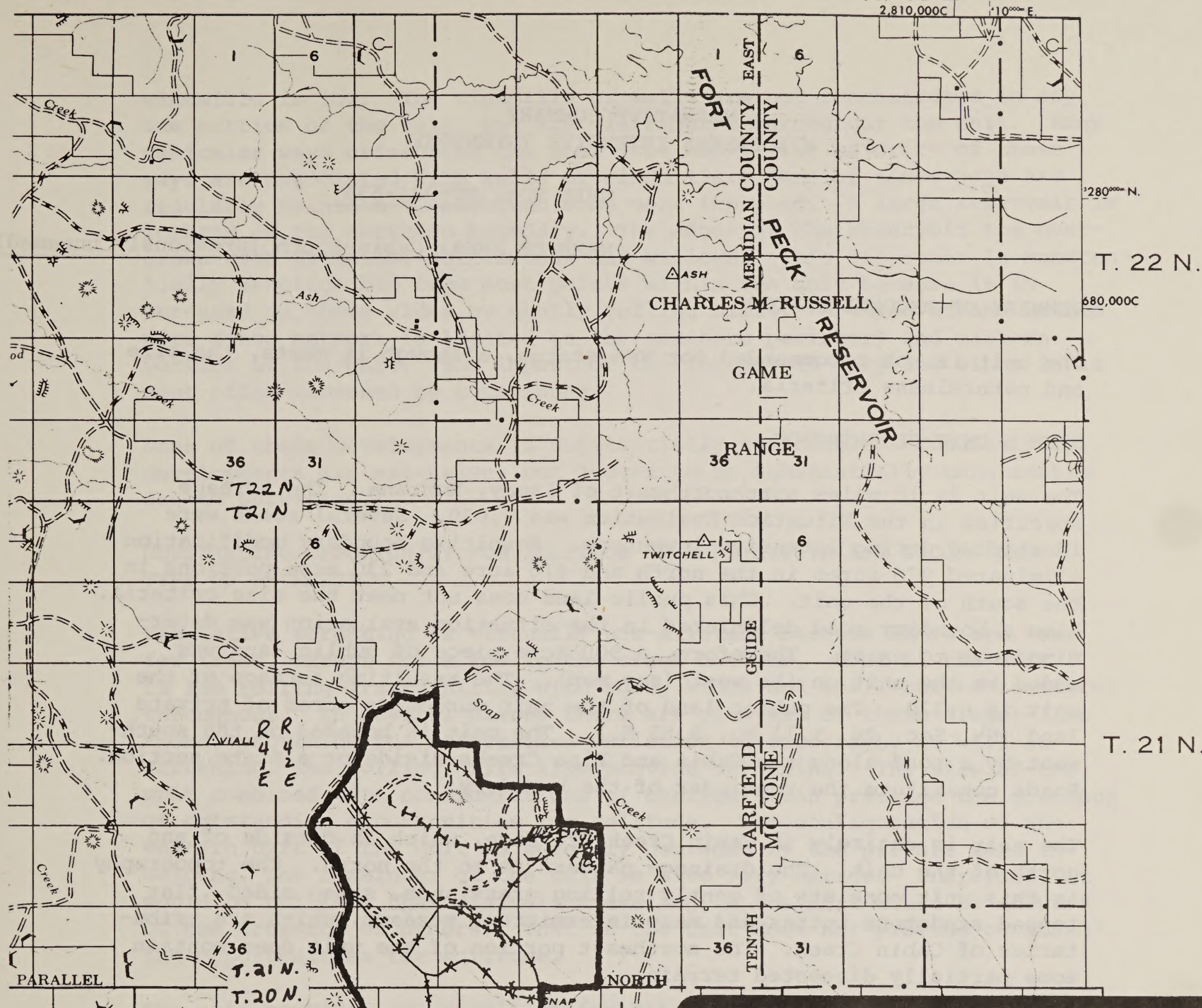
PARALLEL

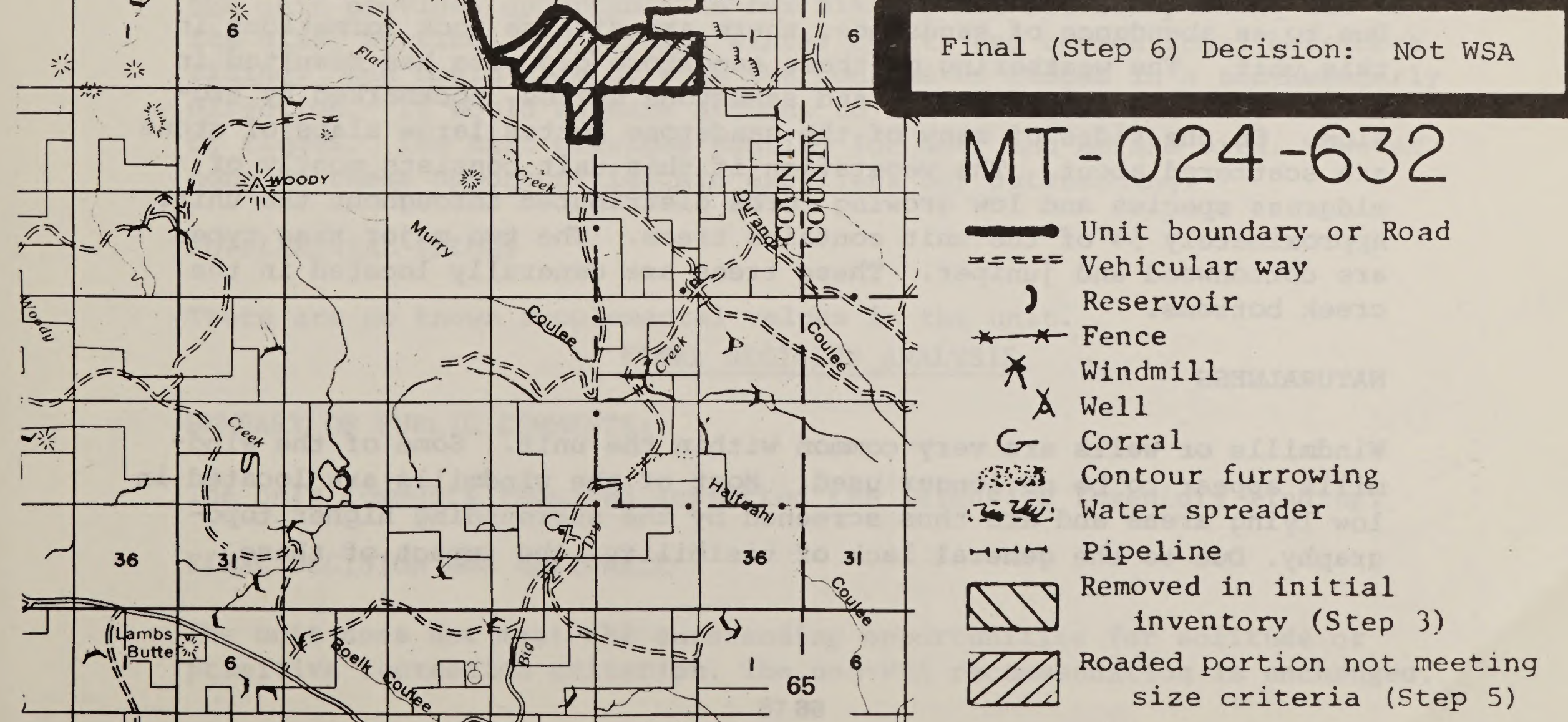




\section{NARRATIVE SUMMARY \\ WILDERNESS INTENSIVE INVENTORY}

UNIT NO: $\quad$ MT-024-634

NAME OF AREA: Cabin-South (previously unnamed)

\section{SUMMARY OF RECOMMENDATION}

The unit is not recommended for WSA status, although it meets, the size and naturalness criteria.

\section{SIZE \& UNIT DESCRIPTION}

The unit is 10 miles northnortheast of Ismay, Montana. The acreage specified in the Situation Evaluation was 7,030. Several roads were identified during intensive inventory. Resulting boundary modification eliminated 970 acres in the north and 410 acre and 230 acre portions in the south of the unit. This public land does not meet the size criteria. Also a boundary road deliniated in the situation evaluation was determined not to exist. Therefore, a 900 acre piece of public land was added to the unit on the west (see map). The resulting acreage of the unit is 6,320 . The public land of the unit surrounds acres of private land (N $\frac{1}{2}$, Sec. 26, T.11 N., R.55 E.). The unit is bounded on the southwest by a road along the Cabin and Pine Creeks divide or a state section. Roads constitute the remainder of the boundary.

The unit is entirely in Cabin creek drainage, which is outside of and north of the unit. The drainage pattern is to the north. The topography in this unit consists of gently rolling grasslands, steep sided, flat topped sandstone buttes and many intermittent streams, which are tributaries of cabin creek. The northeast portion of the unit does contain some partially dissected terrain.

Due to an abundance of sandstone, there are diverse rock formations in this unit. The weathering of these sandstone deposits has resulted in many large flat-topped buttes and sandstone spires, pockmarked by erosion. On the sides of many of the sandstone buttes large slabs of stone are scattered about. The vegetation if this unit consists mostly of midgrass species and low growing forbs distributed throughout the unit. Approximately 5\% of the unit contains trees. The two major tree types are cottonwood and juniper. These trees are generally located in the creek bottoms.

\section{NATURALNESS}

Windmills or wells are very common within the unit. Some of the windmills appear to be no longer used. Most of the windmills are located in low lying areas and are thus screened by the surrounding higher topography. Due to the general lack of visibility, the impact of these 
windmills is low. The windmills or wells are not concentrated in any one portion of the unit, but are distributed throughout the unit. Many vehicular ways crisscross the unit (see map). The majority of these ways are associated with wells or windmills. None of these rays are regularly maintained, although some were improved. A large reservoir is located on the northern boundary. The edges of the reservoir are overgrown with cattails, cottonwoods and willows. This reservoir is substantially unnoticeable from most points within the unit because it is screened on three sides by gently rolling hills. A three strand barbed wire fence network is located in the southern periphery and eastern portion of the unit. The impact of the fencing is very low since it is most often screened by topography.

None of these developments is substantially noticeable. Cumulatively, developments are extensive, but judged to be substantially unnoticable due to screening.

OUTSTANDING OPPORTUNITY FOR SOLITUDE OR A PRIMITIVE AND UNCONFINED TYPE OF RECREATION

Vegetative screening is virtually non-existent because there are very few trees, except for a few in the creek bottoms. Most of the unit is low rolling grassy hills, with rocky knobs and small buttes scattered throughout. In several places there are clusters of these finger-like knobs, providing for interesting variation in topography as well as screening. The rolling hills also provide screening. The size of the unit combined with considerations of configuration preclude the presence of outstanding opportunities for solitude. The configuration of the western part of the unit is severely degraded by the private land inholding. The remainder of the unit is also very narrow. Therefore, it would be unlikely that visitors traveling in the unit would be unaware of the presence of others. That is the unit does not provide outstanding opportunities for solitude.

The unit provides opportunities for hiking, but not backpacking due to its size, hunting, and perhaps winter sports and recreational horseback riding. One could ride or walk the coulees or ridges in a southwesterly direction. It would be more arduous to travel across the many coulees or ridges. The unit provides hunting for deer and upland bird. However, none of these opportunities are excellent nor outstanding.

\section{SUPPLEMENTAL VALUES}

T'here are no known supplemental values in the unit. FINAL DECISION ANALYSIS

\section{SUMMARY OF PUBLIC COMMENTS :}

The only comments received supported the Intensive Inventory finding. FINAL DECISION AND RATIONALE:

The unit does not meet the outstanding opportunities for solitude or primitive recreation criterion. The non-WSA recommendation is unchanged. 


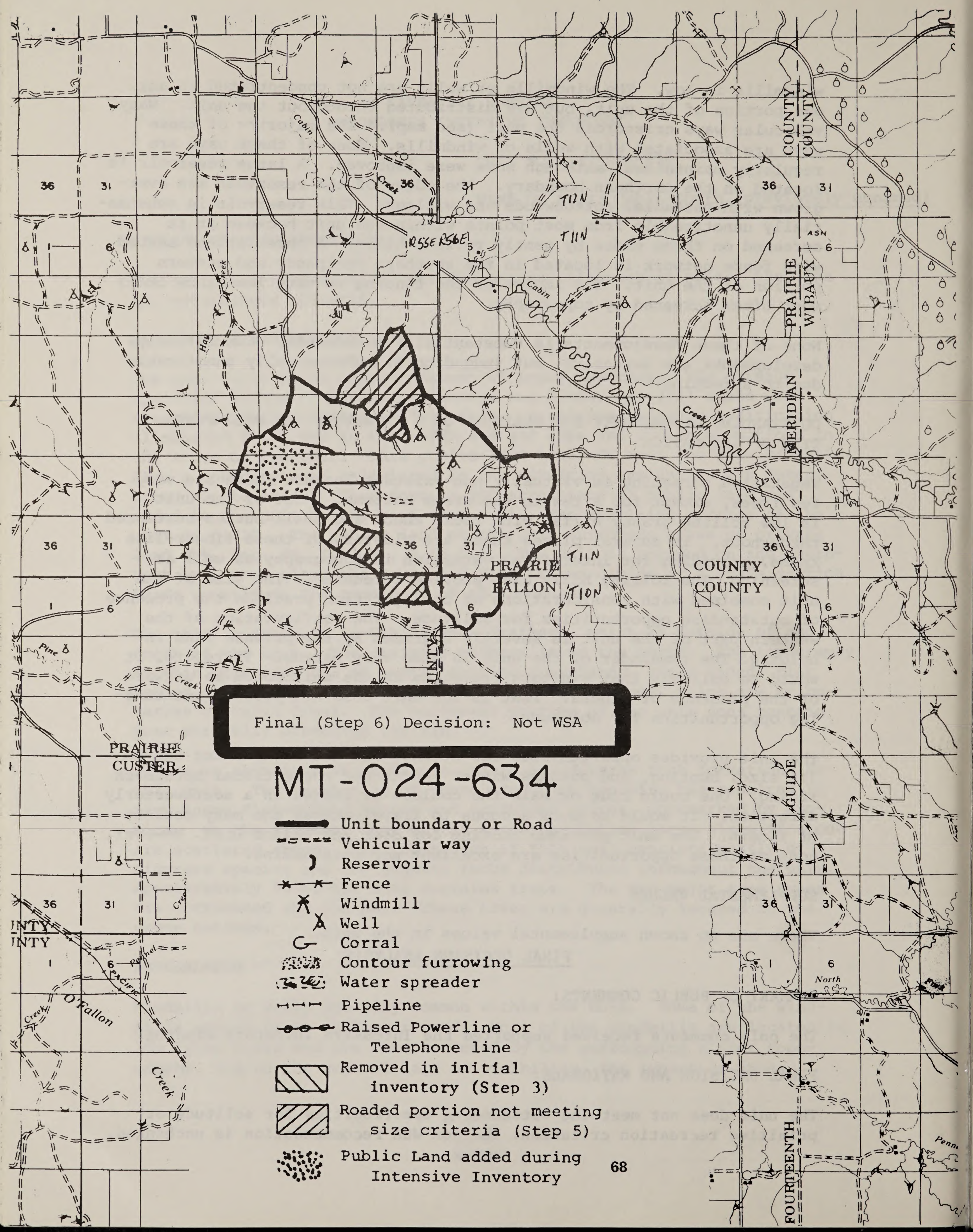




\section{NARRATIVE SUMMARY \\ WILDERNESS INTENSIVE INVENTORY}

UNIT: $\underline{M T-024-635}$

NAME OF UNIT: Timber

Creek

\section{SUMMARY OF RECOMMENDATION}

The unit is not recommended for WSA status, although it meets the size criterion.

\section{SIZE \& UNIT DESCRIPTION}

This unit is 6500 acres in size. There is a 80 acre small private inholding ( $W \frac{1}{2} \mathrm{SW}$, Sec.28, T.15 N., R.46 E.) in the western portion of the unit. The western boundary is private land, as is part of the southern, eastern, and northern boundary. The remainder is bounded by either a state section or a road running through public land. A road was identified during intensive inventory, which extends three miles southeast from the northwest corner. The boundary is modified to exclude the road, but the acreage change is negligible.

Unit 635 is primarily flat grassland dominated by Western Wheatgrass and other grasses and forbs. Timber Creek (intermittent) runs from southeast to northwest through the unit, and with its tributaries provides for some variation in topography in the form of small to medium-size coulees and small ridges. The few trees (juniper) in the unit are found in these coulee bottoms, along with some fairly dense brush in places. The trees and brush cover less than $2 \%$ of the unit.

\section{NATURALNESS}

There are approximately four miles of fences and five windmills in the unit, as well as a four acre reservoir, a three acre reservoir, two small reservoirs, and portions of a nine acre and four acre reservoir. There are about six miles of vehicular ways on the unit - most of them associated with reservoirs and windmills. Most of the developments are west of the eastern quarter of the unit, which is dominated by the headwaters of the creek. There is one small barbed wire exclosure in Section 28.

The developments are conspicuous. The vehicle ways are well defined from use. From most parts of the unit developments are apparent. This is due to their extent and distribution combined with the open topography of the unit. 
OUTSTANDING OPPORTUNITY FOR SOLITUDE OR A PRIMITIVE AND UNCONFINED TYPE OF RECREATION

Unit 635 does not have outstanding opportunities for solitude. Since it is primarily flat there is little topographic screening, except when one is actually in the coulee bottoms. Vegetative screening is virtually non-existent since there are so few trees on the unit. The road which creates a corridor extending well into the unit, significantly impacts the configuartion of the unit. The screening and configurational deficiencies are not overcome by size. The combination of the lack of screening, poor configuration and small size preclude outstanding opportunities for solitude.

Unit 635 does not have outstanding recreational opportunities. The unit is suitable for hiking or horseback riding, although not particularly desirable. The unit is cut by a corridor so the area available for hunting or other recreation is somewhat reduced. Opportunity for antelope hunting is fairly good, judging from the topography and vegetation. No individual or combination of activities is outstanding.

SUPPLEMENTAL VALUES

There are no known supplemental values.

\section{FINAL DECISION ANALYSIS}

SUMMARY OF PUBLIC COMMENTS:

The only comments received supported the Intensive Inventory finding. FINAL DECISION AND RATIONALE:

The unit does not meet the naturalness nor the outstanding opportunities for solitude or primitive recreation criteria. The non-WSA recommendation is unchanged. 


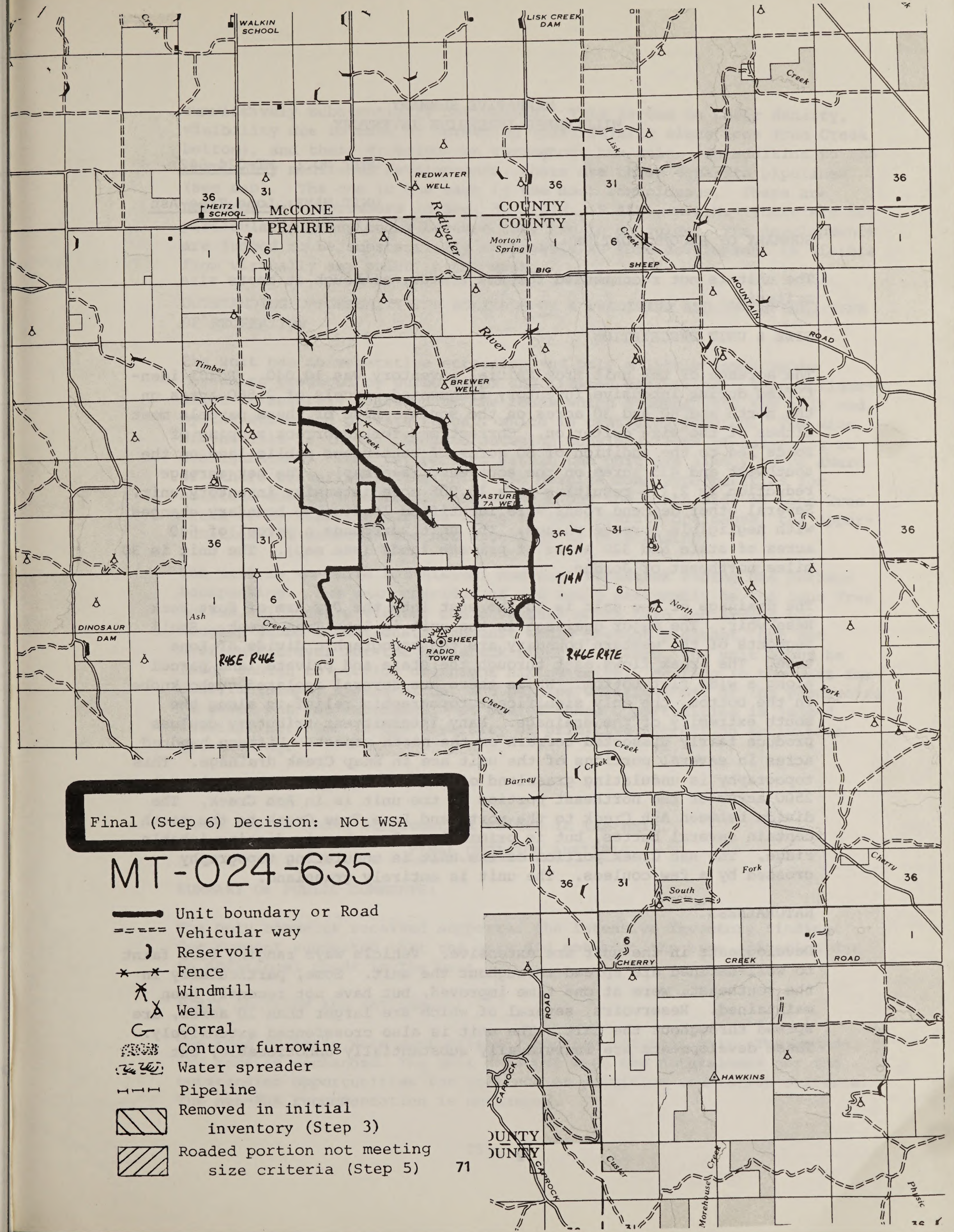




\section{NARRATIVE SUMMARY \\ WILDERNESS INTENSIVE INVENTORY}

UNIT NO.: MT-024-642

UNIT NAME: Lone Tree-Ash

\section{SUMMARY OF RECOMMENDATION}

The unit is not recommended for WSA status, although it meets size criteria.

\section{SIZE \& UNIT DESCRIPTION}

The acreage of the unit from initial inventory was 19,040. Roads identified during intensive inventory fragmented parcels of 2,560 acres on the north and 60 and 30 acres on the south. None of these parcels meet either of the size criterion. Corrections for incorrect mapping of roads led to the addition of 80 acres of contiguous public land on the southwest and 435 acres on the southeast (see map). The net acreage reduction is 2,135 resulting in a 16,905 acre intensive inventory unit. Several other deadend roads were identified leading to boundary changes with negligible acreage change. The unit surrounds a parcel of 640 acres of state and 320 acres of private lands (see map). The unit is 30 miles northeast of Jordan.

The drainage of the unit is to the east into the Dry Arm of Fort Peck Reservoir. The major drainage in the unit is Lone Tree Creek. Small segments of the western boundary are the topographic divide of Lone tree. The creek flows east through the state and private land parcel along a wide flat bottom. While there are several isolated gumbo knobs in the bottom, the only significant topographic relief is along the south extremity of the drainage. Many intermittent tributary coulees produce fairly dissected terrain on the north aspect. Fifteen hundred acres in several portions of the unit are in Snap Creek drainage. This topography is undulating grassland of the south aspect. Approximately 2500 acres of the northeast portion of the unit is in Ash Creek. The divide between Ash Creek to the north and Lone Tree Creek to the south contain several buttes, but is primarily a low, barely distinguishable ridge. The Ash Creek portion of the unit is undulating topography crossed by a few coulees. The unit is entirely grassland.

\section{NATURALNESS}

Developments in the unit are extensive. Vehicle ways ranging from faint to well-defined are spread throughout the unit. Some, particularly in the southeast, were at one time improved, but have not recently been maintained. Reservoirs, several of which are larger than 10 acres, are spread throughout the unit. The unit is also crossfenced extensively. These developments are individually substantially unnoticeable, but 
cumulatively substantially noticeable. This is due to their density, visibility due to lack of screening (particularly along Lone Tree Creek bottom), and their distribution throughout the unit. In addition to the previously mentioned developments, there are three separate pipelines (see map). The one in the east is the most conspicuous. There are numerous waterspreaders in Sec. 3, T.21N., R.4lE., M.P.M. These are not particularly conspicuous because they are in a coulee. The developments are judged to be substantially noticeable as some development is visible from virtually any point in the unit.

OUTSTANDING OPPORTUNITY FOR SOLITUDE OR A PRIMITIVE AND UNCONFINED TYPE OF RECREATION

The unit has no vegetative screening and only a little topographic screening produced by gumbo knobs and limited dissection. The configuration is severely degraded by the roads which deadend into the unit and by the state and private parcel, which is centrally located. The size of the unit is insufficient to outweigh considerations of screening or configuration. That is, parties within the unit are likely to be aware of others traveling in the unit. So despite some opportunities for solitude due to topographic screening along the south side of Lone Tree Creek or by visiting parties being in two separate drainages, the opportunities for solitude are not excellent or outstanding.

The unit is suitable for hiking, hunting, horseback riding and perhaps backpacking. The main corridor of use would presumably be the Lone Tree bottom, although a visitor could venture south onto and around the rougher gumbo formations. The unit would present pleasant, but not difficult travel for the horseback rider or hiker. The unit might be large enough to provide overnight hiking trips. Hunting in the unit for deer, antelope, upland birds, and perhaps waterfowl off of the reservoirs is good, but not excellent. No one of these opportunities is judged outstanding. Nor is the diversity of primitive recreation activities outstanding.

\section{SUPPLEMENTAL VALUES}

There are no known supplemental values in the unit.

\section{FINAL DECISION ANALYSIS}

\section{SUMMARY OF PUBLIC COMMENTS:}

The only comments received supported the Intensive Inventory finding. One comment suggested that the unit did not meet the size criterion due to additional roads in the unit.

FINAL DECISION AND RATIONALE:

The road criteria were appropriately applied for this unit. The boundary remains unchanged. The unit does not meet the naturalness nor the outstanding opportunities for solitude or primitive recreation criteria. The non-WSA recommendation is unchanged. 


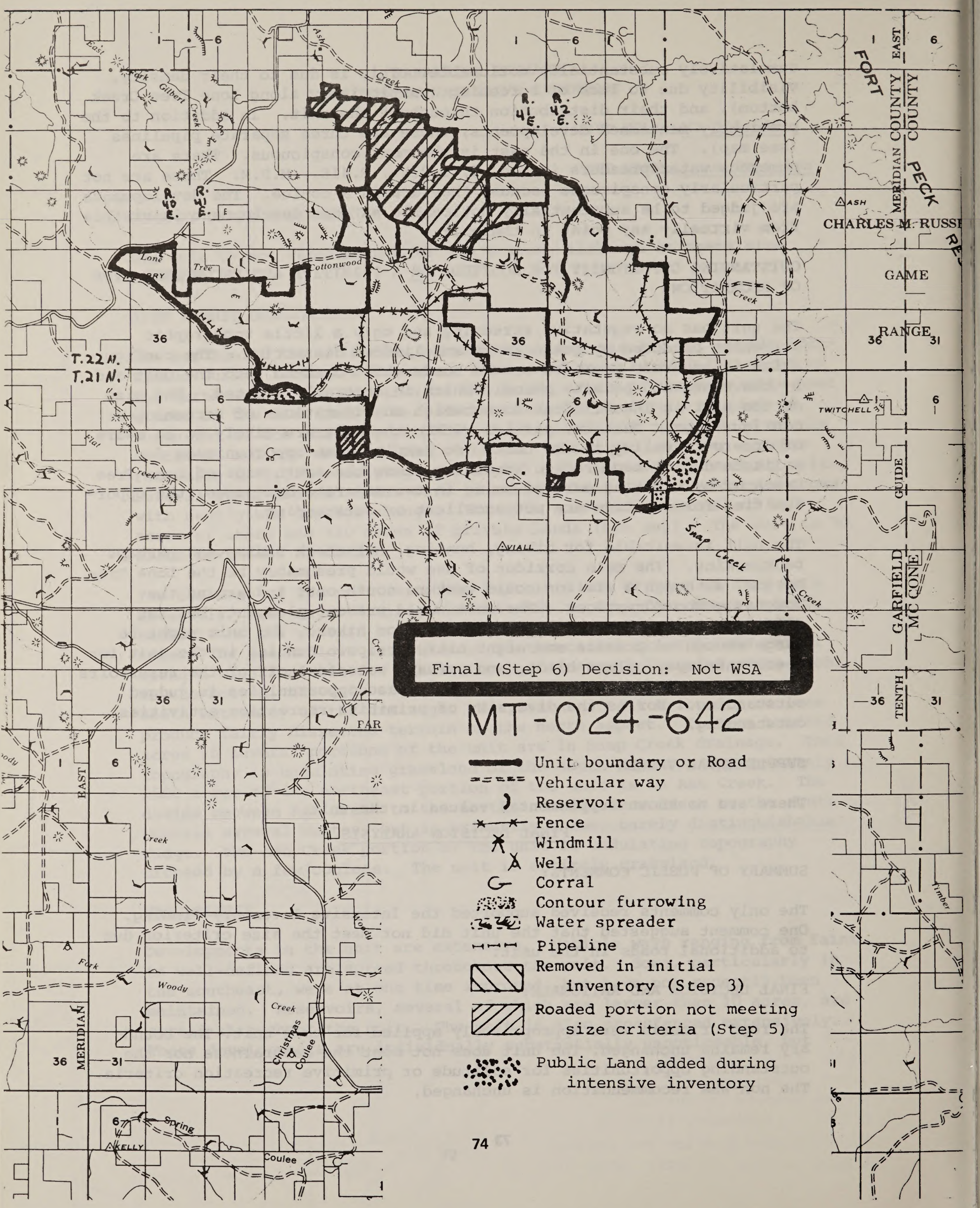


NARRATIVE SUMMARY

WILDERNESS INTENSIVE INVENTORY

UNIT NO.: $\frac{\text { MT-024-643 }}{\text { NAME OF AREA: Sand Arroyo }}$

\section{SUMMARY OF RECOMMENDATION}

The unit is not recommended for WSA status, although it meets the size and naturalness criteria.

\section{SIZE \& UNIT DESCRIPTION}

Unit 643 is 6,990 acres in size. It is located 15 miles southeast of Fort Peck, MT at R. $43 \mathrm{E} ., \mathrm{T} .24$ and $25 \mathrm{~N}$. For the most part it is contiguous to private land. The southwestern portion is a defined road and $\frac{1}{2}$ mile of the west boundary is in common with U.S. Fish and Wildilfe lands.

This unit is basically flat, open grassland (less than 1\% tree cover). It is broken in places by Sand Arroyo and its side drainages which run generally northeast to southwest and drain into Fort Peck Reservoir. Most of the breaks are in the western and southern portions of the unit, while the remainder is almost completely level, with occasional gumbo knobs and buttes. Sagebrush cover is extensive throughout the unit (approximately 80\%).

\section{NATURALNESS}

There are relatively few man-made developments in unit 643. There are nine reservoirs within the boundary, and two others partially within it. These are scattered throughout the unit and no more than two are visible from one another. None of them are larger than eight acres. Several miles of vehicle trails run into the unit. They are, for the most part, associated with reservoirs, and none of them receive regular maintenance. There are approximately six miles of fence, mostly in the southern portion of the unit. The central portion is generally void of developments, probably due to the more rugged topography. None of the developments are particularly obtrusive, and their cumulative impact is not significant.

\section{OUTSTANDING OPPORTUNITY FOR SOLITUDE OR A PRIMITIVE AND UNCONFINED TYPE} OF RECREATION

This unit does not contain outstanding opportunities for solitude because it is lacking significant topographic or vegetative screening. Since the unit consists primarily of open, gently rolling grasslands, with occasional gumbo knobs and ridges, the opportunities for topographic screening are slight. Opportunities for vegetative screening are virtually nonexistant since the dominant vegetative cover are grasses and sagenrush. Although opportunities for solitude, provided by large 
open vistas are present on this unit, the opportunities for solitude are still not outstanding since there is not enough diversity of terrain types to insure adequate dispersal or screening.

Although the open, rolling nature of this unit provides opportunities for activities such as hiking, backpacking, horseback riding and cross country skiing there is no single activity or combination of activities which provide outstanding opportunities for primitive recreation. opportunities for the recreational activities present on this unit are not outstanding and are similar to opportunities for these activities on other areas of public land in the vicinity of the unit.

SUPPLEMENTAL VALUES

There are no known supplemental values in the unit.

\section{FINAL DECISION ANALYSIS}

SUMMARY OF PUBLIC COMMENTS:

One comment noted that this unit is contiguous to USF \& WL land. Other comments received supported the Intensive Inventory finding.

FINAL DECISION AND RATIONALE:

The contiguous USF \& WL lands are along .5 miles of the western boundary of this unit. They do not affect the outstanding opportunities for solitude or primitive recreation of the unit. The unit does not meet the outstanding opportunities for solitude or primitive recreation criterion. The non-WSA recommendation is unchanged. 


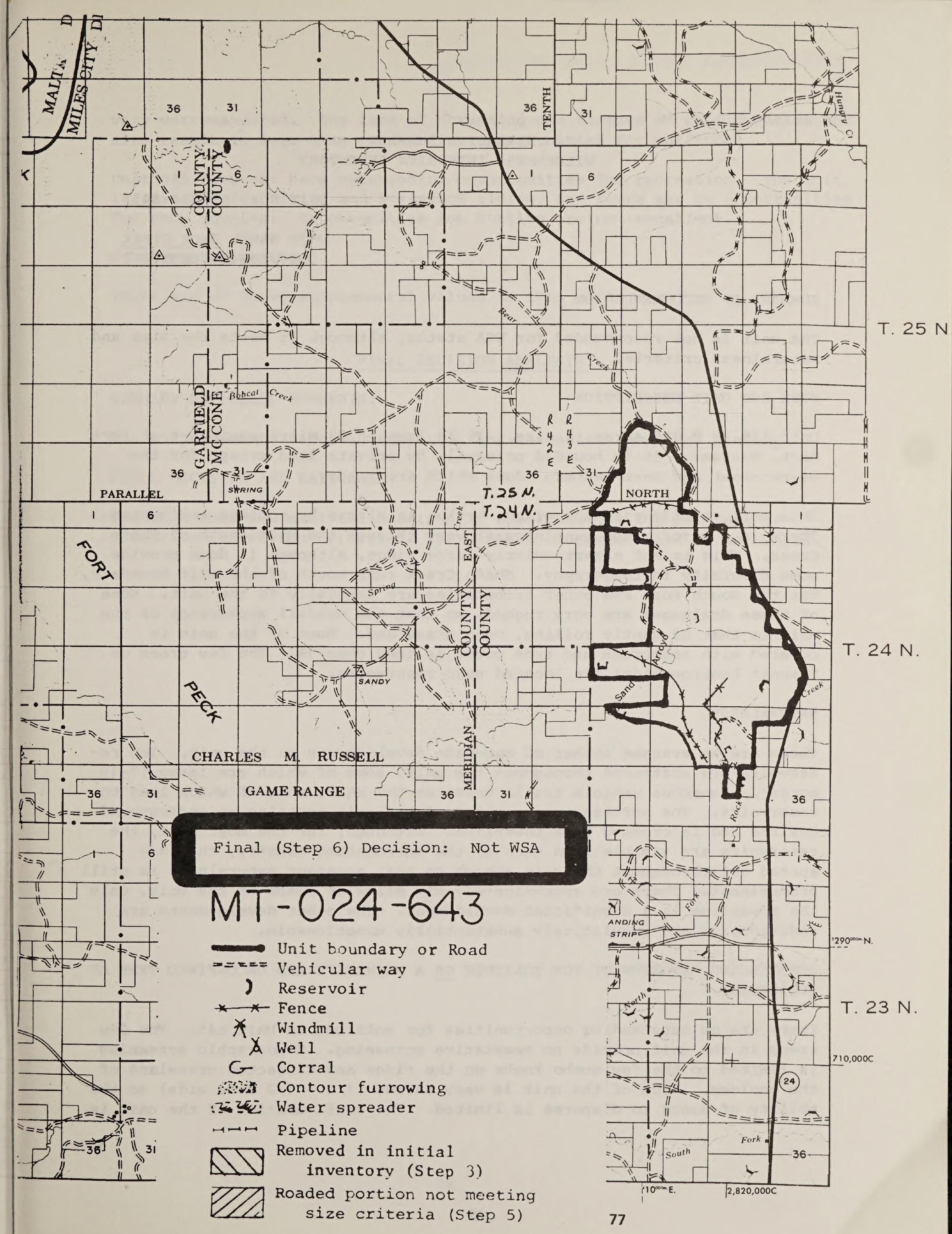




\section{NARRATIVE SUMMARY \\ WILDERNESS INTENSIVE INVENTORY}

UNIT NO: $\underline{\text { MT-024-645 }}$

UNIT NAME: Jack Creek

(previously unnamed)

\section{SUMMARY OF RECOMMENDATION}

The unit is not recommended for WSA status, although it meets the size and naturalness criteria.

\section{SIZE AND UNIT DESCRIPTION}

Unit 645 is 9,720 acres in size. It is located 25 miles southeast of Fort Peck, Montana. It is bounded primarily by private land except for the westernmost and northeastern edges which are roads.

This unit is primarily grassland, broken in places by coulees and buttes. There is a major ridge running east-west through the unit south of shade creek. This is not a particularly large ridge, although it does provide some diversity in topography. Shade creek runs north of the unit boundary, but the South Fork and other tributaries are partially in the unit. None of these drainages are very rugged, so that the overall appearance of the unit is that of gently rolling, open grassland. Much of the unit is covered with sagebrush and tree cover is less than $1 \%$. The few trees on theunit (cottonwoods) are located near reservoirs.

\section{NATURALNESS}

There are an average number of man-made developments on the unit. Ten reservoirs are scattered throughout the unit, some of which are large (7-10 acres). Numerous vehicle trails traverse the unit, most of which lead to reservoirs. The northeastern portion of the unit contains an underground gasline and is crossed by a powerline. Although, for the most part, the reservoirs are visible from much of the surrounding country, they are spread out throughout the unit enough so that apparent naturalness is still predominant. There are approximately six miles of fence on the unit. Only the powerline is a significant development. The other developments are individually and cumulatively substantially unnoticeable.

OUTSTANDING OPPORTUNITY FOR SOLITIDE OR A PRIMITIVE AND UNCONEINED TYPE OF RECREATION

There are no outstanding opportunities for solitude in Unit 645 . The few trees in the unit provide no vegetative screening. Topographic screening is limited to the few gumbo knobs on the ridge and dissected grassland of the coulees. Much of the unit is very narrow $(1 / 4-1 / 2$ mile wide) so the ability of users to disperse is limited. The configuration of the unit is 
very gerrymandered. The lack of screening and factors of configuration and size result in less than outstanding opportunities for solitude.

Unit 645 does not have outstanding opportunities for recreation. The unit is suitable for hiking and horseback riding, and there may be opportunities for rock hunting. Opportunities for hunting are not excellent.

SUPPLEMENTAL VALUES

There are no known supplemental values in this unit.

\section{FINAL DECISION ANALYSIS}

SUMMARY OF PUBLIC COMMENTS:

The only comments received supported the Intensive Inventory finding.

FINAL DECISION AND RATIONALE:

The unit does not meet the outstanding opportunities for solitude or primitive recreation criterion. The non-WSA recommendation is unchanged. 
$\longrightarrow$ Unit boundary or Road

$====$ Vehicular way

) Reservoir

* $*$ Fence

$x$ Windmill

a Well

G Corral

Contour furrowing

: water spreader

サロル Pipeline

Ty Removed in initial

A inventory (Step 3)

7 Roaded portion not meeting

(Step 5)

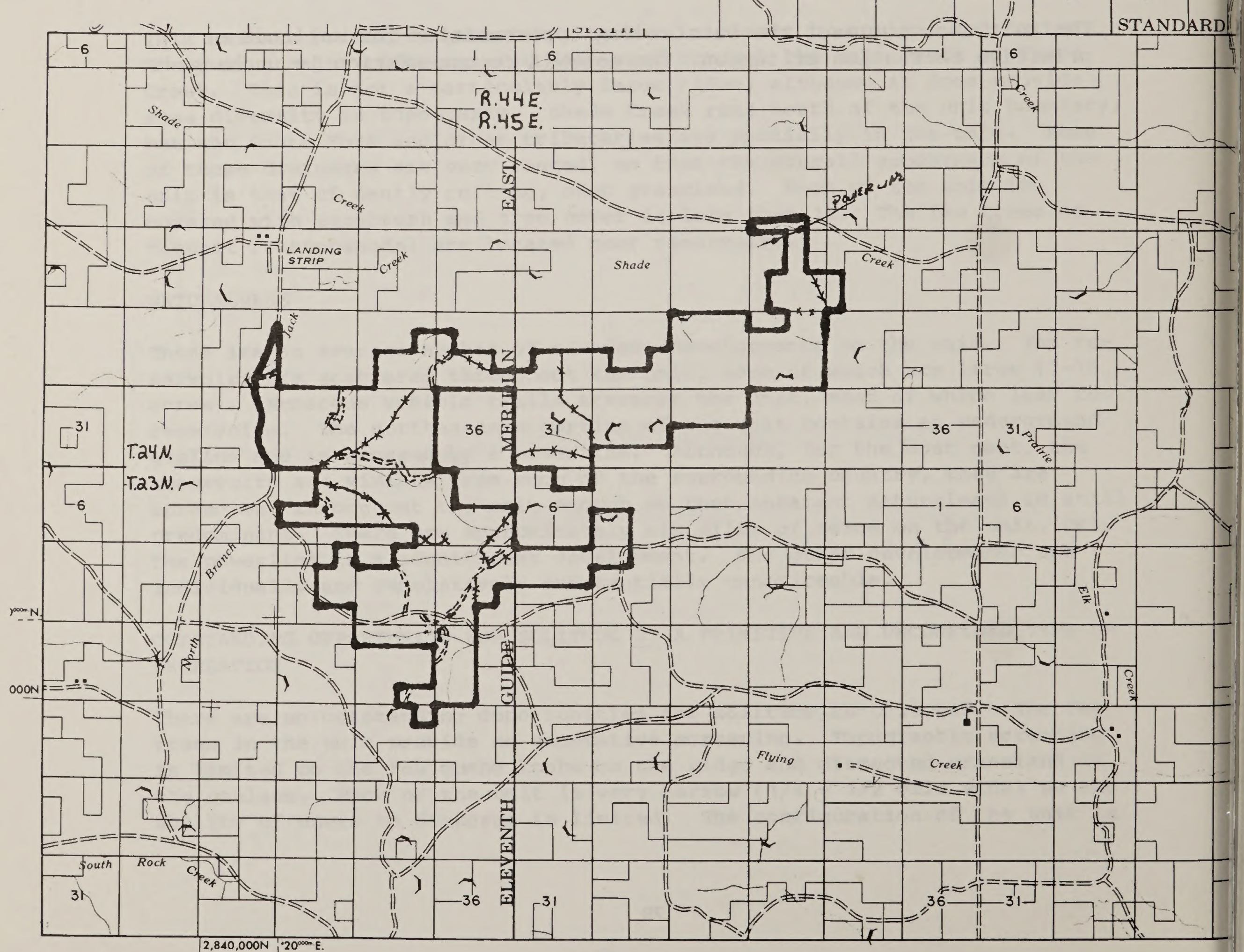


NARRATIVE SUMMARY

WIIDERNESS INTENSIVE INVENTORY

\author{
UNIT NO.: $\quad$ MT-024-646 \\ UNIT NAME: MCGuire Creek \\ (formerly unnamed)
}

SUMMARY OF RECOMMENDATION

The unit is not recommended for WSA status, although it meets the size criterion.

\title{
SIZE AND UNIT DESCRIPTION
}

The acreage of the initial inventory unit was 13,440 acres. Roads were identified during intensive inventory which fragment the unit into four portions (see map). An eastern portion, generally east of the private inholding, has an acreage of 3,720. The portion in the northwest of the unit has an acreage of 3,840. A portion in the southernmost part of the unit has an acreage of 100. None of these three roadless areas of public land meet any of the size criteria. The remainder of the unit has an acreage of 5,780 and meets the 5,000 acre size criterion. The unit is approximately 30 miles south of Ft. Peck, Montana. It is east of and partially bordered on the west by Montana Highway 24. Only the 5,780 acre portion will be considered in the remainder of this intensive inventory report.

The entire unit is drained by several intermittent tributaries of McGuire Creek which is out of the unit and south of it. The major tributary is Rough Prong McGuire Creek which drains the central two-thirds of the unit and flows southwesterly. The topography of the southeastern half of the unit is dominated by the divide south of Rough Prong McGuire Creek which contains some deep coulees and scattered buttes. The northwest half of the unit is undulating with virtually no dissected terrain. The vegetation on the unit is exclusively grass, forbs, and some sagebrush. There are no trees on the unit.

\section{NATURALNESS}

Range developments are the major imprint of man in the unit with the exception of a raised telephone line along part of the western boundary and a sealed well on the northern boundary. There are seven reservoirs in the unit, each four acres or less. Those in the east of the unit are, to a considerable extent, topooraphically screened. The three reservoirs along the west boundary are not so well screened, but no one is substantially noticeable. There are four miles of fence in the southern portion of the unit. Vehicle ways exist in the unit in four places. The most well-defined one is in the northwest corner. No one of these developments is substantially noticeable. However, cumulatively they are substantially noticeable. 
This is due to a combination of the density and distribution of the developments and their visibility due to marginal screening.

OUTSTANDING OPPORTUNITY FOR SOLITUDE OR A PRIMITIVE AND UNCONFINED TYPE OE RECREATION

The unit displays some topographic screening in the southeast, but no vegetative screening anywhere. The configuration of the unit is compact with only a few protrusions along the eastern boundary. Only along the north boundary does the boundary correspond to a topographic feature (a ridge). The unit is not large enough to overcome the general lack of screening despite fairly good configuration. A visitor might find isolated pockets inthe southeast which provide opportunities for solitude, but the opportunities are not outstanding within the unit.

Primitive recreational activities for which the unit provides opportunities include hunting and hiking. Neither of these opportunities could be considered excellent.

SUPPLEMENTAL VALUES

The unit has no known supplemental values.

\section{FINAL DECISION ANALYSIS}

SUMMARY OF PUBLIC COMMENTS:

The only comments received supported the Intensive Inventory finding. FINAL DECISION AND RATIONALE:

The unit does not meet the naturalness nor the outstanding opportunities for solitude or primitive recreation criteria. The non-WSA recommendation is unchanged. 
Final (Step 6) Decision: Not WSA

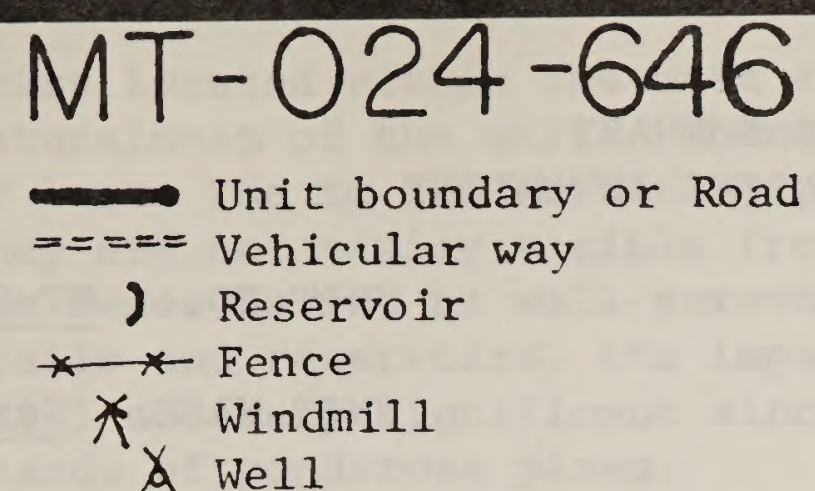

G Corral

Wis Contour furrowing

: Water spreader

円セロ Pipeline

\$1 Removed in initial $72 \begin{gathered}\text { Roaded portion not meeting } \\ \text { size criteria (Step 5) }\end{gathered}$

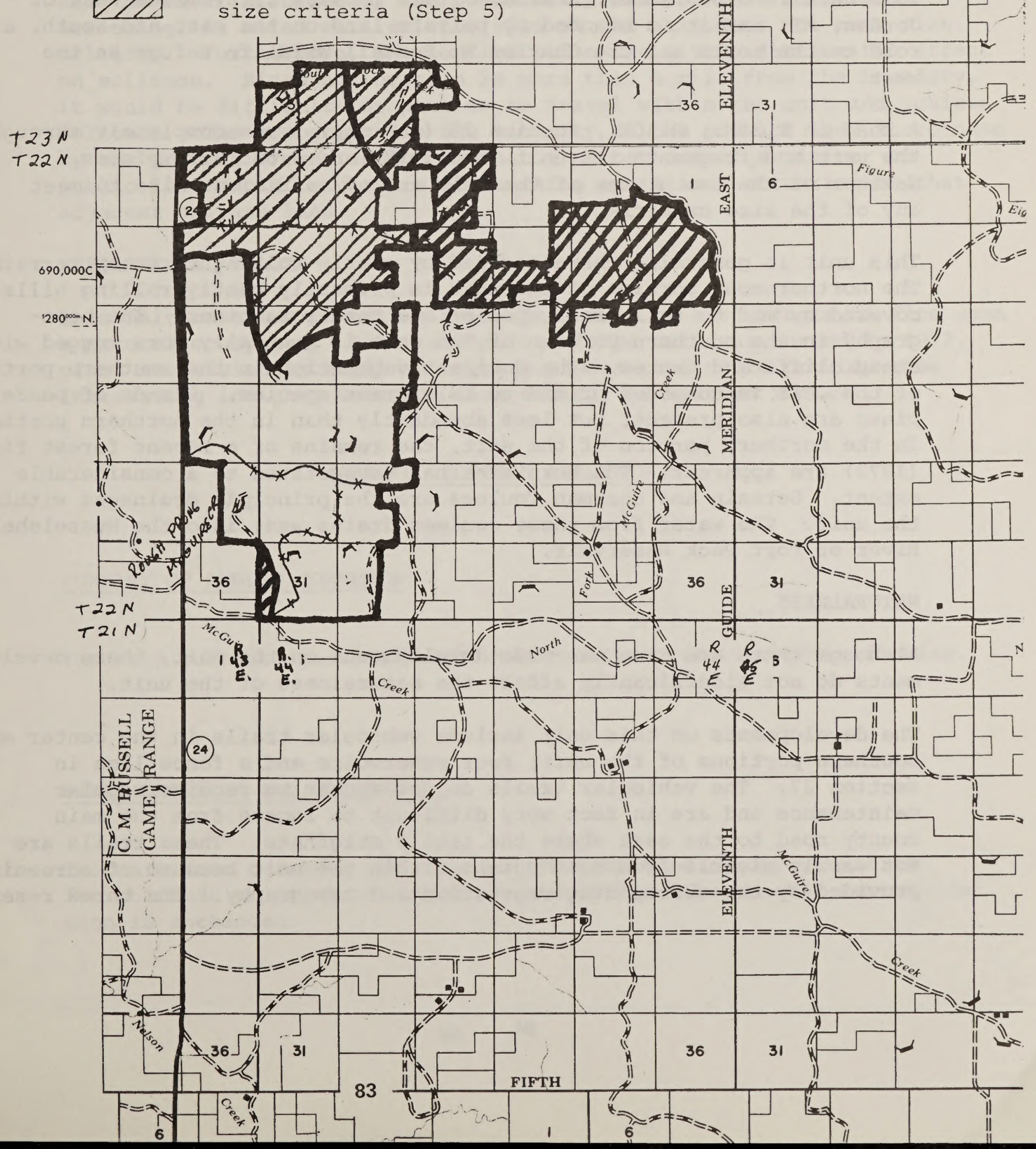


UNIT NO.: $\quad$ MT-024-648

UNIT NAME: Germaine Coulee

\section{SUMMARY OF RECOMMENDATION}

The unit is not recommended for WSA status, although the roadless areas it contains do meet the naturalness criterion.

\section{SIZE \& UNIT DESCRIPTION}

This unit is 5,065 acres in size. It is located fifty miles west of Jordan, MT, and it is bounded by private land on the east and south, a road to the north and the Charles M. Russell Wildlife Refuge on the west.

A road in T.19N., R.30E., Section 23 (see map), runs completely through the unit and fragments the unit into 1,380 and 3,685 acre pieces. Neither of the two pieces of the unit are of sufficient size to meet any of the size criteria.

This unit is generally characterized by gently rolling to steep terrain. The northernmost portion of the unit is primarily gently rolling hills, covered by mid to tall grass species and ponderosa pines. The topography in the southern portion of the unit is generally more rugged with steep cliffs and buttes. The dominant vegetation in the southern portion of the unit is composed of mid to tall grass species. Stands of ponderosa pines are also present, but less abundantly than in the northern portion. In the northern portion of the unit, the remains of a recent forest fire (1972) are apparent. The burn area has revegetated to a considerable extent. Germain and Sherman coulees are the principle drainages within the unit. The water from these coulees drains west into the Musselshell River or Fort Peck Reservoir.

\section{NATURALNESS}

Although there are some man-made developments on the unit, these developments do not significantly affect the naturalness of the unit.

The developments on this unit include vehicular trails in the center and southern portions of the unit; four reservoirs and a fence line in section 27. The vehicular trails do not appear to receive regular maintenance and are in fact very difficult to locate from the main county road to the east where the trails originate. These trails are not easily visible from most points within the unit because of screening provided by the surrounding vegetation and topography. The three reser- 
voirs located within the unit also do not significantly affect the naturalness of the unit. These reservoirs are small in size, four acres or less. Due to the screening provided by the surrounding topography, they are not easily visible from most points within the unit. Although the fence is not as well screened by the surrounding topography as the trails and reservoirs, its impact upon the naturalness of the unit is still not very significant since portions of the fence are screened by stands of ponderosa pines.

\section{OUTSTANDING OPPORTUNITY FOR SOLITUDE OR A PRIMITIVE AND UNCONFINED} TYPE OF RECREATION

Due to the broken topography and the presence of stands of ponderosa pines throughout the unit, there are opportunities for solitude. The many rolling hills and ridges provide excellent topographic screening and the cover afforded by the ponderosa pines provides additional screening. As noted earlier, the size of the unit does not meet size criteria. Furthermore, the configuration has a very detrimental effect on solitude. Since no location is more than $\frac{1}{2} \mathrm{mile}$ from the boundary, it would be difficult for parties to travel within the unit and achieve solitude. The topography in the vicinity of the private land surrounded by the unit is broken enough so that (in most cases) a visitor on public land would be unaware of ranching operations occurring on that adjacent private land.

\section{SUPPLEMENTAL VALUES}

This unit contains potential as a study area of the effects of fire upon a natural ecosystem. Since a portion of the unit was burned in 1972, plant succession is still an ongoing process and could provide some interesting insights into the fire ecology of eastern Montana.

\section{FINAL DECISION ANALYSIS}

SUMMARY OF PUBLIC COMMENTS:

The only comments received supported the Intensive Inventory finding.

FINAL DECISION AND RATIONALE:

The unit does not meet the size nor the outstanding opportunities for solitude or primitive recreation criteria. The non-WSA recommendation is unchanged. 
Final (Step 6) Decision: Not WSA

MT-024-648

Unit boundary or Road

$====$ Vehicular way

) Reservoir

* $*$ Fence

X Windmill

A We11

$G$ Corral

Wis Contour furrowing

: Water spreader

カヤ円 Pipeline

$\$$ Removed in initial

A inventory (Step 3)

77 Roaded portion not meeting

size criteria (Step 5)

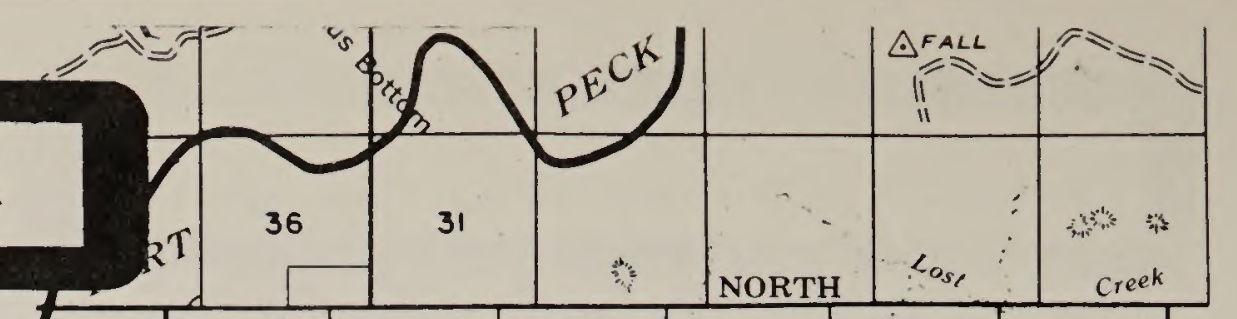

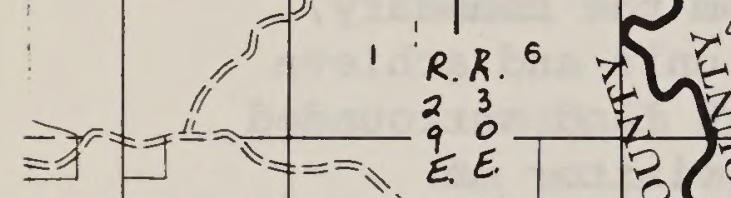

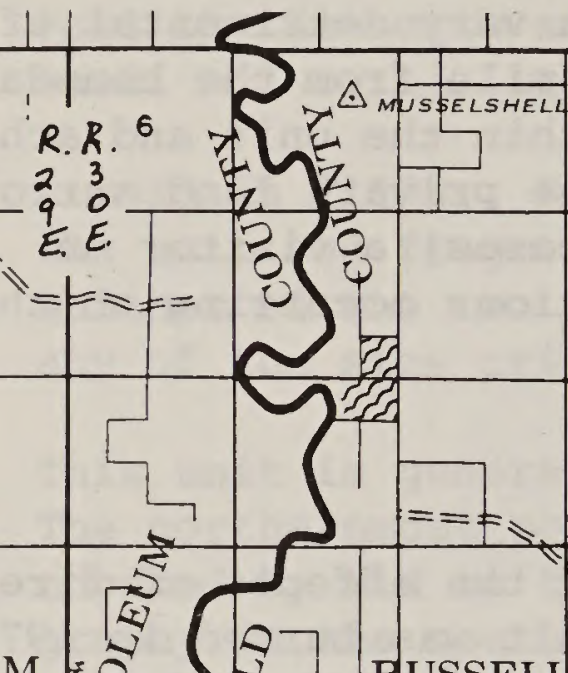

HARLES

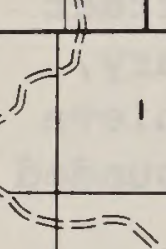


NARRATIVE SUMMARY

WILDERNESS INTENSIVE INVENTORY

\author{
UNIT NO.: $\quad$ MT-024-649 \\ UNIT NAME: South Fork Little \\ Squaw Creek
}

\title{
SUMMARY OF RECOMMENDATION
}

The unit is not recommended for WSA status, although it meets the size and naturalness criteria.

\section{SIZE AND UNIT DESCRIPTION}

A boundary revision in the northeast corner of the unit occurred during the initial inventory (see map). Several additional roads were identified during intensive inventory which led to boundary revisions, but negligible acreage reduction. The size of the unit remains the same as that of the Final Initial Inventory $(16,400)$. The unit is generally bounded on the north and south by private lands and on the west and east by roads. There is one parcel of 640 acres of state and 960 acres of private land surrounded by public land of the unit. This is in the western part of the unit. Approximately 1.75 miles of the northwest boundary is common with U.S. Fish and Wildlife land. There is a maximum of 470 acres of US FWL roadless land contiguous to the unit, none of which is being recommended for wilderness as part of the F\&WL wilderness review process.

The South Fork Little Squaw Creek, a major tributary of Squaw Creek, flows north-northwesterly through the unit and drains most of it. Portions of the unit in the northwest and northeast drain directly into squaw Creek, which is just north of the unit. The south Fork of Little Squaw Creek meanders within a narrow $(.25$ mile) bottom with steep walls and a few cliffs rising above it. The remainder of the unit is dissected by intermittent tributaries. The topographic relief is most pronounced alona the south Fork Little squaw and diminishes somewhat in the southeastern and western parts of the unit. The ridgetops are fairly wide and covered with grass. Small stands of ponderosa pine and some juniper are scattered throughout the unit. They generally occur on north-facing slopes and cover approximately $20 \%$ of the unit. A considerable portion of the unit was burned in the last decade.

\section{NATURALNESS}

Works of man consist almost exclusively of range improvements. Reservoirs and fences are spread throughout the unit. There is also some surface disturbance caused by mechanized equipment during wildfire control. The size and vegetation around the reservoirs vary somewhat. However, they are each inconspicuous due to the topography and in some cases vegetative screening. No one reservoir is substantially noticeable. A similar situation exists 
for fences and vehicle ways. Cumulatively, the impacts of the developments on naturalness are substantially unnoticeable.

OUTSTANDING OPPORTUNITY FOR SOLITUDE OR A PRIMITIVE AND UNCONFINED TYPE OF RECREATION

The many coulees in the unit provide considerable topographic screening. This is most pronounced in the vicinity of the south Fork Little squaw creek and less pronounced along the western boundary and the southeast portion of the unit. Vegetative screening is provided by the scattered stands of trees, primarily along the west and southern boundary of the unit. The interrelationship of configuration and size is complex for this unit. The unit is severely gerrymandered by private ownership patterns and roads. It is this configuration which could preclude visitors within the unit from avoiding the sights and sounds of each other. The hest opportunities for solitude in the unit occur between Curry Coulee and South Fork Little Sauaw Creek in the southern part of the unit, hut these are not excellent or outstanding.

Activities or opportunities for primitive and unconfined recreation which exist in the unit include hiking, hunting, and perhaps winter sports. None of these opportunities is excellent. Nor is there an outstanding opportunity for primitive and unconfined recreation due to a diversity of excellent opportunities.

SUPPLEMENTAL, VAL,UES

There are no known supplemental values in the unit.

\section{FINAL DECISION ANALYSIS}

SUMMARY OF PUBLIC COMMENTS :

The only comments received supported the Intensive Inventory finding. FINAL DECISION AND RATIONALE:

The unit does not meet the outstanding opportunities for solitude or primitive recreation criterion. The non-WSA recommendation is unchanged. 


\section{NARRATIVE SUMMARY \\ WILDERNESS INTENSIVE INVENTORY}

UNIT NO: $\quad$ MT-024-650

NAME OF AREA: Jack Lane Coulee

\section{SUMMARY OF RECOMMENDATION}

The unit is not recommended for WSA status, although it meets the size and naturalness criteria.

\section{SIZE \& UNIT DESCRIPTION}

Unit 650 is 8540 acres is size. There is one private inholding surrounded by the unit, consisting of 320 acres. It is bounded primarily by private land except for a small portion of the western boundary, which is a road.

For the most part, unit 650 is north of Lodgepole Creek. Numerous coulees originate in the unit and run south out of the unit into Lodgepole Creek. This creates some breaks with varying degrees of steepness and size. Some of the breaks are characterized by sandstone pillars, ledges and caves, giving a rugged and picturesque appearance to the landscape. The breaks rise up to rolling grassy benches which open to some wide grasslands (20\% of the unit) and rolling hills. There are numerous trees throughout the unit, concentrated primarily near the coulees and on hillsides. Two of the coulees are dominent. These are seventy-nine Coulee which is the major drainage in the unit and is in the central portion, and Jack Lane Coulee, which cuts through the eastern portion of the unit. The vegetation consists primarily of shortgrass species, sagebrush, and ponderosa pine.

\section{NATURALNESS}

A large area in the western portion of the unit burned in 1973 and numerous fire ways were built at that time. These ways have not been maintained since, and have probably received very little use as well. Several vehicle ways exist in the eastern portion of the unit. These appear to be used for purposes of maintaining feeders, fences and salt licks. One of the vehicle ways leads to a reservoir in the eastern portion of the unit while another, which is very faint, at one time led to a. windmill in the southeastern portion of the unit. There are fences on the eastern portion of the unit. Approximately $2 \frac{1}{2}$ miles are on the boundary, while the rest is scattered through the unit. Some of the fences are rather obtrusive, as they have red metal fenceposts and 4 or 5 strands of wire. In addition to the reservoir in section 21, there is one other reservoir in the eastern portion of the unit (T.18 N., R.31 E., Sec. 20) and a tip of one in the western portion. None of the developments are overly obtrusive individually, and the cumulative effects are not substantially noticeable. 
OUTSTANDING OPPORTUNITY FOR SOLITUDE OR A PRIMITIVE AND UNCONFINED TYPE OF RECREATION

There is screening provided by topographic features and, to a lesser extent by trees, in the coulees which predominate in the southern portion of the unit. In the north, the grassed rolling hills provide considerably less screening, although feelings of spaciousness are provided: The configuration of the unit is contorted by roads and the inholding. The unit is almost fragmented into four portions by these ownership and road considerations. Considerations of size and configuration preclude the existence of outstanding opportunities for solitude, despite some screening in the unit.

Horseback riding on the benches would be worthwhile, although it would be difficult if not impossible to ride in the bottoms of some of the coulees. On foot a visitor could cover the entire unit, and it would be especially worthwhile to walk to some of the sandstone pillars and ledges, particularly if one is interested in photography. Opportunities for hunting deer are quite good on this unit. However, opportunities for primitive recreation are not excellent for any activity or collection of activities.

SUPPLEMENTAL VALUES

The unit has no known supplemental values.

\section{FINAL DECISION ANALYSIS}

SUMMARY OF PUBLIC COMMENTS:

The only comments received supported the Intensive Inventory finding. FINAL DECISION AND RATIONALE:

The unit does not meet the outstanding opportunities for solitude or primitive recreation criterion. The non-WSA recommendation is unchanged. 


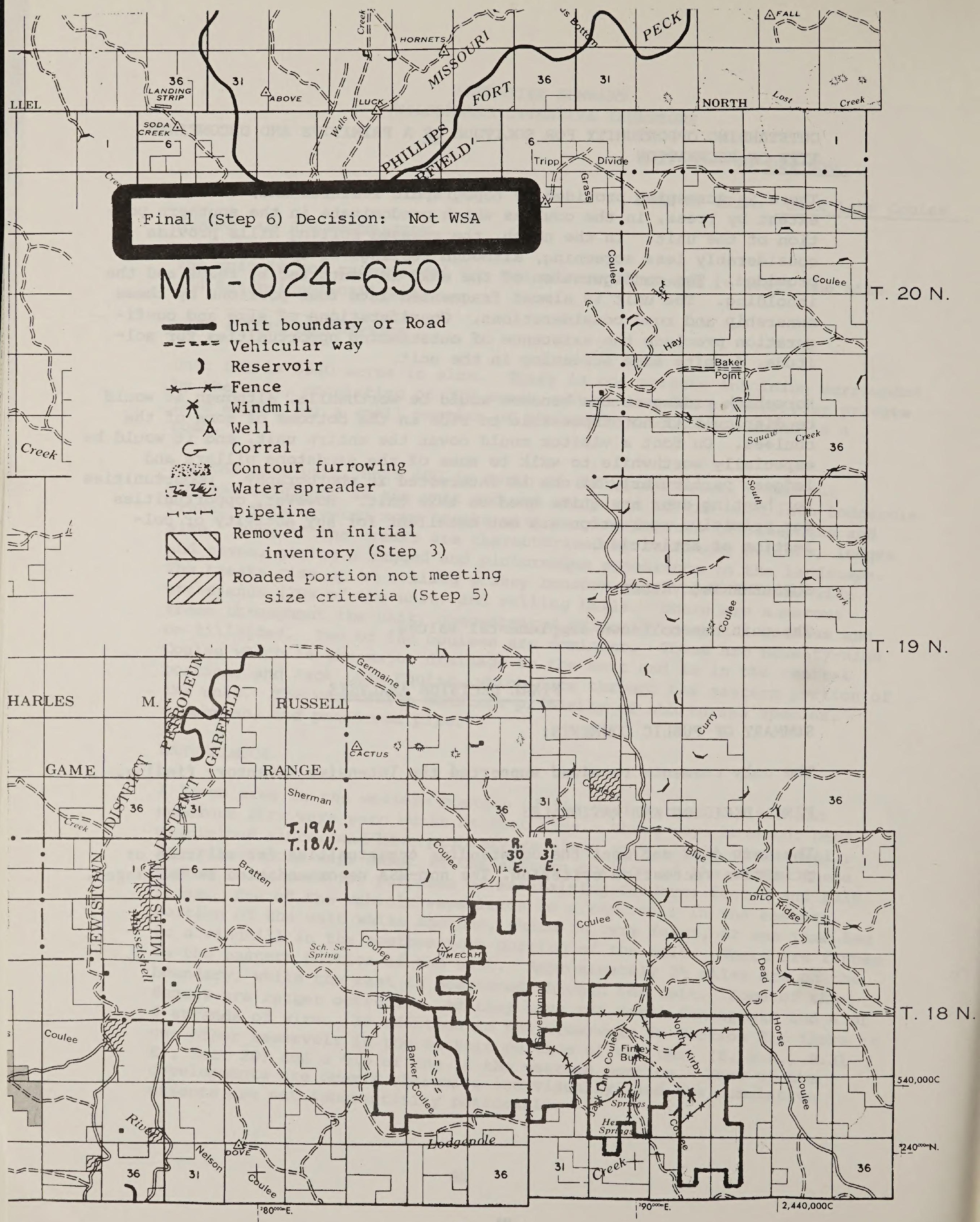


NARRATIVE SUMMARY

WILDERNESS INTENSIVE INVENTORY

UNIT NO.: $\quad$ MT-024-652

UNIT NAME: Lodgepole Creek

\section{SUMMARY OF RECOMMENDATION}

The unit is not recommended for WSA status, although it meets the size and naturalness criteria.

\section{SIZE \& UNIT DESCRIPTION}

The unit is 18 miles north of Mosby, Montana. Roads (deadending into the unit) were identified during intensive inventory which resulted in boundary changes with negligible acreage reductions. The acreage of intensive inventory remains the same $(7,580)$ as of the initial inventory unit. The boundaries of the unit are state or private land, except for the identified road and short segments on the north (Sec. 3 and 4, T.18N., R.3lE.) and the south (Sec. 20, T.17N., R.3lE.).

The unit straddles the divide between Lodgepole Creek and the South Fork of Lodgepole creek. Their confluence is less than a mile northwest of the western end of the unit. The elevations range from over 2,900' along the ridge to less than $2,450^{\prime}$ at the end of the unit. The terrain is dissected at the western end of the unit and moderates in the east to rolling grassland with isolated coulees. Approximately $20 \%$ of the unit is covered with stands of ponderosa pine, 60 acres or smaller. These are generally on northern aspects, although many are on the flat ridges that occur in the eastern end of the unit. In addition, there are individual pines scattered throughout the unit. So, although the dominant vegetation is grasses, the effect is one of intermixed forest and grassland.

\section{NATURALNESS}

Developments are spread throughout the unit. Vehicle ways branch off of the road which penetrates into the unit. Other ways are concentrated in the eastern end of the unit. Even those that are well defined through use are not substantially noticeable, primarily because of vegetative screening. There are also some fire trails in the western end of the unit. Reservoirs are spread throughout the unit. They are, particularly those in the west, screened considerably by both topography and vegetation. Fences are spread throughout the unit and are often paralleled by vehicular ways. There is also a pit associated with a dry oil well in the unit (T.17N., R.50E., Sec. 8). The density of these developments is large. However, individually and collectively, they are substantially unnoticeable because they are not very conspicuous due to screening. 
OUTSTANDING OPPORTUNITY FOR SOLITUDE OR A PARIMITIVE AND UNCONFINED TYPE OR RECREATION

The unit contains both topographic and vegetative screening. However, the configuration of the unit is extremely gerrymandered by land ownership patterns. For example, the quarter of the unit east of Kirby Coulee is almost separate from the remainder of the unit. The boundary in the central part of the unit created by the road almost bisects the unit. These deficiencies of configuration and size are not outweighed by factors of screening. So, within the confines of the unit, it is unlikely that visitors could avoid encountering each other due to the configuration and size factors. The unit does not have excellent opportunities for solitude.

The unit provides opportunities for deer hunting, hiking, and horseback riding. Travel along the main ridge could be pleasant and more arduous off of it. Hunting in the unit might be challenging due to the cover. However, none of the opportunities for these activities are excellent.

SUPPIJEMENTAL VALUES

There are no known supplemental values in the unit.

\section{FINAL DECISION ANALYSIS}

SUMMARY OF PUBLIC COMMENTS:

The only comments received supported the Intensive Inventory finding. FINAL DECISION AND RATIONALE:

The unit does not meet the outstanding opportunities for solitude or primitive recreation criterion. The non-WSA recommendation is unchanged. 
The unit is not recommended for WSA status, although it meets the size and naturalness criteria.

SIZE \& UNIT DESCRIPTION

This unit meets the 5,000-acre size criterion by being 6,850 acres in size. It is surrounded primarily by private land, although the western and part of the eastern boundaries are roads. A road was identified during the intensive inventory which necessitated a boundary change in the southwest corner of the unit. The acreage reduction is 540 acres, which results in a 6,310-acre roadless unit. This unit is located 15 miles west of Brusett. There is a 480 -acre block of private land along Squaw Creek which is surrounded by the public land of the unit.

This unit is rather diverse in topography being dominated in the west by breaks, buttes and coulees. Moving eastward, one sees the transition to rolling hills and more gentle terrain. Squaw Creek runs through the center of the unit, although less than a mile of it is on public land. Together with its tributaries, it influences much of the topography in the unit. There are curiously shaped sandstone formations throughout the unit, and some magnificent white cliffs in the central portion. The vegetation consists primarily of shortgrass prairie species, and there is an abundance of ponderosa pine, particularly in the west.

\section{NATURALNESS}

There are very few manmade developments in the western and northern portions of the unit. Fences run through the central portion of the unit, and there are several small reservoirs located primarily on the edges of the unit. None of these are very intrusive due to the terrain nor do they detract greatly from the naturalness of the unit. Vehicular ways are rather uncommon in this unit. There are several short segments of vehicle trails (see map), which are also not conspicuous. The individual and cumulative impacts of these developments are substantially unnoticeable 
ÔUTSTANDING OPPORTUNITIES FOR SOLITUDE OR A PRIMITIVE AND UNCONFINED TYPE OF RECREATION

The abundance of trees, particularly in the western portion, adds to the feeling of solitude one gets, as well as providing welcome shade. Screening is also provided by the topography of the unit. Breaks, coulees and buttes remove a person from the sight and sound of another, and in the eastern portion the more open rolling hills provide a feeling of spaciousness. Walking in the dry creek beds affords an opportunity for solitude because the view to either side and beyond the next bend is blocked. The effect of size and configuration on the opportunities for solitude in the unit are significant. Approximately $10 \%$ of the acreage of the unit is contained in narrow peninsulas which project out along the west boundary. The portion of the unit south of the Wolf and Squaw Creeks divide is significantly affected by the private land constriction along Squaw Creek. This gerrymandered configuration combined with size precludes outstanding opportunities for solitude.

There are opportunities for recreation in this unit. The diversity of topography and unusual sandstone formations provide some spectacular scenery. Walking through the unit is not difficult, but it is varied enough to be interesting. The unit is good for horseback riding because the spots providing scenic vistas can readily be reached and nearly all of the unit is accessible on horseback. There are deer in the breaks and antelope in the more open portions, which provides opportunities for hunting. However, the opportunities for any one of these activities is neither outstanding nor excellent.

\section{SUPPLEMENTAL VALUES}

This unit does contain some spectacular scenic qualities due to the unique sandstone formations and the brightly colored exposed strata.

\section{FINAL DECISION ANALYSIS}

SUMMARY OF PUBLIC COMMENTS:

The only comments received supported the Intensive Inventory finding.

FINAL DECISION AND RATIONALE:

The unit does not meet the outstanding opportunities for solitude or primitive recreation criterion. The non-WSA recommendation is unchanged. 


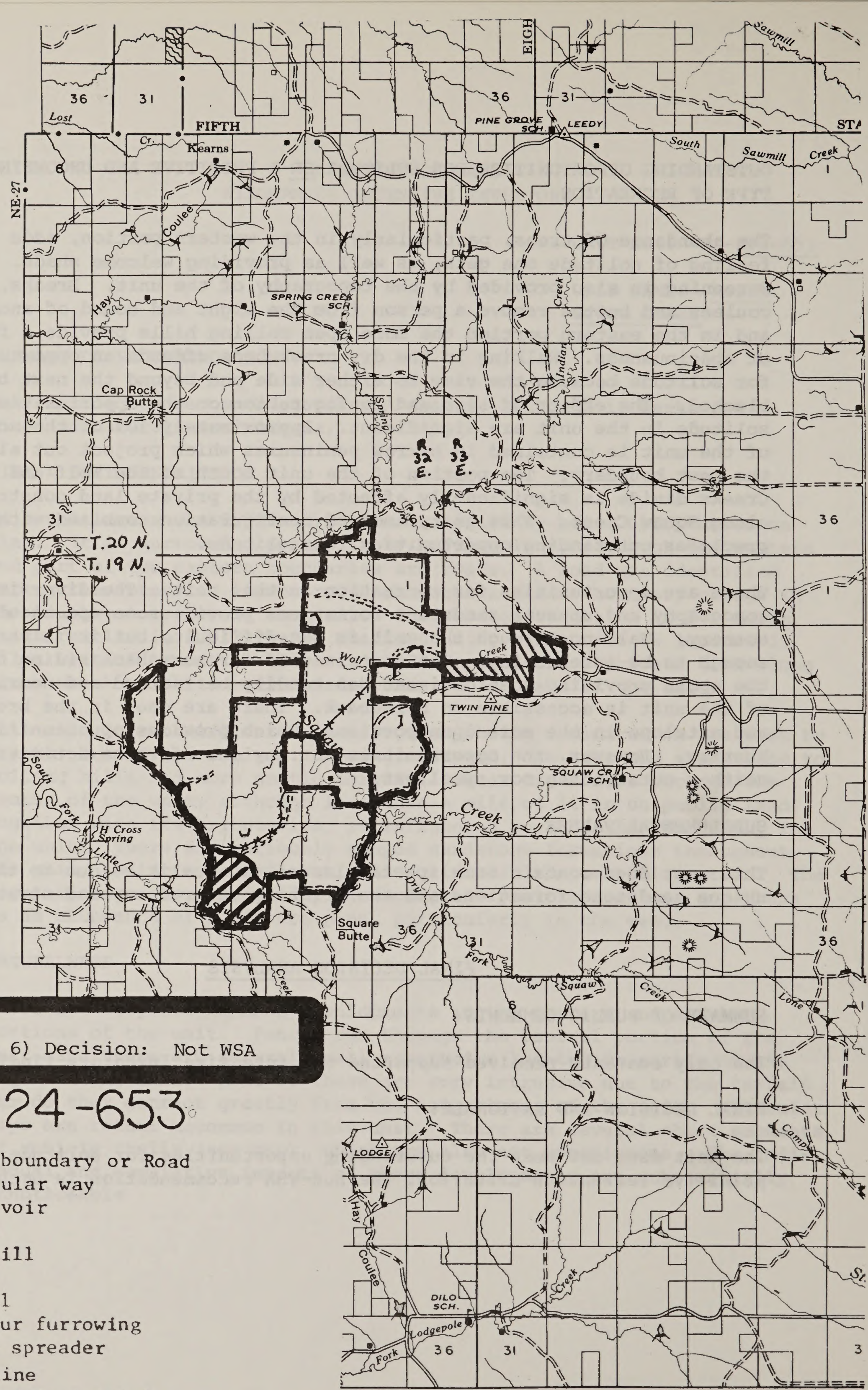

\section{カーM Pipeline}

Removed in initial

inventory (Step 3)

77 Roaded portion not meeting 
UNIT NO.: $\quad$ MT-024-654

UNIT NAME: Squaw Creek

SUMMARY OF RECOMMENDATION

The unit is not recommended for WSA status, although it meets size and naturalness criteria.

\section{SIZE \& UNIT DESCRIPTION}

This 7,070-acre unit is composed entirely of public land and it is bordered by roads or private land on the west and east. The rest of it is composed of private lands. A road, identified in the initial inventory penetrates from the southern boundary north into the unit. A road was identified during intensive inventory, which necessitates a boundary change. This road now forms the southwest boundary (see map). The acreage of the public land southwest of the road is 1,075. It will not be considered in intensive inventory as it does not meet any of the size criteria. The acreage of the remainder of the unit is $5,995$.

The topography in this unit can be divided into two basic types. The eastern and western portions are primarily rolling grasslands with occasional gumbo knobs topped with sandstone formations. Shallow coulees are also quite frequent in these two portions of the unit. Extensive stands of ponderosa pine mixed with junipers cover most of the hillsides within the unit. Small stands of cottonwoods can be found growing in the bottoms of the coulees and streams. Approximately twenty percent of the entire unit is covered with trees. The central portion of the unit is characterized by deep ravines, steep gumbo domes and flat-topped buttes. The dissected topography and the varying colors of the exposed strata provide spectacular vistas and rugged terrain.

Ponderosa pines and juniper trees are located on most of the hillsides and frequently small stands can be found growing on the tops of the buttes. The vegetation in this unit is primarily low growing forbs and short to midgrass prairie species.

\section{NATURALNESS}

The developments which exist within the unit include four reservoirs, a pipeline, barbedwire fences, and several vehicular ways (see map). The impact of the reservoirs and the fence is slight due to the fact that topographic screening effectively reduces their visibility from most areas within the unit. The presence of the pipeline is not a major impact upon the naturalness of the unit. This is due to the fact that the pipeline is barely discernible, the disturbed area having already revegetated extensively. The major impact associated with the pipeline is the presence of a road, which forms part of the boundary of the unit and is not within the unit. 
None of the developments in the unit have a significant impact on the naturalness of the unit. Each is inconspicuous because of screening. Their cumulative impact is also substantially unnoticeable.

\section{OUTSTANDING OPPORTUNITY FOR SOLITUDE OR A PRIMITIVE AND UNCONFINED TYPE OF RECREATION}

The diversity of terrain types and the presence of some tree cover provide screening. The rolling hills in the eastern and western portions of the unit provide some topographic screening, but it is the open spaces and vistas which provide the feelings of solitude. Opportunities for solitude in the central portion of the unit are derived primarily from topographic and vegetative screening. The dissected topography in this portion of the unit would effectively screen users from one another. The presence of trees on the sides and summits of the buttes would lessen the impact of the presence of different users within the unit. The size and shape of the unit is also an important consideration for assessing the opportunities for solitude. The unit is not a large unit (5,995 acres after necessary boundary adjustments). The shape of the unit significantly impacts the opportunities for solitude. The road along the pipeline severely gerrymanders the configuration of the unit. There is no location in the unit which is a mile or more from the boundary. This is the result of the interrelationship of the size and configuration of the unit. So, despite some topographic and vegetative screening, opportunities for solitude are not outstanding.

Although opportunities for recreation do exist, there is no single activity or combination of activities which provide outstanding opportunities for recreation.

The different types of primitive recreation which could occur in this unit include hiking, horseback riding, photography, rock collecting and hunting. The rolling grasslands of the eastern and western portions of the unit are suited for hiking and horseback riding. The more rugged terrain in the central portion of the unit would be challenging to the hiker, although possibly too rough for extensive horse travel. Nature and wildlife photography is another form of recreation which could be pursued in this unit. The spectacular vistas found throughout the unit, particularly in the central portion of the unit, could be good photographic subjects. The presence of deer and antelope scat and several sightings of grouse indicate that opportunities for wildlife photography and hunting do exist within the unit. The presence of sandstone ledges and many exposed rock types in the central portion of the unit may provide opportunities for rock and mineral hunting and collecting.

\section{SUPPLEMENTAL VALUES}

There are no known supplemental values on the unit. However, the scenic values are very good, although typical of the vicinity. 


\section{FINAL DECISION ANALYSIS}

SUMMARY OF PUBLIC COMMENTS:

The only comments received supported the Intensive Inventory finding.

FINAL DECISION AND RATIONALE:

The unit does not meet the outstanding opportunities for solitude or primitive recreation criterion. The non-WSA recommendation is unchanged. 


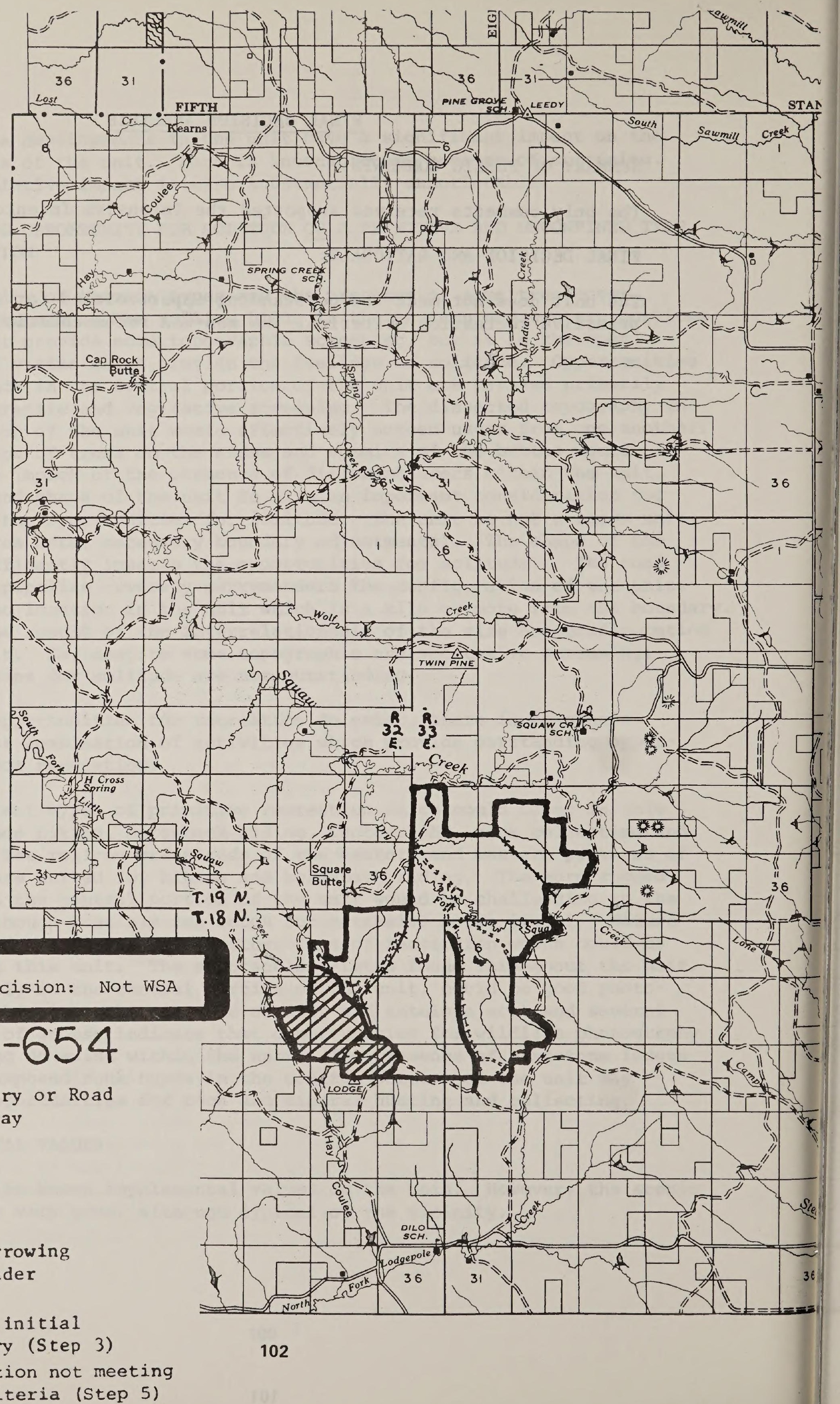




\section{NARRATIVE SUMMARY \\ WILDERNESS INTENSIVE INVENTORY \\ UNIT NO.: $\quad$ MT-024-661 \\ UNIT NAME: Maloney Hill}

\section{SUMMARY OF DECISION}

The unit is not recommended for WSA status, although a portion of it meets the size and naturalness criteria.

\section{SIZE AND DESCRIPTION}

The acreage of the final initial inventory unit was 17,120. Recalculation, prior to boundary modifications in the intensive inventory, resulted in an acreage of 15,850. Roads identified during intensive inventory fragmented the unit into three roadless areas. Subunit " $A$ " has an acreage of 75 . Subunit " $B$ " has an acreage of 4100 (see map). Neither meets the size criterion. Subunits "A" and "B" will not be addressed further in this report. The remaining 11,675 acres meet the 5000 -acre size criterion. The unit has a common boundary along the north with Fish and Wildlife land. The west boundary is the Hell Creek Park road or private or State land. The remainder of the boundary is roads or nonpublic land. The unit is 20 miles north of Jordan, Montana.

The unit is drained northwesterly by several tributaries (Hart Creek, Reid, Burdick and Jordan Coulees) of Hell Creek, which is out of the unit. Reid Coulee and its main tributary, East Reid Coulee, drain the eastern $75 \%$ of the unit. The western extent of Reid Coulee is School Section Divide. Only .3 miles of the main stem of Reid Coulee is in the unit. It is in a 1/4-mile corridor of public land which connects the east and west drainages of Reid Coulee. The remainder of Reid Coulee drainage is separated by extensive private land or public land not meeting the size criterion. The portion of the unit east of Reid Coulee is almost entirely in East Reid Coulee. It is moderately dissected and interspersed with gumbo ridges and knobs. The northern extent of East Reid Coulee is a large flat-topped ridge almost corresponding to the F\&WL and BLM boundary. However, 800 acres in the northeast corner of the unit are drained by Burdick Coulee. The topography of the unit between School Section Divide and Reid Coulee is rolling grassland in the south and moderately dissected land in the north (in the vicinity of Maloney Hil1). The northwest corner of the unit (in Jordan Coulee) is very heavily dissected. A small piece in the southwest of the unit is in the headwaters of Hart Creek. It is rolling grassland.

\section{NATURALNESS}

Developments in the unit include a reservoir in Burdick Coulee and one south of East Reid Coulee. A vehicle way runs the length of School Section Divide. It is distinct at the south end and generally faint 
along the rest of its length. There are two vehicle ways branching off of the School Section Divide way (see map). This way crosses Reid Coulee at the northern boundary of the unit (sec. 19, T. 21 N., R.38 E.) east of Reid Coulee, the way is on the ridge north of East Reid coulee. These eight miles of way within the unit were improved where needed to provide access in 1973 (under BLM contract). It was last maintained in 1975, however, it is not passable in several locations. There is major surface disturbance intermittently along the route, although much of it has revegetated. Several miles of fencing and two reservoirs exist in the western part of the unit (see map). Finally there is a raised powerline along parts of the boundary road between subunits "B" and "C". A powerline, approximately 1.25 miles long, branches off of this northward into the unit within sections 20,29 and $32, T_{.} 21 \mathrm{~N} ., \mathrm{R}_{.} 38 \mathrm{E}$. (see map). It should be noted that these lines are small portions of an extensive network of powerlines, the remainder of which are on private land or public land in subunit "B".

The reservoirs, the vehicles ways and the fencing are substantially unnoticeable. The section of powerline is visible from the west (looking up the coulee it crosses), but generally not from the other directions. It, too, is substantially unnoticeable. Finally, the developments are cumulatively substantially unnoticeable.

OUTSTANDING OPPORTUNITY FOR SOLITUDE OR A PRIMITIVE AND UNCONFINED RECREATION ANALYSIS

For the purposes of solitude, it should be noted that the unit is essentially two separate parcels (see map) contiguous only by a .25 mile "neck". These two parcels are, for the purpose of solitude, unrelated. Parcel " $C$ " is moderately dissected and contains numerous gumbo knobs. There are a few individual and small stands of ponderosa pine in the western portion of the parcel. So while there is some topographic screening, there is very little vegetative screening. The size of the parcel is 6,050 acres. The configuration of the unit is approximately square and the boundaries lay very close to topographic features. However, the topographic screening and configuration are not sufficient to provide outstanding opportunities for solitude for a unit of this size.

The 5625-acre parcel west of Reid Coulee (Parcel "D") is dominated by School Section Ridge. This flat-topped ridge is partially contained within a state section (section 36, T.21N., R.37E.). The undulating ridge is skirted, particularly on the east slope, by several large buttes and some moderately dissected terrain. In the northwest, in the vicinity of Jordan Coulee, there is some heavily dissected terrain. The southern portion of this parcel is rolling grassland. So while portions of the unit have screening, the general lack of topographic and vegetative screening combined with gerrymandered configuration preclude the existence of outstanding opportunities for solitude. This is especially obvious from points along School Section Divide. 
The two parcels, either separately or together, do not have outstanding opportunities for solitude.

The unit has opportunities for hiking and hunting. Ridge hiking opportunities exist on School Section Divide and the ridges north and south of East Reid Coulee. It would be more arduous to hike across drainage patterns. These hiking opportunities are not excellent nor outstanding. Hunting for antelope and deer is quite good, but not outstanding. No one activity nor the diversity of activities provide outstanding opportunities for recreation.

SUPPLEMENTAL VALUES

The unit has no known ecological, geological, scientific, educational or historical values. The unit does not have scenic values.

\section{FINAL DECISION ANALYSIS}

SUMMARY OF PUBLIC COMMENTS:

The only comments received supported the Intensive Inventory finding. FINAL DECISION AND RATIONALE:

The unit does not meet the outstanding opportunities for solitude or primitive recreation criterion. The non-WSA recommendation is unchanged. 


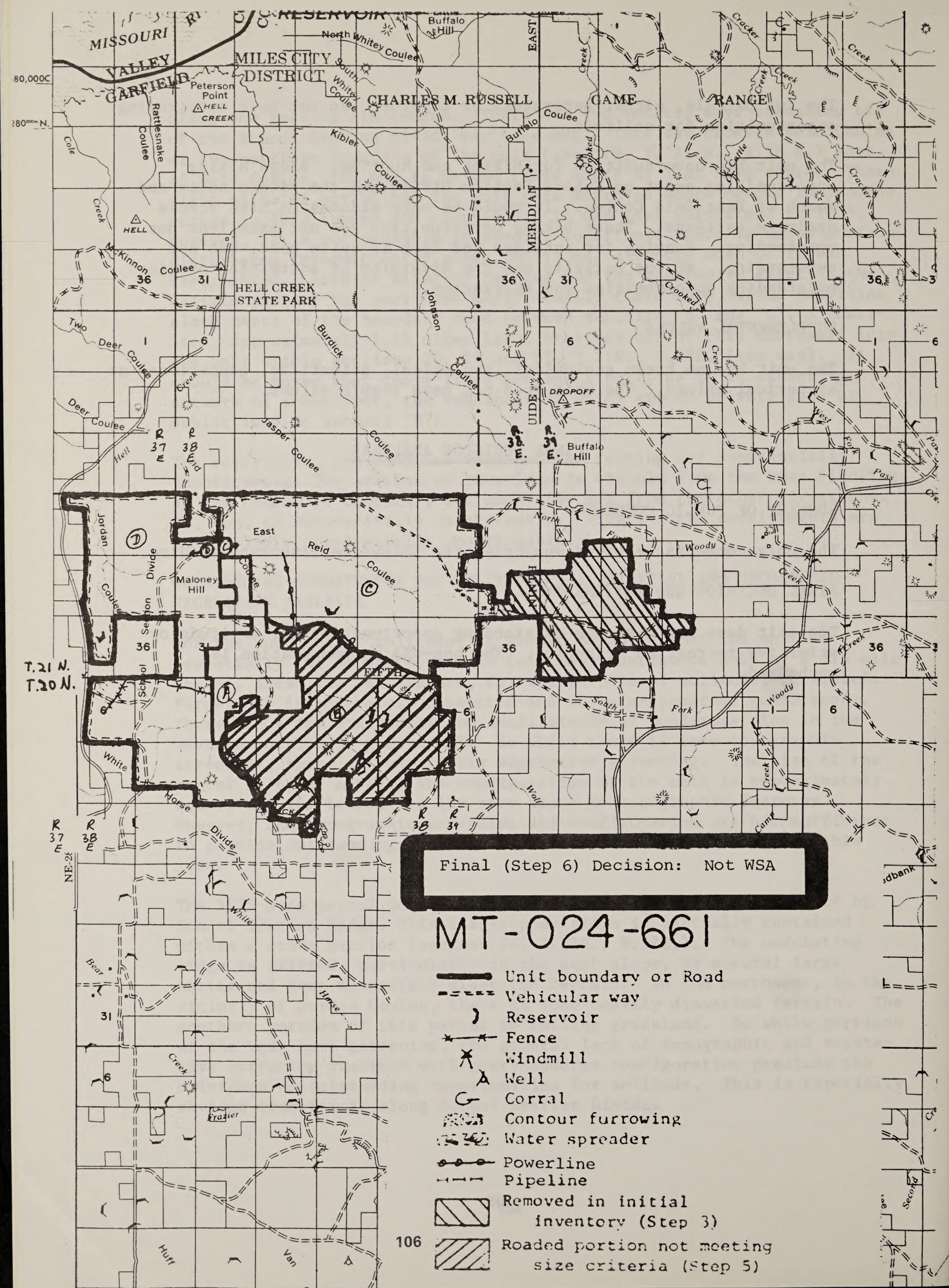




\section{NARRATIVE SUMMARY \\ WILDERNESS INTENSIVE INVENTORY}

UNIT NO: $\quad$ MT-024-662

UNIT NAME: Crooked Creek

\section{SUMMARY OF RECOMMENDATION}

The unit is not recommended for WSA status, although it meets the size and naturalness criteria.

\section{SIZE \& UNIT DESCRIPTION}

This unit is located 20 miles north-northeast of Jordan, MT. It is 6,530 acres is size. The unit is contiguous to Fish and Wildlife land along 2.25 miles of the northern boundary. A parcel of private land, 640 acres in size (in Secs. 29,30,32, \& 33, T.22 N., R.39 E., m.p.m.), is surrounded by either this unit or F \& WL land.

Unit 662 is, for a major part, very broken on topography. Crooked Creek runs northwesterly through the unit, and with its many branches and tributaries dominates the topography. There are some small portions of open grassy plains dispersed throughout, especially in the northernmost tip and on coulee rims.

The drainage of Crooked Creek provides spectacular scenery. Gumbo knobs, sandstone formations and various colors of sediment combined with dramatic drop-offs along the southern boundary and an expensive view make the unit scenic. The view of Fort Peck Lake to the north also adds to the scenic quality of this unit.

\section{NATURALNESS}

This unit is primarily affected by the forces of nature. There are very few man-made developments and their impact is low. There is a vehicle trail approximately .75 of a mile long in the southwestern portion of the unit. There is one dry reservoir and culvert on the northern boundary, and another reservoir that straddles the boundary on the west. In the northernmost section in the unit there is one mile of telephone line. Also in section 21 there is approximately one mile of fence.

OUTSTANDING OPPORTUNITY FOR A SOLITUDE OR A PRIMITIVE AND UNCONFINED TYPE OF RECREATION

Although the opportunities for topographic screening exist throughout the unit, it is most prevalent in the western portion. This deeply dissected topography would serve to effectively screen different parties. Approximately five percent of the western portion is covered by stands of ponderosa pine and juniper trees. These trees also serve to visually and physically separate the visitors in this unit. This factor of 
vegetative screening is especially true on the slopes of the many gumbo buttes and ridges. Although the ridgetops in the western portion are rather exposed the presence of many rock (sandstone) outcrops also provided a degree of visual and physical screening. The gently rolling topography and the open expanses in the eastern portion of the unit provide opportunities for solitude that are derived from uninterrupted expanses. This part of the unit also provided opportunities for solitude through topographic and vegetative screening, contributed by the shallow coulees and small stands of junipers on the slopes of the ridges. However, these screening factors do not alone determine that the unit provided outstanding opportunities for solitude. Configuration is a significant factor in determining the opportunities for solitude of this unit. The unit is severely constricted along Crooked Creek. Of course the unit is contiguous public land, but the opportunities for solitude on the west side of Crooked Creek are not heavily affected by that on the east. A significant portion of the 6,530 acres of the unit is on each side of the constriction. That is, the combination of size and configuration is such that the unit does not have outstanding opportunities for solitude. The screening characteristics are not sufficient to provide outstanding opportunities in either the west or east portion or the unit as a whole.

The recreational activities most suited to this unit include hunting, hiking and backpacking, horseback riding, bird watching, and photography. Habitat type and the presence of scat suggests that either mule deer, pronghorn antelope and grouse exist throughout the unit and would provide opportunities for hunting. The rugged topography in the western portion of the unit and the more gently rolling and open topography of the eastern portion of the unit provide recreational opportunities for the hiker or the backpacker. One could either walk the coulees, climb the ridges or hike across gently rolling grasslands. The open grasslands of the eastern portion of the unit are better suited for horseback riding. The scenery provided by the ruggedness and the colors of the badlands provide opportunities for nature photography. The presence of mule deer, pronghorn antelope, many different kinds of birds and other forms of wildlife also provide opportunities for nature photography and wildlife observation.

The opportunities for no one of these activities is outstanding nor is the combination of opportunities outstanding.

\section{SUPPLEMENTAL VALUES}

The unit has scenic values (discussed in earlier sections). It also may have paleontalogical resources of scientific value. 
SUMMARY OF PUBLIC COMMENTS:

One comment suggested that the unit should be a WSA, because it was contiguous to USF. \& WL lands. All other comments supported the Intensive Inventory finding.

\section{FINAL DECISION AND RATIONALE:}

The USF \& WL land is not proposed for wilderness in their recommendation to Congress. The 640 acres of private land along Crooked Creek would affect the configuration of a combined USF \& WL and BLM unit just as seriously as it does the BLM unit. The unit does not have the characteristic of outstanding opportunities for solitude or primitive recreation. The non-WSA recommendation is unchanged. 


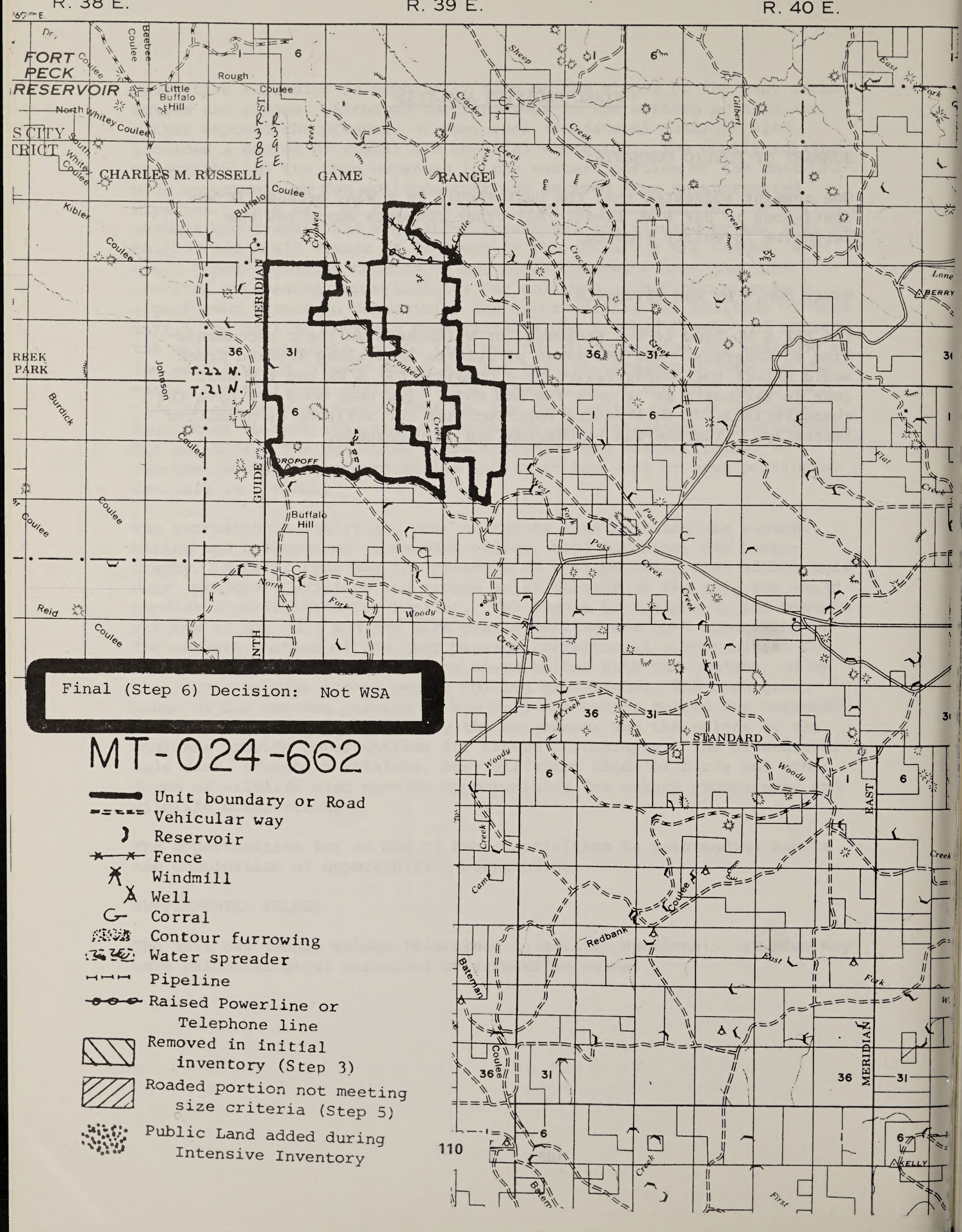




\section{NARRATIVE SUMMARY \\ WILDERNESS INTENSIVE INVENTORY}

UNIT NO. MT-024-665
NAME OF AREA: Woody Flat

\section{SUMMARY OF RECOMMENDATION}

The unit is not recommended for WSA status, although it meets the size and naturalness criteria.

\section{SIZE \& UNIT DESCRIPTION}

The unit is 25 miles east northeast of Jordan, Montana. The acreage of the unit is 9,800. A state section ( 640 acres) is surrounded by the unit. The unit is contiguous to 36 roadless acres of U.S. Fish and Wildlife Service land (Sec. 23, T.20 N., R. 42 E.) The unit boundary is a residual of public land unit that was considered in the Northern Tier accellerated inventory.

The unit contains tributary drainages of Big Dry Creek to the east. They are Flat Creek, Murray Coulee and Woody Creek. Only a small ( 3 mile) portion of the main stream of Flat Creek is in the (northeast corner of the) unit. However, many of its unnamed tributary coulees drain the northern half of the unit. The topography of this drainage is flat undulațing grassland and sage.

There are several gumbo knobs interspersed in this drainage. The divide of thin drainage and Woody Creek is barely discernable, except for two 150' high gumbo buttes. The divide between Flat and Murray drainages passes through the state section. It is more percipitous and mildly dissected.

Murray Coulee drains approximately 1500 acres of public land in the eastern part of the unit. The topography is rough except for the very southeastern bottom of the coulee. There is very little grass, some sage, and a few cottonwood trees along the coulee bottom.

Five named tributary coulees (Arnold, Breeze Basin, Coal Slack, Totton, and Steel) drain south into Woody Creek, which is outside of the unit. The topography varies from smooth and undulating on the west to mildly dissected on the east.

\section{NATURALNESS}

Developments are concentrated in the western portion of the unit. In addition to the vehicular ways (see map) there are some old intermittent seismograph trails and old blading along some of the fence lines. Five 
reservoirs are in the unit. Each is visible for a considerable distance from high vantage points, but from most of the unit their presence is not apparent. There are two segments of powerline in the unit. Approximately .75 miles at the south end (Sec.29 T.20 N., R.42 E., M.P.M.). The segment within the unit is visible from small areas along the south end of the unit. A second segment of line powers a well pump in (Sec.22, T. 20 N., R.42 E., M.P.M.) It is visible from the flats of Murray Coulee and occasionally from the dissected terrain above in the coulees.

The sign of man on an individual basis are substantially unnoticeable. Their cumulative effect is also substantially unnoticeable.

\section{OUTSTANDING OPPORTUNITY FOR SOLITUDE OR A PRIMITIVE AND UNCONFINED TYPE OF RECREATION}

There is no vegetative screening in the unit. The Flat and woody Creek drainages are rolling hillocks dissected by many intermittent coulees. There are opportunities for solitude in the coulee bottoms. However, from the hillocks in each drainage one can view most of the rest of the drainage. Murray Coulee is more heavily dissected. The opportunities for solitude are therefore greater than the remainder of the unit, but they are not outstanding. For the unit as a whole, the size of the unit and topographic screening are insufficient to provide outstanding opportunities for solitude.

The unit has opportunities for hiking and hunting. The hunting potential is typical of eastern Montana in that the terrain and animal populations are also typical. There is good potential for antelope hunting and some potential for deer and bird hunting. Hiking opportunities are also typical. Neither can be considered outstanding individually or together.

\section{SUPPLEMENTAL VALUES}

There are no known significant supplemental values in the unit.

\section{FINAL DECISION ANALYSIS}

\section{SUMMARY OF PUBLIC COMMENTS:}

One comment suggested that the unit be a WSA because it is contiguous to USF \& WL land. Other comments received supported the Intensive Inventory finding.

\section{FINAL DECISION AND RATIONALE:}

The 36 acres of contiguous lands do not affect the outstanding opportunities for solitude or primitive recreation. The unit does not have outstanding opportunities for solitude or primitive recreation. The non-WSA recommendation is unchanged. 


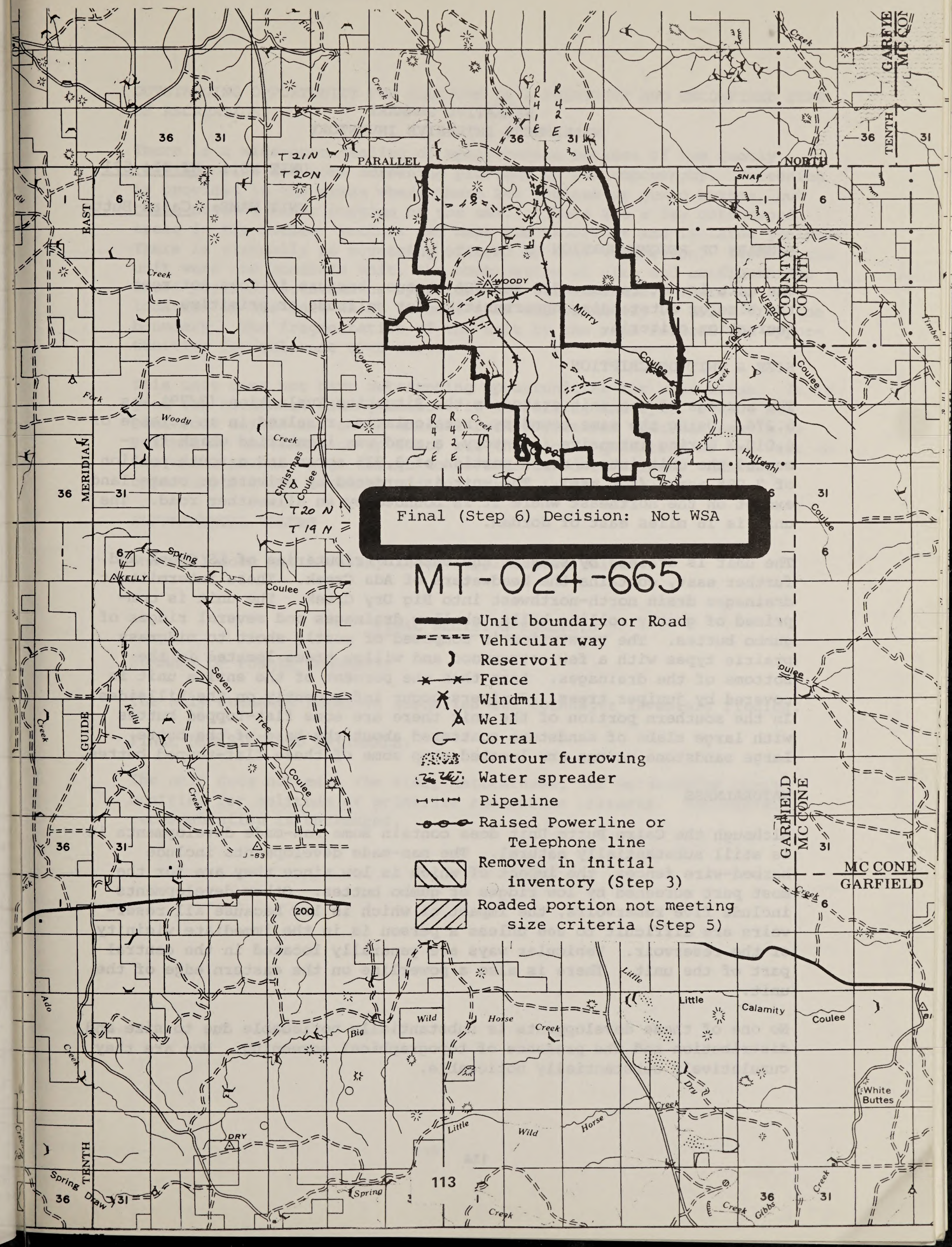




\section{NARRATIVE SUMMARY \\ WILDERNESS INTENSIVE INVENTORY}

UNIT NO.: $\quad \underline{M T-024-671}$

UNIT NAME: Cairn Butte

SUMMARY OF RECOMMENDATION

The unit is not recommended for WSA status, because it does not meet the size or outstanding opportunities for solitude or primitive recreation criteria.

\section{SIZE \& UNIT DESCRIPTION}

The acreage of the unit stated in the Situation Evaluation (3/79) was 5,270 . Using the same boundary, recalculation resulted in an acreage of 6,010. During intensive inventory, a road was identified which fragmented the unit into a north portion of 3,925 acres and a south portion of 2,085 acres (see map). The unit is bordered by private or state land except on the northeast where it is bounded by an allweather road. The unit is 16 miles east of Jordan.

The unit is drained by some of the eastern tributaries of LS Creek and, further east, contains the headwaters of Ada Creek. These intermittent drainages drain north-northwest into Big Dry Creek. The unit is comprised of gently rolling hills, shallow drainages and several ridges of gumbo buttes. The vegetation is composed of mostly short to midgrass prairie types with a few cottonwood and willow trees located in the bottoms of the drainages. Less than one percent of the entire unit is covered by juniper trees. Junipers occur infrequently on the hillsides. In the southern portion of the unit there are some flat-topped buttes with large slabs of sandstone scattered about the base of the butte. Large sandstone cairns are located atop some of these flat-topped buttes.

\section{NATURALNESS}

Although the Cairn Butte Unit does contain some man-made developments it is still substantially natural. The man-made developments include barbed-wire fences, the impact of which is low since they are for the most part screened by low ridges or gumbo buttes. Other developments include five reservoirs, the impact of which is low because all reservoirs are difficult to see unless a person is in the immediate vicinity of the reservoir. Vehicular ways are generally located in the central part of the unit. There is also a powerline on the eastern edge of the unit.

No one of these developments is substantially noticeable due to size and distribution and the presence of topographical screening. Nor are they cumulatively substantially noticeable. 
OUTSTANDING OPPORTUNITY FOR SOLITUDE OR A PRIMITIVE AND UNCONFINED TYPE OF RECREATION

There is a wide-open feeling of spaciousness because of the gently rolling hills and some screening provided by the topography. Screening is provided in the areas where there are coulees or gumbo buttes, but these cover a minor portion of the unit. There are a few cottonwood trees in the coulee bottoms and near the reservoir and isolated juniper. There is virtually no screening offered by this vegetation. Even if the unit were one roadless unit, the combination of size and configuration would preclude outstanding opportunities for solitude. There is no location in the unit which is more than approximately .5 miles from the boundary. The fragmentation of the unit by the road reduced the opportunities for solitude even more.

This unit does not have outstanding opportunities for recreation. It is good for horseback riding because it is rolling and open. There are some rock cairns and other unusual rock formations that can easily by reached by horseback or on foot, but the scenic qualities of the unit on the whole are not high enough to be considered excellent. Hunting opportunities for antelope and deer exist in the unit.

SUPPLEMENTAL VALUES

Unit 671 does not have any known supplemental values.

\section{FINAL DECISION ANALYSIS}

SUMMARY OF PUBLIC COMMENTS:

The only comments received supported the Intensive Inventory finding.

\section{FINAL DECISION AND RATIONALE:}

The unit does not meet the size, naturalness, nor outstanding opportunities for solitude or primitive recreation criteria. The non-WSA recommendation is unchanged. 


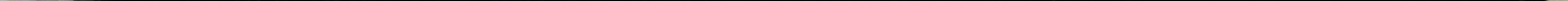




\title{
NARRATIVE SUMMARY \\ WILDERNESS INTENSIVE INVENTORY
}

\author{
UNIT NO.: $\underline{\text { MT-024-676 }}$ \\ UNIT NAME: Newhouse Coulee \\ (previously named)
}

\section{SUMMARY OF RECOMMENDATION}

The unit is not recommended for WSA status, although it meets the size and naturalness criteria.

\section{SIZE \& UNIT DESCRIPTION}

The acreage of the roadless unit remains 9,000 after the intensive inventory. The unit is approximately twelve miles north of Mosby. Portions of the north boundary are a road along the divide north of Calf Creek and a portion of the west boundary is the Musselshell County road.

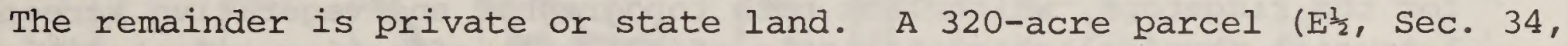
T. 17 N., R. 30 E., M.P.M.) of private land is surrounded by the unit.

Most of the unit is in Calf Creek drainage, although a peninsula of approximately 350 acres in the northeast is in Lodgepole Creek drainage. Calf Creek flows through a neck in the unit (Sec. 13, T. 16 N., R. 30 E., M.P.M.) for about .5 miles. Private land along the remainder of the bottom constructs the boundary and effectively divides the unit into two portions. The southwest portion is approximately 2500 acres and contains intermittent tributaries which flow northeasterly out of the unit and into Calf Creek. The 6500-acre northeast portion contains the major portion of several named tributary coulees (North wilson, Lower and Upper Newhouse, and Sheep Coulees) of Calf Creek. These flow southwesterly out of the unit and into Calf Creek. The topography, while not true breaks, is fairly rough country. Elevations range from 2950' along the Calf Creek divides on the northeast and southwest to $2500^{\prime}$ in the bottom.

The topography of the unit is similar everywhere, although the ridges in the vicinity of the Newhouse Coulee are somewhat steeper and form more dissected coulees than those in the remainder of the unit. The ridgetops are grassy benches dotted with scattered ponderosa pine. Stands of ponderosa pine (generally without crown closure) occur on some of the moderate north aspects. Altogether, these stands cover approximatley $10 \%$ of the unit.

\section{NATURALNESS}

Most developments in the unit are exclusively range-oriented. Three revervoirs exist in the southern portion of the unit. Several very faint vehicular trails extend off of the country road east onto the unit. Another reservoir is near the northern boundary (Sec. 23, T. 17 N., R. 30 E., M.P.M.). Fences parallel the north and east 
boundaries. Finally, there is a family cemetary on the boundary in the northwest corner of the unit (NENE, Sec. 31, T. 16 N., R. 30 E.). It has approximately 15 graves and is surrounded by a cyclone fence.

The individual impacts of the developments are not significant. The fences are not very apparent due to the terrain and vegetation. In any event, they are very close to the edges of the unit. The reservoirs are also not very apparent for similar reasons. From any location in the unit, other than the immediate vicinity of the developments, one cannot see on-site development. That is, the individual and cumulative effects of the developments in the unit are substantially unnoticeable.

\section{OUTSTANDING OPPORTUNITY FOR SOLITUDE OR A PRIMITIVE AND UNCONFINED TYPE OF RECREATION}

The topography of the unit is such that some topographic screening is provided, particularly when viewing northwesterly or southeasterly. The stands of ponderosa pine provide some vegetative screening, although not for the ridgetops, which lack both topographic and vegetative screening. A crucial physical characteristic of the unit affecting opportunities for solitude is the interrelationship between size and configuration. The unit is constricted by private land ownership patterns into southwest and northeast portions. The opportunities for solitude of either portion is not enhanced by the other portion. In addition, the 320-acre inholding affects the configuration of the unit. Primarily due to this combination of configuration and size, the unit does not have outstanding opportunities for solitude.

The unit provides opportunities for hiking, hunting, birdwatching, photography and perhaps snowshoeing. None of these opportunities can be judged outstanding. Hikers, for example, might have a pleasant experience on the ridgetops or a fairly arduous hike across coulees. However, the opportunities are not excellent. The combination of activities is not judged to be outstanding.

\section{SUPPLEMENTAL VALUES}

There are no known supplemental values in the unit.

\section{FINAL DECISION ANALYSIS}

SUMMARY OF PUBLIC COMMENTS:

One comment suggested that the unit be combined with proposed WSA MT 024-675 for study purposes. All other comments supported the intensive inventory finding.

FINAL DECISION AND RATIONALE:

The boundary between units MT 024-676 and MT 024-675 is a road by the BLM road definition. Therefore, the units will continue to be considered as separate roadless areas and inventory units. The unit does not meet the outstanding opportunities for solitude ot primitive recreation criterion. The non-WSA recommendation is unchanged. 


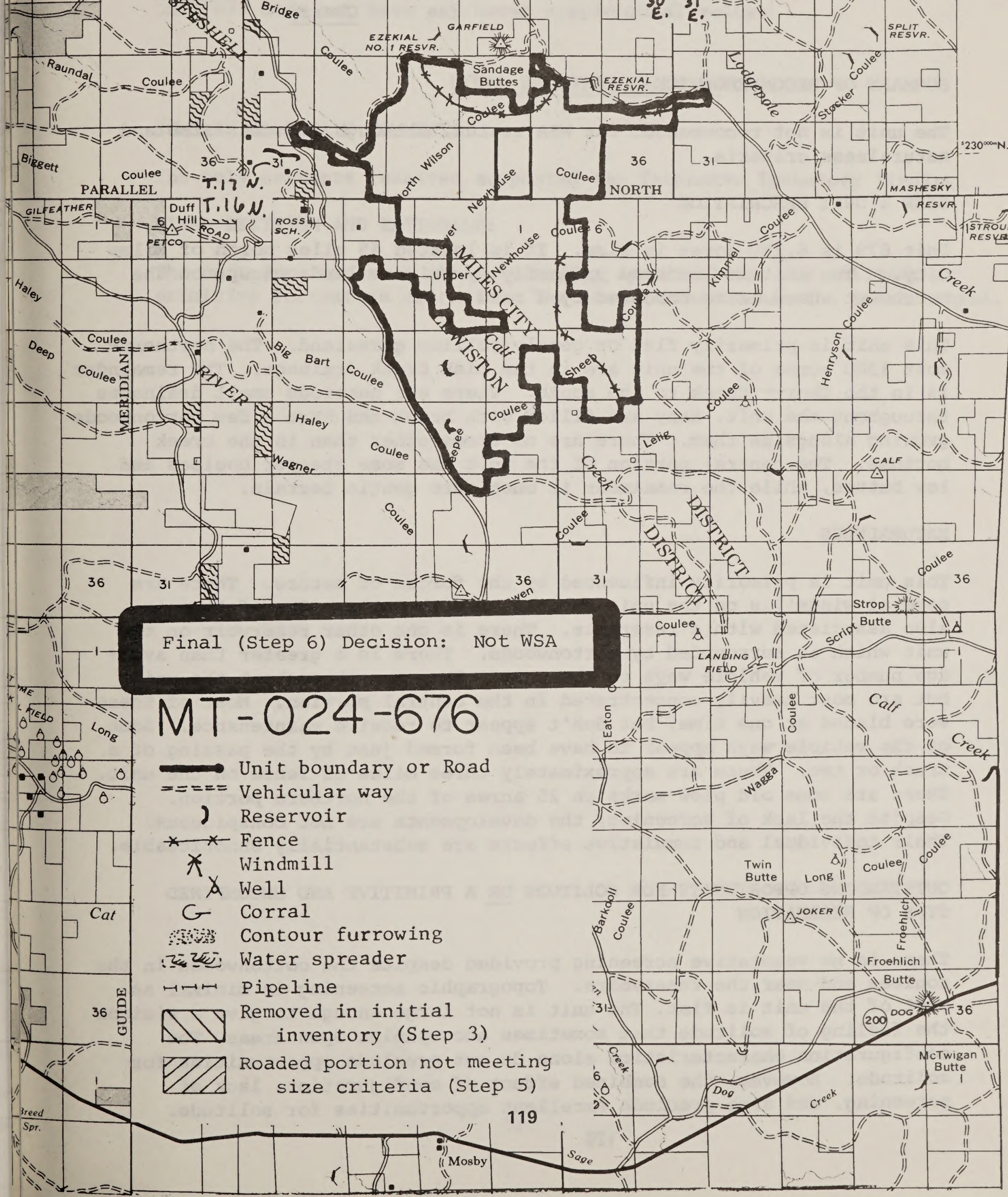




\author{
UNIT NO.: $\quad$ MT-024-679 \\ UNIT NAME: Lisk- \\ Cherry
}

\title{
SUMMARY OF RECOMMENDATION
}

The unit is not recommended for WSA status, although it meets size and naturalness criteria.

\section{SIZE \& UNIT DESCRIPTION}

Unit 679 is 6,150 acres in size. It is located 45 miles north of Miles City. The unit is bordered primarily by private land, except on the northwest where it is bordered by a road.

This unit is primarily flat or gently rolling grassland. The northernmost 1300 acres of the unit are in the Lisk Creek drainage. The remainder is in the Cherry Creek to the south. There are numerous small drainages throughout the unit. Many are filled with brush and have a few cottonwoods growing alongside them. There are no trees other than in the creek bottoms. The central portion of the unit has some steeper coulees and low buttes, while the remainder is much more gentle terrain.

\section{NATURALNESS}

This unit is primarily influenced by the forces of nature. There are several windmills on the unit associated with wells. One of them is also associated with a reservoir. There is one other reservoir on the unit which is surrounded by cottonwoods. There is a greater than average number of vehicle ways on the unit. They run throughout the unit, but are most heavily concentrated in the central portion. Most of these were bladed at one time, but don't appear to receive maintenance. Some of the vehicle ways appear to have been formed just by the passing of a truck or two. There are approximately three miles of fence on the unit. There are some old plow marks on 25 acres of the northern portion. Despite the lack of screening, the developments are not conspicuous. Their individual and cumulative effects are substantially unnoticeable.

OUTSTANDING OPPORTUNITY FOR SOLITUDE OR A PRIMITIVE AND UNCONFINED TYPE OF RECREATION

There is no vegetative screening provided despite the cottonwoods in the coulees and near the reservoirs. Topographic screening is minimal as most of the unit is flat. The unit is not large enough to give a visitor the feeling of solitude that sometimes accompanies open areas. The configuration characteristics alone do not preclude opportunities for solitude. However, the combined effect of configuration, lack of screening, and size preclude excellent opportunities for solitude. 
The opportunities for hiking or horseback riding are not excellent. opportunities for deer or antelope hunting exist. Opportunities are not outstanding for any one primitive recreational activity nor any combination of activities.

SUPPLEMENTAL VALUES

Unit 679 does not have any known supplemental values.

\section{FINAL DECISION ANALYSIS}

SUMMARY OF PUBLIC COMMENTS:

The only comments received supported the Intensive Inventory finding. FINAL DECISION AND RATIONALE:

The unit does not meet the outstanding opportunities for solitude or primitive recreation criterion. The non-WSA recommendation is unchanged. 


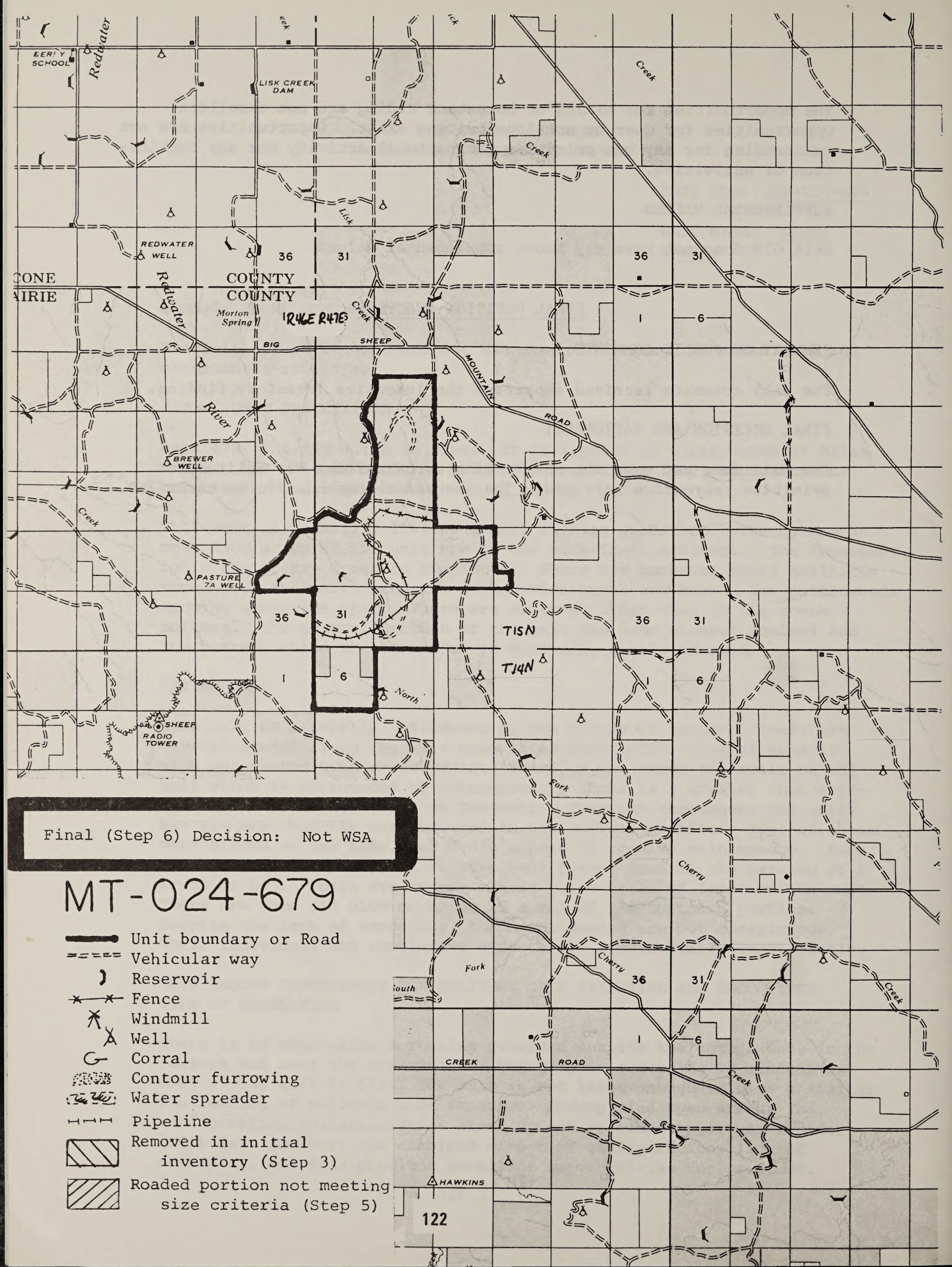


NARRATIVE SUMMARY

WILDERNESS INTENSIVE INVENTORY

UNIT NO.: $\quad$ MT-024-685

NAME OF AREA: Brakett Creek

\section{SUMMARY OF RECOMMENDATION}

The unit is not recommended for WSA status, although it does meet

the size criterion.

\section{SIZE \& UNIT DESCRIPTION}

The size of the inventory unit is 7,130 acres. It is bounded by roads or private land. It is located approximately fifteen miles north of Terry, Montana.

The unit is almost exclusively in the Brakett Creek and the west fork of Brakett Creek drainages. Brakett Creek flows from north to south and drains the northern half of the unit. The West Fork drains the southwest portion of the unit. Approximately 600 acres in two places along the east boundary are in the Cottonwood Creek drainage. All three drainages are intermittent. The topography of the Cottonwood Creek and West Fork of Brakett Creek drainages are level undulating grassland. The topography of Brakett Creek has more relief. It is paralleled by two fairly steep drops of $100^{\prime}$ and a mile apart. There are isolated trees in this drainage particularly along Brakett Creek.

\section{NATURALNESS}

The West Fork of Brakett Creek and Cottonwood Creek drainages contain many signs of man which are conspicuous. There is a system of powerlines in the West Fork drainage. Due to the lack of screening, it is very obtrusive. These provide power to several pumps which have associated stock tanks. There are also several windmills in the unit. Two vehicle ways are very conspicuous. One runs along the West Fork of Brakett Creek and is paralleled by a powerline. The other is along the divide between West Brakett and Brakett Creeks. In addition, there are numerous other vehicular ways in the unit. One of two reservoirs in the unit is apparent. It is near the southern boundary (SWNW Sec.23, T.14 N., R.50 $\mathrm{E}$. The other is in Brakett Creek and is topographically screened. Of the many fences in the unit, those in West Brakett and Cottonwood Creeks are visible from most of the drainage. Several quarter sections in the south part of the unit and much of Cottonwood Creek has been cultivated. 
The unit does not meet the naturalness criterion. Powerline, fences and vehicle ways are substantially noticeable due to their extent and distribution and the physiography of the unit.

\section{OUTSTANDING OPPORTUNITY FOR SOLITUDE OR A PRIMITIVE AND UNCONFINED} TYPE OF RECREATION

There are no opportunities for solitude in the West Brakett or Cottonwood drainages. This is due to total lack of vegetative or topographic screening. There is no vegetative, but some topographic screening within, Brakett Creek. The only opportunities for solitude are provided by the many small tributary coulees interspersed with a few small knobs. However, the opportunities for solitude are not outstanding within that drainage nor the unit as a whole.

There is no physical characteristics of the unit that provide outstanding opportunities for recreation. The activities that the unit lends itself to are hunting and perhaps hiking. Neither is distinguished. Nor are they in combination distinguished.

\section{SUPPI,EMENTAL VALUES}

There are no known supplemental values in the unit.

\section{FINAL DECISION ANALYSIS}

\section{SUMMARY OF PUBLIC COMMENTS :}

The only comments received supported the Intensive Inventory finding.

\section{FINAL DECISION AND RATIONALE:}

The unit does not meet the naturalness nor the outstanding opportunities for solitude or primitive recreation criteria. The non-WSA recommendation is unchanged. 


\title{
NARRATIVE SUMMARY \\ WILDERNESS INTENSIVE INVENTORY
}

\author{
UNIT NO.: $\quad$ MT-024-691 \\ NAME OF AREA Stellar Creek
}

\section{SUMMARY OF RECOMMENDATION}

The unit is not recommended for WSA status, because it meets none of the criteria.

\section{SIZE \& UNIT DESCRIPTION}

The unit is 30 miles north northwest of Forsyth. A road was identified during intensive inventory (see map) which fragments the unit into two pieces. The southeast portion has an acreage of 2550 and the northwest 2750. An acreage recalculation of the whole unit indicate that it is 5300 acres rather than the 5100 stated in the Situation Evaluation. The intensive inventory will be completed despite the fact that thr unit will not meet the 5,000 acre or practicable size criterion.

The major topographic relief of the unit is the southwest side of the divide between Stellar Creek to the south and Little Porcupine Creek to the northwest. The ridge consists of low gumbo knobs moderating towards the northwest end.

Approximately 3 miles of this 100' high steep slope are within the southeast end of the unit. However, it is a major feature only in that the remainder of the unit is so uniform. The Stellar Creek drainage of the unit is very smooth topography sparsely covered with grass. The Porcupine Creek side constitutes about $25 \%$ of the acreage along the northwest side of the unit. It is barely dissected and almost void of vegetation.

\section{NATURALNESS}

There are five miles of vehicular ways in the unit, two miles of which run along the divide (Sec. 28 \& 34, T.11 N., R.39 E.). There's a reservoir (in Sec.29, T.11 N., R.39 E.) along the road discussed under size. There's also a pit reservoir in the unit and a portion of a large reservoir in the northeast corner. Three miles of fence, three drill holes (with casing above ground level) and some contour furrowing are in the unit. 
While the extent of developments is not large, they are so apparent cumulatively as to be substantially noticable.

OUTSTANDING OPPORTUNITY FOR SOLITUDE OR A PRIMITIVE AND UNCONFINED TYPE OF RECREATION

There is no vegetative nor topographic screening in the unit. The size of the unit is not large enough to provide outstanding opportunities for solitude by size alone. Almost any location in either drainage of the unit is visible from any other location in that drainage.

There are no attributes of the unit which provide any quality recreational activity. No collection of possible activities could exist on the unit which would provide a diversity of activities judged outstanding.

SUPPLEMENTAL VALUES

There are no known supplemental values in the unit.

\section{FINAL DECISION ANALYSIS}

SUMMARY OF PUBLIC COMMENTS:

The only comments received supported the Intensive Inventory finding. FINAL DECISION AND RATIONALE:

The unit does not meet the size, naturalness, nor outstanding opportunities for solitude or primitive recreation criteria. The non-WSA recommendation is unchanged. 


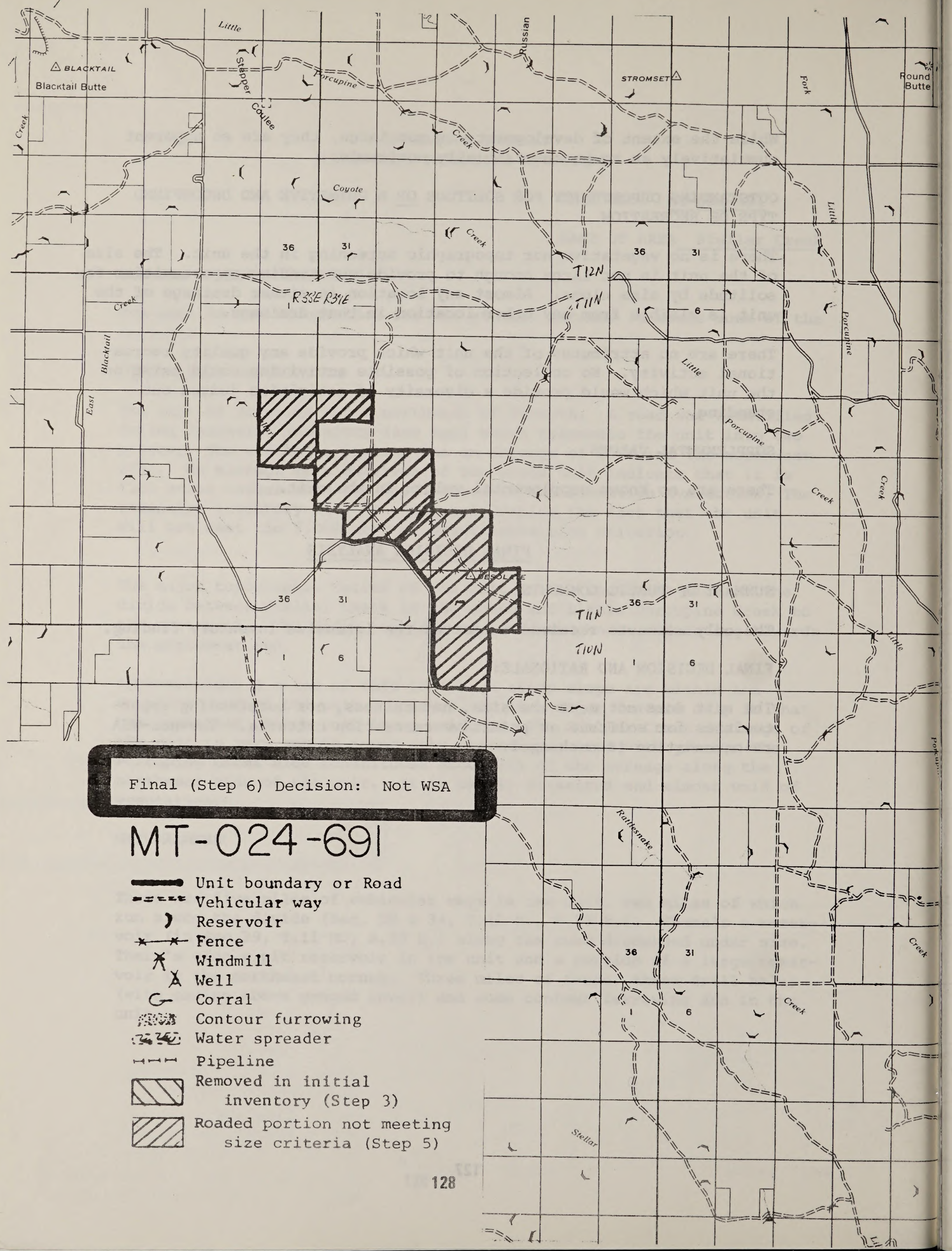


The unit is not recommended for WSA status, although it meets the size and naturalness criteria.

\section{SIZE \& UNIT DESCRIPTION}

This unit is the NW $\frac{1}{4}$ of R. 38 N., T. 22 N., (M.P.M.) and is 160 acres in size. It is contiguous to 14,744 acres (East Hell Creek) of land recommended for wilderness by the U.S. Fish and Wildlife Service (F\&WL) along the .5 mile western boundary.

The unit is entirely within the drainage of Crooked Creek to the east and just east of the divide between Crooked Creek and Kibler (\& unnamed coulees) to the west. The BLM unit is cut through the center from northwest to southeast by a shallow coulee. There are a few small knobs, but the overall topography is best characterized as being flat. The vegetation is generally grassland, although there is a narrow stringer of pines, perhaps 150 yards long, intruding into the unit along the north boundary and other scattered trees.

\section{NATURALNESS}

The only work of man in the unit is a fence along the west boundary. This is substantially unnoticeable, although its location coincides with the boundary between F\&WL and BLM administered lands.

\section{OUTSTANDING OPPORTUNITY FOR SOLITUDE OR A PRIMITIVE AND UNCONFINED TYPE OF RECREATION}

The unit has practically no vegetative nor topographic screening. Due to these factors and its small size it does not have outstanding opportunities for solitude. However the unit may also meet the solitude criterion when evaluated in conjunction with the contiguous F\&WL lands. It does not meet the criterion when evaluated in this fashion either. This is due to the combined effect of configuration and, more important, topographic considerations. The unit protrudes out and is in an entirely different drainage from any of the F\&WL land which is in close proximity to the BLM land. Since the BLM land is not related to the F\&WL land (other than by simple contiguity), it is judged not to have outstanding opportunities for solitude in conjunction with it. 
The rationale for the outstanding opportunities for primitive recreation are analogous to those for the outstanding opportunities for solitude criterion. The unit does not itself have outstanding opportunities for primitive recreation nor have outstanding opportunities for primitive recreation in conjunction with the contiguous $\mathrm{F} \& W L$ land.

SUPPLEMENTAL VALUES

There are no known supplemental values in the unit.

\section{FINAL DECISION ANALYSIS}

\section{SUMMARY OF PUBLIC COMMENTS:}

The only comments received supported the Intensive Inventory finding. FINAL DECISION AND RATIONALE:

The unit does not meet the outstanding opportunities for solitude or primitive recreation criterion. The non-WSA recommendation is unchanged. 
R. $37 \mathrm{E}$.

R. $38 \mathrm{E}$.

R23N R. 39 E.
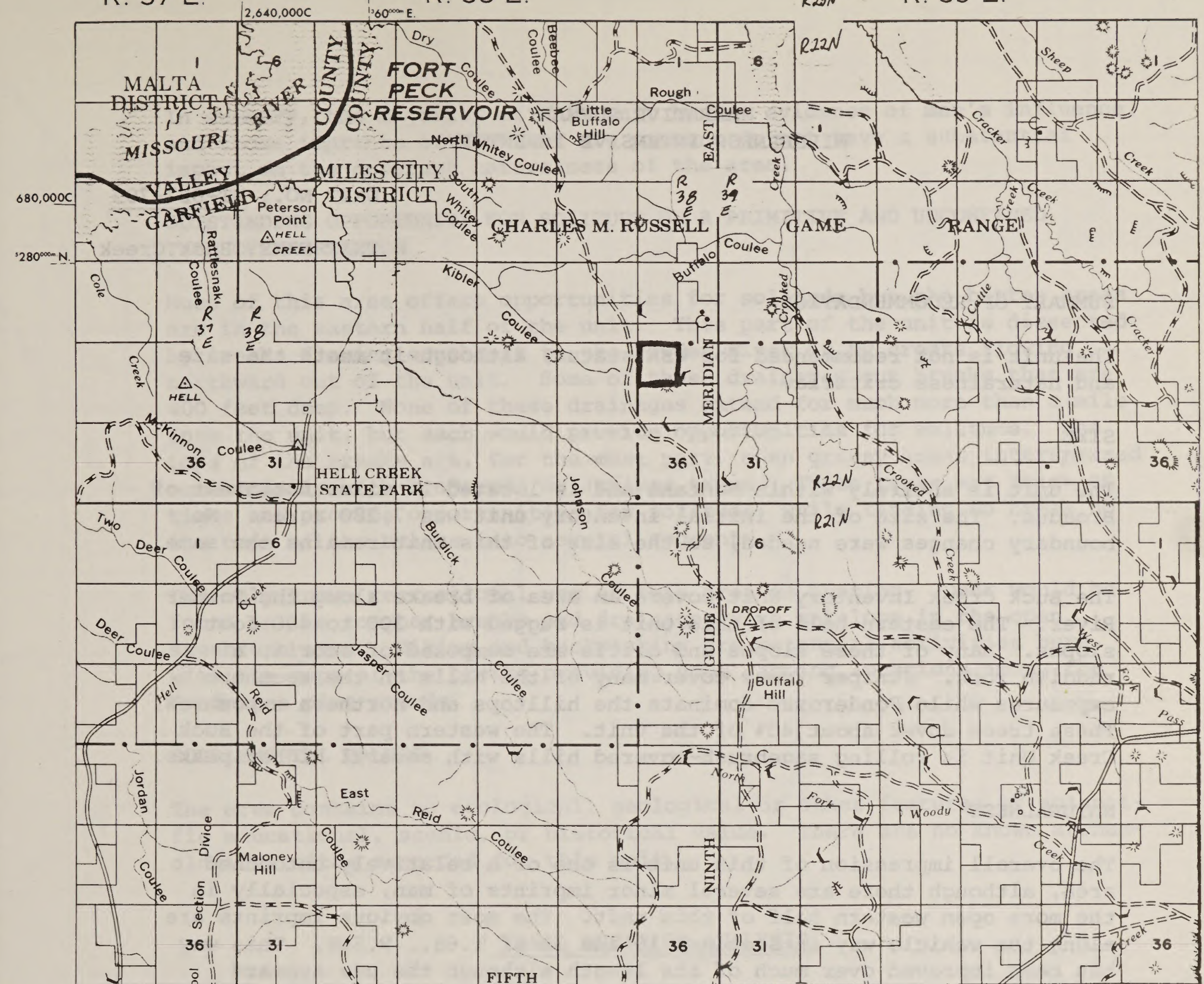

$200-2$ 
The unit is not recommended for WSA status, although it meets the size and naturalness criteria.

SIZE

The unit is entirely within Montana and is located 15 miles southwest of Broadus. The size of the initial inventory unit was 7,280 acres. No boundary changes were needed, so the size of this unit remains the same.

The Buck Creek Inventory Unit covers an area of breaks along the Powder River. The eastern half of this unit is rugged with 300 to 400 foot slopes. Many of these slopes and cliffs are composed of scoria, a reddish rock. Juniper trees cover many of the hills on the southern exposures while Ponderosas dominate the hilltops and northern exposures. These trees cover about $40 \%$ of the unit. The western part of the Buck Creek Unit is rolling sagebrush-covered hills with several higher peaks.

\section{NATURALNESS}

The overall impression of this unit is one of a relatively untouched area, although there are several minor imprints of man, especially in the more open western half of this unit. The most obvious imprints are along the vehicle way in sections 19 and 30 of T.6S., R.50E. This way has been improved over much of its length although the use appears minimal at this time, and at least one creek crossing is impassable because of a lack of maintenance. Nevertheless, the scars of the bladed sections are apparent. Parallel with this vehicle way is a water pipeline which was buried in late 1976. This project (M35163) includes a 50-foot right-of-way for the grazing permittee, who had the work done. Also along this vehicle way is a drill hole site which has mostly recovered, and a small reservoir which has only a very small impact on the immediate area.

A second vehicle way appears to be unused at this time and it was impossible to follow this route up a steep hill in section 19, T.6S., R.50E., because of its deterioration. The vehicle way continues to a reservoir in Section 18, but the reservoir was observed from a high point a mile to the west.

A third vehicle way is in section 13, T.6S., R.49E., and appears unused. Four additional reservoirs appear in this unit. Three of them are very small. The largest, in section 14, T.6S., R.49E., is half in the unit. There are about 6 miles of fence in this unit. 
In summary, the majority of this unit has no evidence of man's influence, and those imprints of man that are present do not have a substantial impact on the apparent naturalness of the area.

OUTSTANDING OPPORTUNITY FOR SOLITUDE OR A PRIMITIVE AND UNCONFINED TYPE OF RECREATION

Much of this area offers opportunities for solitude but the better areas are in the eastern half of the unit. This part of the unit is dissected by creeks flowing southeast to the Powder River or by creeks flowing northward out of the unit. Some of these drainages cut breaks that are 400 feet deep. None of these drainages extend for much more than a mile into the unit, but each would provide opportunities for solitude. The tops of the breaks are, for the most part, open grassy areas interspersed occasionally with Ponderosa or Juniper trees. These trees are thick at times and provide opportunities for solitude, while tending to break up the tops of the breaks into several segments.

The only known recreational use of this area is hunting. Deer would be found in the rougher breaks and drainages with antelope in the open sagebrush area. Hiking and backpacking are potential activities here, with the tops of the breaks providing good camping locations among the Ponderosa pine stands.

\section{SUPPLEMENTAL VALUES}

The area contains no ecological, geological or other features of scientific educational, scenic, or historical value. There are no known archaeological sites recorded for this unit.

\section{FINAL DECISION ANALYSIS}

SUMMARY OF PUBLIC COMMENTS:

The only comments received supported the Intensive Inventory finding. FINAL DECISION AND RATIONALE:

The unit does not meet the outstanding opportunities for solitude or primitive recreation criterion. The non-WSA recommendation is unchanged. 


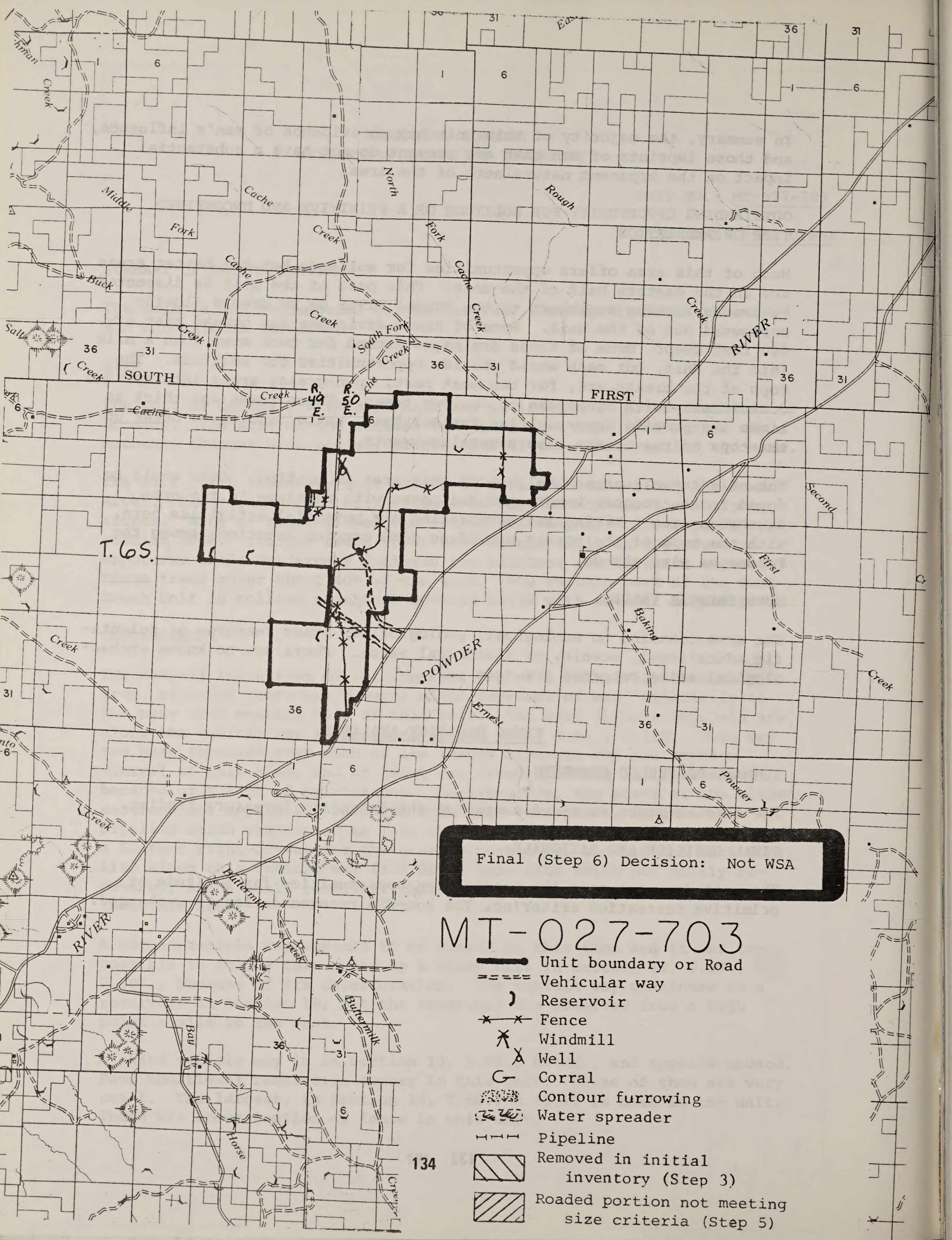


UNIT NO.: $\quad$ MT-027-704

UNIT NAME: Rough Creek

\section{SUMMARY OF RECOMMENDATION}

The unit is not recommended for WSA status, although it meets the size and naturalness criteria.

\section{SIZE \& UNIT DESCRIPTION}

The unit is located 14 miles southwest of Broadus and is entirely within Montana. The actual size of the initial inventory unit was 5,280 acres. The Situation Evaluation listed the acreage as 5,400, but was in slight error.

One road was found in the unit that would cut off a segment of about 90 acres. That road enters the unit in Sec. 13, T.5S., R.49E. and extends to the north-central part of Sec. 19, T.5S., R.5OE. The major reason for the road seems to have been a drilling site in the southeast corner of Sec. 13. Extensive cuts in the hill and fills were made and one obvious tree clearing was located near the drilling site. The road appears to have been maintained since it was developed and it is still in good condition even with the sometimes steep grade. There has been useage because of paths through the grassy cover now on much of the road. The boundary of the unit should be adjusted to exclude 90 acres that this road cuts off, leaving the unit size at 5,190 acres.

The Rough Creek unit covers an area of moderate breaks along the Powder River. This is one of a series of breaks beginning around Broadus, Montana, and continuing southwestward to the Wyoming border where these breaks are more spectacular. Fairly dense stands of ponderosa pine cover the ridgetops and northern slopes of the hills with the other $85 \%$ of the unit consisting of sagebrush and grasses. This unit appears affected primarily by the forces of nature, although there are several vehicle ways or roads into the Rough creek unit.

\section{NATURALNESS}

The vehicle way with the most potential impact on the area is probably the segment in the northern part of Sec. 20, T.5S., R.50E. This vehicle way has been improved in several places. But rancher Doug Randall, who has a grazing permit in this area, has not maintained or used this road since the winter of '77-'78 partly because of the last two severe winters. The BIM put in a water pipeline along the way which is now virtually invisible.

Another vehicle way enters the unit in Sec. 8, T.5S., R.50E. and ends in Sec. 17 The way has been improved, but use seems nonexistent. A third vehicle way goes to a reservoir and a windmill (out of the unit and was 
not seen), but this way is barely visible. A fourth way is an extension of the road in Sec. 13, T.5S., R.49E. This vehicle way is in good condition, and winds through trees, some of which were probably cleared. Use is light and fades out to nothing in the northeast part of Sec. 19, T.5S., R. 50E.

There are three small reservoirs in the unit, two of which appear older with heavy vegetation on the dam and around the shore. A third reservoir was not seen even though the inventory team passed near it. It is located in a deep draw. However, the dam itself could be seen by looking carefully up Rough Creek from about a half-mile downstream.

The majority of the Rough Creek unit contains no evidence of man's influence and those impacts that do exist do not have a substantial impact on the apparent naturalness of the area.

OUTSTANDING OPPORTUNITY FOR SOLITUDE OR A PRIMITIVE AND UNCONFINED TYPE OF RECREATION

This unit consists basically of one major ridge running between Cache Creek (out of the unit) on the south and Rough Creek on the north. There are opportunities for solitude in most of this unit with the best opportunities being on the ridge. The main ridge and the side ridges branching off are covered with ponderosa pines, especially the northern slopes.

The upper Rough Creek drainage, centered around Section 17, provides another area with opportunity for solitude, although not as good as the tree-covered ridges. This drainage forms an amphitheater with few opportunities for topographic or vegetative screening. The Creeks themselves provide some screening within the amphitheater. This unit provides good opportunities for solitude considering its relatively small size $(5,190$ acres), but even these opportunities are not outstanding.

Hunting is the only known recreational use in the Rough creek unit right now. Deer hunting is very good in and around this unit. There is the potential for backpacking and hiking, especially along the ridges.

Horseback riding would not be difficult except for the steep slopes coming off the ridges. This unit is in the Fort Union geologic formation and several ledges containing hundreds of gastropods were noted. Fossil collecting might be productive in this area. None of these activities is excellent or outstanding, nor are outstanding opportunities provided by the diversity of activities. 
This unit contains exposed beds of Tertiary fossils, although these fossils are common in the Fort Union formation covering much of southeastern Montana.

There are two recorded cultural sites in this unit. Both contain lithic scatter (porcellanite, chert flakes and tools, etc.), and these sites are common throughout the region.

\section{FINAL DECISION ANALYSIS}

SUMMARY OF PUBLIC COMMENTS :

The only comments received supported the Intensive Inventory finding. FINAL DECISION AND RATIONALE:

The unit does not meet the outstanding opportunities for solitude or primitive recreation criterion. The non-WSA recommendation is unchanged. 


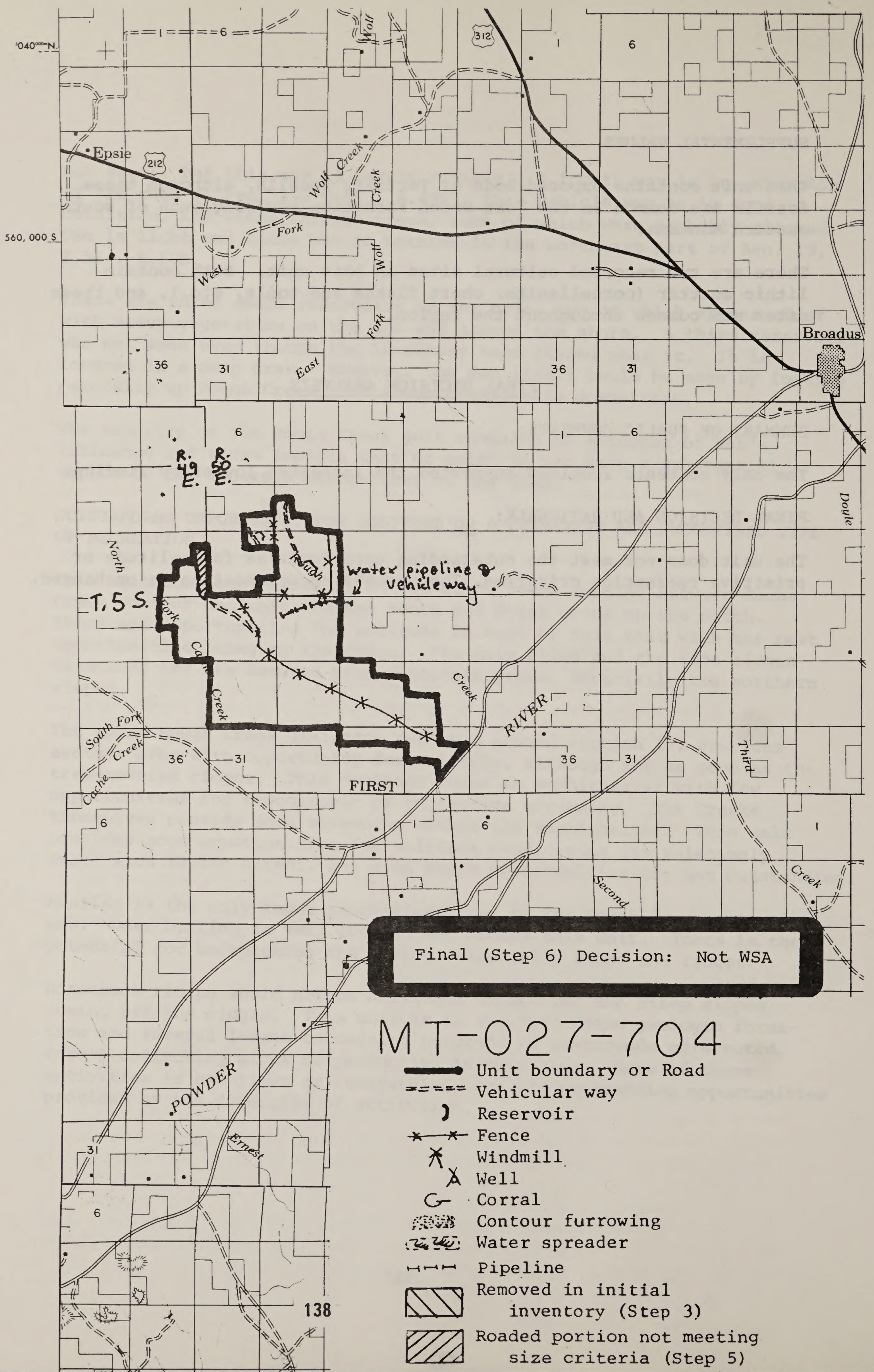


NARRATIVE SUMMARY

WILDERNESS INTENSIVE INVENTORY

UNIT NO.: $\quad$ MT-027-709

UNIT NAME: Dry Creek

\section{SUMMARY OF RECOMMENDATION}

The unit is not recommended for WSA status, although it meets the size and naturalness criteria.

\section{SIZE \& UNIT DESCRIPTION}

The unit is located 17 miles southwest of Ekalaka and is entirely within Montana. The Situation Evaluation listed this unit size as 8480 although recalculation resulted in 9200.

During the intensive inventory, one boundary adjustment was found necessary. A road cut across the southwestern part of this unit in Sec. 21, T.1S., R.55E. Boundary adjustments removed 90 acres from this unit. The final size of the Dry Creek unit is 9,110 acres.

The Dry Creek Inventory Unit encompasses an interesting variety of scenery. The westernmost 2 or 3 sections include badlands-type terrain of various shades of white and gray mudstone. Many of these knobs are mostly barren of vegetation with intricate drainage patterns. A grasscovered ridge runs northwest-southeast along the southern boundary of the unit with many of the hills on the ridge covered with trees. There are some junipers on the southern exposures with junipers and ponderosa on the northern slopes, covering about 5\% of the unit. The far eastern portion of the Dry Creek unit is open rolling grassland with Dry Creek drainages covering much of the area, although these drainages are shallow.

\section{NATURALNESS}

The overall impression of the Dry Creek unit is one that has been affected primarily by the forces of nature, but there are a few important exceptions where man's imprint is present.

The most obvious of these imprints are the several vehicle ways evenly distributed throughout the unit. One of these vehicular ways enters the unit in Sec. 15, T.1S., R.55E., and ends after a half mile near a reservoir. Aerial photos show a trail continuing around to the east side of this 4-acre reservoir, but the tracks are very faint. This way was improved in some places, but is not maintained now. However, the way is easily passable considering the mudstone "gumbo" it goes over; and the destination might be a dump which is located in a drainage near the above reservoir. Also, an oil and gas well was drilled, but the site appears to have recovered. Only a rusty pipe marks the spot. 
Another vehicular way goes south from the county road in T.1S., R.56E., Sec. 7, leaves the unit in Sec. 24, T.1S., R.55E., continues south generally parallel to the unit and dips back inside the unit a couple times, finally leaving the unit and curving around the southeastern tip of Dry Creek Unit. The vehicle way is well used and in fair condition even though it crosses a couple of drainages. There is a bench cut into a hill inside the unit. The vehicle way has not been maintained recently. Although maintenance is not needed over a vast majority of this way, there are a few places where vehicles have made new paths around rutted slopes. Along this vehicle way in Sec. 13 are some developments such as a small building, corral, windmill and reservoir.

The three other vehicles ways in the Dry Creek unit have less impact and would probably revegetate relatively fast if use discontinued. One windmill is located in T.IS., R.56E., Sec. 30 and six other reservoirs are in the unit, most of them within a quarter mile of the road forming the unit's northern boundary. The unit has a little over 10 miles of fence which for the most part blends in with the landscape. An exception is the east-west running fence in the north side of the Dry Creek unit. This is no doubt due to present grazing practices, but the vegetation difference on opposite sides of the fence is noticeable.

In summary, the majority of the unit contains little evidence of man's influence, but portions of the area have a concentrated variety of human imprints visible. The cumulative effect of these developments is substantially unnoticeable.

OUTSTANDING OPPORTUNITY FOR SOLITUDE OR A PRIMITIVE AND UNCONFINED TYPE OF RECREATION

There seems to be three areas of the Dry Creek unit that provide opportunities for solitude. Much of the unit is open and moderately rolling with very little topographic or vegetative screening.

One area providing good opportunities for solitude is a drainage in the badlands section in the northwest corner of the unit. This drainage is very dissected although not too deep. A valley forms, being about one mile by one and a half miles in size. The intricate design of the erosion pattern is seen from higher points, and one in the drainage could easily be shielded from others in the unit. It might be noted, though, that the Howell ranch is located two miles southwest of this drainage out of the unit and out of sight, but engine noises were heard from that direction, probably either a tractor or pump. Whitetail Creek runs through the eastern portion of the unit and it provides good opportunities for solitude. This drainage is about 80 to 100 feet below the general terrain and several fingers of the drainage combined with isolated clumps of junipers and ponderosas offer some solitude. A third area provides good screening and this is due to the topography and the trees. The ridge in the south central portion of the unit has several knobs with trees growing on northern exposures. These trees are not thick but could provide good screening opportunities. 
As a whole, the Dry Creek Inventory Unit provides fair to good but not outstanding, opportunities for solitude.

The major recreational use of this area is currently hunting. The badlands of the unit provide good habitat for mule deer while the eastern portion with its open grasslands provides good pronghorn habitat. Hunting is very good here as it is in much of the surrounding breaks east of the Powder River. Hiking would be interesting in the badlands formations and Whitetail Creek, although the challenge of the terrain is only moderate. More likely hiking would provide a good opportunity for sightseeing and looking for fossils like dinosaur bones occasionally found in this geologic formation. None of the activities is excellent nor are outstanding opportunities for primitive recreation provided by a diversity of activities.

\section{SUPPLEMENTAL VALUES}

No special ecological or geological values were noted in the unit. There are no known archaeological sites recorded in this area. The scenery is interesting but very typical to the region.

\section{FINAL DECISION ANALYSIS}

SUMMARY OF PUBLIC COMMENTS:

The only comments received supported the Intensive Inventory finding. FINAL DECISION AND RATIONALE:

The unit does not meet the outstanding opportunities for solitude or primitive recreation criterion. The non-WSA recommendation is unchanged. 


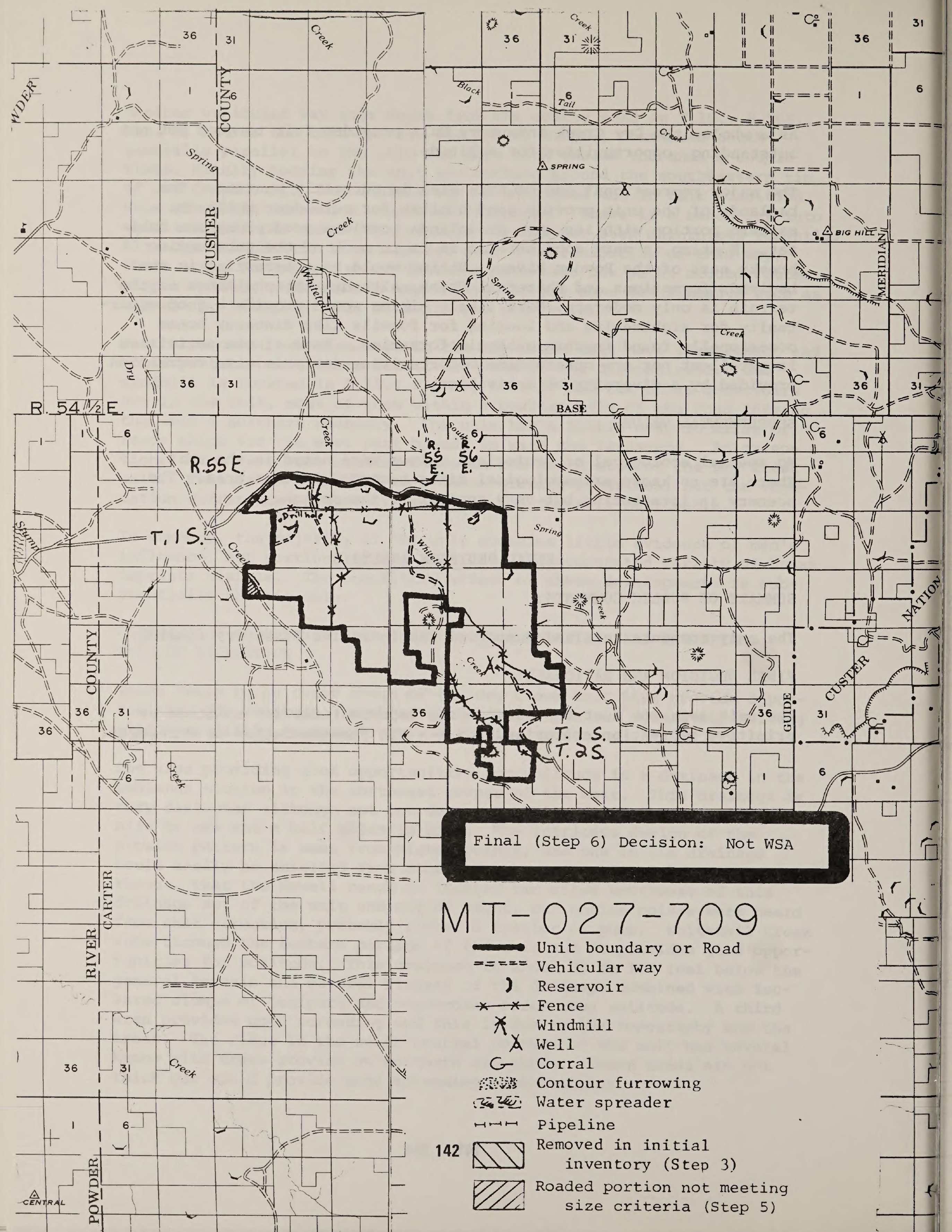


NARRATIVE SUMMARY

WILDERNESS INTENSIVE INVENTORY

UNIT NO.: $\underline{\text { MT-027-710 }}$

UNIT NAME: Spring Creek

SUMMARY OF RECOMMENDATION

The unit is not recommended for WSA status, although it meets the size and naturalness criteria.

\section{SIZE \& UNIT DESCRIPTION}

This unit is located 14 miles west-southwest of Ekalaka and is entirely within Montana. The size of this unit was listed as 9,960 acres in the Situation Evaluation. This was in error and the correct size of the Spring Creek Unit is 10,600 acres.

The dominant feature of the Spring creek Unit is the line of breaks in the northern part of the unit. This ridge begins rising in the west and in the northeast part of the unit reaches a height of 300 feet above the surrounding terrain. This ridge has a very steep slope on the southern exposure, while several drainages run north off the gently sloped northern exposures. The rest of the unit (about $60 \%$ ) is relatively flat with spring creek and its meandering tributaries flowing west out of the unit. Vegetation is predominantly sagebrush and grasses with some scattered juniper trees and ponderosas dotting the breaks in the north. A few trees also cover the hills in the extreme southern tip of the unit.

\section{NATURALNESS}

The Spring Creek Unit appears to be relatively natural, with a few obvious exceptions. The narrow arm in the southwest corner of the unit contains numerous segments of vehicle ways. There are at least 6.5 miles of vehicle ways concentrated in sections 26, 35, 27 and 22 of T.1N., R.55E. The Blair Ranch is within a quarter mile of the unit and most or all of these vehicle trails are used for ranch operations.

Another vehicle way enters the unit in Section 10, T.1N., R.55E. and continues into section 11 where it fades out. The vehicle trail in Section 10, though, is distinct in most places and goes to a small reservoir. An underground waterline enters the unit along this trail, going to a small stocktank. The reservoir is very small and the site has revegetated.

A vehicle way enters the Spring Creek Unit in Section 7, of T.11N., R.56E., continues into Section 8, splits into two ways with both ways ending in section 17. The westernmost fork of the way ends 
at a hand pump in Section 17. The east fork fades out at the fence in Section 17. There are 17 miles of fence in the unit, much of in constructed with metal posts. Much of the fence along the ridge in the northeast part of the unit was placed along a bladed path, with another way alongside. This trail is now impassable. The lines created by these bladed paths are visible at times from this corner of the unit.

There is an old oil drill hole in section 14, T.IN., R.55E. A bladed path goes to the site. The site was not visited because the trail to it seemed to fade out as it crossed spring creek. However, the bladed path was noticed from a high point in the southwest corner of section 7, T.1N., R.56E., about 1.5 miles distant. The straight line and vegetational changes were noticed when trying to locate the site from the high point.

A windmill was seen in the center of section 19, T.1N., R.56E. A vehicle trail to it was not located, however.

OUTSTANDING OPPORTUNITY FOR SOLITUDE OR A PRIMITIVE AND UNCONFINED TYPE OF RECREATION

The northern edge of the unit with its breaks and drainages provides the best opportunities for solitude, however, these are not outstanding. There is some vegetational screening with the ponderosa and juniper trees, but these are sparse. The several drainages provide good screening, but most of these drainages are very short, at least as they lay on public land. The eastern arm of the Spring Creek Unit has some opportunities for solitude because of isolated hills of badlands-type erosion. However these breaks are almost entirely on the private land just out of the unit.

The rest of the unit, the southern half, is relatively flat. Only limited opportunities for solitude exist in the different shallow drainages of Spring Creek.

The only known recreational use of the area at present is hunting. Deer would be found along Spring Creek and the breaks of the northern edge of the unit. Hiking and camping activities would have good potential here. The breaks and drainages of the northern part of the unit provide fairly rugged terrain for hiking, while the broken terrain of the breaks is scenic.

\section{SUPPLEMENTAI VALUES}

The breaks in the northern part of the unit, while not at all unique to this region, are scenic. As seen from the southern portion of the unit, the breaks appear to form cliffs. But when located on top of the breaks, one can appreciate the rugged badlands-type erosion found along the main ridge in the northern half of the unit. 


\section{FINAL DECISION ANALYSIS}

SUMMARY OF PUBLIC COMMENTS:

The only comments received supported the Intensive Inventory finding. FINAL DECISION AND RATIONALE:

The unit does not meet the outstanding opportunities for solitude or primitive recreation criterion. The non-WSA recommendation is unchanged. 


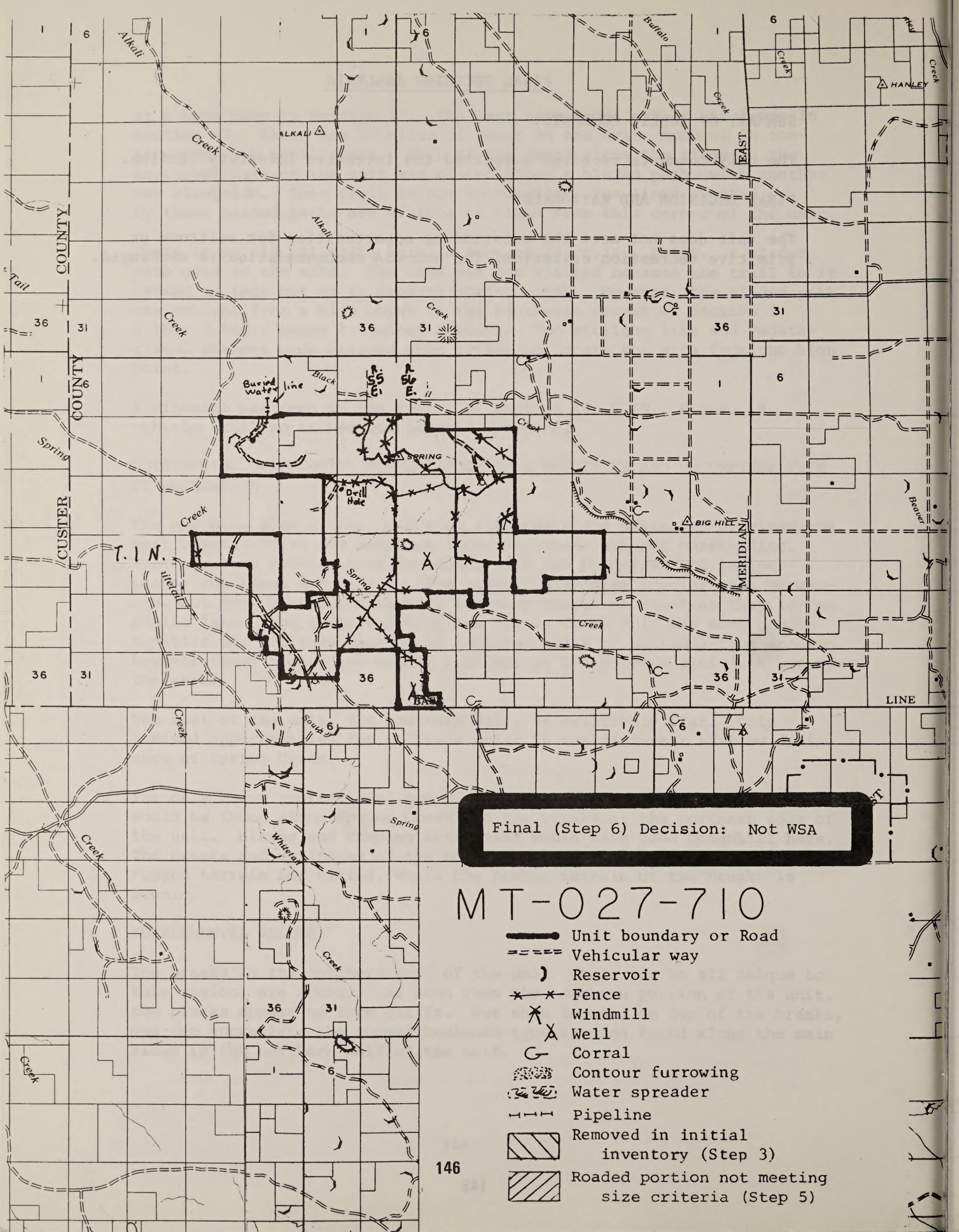




\section{SUMMARY OF RECOMMENDATION:}

The unit is not recommended for WSA status although it meets the size criterion.

\section{SIZE AND UNIT DESCRIPTION:}

The unit is located 20 miles south of Ekalaka and is entirely within Montana. The size of the initial inventory unit is 43,870 acres. The 38,000 acres listed in the Situation Evaluation was in error, partly because of the difficulty in counting acreage with the irregular boundaries. This unit is actually made up of four separate segments, each separated from the other by an area that was removed from intensive inventory by the State Director in August, 1979. These areas obviously did not have wilderness potential. Segment A consisted of 13,100 acres, Segment B had 9,170 acres, Segment C had 14,120 acres, and Segment D had 7,480 acres (see attached map).

There are several roads found within this unit that require boundary changes. Two roads in segment $A$ cut the area into three sections; two of which are much smaller than 5,000 acres. These two segments removed totaled 4,930 acres. The remaining portion of segment A consists of 8,170 acres. Two other road segments (see Naturalness Narrative) require boundary changes, but no acreage is lost. The final size of the Lone Tree Inventory Unit is 38,940 acres.

The Lone Tree Inventory Unit consists of gently rolling hills and flat terrain with grasses and stunted sagebrush being the dominant vegetation. There are probably less than 10 trees in the entire unit.

\section{NATURALNESS :}

It is difficult to travel any distance at all in this unit without noticing evidence of human imprints. Each of the four segments of the Lone Tree Unit contains similar terrain and is similar in the types and density of developments. All of the segments will be included together in the narrative, with reference to a particular segment only when discussing specific developments.

The four parts of the Lone Tree Unit have 75 reservoirs, about 80 miles of fence and probably 60 or more miles of vehicle ways. Also in segment $B$ is a levee which has a road on it for about 2.5 miles. This levee is obvious through much of segment $B$ and the road on top ends when the levee ends in Sections 10 and 6 of T.3S., R.59E. 
Additional contour furrowing projects were found in segments C and D. These projects are located in sections 24 and 25 of T.2S., R.58E., Section 4 and 9, of T.3S., R.58E., and section 6 of T.3S., R.57E. The waterspreader project already mapped in segment $\dot{D}$ is actually contour furrowing.

Most of the reservoirs found in the unit are of a small size (one acre or less), but there are so many and are so evenly spaced that one is aware of them almost anywhere in the unit. The lines of the dams, the water itself, or the green vegetation around the shorelines all provide noticeable contrast with the surrounding prairie.

Vehicle ways are very numerous with most of the ridges having them. Many of these ways are in as good condition as nearby roads through vehicle use.

While fences are found in all of the roadless areas, the excess fences found in this unit make it hard to move around more than a mile or so and not feel the presence of these impacts. This might be in large part to the extremely flat terrain, and the long unbroken lines created by the fences.

In summary, the majority of this unit contains excessive evidence of man's influence and the area does not appear natural.

OUTSTANDING OPPORTUNITY FOR SOLITUDE OR A PRIMITIVE AND UNCONFINED TYPE OF RECREATION :

The opportunities for solitude are virtually absent from any of the segments except C. Segment A consists essentially of a low ridge running through the entire length of the segment. Segments $B$ and D are in the opposite situation, each with a wide open valley in the center of them, bounded on their borders by shallow ridges. Only segment $C$ appears to have opportunities for solitude. This is in part due to the segment having two ridges breaking up the otherwise flat topography. The relatively large size (14,120 acres) also contributes opportunities for solitude. But even these factors don't play a strong enough role to provide outstanding solitude opportunities.

The only known recreational use of this unit is presently hunting. Antelope hunting has traditionally been good here as well as in much of the rest of southeastern Montana. Other possible recreation activities here could include hiking and backpacking.

\section{SUPPLEMENTAL VALUES :}

The Lone Tree area has no known ecological, geological or other features of scientific, educational, scenic, or historical value. 
SUMMARY OF PUBLIC COMMENTS:

The only comments received supported the Intensive Inventory finding.

FINAL DECISION AND RATIONALE:

The unit does not meet the naturalness nor the outstanding opportunities

for solitude or primitive recreation criteria. The non-WSA recommendation is unchanged. 


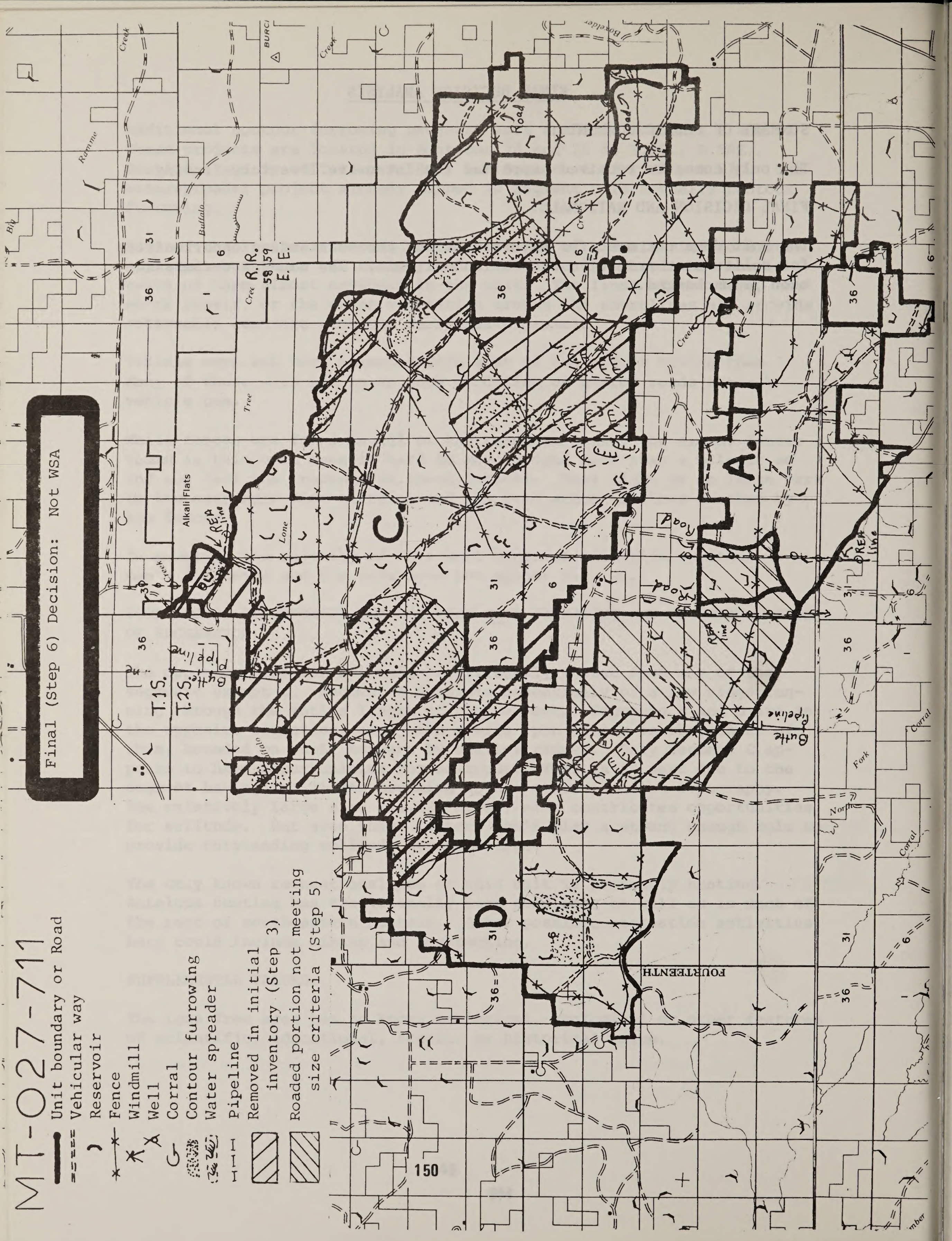


The unit is not recommended for WSA status although it meets the size and solitude criteria.

\section{SIZE AND UNIT DESCRIPTION :}

This unit is located 25 miles south-southwest of Ekalaka and is entirely in Montana. The size of the initial inventory unit was 37,480 acres. Six roads were found within this unit that require boundary modifications. Three of these roads cut off segments totaling 2,560 acres.

The first road begins at the boundary road in T.3S., R.58E., Section 31 and leaves the unit on the western edge of T.4S., R.58E., Section 6 , requiring a 900-acre segment of this unit to be dropped from further consideration. A second road enters the unit in T.3S., R.57E., Section 28 and continues northward 1.5 miles to the east-west fenceline also in Section 28. A third road enters the unit in T.4S., R.57E., Section 19 and extends northward leaving the unit in the southeast corner of section 18. A 620-acre segment of this unit is cut off by this road. The road continues northward along the unit boundary, entering again in T.4S., R.57E., Section 8 and continues to the center of section 6 . No acreage is lost due to this boundary modification. Another road segment enters the unit in section 17 of T.3S., R.56E. and continues for 2 miles to the fenceline in the center of Section 24, T.3S., R.55E. No acres were lost due to this boundary change. A final road is in the southwest corner of Section 3, T.3S., R.55E. and the northwest corner of Section 10, T.3S., R.55E. The road has been improved and there is a concrete creek crossing with culvert pipe. This road removes a 1,040 acre segment west of it from further consideration. Thus, the final size of Corral Creek is 34,920 acres.

The Corral creek Unit generally consists of rolling or flat grasslands with sagebrush, pricklypear cactus and grasses as the dominant vegetation. In the center of the unit a ridge extends north-south with breaks on the west side of the ridge. Some junipers dot the breaks, and ponderosa pines are located on a few north slopes in the extreme northern part of these breaks. These trees cover less than 1\% of the unit. The eastern half of this unit has an elevation around 3500 feet while the breaks drop about 200 feet to the west. The western arm of this unit is around 3200 feet in elevation.

\section{NATURALNESS :}

The cumulative impact of man's work is substantially noticeable in a majority of the unit. There are 60 reservoirs scattered throughout the unit with many of these being 5 acres in size and two of them being around 40 acres each. A ditch flows from one reservoir in section 35 , T.3S., R.57E. for about 1 mile to the unit boundary. The many reser- 
voirs are visible from most of the area except the very center of the unit.

Two fenced enclosures contain about 2,250 acres of contour furrowing with extreme vegetation contrasts and lines visible. Walking through the two projects is difficult because of the danger of stepping wrong on the 8 to 10-inch deep furrows. One furrowing project is located in Sections 12, 13, 24 of T.3S., R.56E. and Sections 7, 18, 19 of T.3S., R.57E. The other project is located in Sections 20, 21, 22, 27, 28, 29 of T.3S., R.57E.

The Butte Pipeline runs north-south through the unit for 2.5 miles. The greatest impacts of the pipeline in this particular unit are the vehicle trail along it and the fenced enclosure around an above-ground valve. Two REA powerlines run through the unit for a total of 3 miles in section 30,31 of T.3S., R.58E. and Section 6 of T.4S., R.58E. The unit contains 65 miles of fence with much of it having red metal posts.

There are also 52 miles of vehicle ways of varying impacts. The way with the most impact is that one which follows the ridge from north to south through the entire unit. The southern part of this vehicle way is actually a road. The northern two miles of this vehicle way is in excellent condition, well used and disturbs the vegetation in places as if it had been bladed. But no local ranchers contacted knew of any improvements along this way. Many. of the ridges in the breaks area have vehicle trails that are well entrenched in the soft bentonitic soil.

An oil drill hole site is located in section 13 of T.3S., R.56 E. This site has recovered except for the drill hole pipe. Other impacts noted include a dike (.3 miles) on the north side of a 40-acre reservoir in Section 4 of T.4S., R.57E. and numerous old tires used for erosion control on another 40-acre reservoir in section 24 of T.3S., R.55E.

OUTSTANDING OPPORTUNITY FOR SOLITUDE OR A PRIMITIVE AND UNCONFINED TYPE OF RECREATION :

The Corral Creek Unit provides outstanding opportunities for solitude on the basis of its large size and extended east-west arms. The unit is about 20 miles long although the east and west arms of the unit are never more than a mile wide. The topography of this unit provides very little screening except in the breaks at the center of the unit. There is also a lack of vegetative scfeening. The few junipers and ponderosas in the breaks are generally too scattered to provide much vegetative screening. It needs to be mentioned that any unit size reduction attempted that might be able to create a part of the unit appearing relatively natural would also lessen the opportunities for solitude.

The only known recreational use of this area is hunting. Antelope are found on the open flatlands while deer would be found in the breaks and along Timber creek in the extreme west. Hiking and backpacking activities have some potential in this unit as does horseback riding.

\section{SUPPLEMENTAL VALUES}

No supplemental values were noted in this unit. There are no recorded archaeological sites for this unit either. 
FINAL DECISION ANALYSIS

SUMMARY OF PUBLIC COMMENTS:

The only comments received supported the Intensive Inventory finding.

FINAL DECISION AND RATIONALE:

The unit does not meet the naturalness criterion. The non-WSA recommendation is unchanged. 
The unit is not recommended for WSA status although it meets the size criterion.

\section{SIZE AND UNIT DESCRIPTION:}

The unit is located 30 miles south-southwest of Ekalaka and is entirely within Montana. The size of the initial inventory unit was 7,480 acres. No roads were found in the unit and the final size of the Muskrat inventory unit is 7,480 acres.

The Muskrat inventory unit covers very flat terrain. The topography is gently rolling land with sagebrush and grasses being the dominant vegetation. A few trees line Muskrat Creek in the extreme eastern portion of the unit.

\section{NATURALNESS :}

This area is heavily developed. The majority of the unit has imprints of man which have a substantial impact on the apparent naturalness of the unit. They are cumulatively substantially unnoticeable.

The Butte Pipeline has a 50-foot right-of-way passing for four miles through the unit. The impact of this development, however, is minor compared to some others. One barely notices the pipeline even while standing on it and looking along the route. The many various water projects cause the major impacts on this unit. A waterspreader project in the northern part of the unit has dikes covering about 450 acres in Sections 22, 23 and 27 of T.4S., R.57E. These dikes and the reservoirs in the area severely impact the area. Another group of waterspreaders is located in sections 34 and 35 of T.4S., R.57E. and the dikes are visible from much of the unit. Five reservoirs dot the southern portion of the unit with one being at least 25 acres in size. A right-of-way exists for a ditch that goes from the large reservoir southeastward to the edge of the unit. About eleven miles of vehicle ways and 12 miles of fence are located in the unit, but none of these are substantial impacts on the unit as a whole.

OUTSTANDING OPPORTUNITY FOR SOLITUDE OR A PRIMITIVE AND UNCONFINED TYPE OF RECREATION:

The Muskrat unit offers very little opportunity for solitude. The unit is fairly flat and shaped so as to prevent visitors from finding solitude 
here. The area consists of three low ridges running east-west with flat terrain laying betweein them. One person in the southern two-thirds of this unit would probably notice anyone else in that part of the unit.

The only known recreational use of this area is hunting. Antelope hunting is usually good here as it is in most of southeastern Montana. The potential for additional recreational activities appears lacking.

SUPPLEMENTAL VALUES:

The Muskrat unit does not contain any known ecological, geological or other features of scientific, educational, scenic, or historical value. There are no recorded archaeological sites in this unit.

\section{FINAL DECISION ANALYSIS}

SUMMARY OF PUBLIC COMMENTS:

The only comments received supported the Intensive Inventory finding. FINAL DECISION AND RATIONALE:

The unit does not meet the naturalness nor the outstanding opportunities for solitude or primitive recreation criteria. The non-WSA recommendation is unchanged. 
R. $57 \mathrm{E}$.

R. $58 \mathrm{E}$

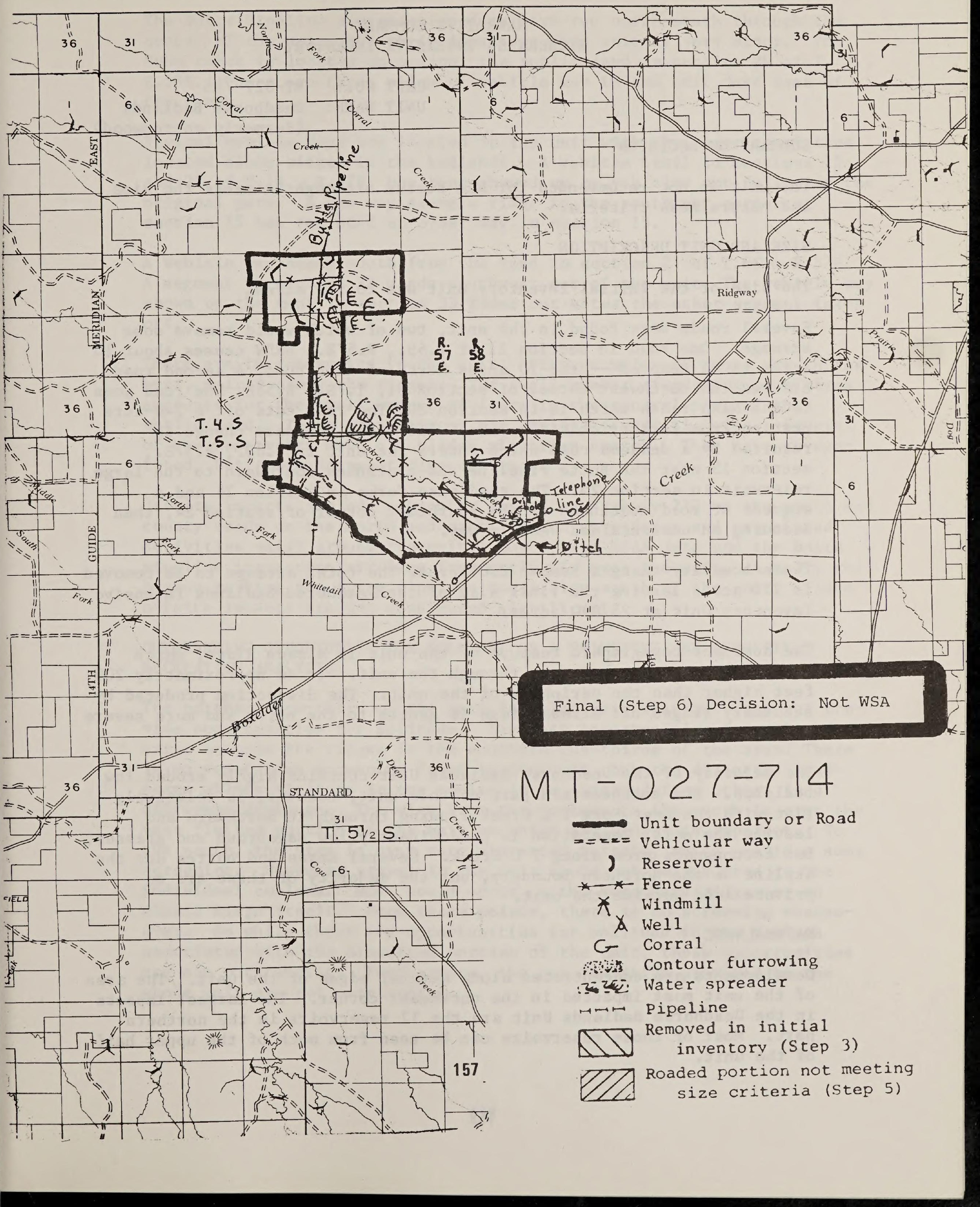




\section{NARRATIVE SUMMARY \\ WILDERNESS INTENSIVE INVENTORY}

UNIT NO.: $\quad$ MT-027-715

UNIT NAME: Deadhorse Badlands

(formerly cottonwood)

SUMMARY OF DECISION

The unit is not recommended for WSA status although it meets the size and naturalness criteria.

\section{SIZE AND UNIT DESCRIPTION}

The size of the initial inventory unit was 26,140 acres.

Several roads were found in the unit, two of which would remove some acreage. One road in section 21 of T.6S., R.57E., NESW causes about 10 acres to be removed -- the 10 acres north of that road. A second road crosses the northwest corner of section $31, \mathrm{~T} .7 \mathrm{~S} ., \mathrm{R} .58 \mathrm{E}$. The road goes to the Nuhn ranch which is in section 20. The road cuts off a 240-acre portion from further consideration. One other boundary change is required by a deadend road which enters the unit in T.6S., R.57E., section 13 near the Butte Pipeline and continues southward to the large reservoir in section 25. The road also forks in section 24 and a segment of road continues to the southeast corner of section 24 , then becoming an unmaintained vehicle way.

These boundary changes remove 250 acres. The total acreage to be removed is 250 acres leaving the final size of the Deadhorse Badlands Intensive Inventory Unit at 25,890 acres.

The dominant topographic feature of the unit is Alzada Ridge, which generally runs east and west through the unit. It is approximately 200 feet higher than the periphery of the unit. The dissection produced by secondary ridges of $\mathrm{Alzada}$ Ridge is gentle to the north and more severe to the south.

The majority of the Deadhorse Badlands Unit contains highly eroded low badlands. The northeastern part of this unit, however, is relatively flat with the East Fork T L Creek flowing through it northward and leaving the unit. Vegetation is predominantly low sagebrush and grasses, but cottonwoods grow along $\mathrm{T}$ L Creek. Several mesas and buttes dot the skyline on the northern boundary, but the majority of these are on private land outside the unit.

\section{NATURALNESS}

Developments are concentrated along several edges of the unit. The area of the unit most impacted in the northeast corner. The largest impacts in the Deadhorse Badlands Unit are the 12 reservoirs in the northern part. Most of those reservoirs can be seen from much of the upper half of the unit. 
The Butte Pipeline and associated markers run north-south through the center of the unit, but their impact on this unit is very minor. The Nuhn ranch is located up against the public land in section 20 of T.7S., R.58E. There are three miles of vehicle way in the unit just east of the ranch.

Several vehicle ways are located in the unit with the majority of them located along ridges in the badlands. A vehicle trail in sections 15 and 22 of T.7S., R.57E. has been chewed up by vehicles not following the original path. A new way along a ridge in the southwest corner of section 15 has replaced an older way in section 15.

A vehicle way heads south from the road in section 21 of T.6S., R.57E. A segment in section 33 heads southwest out of the unit. The vehicle way shown on the maps in section 33 fades out after the other segment takes off.

There are 16 reservoirs in the unit. Fifteen miles of fence are in the unit, mainly along the ridges. The small number of grazing permittees accounts for the small amount of fence in the central part of this public land. There are numerous old exploratory drill holes. Several of the reservoirs have old bladed airstrips nearby. They have revegetated, but there is vegetative contrast.

Offsite impacts include vehicular travel on Highway 212 on the south and county roads on the north and east. Ranch structures and associated activities exist around the unit. Low-flying USAF jets and the Butte pipeline inspection airplane frequently fly over the unit. A tall, red beacon marking the Butte pipeline route lies south of the unit. These offsite impacts are not considered significant.

\section{OUTSTANDING OPPORTUNITY FOR SOLITUDE OR A PRIMITIVE AND UNCONFINED RECREATION ANALYSIS}

The northern one-third of the unit is relatively flat and does not provide opportunities for solitude. The best opportunities for solitude exist between the ridges in the southern two-thirds of the area. There is no vegetative screening found in the unit, but the dissected landscape allows visitors in one coulee to be shielded from others in a different drainage. The view from the coulees to the north is over the vast flatter portion of the unit on which any object is apparent. To the south, the view is over more dissected terrain, which provides some screening. However, travel in the unit could not be isolated in the individual coulees. Most would occur on the secondary ridges or on Alzada Ridge itself. From these points, there is no screening whatsoever. So while there are opportunities for solitude in the coulees associated with the dissected portion of the unit, those opportunities are not outstanding. Furthermore, the opportunities provided by the whole unit are not outstanding. 
Big game hunting is the only known recreational use of this area at present. Deer and antelope are found in this area. Hiking and backpacking offer some potential recreational opportunities.

SUPPLEMENTAL VALUES

There are no known archaeological sites in this unit. No other supplemental values were noted for this area.

\section{FINAL DECISION ANALYSIS}

SUMMARY OF PUBLIC COMMENTS:

Many comments were received regarding this unit. Preferences for and against WSA status were expressed.

Several comments noted the existence of airstrips and exploration drill holes, which were not mentioned in the step 5 narrative. A large number of the commenters felt that developments were so apparent that the unit did not possess the characteristic of naturalness. Many commenters also suggested that offsite developments and activities affected opportunities for solitude. Some commenters felt that the unit did not have outstanding opportunities for solitude due to lack of screening or that the open grasslands did not provide outstanding opportunities for solitude. Many comments suggested that rattlesnakes, weather and bad water were hazards and contributed to poor opportunities for recreation. A comment noted that the unit provided good hunting.

Phase II concerns of WSA status that were expressed include problems of coyote and weed control. Oil, gas, uranium and bentonite potentials were noted. Concerns were expressed regarding facility maintenance and fire control activities.

FINAL DECISION RATIONALE:

A reassessment was made of the naturalness of the unit. The comments regarding offsite impacts were treated under naturalness. The onsite developments are not apparent within the context of the whole unit. The magnitude of the offsite impacts is low enough or those impacts occur infrequently enough as to not be significant.

The relationship of size and screening is crucial in determining whether the unit has outstanding opportunities for solitude and comments were received on this point. After carefully reassessing the unit, it was determined that it does not meet that characteristic. Given the size of the unit, it contains insufficient screening to provide outstanding opportunities for solitude. 
The hazards associated with the unit contribute challenge to the opportunities for primitive recreation. Nevertheless, no recreational activity is outstanding nor is the diversity of activities outstanding.

The unit does not meet the outstanding opportunities for solitude or primitive recreation criterion. This unit will not be studied for potential wilderness designation. 
$\curvearrowleft:$

रि:

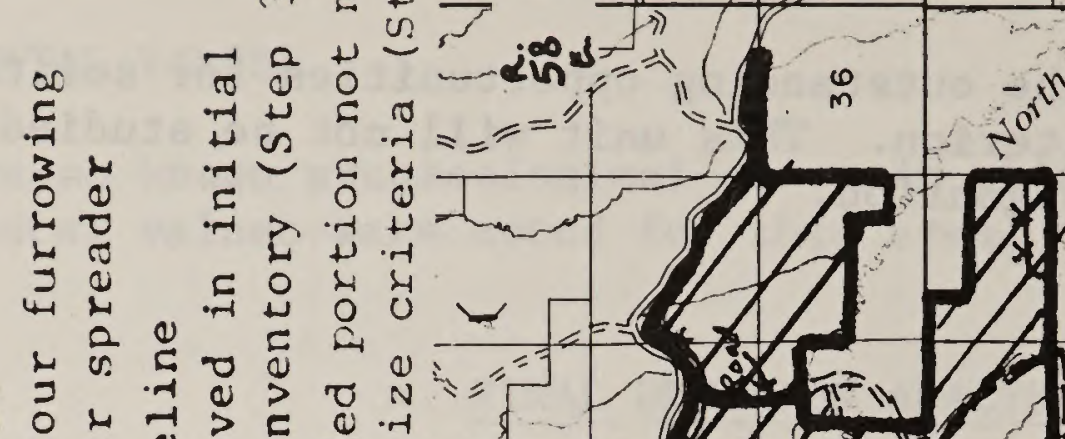

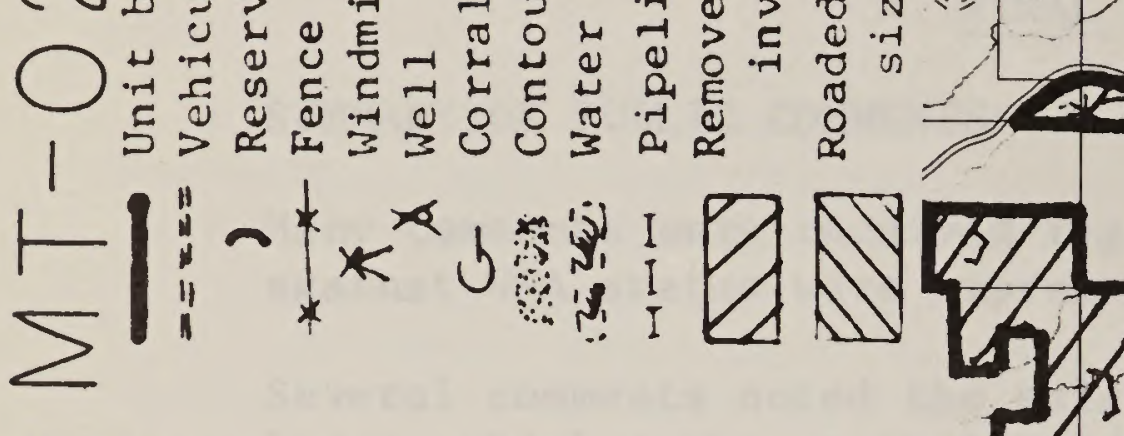

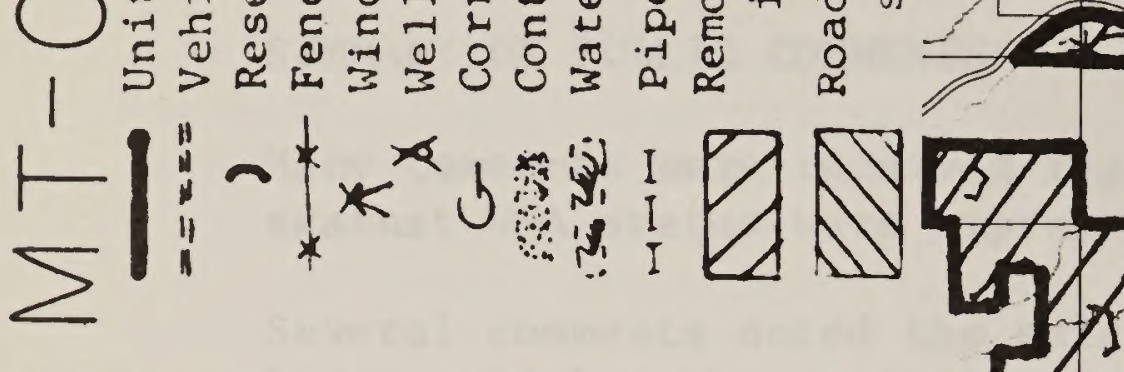

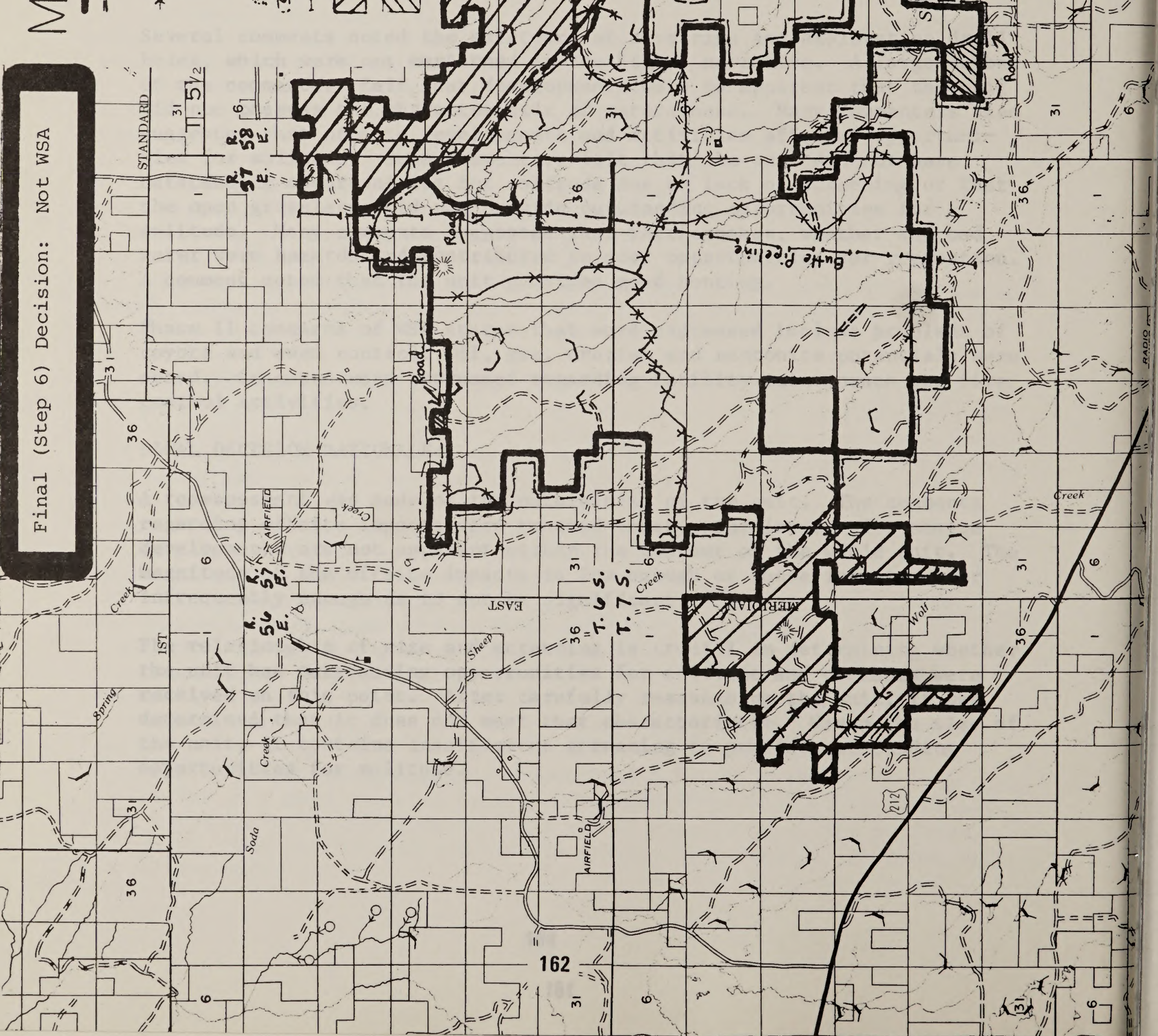




\title{
NARRATIVE SUMMARY \\ WILDERNESS INTENSIVE INVENTORY
}

\author{
Unit No.: $\quad$ MT-027-716 \\ Unit Name: Prairie Dog
}

SUMMARY OF RECOMMENDATION

The unit is not recommended for WSA status, although all three sub-units meet the size criteria and two of the sub-units meet the naturalness criterion.

SIZE

The unit is 22 miles north of Alzada and is entirely within Montana. The size of the Prairie Dog unit is listed as 39,720 acres; the actual size is 40,025 acres. This unit was treated differently than other roadless areas during the initial inventory due to its complex configuration. The unit consisted of six segments connected by $\frac{1}{4}$ or $\frac{1}{2}$ mile corridors of public land. Two of the six segments were each under 5,000 acres in size and were removed from further wilderness consideration by the State Director in August, 1979. The total acreage removed was 7,960 acres. However both of these segments were inventoried during the intensive inventory, and the recommendation for the Prairie Dog unit was not affected by the two segments' inclusion or exclusion in the intensive inventory.

Several roads found in the unit create many segments. Seven of these segments have sizes varying from 10 acres to 2,310 acres. Boundary changes are necessary as these segments do not meet the 5,000 acre size criterion. The Prairie Dog unit is divided by roads into 3 sub-units, each containing more than 5,000 acres. These sub-units will be identified as either $716 \mathrm{~A}, 716 \mathrm{~B}$ or $716 \mathrm{C}$. The sub-unit $716 \mathrm{~A}$ is the northernmost, while $716 \mathrm{C}$ is the southeastern part of the Prairie Dog unit (see attached map). These sub-units will be discussed separately in some of the narratives, and will be combined in other narratives.

The first road in the Prairie Dog unit heads southeastward from the county road along Box Elder Creek, with $716 \mathrm{~A}$ formed north of this road. The road also cuts off a 15 acre and a 10 acre segment of $716 \mathrm{~A}$ from the southeast corner of T.5 S., R. 59 E., Section 3 and the southwestern part of T.5 S., R.59 E., section 1 respectively. A road enters $716 \mathrm{~A}$ in Section 6 of T.4 S., R.60 E., heads northward and leaves 716A in the northeast corner of section 32 of T. 4 S., R. 60 E. An 810 acre segment is cut off by this road. Another road passes through the extreme eastern tip of the above removed segment.

A total of 885 acres are removed from further consideration in $716 \mathrm{~A}$; the final size of $716 \mathrm{~A}$ is 6,590 acres.

Prairie Dog sub-unit $716 \mathrm{~B}$ is located south of $716 \mathrm{~A}$ and west of a road unit inters the unit in Section 20, T.6 S., R.61 E., and leaves the unit 
in the southwest corner of section 30, T.5 S., R.61 E. Another road heads west from the above road in section 20, T.5 S., R. 61 E. and leaves the unit on the west side of Section 27, T.5 S., R.60 E. This road removes from $716 \mathrm{~B}$ a 2,310 acre segment north of it. A road enters $716 \mathrm{~B}$ off the county road in Section 19 of T.5 S., R.59 E. and leaves the unit in the center of Section 28, T.5 S., R.59 E. A 2,210 acre segment is removed from 716B. A road heads southwest in section 11, T.5 S., R.59 E. from the road that forms the southern boundary of.716A. This road leaves the unit while still in section 11 and removes a 20 acre segment from $716 \mathrm{~B}$.

A total of 4,540 acres are removed from further consideration in $716 \mathrm{~B}$; the final size of $716 \mathrm{~B}$ is 14,990 acres.

Prairie Dog sub-unit $716 \mathrm{C}$ contains one road that heads northwestward from the boundary road in section 34 of T.6 S., R.61 E. and leaves the unit in Section 27. A 670 acre segment west of this road is removed from $716 \mathrm{C}$. The final size of $716 \mathrm{C}$ is 12,350 acres.

\section{NATURALNESS \& UNIT DESCRIPTION}

The Prairie Dog $716 \mathrm{~A}$ consists of relatively flat terrain through most of it, with eroded slopes at the extreme eastern edge. These slopes form the base for a mesa located outside of 716A. Vegetation consists of sagebrush, prickly pear cactus and grasses.

This unit contains 14 small reservoirs, 10 miles of fence and 3 miles of vehicle ways. A small corral is located by a reservoir in section 29, T.4 S., R.60 E. There is a high density of reservoirs in $716 \mathrm{~A}$, but they are rarely seen due to the slanting landscape. The overall appearance of $716 \mathrm{~A}$ is that of an area affected primarily by the forces of nature.

The central part of $716 \mathrm{~B}$ consists of gentle badlands erosion with the edges and extended arms of the sub-unit being relatively flat. The Finger Buttes is a scenic area of southeastern Montana consisting of limestone spires and pine-covered buttes. However, these formations are almost entirely out of the roadless area. The public lands boundary includes the flatland between the formations, and that is all. The main portion of the Finger Buttes occurs on a small strip of public land not connected to this roadless area.

This sub-unit appears relatively natural although there are several impacts, especially along its edges. There are 36 reservoirs in $716 \mathrm{~B}$; most are 2 acres or less in size. Two water spreader projects are found in the unit with the dikes covering a total of 1,000 acres. The two projects are located in section 17 \& 20 of T.5 S., R.59 E., and Section 25, T.5 S., R.60 E. and sections $19 \& 30$ of T.5 S., R.61 E. There are 22 miles of fence in the unit with much of it forming obvious lines and consisting of metal posts. There are 13 miles of vehicle trails in $716 \mathrm{~B}$. 
The sub-unit $716 \mathrm{C}$ is relatively flat and is covered by grasses and sagebrush. A few small creeks meander across the unit in various parts of it. The area does contain some substantial impacts to parts of it, and the cummulative impacts create an area not affected primarily by the forces of nature. The largest impacts on $716 \mathrm{C}$ are the dikes from several water spreader projects. These dikes cover about 1600 acres in sections 29 and 30 of T.5 S., R. 61 E., Section 10 of T.6 S., R.62 E., Section 17,18,19 and 20 of T.6 S., R.62 E., and section 24 of T.6 S., R.61 E. A ditch is located in section 33 of T.5 S., R. 61 E. for about a mile. There are 21 reservoirs in $716 \mathrm{C}$ with 2 or 3 of them being 5 acres in size and the rest being 2 acres or less. This sub-unit contains 20 miles of fence. Fifteen miles of vehicle ways are located in 716C. Some segments of vehicle trails in section 29 of T.5 S., R.6I E. could not be found although they appear on topographic maps.

OUTSTANDING OPPORTUNITY FOR SOLITUDE OR A PRIMITIVE AND UNCONFINED TYPE OR RECREATION

None of the Prairie Dog sub-units were found to contain outstanding opportunities for solitude. Opportunities for solitude are lacking in $716 \mathrm{~A}$ and $716 \mathrm{C}$. Sub-unit $716 \mathrm{~B}$ has opportunities for solitude in the very center of it due to the eroded ridges here. But these opportunities are not outstanding. Nowhere is there any vegetative screening. It should be noted that direction of movement through $716 \mathrm{~B}$ and $716 \mathrm{C}$ is very limited due to the narrow corridors of public land in these roadless areas.

The only known recreational activity on the Prairie Dog unit is hunting. Antelope are found throughout the grasslands of this part of Montana. Hiking and backpacking would be potential activities, especially for 716B, however this unit would probably not provide quality experiences for these activities.

SUPPLEMENTAL VALUES

No supplemental values were found in the unit. There are no recorded archeological sites for the Prairie Dog Unit.

\section{FINAL DECISION ANALYSIS}

SUMMARY OF PUBLIC COMMENTS:

The only comments received supported the Intensive Inventory finding. FINAL DECISION AND RATIONALE:

The unit does not meet the outstanding opportunities for solitude or primitive recreation criterion. The non-WSA recommendation is unchanged. 


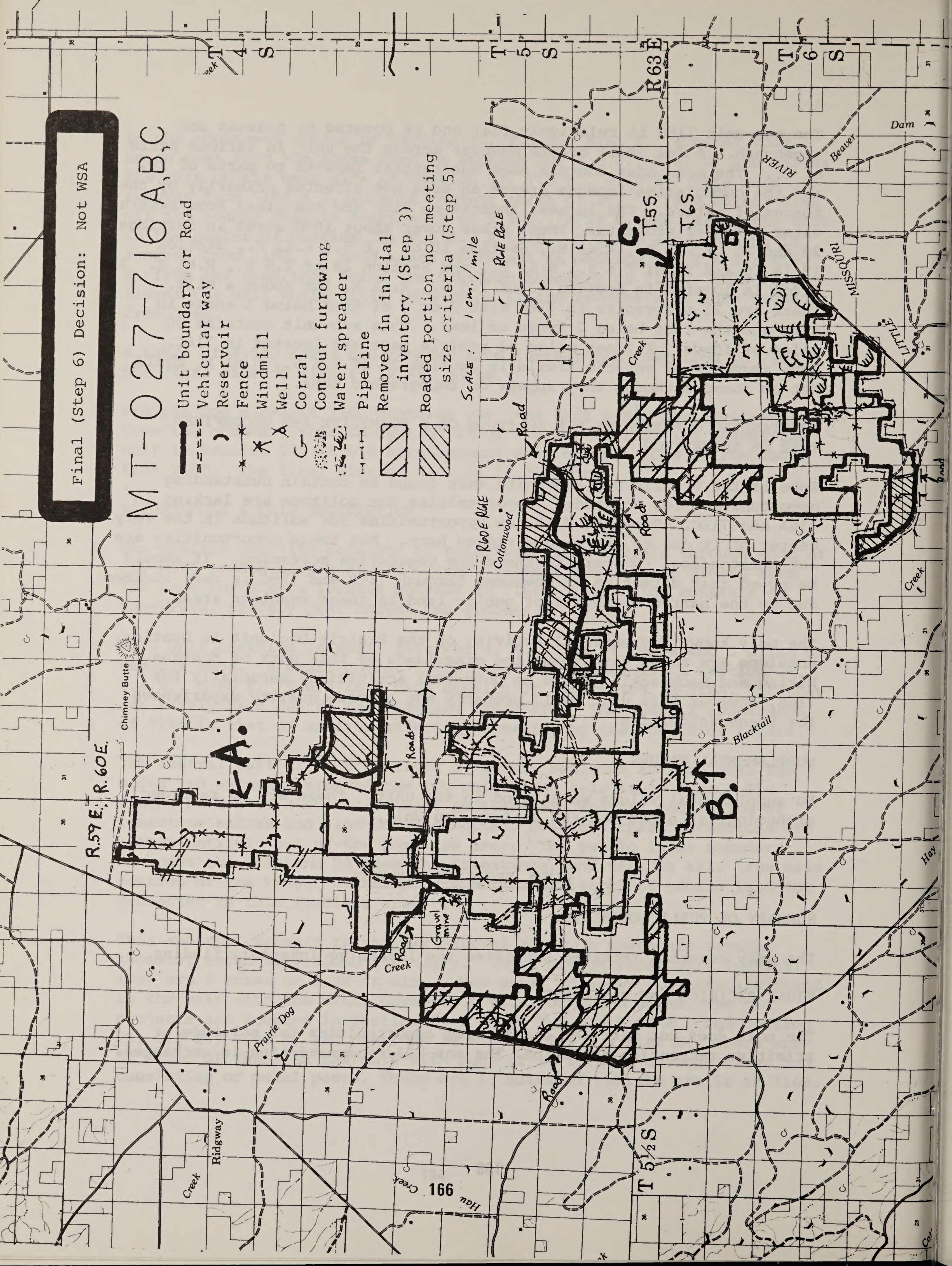




\section{UNIT NO.: $\quad \underline{M T-027-717}$ \\ UNIT NAME: Beaver Dam}

\section{SUMMARY OF RECOMMENDATION :}

The unit is not recommended for WSA status although it meets the size criterion.

\section{SIZE AND UNIT DESCRIPTION:}

Unit 717 is 14,040 acres in size and is located on the South Dakota border 15 miles north of the Wyoming border. This new size calculation takes the South Dakota acreage into consideration, something that was not done for the situation Evaluation.

\section{NATURALNESS :}

The topography of this unit is characterized by large open expanses of rolling grasslands and sagebrush. Occasional gumbo buttes and low ridges are scattered throughout the unit. The dominant forms of vegetation are short-grass species and sagebrush. The topography and vegetatic previously described are uniform throughout the unit.

The developments on this unit include numerous vehicular trails, reservoirs and several miles of fencing. This unit contains a higher than average density of developments, and the cumulative effects of these impacts significantly affect the basic natural qualities of the unit. The vehicle trails are for the most part faint tracks that do not appear to have been improved, and the trails receive only occasional spot maintenance.

There are numerous reservoirs on the unit, but the majority of these are one acre or less. Most of the reservoirs are easily visible due to the open, rolling terrain, and they are small in size and distributed evenly through the unit.

The most obtrusive developments on the unit are the many barbed-wire fences. These fences crisscross the unit and are for the most part highly visible. Positions of many of the fences are obscured by shallow coulees or creek bottoms.

OUTSTANDING OPPORTUNITY FOR SOLITUDE OR A PRIMITIVE AND UNCONFINED TYPE OF RECREATION.

Unit 717 does not have outstanding opportunities for solitude. There are no major variations in topography and only minor elevation changes. There are places where it is possible to be hidden from view by a small 
gumbo knob or by being in one of the shallow coulees which are scattered throughout the unit. Since the unit is virtually void of trees there is no vegetative screening.

Unit 717 does not have outstanding opportunities for recreation -either for one activity in particular or a diversity of activities. It is well-suited to horseback riding because of the gentle, open terrain. opportunities for hiking or photography in the unit are not outstanding. Antelope and upland game bird hunting opportunities are very good as they are in the entire region.

SUPPLEMENTAL VALUES :

Unit 717 does not have any known supplemental values.

\section{FINAL DECISION ANALYSIS}

SUMMARY OF PUBLIC COMMENTS:

The only comments received supported the Intensive Inventory finding.

FINAL DECISION AND RATIONALE:

The unit does not meet the naturalness nor the outstanding opportunities for solitude or primitive recreation criteria. The non-WSA recommendation is unchanged. 



\section{SUMMARY OF RECOMMENDATION:}

The unit is not recommended for WSA status although it meets the size criterion.

\section{SIZE AND UNIT DESCRIPTION:}

The unit is located at the South Dakota and wyoming borders. The acreage ofthe unit is 17,140 acres. Of this, 600 are in South Dakota and 16,540 are in Montana. [In the Situation Evaluation (Step 2), only the Montana acreage was listed. However, the South Dakota portion of the unit was displayed on the Situation Evaluation map.]

A road identified during intensive inventory necessitates a boundary modification, all of which is in Montana (see map). This 476-acre portion reduces the acreage of the unit to 16,664 .

The northern half of the unit is drained by tributaries of the Iittle Missouri River (Flkhorn and Horse Creeks) to the northwest. The southern portion of the unit is drained by Indian Creek, a tributary of the Belle Fourche River. All streams in the unit are intermittent. The divide between the two rivers has an elevation of $3660^{\prime}$. It is barely discernible because the topography on either side is very similar and the lowest point in the unit is about $3230^{\circ}$.

Both ridges and coulees are smooth with small elevational changes. The effect is level terrain with undulating topography. The vegetation is generally grassland with some sagebrush and a few shrubs. There are no trees in the unit.

\section{NATURALNESS :}

Developments apparent in the unit are pervasive. Many more reservoirs, vehicular ways, and fences were identified than were mapped in the Situation Evaluation. The vehicular ways were very apparent due to their extent, layout and use. Reservoirs varied in size from between one and eight acres and were very numerous. Fences were very visible due to their extent and the open topography. There are several cattle licks and rubs in the unit. A dry oil well and pad (in NWSE Section 9, T.8S., R62E.) is well revegetated and barely noticeable. 
Any one section of fence or vehicle way or any one reservoir is substantially unnoticeable. However, the cumulative effect of reservoirs, fences or vehicle ways is substantially noticeable. And the cumulative effect of range improvements is massive. This is due to their large density and distribution throughout the unit (i.e., one can stand anywhere in the unit and in any direction view a range development).

OUTSTANDING OPPORTUNITY FOR SOLITUDE OR A PRIMITIVE AND UNCONFINED TYPE OF RECREATION:

The unit has no veqetative screening whatsoever. The topography is smooth and so, despite its coulees and draws, the unit lacks topographic screening. The lack of screening alone is sufficient to preclude outstanding opportunities for solitude. In addition, the configuration of the unit is extremely gerrymandered. The configuration further denigrates opportunities for solitude.

The only potential recreational activity for the unit is hunting, and it is not outstanding. The opportunities for primitive recreation are not outstanding for any one activity nor for any collection of activities.

SUPPLEMENTAL VALUES:

There are no known supplemental values in the unit.

\section{FINAL DECISION ANALYSIS}

SUMMARY OF PUBLIC COMMENTS:

The only comments received supported the Intensive Inventory finding.

FINAL DECISION AND RATIONALE:

The unit does not meet the naturalness nor the outstanding opportunities for solitude or primitive recreation criteria. The non-WSA recommendation is unchanged. 


\section{SUMMARY OF RECOMMENDATION}

The unit is not recommended for WSA status and does not meet any criteria. SIZE \& UNIT DESCRIPTION

The unit is located 45 miles southwest of Broadus and straddles the Montana-Wyoming border. The size of the initial inventory unit was 6,120 acres. Several roads are found in this unit, two of which segment the unit. One road runs north-south from the boundary in section 33, T.9S., R.46E., M.P.M., through Section 32 and leaves the unit in section 33 again, on the Wyoming boundary. The segment removed by this road was 1,375 acres. A road enters the unit in section 27, T.95., R.46E. M.P.M., and runs parallel to the unit boundary, leaving the unit in Section 26. The segment removed from the unit is 15 acres. Thus, the final size of the unit is 4,730 acres.

This unit contains a ridge in the northern portion from which drainages run off to the south. Vegetation is predominantly sagebrush and grasses with ponderosa pines covering about $5 \%$ of the unit along the arainage.

\section{NATURALNESS}

The major impacts of the Fence Creek Unit are the numerous roads and bladed vehicle trails. Every vehicle trail in the unit appears to have been improved by blading at one time or another. A vehicle trail runs through sections 31 and 32, although maintenance is lacking. Another trail runs from the boundary of the unit in section 27, T.9S., R.46E., M.P.M., and crosses North Fence Creek in Section 35. There has been extensive blading on this trail, especially where it drops off the hill in Section 35.

The major impact of the unit is the road and two oil wells in sections 24 and $35, T .58 \mathrm{~N} ., \mathrm{R} .77,78 \mathrm{~W}$. in Wyoming. The road to the oil wells is well built and gravelled with scoria. A bladed path also climbs to the top of a hill in the western part of section 30. At the top of this hill is a large bladed clearing of unknown use. The path up this hill does not appear to have regular use, although the impact on the area is great. The two oil wells further impact the area because of the structures present and the noise of the wells themselves.

There are two small reservoirs in the unit and about 4 miles of fence. These impacts are very minor compared to the roadwork in this unit. A drill hole in the southeast corner of section 35 was not seen although there is a corral there. Pipelines run from the two oil wells southward out of the unit, but again, the roads are the major impacts. 
OUTSTANDING OPPORTUNITY FOR SOLITUDE OR A PRIMITIVE AND UNCONFINED TYPE OF RECREATION

Opportunities for solitude exist in the drainages of this unit. North Fence Creek has the topography and some Ponderosa pine trees to shield visitors from one another. These opportunities for solitude are not, however, outstanding. It must be mentioned that the engine noise from the two oil wells in the unit is very noticeable within a half mile or so.

Deer hunting is the major recreational use in this unit. Hiking and backpacking would have some potential in this area.

SUPPLEMENTAL VALUES

No supplemental values were found to exist inside the unit. There are no recorded archaeological sites within the unit either.

\section{FINAL DECISION ANALYSIS}

SUMMARY OF PUBLIC COMMENTS :

The only comments received supported the Intensive Inventory finding. FINAL DECISION AND RATIONALE:

The unit does not meet the size, naturalness, nor outstanding opportunities for solitude or primitive recreation criteria. The non-WSA recommendation is unchanged. 

R. $45 \mathrm{E}$.
R. $46 \mathrm{E}$.
R. 47 E.

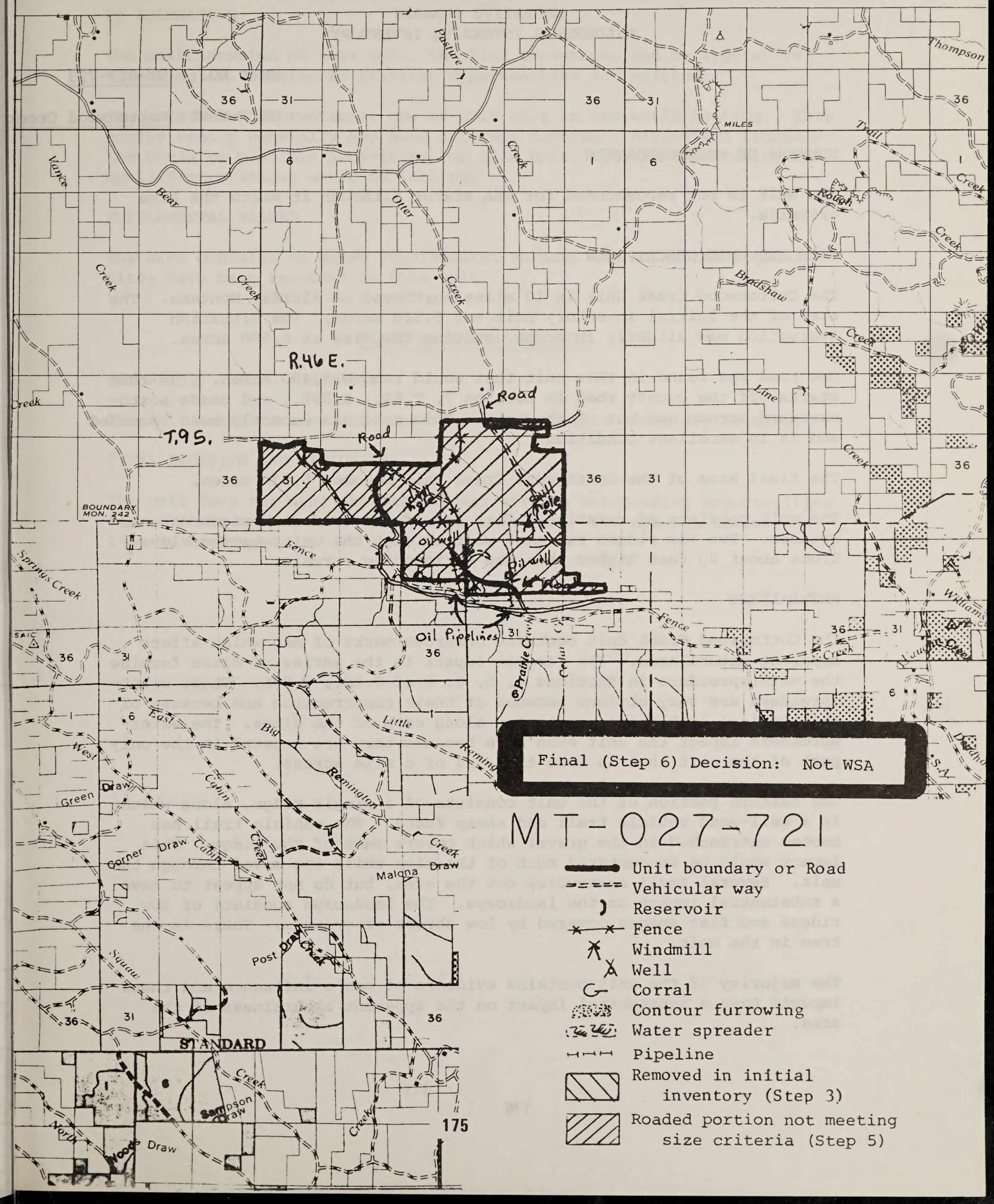




\section{SUMMARY OF RECOMMENDATION}

The unit is not recommended for WSA status although it meets the size criteria.

\section{SIZE AND UNIT DESCRIPTION}

The Cottonwood Creek Unit is 10 miles northwest of Alzada, Montana. The size of the initial inventory unit was 6,520 acres. The Situation Evaluation was slightly in error, stating the size as 6,590 acres.

One road was found in this unit that would remove 1,490 acres. The road starts off the county road in section 7, T.8S., R.59E., and heads southeastward across and out of the unit. This road has recently been regraded and is in excellent condition.

The final size of the Cottonwood Creek Unit becomes 5,030 acres.

The unit consists of relatively flat terrain covered with sagebrush and grasses. Two low ridges run east-west through the unit, having elevations about 20 feet higher than the surrounding terrain.

\section{NATURALNESS}

The Cottonwood Creek Unit contains numerous marks of man which affect apparent naturalness. The largest impact is the series of dikes forming the waterspreaders in sections 4, 5, 8, 9 of T.8S., R.59E. These waterspreaders are very obvious because of their construction and because of the atypical lush green vegetation along each of the dikes. The waterspreaders impact the unit even more because they are located in the only part of the unit that is more than $3 / 4$ of a mile across.

The eastern portion of the unit consists of a single ridge, along which is a well-used vehicle trail and sheep fence. The vehicle trail has become entrenched in the gravel which covers much of the ridge. This impact would be encountered much of the time while one moved through the unit. Several small reservoirs dot the area, but do not appear to have a substantial impact on the landscape. The landscape consists of low ridges and flat spaces covered by low shrubs or grasses. There is one tree in the unit.

The majority of the unit contains evidence of man's influence and these impacts have a substantial impact on the apparent naturalness of the area. 
OUTSTANDING OPPORTUNITY FOR SOLITUDE OR A PRIMITIVE AND UNCONFINED TYPE OF RECREATION

The configuration of this unit, the flat topography and no vegetative screening all combine to restrict opportunities for solitude.

The only known recreational use of this unit is presently hunting. This entire region generally had good antelope hunting. Hiking and backpacking would be possible activities for this unit, but the opportunity for quality experiences would be lacking.

SUPPLEMENTAL VALUES

The area contains no known supplemental values, and no archaeological sites have been recorded on this unit.

\section{FINAL DECISION ANALYSIS}

\section{SUMMARY OF PUBLIC COMMENTS:}

The only comments received supported the Intensive Inventory finding.

FINAL DECISION AND RATIONALE:

The unit does not meet the naturalness nor the outstanding opportunities for solitude or primitive recreation criteria. The non-WSA recommendation is unchanged. 


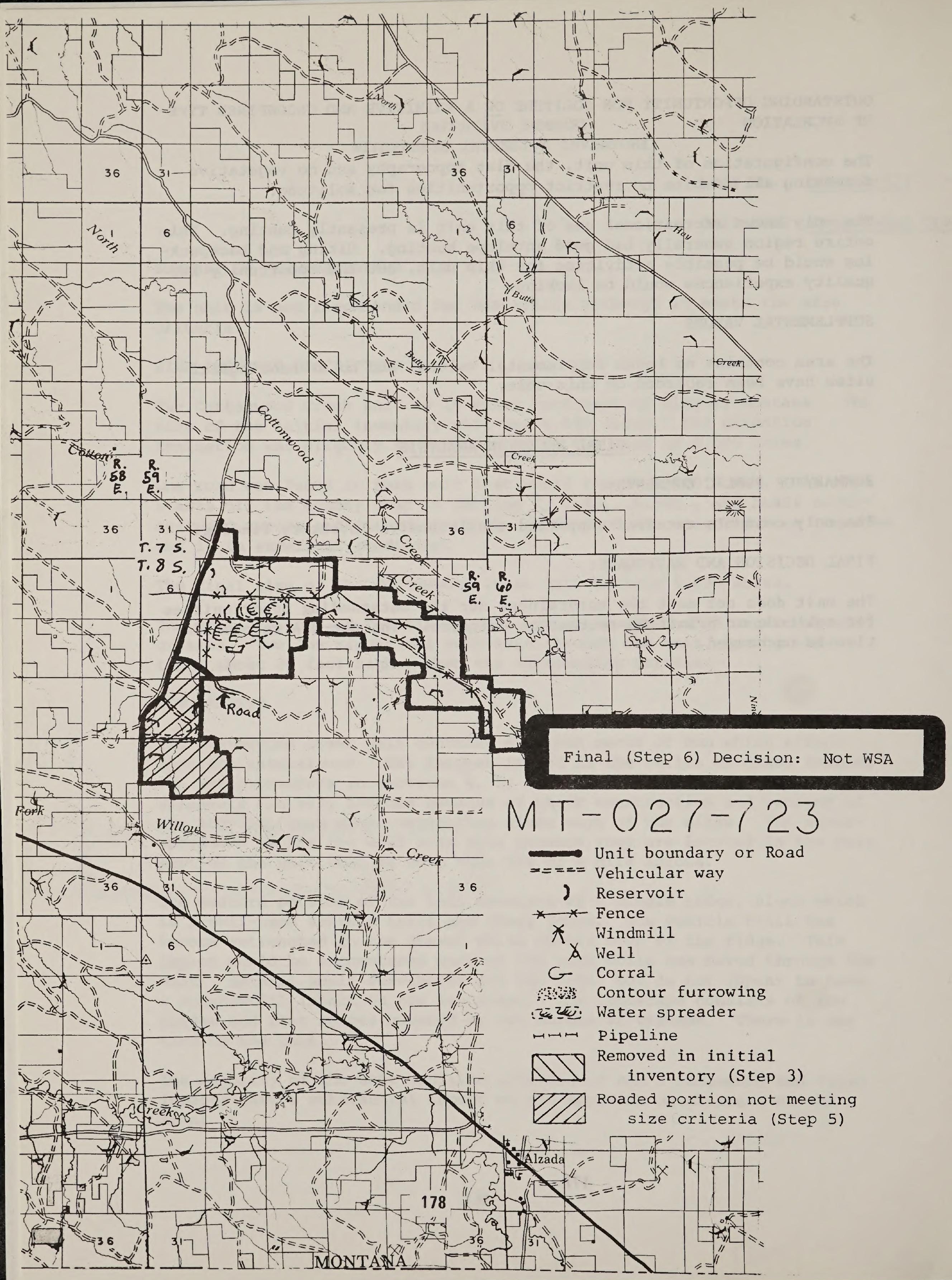


Unit Number: $\underline{\text { MT-027-719 }}$

Unit Name : Owl Creek Unit

\section{SUMMARY OF RECOMMENDATION}

The unit is not recommended for WSA status although it meets the size criterion.

\section{SIZE AND UNIT DESCRIPTION}

This unit is located on the Wyoming border 5 miles from South Dakota. The acreage of the unit is 14,667. The existence of several road segments was documented (see map). However, they do not result in any fragmentation and resulting acreage reduction.

The majority of Unit 719 is located in R.61 \& 62E. and T.9 S., M.P.M. The unit is bounded on all sides by private land with state school sections located within the unit in sections 16 and 36 . The southernmost portion of the unit is located in Wyoming (T.58 N., R.66 W., Sec. $35,26,25,30)$. Private property in sections 10,11, 24, 25 26, 27, 30 and 31 are also located within the unit.

Owl Creek, the major drainage within the unit, drains in a southeasterly direction. The majority of the unit, with the exception of a southeastnorthwest trending ridge on the east side of Owl Creek, is open, gently rolling topography. Many shallow coulees and ravines are located in the vicinity of this ridge, providing some topographic relief. A deeply dissected gumbo ridge is located in the northernmost section of this unit.

The vegetation in this unit is primarily sagebrush and midgrass species, with ocassional cottonwoods growing in the creek bottoms. Vegetation is rather sparse on the gumbo ridges, particularly the ridge in the northern portion of the unit.

\section{NATURALNESS}

The density of developments on this unit is high. There are 20 miles of fence, six hundred and forty acres of contour furrows in the extreme southwest corner of the unit and 34 reservoirs. The majority of the reservoirs are one acre or less but due the lack of topographic or vegetative screening, these reservoirs are readily apparent.

Reservoirs are located throughout the entire unit and are in most cases less than a mile apart. Due to the flat open terrain, the reservoirs as well as the other developments fences, cattle feeders etc. are highly visible from most points within the unit. There are numerous vehicular ways throughout the unit. 
This unit does not contain outstanding opportunities for solitude; it lacks any significant topographic or vegetative screening. "The majority of the unit consists of flat, open grasslands that provide no opportunities for topographic or vegetative screening. The only portion of the unit which contains any opportunities for topographic screening is the ridge in the southwestern portion of the unit. This ridge still does not provide significant opportunities since a person standing on the ridgetop can see nearly all points within the unit and can be seen from nearly all points within the unit.

Although opportunities for primitive recreation are present on this unit, the opportunities are not outstanding. Opportunities for hiking and backpacking can be found throughout the unit, in both the more open areas and in the rugged terrain of the gumbo ridges. Horseback riding is most suitable in the open, level portions of the unit. Rock collecting and nature photography could be done throughout the unit. Several sightings of pronghorn antelope and grouse indicates that hunting might be an important recreation activity in this unit.

SUPPLEMENTAL VALUES:

At the present time it is not known if this unit contains any outstanding supplemental values.

\section{FINAL DECISION ANALYSIS}

SUMMARY OF PUBLIC COMMENTS:

The only comments received supported the Intensive Inventory finding. FINAL DECISION AND RATIONALE:

The unit does not meet the naturalness nor the outstanding opportunities for solitude or primitive recreation criteria. The non-WSA recommendation is unchanged. 


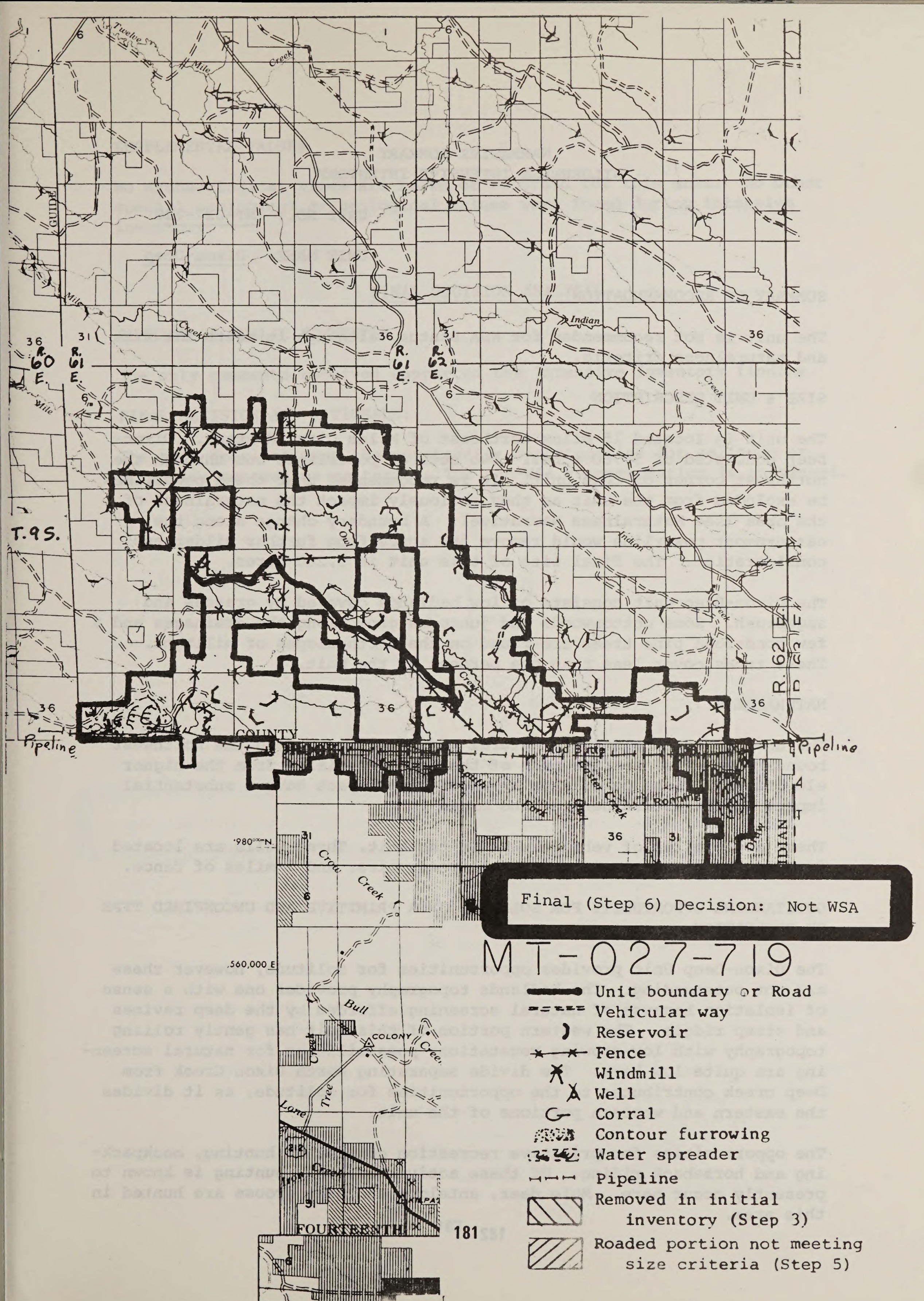




\section{SUMMARY OF RECOMMENDATION}

The unit is not recommended for WSA status, although it meets the size and naturalness criteria.

\section{SIZE \& UNIT DESCRIPTION}

The unit is located 15 miles northeast of Miles City, Montana. DixonDeep consisted of 5,760 acres. Two sets of powerlines cut through the northwest corner of this unit. It is recommended that these powerlines be excluded from the unit as they obviously impact the naturalness of the area (see Naturalness Narrative). A boundary change along the easternmost powerline would remove 560 acres from further wilderness consideration. The final size of this unit is 5,200 acres.

The Dixon-Deep Unit consists of low badlands covered by grasses and sagebrush. Some cottonwoods and junipers grow along the drainages and a few ponderosa pine trees are found on the north slopes of hilltops. These trees cover less than one percent of the unit.

\section{NATURALNESS}

The unit appears relatively natural the powerlines along the northwest boundary are visible from much of the unit especially from the higher elevations. These powerlines as an offsite impact have a substantial impact on the naturalness of the area.

There are 6 miles of vehicle ways in the unit. Three wells are located in Dixon-Deep, along with two small reservoirs, and 7 miles of tence.

OUTSTANDING OPPORTUNITY FOR SOLITUDE OR A PRIMITIVE AND UNCONFINED TYPE OF RECREATION

The Dixon-Deep Unit provides opportunities for solitude, however these are not outstanding. The badlands topography provides one with a sense of isolation because of natural screening afforded by the deep ravines and steep ridges. The western portion of this unit has gently rolling topography with low-growing vegetation; possibilities for natural screening are quite low here. The divide separating North Dixon Creek from Deep creek contributes to the opportunities for solitude, as it divides the eastern and western portions of the unit.

The opportunities for primitive recreation consist of hunting, backpacking and horseback riding. Of these activities, only hunting is known to presently occur here. Mule deer, antelope and sage grouse are hunted in this area. 
SUPPLEMENTAI VALUES

No archaeological sites are known or recorded for this unit. No other special ecological or geological values were found during intensive inventory.

\section{FINAL DECISION ANALYSIS}

SUMMARY OF PUBLIC COMMENTS :

The only comments received supported the Intensive Inventory finding. FINAL DECISION AND RATIONALE:

The unit does not meet the outstanding opportunities for solitude or primitive recreation criterion. The non-WSA recommendation is unchanged. 


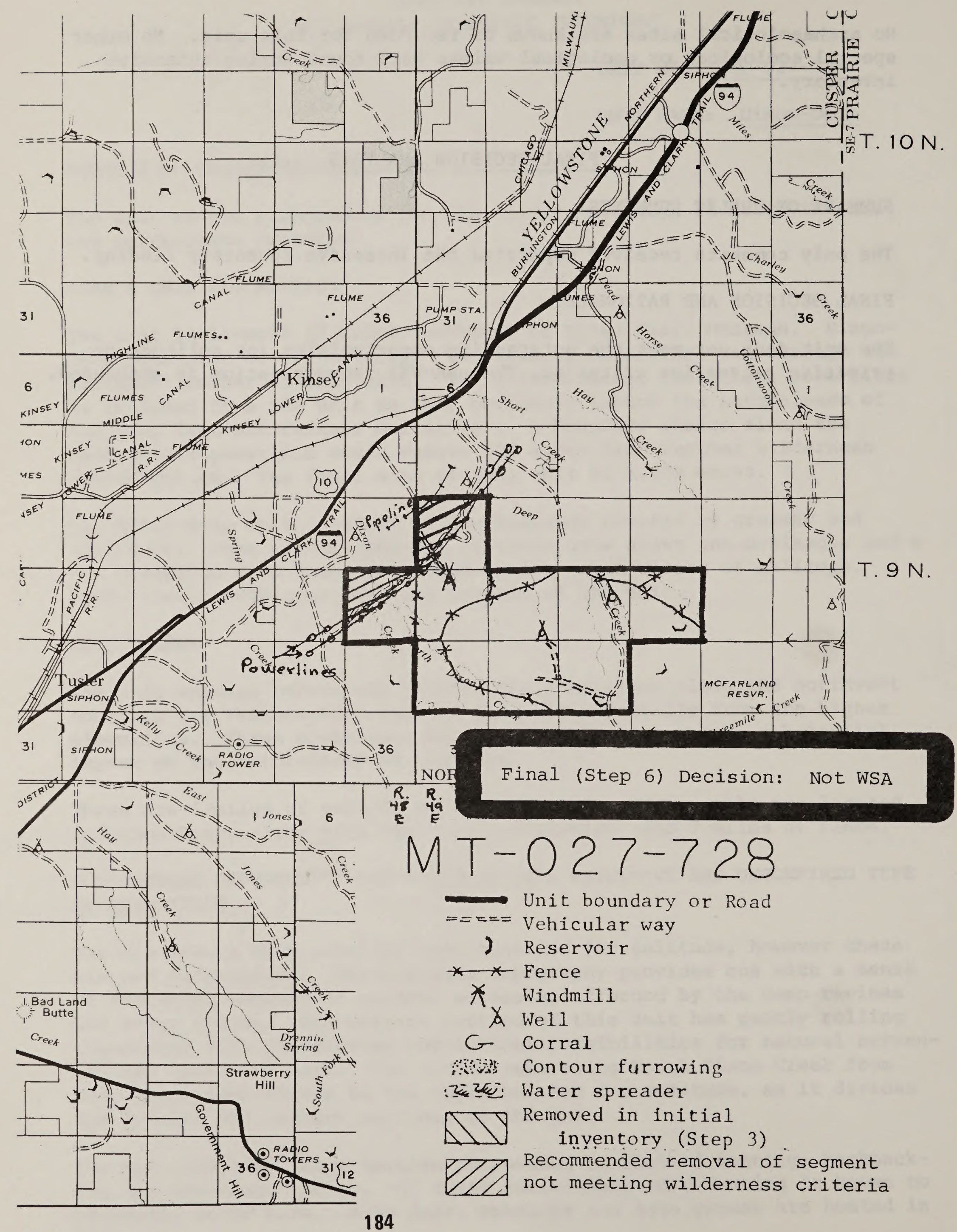




\section{UNIT NO.: $\quad$ MT-027-729 \\ UNIT NAME: Willow Creek}

\section{SUMMARY OF RECOMMENDATION}

The unit is not recommended for WSA status although it meets the size and naturalness criteria.

\section{SIZE AND UNIT DESCRIPTION}

The unit is 15 miles west of Alzada and entirely within Montana. The size of the initial inventory unit was 9,100 acres. The Situation Evaluation stated the size as 6,464 , but was greatly in error.

Two roads were found within this unit. One of the roads, combined with a large waterspreader project, removed 2,140 acres from the unit. This road begins in section 11, T.9S., R.57E. off the boundary, continues to the southwestern corner of Section 11, heads south through Sections 14, 23, and 26. At this point, the road hits dikes from a 1,200-acre waterspreader project in sections 13, 14, 24, and 25 of T.9S., R.57E. The new boundary should drop from the road south as the road enters section 25. The boundary line would follow the section line down to the Ridge Road boundary on the south side of the unit.

The second road found runs north-south through the center of section 8 of T.9S., R.57E. The 2,030-acre segment west of this road should be excluded from the unit.

Thus, the final size of the Willow Creek Unit is 4,930. Even though this is below 5,000 acres, the arbitrary boundary line drawn from the road to the waterspreader dikes in section 25, T.9S., R.57E., should not automatically remove this unit from intensive inventory just because of a 70-acre margin.

The Willow Creek Unit consists of low rolling hills and flat land covered with sagebrush and grasses. There are a couple of trees along Willow Creek in the north part of the unit.

\section{NATURALNESS}

The waterspreader dikes in sections 13, 14, 23, 24, 25 of T.9S., R.57E. have a severe impact on the naturalness of the area. These dikes, combined with the road to the west of these, required the removal of a segment of this unit. 
The remainder of the unit, 4,930 acres, contains 9 reservoirs, all very small but one, which is about 5 acres. This larger reservoir is hard to see from any of the ridges around it. There are 8 miles of fence also in the remainder of the unit, half of that being along the road in Sections 11, 14 and 23. The Butte Pipeline runs through the unit's center on a north-south line, but appears very faint in most of the unit. The pipeline is a little more apparent in the northern part of the unit because of the vegetational contrast of the removed sagebrush. The vehicle trail in section 4 was not visited, but the same trail in Section 3 (out of the unit) was almost invisible and very hard to follow.

The impacts of the unit are not substantially noticeable, but only because the majority of vehicle ways and the waterspreader dikes are excluded from further wilderness consideration by the two roads in the unit.

OUTSTANDING OPPORTUNITY FOR SOLITUDE OR A PRIMITIVE AND UNCONFINED TYPE OF RECREATION

There is very little opportunity for solitude in this unit. A ridge in the center of the unit separates the flat Willow Creek drainage on the north from the drainage on the south and along the Ridge Road (southern boundary). There is very little topographic screening and no screening by vegetation.

The only known recreational use of this area is now hunting. Antelope hunting is good in much of this part of the region. Hiking and camping on this unit have some potential although the opportunity for these is not great.

SUPPLEMENTAL VALUES

The area was not found to contain any ecological, geological or other features of scientific, educational, scenic, or historical value.

\section{FINAL DECISION ANALYSIS}

SUMMARY OF PUBLIC COMMENTS :

The only comments received supported the Intensive Inventory finding. FINAL DECISION AND RATIONALE:

The unit does not meet the outstanding opportunities for solitude or primitive recreation criterion. The non-WSA recommendation is unchanged. 
UNIT NO.: $\quad$ MT-027-730

UNIT NAME: Whitetail

SUMMARY OF RECOMMENDATION:

The unit is not recommended for WSA although it meets the size and naturalness criteria.

\section{SIZE AND UNIT DESCRIPTION:}

The unit is located 19 miles west southwest of Ekalaka and is entirely within Montana. The size of this unit is 5,120 acres. This inventory unit is bordered on the west, south, and on the east by roads. This latter road was noted as the result of public input in the spring of 1979 and the area (730 acres) east of this road was dropped from intensive inventory by the state Director in August, 1979.

The Whitetail Inventory Unit covers an area of badlands a few miles east of the Powder River. The western half of the unit consists of highly eroded badlands with only scattered sagebrush and grasses. In contrast, the eastern section has grassy hills with ponderosa and juniper trees covering the tops and northern exposures.

\section{NATURALNESS :}

This area appears relatively natural overall, but there are some notable imprints of man. The developments associated with grazing are seen in different sections of the unit and consist of fences, vehicle trails and windmills. In section 29 and 32, T.IN., R.55E., there are two windmills with vehicles trails leading to them off of an old road. This old road has been bladed in many places, is used for access today, but does not appear to be maintained any longer. Sagebrush and grasses have revegetated most of the cuts, although these excavations are still noticeable. This old road continues further south to another windmill on Sec. 3, T.1S., R.55E., but is presently washed out at the creek crossing just north of the county road in Sec. 10, T.1S., R.55E.

Two other windmills, located in the eastern half of the Whitetail Inventory Unit, have grass-covered vehicle trails leading to them with only the windmills in Sec. 2, T.1S., R.55E. out of sight from most of the unit.

In summary, the majority of this unit has no evidence of man's influence. OUSTANDING OPPORTUNITY FOR SOLITUDE OR A PRIMITIVE AND UNCONFINED TYPE OF RECREATION

The best opportunities for solitude in this unit are in the badlands area in the western section of Whitetail. Even these opportunities for 
solitude are only fair to good, mainly because of the small size and shape of the unit. A person can walk across the unit in a half hour in most places, although the dissected terrain of these badlands would screen out most human activities, either those in or out of this unit. The eastern segment of the Whitetail unit offers only fair opportunities for solitude with the trees on the hilltops providing some screening from sights or sounds of other people in the unit. It is worth noting, also, that two ranches are located a quarter mile outside of the unit on the extreme eastern edge, but would not be noticeable in the vast majority of Whitetail.

The major recreational use of the Whitetail area is now hunting. There is good habitat for mule deer in the badlands section with good opportunities for pronghorn in the open grassy areas. In addition this and other areas of public land in the vicinity are subject to hunting of furbearing animals like coyotes in the winter, mainly by local residents. This hunting is good although the methods employed (hunting from planes and snowmobiles) would not be allowed in a wilderness area. There are possibilities for hiking and horseback riding, although the terrain provides only a moderate degree of challenge. One can walk across the unit in about 30 minutes in most places. In summary the size, shape and other physical characteristics of the Whitetail unit provide for quality hunting, but nothing outstanding. In addition, the diversity of opportunities for other types of primitive recreation is low with little challenge likely to be found.

\section{SUPPLEMENTAL VALUES}

No special ecological or geological values were found during intensive inventory. There are no archaeological sites known or recorded for this unit either.

\section{FINAL DECISION ANALYSIS}

\section{SUMMARY OF PUBLIC COMMENTS :}

The only comments received supported the Intensive Inventory finding.

FINAL DECISION AND RATIONALE:

The unit does not meet the outstanding opportunities for solitude or primitive recreation criterion. The non-WSA recommendation is unchanged. 

NARRATIVE SUMMARY

WILDERNESS INTENSIVE INVENTORY

UNIT NO.: $\underline{\text { MT-027-732 }}$

UNIT NAME: CrOW

\section{SUMMARY OF RECOMMENDATION}

The unit is not recommended for WSA status, although it meets the size criterion.

\section{SIZE \& UNIT DESCRIPTION}

The Crow Inventory Unit is located 33 miles northwest of Alzada and is entirely in Montana. The size of the initial inventory unit was 20,810 acres. No boundary changes were required so the final unit size is 20,860 acres.

The Crow Unit contains a ridge running north-south through the entire unit. East of the divide, terrain is very flat and the vegetation consists of sagebrush and grasses. Breaks form along the west side of the divide with elevations dropping about 200 feet from the top of the ridge. Vegetation consists primarily of sagebrush and grasses, but some junipers and a few isolated ponderosa pines dot some drainages of the breaks. These trees cover less than $2 \%$ of the unit.

\section{NATURALNESS}

There are numerous human imprints in this unit and the cummulative impacts of these imprints are substantially noticeable. The greatest impacts on the Crow Unit are the numerous vehicle ways. There are 42 miles of vehicle ways and many have been improved in the past. Many of these vehicle trails are well used, but no evidence of recent maintenance was found. A majority of these vehicle ways are located on the flat terrain east of the divide, but several ridges in the breaks west of the divide have vehicle ways along them.

There are two oil drill hole sites in the unit, one in section 28 of T.4S., R.56E. and one in Section 25 of T.5S., R.55E. This later drill hole has a deep blading scar on the hillside just approaching the site. There are 18 reservoirs located in the crow unit, with one reservoir of about 15 acres and the rest less than 5 acres each. The unit also contains 25 miles of fence. A waterspreader project has dikes located on about 200 acres of Sections 2 and 3 of T.5S., R.56E. There are also some waterspreader dikes on private property in section 9 of T.6S., R.56E., that may overlap onto Section 8 in the Crow Unit. An underground water pipeline extends from a spring in section 30, T.5S., R.56E. for about .5 miles into section 25 of T.5S., R.55E. The pipeline was not seen, however, as it passes under the vehicle trail near its origin. 
OUTSTANDING OPPORTUNITY FOR SOLITUDE OR A PRIMITIVE AND UNCONFINED TYPE OF RECREATION

Opportunities for solitude are lacking east of the divide, but the numerous drainages in the breaks west of the divide do offer opportunities. However, these opportunities for solitude are not oustanding. The sparse covering of juniper trees provides only limited vegetative screening. Furthermore, the configuration of this unit is such as to impede one's movement through the unit. There are several arms of private property that only allow $1 / 4$ to 3/4-mile public land corridors as one moves through the unit.

The major recreational use of the Crow Unit is hunting. Antelope roam the flat areas east of the divide and deer are found in the drainages of the breaks. Backpacking and horseback riding are potential activities here, especially in the breaks.

SUPPLEMENTAL VALUES

No supplemental values were found to exist within the unit. There are no recorded archaeological sites in the Crow Unit either.

\section{FINAL DECISION ANALYSIS}

SUMMARY OF PUBLIC COMMENTS:

The only comments received supported the Intensive Inventory finding.

FINAL DECISION AND RATIONALE:

The unit does not meet the naturalness nor the outstanding opportunities for solitude or primitive recreation criteria. The non-WSA recommendation is unchanged. 


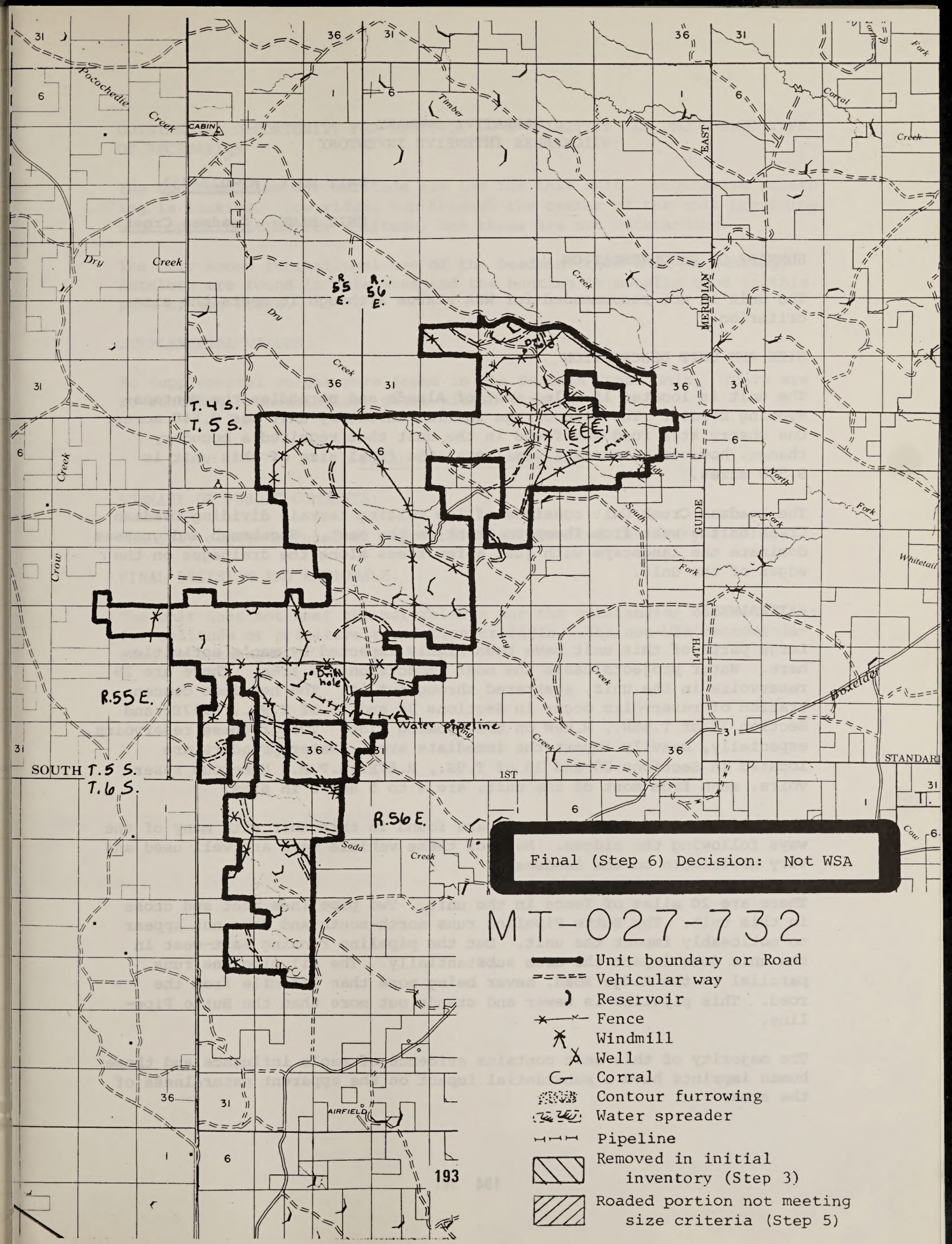




$$
\begin{aligned}
& \text { UNIT NO.: } \quad \underline{\text { MT-027-733 }} \\
& \text { UNIT NAME: Deadman Creek }
\end{aligned}
$$

\section{SUMMARY OF RECOMMENDATION}

The unit is not recommended for WSA status although it meets the size criterion.

\section{SIZE AND UNIT DESCRIPTION}

The unit is located 15 miles west of Alzada and straddles the MontanaWyoming border. The size of the initial inventory unit was 9,540 acres. One cherry stem road was found in the unit that required a boundary change, however no acreage was lost. The final size of this unit is 9,540 acres.

The Deadman Creek Unit consists of low rolling terrain dividing Deadman Creek on the west from Thompson Creek on the east. Sagebrush and grasses dominate the landscape with just a few trees along the drainages on the edges of the unit.

\section{NATURALNESS}

Large parts of this unit have been highly impacted by man's activities here. Water projects cause the most impacts on the area. There are 29 reservoirs in the unit, scattered throughout it. The heaviest concentration of reservoirs occur in sections 34 and 35 of T.9S., R.57E. and Section 25 of T.58N., R. 66W on the Wyoming side. Two of these reservoirs, especially, heavily impact the immediate area. Waterspreaders are located in Sections 25 and 35 of T.9S., R.57E. M.P.M. Numerous reservoirs, seen from most of the unit, are 4 to 5 acres in size.

About 25 miles of vehicular ways are found in this unit with many of the ways following the ridges. Many of these vehicle ways are well used and very noticeable on the landscape.

There are 20 miles of fence in the unit. Two pipelines meet and cross in this unit. The Butte Pipeline runs north-south and does not appear to noticeably impact the unit. But the pipeline running east-west in the unit does impact the area substantially. The oil pipeline runs parallel to the Ridge Road, never being more than $3 / 4$ mile from the road. This pipeline is newer and stands out more than the Butte Pipeline.

The majority of this unit contains evidence of man's influence and these human imprints have a substantial impact on the apparent naturalness of the area. 
OUTSTANDING OPPORTUNITY FOR SOLITUDE OR A PRIMITIVE AND UNCONFINED TYPE OF RECREATION

The opportunities for solitude are low for this unit. Vegetative screening is lacking. Low ridges run through the center of the unit providing some opportunities for solitude, but these are not outstanding.

The only known recreational use of the Deadman Creek Unit is hunting. Antelope are found in this area and the hunting is usually good in this part of the state.

SUPPLEMENTAL VALUES

No supplemental values were found in the Deadman Creek Unit. There are no recorded archaeological sites within this unit.

\section{FINAL DECISION ANALYSIS}

SUMMARY OF PUBLIC COMMENTS:

The only comments received supported the Intensive Inventory finding.

FINAL DECISION AND RATIONALE:

The unit does not meet the naturalness nor the outstanding opportunities for solitude or primitive recreation criteria. The non-WSA recommendation is unchanged. 


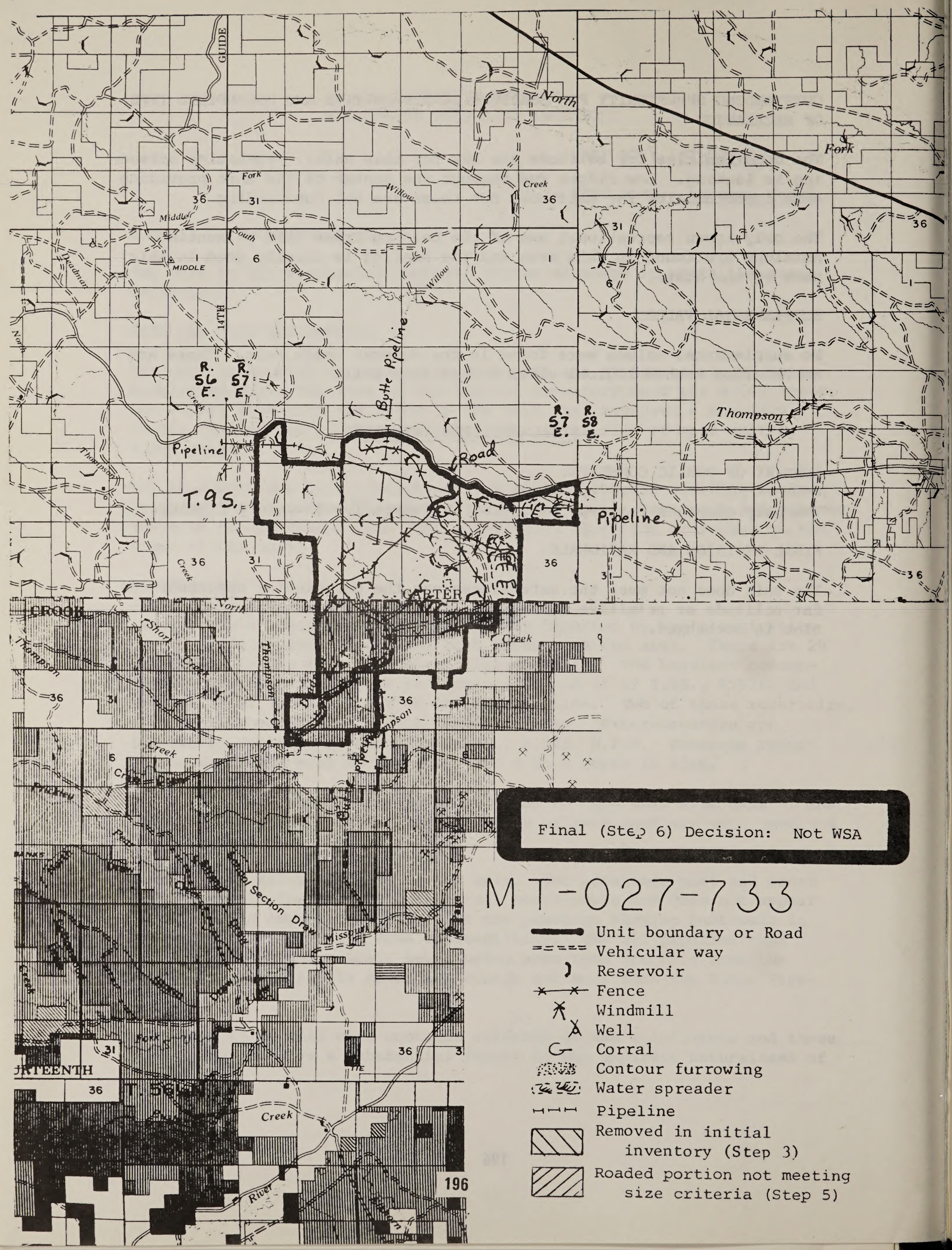


The unit is not recommended for WSA status although it meets the size criterion.

\section{SIZE AND UNIT DESCRIPTION}

The unit is located 30 miles north northwest of Alzada and is entirely within Montana. The size of the Whitetail Creek inventory unit is 6,250 acres.

The Whitetail Creek Unit is essentially flat with one 100-foot ridge forming the northern boundary. A very good road follows this ridge, and in turn, forms the north boundary. There are probably no trees in the unit, while low sagebrush and grasses dominate.

\section{NATURALNESS}

Some of the developments in the unit greatly impact the area and also cover a high percentage of its acreage. A large waterspreader dike system is located in Sections $8,9,10$ and 15 of T.5S., R.57E. These dikes are visible from much of the unit. Another smaller system of dikes is located in sections 17, 18, and 19. Also located within a half-mile of these dikes are two reservoirs, one of four acres, and another of about 20 acres.

The Butte Pipeline runs north-south for a mile in Section 10 of T.5S., R.57E. The impact of the pipeline is more apparent in this unit than it is in some others, partly because of a vehicle trail which follows it.

REA telephone line runs for 2.5 miles in the northern part of the unit, generally following the boundary road and staying within a quarter mile of the road.

There are 5.5 miles of fence, 3 miles of vehicular ways and 14 other reservoirs in this unit. These other reservoirs are small, being one acres or less.

The majority of this unit contains evidence of man's influence and these developments have a substantial impact on the apparent naturalness of the area. 
OUTSTANDING OPPORTUNITY FOR SOLITUDE OR A PRIMITIVE AND UNCONFINED TYPE OF RECREATION

This unit does not provide opportunities for solitude. The unit is oddshaped, usually being one mile wide or less. There is no topographic or vegetative screening. A person walking in this unit would probably be aware of another person virtually anywhere else in the unit.

Presently the only known recreational use of the Whitetail Creek Unit is hunting. Antelope hunting is traditionally good in this region. Potential opportunities for other types of recreation appear lacking.

SUPPLEMENTAL VALUES

No supplemental values were found to exist in this unit.

\section{FINAL DECISION ANALYSIS}

SUMMARY OF PUBLIC COMMENTS:

The only comments received supported the Intensive Inventory finding. FINAL DECISION AND RATIONALE:

The unit does not meet the naturalness nor the outstanding opportunities for solitude or primitive recreation criteria. The non-WSA recommendation is unchanged. 


\title{
LEWISTOWN DISTRICT
}

\author{
INVENTORY UNITS
}

TO BE DESIGNATED

\section{WILDERNESS STUDY AREAS}

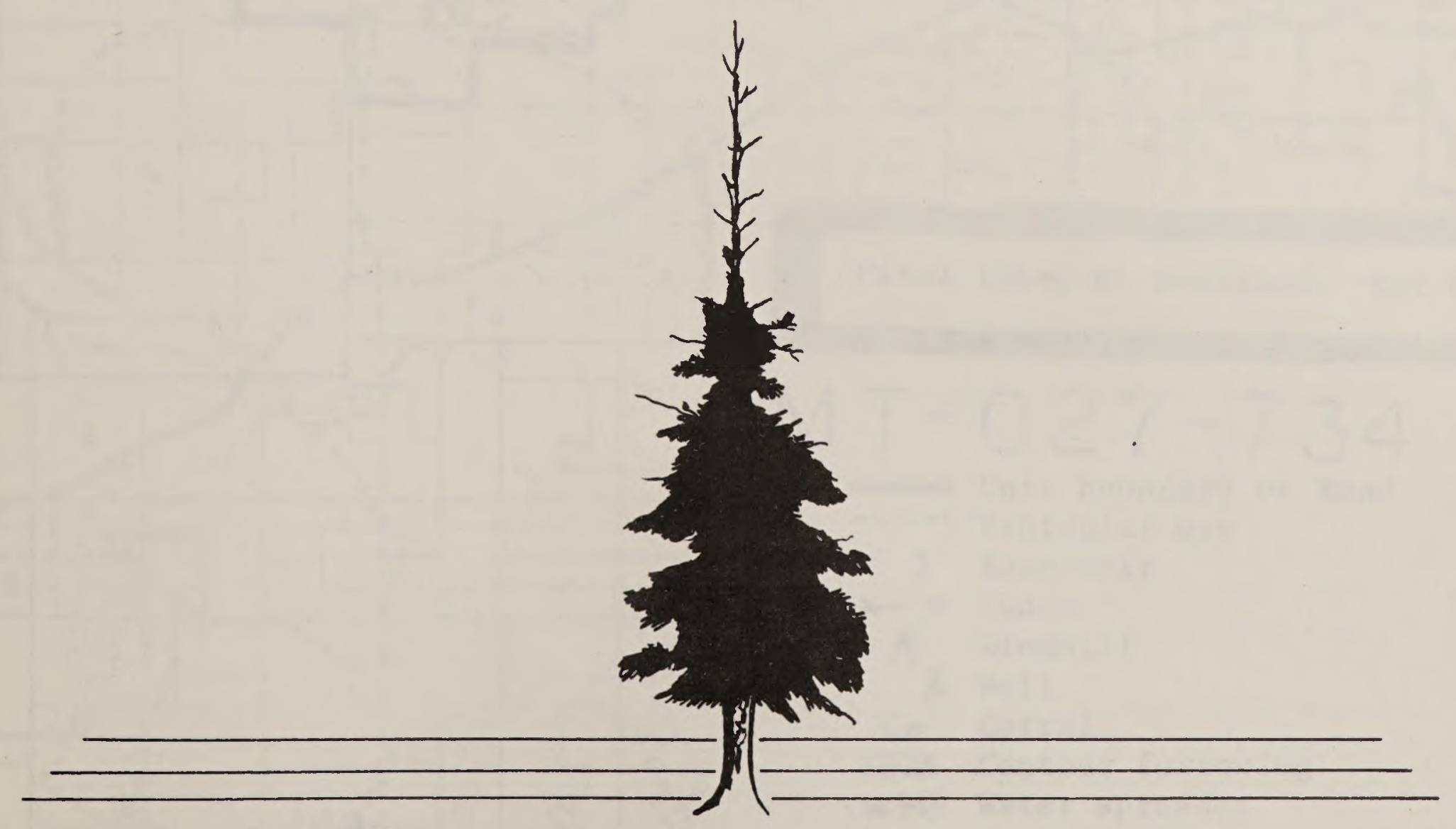



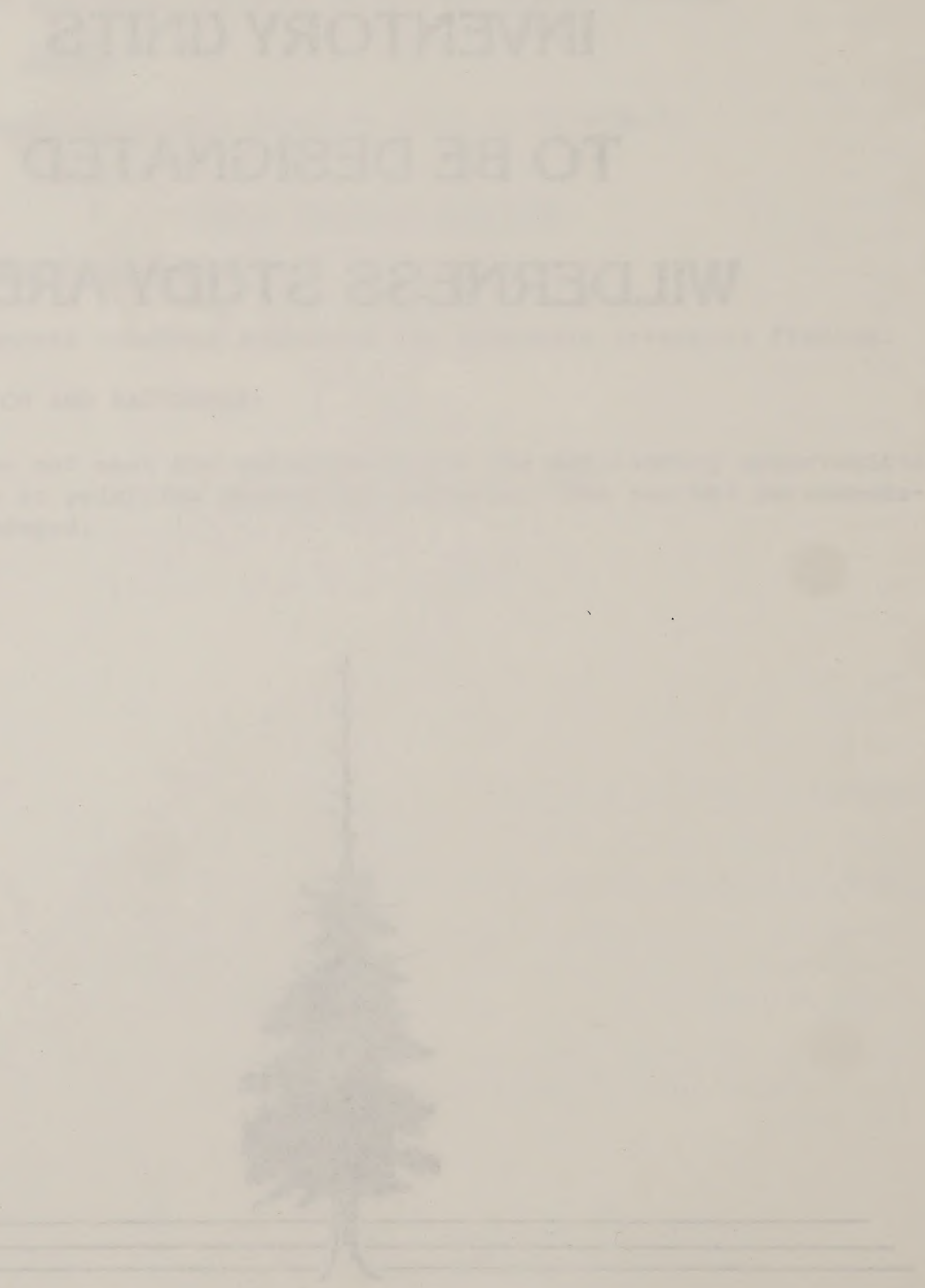
UNIT NO.: MT-067-206

UNIT NAME: Pryor Mountain

\section{WILDERNESS CHARACTERISTICS NARRATIVE SUMMARY}

Pryor Mountain Unit (MT-067-206) is located in Carbon County, Montana, and Bighorn County, Wyoming. Situated 15 miles north of Lovell, Wyoming, the unit is bounded by roads on the east and west, by Custer National Forest land to the northwest and a graveled county road to the south. The unit contains approximately 18,067 acres.

The unit rises from an elevation of 3,900 feet in the south to 8,500 feet in the north. The topography and vegetation vary from an arid Sonoran landform in the south, to mountain foothills in the middle covered with juniper, mountain mahogany and patches of timber, to dense Douglas fir forests, steep cliffs and open mountain meadows in the north.

The area is a portjon of the Pryor Mountain Wild Horse Range and has thus been protected from adverse development in recent years. Old mining activity exists in several portions of the unit including a major workings in T. 9 S., R. 28 E., Sec. 7. This portion of 240 acres is a safety hazard and visual blight which is quite unnatural and has been cut out of the unit. On the southeast border lies an electric power transmission line, a portion of a stock trail, old uranium prospecting scars, and a vehicle trail commonly used to view wild horses. This southern edge is bounded by a heavily used, graveled county road. The combination of these factors minimizes the naturalness of this southern end and results in the exclusion of approximately 880 acres from wilderness study. An area of 20 acres in T. 58 N., R. 95 W., Sec. 20 containing a corral and two trailers was mistakenly left in the unit and has been cut out of the boundary.

The remaining portion of the area, 16,927 acres, approximately, contains only scattered uranium prospects, three exclosures, two stock corrals, 3.5 miles of minimal vehicle way and one identified road servicing a stock corral in T. 9 S., R. 28 E., Sec. 29, 32, and 33. These developments are dispersed or are screened such that they have little impact upon the naturalness of this area.

Except for around the unnatural areas described above, a mixture of topographic and vegetative screening offers solitude opportunities in the lower sections. The mountain topography in the north is characterized by steep cliffs, dense timber and outstanding opportunities for solitude.

There are good opportunities for hiking, backpacking, horseback riding, photography, rock climbing, nature study including wild horse viewing, hunting, caving, and sightseeing of geologic and paleontologic features. The diversity and outstanding quality of primitive and unconfined recreation qualifies this unit for wilderness study. 
Supplemental values include picturesque geologic features, caves, colorful scenery, deposits of vertebrate and invertebrate fossils and the existence of the wild horses.

The possibility of inclusion of about 1,000 acres of Forest Service land east of Burnt Timber Canyon road in parallel management if Pryor Mountain is designated a wilderness is an option.

\section{FINAL DECISION ANALYSIS}

Summary of Public Comments:

Two substantive comments were received. One comment stated that evidence of man's activities in the area could be rehabilitated and that the unit should be considered for future wilderness study due to its proximity to a USFS RARE II unit, naturalness, terrain, solitude and excellent opportunities for unconfined primitive recreation. The other commenter felt that although the area had geologic interest, the influence of reservoirs, previous mining activity, a BLM test plot, cattle trails, and roads disqualify the northern section from further wilderness study.

Final Decision and Rationale:

This unit will be further studied for wilderness. The portions of the unit remaining are natural. Topography and vegetation combine to give outstanding solitude. Outstanding primitive recreation opportunities and supplemental values further add to the unit's wilderness characteristics. 


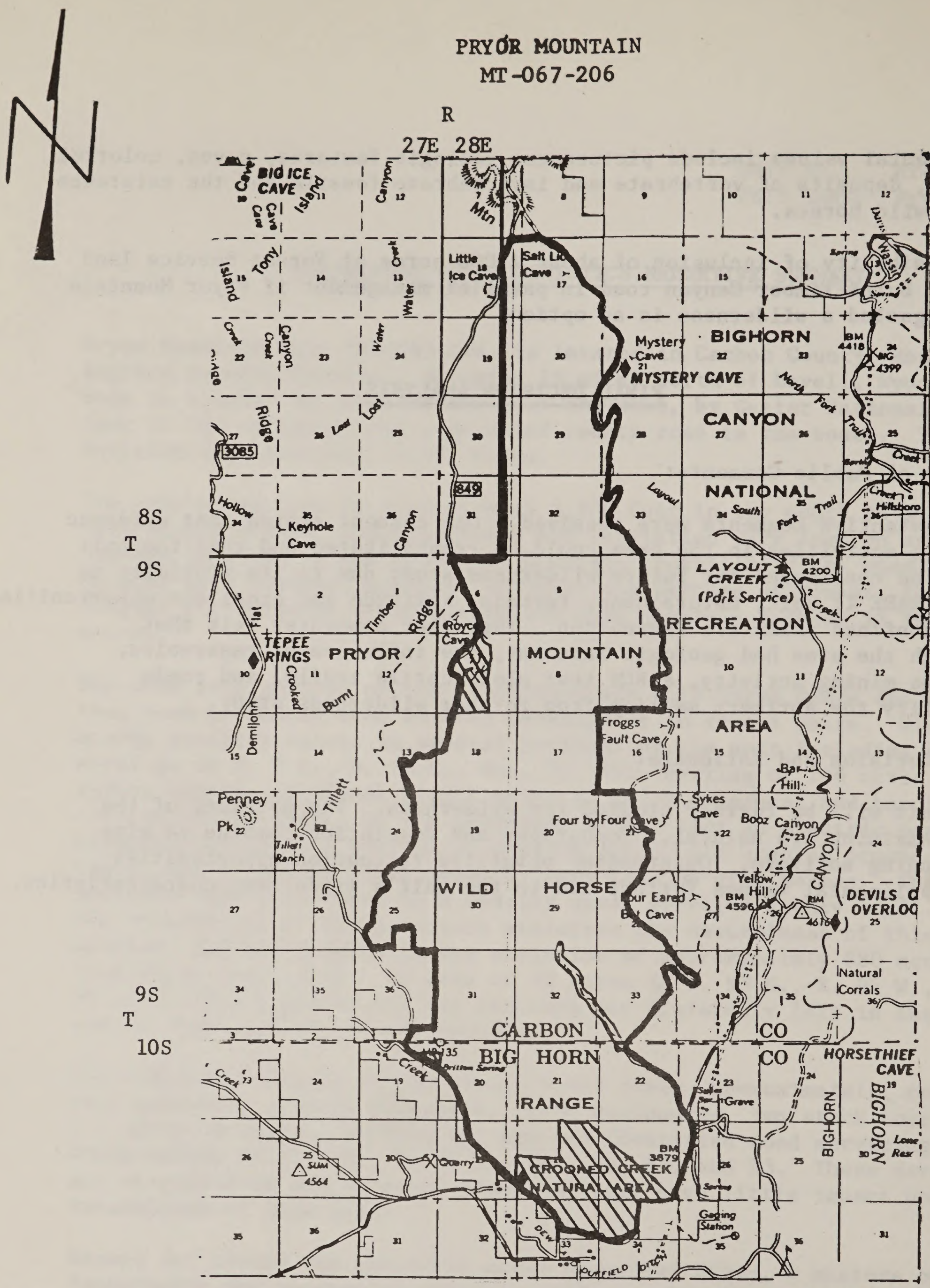

SCALE $1: 126,720$

$\frac{1}{2}$ inch $=1$ mile
IEGEND

MIV UNIT OR PORTION OF UNIT LACKING WILDERNESS CHARACTERISTICS (NOT RECOMMENDED AS WSA)

AREA DELETED FROM ORIGINAL INVENTORY UNIT DUE TO ROAD IDENTIFICATION

AREA ADDED DUE TO ROAD IDENTIFICATION

PRTVATE OR STATE INHOLDINGS 
UNIT NO.: $\quad$ MT-067-207

UNIT NAME: Bighorn

Tack-on

\section{WILDERNESS CHARACTERISTICS NARRATIVE SUMMARY}

The Bighorn Tack-on Unit (MT-067-207) is composed of two parcels of land located in Carbon County, Montana, and Bighorn County, Wyoming. The two portions originally contained 5,500 acres. Situated 17 miles north of Love11, Wyoming the unit is sandwiched between the Sykes Ridge road and Bighorn Canyon National Recreation Area administered by the National Park Service. The contiguous Park Service lands were identified as Wilderness Study Areas in 1977. Approximately 1,000 acres of Park Service land was mistakenly included in the original proposal and has been excluded from the acreage total and boundaries of the area. The unit now contains approximately 4,550 acres.

Both of these areas are steep, timber covered lands which are in an essentially natural condition. As both areas lie on the crest of Sykes Ridge, offsite impacts such as traffic on the Bad-pass Highway or the Forest Service's Dryhead Overlook are visible, but are so distant that their effect is dissipated. Within the units, themselves, heavy forestation makes for excellent solitude. A variety of recreational forms are possible within the areas. Numerous caves, paleontological and cultural remains and outstanding scenery offer not only recreational opportunities but are also important supplemental features. Hiking, climbing on the somewhat loose limestone rock, viewing the game animals and wild horses and hunting opportunities combine to make these small sections attractive for outdoor recreation. These two units of the Bighorn Tack-on are recommended for wildness study status.

\section{FINAL DECISION ANALYSIS}

Summary of Public Comments:

Two comments were received. One stated that the unit deserves further consideration for its solitude, contiguity to a Park Service Wilderness proposal, excellent primitive recreation even though it contains evidence of man's activity. The other letter writer felt that although the area had wilderness characteristics a reservoir straddling the border needed to be evaluated before a WSA decision was reached.

Final Decision and Rationale:

The two portions of the unit will be further studied. These areas contiguous to a Park Service Wilderness proposal are natural and contain outstanding opportunities for solitude and primitive recreation in conjunction with the Park Service Unit. 
BIG HORN TACK $-\mathrm{ON}$ MT $-067-207$

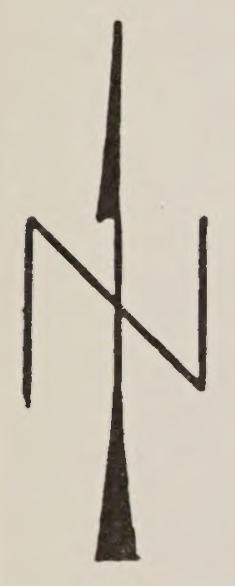

SCALE $1: 126,720$ b inch $=1$ mile

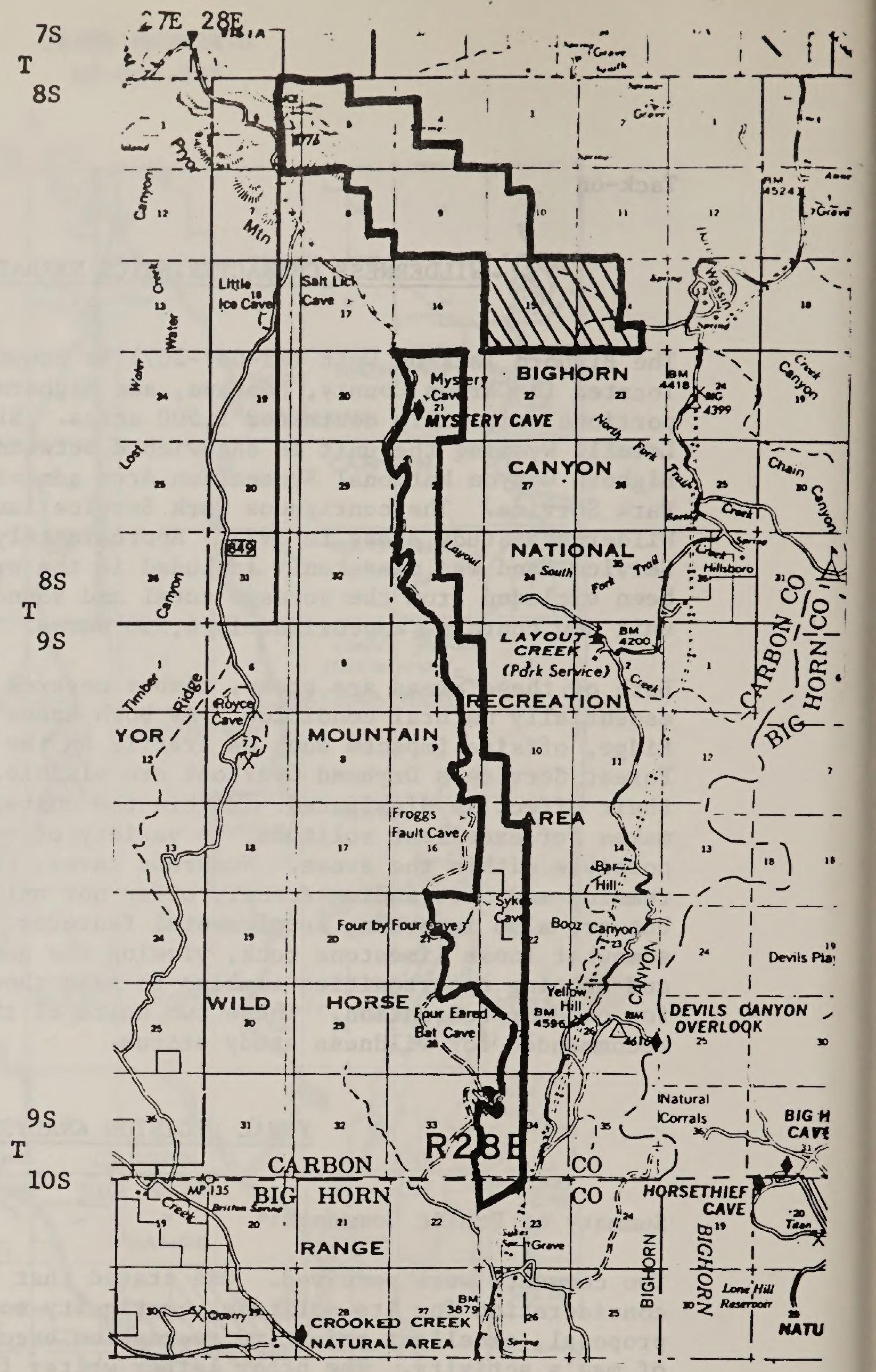

\section{IEGEND}

WV UNIT OR PORTION OF UNIT LACKING WILDERNESS CHARACTERISTICS (NOT RECOMMENDED AS WSA)

AREA DELETED FROM ORIGINAL INVENTORY UNIT DUE TO ROAD IDENTIFICATION

AREA ADDED DUE TO ROAD IDENTIFICATION PRIVATE OR STATE INHOLDINGS 
UNIT NO.: $\quad$ MT-067-212

UNIT NAME: Twin Coulee

\section{WILDERNESS CHARACTERISTICS NARRATIVE SUMMARY}

Twin Coulee Unit (MT-067-212) is located in Golden Valley County, Montana. The unit contains 6,870 acres. The area is sited on the southeast flank of the Snowy Mountains and is surrounded on two sides by heavily timbered, Lewis and Clark National Forest lands. The ad jacent Forest Service lands, RARE II number 1-739, are being studied for wilderness suitability under the Montana Wilderness Study Bill (1977). Elsewhere, the unit is bounded by Red Hill Road on the east and by private lands on the south.

This area is densely forested with ponderosa pine and Douglas fir. Some minor partial logging has been done in the center of the unit but is not very noticeable at present. Even the old logging road into the harvest area is totally revegetated such that it is a minor impact on naturalness. The thick vegetation, when coupled with the parallel, deep drainage, offers excellent solitude but limits recreational activity. Hunting, hiking, camping, and nature study would all be restricted by the vegetation and topography of the unit. The scenery is attractive, especially in spring when wild flowers bloom, but is again blocked from some vantage points by the forests. Prehistoric cultural sites and the interesting geology of the entire Snowy Mountains group are additional supplementary values. Due to its naturalness, contiguity with Forest Service lands, and excellent opportunities for solitude, Twin Coulee is recommended for wilderness study status.

\section{FINAL DECISION ANALYSIS}

Summary of Public Comments:

The only substantive comment stated that existing human impacts were being covered by natural processes. The area's wildlife, scenery, geologic formations, former use by Indians, and solitude qualify the area for further study.

Final Decision and Rationale:

This unit will be further studied for wilderness. The unit's contiguity with the Forest Service study unit, outstanding solitude enhanced by thick vegetation, and natural appearance qualify the unit. Primitive recreation opportunities are not outstanding. 
UNIT NO.: $\quad$ MT-068-231

UNIT NAME: Two Calf Creek

WILDERNESS CHARACTERISTICS NARRATIVE SUMMARY

Two Calf Creek Unit (MT-068-231) is in Fergus County, Montana. The unit is situated 5 miles south of the Missouri River and 22 miles northeast of Winifred, Montana. The area contains approximately 15,000 acres.

The unit follows the line of two drainages and encloses an area of rough, broken land heavily forested with ponderosa pine and Douglas fir. In the northwestern portion the topography is more rolling and forest vegetation is more patchy. The area is bounded by the Middle Two Calf Branch Road to the northeast and east and by State and privately owned land elsewhere.

The area is presently used for livestock grazing and hunting. The use of the area for grazing has led to the construction of 20 reservoirs, 3 water wells, 10 miles of fence, a metal corral on the western edge of the unit, 5 minor vehicle ways, and 3 identified roads. One road cuts off 170 acres in the west of the unit and penetrates into the area as a dead-end road in T. 22 N., R. 22 E., Sec. 30, 31, and 32. Another road bisects from the first in T. 22 N., R. 21 E., Sec. 22 and 27 . The third road branches $3 / 4$ mile from the first in T. 22 N., R. 22 E., Sec. 29 and 30 .

The southern portion of Two Calf is essentially natural. A scattering of four reservoirs and two water wells are well camouflaged by the extensive forest vegetation and rough land texture around the South Fork and Two Calf Creeks. The narrow center of the unit is heavily impacted by the clustering of a well, pipeline, water tank, vehicle trail, and eight reservoirs. The northwestern edge of the area is also unnatural as two large reservoirs, two identified roads, a corral, and a boundary fence stand out intrusively in that open, rolling, and minimally forested portion of the unit. In order to remove these flawed sections of the unit from further consideration a corridor has been drawn around the 2 roads and 6 reservoirs in T. 22 N., R. 22 E., Sec. 19, 29, 30, 31, and 32. Also a line has been drawn across the middle of sections 21 and 22 , T. 22 N., R. 21 E., to remove 2 roads, 3 large reservoirs, a corral and fence lines whose influence is perceived as unnatural. The dry gas hole, water well with attached pipeline and water tank, reservoir, and portions of two vehicle trails have also been removed in T. 22 N., R. 22 E., Sec. 21.

The end result of the removal of this unnatural acreage is a narrow $\frac{1}{2}$ mile corridor in the center of the unit separating private land from a heavily impacted area. A further parcel of 1,200 acres hangs by a $\frac{1}{4}$ mile strip to the southwest side. Outstanding opportunities for solitude are not available in these narrow boundary areas. Therefore, the boundaries will be drawn across those two peninsulas, thereby removing 4,580 acres in the northwest and 1,200 acres in the southwest of the unit. Outstanding 
solitude opportunities in the remaining portion of the area are ensured by the rough topography of the creek drainages and by the extensive forestation surrounding these drainages.

Hunting for deer, hiking, and horsepacking are possible recreational activities in the unit. There are no special attributes within the unit, however, which would create an outstanding primitive recreational opportunity.

The scenery within the unit, while not spectacular, is the only supplemental attribute known in the area.

\section{FINAL DECISION ANALYSIS}

Summary of Public Comments:

The single comment made the following points. Interim wilderness management precludes multiple use of mineral exploration. Wilderness areas contain needed mineral values which would decrease dependence upon foreign imports. Access roads and enclosed deeded land decreases wilderness values.

Final Decision and Rationale:

The southern portion of this unit will be retained for further study. This section has outstanding opportunities for solitude and contains opportunities for primitive recreation. This portion of the unit also appears natural. Lack of naturalness, and solitude values seriously compromised by a density of range improvements and roads disqualify the rest of the unit. 
TWO CALF CREEK

MT $-068-231$

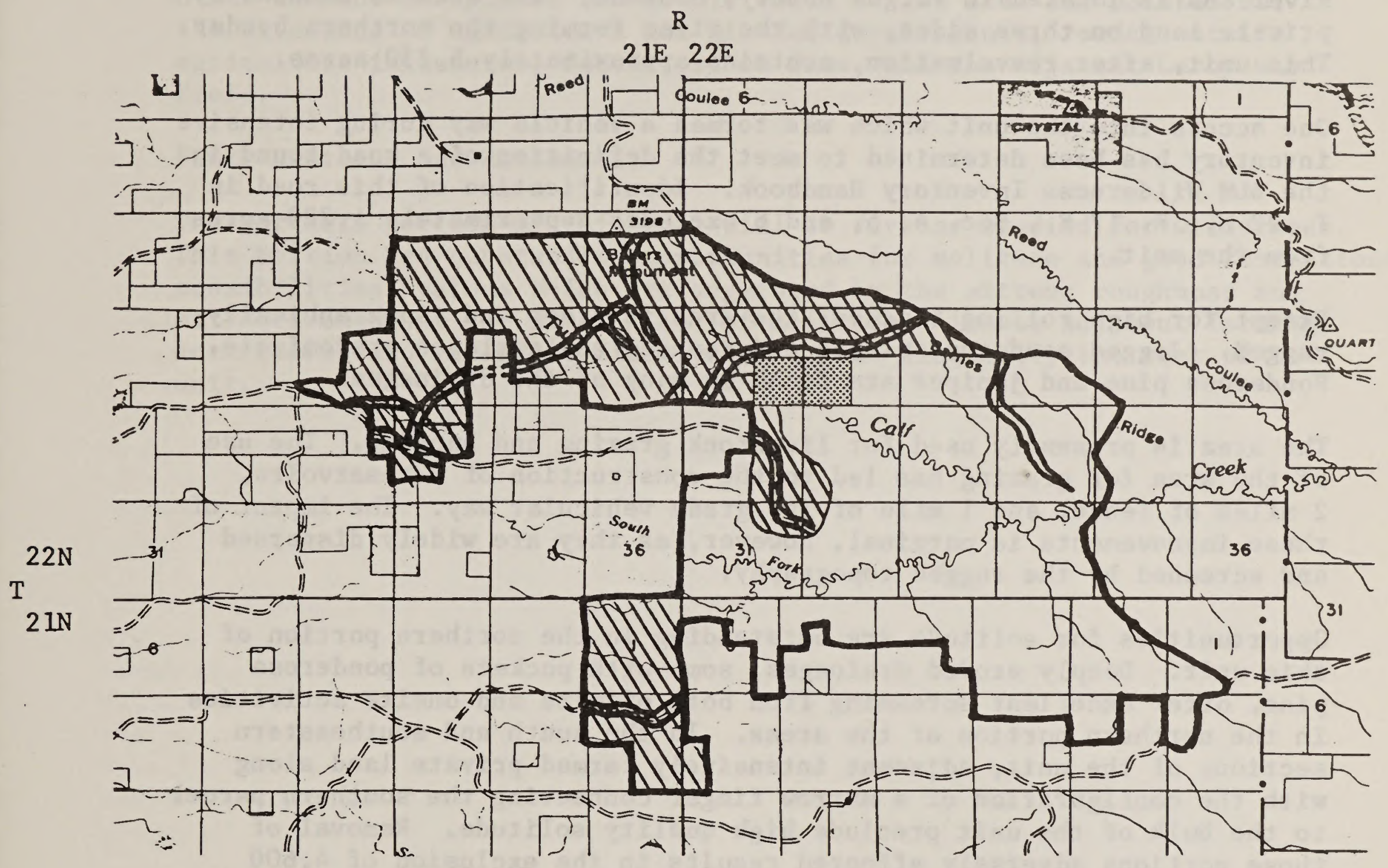

IEGEND

SCALE $1: 126,720$

\& inch $=1$ mile
MIIV
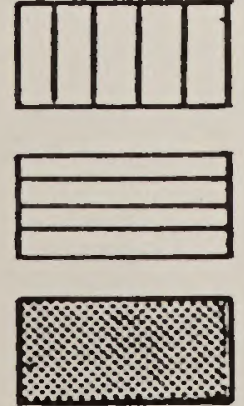

\section{LEGEND}

UNIT OR PORTION OF UNIT LACKING WILDERNESS CHARACTERISTICS (NOT RECOMMENDED AS WSA)

AREA DELETED FROM ORIGINAL INVENTORY UNIT DUE TO ROAD IDENTIFICATION

AREA ADDED DUE TO ROAD IDENTIFICATION

PRIVATE OR STATE INHOLDINGS 
UNIT NO.: MT-068-244

UNIT NAME: Dog Creek South

\section{WILDERNESS CHARACTERISTICS NARRATIVE SUMMARY}

Dog Creek South Unit (MT-068-244) borders the south bank of the Missouri River and is located in Fergus County, Montana. The area is bounded by private land on three sides, with the river forming the northern border. This unit, after reevaluation, contains approximately 5,230 acres.

One access into the unit which was termed a vehicle way during intensive inventory has been determined to meet the definition of a road found in the BLM Wilderness Inventory Handbook. Identification of this road in T. $22 \mathrm{~N}$, , R. $17 \mathrm{E}$., Sec. 4, 5, and 6 excludes approximately 1,720 acres from the unit.

Except for high rolling benches, the area is steep and topographically rugged. Jagged sandstone cliffs and rounded shale slopes predominate. Ponderosa pine and juniper are found in many of the drainages.

The area is presently used for livestock grazing and hunting. The use of the area for grazing has led to the construction of 6 reservoirs, 2 miles of fence, and 1 mile of low grade vehicular way. The impact of these improvements is marginal, however, as they are widely dispersed and screened by the rugged topography.

Opportunities for solitude are outstanding in the northern portion of this unit. Deeply eroded drainages, some with pockets of ponderosa pine, offer excellent screening from both offsite and onsite activities in the northern portion of the areas. In the south and southeastern sections of the unit, adjacent intensively farmed private land along with the configuration of a narrow finger connecting the southern parcel to the bulk of the unit preclude high quality solitude. Removal of those portions adversely affected results in the exclusion of 4,600 acres in the south and 320 acres in the southeast due to lack of solitude and natural appearance.

Good hunting and fishing along the Missouri River, attractive scenery and unusual geologic features to view or photograph do exist in the area. However, these primitive recreational opportunities do not exceed in variety or uniqueness those of adjacent lands.

The scenery, remnants of the homesteading era, and signs of use by the Plains Indians are supplemental values within the unit. 
Summary of Public Comments:

Two comments were received. One admitted the existence of range improvements but felt that other values qualified the area for wilderness study. The other comment downplayed the scenic value of the area and pointed out the existence of agriculture and mineral developments, roads, outside agriculture influences, fences, stock dams, and the adjacent Leroy Gas Field.

Final Decision and Rationale:

The northern portion of this unit will be further studied for wilderness. This portion has outstanding opportunities for solitude and good recreational possibilities, values which are augmented by the extreme roughness and attractiveness of the area. Lack of solitude, closely adjacent farming activities, and the identification of a road disqualify the rest of the unit. 
DOG CREEK SOUTH

MT-068-244

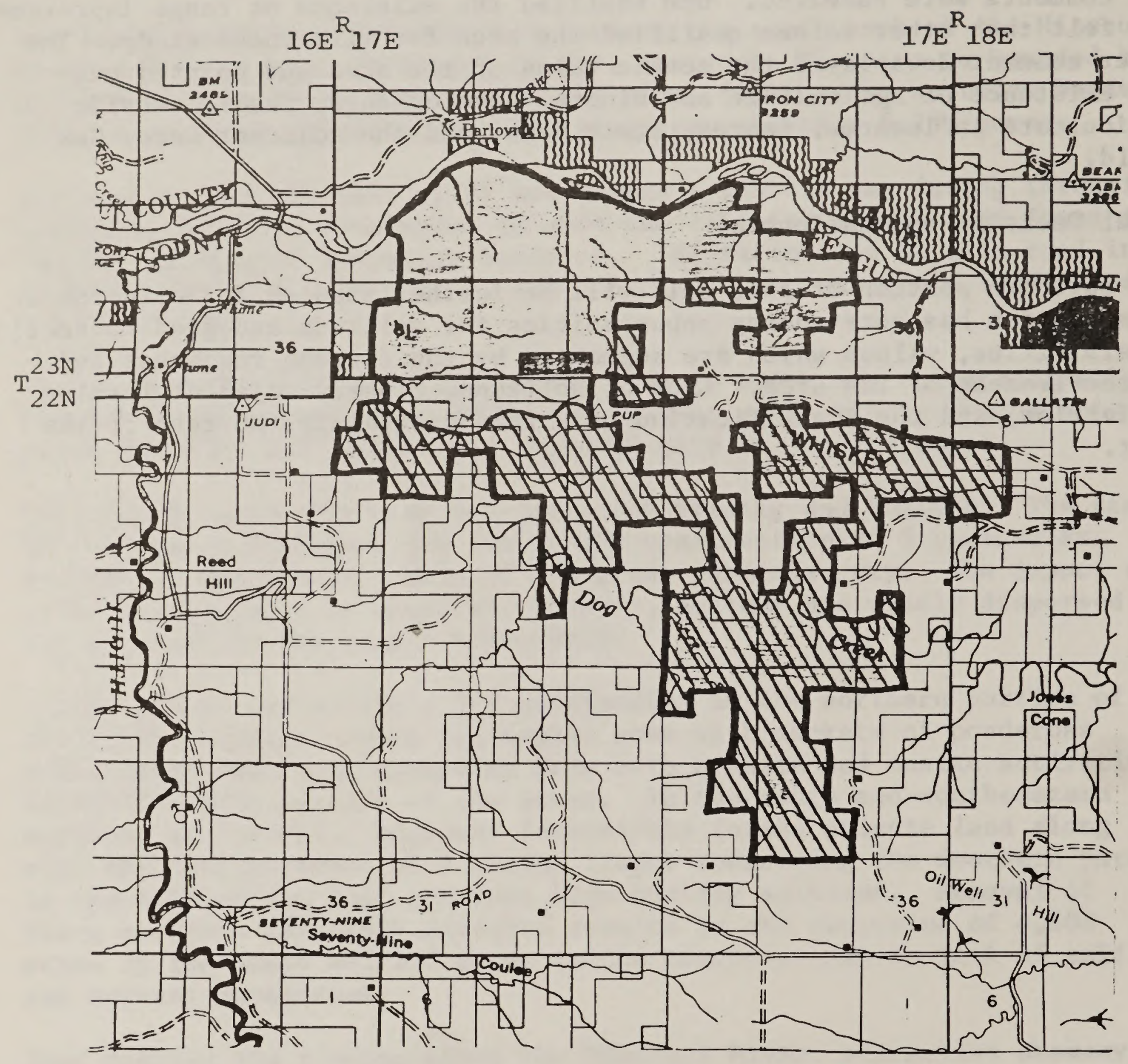

LEGEND

SCALE $1: 126,720$

inch $=1$ mile
MIIV
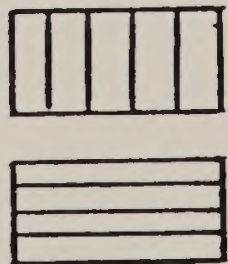

$\%$

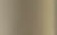


UNIT NO.: $\quad$ MT-060-250

UNIT NAME: Stafford

\section{WILDERNESS CHARACTERISTICS NARRATIVE SUMMARY}

The Stafford Unit (MT-060-250) parallels the north shore of the Missouri River between the P.N. and Stafford Ferry crossings in South Blaine County. The 7,177 acre unit was originally bounded by private and Montana State land and the Stafford Ferry road.

A new boundary was established along a vehicle trail located in sections 28 and 29 of T. 23 N., R. 18 E. The trail has occassionally provided access to manage livestock in the area. A 2,477 acre parcel lies east of this new boundary and a 4,700 acre parcel lies west of it.

The unit is an extension of the Missouri Breaks with a topography of flat ridgetops that steeply descend towards the Missouri River. The steeper slopes reach grades of $90 \%$ or more with soils of ten too loose to support vegetation. Where vegetation grows, the terrain is predominantly covered with prairie grasses, sagebrush, and greasewood. Patches of cottonwoods parallel the river and conifers (juniper \& pine) grow in coulee pockets but they are both a very small percentage of the overall vegetation.

The areas rugged and dissected terrain has allowed little human development to take place. The parcel of land west of the vehicle way that forms the new boundary (see map) has short stretches of barbed wire fence, three vehicle ways, and one small retention reservoir. Within the parcel east of the vehicle way, there are short stretches of barbed wire fence, two other vehicle ways, a dry gas well, and one retention reservoir. These impacts are primarily the result of past livestock management and are well hidden by the area's broken topography.

Opportunities for solitude or a primitive and unconfined type of recreation are not outstanding east of the new eastern boundary. The areas narrow configuration and small size requires a person to constantly search for seclusion. The ferry crossing, the farmland across the river, and the county road are easily visible to a person within this parcel. Activity from these intrusions compound the problem for seclusion. Recreation activities such as hunting, hiking, and camping can occur within the parcel, however, the unit's steep topography limits these activities.

Opportunities for solitude west of the new boundary are outstanding. The extremely dissected topography and the lack of visible impacts allow a person to easily find seclusion. However, opportunities for a primitive and unconfined type of recreation are less than outstanding because recreational activities such as those described in the previous paragraph are neither unique nor of greater quality than those of surrounding areas. 
The unit lies within the Upper Missouri Wild \& Scenic River corridor. Persons who pass the unit along the river witness a scenic topography rich with historic features. Long before Lewis \& Clark passed along the units shore, Native Americans hunted the river leaving behind tipi rings and lithic scatter. When the steamboats arrived in the area, numerous persons homesteaded the unit and one building site remains. The trail that now form the units eastern boundary was once used to salvage a steamboat that had grounded on the river's shores.

\section{FINAL DECISION ANALYSIS}

Summary of Public Comments:

Conservation groups strongly felt that the unit should be considered for future study. However, other individuals strongly felt the area was impacted by the ferry crossing, the county road that borders the unit, and offsite farming. Others were concerned about the units impact on the proposed Fuelco pipeline crossing and further gas exploration.

Final Decision and Rationale:

A boundary has been drawn along a vehicle way which will form the new eastern boundary of the unit. Approximately 2,700 acres of public land lying to the east of the vehicle way will be eliminated from further wilderness consideration. This parcel is apparently natural but contains neither outstanding opportunities for primitive and unconfined types of recreation or solitude as explained earlier in the wilderness characteristics summary.

The parcel of land west of the new boundary contains 4,700 acres and is apparently natural. This portion of the unit has outstanding opportunities for solitude but opportunities for a primitive and unconfined type of recreation are not outstanding. Even though this parcel has less than 5,000 acres, a review of public comments, has indicated that this portion of the unit is strongly recommended for future study. This portion of the unit will be studied for wilderness suitability. 


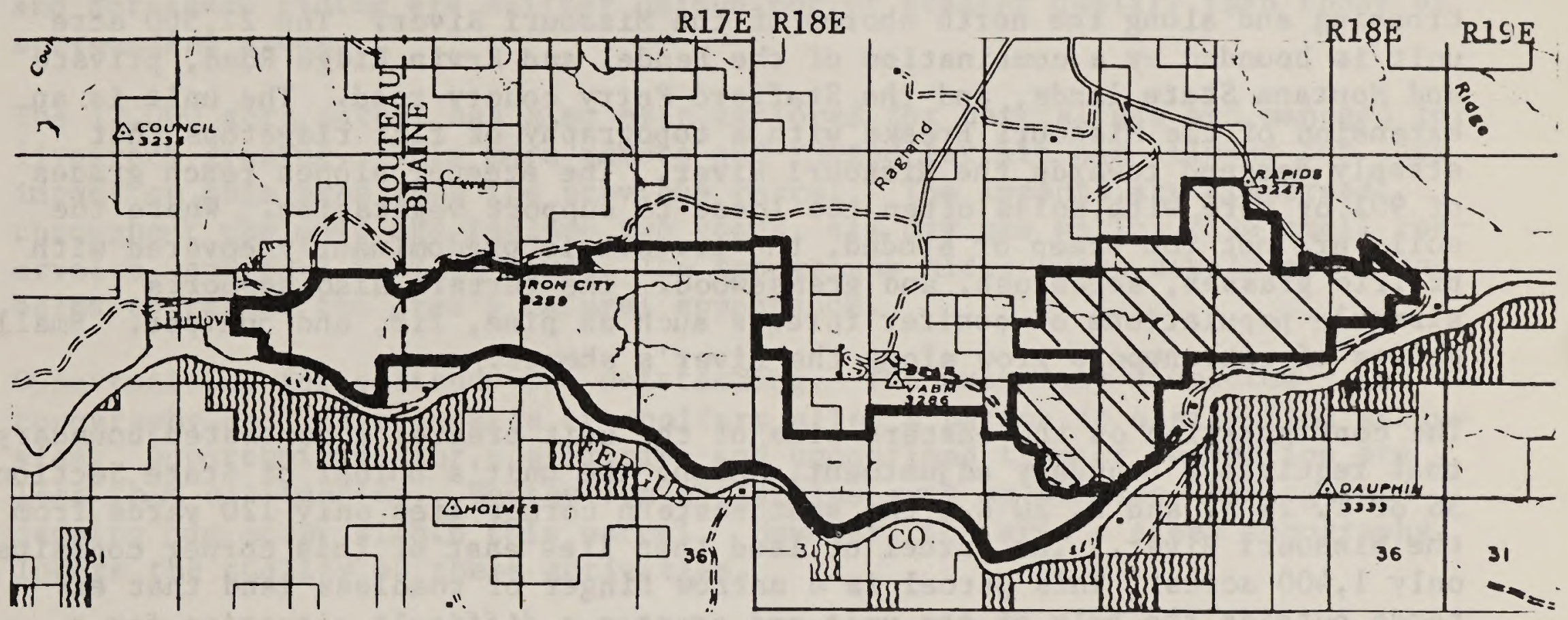

SCALE $1: 126,720$

$\frac{1}{2}$ inch $=1$ mile
MIIV
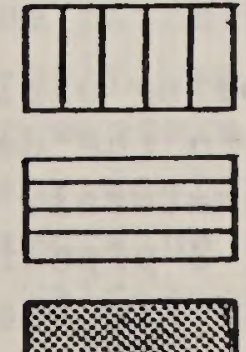

\section{LEGEND}

UNIT OR PORTION OF UNIT LACKING WILDERNESS CHARACTERISTICS (NOT RECOMMENDED AS WSA)

AREA DELETED FROM ORIGINAL INVENTORY UNIT DUE TO ROAD IDENTIFICATION

AREA ADDED DUE TO ROAD IDENTIFICATION

PRIVATE OR STATE INHOLDINGS 
UNIT NO.: MT-060-253

UNIT NAME: Ervin Ridge

\section{WILDERNESS CHARACTERISTICS NARRATIVE SUMMARY}

The Ervin Ridge Unit (MT-060-253) lies 3 miles east of the Stafford Ferry Crossing and along the north shores of the Missouri River. The 22,500 acre unit is bounded by a combination of the Pendel and Ervin Ridge Road, private and Montana State lands, and the Stafford Ferry county road. The unit is an extension of the Missouri Breaks with a topography of flat ridgetops that steeply descend towards the Missouri River. The steeper slopes reach grades of $90 \%$ or more with soils of ten too loose to support vegetation. Where the soils are not too steep or eroded, the terrain is predominantly covered with prairie grasses, sagebrush, and greasewood. The terrain also supports sizeable populations of conifer forests such as pine, fir, and juniper. Small groves of cottonwoods grow along the river's shores.

The configuration on the eastern side of the unit creates a congested boundary that requires a boundary adjustment. Along the unit's border of State Section 36 of T. $24 \mathrm{~N}$. and R. $20 \mathrm{E}$., the southeastern corner lies only 120 yards from the Missouri River. The parcel of land that lies east of this corner contains only 1,400 acres. This parcel is a narrow finger of roadless land that extends outside the bulk of the unit and creates a difficult situation for a person to find an outstanding opportunity for solitude or a primitive and unconfined type of recreation. For these reasons, the boundary is drawn from the southeastern corner of the State Section to the Missouri River and the parcel east of the boundary will not be included for future wilderness study.

A boundary adjustment is made to omit from future wilderness study a 360 acre parcel of land in Sections 21 and 20 of T. 24 N. and R. 19 E. The boundary, which is drawn along the eastern side of Section 21 , will eliminate the 2 roads, pipeline, producing gas well, and allotment boundary fence that lie in this long and narrow parcel.

The intensive inventory led to the discovery of a road that nearly bisects the unit into two large parcels. The road is located in Sections 26, 27, and 36 of T. $24 \mathrm{~N}$. and R. $19 \mathrm{E}$. It provides access to a reservoir and State land that is currently leased for grazing. The parcel south and west of the road has approximately 10,800 acres and has been severely impacted. The parcel north and east contains approximately 12,000 acres and is in a more pristine state. Connecting the 2 parcels of land is a narrow strip of land that is $1 / 4$ mile wide and lies along the northwest boundary of Section 1 in $\mathrm{T} .23 \mathrm{~N}$. and R. $19 \mathrm{E}$. Because the 2 parcels have been impacted differently and they are connected by a congested boundary, the boundary is along the west side of Section 1 .

The southwest parcel is extensively being explored for natural gas and managed for livestock grazing. This has led to the development of numerous impacts that have made the area apparently unnatural. The impacts include 6 roads, 10 dry gas wells, 3 producing gas wells, 2 pipelines, 8 small reservoirs, and 10 vehicle ways. Nearly all the activity has been occurring on the ridgetops that overlook the river. 
Opportunities for solitude or primitive and unconfined types of recreation are not outstanding within this parcel. Because of the many roads that follow ridgetops, land without wilderness characteristics penetrates the unit and creates a situation where an individual or group would have to seek out a secluded spot in the drainage bottoms or along the river and stay there. This situation precludes classifying the opportunity for solitude as outstanding. Opportunities for a primitive and unconfined type of recreation are less than outstanding because recreational activities such as hiking, camping, hunting, and horseback riding are neither unique nor of greater quality than those of surrounding areas.

The 12,000 acre parcel has also been explored for natural gas and managed for livestock grazing. This more remote and rugged terrain has allowed for less impact on this area than the previous parcel. The impacts are dispersed throughout the unit and include two roads, six dry gas wells, five small reservoirs, and five vehicle ways. The topography hides these developments and helps to retain the area's natural appearance.

Opportunities for solitude are outstanding. The extremely dissected topography and large pockets of conifers allow a person to easily find seclusion. Opportunities for a primitive and unconfined type of recreation are less than outstanding. Recreation activities such as hunting, hiking, and camping can occur within this parcel. However, the area's steep topography lowers the quality of these activities.

The unit lies within the Upper Missouri Wild and Scenic River corridor. Persons who pass the unit along the river witness scenic topography rich with historic features. Long before Lewis and Clark passed along the unit's shore, Native Americans hunted the river leaving behind tipi rings and lithic scatter. When the steamboats arrived in the area, numerous persons homesteaded the unit and two bulding sites remain.

\section{FINAL DECISION ANALYSIS}

Summary of Public Comments:

Reaction by the public was mixed. Conservation groups felt that the unit should be considered for future study. Local groups strongly felt the unit did not meet wilderness characteristics. The roads, offsite intrusions, dry and producing gas wells, reservoirs, and fences all give the area an unnatural appearance. They were also concerned that future gas exploration will be curtailed by wilderness study designation.

Final Decision and Rationale:

The unit is subdivided into three parcels due to congested boundaries and a road. The middle parcel is the only one that will be studied for future wilderness suitability. The far western parcel has been impacted by gas exploration and livestock management facilities to create an unnatural appearance. The most eastern parcel contains only 1,400 acres and does not meet the size criteria as defined by the Wilderness Inventory Handbook. 


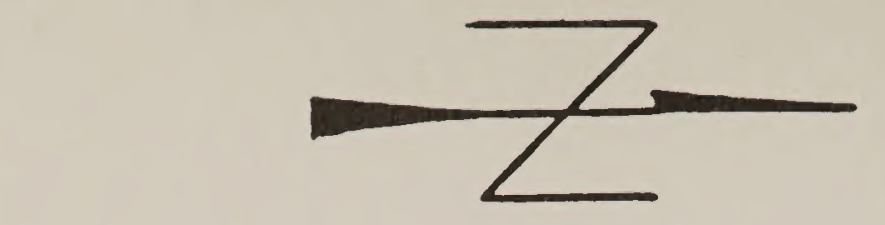

ERVIN RIDGE

MT-066-253

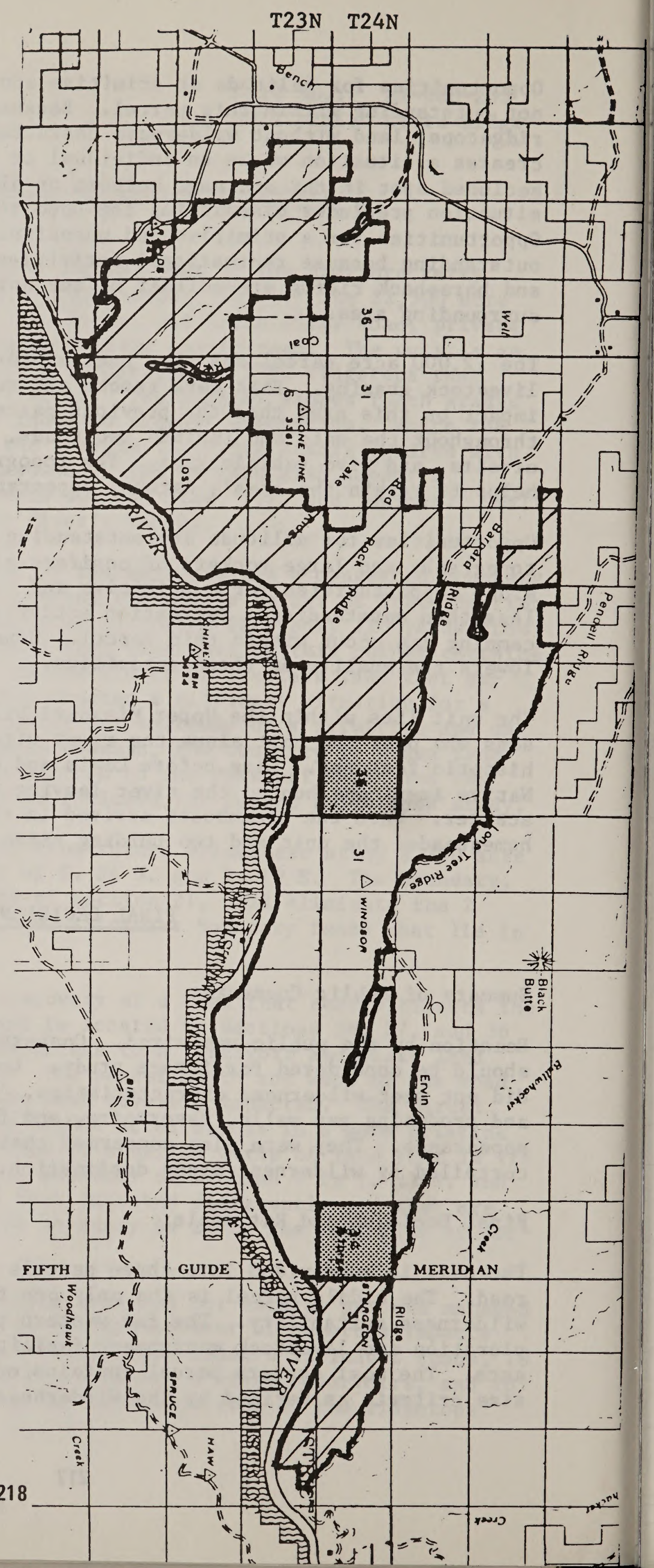


UNIT NO.: $\quad$ MT-060-256

UNIT NAME: Cow Creek

\section{WILDERNESS CHARACTERISTICS NARRATIVE SUMMARY}

The Cow Creek Unit (MT-060-256) lies approximately 60 miles south of Harlem, Montana, and north of the Cow Island Recreation Area. The 71,100 acre unit is bounded by roads and private and state land.

Despite flat prairie sections near the north, northwest, and southwest boundaries, the unit has a rugged and dissected appearance formed by the many drainages that feed into Cow Creek. The bluffs overlooking parts of Bull Creek, Winter Creek, and Hay Coulee of ten drop sharply creating wall like appearances. Where neither landforms are too steep nor soils too loose, the terrain is predominantly covered with prairie grasses, sagebrush, and greasewood. The terrain also supports sizeable populations of conifers such as pine, fir, and juniper. Large groves of cottonwoods grow along the shores of Cow Creek.

The configuration on the northwest side of the unit creates a congested boundary that requires a boundary adjustment. Along the unit's border with private land at Section 35 of T. $25 \mathrm{~N}$. and R. 21 E., the southwestern corner lies $1 / 2$ mile from the border of another private parcel in Section 10 of $\mathrm{T} .24$ N. and R. 21 E. A boundary is drawn to connect these two private sections and creates a 15,000 acre parcel of land north of the border. Impacts resulting from both gas exploration and livestock management are numerous and give this portion of the area an unnatural appearance. The flat terrain limits a person's ability to find solitude. The impacts on the area include 12 vehicle ways, 14 reservoirs, 14 dry gas wells, and 3 capped gas we 11 s. This parcel is not included for future wilderness study.

A boundary adjustment was made to exclude from future wilderness study a 1,000 acre parcel of land. It lies above the 3,200 foot contour line in Sections 1 , 2 , and 12 of T. $25 \mathrm{~N}$, and R. 21 E., and Section 6 of T. $25 \mathrm{~N}$. and R. 22 E. The parcel has three small reservoirs and is bounded on three sides by well used roads which significantly detract from the area's naturalness. Since the area is flat and lacks tall growing vegetation, the parcel lacks solitude.

The inventory identified five roads that resulted in the elimination from future wilderness study of five parcels of land, each containing less than 5,000 acres. The first road crosses through T. $25 \mathrm{~N}$. and R. $21 \mathrm{E}$., to State Section 36. The second road crosses section 26 of T. $25 \mathrm{~N}$. and R. $22 \mathrm{E}$. The third road traverses the eastern end of Section 12 in T. 24 N. and R. 22 E. The fourth road enters Section 31 of T. $25 \mathrm{~N}$. and R. $23 \mathrm{E}$., and Sections 5 and 6 of T. 24 N. and R. 23 E. The fifth road crosses Sections 21, 22, 23, and 24 of T. $24 \mathrm{~N}_{0}$, and R. $23 \mathrm{E}$.

The final boundary adjustment is the result of both a congested boundary and roads found during the intensive inventory. A road traverses Cow Creek connecting State Section 36 in T. $25 \mathrm{~N}$. and R. $21 \mathrm{E}$., with the private land in Section 18 of T. $24 \mathrm{~N}$. and R. $22 \mathrm{E}$. A 9,500 acre parcel of land lies west of 
the road that is connected with the remainder of the unit by a narrow strip of land. The 600 yard wide strip is between the south border of the private land in Section 32 of $T .24 \mathrm{~N}$. and R. $22 \mathrm{E}$., and north border of the private land in Section 5 of T. $23 \mathrm{~N}$. and R. $22 \mathrm{E}$. Because the two parcels have been impacted differently and are connected by a congested boundary, the boundary is drawn between the two private parcels.

The 9,500 acre parcel has two roads that penetrate into the unit. Impacts within the parcel lie along or near the roads and include five dry gas wells, one reservoir, and three vehicle ways. Although the area has few impacts and retains its natural appearance this parcel has neither outstanding opportunities for solitude nor a primitive and unconfined type of recreation. Because of the two roads that enter the unit, lands without wilderness characteristics penetrate the area and create a situation where an individual or group would have to seek out a secluded spot in the drainage bottoms or along the river and stay there. This situation precludes classifying the opportunity for solitude as outstanding. Opportunities for a primitive and unconfined type of recreation are less than outstanding because recreational activities such as hiking, camping, hunting, and horseback riding are neither unique nor of greater quality than those of surrounding areas.

The area that will be studied for wilderness includes 36,200 acres. Although it has also been explored for natural gas and is managed for livestock grazing, the area's remoteness and rugged terrain have allowed for less impacts on the area. The impacts include 6 dry gas wells, 15 vehicle ways, 5 roads, and a small reservoir. The topography and tall growing vegetation hide these impacts and help to retain the area's natural appearance.

Opportunities for solitude are outstanding. The extremely dissected topography and large pockets of conifers allow a person to easily find seclusion. Opportunities for a primitive and unconfined type of recreation are less than outstanding. Recreation activities such as hunting, hiking, camping, and horseback riding can occur within this parcel, but these opportunities are limited by the terrain.

The unit not only lies within a small portion of the Upper Missouri Wild and Scenic River corridor, but it is also rich with scenic beauty and historical features.

\section{FINAL DECISION ANALYSIS}

Summary of Public Comments:

Reaction by the public was mixed. Conservation groups proposed expansion of the unit based on unique wilderness values. Other persons felt the area was greatly impacted by former homesteads, livestock management facilities, and mineral development.

Final Decision and Rationale:

The unit is divided into numerous parcels due to roads and congested boundaries. The largest parcel is the only one that will be studied for 
wilderness suitability. It is fairly remote and has very diverse terrain. The remaining parcels are either too small, or too impacted to warrant further wilderness study. 
UNIT NO.: MT-065-266

UNIT NAME: Antelope

\section{WILDERNESS CHARACTERISTICS NARRATIVE SUMMARY}

The Antelope Creek Unit (MT-065-266) is 1ocated in the southwestern portion of the Phillips Resource Area. It borders both the Upper Missouri Wild and Scenic River and CMR Wildlife Refuge's proposed "Antelope Creek" Wilderness Area.

This unit lies primarily in the Missouri Breaks and the topography is characterized by alternating coulees and ridges. The original size of this unit was 21,500 acres.

Intrusions to naturalness in this unit are located in the northern portion of the unit. Two roads and four vehicular ways provide access to private and State parcels and for mineral exploration, hunting, and livestock operations. There are also numerous vehicle ways which were created by hunters running out the ridges. The road through the state parcel extends south to the CMR boundary. There are also three vehicular ways from the eastern boundary, which provide access to reservoirs and a water well. There are 10 reservoirs and 1 well within this unit, but these are all located within the northern half of the unit with the exception of Butch Cassidy Reservoir. There are also two abandoned gas wells on the northern half of the unit. The intrusions within the northern half of this unit do detract from naturalness of the unit. The southern half of the unit has relatively few intrusions and the intrusions that are present do not detract significantly from the naturalness.

The northern portion of the unit consists of rolling prairie vegetated by sagebrush and grass. This portion also includes the heads of many of the coulees that run north/south to the Missouri River. Only in the heads of these coulees can solitude be obtained for the rest of the northern portion has little screening.

The southern portion of the unit is comprised solely of breaks topography and river bottom. The area is covered with scattered stands of ponderosa pine and sagebrush/grass. There is ample solitude within this southern portion of the unit since it is comprised of breaks topography and has vegetative screening. There is some possibility of observing other persons within the unit from some of the high ridges but in general, the southern portion of the unit has outstanding opportunities for solitude.

The unit provides opportunities for hunting, horseback riding, hiking, photography, and wildlife observation, but again the southern half of the unit provides the best opportunities for these pursuits.

The supplemental values include the remnants of two log cabins, a MaximillianBodmer Campsite, rock cairns, and isolated projectile points. 


\section{FINAL DECISION ANALYSIS}

Summary of Public Comment:

One comment suggested that these lands are just as important to preserve as the more mountainous regions. A region such as this provides habitat for wildlife and provides an opportunity for solitude.

Another comment stated that there are many man-made structures in or near this unit. There is a county road between the Antelope Creek Unit and another proposed WSA. However, there are access roads within the boundaries of this unit. The unit also contains fences, homestead remains, reservoirs, and at least one coal mine. This unit also has private property located within its boundaries. There are also intrusions outside the unit. Ranches and farms can be seen near the unit, there are vehicle sounds from a nearby highway, lights from nearby gold mines, and sounds from low flying aircraft.

Final Decision and Rationale:

The majority of the intrusions that detract from the naturalness of this unit are located in the northern half. The northern half also does not have outstanding opportunities for solitude or primitive and unconfined forms of recreation. Therefore the northern portion of this unit will not be studied for wilderness.

The new northern boundary of the unit will begin in T. $23 \mathrm{~N}$., R. $23 \mathrm{E}$., Section 26 and follow a vehicle way for approximately $3 / 4$ of a mile. The boundary will run across Sections 26 and 27 just above the center line. In Section 28 the boundary will follow another vehicular way located near the top of the section. The boundary will continue west along the dividing line between sections 29 and 20 until it gets to the middle of the section. There the boundary turns north to the middle of Section 20 where it again turns west and cuts through the middle of Section 19 and Section 24 of T. 23 N., R. 22 E. In Section 23 the boundary will turn north and follow a vehicular way until it joins the old boundary. Because of the road which runs south through T. 23 N., R. 23 E. Sections 28 and 33, the southern portion will be divided into two segments. The east segment contains approximately 2,340 acres but will be studied because it is contiguous to the CMR Wildlife Refuge's proposed Antelope Creek Wilderness Area. The western segment contains 7,060 acres. In the northern portion 12,100 acres will not be studied. 


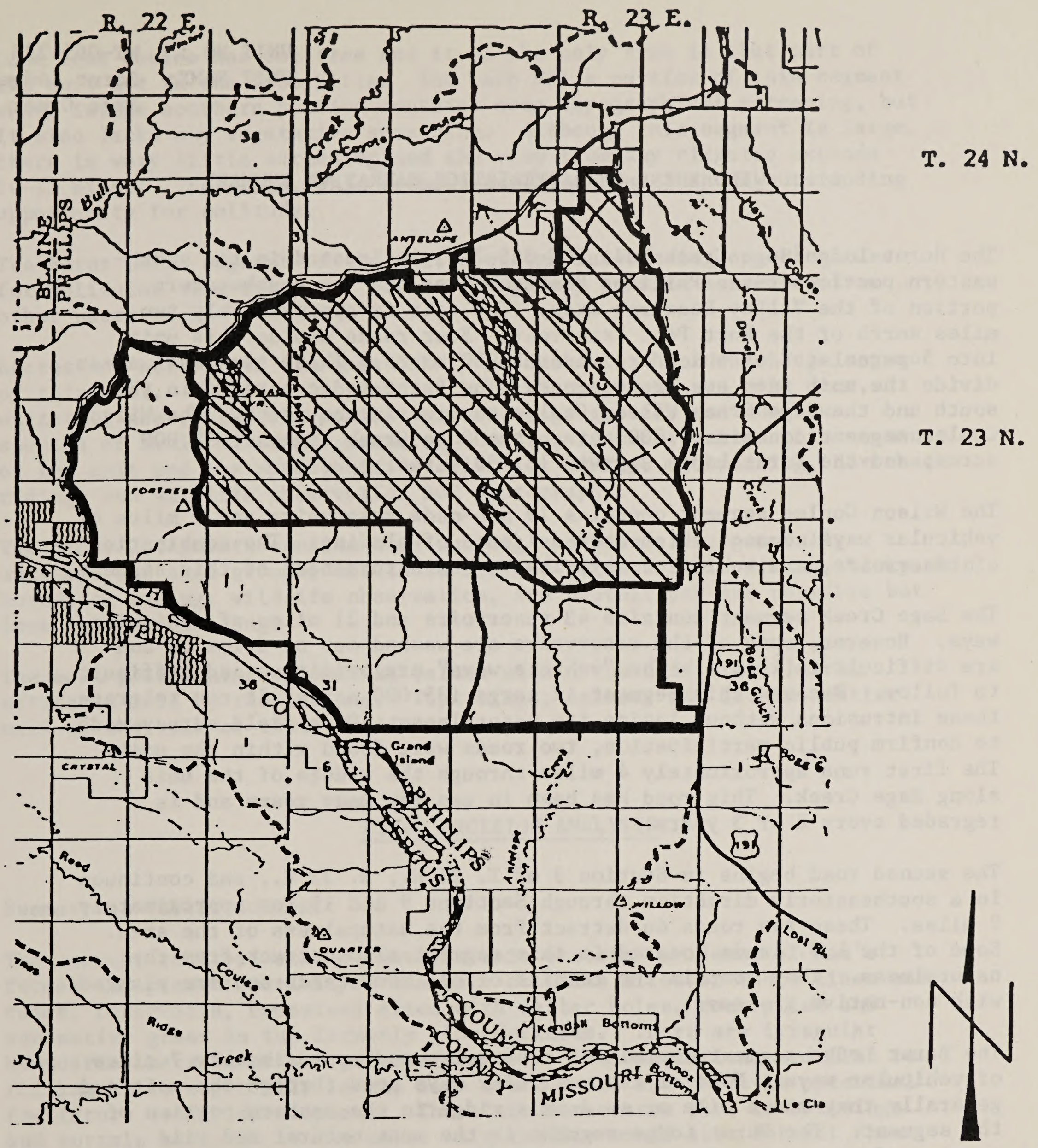

LEGEND

SCALE $1: 126,720$

inch $=1$ mile
W UNIT OR PORTION OF UNIT LACKING WILDERNESS CHARACTERISTICS (NOT RECOMMENDED AS WSA)

AREA DELETED FROM ORIGINAL INVENTORY UNIT DUE TO ROAD IDENTIFICATION

AREA ADDED DUE TO ROAD IDENTIFICATION

PRIVATE OR STATE INHOLDINGS 


\section{WILDERNESS CHARACTERISTICS NARRATIVE SUMMARY}

The Burnt Lodge/Sage Creek Unit (MT-065-278) is located in the southeastern portion of the Phillips Resource Area and the southwestern portion of the Valley Resource Area. The unit is approximately two miles north of the Fort Peck Reservoir. Four roads divide this unit into 5 parcels, 2 of which are under 5,000 acres. These two small areas divide the unit into two large areas. The Burnt Lodge portion in the south and the Sage Creek/Wilson Coulee portion in the north. The Wilson Coulee segment contains 9,000 acres, the Sage Creek segment, 35,000 acres, and the Burnt Lodge segment 15,000 acres.

The Wilson Coulee segment contains 19 man-made reservoirs and 7 miles of yehicular ways some of which show evidence of blading. The combination of reservoirs, and vehicular ways lowers the naturalness of this segment.

The Sage Creek segment contains 43 reservoirs and 21 miles of vehicular ways. However, many of the reservoirs are washed out or dried up and are difficult to locate. The "vehicle ways" are primitive and difficult to follow. Because this segment is large $(35,000$ acres) it can tolerate these intrusions without losing its naturalness. On a field survey made to confirm public participation, two roads were found within the unit. The first runs approximately 4 miles through the middle of the unit along Sage Creek. This road has been in use for many years and is regraded every 2 or 3 years.

The second road begins in Section 9 of T. 25 N., R. 33 E., and continues in a southeasterly direction through Sections 9 and 15 for approximately 2 miles. These two roads do detract from the naturalness of the area. Some of the L.U. lands located in this segment also detract from the naturalness. They contain the remains of old homesteads and are planted with non-native grasses.

The Burnt Lodge segment contains 3 reservoirs and approximately 7 miles of vehicular ways. None of the vehicular ways goes through the unit and generally they run a mile or so down a ridge in the eastern portion of the segment. The Burnt Lodge segment is the most natural and wild portion of the unit. The dissected breaks topography and conifer trees screen the few impacts that exist.

The Wilson Coulee segment is rather small (9,000 acres) and contains little vegetative or natural screening. Consequently, this area has less than outstanding opportunities for solitude. The Sage Creek segment is much larger $(35,000$ acres) but it too has little vegetative screening. 
Lone Tree Coulee has one tree and it is the only tree in that part of the unit not in the Larb Hills. The Larb Hills portion of this segment which is the southern portion contains some topographical screening, but it also lacks any vegetative screening. Although this segment is large, there is very little screening and the view from any ridgetop extends 10-15 miles. Therefore, this segment contains less than an outstanding opportunity for solitude.

The Burnt Lodge segment of the unit contains outstanding opportunities for solitude. The trees and breaks topography provide screening from other users.

Recreation activities are most likely to occur in the Burnt Lodge segment of this unit. Within this timbered breaks topography are mule deer, whitetail deer, elk, sharptailed grouse, sage grouse, and numerous species of small birds and mammals. Hunting is excellent in this segment of the unit and the opportunities exist for hiking, backpacking, horseback riding, and wildlife observation and photography.

The other 2 segments contain some hunting opportunities, generally antelope and sage grouse, but these are not outstanding. Hiking, backpackin horseback riding, wildlife observation, and photography are possible but less than outstanding.

The most prevalent supplemental values within the unit are cultural artifacts left by the Indians. Tipi rings, cairns, and lithic scatter make up the bulk of these artifacts.

\section{FINAL DECISION ANALYSIS}

Summary of Public Comment:

The comment received stated that the unit contains evidence of man's former and present activity. The unit contains miles of fence lines and roads, reservoirs, homestead sites with cellar holes, rock piles and non-native grass in the formerly plowed fields. There are irregular boundaries because of the private property, low vegetation, and flat to rolling hills especially in the Sage Creek Unit, and there is potential for future energy development. There are structures such as buildings and corrals adjacent to the unit. Air traffic would also detract from wilderness values. The control of noxious weeds and predators could become a problem to ranchers if the area becomes designated as wilderness.

Final Decision and Rationale:

Only the Burnt Lodge segment of the Burnt Lodge/Sage Creek Unit will be studied for wilderness. Of the entire unit this is the only segment that contains outstanding naturalness and outstanding opportunities for solitude and primitive forms of recreation. 
barat an

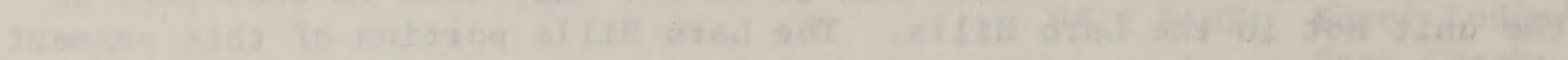
-

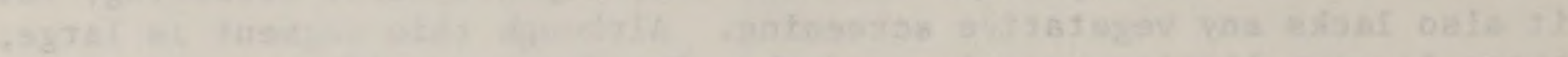

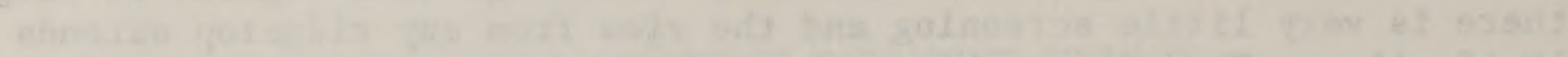

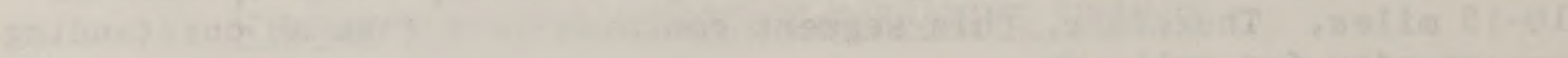

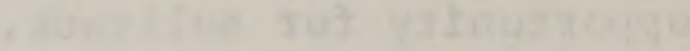

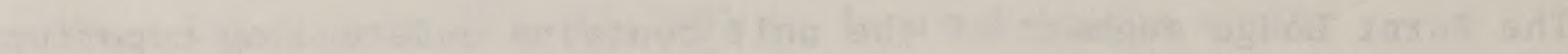

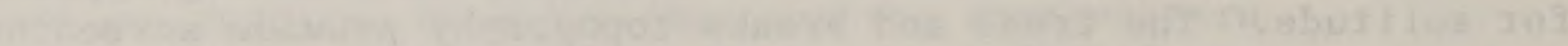

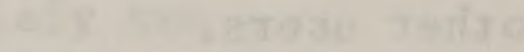

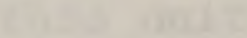

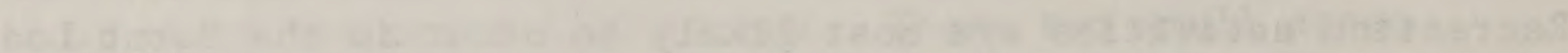

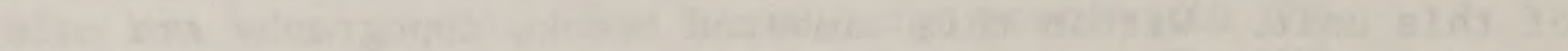

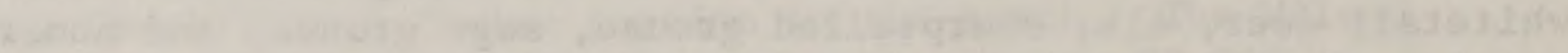
and and (14:

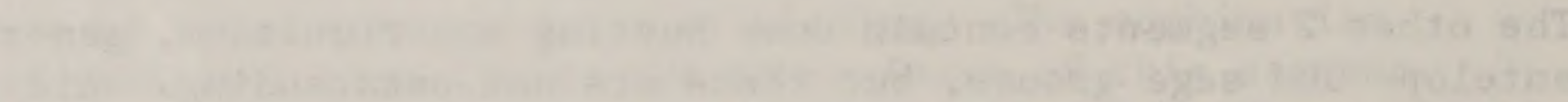

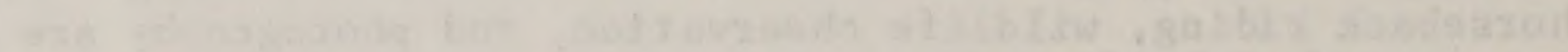

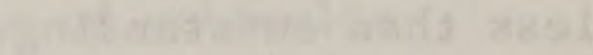

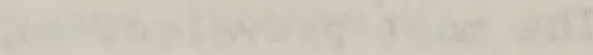

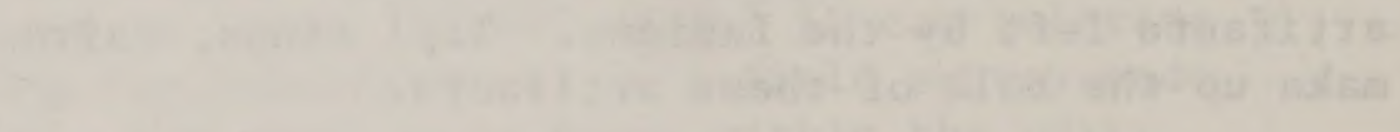

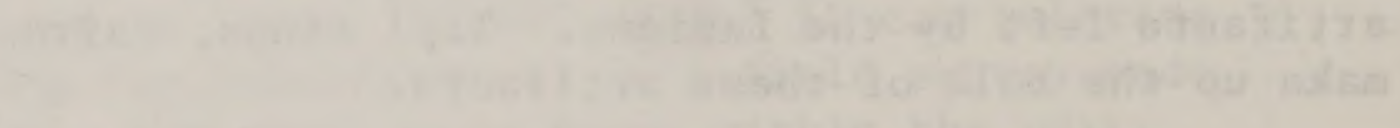

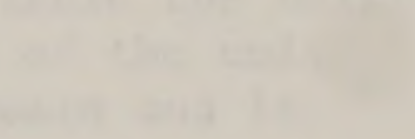

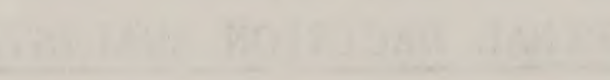

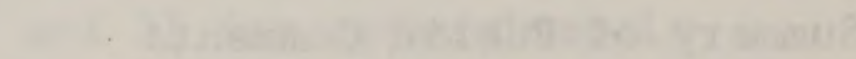

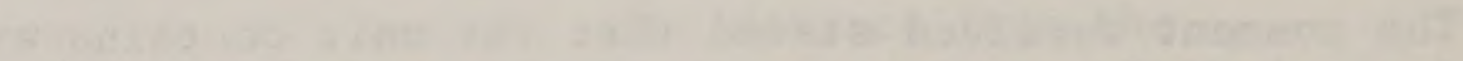

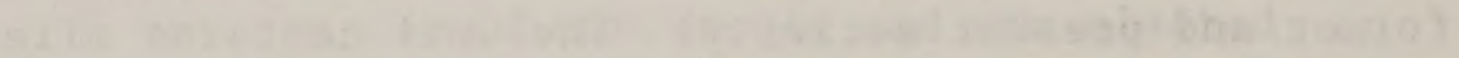

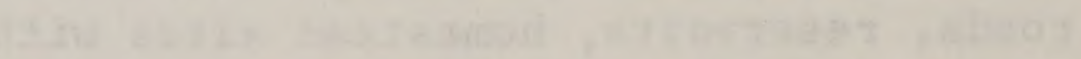

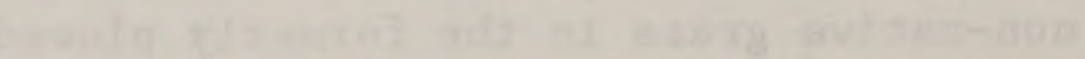

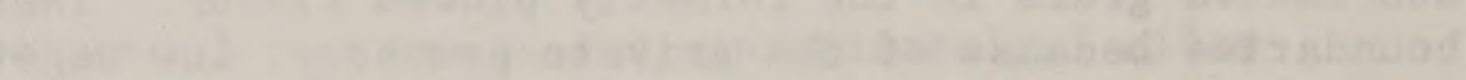
ann

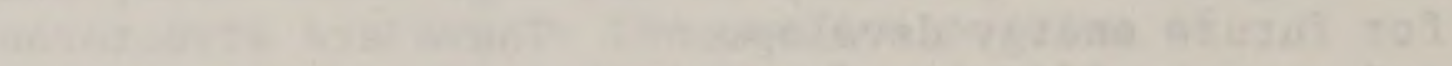

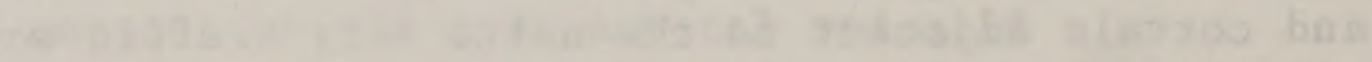

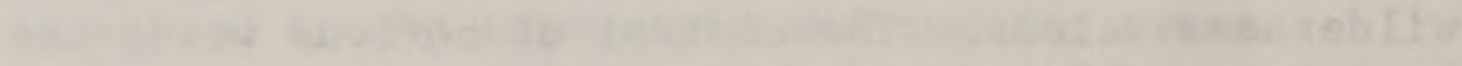

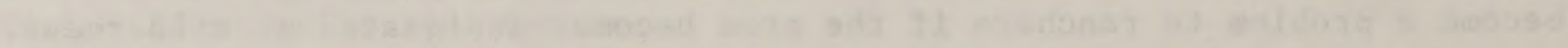

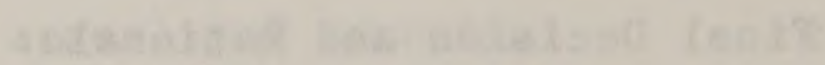

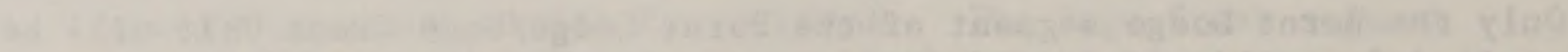

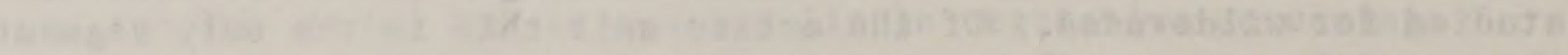

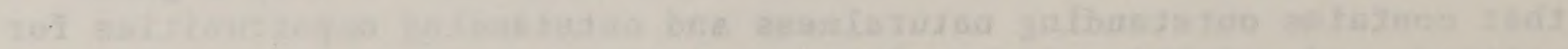

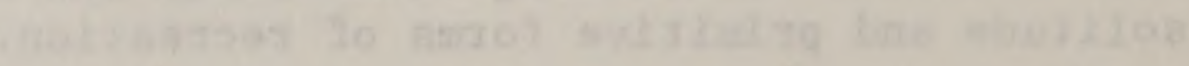




\section{LEWISTOWN DISTRICT}

\section{INVENTORY UNITS}

DROPPED FROM

\section{WILDERNESS CONSIDERATION}

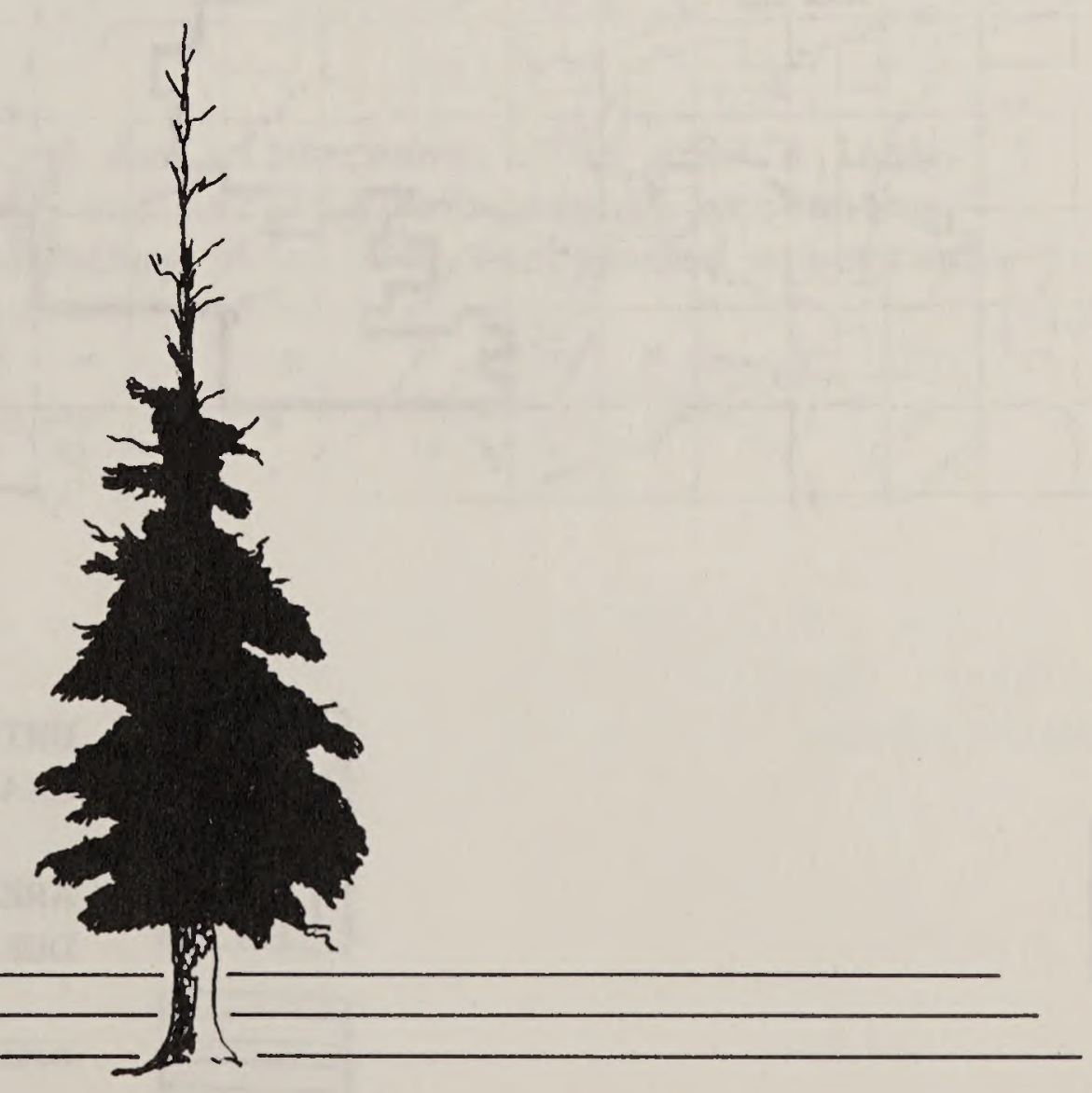



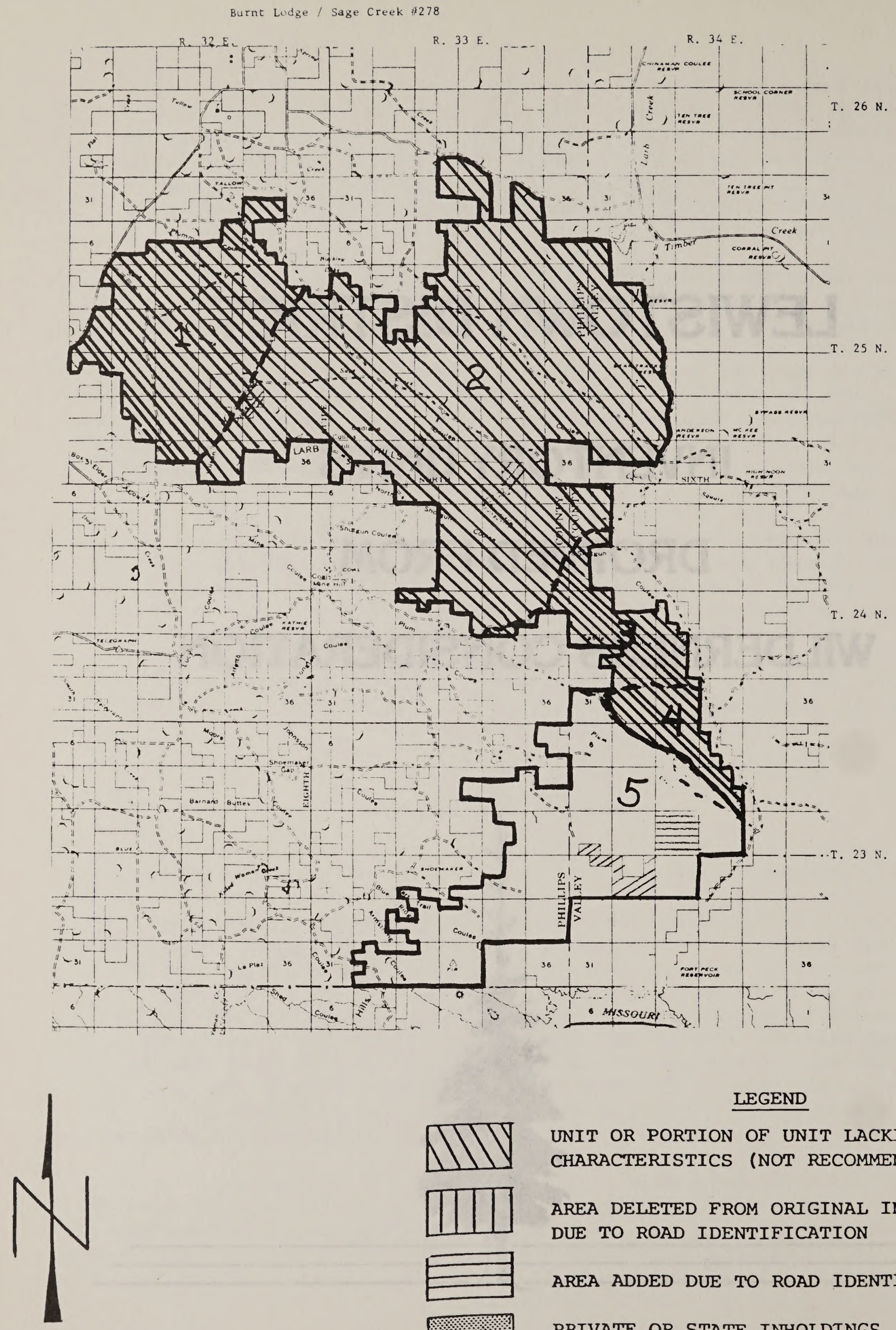

LEGEND

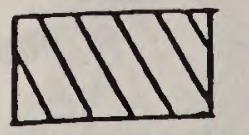

UNIT OR PORTION OF UNIT LACKING WILDERNESS CHARACTERISTICS (NOT RECOMMENDED AS WSA)

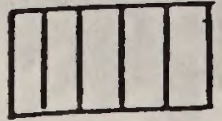

AREA DELETED FROM ORIGINAL INVENTORY UNIT DUE TO ROAD IDENTIFICATION

AREA ADDED DUE TO ROAD IDENTIFICATION

PRIVATE OR STATE INHOLDINGS 
UNIT NO.: $\quad$ MT-067-200

UNIT NAME: Dry Creek

\section{WILDERNESS CHARACTERISTICS NARRATIVE SUMMARY}

Dry Creek Unit (MT-067-200) is an area of approximately 5,860

acres located in Carbon County, Montana. The unit is situated $1 \frac{1}{2}$ miles northwest of Belfry, Montana and is a quarter mile to the west of Montana Highway 308. Private and State lands form the unit's irregular boundaries. Characterized by rolling open landform, the unit contains only scattered trees in its western portion.

Although Dry Creek is in a near-natural condition, there is a lack of vegetative and topographic screening. Drainages are oriented such that the sounds of passing vehicles on Highway 308 penetrate deeply on the east side. These signs of man's presence are disruptive to solitude values. Hunting and horseback riding are the only primitive recreation opportunities identified and neither was considered outstanding. No supplementary values were noted in the area.

\section{FINAL DECISION ANALYSIS}

Summary of Public Comments:

One comment pointed out dams, wells, springs, private fences, roads and an interior fenced grazing area as reasons for wilderness disqualification.

Final Decision and Rationale:

This unit will not be further studied for wilderness. The area's lack of solitude due to sparse vegetative and lack of topographic screening, offsite impacts and less than outstanding primitive recreation opportunities disqualifies it as wilderness. 


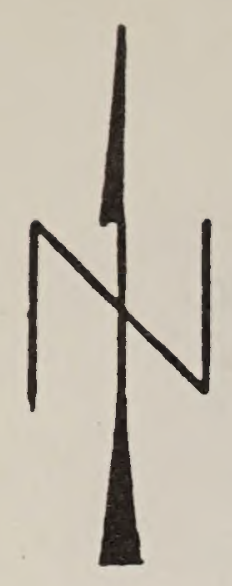

DRY CREEK

MT-067-200

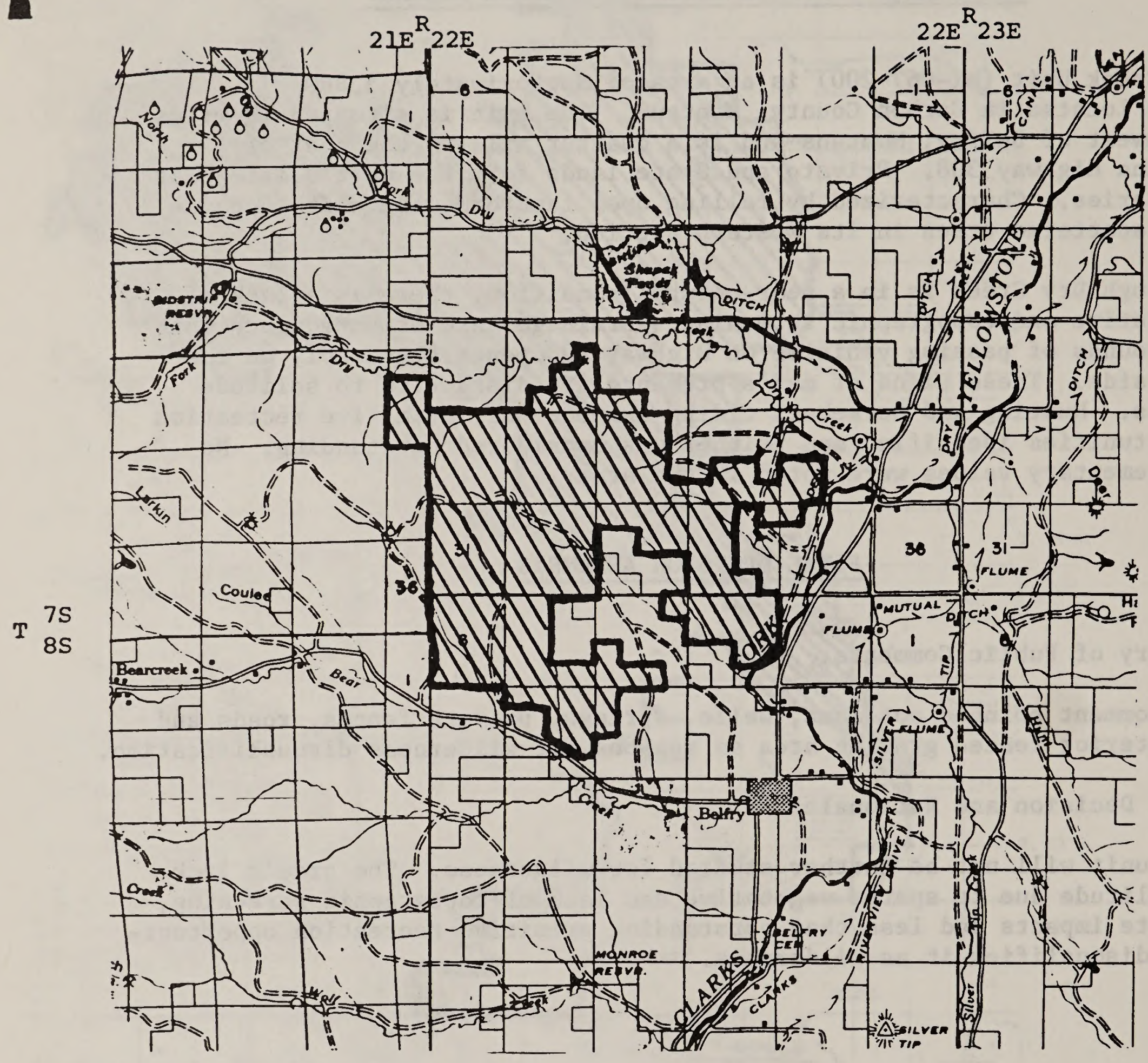

LEGEND

SCALE $1: 126,720$

$\frac{1}{2}$ inch $=1$ mile
DU UNIT OR PORTION OF UNIT LACKING WILDERNESS CHARACTERISTICS (NOT RECOMMENDED AS WSA)

AREA DELETED FROM ORIGINAL INVENTORY UNIT DUE TO ROAD IDENTIFICATION

AREA ADDED DUE TO ROAD IDENTIFICATION

PRIVATE OR STATE INHOLDINGS 
UNIT NO.: $\quad$ MT-067-201

UNIT NAME: Deer Mountain

\section{WILDERNESS CHARACTERISTICS NARRATIVE SUMMARY}

Deer Mountain Unit (MT-067-201) is located in Carbon County, Montana. The area contains 6,970 acres. Situated 5 miles east of Belfry, Montana, the unit is most easily accessed by Cottonwood Creek Road which also forms 1 ts eastern boundary. The northern boundary is Hatcher Pass Road and the west and south limits are formed by a combination of private holdings and the Hunt Creek Road.

A scattering of range improvements and a natural gas pipeline are located within the area. Due to dispersion of the range improvements and revegetation of soil disturbed during construction of the gas pipeline, the improvements do not seriously detract from the area's naturalness. The unit is formed by a single, narrow, north-south ridgeline sparsely vegetated by conifers on the top of the ridge and in the draws. Due to this configuration, open and vertical, only very small areas are adequately screened to offer any solitude. Recreational pursuits available in the unit are hiking, horseback riding, nature study, and hunting. None of these is of exceptional quality and better opportunities are available nearby. The unit's topography consists of a high ridgeline that drops off abruptly to the east. This type of landform is known as a cuesta scarp. The presence of this interesting landform and the associated scenery are probably the best supplemental values of the Deer Mountain Unit.

\section{FINAL DECISION ANALYSIS}

Summary of Public Comments:

The sole commenter pointed out the presence of the natural gasline crossing the unit and communications installations offsite nearby. Also, attention was drawn to fences, roads, dams, wells, springs, and potential energy deposits within the unit.

Final Decision and Rationale:

This unit will not be further studied for wilderness. Although the area is essentially natural, its open, narrow, and vertical configuration makes for less than outstanding solitude. Recreational activities are not outstanding individually or together. 


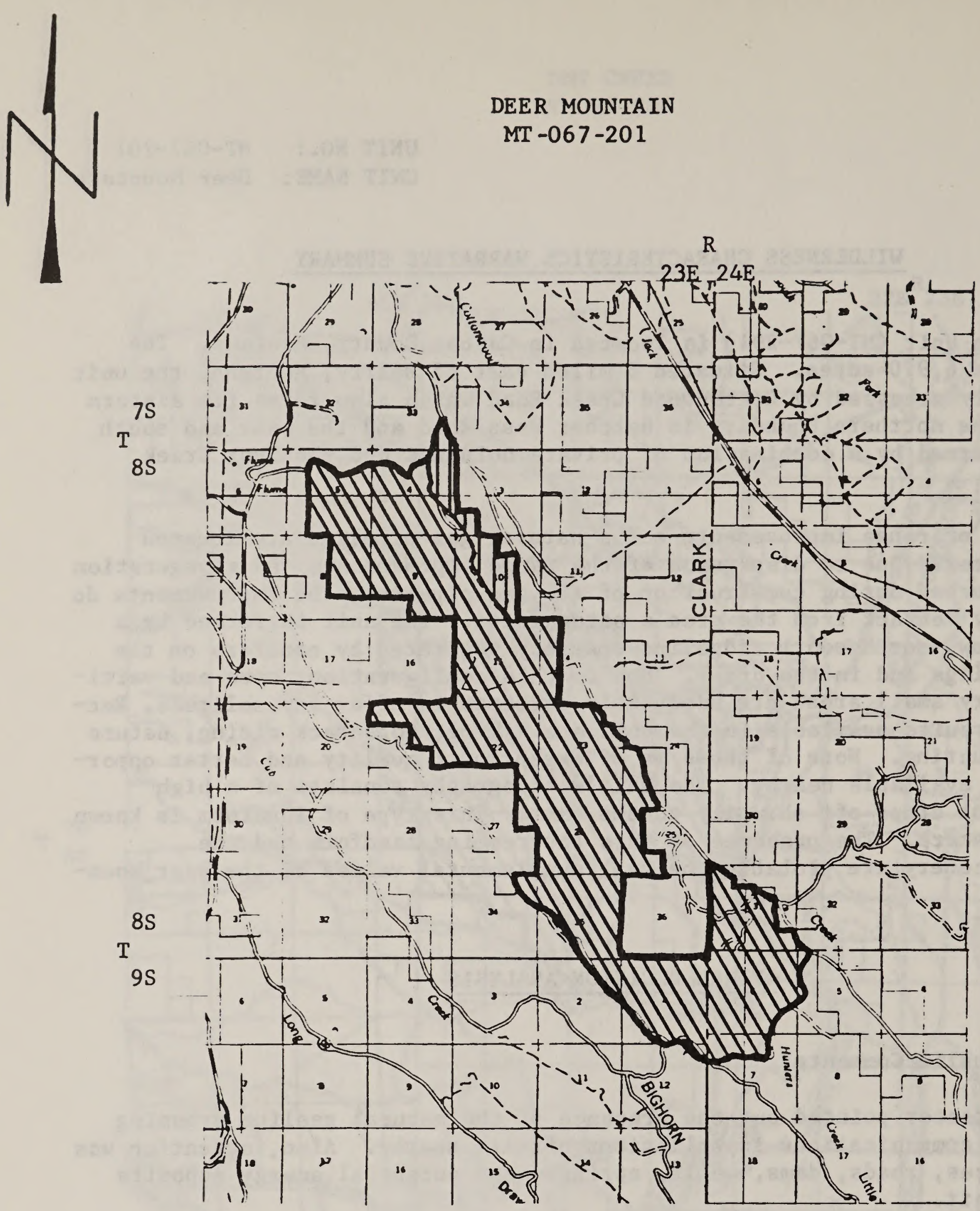

SCALE $1: 126,720$

$\frac{1}{2}$ inch $=1$ mile

\section{LEGEND}

W UNIT OR PORTION OF UNIT LACKING WILDERNESS CHARACTERISTICS (NOT RECOMMENDED AS WSA)

AREA DELETED FROM ORIGINAL INVENTORY UNIT DUE TO ROAD IDENTIFICATION

AREA ADDED DUE TO ROAD IDENTIFICATION

PRIVATE OR STATE INHOLDINGS 
UNIT NO.: $\quad$ MT-067-204

UNIT NAME: Bear Creek

\section{WILDERNESS CHARACTERISTICS NARRATIVE SUMMARY}

Bear Creek Unit (MT-067-204) is located in Carbon County, Montana, and Bighorn County, Wyoming. The unit contains 9,500 acres. The area is bounded by Bear Canyon Road on the north, Gyp Springs Road on the east, Blue Wash Road on the west, and by Lewis Road on the south. From flat prairie on the west and north, Bear Creek rises to low bentonite domes and ridges in the center section. The only vegetation in the unit is sparse range grasses, sagebrush, and scrub timber. The unit is heavily impacted by bentonite mining in its west half to such a degree that the western portion does not appear natural. Only the rougher central and southern sections appear natural. Likewise, the heavy developmental work, the unvaried topography, and lack of vegetative screening preclude a sense of solitude within the area. No outstanding opportunities for nonmotorized recreation are to be found in this barren, open area. The prehistoric carvings on the cliffs of Petroglyph Canyon are the only noteworthy resource in the area except, of course, the bentonite deposits.

\section{FINAL DECISION ANALYSIS}

Summary of Public Comment:

No substantive comments were received.

Final Decision and Rationale:

This unit will not be further studied for wilderness. Unvaried topography, lack of vegetative screening, and extensive, active bentonite mining make for flawed natural appearance and few opportunities for solitude. No outstanding opportunities for primitive recreation exist in the unit. 


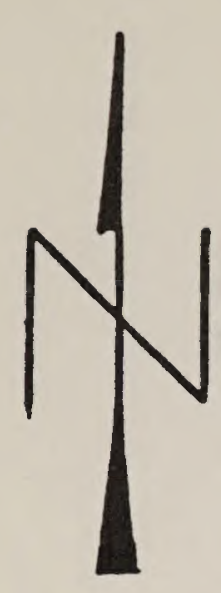

BEAR CREEK

$M T-067-204$

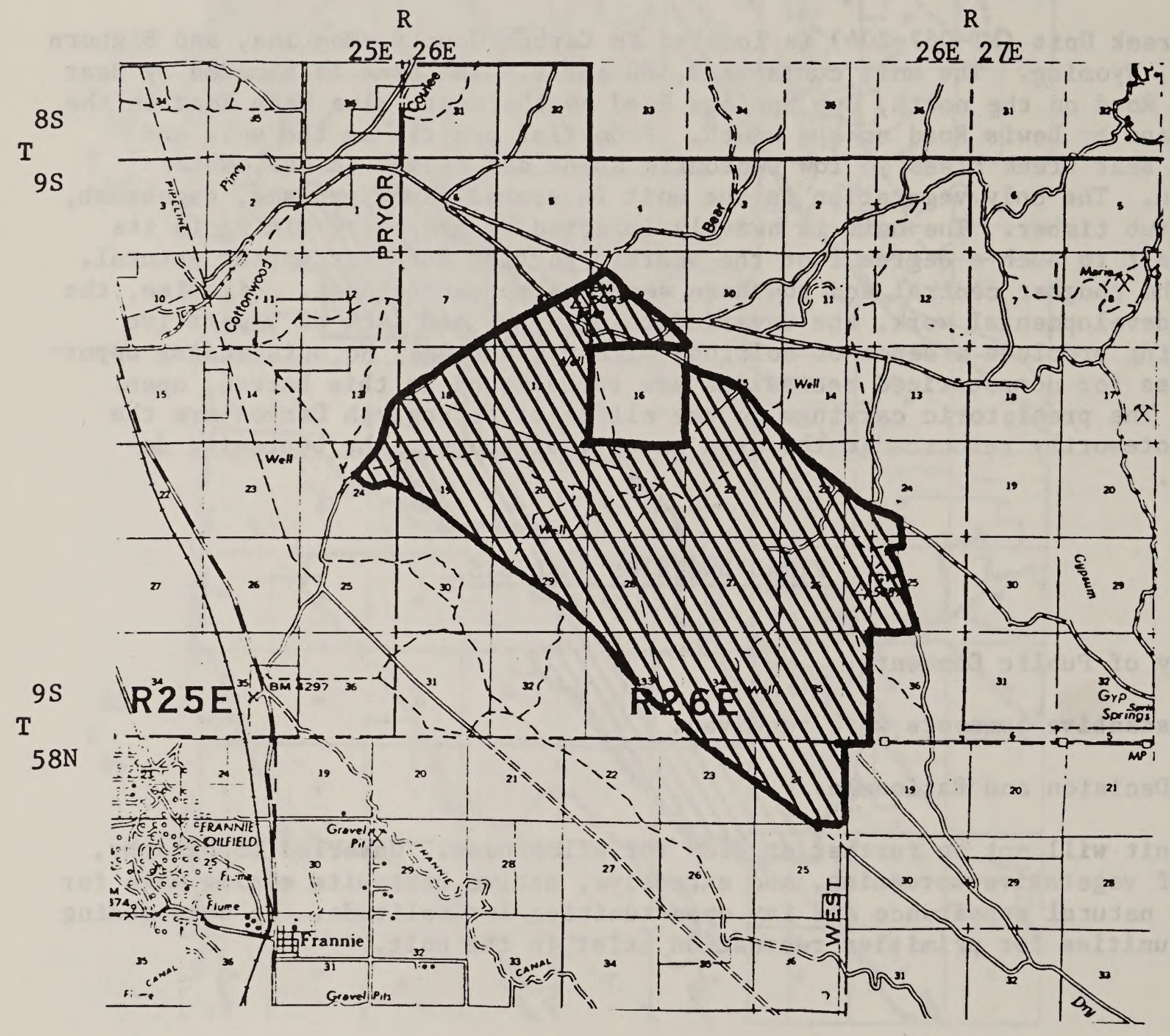

SCALE 1:126,720

z inch $=1$ mile
MIIV
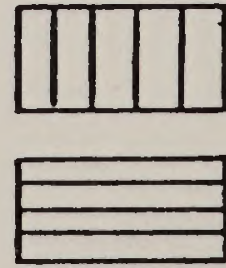

\section{LEGEND \\ UNIT OR PORTION OF UNIT LACKING WILDERNESS CHARACTERISTICS (NOT RECOMMENDED AS WSA)}

AREA DELETED FROM ORIGINAL INVENTORY UNIT DUE TO ROAD IDENTIFICATION

AREA ADDED DUE TO ROAD IDENTIFICATION

PRIVATE OR STATE INHOLDINGS 
UNIT NO.: $\quad$ MT-067-205

UNIT NAME: Burnt Timber Canyon

\section{WILDERNESS CHARACTERISTICS NARRATIVE SUMMARY}

Burnt Timber Canyon Unit (MT-067-205) is located in Carbon County, Montana, and Bighorn County, Wyoming. The area is bounded by maintained roads and private land on the east, west and south and by U.S. Forest Service land to the north. The area is adjacent to the Forest Service recommended RARE II Area 1-362, Lost Water Canyon. In consultations with the Forest Service it was decided that the Lost Water Canyon Unit could stand on its own values and would not be augmented by addition of this BLM area.

Bisected by the deep, sculptured Burnt Timber Canyon, the unit contains rugged topography and colorful rock formations. Heavy Douglas fir vegetation is found in the canyon bottoms and Mountain Mahogany, Scrub Juniper and sage is scattered throughout the rest of the area.

The unit has been used primarily for uranium mining, livestock grazing and as a wild horse preserve. As a result of this activity the unit contains a water saver, an exclosure, a horse trap, a number of uranium test pits especially on the northwest side, approximately 7 miles of vehicle ways, 3 miles of fence, a developed spring and 4 identified roads.

One road services a water saver in T. 9 S., R. 27 E., Section 13. One road enters into the open bench on the northwest side. The other 2 roads cutoff portions of the unit; one removes 280 acres from the southeast arm of the area and the other cuts the unit in half.

With an exclosure, numerous uranium prospecting pits, and identified road all found on a gently downsloping, unforested bench, the Demijohn Flat on the northwest side does not appear natural. Neither does the southern tip of the unit into Wyoming contain natural values. This acreage, a narrow 1 mile wide strip, is heavily impacted by the agricultural activities of the adjoining private land that fences both sides. The southern portion of the strip is used as a garbage dump.

Given the portions of the area which are not natural in appearance, and the road situation as previously described, the area is composed of two subsections of approximately 4,600 acres in the north and 4,750 acres in the south. As both of these are less than the 5,000 acres found in the 1964 Wilderness Act, as the wilderness values are not exceptional, and as the weight of public opinion does not support the area, the area will not be further studied for wilderness. 
Within the Crooked Creek and Burnt Timber Canyon, solitude is excellent, although if there were more than 2 or 3 parties present the narrow confines of these drainages would tend to increase the chances of meeting. Elsewhere, the low lying and forest vegetation and broken terrain would supply outstanding solitude.

Archeological sightseeing, caving opportunities, hunting and fishing, horseback riding, hiking and nature study including wild horse viewing are all possible within the unit. The combination of these activities makes for an outstanding opportunity for recreation.

Supplemental values includes rich geological formations including those carrying fossilized deposits, wild horses and spectacular scenery.

FINAL DECISION ANALYSIS

Summary of Public Comments:

A single comment pointed out the proximity of the Tillett ranch as an intrusion the area's potential for uranium exploration and an existing $4 \mathrm{WD}$ trail.

Final Decision at Rationale:

This unit will not be further studied for wilderness. The combination of a dividing raod and extensive areas of unnatural land make for less than 5,000 acres of wilderness value land. The unit does contain outstanding opportunities for primitive recreation and solitude. 
UNIT NO.: MT-067-210

UNIT NAME: Yellows tone Islands

\section{WILDERNESS CHARACTERISTICS NARRATIVE SUMMARY}

The nine Yellowstone Islands Unit (MT-067-210) are located in Sweet Grass, Stillwater, and Yellowstone Counties, Montana. The islands range from 6 to 96 acres in size.

Most islands are essentially in a natural condition. Typically, the western islands are vegetated with old growth willow with an understory of shrubs and grasses. As one progresses east, cottonwoods predominate, but willows, thick shrubs and even open meadows of range grasses are found. Due to extensive developments along the river banks, and the islands' small size, a sense of isolation from the works of man is impossible to find. Interstate highway 90 and a main line of the Northern Pacific Railroad both parallel the river. There is extensive agricultural development and residential housing immediately adjacent to most islands. None of the possible recreational activities are unique to the islands and, in fact, similar or better opportunities are found elsewhere along the river shoreline. Other than views of some of the region's major mountain ranges, no supplementary values were noted during inventory.

\section{FINAL DECISION ANALYSIS}

Summary of Public Comment:

The only input agreed that the islands do not meet wilderness study area criteria but felt that critical wildlife habitat on the islands should be protected.

Final Decison and Rationale:

Although essentially natural, major transportation lines, agricultural development, and human habitation immediately adjacent across the river limit solitude. There are no outstanding recreational opportunities. 


$$
\begin{aligned}
& \text { UNIT NO.: } \frac{\frac{\text { MT-067-211 }}{\text { MT-068-217 }}}{\text { UNIT NAME: The Big Snowies }} \frac{\text { Tack-ons }}{\text { Then }}
\end{aligned}
$$

\section{WILDERNESS CHARACTERISTICS NARRATIVE SUMMARY}

The Big Snowies Tack-ons, units number MT-067-211 and MT-068-217, are nine parcels of land adjacent to the Big Snowies in the Lewis and Clark National Forest. The nine parcels are located in Golden Valley and Fergus Counties, and contain a total of 1,725 acres. These areas are all considerably less than 5,000 acres, but meet the size criteria in conjunction with the larger Big Snowies Wilderness Study Area - RARE II-1-739.

Logging activities have adversely affected naturalness on five units. There are signs of man's former presence in these units in the form of vehicle trails originally used as haul roads, remaining stumps and some cut slash material. The presence of heavily traveled county roads on the borders of four units limit opportunities for solitude. In these units the downsloping topography combined with the small size maximizes the effects of these offsite intrusions. Four units do contain some opportunities for solitude but it is not of outstanding quality and does not add to the opportunities for solitude available in the Forest Service Wilderness Study Area.

Hiking, primitive camping, nature study, rock scrambling, hunting, ski touring, and geologic study are all possible forms of recreation found in the units. Small size and difficult terrain limit the scope or number of the above activities available in a particular unit. None of the units offer an outstanding opportunity for primitive and unconfined recreation.

Other than scenery and an unusual stand of Englemann spruce in one unit, no other supplemental features are known to exist.

\section{FINAL DECISION ANALYSIS}

Summary of Public Comments:

No substantive comments were received.

Final Decision and Rationale:

These units will not be further studied for wilderness. Because these units do not offer outstanding opportunities for solitude or primitive recreation, and add nothing to the wilderness values of the RARE II area, they do not meet the criteria for study. 


\section{BIG SNOWIES TACK-ONS \\ MT -068-217 \\ MT $-067-211$}

$\mathrm{R}$

R

17E 18E

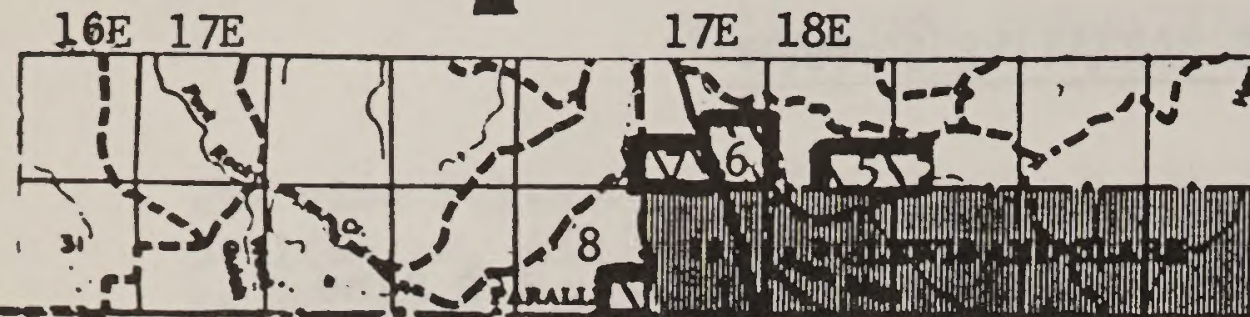

R

$18 \mathrm{E} \quad 19 \mathrm{E}$

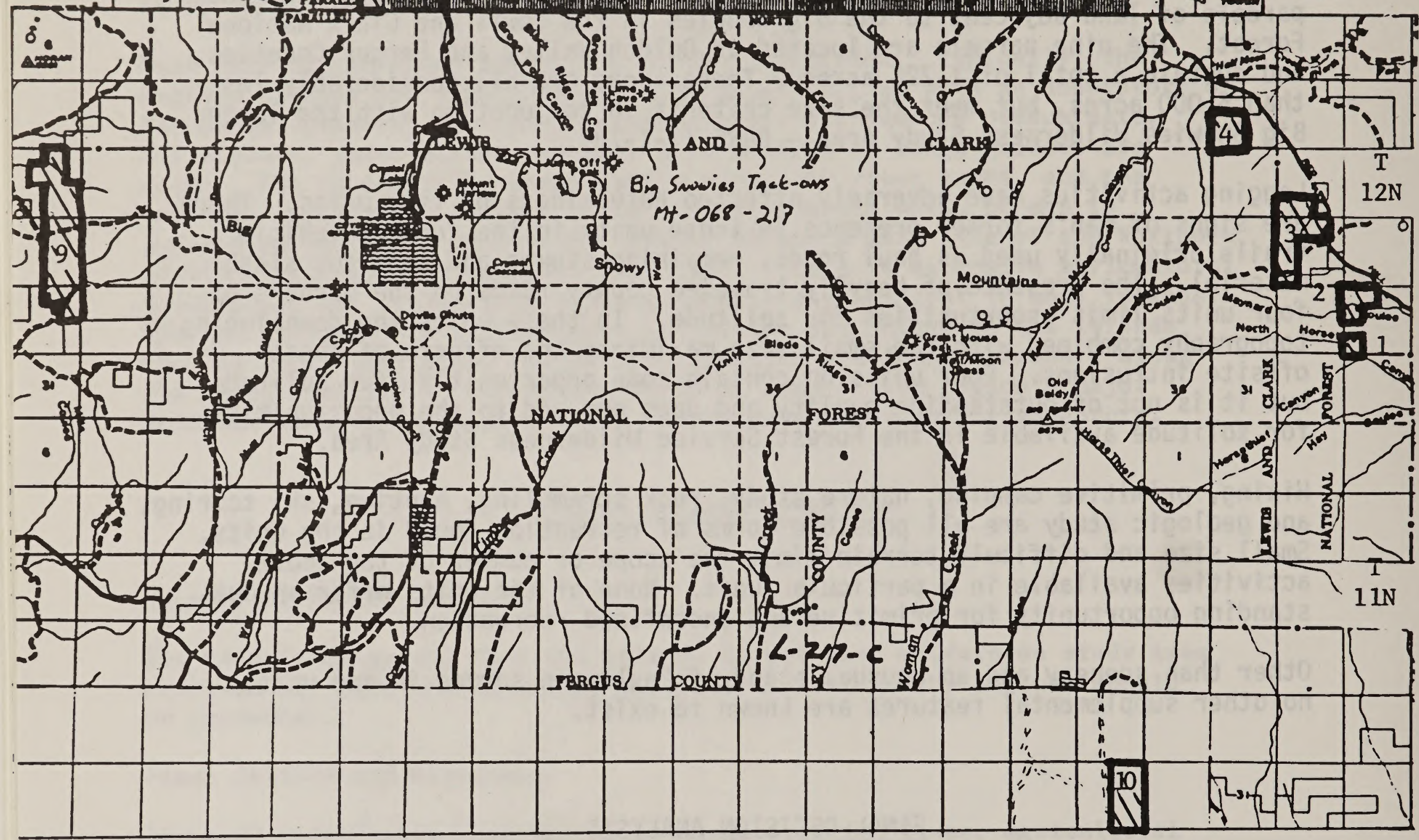

IEGEND

SCAIE $1: 126,720$

b inch $=1$ mile
MIIV
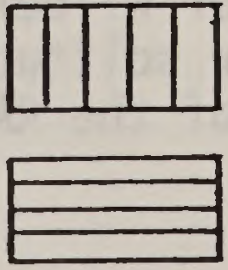

mow

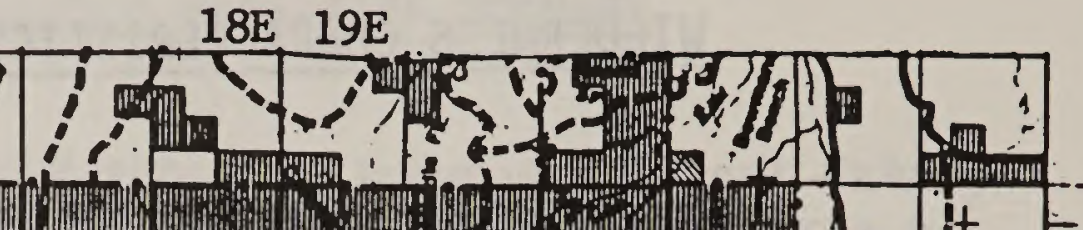
it $=\mathrm{T}$ $13 \mathrm{~N}$ 
UNIT NO.: MT-068-216

UNIT NAME: Middle Fork of

Judith Tack-on

\section{WILDERNESS CHARACTERISTICS NARRATIVE SUMMARY}

The Middle Fork of Judith Tack-on Unit (MT-068-216) is located in Judith Basin County, Montana. The area is situated about 12 miles southwest of Utica, Montana, on the eastern edge of the Lewis and Clark National Forest. The total acreage is 145.13 acres.

This unit was withdrawn to the Fish and Wildlife Service by Public Land Order 962 dated May 14, 1954. The land was withdrawn for use by the Montana Department of Fish, Wildlife and Parks in connection with the Judith River Game Range. As such, it is not subject to wilderness review under Section 603 of the Federal Land Policy and Management Act.

\section{FINAL DECISION ANALYSIS}

Summary of Public Comments:

No substantive comments were received.

Final Decision and Rationale:

As the land is withdrawn for use by the Judith Game Range, this parcel will not be further studied for wilderness. 
MIDDLE FORK OF THE JUDITH TACK -ON

MT -068-216

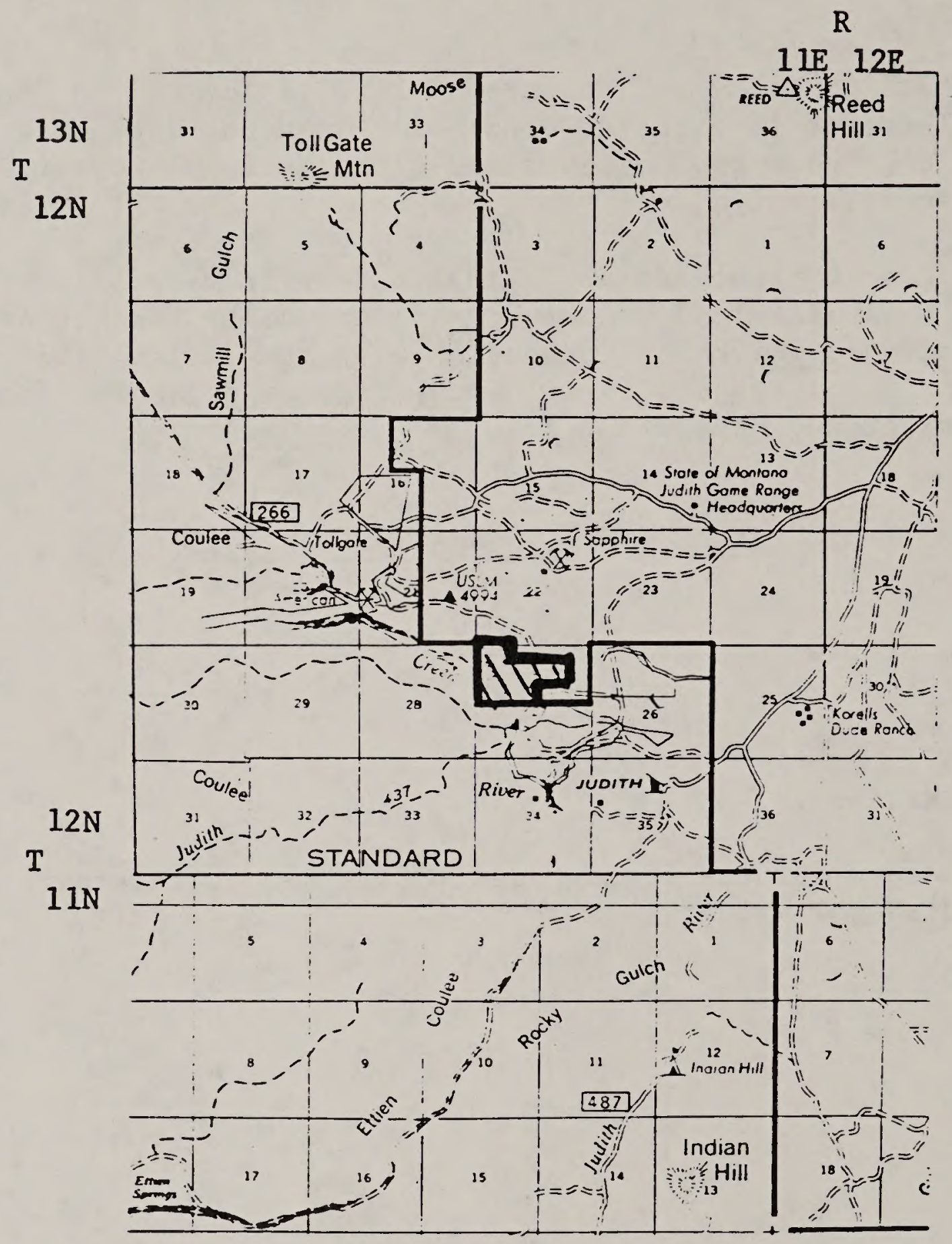

SCALE $1: 126,720$

$\frac{1}{2}$ inch $=1$ mile

MIIV
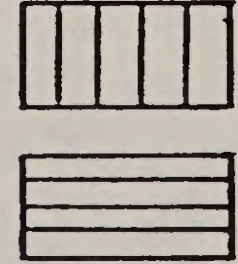

\%om

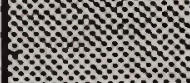

\section{LEGEND}

UNIT OR PORTION OF UNIT IACKING WILDERNESS CHARACTERISTICS (NOT RECOMMENDED AS WSA)

AREA DELETED FROM ORIGINAL INVENTORY UNIT DUE TO ROAD IDENTIFICATION

AREA ADDED DUE TO ROAD IDENTIFICATION

PRIVATE OR STATE INHOLDINGS 


\author{
UNIT NO.: $\quad$ MT-068-221 \\ MT-068-222 \\ UNIT NAME: Cottonwood Creek - \\ West Cottonwood Creek
}

\title{
WILDERNESS CHARACTERISTICS NARRATIVE SUMMARY
}

Cottonwood Creek - West Cottonwood Creek Units (MT-068-221 and 222), are combined because they were separated in error on the situation evaluation documents. Originally, there were 13,000 acres within the unit's boundaries. This acreage was decreased to 12,650 acres by the identification of a road in the southeast corner. The unit is composed of the broad bottom and side drainages of Cottonwood Creek. Ridges are topped with trees, but the flat bottoms and upland areas are open and vegetated with grasses and sage.

Due to remnants of early developments, reservoirs, other range improvements, heavy grazing and a large number of vehicular ways, the land is segregated and many parts of the unit do not appeár natural. However, about 5,000 acres of undeveloped land in the northern part of the unit is natural. Intensive farming activities right up to the border of the unit will impact solitude. The broad, open valley which makes up much of the unit is also not conducive to solitude. The more vegetated and rolling side drainages and ridges offer no more than marginal opportunities for isolation. This same topography limits the enjoyment of activies such as hiking, camping, horseback riding and nature study. As a hunting area, opportunities are similar to much of the Musselshell Breaks, but extensive grazing in this unit creates some pressure on wildlife, and decreases the quality of the hunting opportunity. Other than some remnants from the homesteading era, no supplemental values are known to exist in the area.

\section{FINAL DECISION ANALYSIS}

Summary of Public Comments:

No substantive comments were received.

Final Decision and Rationale:

This unit will not be further studied for wilderness. The only 5,000 acre block of the unit which retains its natural characteristics lacks opportunities for solitude and primitive recreation. The broad, open valley which makes up most of the unit along with intensive offsite agriculture precludes high-quality solitude. The few recreational opportunities are not of high quality. 


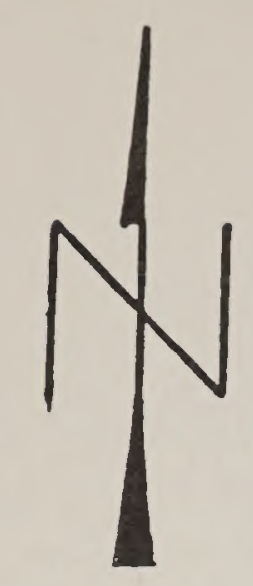

COTTONWOOD CREEK/WEST COTTONWOOD CREEK

MT $-068-221 / 222$

$\mathrm{R}$

28E 29E

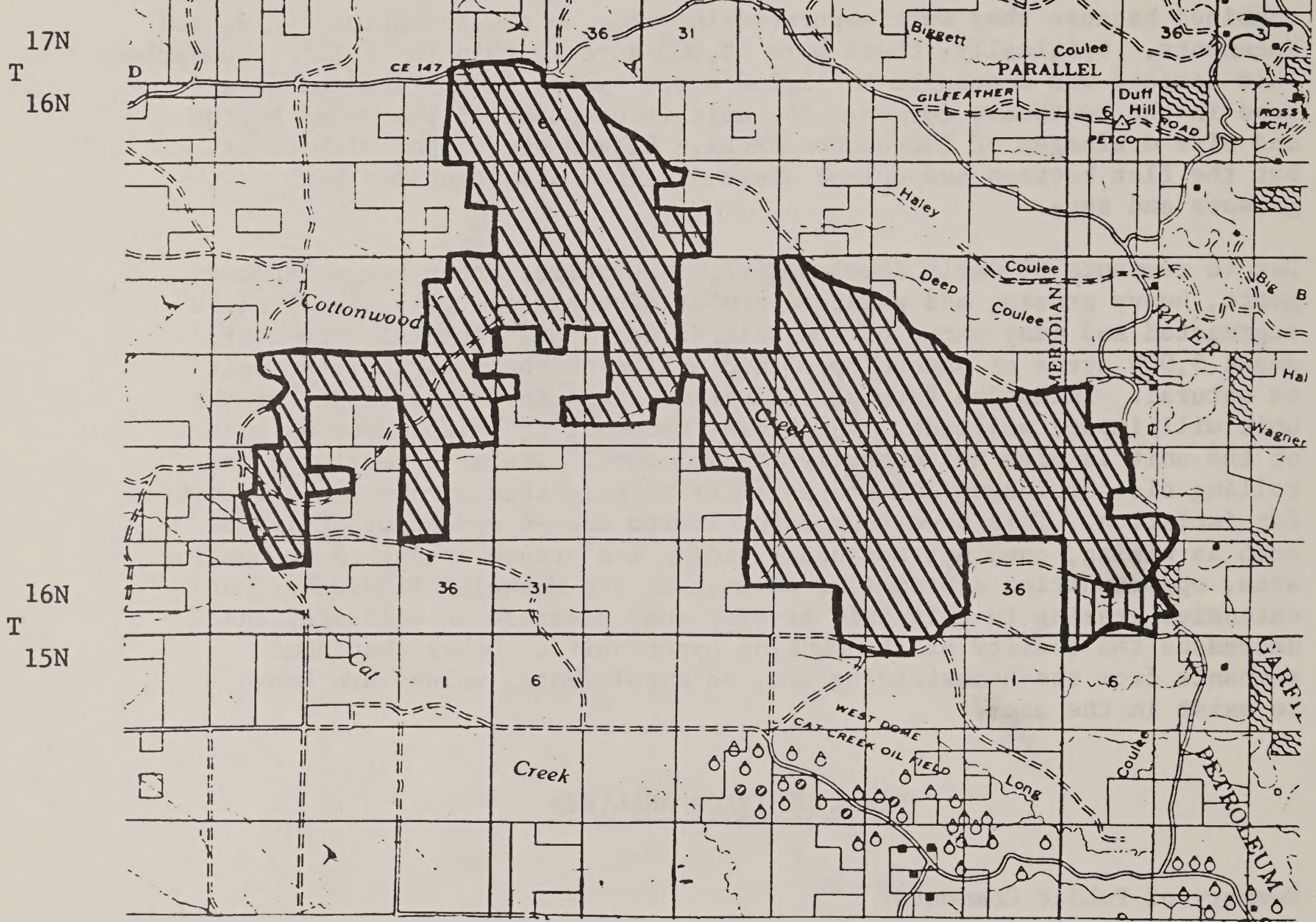

LEGEND

SCALE $1: 126,720$

l $\mathrm{inch}=1 \mathrm{mile}$

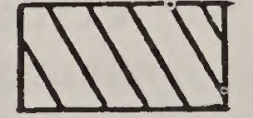

UNIT OR PORTION OF UNIT LACKING WILDERNESS CHARACTERISTICS (NOT RECOMMENDED AS WSA)

AREA DELETED FROM ORIGINAL INVENTORY UNIT DUE TO ROAD IDENTIFICATION

AREA ADDED DUE TO ROAD IDENTIFICATION

PRIVATE OR STATE INHOLDINGS 
UNIT NO.: $\quad$ MT-068-223

UNIT NAME: Blood Creek

\section{WILDERNESS CHARACTERISTICS NARRATIVE SUMMARY}

Blood Creek Unit (MT-068-223) is located 5 miles west of the Musselshell River and 17 miles northeast of Winnett, Montana. The unit originally totalled 20,100 acres, not including 940 acres of enclosed private land. This acreage is further divided by a $1 \frac{1}{2}$ mile strip of totally unnatural land straddling the Blood Creek drainage. The removal of the impacted land from the boundaries leaves two units, 4,300 acres to the north and 7,300 acres to the south.

The Blood Creek drainage which bisects the unit east-west is a broad, flat valley filled with roads, range improvements, a homestead, and expansive plantings of non-native crested wheat, such that it appears unnatural. Elsewhere, scattered range improvements and vehicle trails are adequately screened such that they don't create a major impact on naturalness. The only exception is an area of contour furrowing in the south of the unit, which looks quite unnatural. North of Blood Creek, steep, forested terrain permits pockets of solitude. The complex border and enclosed private land in the southern parcel, when added to the rolling terrain and scattered vegetation patterns, does not allow for outstanding solitude opportunities. Hunting, nature study, especially of raptor populations, hiking and camping are all possible activities in the area. However, no outstanding opportunities for these activities were noted. Two homesteads and the expansive scenery were the only supplemental values known in the area.

\section{FINAL DECISION ANALYSIS}

Summary of Public Comments:

The sole response indicated the presence of LU lands, dams, fences, roads, surrounding private land and irregular boundaries which preclude wilderness consideration.

Final Decision and Rationale:

This unit will not be further studied for wilderness. Much of the unit appears natural, however, the broad, open terrain, scattered vegetation patterns and complex border preclude outstanding solitude. No outstanding varieties or opportunities for primitive recreation exist in the area. 


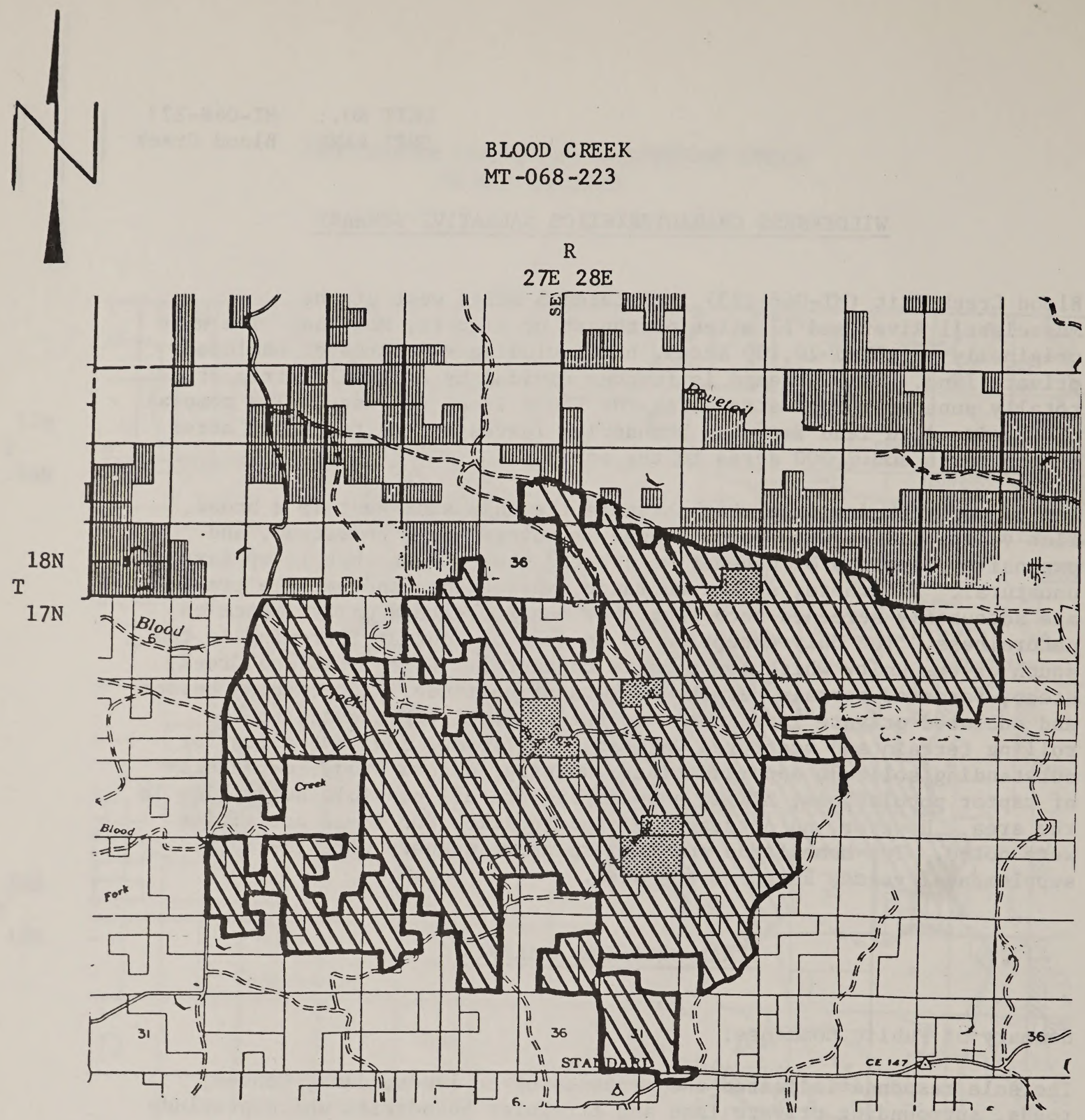

LEGEND

SCAIE $1: 126,720$

$\frac{1}{2}$ inch $=1$ mile
MIIV
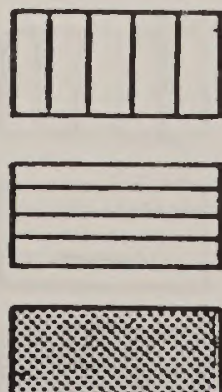

UNIT OR PORTION OF UNIT LACKING WILDERNESS CHARACTERISTICS (NOT RECOMMENDED AS WSA)

AREA DELETED FROM ORIGINAL INVENTORY UNIT DUE TO ROAD IDENTIFICATION

AREA ADDED DUE TO ROAD IDENTIFICATION

PRIVATE OR STATE INHOLDINGS 
UNIT NO.: $\quad$ MT-068-224

UNIT NAME: Dovetail Creek

\section{WILDERNESS CHARACTERISTICS NARRATIVE SUMMARY}

Dovetail Creek Unit (MT-068-224) is located in Petroleum County, Montana. The unit is located south of the Missouri River and west of the Musselshell River. The total unit's size is approximately 24,380 acres.

This is a large unit, open and lightly rolling to the west, and more forested and rugged closer to the Musselshell River. Roads have divided the area into four subunits. The entire area is basically in a natural condition, with assorted vehicle trails and range improvements adequately scattered or screened such that they are of minor impact. The rolling topography, vegetation patterns, and effects of forest fire preclude a high degree of isolation. Pockets of solitude are found in the far northern portion of the north subunit, aided by forest vegetation and "breaks" topography, but these pockets are so scattered as to not constitute an outstanding solitude opportunity. Although hunting, hiking, and horseback riding are all possible recreational activities, the area's lack of scenery, other supplemental values and, for the most part, minimal variety preclude an exceptional experience. Fossil collecting on the higher ridges may be good. Supplemental interest is limited to two homestead sites.

\section{FINAL DECISION ANALYSIS}

Summary of Public Comments:

The received comments stated that the opportunity for solitude in the unit was poor due to enclosed LU land, vehicle way easement, irregular boundary and contiguous private land activities.

Final Decision and Rationale:

This unit will not be further studied for wilderness. Although most of the unit is natural, roads divide it up into four subsections. These individual subunits lack outstanding solitude due to rolling topography and limiting vegetation patterns. The area's lack of scenery and minimal variety preclude an outstanding recreational experience. 
1

DOVETAIL CREEK

MT-068-224

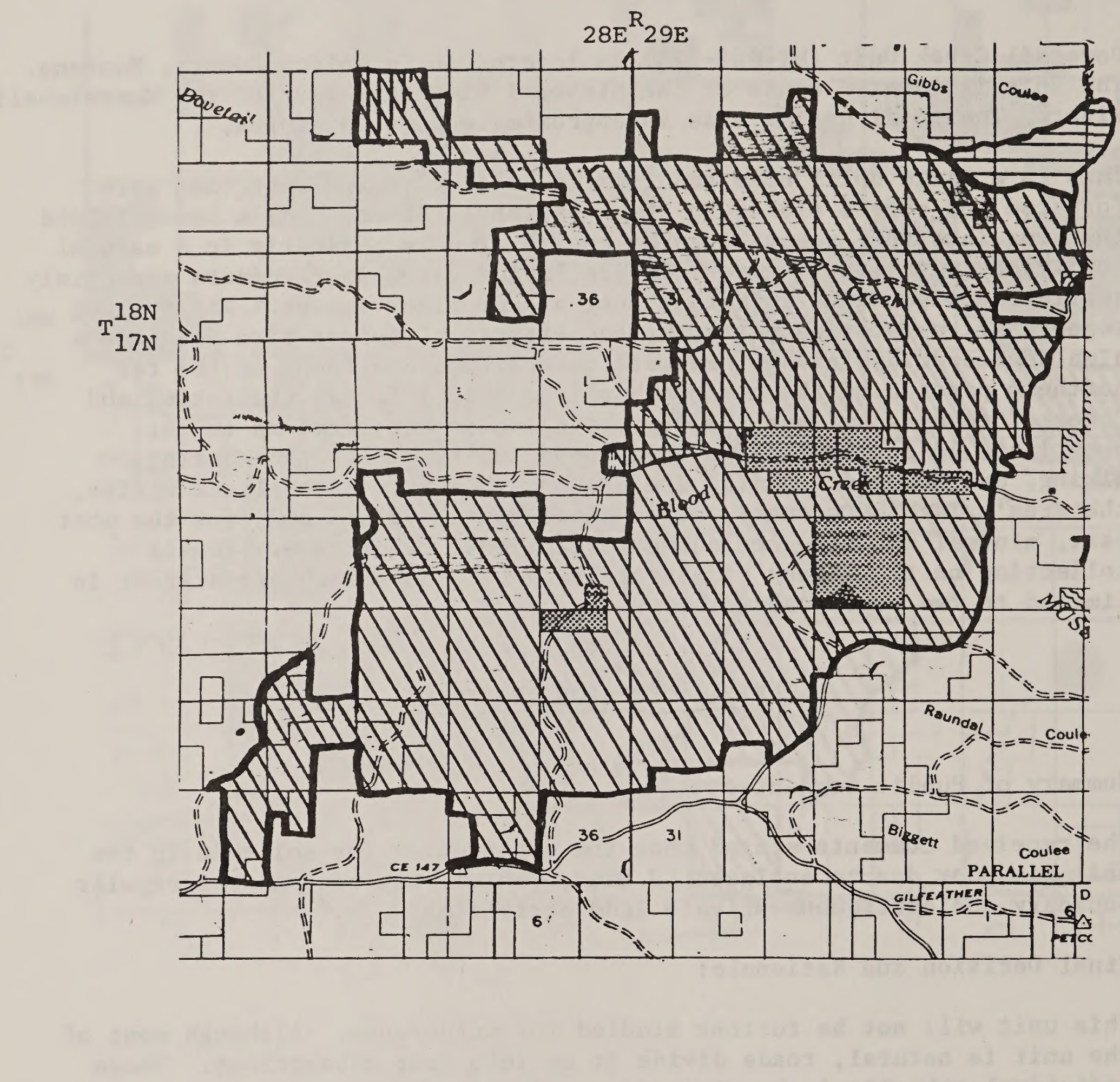

LEGEND

SCALE $1: 126,720$

$\frac{1}{2}$ inch $=1$ mile
MIIV
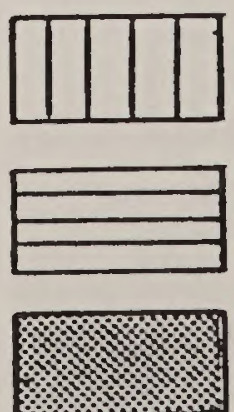

UNIT OR PORTION OF UNIT LACKING WILDERNESS CHARACTERISTICS (NOT RECOMMENDED AS WSA)

AREA DELETED FROM ORIGINAL INVENTORY UNIT DUE TO ROAD IDENTIFICATION

AREA ADDED DUE TO ROAD IDENTIFICATION PRIVATE OR STATE INHOLDINGS 
UNIT NO.: $\quad$ MT-068-225

UNIT NAME: Arrow Creek

\section{WILDERNESS CHARACTERISTICS NARRATIVE SUMMARY}

Arrow Creek Unit (MT-068-225) is located in Fergus County, Montana. The area contains approximately 9,100 acres and is situated about 20 miles north of Stanford on Montana Route 80. The unit is a long, narrow strip of public land, 10 miles in length and bordered by private land.

Throughout much of Arrow Creek, one is confronted with signs of man's works. In some of the deeper drainages, where it was too steep for range improvements or vehicular trails, the area does remain natural. Opportunities for solitude are limited in this unit. The long, narrow configuration is such that it is impossible to isolate oneself from outside influences in a majority of the unit. The State highway and the Milwaukee Railroad follow the northern border for half the unit's length. The sights and sounds of these developments are constant reminders of man's presence. The unit's boundaries are step-shaped, and fingers of private land constantly separate blocks of public land. In this type of configuration, with an extensive farming operation on the private land, it is difficult to screen oneself from these impacts. Opportunities for solitude are few and not outstanding. Opportunities for hiking and camping exist in the unit, but as the scenery is not exemplary, and no special supplemental values are present in the unit, a motive for such activities is lacking. Hunting for deer and upland game birds is probably the best recreational opportunity in the Arrow Creek area. These hunting opportunities, while good, are similar to opportunities throughout this part of Montana, and are not outstanding for the unit itself.

The only known supplemental value is historical. A vehicular way through the center of the unit was used at one time as a stage route from Fort Benton to Stanford.

\section{FINAL DECISION ANALYSIS}

Summary of Public Comments:

The sole input supported wilderness study as the offsite influences are not that intrusive or are compatible with wilderness and the opportunities for solitude and quality wildife habitat were good.

Final Decision and Rationale:

This unit will not be further studied for wilderness. Only in the deeper drainages is this unit natural. Opportunities for solitude are limited by the long, narrow configuration, major offsite impacts and marginal vegetative screening. Recreational opportunities are in no way exceptional. 
UNIT NO.: $\quad$ MT-068-227

UNIT NAME: Arme11's Creek

\section{WILDERNESS CHARACTERISTICS NARRATIVE SUMMARY}

Arme11's Creek Unit (MT-068-227) is located 10 miles south of the Missouri River and 18 miles east of Winifred, Fergus County, Montana. The area is bounded on all sides by private land and State administered land. This unit contains approximately 18,750 acres, not including 640 acres of private inholdings.

Armell's Creek follows the path of three creeks and includes the drainage bottoms and timbered ridges on either side. The topography is rougher and more heavily wooded on the east than the west side of the unit.

The area is presently used primarily for livestock grazing and hunting. Livestock management needs have resulted in the construction of seven reservoirs, several fire rehabilitation reseeding spots, ten miles of fence, and a water well on an enclave of private land. There are also seven identified roads which effectively fragment the unit. Two of these roads access parcels of private land in T. 21 N., R. 22 E., Sec. 19 and 20 and T. 21 N., R. 22 E., Sec. 23. One services a fence line in T. 21 N., R. 22 E., Sec. 28, 33, and 34. One leads to a stock tank in T. 21 N., R. 21 E., Sec. 25. The fifth road allows maintenance of a fence line in T. 21 N., R. 21 E., Sec. 25 and T. 21 N., R. 22 E., Sec. 30. The sixth road is primary access to a newly reconstructed reservoir in T. $21 \mathrm{~N} .$, R. $21 \mathrm{E}$, , Sec. 33. The final road is located in T. 20 N., R. 22 E., Sec. 5, 6, and 8 and accesses private buildings in the bottom of Armell's Creek. The identification of these roads divides the unit such that the largest portion is 4,600 acres, less than the 5,000 acre requirement in the 1964 Wilderness Act.

Much of the unit is natural in appearance. Scattered remains of the homestead era and a working ranch adversely affect solitude values in the western and southern portions of the unit. However, in most of the unit the range improvements are dispersed throughout, the private lands are undeveloped, and the unit's vegetative screening ensures an essentially natural appearance.

The northern and eastern portions of the area have outstanding pockets of solitude while the more open drainage patterns and minimal forest vegetation which characterize the southern, eastern, and western portions do not offer such opportunities.

The primary recreational activity, hunting, is not recognized as having any special game species or outstanding opportunities not available in many portions of Montana. Camping, hiking, nature study, horseback riding, and photography are possible but none are of outstanding quality.

Supplemental values include attractive "breaks" scenery and importance as a critical watershed. 
Summary of Public Comments:

One comment felt that the unit should not be further considered due to enclosed private land, proven gas resources, reduction of the area's tax base if the unit were designated wilderness, and present activity of man within the unit. The writer also pointed out stock dams, artesian wells, fences, and the use of the area by recreationists and the grazing district.

Final Decision and Rationale:

This unit will not be further studied for wilderness. The network of roads divide the unit into sectors, all of which are less than 5,000 acres. Neither the intrinsic values of the area nor the weight of public comment suffice to consider study of the parcels less than 5,000 acres. 
ARMELLS CREEK

MT-068-227

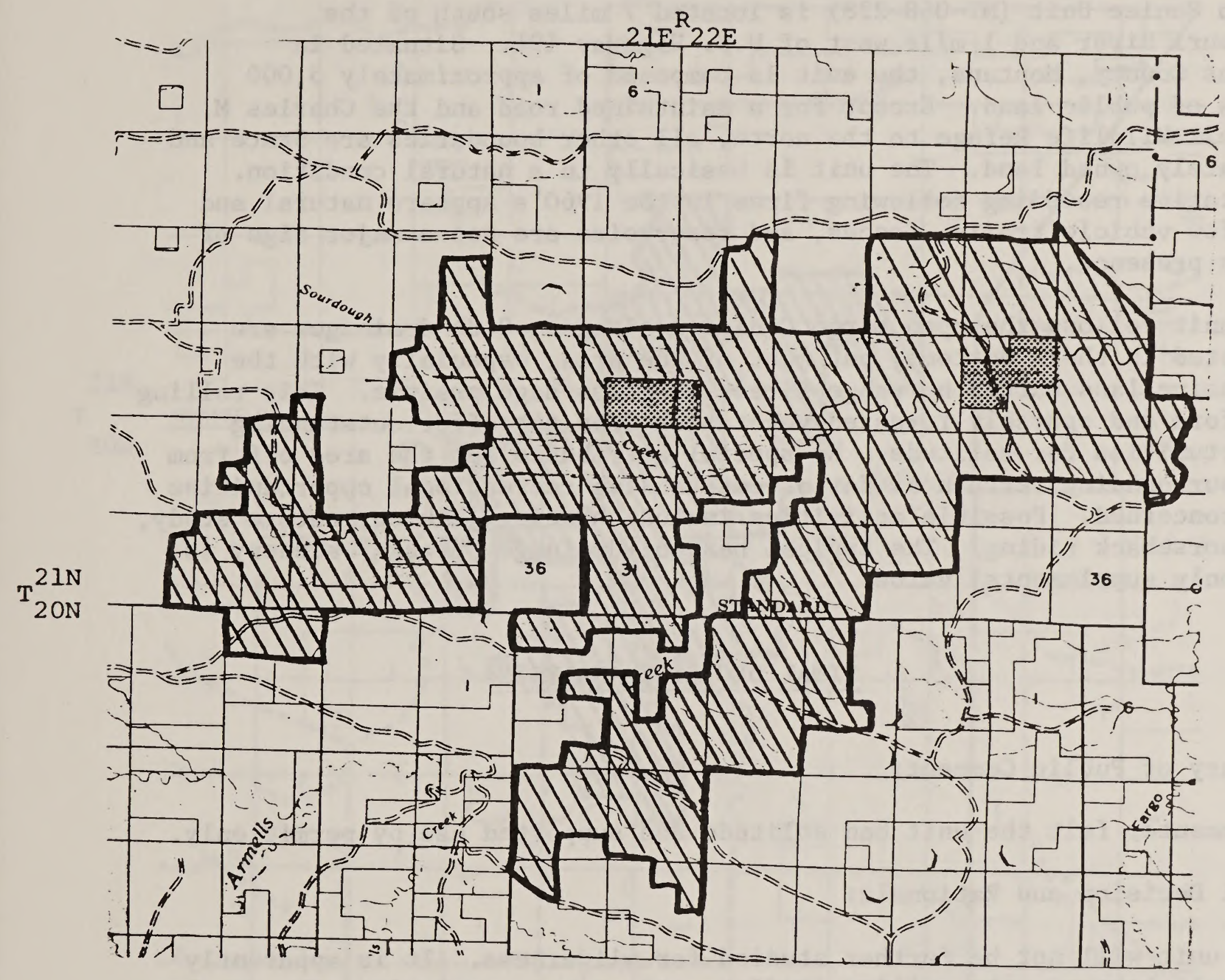

LEGEND

SCALE $1: 126,720$

inch $=1$ mile
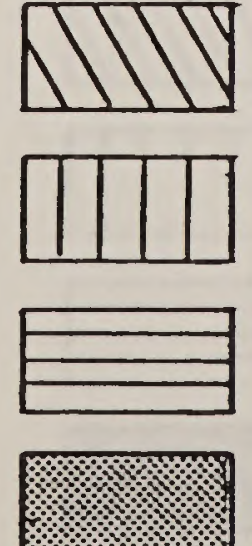
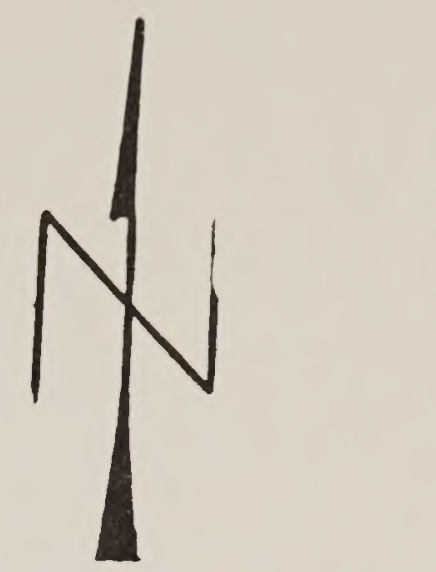
UNIT NO.: $\quad$ MT-068-228

UNIT NAME: Fargo Coulee

\section{WILDERNESS CHARACTERISTICS NARRATIVE SUMMARY}

Fargo Coulee Unit (MT-068-228) is located 7 miles south of the Missouri River and 1 mile west of U.S. Highway 191. Situated in Fergus County, Montana, the unit is composed of approximately 5,000 acres of public land. Except for a maintained road and the Charles M. Russell Wildlife Refuge to the north, all other boundaries are State and privately owned land. The unit is basically in a natural condition. Vegetative reseeding following fires in the 1960's appears natural and the few vehicle trails, fences, and reservoirs are not a major sign of man's presence.

The unit follows the open Fargo Coulee drainage. Side drainages are forested in their bottoms, but most of the area, especially with the extensive land burned by range fires, is grass-sage prairie. This rolling landform and sparsely forested vegetation does not offer outstanding opportunities for solitude. No special attributes set the area off from the surrounding terrain as far as outstanding recreational opportunities are concerned. Possible activities include hunting, hiking, nature study, and horseback riding. The typical head-of-drainage "breaks" scenery is the only supplemental value.

\section{FINAL DECISION ANALYSIS}

Summary of Public Comment:

A commenter felt the unit had solitude and supported use by permit only.

Final Decision and Rationale:

This unit will not be further studied for wilderness. It is apparently natural; however, the rolling landform and sparse vegetation, the result of a fire, offer less than outstanding solitude. No outstanding primitive recreation values exist in the unit. 
FARGO COULEE

MT $-068-228$

$\mathrm{R}$

22E $23 E$

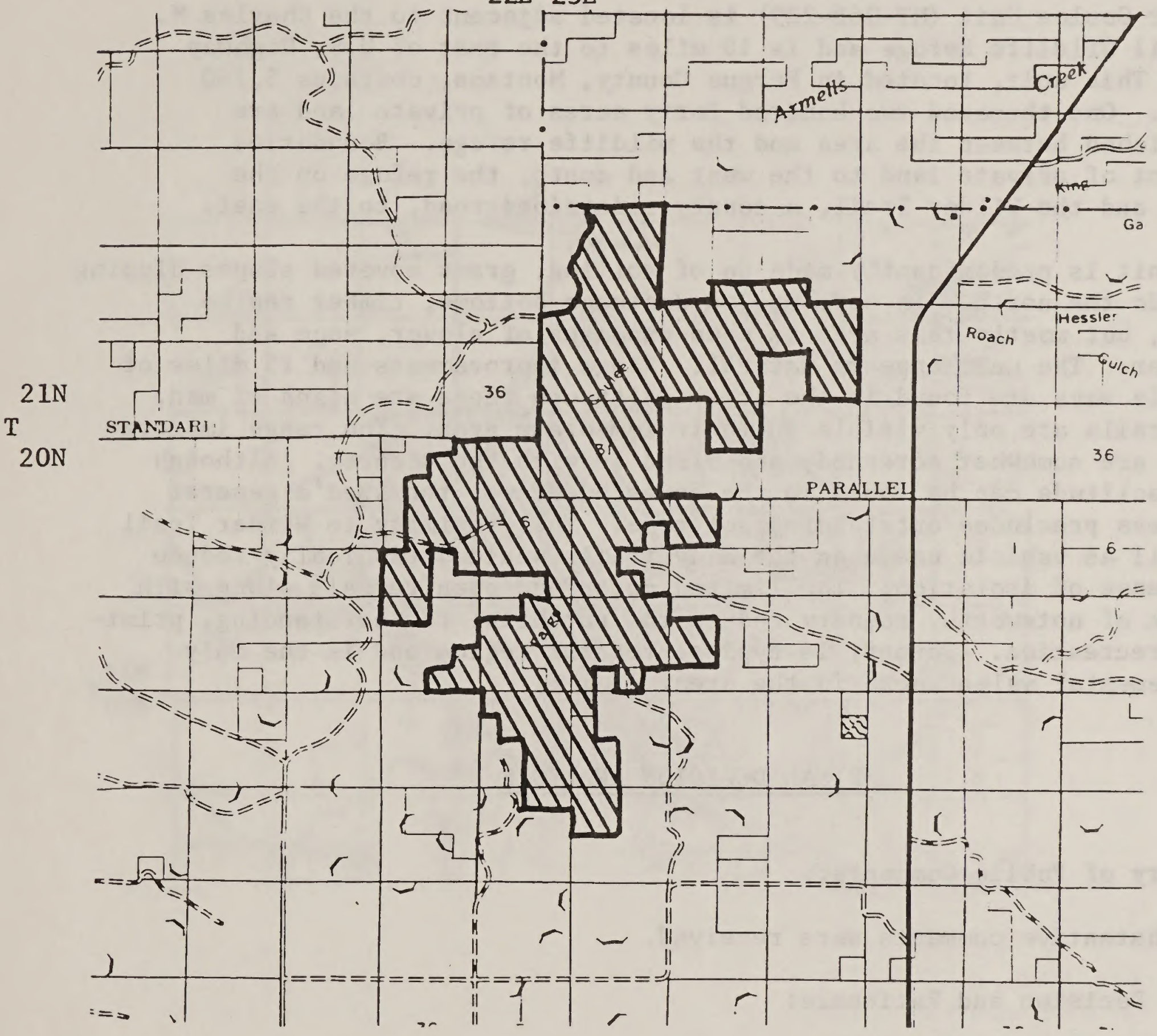

IEGEND

SCAIE $1: 126,720$

$\frac{1}{2}$ inch $=1 \mathrm{mile}$
MIIIV
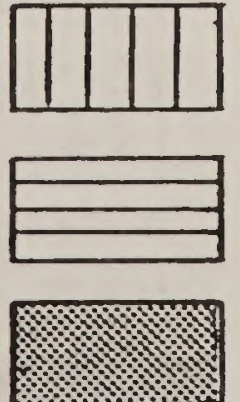

UNIT OR PORTION OF UNIT LACKING WILDERNESS CHARACTERISTICS (NOT RECOMMENDED AS WSA)

AREA DELETED FROM ORIGINAL INVENTORY UNIT DUE TO ROAD IDENTIFICATION

AREA ADDED DUE TO ROAD IDENTIFICATION

PRIVATE OR STATE INHOLDINGS 
UNIT NO.: $\quad$ MT-068-229

UNIT NAME: Carter Coulee

\section{WILDERNESS CHARACTERISTICS NARRATIVE SUMMARY}

Carter Coulee Unit (MT-068-229) is located adjacent to the Charles M. Russell Wildlife Refuge and is 10 miles to the east of U.S. Highway 191. This unit, located in Fergus County, Montana, contains 5,760 acres. One thousand two hundred forty acres of private land are sandwiched between the area and the wildlife refuge. Boundaries consist of private land to the west and south, the refuge on the north and the Wilder Trail, a county maintained road, to the east.

The unit is predominantly made up of rolling, grass covered slopes dipping towards the north. In more eroded drainage bottoms, timber can be found, but mostly this area is open expanses of clover, sage and juniper. The unit appears natural. Range improvements and 15 miles of vehicle ways are found in the area. Although these are signs of man, the trails are only visible in their immediate area. The range improvements are somewhat screened, and blend in with the scenery. Although some solitude can be found in the forested draws, the area's general openness precludes outstanding solitude. The proximity to Wilder Trail as well as vehicle usage on the many trails would periodically reduce the sense of isolation. The limited cover and open terrain along with a lack of noteworthy scenery reduce the potential for outstanding, primitive recreation. Scenery is typical for the region and is the only supplemental value known in the area.

\section{FINAL DECISION ANALYSIS}

Summary of Public Comments:

No substantive comments were received.

Final Decision and Rationale:

This unit will not be further studied for wilderness. Although it appears natural, the area's openness makes an outstanding solitude experience problematic. Primitive recreation possibilities are, likewise, less than outstanding. 
CARTER COULEE

MT-068-229

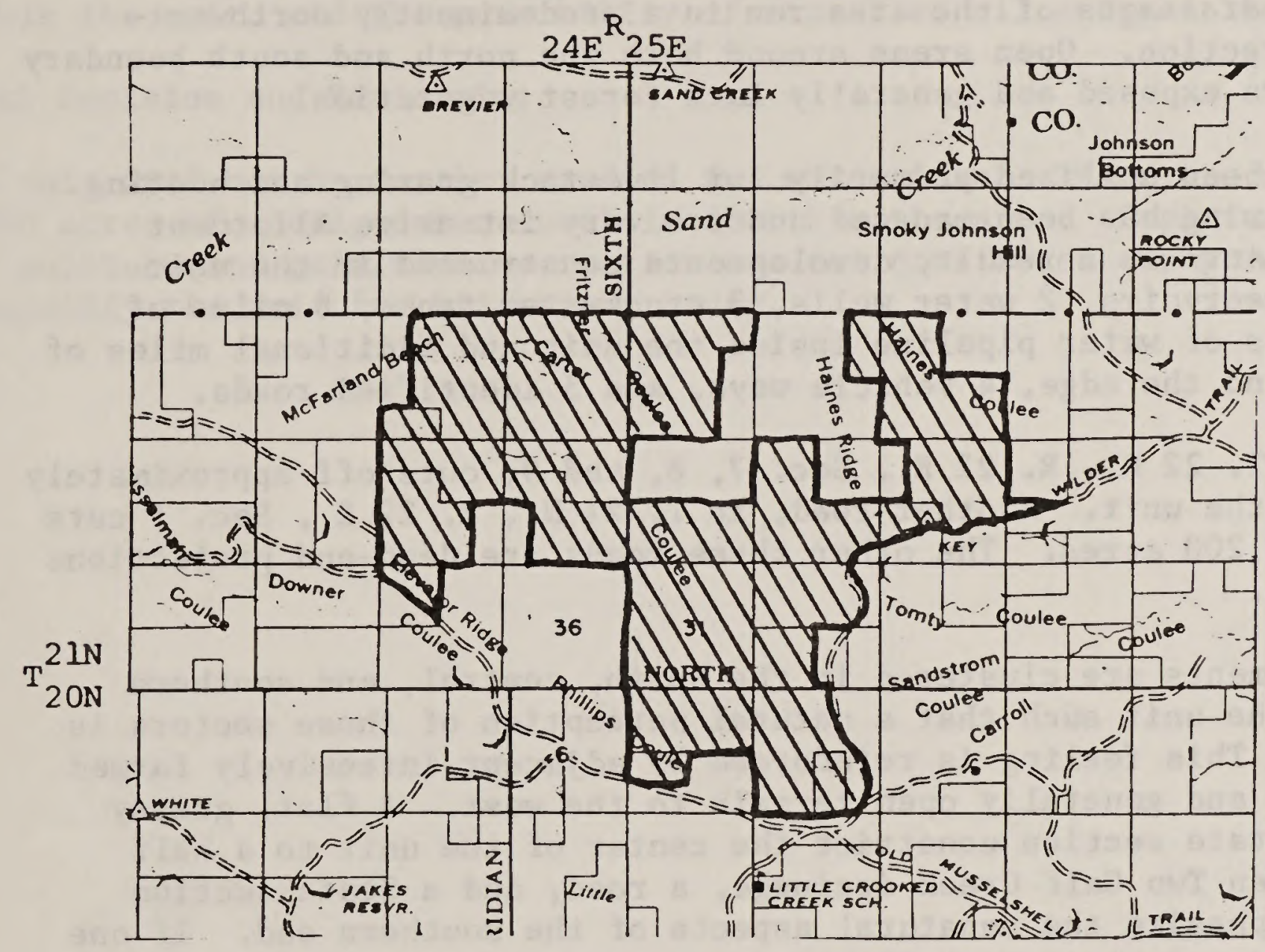

SCALE $1: 126,720$

$\frac{1}{2}$ inch $=1 \mathrm{mile}$
MIIV
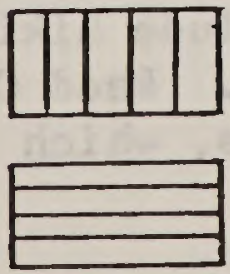

mo.

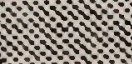

$\ldots$
LEGEND

UNIT OR PORTION OF UNIT LACKING WILDERNESS CHARACTERISTICS (NOT RECOMMENDED AS WSA)

AREA DELETED FROM ORTGINAL INVENTORY UNIT DUE TO ROAD IDENTIFICATION

AREA ADDED DUE TO ROAD IDENTIFICATION

PRIVATE OR STATE INHOLDINGS 
UNIT NO.: $\quad$ MT-068-232

UNIT NAME: Reed Coulee

\section{WILDERNESS CHARACTERISTICS NARRATIVE SUMMARY}

Reed Coulee Unit (MT-068-232) is located in Fergus County, Montana. It is surrounded by roads to the north and south, and by private land to the west. The eastern portion of the unit bounds the Charles M. Russell National Wildlife Refuge. The unit contains approximately 10,130 acres.

The forested drainages of the area run in a predominantly northwestsouthwest direction. Open areas around both the north and south boundary roads are more exposed and generally lack forest vegetation.

The area has been utilized primarily for livestock grazing and hunting. Livestock grazing has been managed under a very intensive Allotment Management Plan. As a result, developments constructed in the unit include 15 reservoirs, 2 water wells, 3 stockwater tanks, 6 miles of fence, 3 miles of water pipeline inside the unit and additional miles of pipeline around the edge, 4 vehicle ways, and 5 identified roads.

One road, in T. 22 N., R. 22 E., Sec. 7, 8, and 9, cuts off approximately 880 acres of the unit. Another road, in T. 21 N., R. 22 E., Sec. 1 cuts off a further 200 acres. The other three roads are dead-end projections into the unit.

These improvements are clustered in the north, central, and southern portions of the unit such that a natural perception of those sectors is compromised. This feeling is reinforced by adjacent intensively farmed private land, and generally open terrain to the west. A flat, grassy bench and a State section constrict the center of the unit to a half mile. The open Two Calf Creek drainage, a road, and a State section combine to emphasize the unnatural aspects of the southern end. If one draws boundaries to remove those unnatural lands the end result is 2 parcels of approximately 4,000 acres, and 2,000 acres, both less than the 5,000 acres minimum in the 1964 Wilderness Act. These are neither exceptional wilderness values nor weight of public opinion to justify further consideration of these parcels.

Opportunities for solitude exist in pockets in the secondary drainages and forested side slopes of portions of the unit. However, the factors of protruding fingers of land without natural characteristics, intrusive range developments, and "cherrystem" roads create an extraordinarily congested and narrow boundary area which precludes the experience of outstanding solitude.

Primitive recreational opportunities include hiking, camping, hunting, horseback riding, and scenic photography. Reed Coulee does not contain any high-value recreational opportunities, which would make the area outstanding. 
Although it lacks the deep erosion and variety of colors found adjacent to the Missouri River, the unit does have attractive scenery, along with remnants of former Indian occupation and vertebrate fossil deposits.

\section{FINAL DECISION ANALYSIS}

\section{Summary of Public Comments:}

One comment pointed out the existence of stock dams, water tanks, access roads to those developments, well-traveled road boundaries, deeded land within the unit, and the possibility of cancelled oil and gas leases.

Final Decision and Rationale:

The unit will not be further studied for wilderness. There are not 5,000 acres of contiguous natural land within the area. Opportunities for solitude and primitive recreation are not considered exceptional and disqualify the unit for wilderness study. 


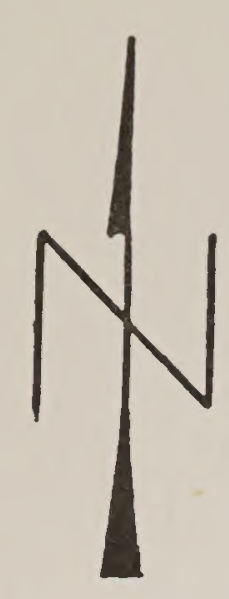

REED COULEE

MT-068-232

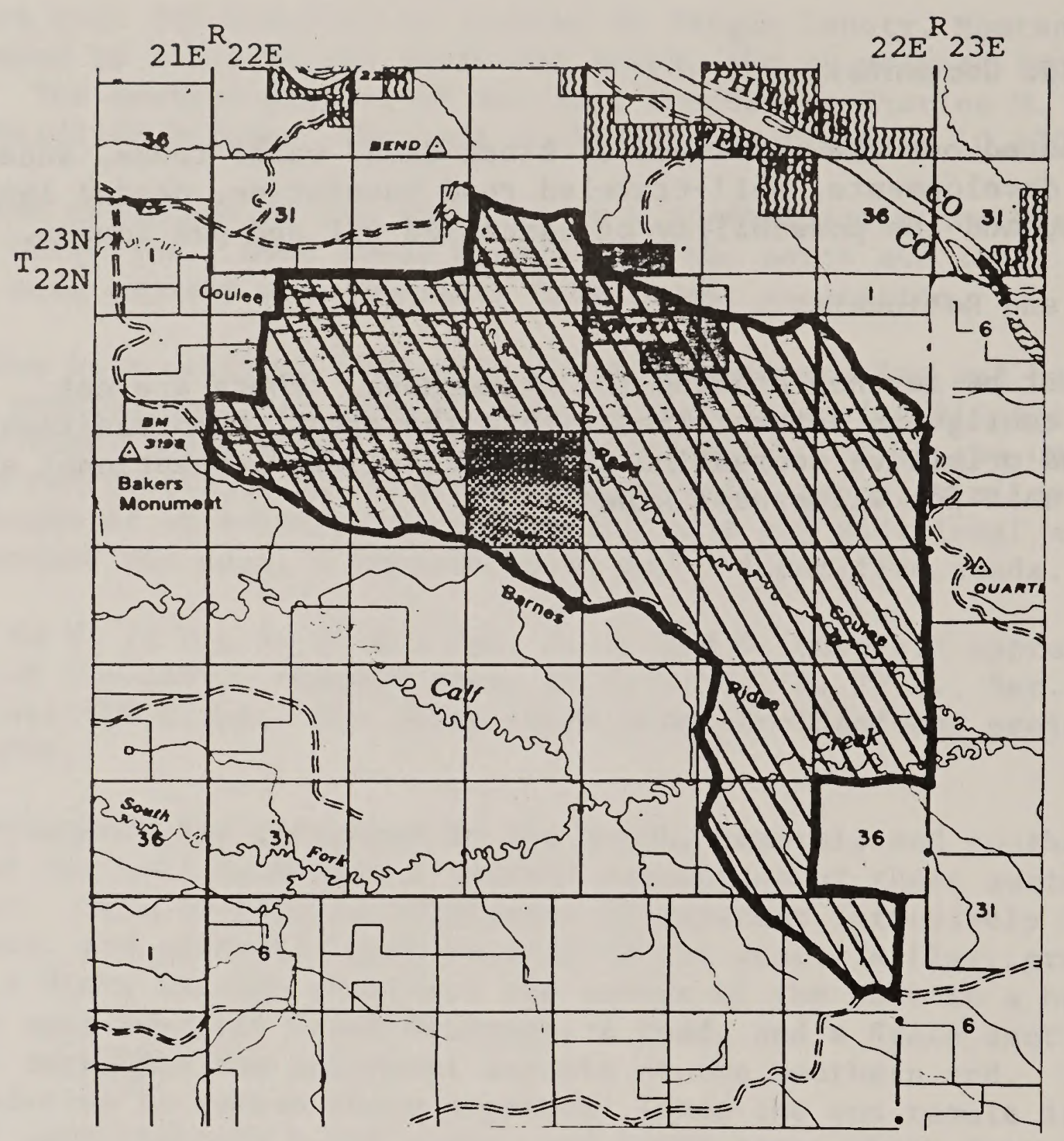

LEGEND

SCALE $1: 126,720$

inch $=1$ mile
MIIV
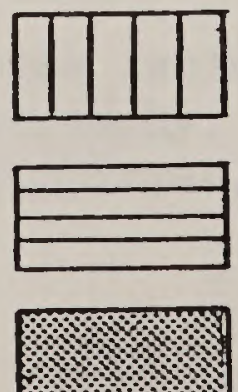

UNIT OR PORTION OF UNIT LACKING WILDERNESS CHARACTERISTICS (NOT RECOMMENDED AS WSA)

AREA DELETED FROM ORIGINAL INVENTORY UNIT DUE TO ROAD IDENTIFICATION

AREA ADDED DUE TO ROAD IDENTIFICATION

PRIVATE OR STATE INHOLDINGS 
UNIT NO.: $\quad$ MT-068-233

UNIT NAME: Drag Creek

\section{WILDERNESS CHARACTERISTICS NARRATIVE SUMMARY}

Drag Creek Unit (MT-068-233) is located in Petroleum County, Montana. The unit is located along the Musselshell River, thirty miles east of U.S. 191 . The unit contains 16,500 acres.

Drag Creek ranges from lightly rolling open terrain in the west to somewhat more broken country near the Musselshell River. The western third of the unit consists of a wide, flat drainage with a number of range improvements and the Drag Creek recreation site which eliminates apparent naturalness in this portion. The eastern section contains only minor, inconspicuous developments. Although pockets of solitude exist in timbered side drainages in the east side, the generally open character of the predominant lower elevations of this portion diminishes the overall quality of solitude. In the western portion extensive inholdings and unforested, open terrain limit solitude. Hunting opportunities are common in this part of Montana, and no outstanding opportunity exists in the Drag Creek Unit.

\section{FINAL DECISION ANALYSIS}

Summary of Public Comments:

The single comment pointed out the existence of LU land, introduced grass species, stock dams, fences, roads, enclosed private land, and irregular boundaries.

Final Decision and Rationale:

This unit will not be further studied for wilderness. The western portion of the unit is unnatural due to the presence of range improvements and a developed recreation site. The eastern section lacks solitude due to generally open character and extensive inholdings. An outstanding opportunity for primitive recreation does not exist in the unit. 

UNIT NO.: $\quad$ MT-068-236

UNIT NAME: West Crooked Creek

\section{WILDERNESS CHARACTERISTICS NARRATIVE SUMMARY}

West Crooked Creek, Unit (MT-068-236) is located in Petroleum County, Montana. The unit is located about 25 miles east of U.S. Route 191. The unit is 2 miles in width over its 5 mile length and contains approximately 10,700 acres of public land, with a 40 acre private inholding. The area is bounded by a combination of private land and Bureau of Land Management maintained roads.

During the field inventory, a road was identified which bisects the area. This division leaves approximately 3,200 acres in the northern portion, and 7,500 acres in the south. The north portion clearly does not meet the 5,000 acre size requirement as defined by the Wilderness Act of 1964 .

Seven reservoirs, 9 miles of fence, and 4 miles of low grade vehicular ways impact the naturalness, especially in the northern half of the unit. One reservoir has just been constructed and the earthwork and construction road have not revegetated. This project is visible from surrounding ridge lines and is an obvious sign of man's work. Much of the southern half is still in a natural condition. There is not an outstanding opportunity for solitude within this unit. A portion of the unit lies within the floodplain of Crooked Creek. A ranch operation adjacent to the unit is visible from some distance and detracts from solitude. The southern area is eroded, and in the breaks there are some opportunities of solitude. Most usage would be channeled to high flat benches, however, where the feeling of isolation would not be outstanding. No outstanding outdoor recreation opportunities were identifed in the unit. Opportunities for hunting, hiking, camping, horseback riding, and cross country skiing were identified. None of these opportunities, alone or as a combination of opportunities, was judged as exceptional. Some scenic values and a possible site for vertebrate fossils were the only supplemental values found in the unit. This area does not qualify for further wilderness inventory.

\section{FINAL DECISION ANALYSIS}

Summary of Public Comments:

The sole respondent felt that solitude in the unit would be limited by the boundary configuration. The unit contains roads, which would affect naturalness. 
Final Decision and Rationale:

This unit will not be further studied for wilderness. Only the southern portion is of adequate size and naturalness to be considered. However, this portion does not have outstanding solitude possibilities due to open land in the creek bottom, an offsite ranch operation and lack of vegetation along the higher elevations. No recreational opportunities, alone or in conjunction, are outstanding. 


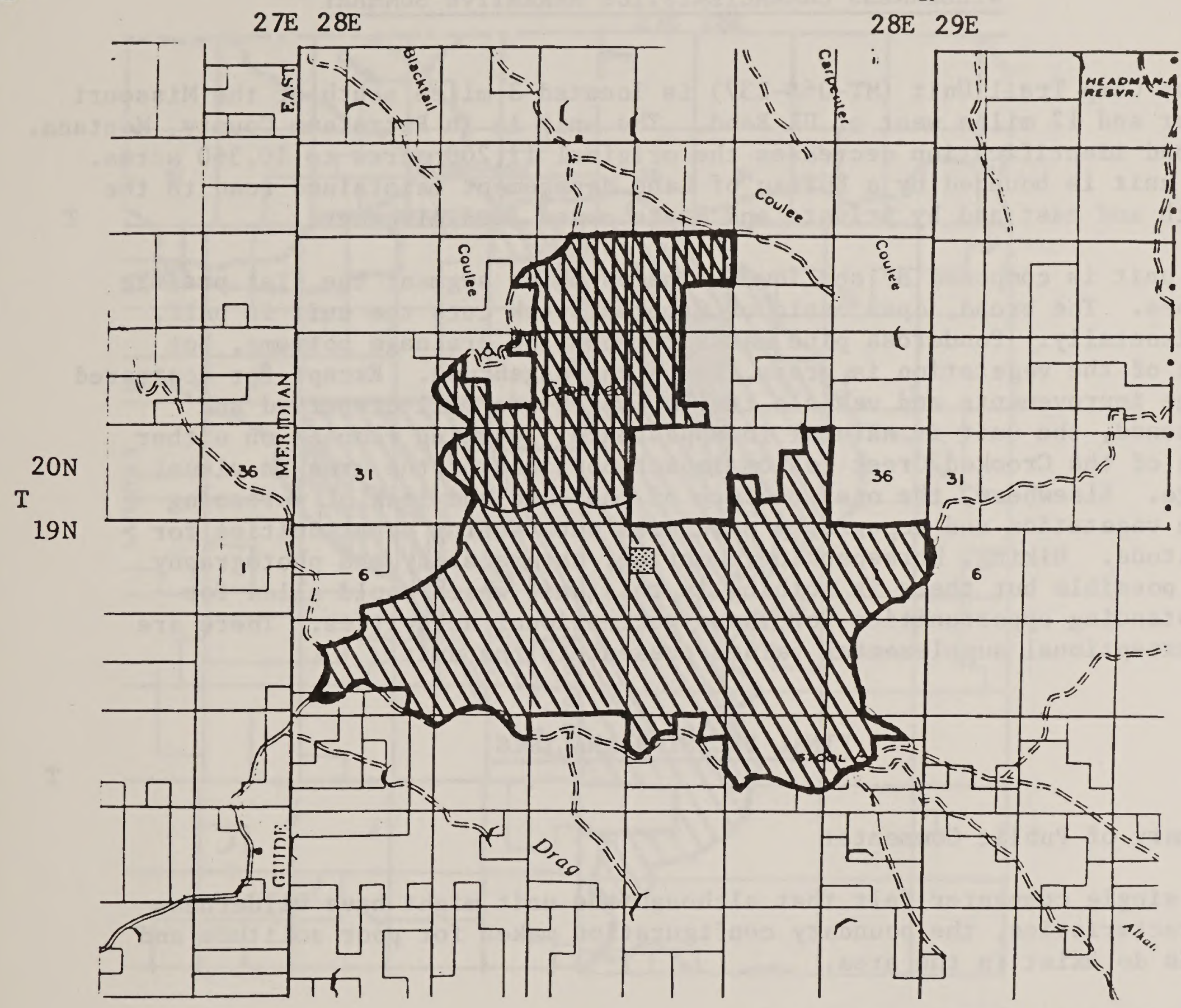

LEGEND

SCATE 1:126,720

is inch $=1$ mile
MIIV
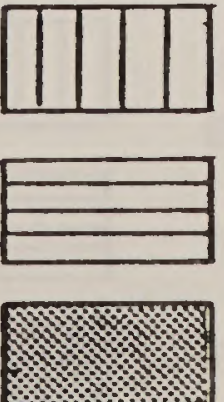

UNIT OR PORTION OF UNIT IACKING WILDERNESS CHARACTERISTICS (NOT RECOMMENDED AS WSA)

AREA DELETED FROM ORIGINAL INVENTORY UNIT DUE TO ROAD IDENTIFICATION

AREA ADDED DUE TO ROAD IDENTIFICATION

PRIVATE OR STATE INHOLDINGS 
UNIT NO.: $\quad$ MT-068-237

UNIT NAME: Horse Camp Trail

\section{WILDERNESS CHARACTERISTICS NARRATIVE SUMMARY}

Horse Camp Trail Unit (MT-068-237) is located 3 miles south of the Missouri River and 12 miles west of UL Bend. The unit is in Petroleum County, Montana. A road identification decreases the original 11,200 acres to 10,360 acres. The unit is bounded by a Bureau of Land Management maintained road to the south and east and by private and State owned land elsewhere.

The unit is composed of shallow drainages which segment the flat prairie slopes. The broad, open basin of Crooked Creek cuts the unit in half, horizontally. Ponderosa pine masks the shallow drainage bottoms, but most of the vegetation is grass, forbs and sagebrush. Except for scattered range improvements and vehicle trails, which are well dispersed and screened, the unit is natural in appearance. Working ranches on either side of the Crooked Creek bottom impact portions of the area in visual range. Elsewhere, the open texture of the land and lack of screening from vegetation and topography precludes outstanding opportunities for solitude. Hiking, horsepacking, hunting, nature study and photography are possible but there is nothing in this unit which would allow for outstanding opportunities for these recreational activities. There are no exceptional supplemental values present in the unit.

\section{FINAL DECISION ANALYSIS}

Summary of Public Comments:

The single commenter felt that although the unit might have wilderness characteristics, the boundary configuration makes for poor solitude and roads do exist in the area.

Final Decision and Rationale:

This unit will not be further studied for wilderness. The unit is bisected by a broad, open drainage and this, plus the open, unvegetated texture on either side and offsite ranch activities preclude a quality solitude experience. The unit is natural in appearance. Nothing in the area would allow for an outstanding primitive recreation opportunity. 


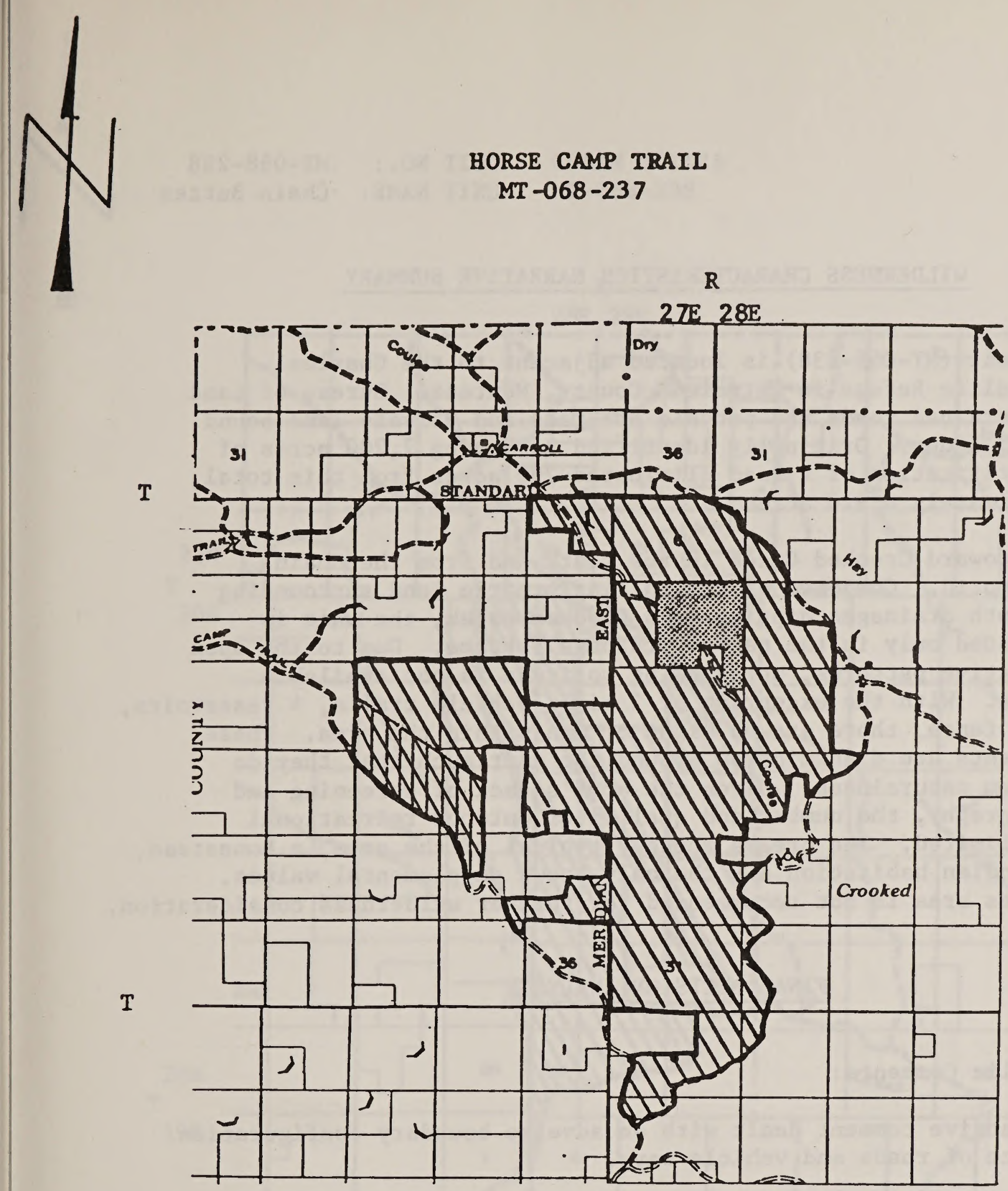

MT $-068-237$

LEGEND

SCALE $1: 126,720$

$\frac{1}{2}$ inch $=1 \mathrm{mile}$
WU UNIT OR PORTION OF UNIT LACKING WILDERNESS CHARACTERISTICS (NOT RECOMMENDED AS WSA)

AREA DELETED FROM ORIGINAL INVENTORY UNIT DUE TO ROAD IDENTIFICATION

AREA ADDED DUE TO ROAD IDENTIFICATION

PRIVATE OR STATE INHOLDINGS 
UNIT NO.: $\quad$ MT-068-238

UNIT NAME: Chain Buttes

\section{WILDERNESS CHARACTERISTICS NARRATIVE SUMMARY}

Chain Buttes Unit (MT-068-238) is located adjacent to the Charles M. Russell Wildlife Refuge in Petroleum County, Montana. Bureau of Land Management maintained roads and parcels of State and private land bound the unit on all sides. Originally identified as having 7,200 acres of land, the identification of a road eliminated 290 acres from this total, leaving approximately 6,910 acres.

The area dips toward Crooked Creek in the south and from the Chain Buttes in the north. Composed of the rolling prairie land surrounding three north-south drainages dipping into Crooked Creek, the unit is open, and forested only in the narrow drainage bottoms. Due to the open form and vegetative patterns, outstanding solitude is not available within the area. With the exception of 2 minor vehicle trails, 4 reservoirs, and 5 miles of fence, there are no signs of man within the area. These minor developments are disseminated around the unit such that they do not detract from naturalness. Given the area's lack of screening and flattened topography, the number and quality of outdoor recreational activities is limited. The breaks scenery typical of the area, a homestead, and signs of Indian habitation are the only known supplemental values. The Chain Buttes area is not recommended for further wilderness consideration.

\section{FINAL DECISION ANALYSIS}

Summary of Public Comments:

The sole substantive comment dealt with an adverse boundary configuration and the presence of roads and vehicle ways.

Final Decision and Rationale:

This unit will not be further studied for wilderness. Although it appears natural, due to the open topographic and vegetative patterns, the unit does not have outstanding solitude. The number of recreational activities is limited and outstanding opportunities are not available. 


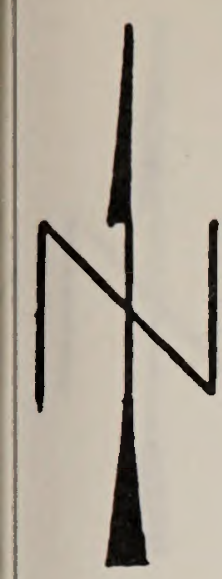

CHAIN BUTTES

MT $-068-238$

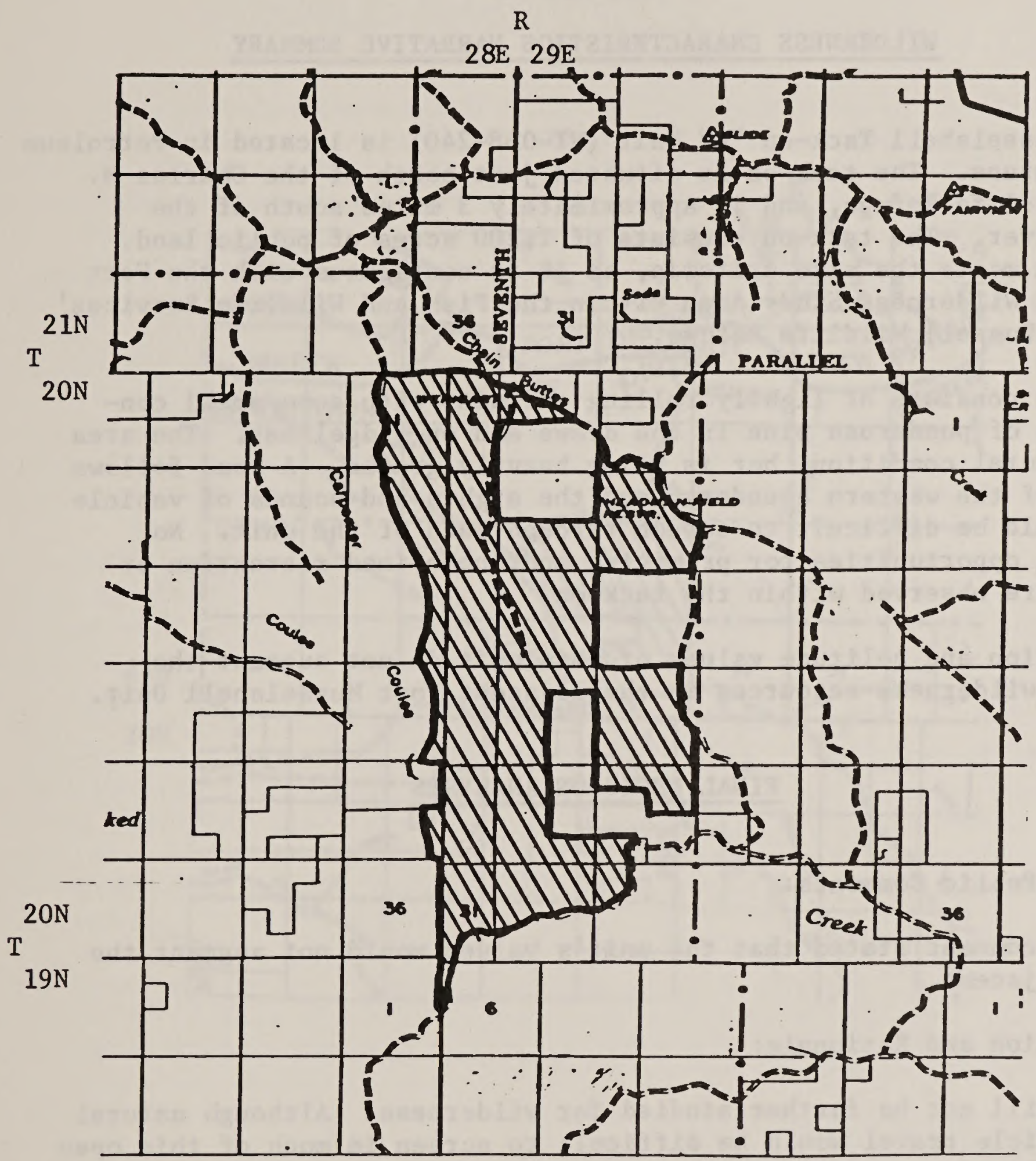

SCALE $1: 126,720$

LEGEND

is inch $=1$ mile

TU UNIT OR PORTION OF UNIT LACKING WILDERNESS CHARACTERISTICS (NOT RECOMMENDED AS WSA)

AREA DELETED FROM ORIGINAL INVENTORY UNIT DUE TO ROAD IDENTIFICATION

AREA ADDED DUE TO ROAD IDENTIFICATION

PRIVATE OR STATE INHOLDINGS 
UNIT NO.: MT-068-240

UNIT NAME: Fort Musselshel1

Tack-on A

\section{WILDERNESS CHARACTERISTICS NARRATIVE SUMMARY}

The Fort Musselshell Tack-on "A" Unit (MT-068-240) is located in Petroleum County, Montana. The tack-on is situated just south of the Charles M. Russell Wildlife Refuge, and is approximately 3 miles south of the Missouri River. The tack-on consists of 1,200 acres of public land. The tack-on meets the size criteria, as it is contiguous with the Fort Musselshell Wilderness Study Area within the Fish and Wildlife Services' Charles M. Russell Wildlife Refuge.

The tack-on consists of lightly rolling terrain, with some small concentrations of ponderosa pine in the draws and on ridgelines. The area is in a natural condition, but is being heavily grazed. A road follows a portion of the western boundary, and the sights and sounds of vehicle traffic would be difficult to screen through much of the unit. No outstanding opportunities for primitive and unconfined recreation or solitude were observed within the tack-on.

The recreation and solitude values of this unit do not augment the identified wilderness resources in the adjacent Fort Musselshell Unit.

\section{FINAL DECISION ANALYSIS}

Summary of Public Comments:

The single comment stated that the unit's values would not augment the FWS unit adjacent.

Final Decision and Rationale:

This unit will not be further studied for wilderness. Although natural offsite vehicle travel would be difficult to screen in much of this open unit and solitude would be compromised. No outstanding primitive recreational opportunities exist in the unit. The area does not significantly add to the contiguous FWS unit. 
FORT MUSSELSHELL TACK-ON A

MT $-068-240$

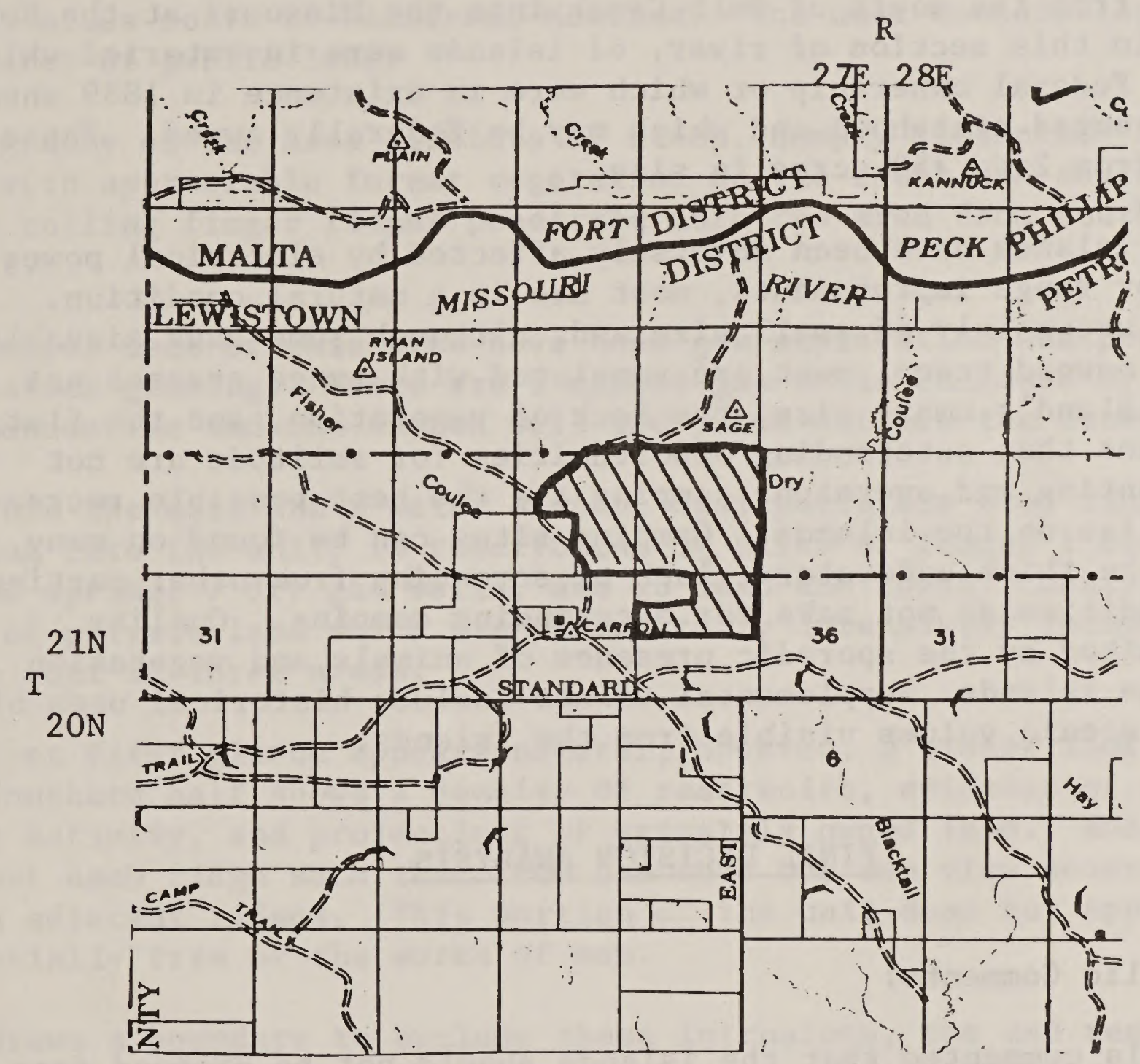

LEGEND

SCALE $1: 126,720$

inch $=1$ mile
MIIV
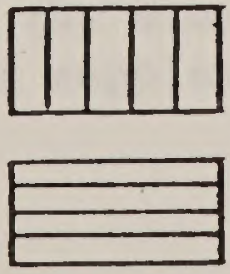

m.

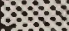

$\ldots$
UNIT OR PORTION OF UNIT LACKING WILDERNESS

CHARACTERISTICS (NOT RECOMMENDED AS WSA)

AREA DELETED FROM ORIGINAL INVENTORY UNIT DUE TO ROAD IDENTIFICATION

AREA ADDED DUE TO ROAD IDENTIFICATION

PRIVATE OR STATE INHOLDINGS 
UNIT NO.: MT-068-243

UNIT NAME: Missouri River Islands

\section{WILDERNESS CHARACTERISTICS NARRATIVE SUMMARY}

The Missouri River Islands Unit (MT-068-243) is located in Central Montana in the counties of Chouteau and Fergus. The river unit flows for 175 miles from the mouth of Belt Creek into the Missouri at the Robinson Bridge. Within this section of river, 62 islands were inventoried which are either in Federal ownership or which were in existence in 1889 when Montana was granted statehood and which may be Federally owned. These islands vary from 2 to 150 acres in size.

Although some islands have been adversely affected by electrical power developments or range improvements, most are in a natural condition. These islands are mainly of small size and, although some have sizeable groves of cottonwood trees, most are vegetated with range grasses and shrubs. The island's small size, the lack of vegetation, and the flat topography means that outstanding opportunities for solitude are not available. Hunting and overnight camping are the best possible recreational activities on the islands. Camping sites can be found on many islands, but the thick understory, lack of screening from other parties, and insect densities do not make for outstanding camping. Quality hunting is limited by the sporadic presence of animals and vegetation patterns on the islands. Supplemental values include historical uses of the river and scenic values visible from the islands.

\section{FINAL DECISION ANALYSIS}

Summary of Public Comments:

Some individuals commented that the islands should not be dropped from further wilderness study because of their small size. The islands provide needed protection for wildlife habitat.

Final Decision and Rationale:

The islands will not be studied for wilderness. Some islands do not have a natural appearance due to range improvements and electrical power developments. Those islands that retain their natural appearance are neither large enough nor provide enough screening to provide an outstanding opportunity for solitude. Opportunities for a primitive and unconfined type of recreation are less than outstanding due to the thick vegetative understory and small size. 
UNIT NO.: $\quad$ MT-068-245

UNIT NAME: Chimney Bend

WILDERNESS CHARACTERISTICS NARRATIVE SUMMARY

Chimney Bend Unit (MT-068-245) is located in Fergus County, Montana, and is bounded by the Missouri River on the north. The unit is situated approximately 15 miles north of Winifred, Montana. The unit contains approximately 16,600 acres of public land.

The topography of the area consists of steep, deeply dissected "breaks" covered with appreciable forest vegetation on the south and southeast. Flat and rolling finger ridges penetrate into the area from southeast to northwest.

The two major uses of this area have been gas exploration and production and livestock grazing. There are 5 capped gas wells enclosed by the unit's boundaries and one capped well 200 yards outside the area.

Also within the unit are 2 water savers, easily visible atop ridges

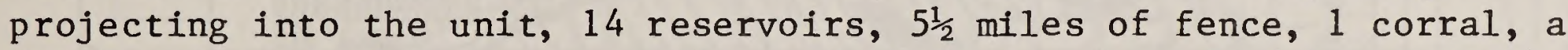
developed spring, 7 dry gas wells, and 10 dead-end roads (cherrystems). Fingers of private land which are periodically intensively farmed project into the unit in three areas.

The unit at first glance appears natural; however, a closer look at the unit's southern half shows a density of reservoirs, evidence of past gas drilling activity, and projections of privately owned land. Roads finger out each ridge such that from one road one can view several other roads on adjacent ridges. This portion of the unit does not appear to be essentially free of the works of man.

If one draws a boundary to exclude these intrusions, the end result is a narrow strip of land along the river with a congested southern edge, deeply penetrated by narrow fingers of private land and by cherrystem roads. Solitude within the remaining portion will be limited. This is not to say that there is no chance for solitude within the unit. Opportunities are there but their quality is downgraded to something less than outstanding by the configuration of the unit's southern boundary.

Outstanding opportunities for primitive recreation are also not present. Hunting for mule deer and sharptail grouse is good within the unit. Opportunities for hiking, backpacking, horseback riding, and nature viewing and photography exist but none is compellingly attractive.

The area's historical role in the steamboat era and its picturesque "breaks" scenery are the major supplemental values. 
Summary of Public Comments:

Two substantive comments were received. One admitted the imprint of man's activities but felt that these activities were not severe enough to preclude further wilderness study. The other comment pointed out regularly used roads, proven energy value, the Leroy proposed pipeline, fences, reservoirs, the lack of aesthetic value, and the existence of enclosed private and State land.

Final Decision and Rationale:

This unit will not be further studied for wilderness. The density and location of the artifacts of man limits the naturalness of the southern portion of the area. The unit's configuration and the number of cherrystem roads also serve to alter the quality of solitude within the unit. Recreational opportunities are not outstanding compared to those in surrounding areas. 


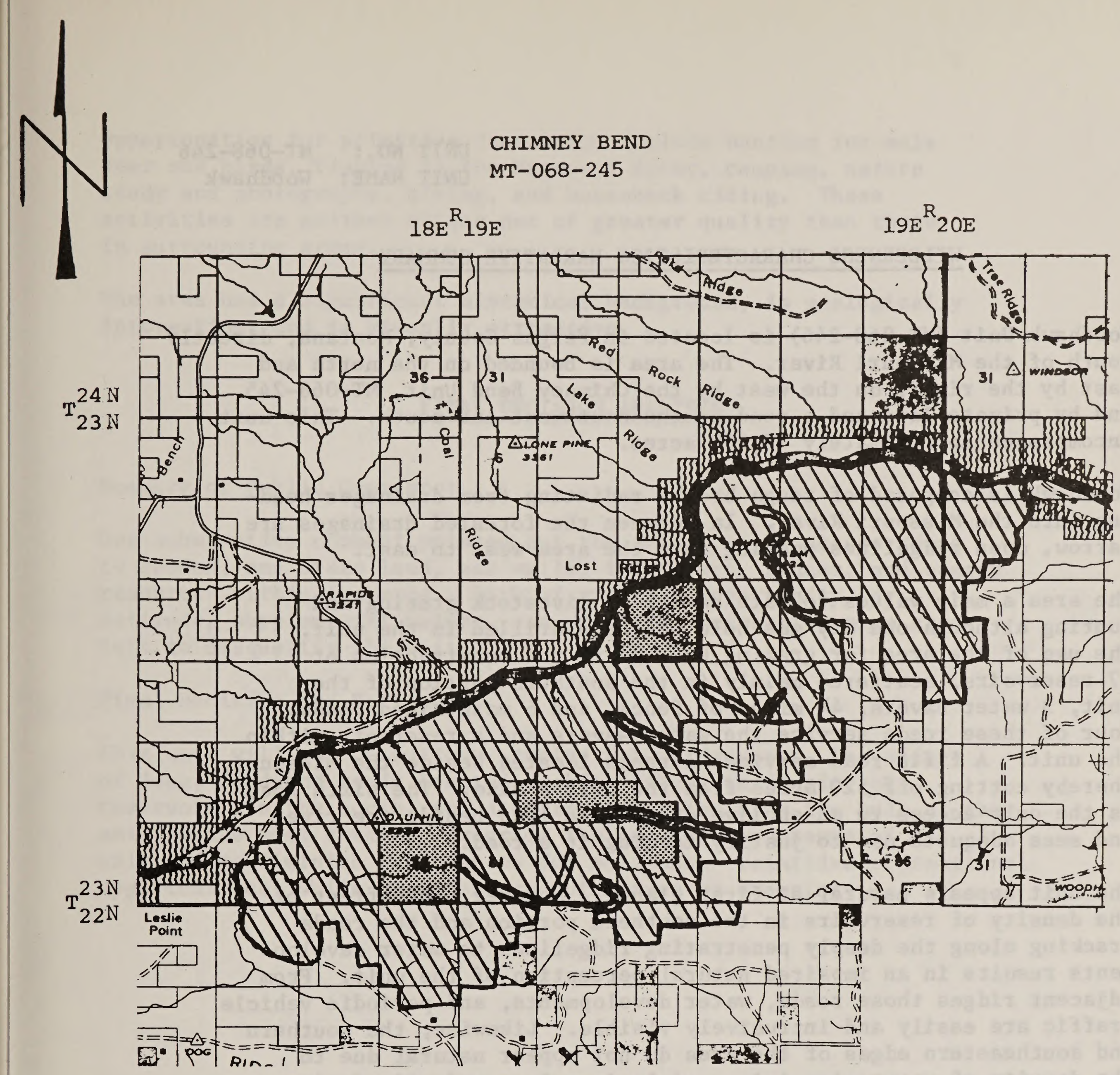

LEGEND

SCALE $1: 126,720$

WV UNIT OR PORTION OF UNIT LACKING WILDERNESS inch $=1$ mile CHARACTERISTICS (NOT RECOMMENDED AS WSA)

AREA DELETED FROM ORIGINAL INVENTORY UNIT DUE TO ROAD IDENTIFICATION

AREA ADDED DUE TO ROAD IDENTIFICATION

PRIVATE OR STATE INHOLDINGS 
UNIT NO.: MT-068-246

UNIT NAME: Woodhawk

\section{WILDERNESS CHARACTERISTICS NARRATIVE SUMMARY}

Woodhawk Unit (MT-068-246) is located in Fergus County, Montana, directly south of the Missouri River. The area is bounded on the north and east by the river, on the west by the Chimney Bend Unit, MT-068-245, and by private land and a road on the southwest and south. This unit encompasses approximately 17,000 acres.

Woodhawk is composed of rough breaks radiating from drainages heading into the Missouri River. In between the forested drainages are narrow, open ridgelines pushing into the area west to east.

The area's main values to date have been livestock grazing and hunting although one dry gas hole has been drilled in the unit. The use of the area for grazing has led to the construction of 17 reservoirs, scattered mainly in the southern portion of the unit, 3 water savers, $4 \frac{1}{2}$ miles of fence, and 6 maintained roads. Four of these roads service the water savers and a reservoir within the unit. A fifth road services a ranch located beside the Missouri, thereby cutting off 520 acres from the unit's size. The sixth road is the only access to an enclave of private land beside the river and sees adequate use to justify terming it a road.

The unit appears natural at first glance. However, the effect of the density of reservoirs in the southern portion and the roads tracking along the deeply penetrating ridgelines to water developments results in an impaired natural perception of the unit. From adjacent ridges those roads, water developments, and periodic vehicle traffic are easily and intrusively visible. Likewise, the southern and southeastern edges of the area do not appear natural due to the density of reservoirs lying mainly in unforested side drainages or bottoms of Woodhawk Creek.

If one draws a boundary to exclude these intrusions, one is left with a narrow finger of roadless land extending on the northwest and a congested, narrow boundary area to the west of the bulk of the unit. Opportunities for outstanding solitude are severely compromised by the configuration of the area. This is not to suggest that there is no possibility of finding solitude. One can be alone within the unit, but the ingress of roads, terminated by water savers which require periodic maintenance and the penetration of lands without wilderness characteristics severely diminishes the quality of the experience. 
Opportunities for primitive recreation include hunting for mule deer and birds, fishing in the Missouri River, camping, nature study and photography, hiking, and horseback riding. These activities are neither unique nor of greater quality than those in surrounding areas.

The area has a significant historical background, is geologically interesting, and is visually attractive.

\section{FINAL DECISION ANALYSIS}

\section{Summary of Public Comments:}

One substantive comment pointed out the existence of access roads to deeded, and State land, gas wells, reservoirs, fences, and energy resources within the area. Lack of scenery, opportunity for solitude, supplemental values, and primitive recreation were also felt to disqualify the unit.

Final Decision and Rationale:

This unit will not be further studied for wilderness. The effect of long, dead-end roads located on high ridges, a density of reservoirs in the south, and a narrow extension from the bulk of the unit to the west tend to downgrade the natural appearance of the unit and to diminish the chances for solitude. Primitive recreational opportunities, while present, are not unique or exemplary. 


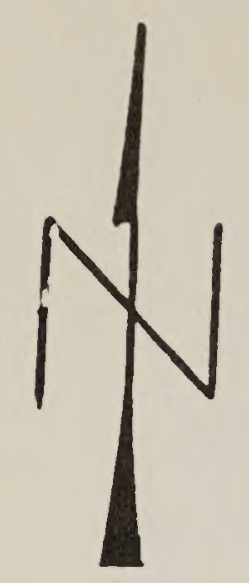

WOODHAWK

MT $-068-246$

$\mathrm{R}$

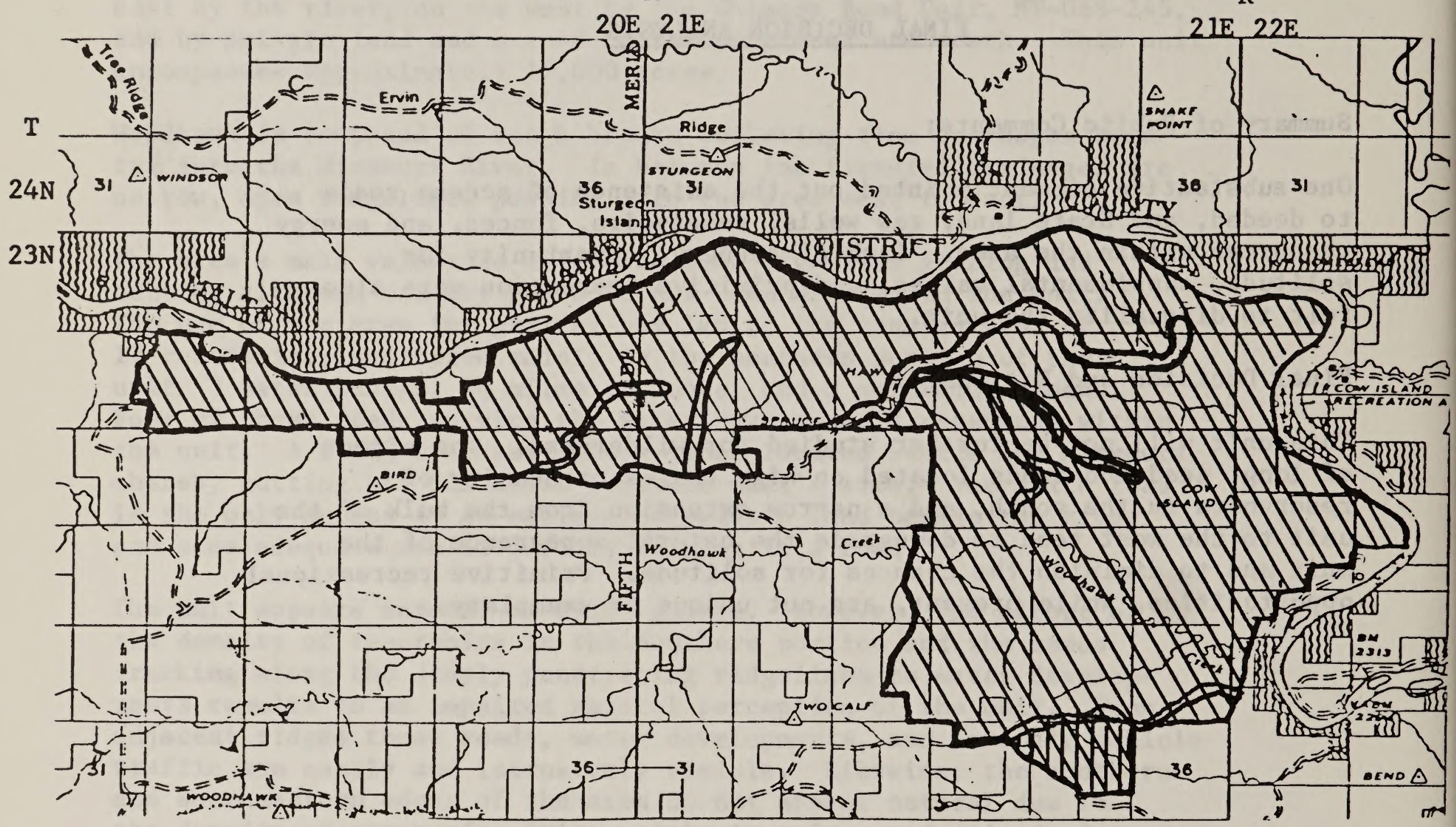

LEGEND

SCALE $1: 126,720$

ł inch $=1 \mathrm{mile}$
MIIV
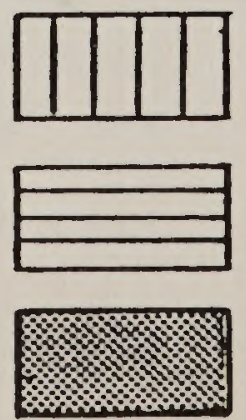

UNIT OR PORTION OF UNIT LACKING WILDERNESS CHARACTERISTICS (NOT RECOMMENDED AS WSA)

AREA DELETED FROM ORIGINAL INVENTORY UNIT DUE TO ROAD IDENTIFICATION

AREA ADDED DUE TO ROAD IDENTIFICATION

PRIVATE OR STATE INHOLDINGS 
UNIT NO.: $\quad$ MT-068-247

UNIT NAME: Woodhawk Creek

\section{WILDERNESS CHARACTERISTICS NARRATIVE SUMMARY}

Woodhawk Creek Unit (MT-068-247) is located in Fergus County, Montana. The unit lies 3 miles south of the Missouri River, and is 20 miles northeast of Winifred. The unit is separated from the Woodhawk area (MT-068-246) by two Bureau of Land Management maintained roads. Elsewhere, private and State lands border.

The original size of the unit was 5,820 acres. Because they lack wilderness characteristics, three parts are not recommended for further study. The deleted areas include 1,440 acres on the southwest side, a Bureau fire rehabilitation study plot, and a new reservoir site. These modifications leave approximately 4,305 acres in the unit. The 1,440 acres deleted in the southwest open onto a flat bench. This area is not natural, as it is impacted by reservoirs, non-native specie plantings, and offsite intensive farming. Elsewhere the unit is rugged and the scene is essentially natural, with the exceptions of the other two small plots recommended for exclusion. Forest vegetation covers the bottoms and side slopes. Outstanding opportunities for solitude are present in this portion of the unit north of Woodhawk Creek. Although several primitive recreation activities, such as hunting and horseback riding are possible, none were judged as outstanding. Scenic, cultural, and geological values are present in the unit.

\section{FINAL DECISION ANALYSIS}

Summary of Public Comments:

There were no substantive public comments.

Final Decision and Rationale:

This area will not be further studied for wilderness. The exclusion of 1,440 acres of non-natural land leaves less than the prerequisite 5,000 acres in the natural remainder. Outstanding solitude opportunities exist in the rugged, wooded remnant of the unit, but outstanding primitive recreation opportunities do not exist. 
WOODHAWK CREEK

MT-068-247

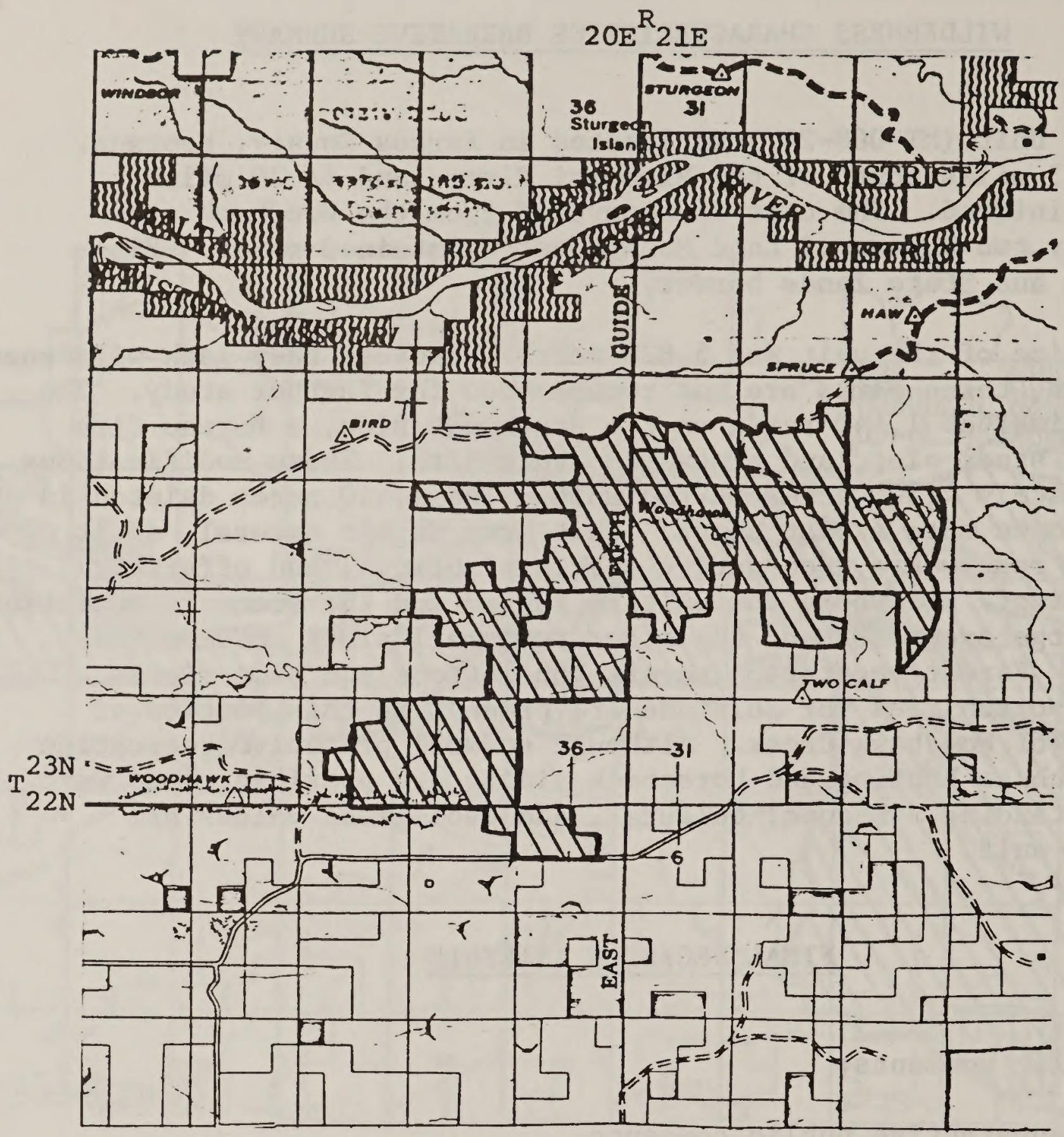

LEGEND

SCAIE $1: 126,720$

1 inch $=1$ mile
MIIV
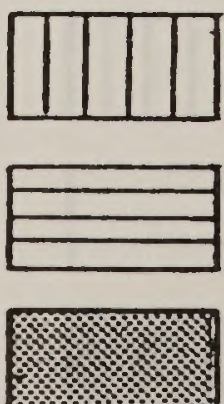
UNIT NO.: $\quad$ MT-060-249

UNIT NAME: Wa11

\section{WILDERNESS CHARACTERISTICS NARRATIVE SUMMARY}

The Wall Unit (MT-060-249) lies 5 miles west of the P.N. Ferry crossing on Montana State Road 1336 and along the north shore of the Missouri River. The 12,200 acre unit is bounded by a combination of private and Montana State 1and.

Two roads were found during the intensive inventory. They divide the unit into 3 parcels, 2 of which are less than 5,000 acres each. The first road crosses the unit through Section 7 of T. 23 N. and R. 15 E. It provides access to private lands along the river and isolates to the west a 1,900 acre portion of the unit. The second road provides access to private lands located in Section 30 of T. $23 \mathrm{~N}$. and R. $15 \mathrm{E}$. A 3,600 acre parcel of land lies west of this road and a 6,700 acre parcel lies east of it.

The unit lies in a rugged and dissected terrain formed by seasonal drainages that flow towards the Missouri River. The terrain is predominantly vegetated with prairie grasses and sagebrush. Patches of cottonwoods parallel the river and conifers (junipers and pines) grow in coulee pockets. Both tree types, however, are difficult to find and are a very small percentage of the overall vegetation.

The area is presently used for the seasonal grazing of livestock. Management for the activity has led to the development of two reservoirs, five vehicular ways, and an electrical line that bisects the unit. The topography hides these developments and helps to retain the area's natural appearance.

Opportunities for solitude or a primitive and unconfined type of recreation are not outstanding. The unit's small size, narrowness, and lack of tall growing vegetation requires a wilderness user to constantly search for seclusion from other persons in the area. Opportunities for hunting, hiking, camping, and horseback riding exist but they are neither unique nor of greater quality than those of surrounding areas.

The unit lies within the Upper Missouri Wild and Scenic River corridor. Persons who pass the unit along the river witness a scenic topography rich with historic features. Long before Lewis and Clark camped on the unit's shore, Native Americans hunted along the river corridor leaving behind tipi rings and lithic scatter. When the steamboats arrived in the area, numerous persons homesteaded the unit and one homesite remains.

\section{FINAL DECISION ANALYSIS}

Summary of Public Comments:

Conservation groups strongly felt that the unit should be considered for future study. However, local persons stated there were two roads which 
crossed the unit. They also felt that because of the unit's narrowness, farming activity along the border of the unit would significantly constrain a person's ability to find solitude.

Final Decision and Rationale:

The unit will not be studied for wilderness. Two roads divide the unit into two parcels of less than 5,000 acres. The portion of the unit that has 6,200 acres is apparently natural but it possesses neither outstanding opportunities for solitude nor a primitive and unconfined type of recreation. 
THE WALI

MT-066-249

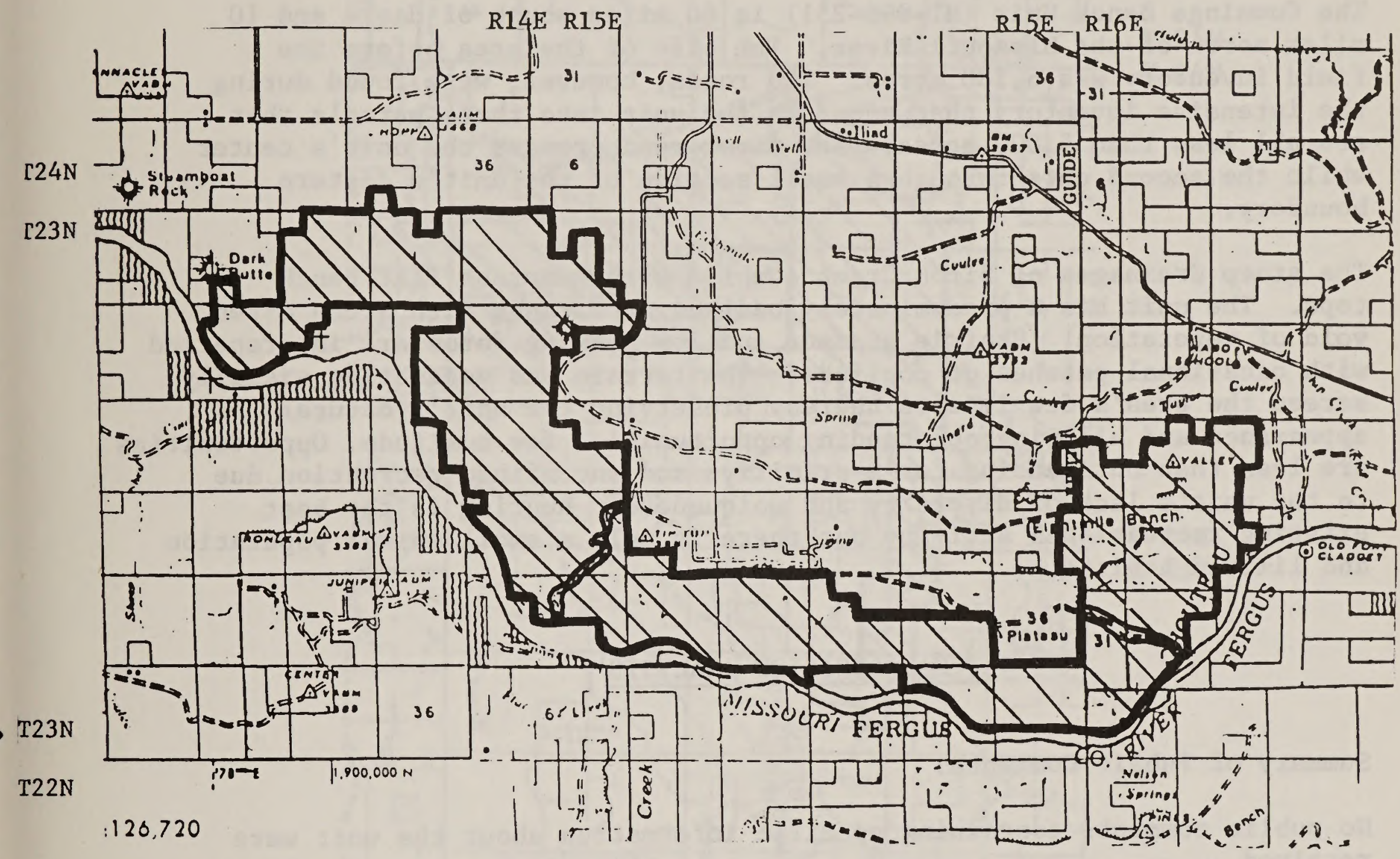

LEGEND

SCALE $1: 126,720$

inch $=1 \mathrm{mile}$
MIIV
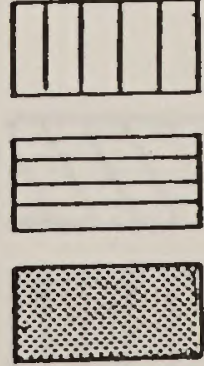

UNIT OR PORTION OF UNIT IACKING WILDERNESS CHARACTERTSTICS (NOT RECOMMENDED AS WSA)

AREA DELETED FROM ORIGINAL INVENTORY UNIT DUE TO ROAD IDENTIFICATION

AREA ADDED DUE TO ROAD IDENTIFICATION

PRIVATE OR STATE INHOLDINGS 
UNIT NO.: MT-066-251

UNIT NAME: Cummings Bench

\section{WILDERNESS CHARACTERISTICS NARRATIVE SUMMARY}

The Cummings Bench Unit (MT-066-251) is 60 miles south of Havre and 10 miles north of the Missouri River. The size of the area before the field inventory was 6,280 acres. Two roads, however, were found during the intensive inventory that separate the unit into three parcels that are all less than 5,000 acres. The first road crosses the unit's center while the second cuts through a small section of the unit's eastern boundary.

The steep drainages of Birch Creek combine with numerous flat bench tops. The unit has a predominately badland appearance with areas often void of vegetation. Prairie grasses and low growing forbs are interspersed with occasional patches of conifers. The terrain and vegetation visually screen the area's few impacts thereby preserving the unit's natural appearance and allowing outstanding opportunities for solitude. Opportunities are less than outstanding for a primitive and unconfined recreation due to the unit's lack of diversity and uniqueness. Hunting is the best existing recreational activity but there is only a small animal population and limited habitat.

\section{FINAL DECISION ANALYSIS}

Summary of Public Comments:

No public comments containing specific information about the unit were received.

Final Decision and Rationale:

The area will not be included for future wilderness study. A road divides the unit into parcels of less than 5,000 acres. 


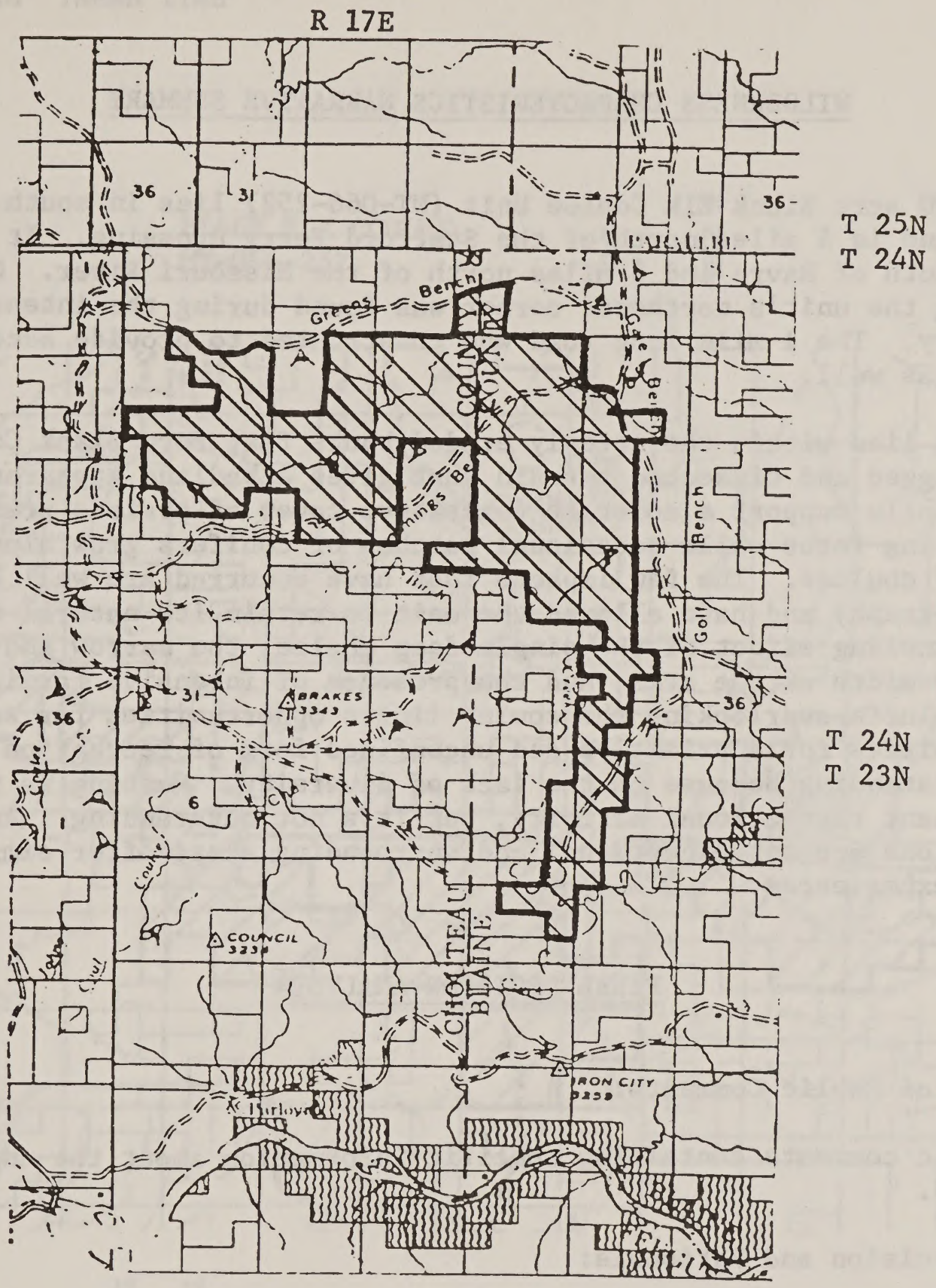

LEGEND

SCALE $1: 126,720$

in inch $=1$ mile
MIIV UNIT OR PORTION OF UNIT LACKING WILDERNESS CHARACTERISTICS (NOT RECOMMENDED AS WSA)

AREA DELETED FROM ORIGINAL INVENTORY UNIT DUE TO ROAD IDENTIFICATION

AREA ADDED DUE TO ROAD IDENTIFICATION

PRIVATE OR STATE INHOLDINGS 
UNIT NO.: $\quad$ MT-066-252

UNIT NAME: Black Elk Coulee

\section{WILDERNESS CHARACTERISTICS NARRATIVE SUMMARY}

The 9,700 acre Black Elk Coulee Unit (MT-066-252) lies in south Blaine County and is 5 miles north of the Stafford Ferry crossing. It is 70 miles south of Havre and 5 miles north of the Missouri River. One road entering the unit's northwest corner was found during the intensive inventory. The $1 \mathrm{mile}$ long road was constructed to provide access to a capped gas well.

The unit lies within the steeply eroded banks that form Black Coulee. It has a rugged and dissected terrain that gives a badland appearance. The clayey soils support a moderate vegetative cover of prairie grasses and low growing forbs while occasional patches of conifers grow along the sides of coulees. The few impacts that have occurred are well hidden by the topography and have allowed the unit to retain its natural appearance. The channeling effect of the single deep coulee, the narrow and cluttered boundary width of the area, and the presence of intensive farming activities on the bluffs overlooking the coulee limits opportunities for solitude. Opportunities for a primitive and unconfined form of recreation are less than outstanding because of the lack of diversity. Hunting is the predominant recreational activity, but it's not outstanding. Animal populations are not exceptional and surrounding areas offer similar or better experiences.

\section{FINAL DECISION ANALYSIS}

Summary of Public Comments:

No public comments containing specific information about the unit were received.

Final Decision and Rationale:

The area will not be studied for wilderness. The area has a very narrow boundary that limits opportunity for solitude. Recreational activities include hunting, camping, and hiking but these activities are not outstanding. 


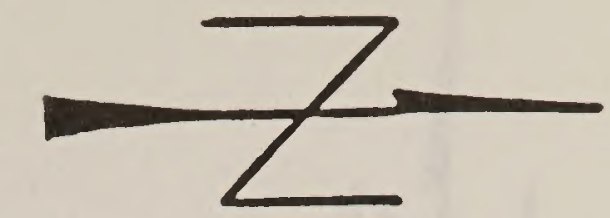

$\begin{array}{lll}\text { BLACK ELK COULEE } & \mapsto & \mapsto \\ \text { MT-066-252 } & N & N \\ \frac{N}{Z} & \text { U }\end{array}$

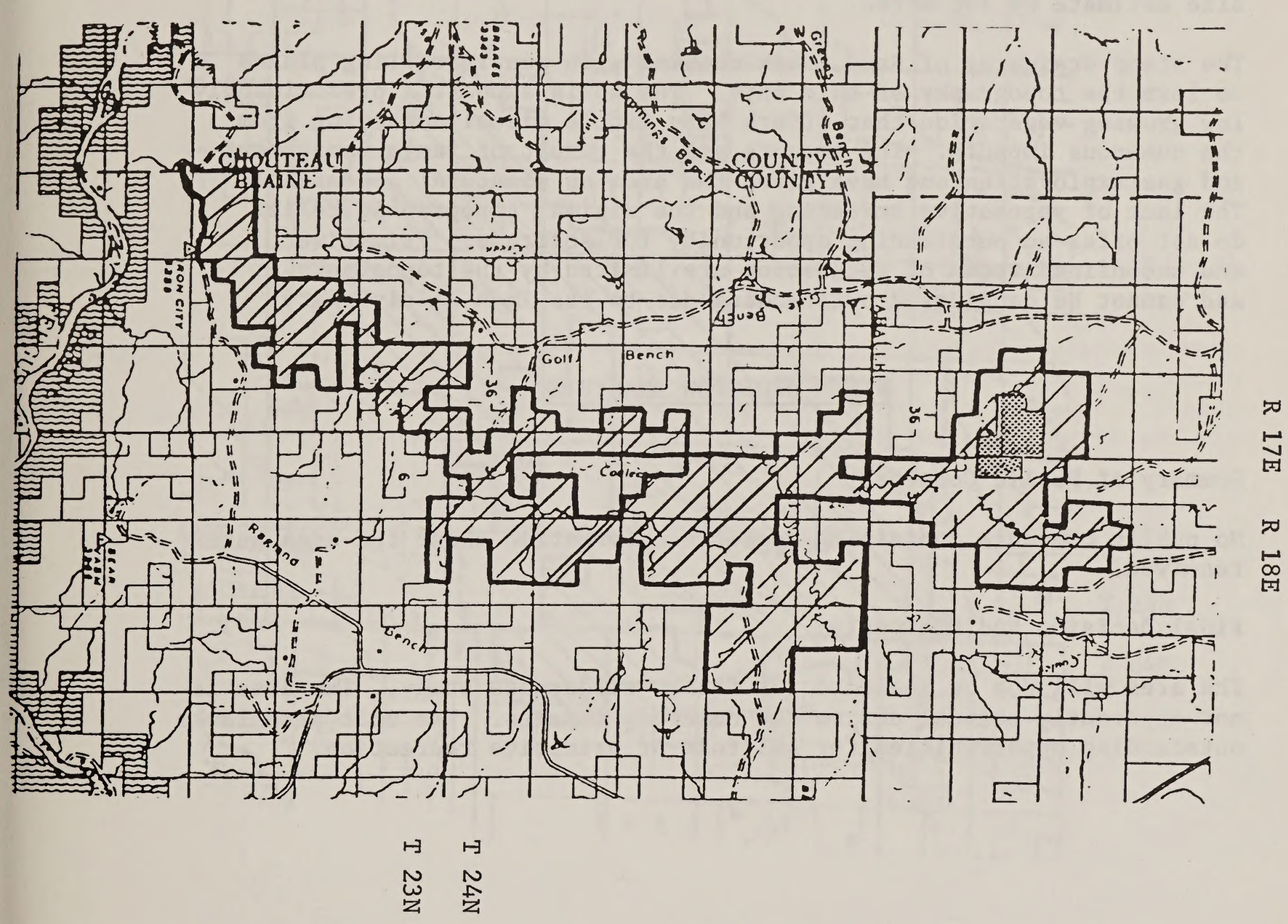

LEGEND

SCALE $1: 126,720$

WU UNIT OR PORTION OF UNIT LACKING WILDERNESS

$\frac{1}{2}$ inch $=1$ mile CHARACTERISTICS (NOT RECOMMENDED AS WSA)

AREA DELETED FROM ORIGINAL INVENTORY UNIT DUE TO ROAD IDENTIFICATION

AREA ADDED DUE TO ROAD IDENTIFICATION

PRIVATE OR STATE INHOLDINGS 
UNIT NO.: $\quad$ MT-066-254

UNIT NAME: Sand Creek

\section{WILDERNESS CHARACTERISTICS NARRATIVE SUMMARY}

This 12,087 acre Sand Creek Unit (MT-066-254) is 60 miles south of Havre and 10 miles north of the Missouri River. Two roads found during the intensive inventory enter the southeast corner of the unit. These two roads combine to decrease the initial inventory size estimate by 130 acres.

The steep drainages of Sand Creek combine with gently rolling plains to form the topography of this unit. The soils support a predominantly low growing vegetation that offers very little visual screening from the numerous impacts. The impacts are the result of range management and gas exploration and have given the area an unnatural appearance. The lack of vegetative screening and the minimal topographic relief do not offer an outstanding opportunity for solitude. Primitive and unconfined types of recreation are limited by the topography and cannot be considered outstanding due to its lack of diversity.

\section{FINAL DECISION ANALYSIS}

Summary of Public Comments:

No public comments containing specific information about the area were received.

Final Decision and Rationale:

The area will not be included for future wilderness study. The area is not apparently natural due to the numerous impacts. The unit also lacks outstanding opportunities for solitude or primitive recreation. 
SAND CREEK

MT-066-254

R 16E R 17 E

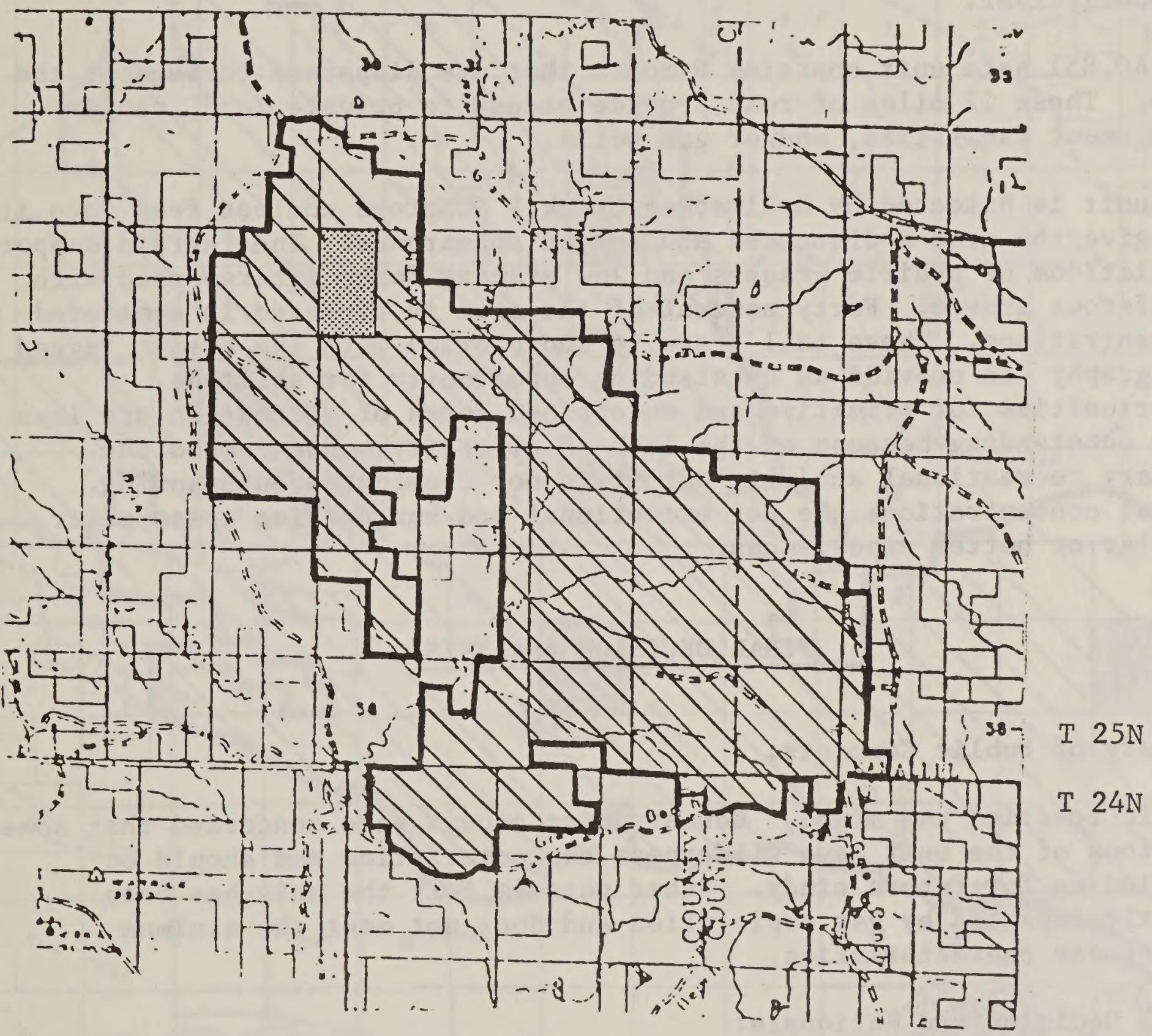

SCALE $1: 126,720$

inch $=1$ mile
LEGEND

WU UNIT OR PORTION OF UNIT LACKING WILDERNESS CHARACTERISTICS (NOT RECOMMENDED AS WSA)

AREA DELETED FROM ORIGINAL INVENTORY UNIT DUE TO ROAD IDENTIFICATION

AREA ADDED DUE TO ROAD IDENTIFICATION

PRIVATE OR STATE INHOLDINGS 
UNIT NO.: MT-066-255

UNIT NAME: Bullwacker

\section{WILDERNESS CHARACTERISTICS NARRATIVE SUMMARY}

The Bullwacker Unit (MT-066-255) is located in south Blaine County. It is approximately 60 miles south of Havre and 1-2 miles north of the Missouri River.

The 40,851 acre unit contains 6 roads that are dispersed throughout the area. These 12 miles of road provide access to private land, range management facilities, and/or gas wells.

The unit is bisected by Bullwacker Creek. Numerous coulees feed into it and give the area a dissected and rugged appearance. The terrain supports populations of prairie grasses and low growing forbs interspersed with coniferous groves. Forty percent of the area is timbered in scattered concentrations. These tall trees in conjunction with the areas' jagged topography can provide an outstanding opportunity for solitude. Opportunities for primitive and unconfined forms of recreation are less than outstanding because of the lack of diversity. Hunting is the primary recreational activity but it is not considered outstanding. Animal concentrations are not exceptional and surrounding areas offer similar or better experiences.

\section{FINAL DECISION ANALYSIS}

Summary of Public Comments:

Public reaction was mixed. Conservation groups were concerned that some portions of the unit have wilderness characteristics and should be carried on for future study. Other persons felt the unit has been greatly impacted by gas exploration and does not meet the minimum wilderness characteristics.

Final Decision and Rationale:

The area has numerous roads and impacts created by gas exploration and livestock management. The 45 vehicle ways, 57 reservoirs, gas lines, and 44 live or dry gas wells give the area an unnatural appearance. This unit will not be included for future wilderness study. 


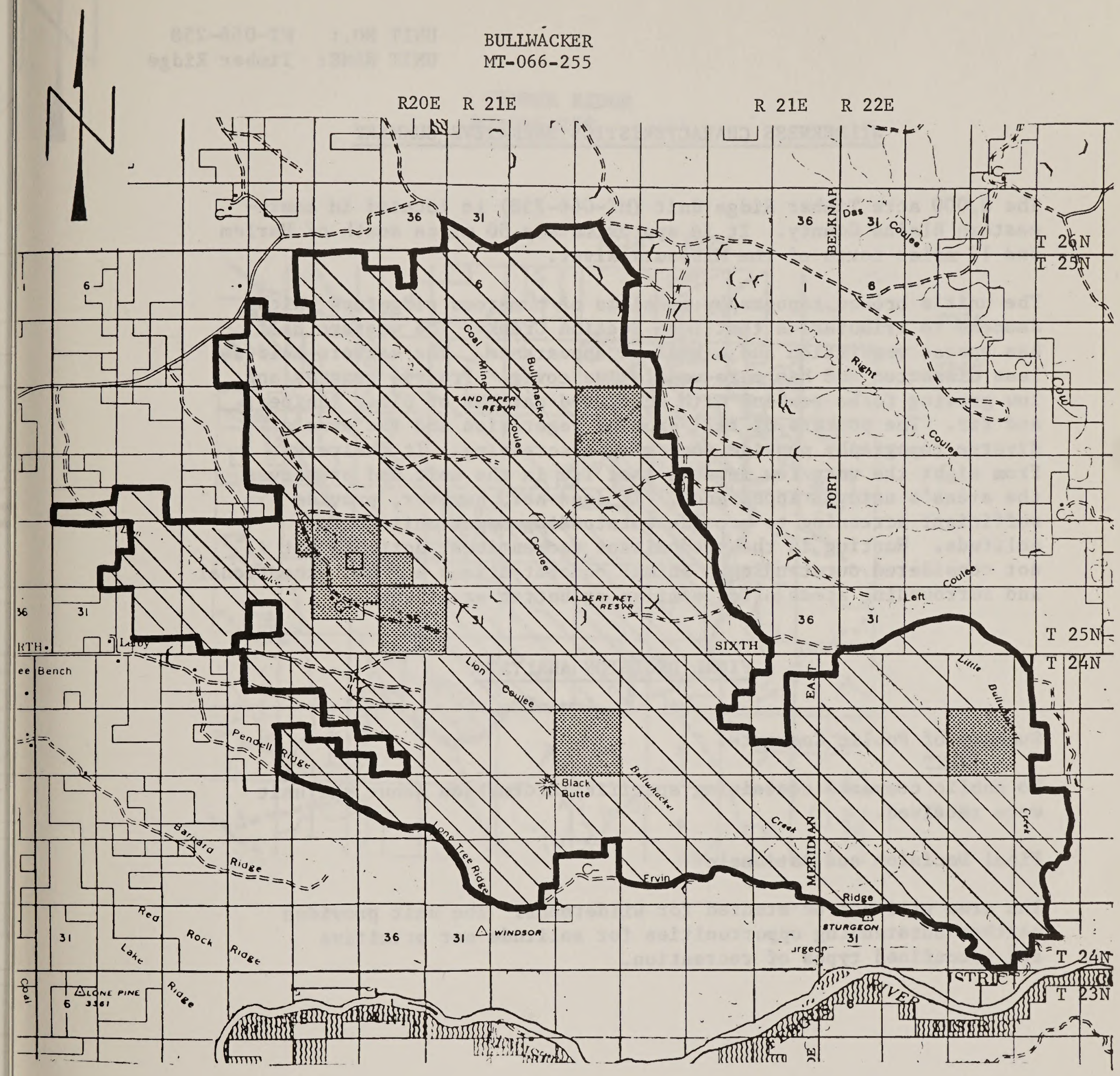

LEGEND

SCALE $1: 126,720$

inch $=1$ mile
W UNIT OR PORTION OF UNIT LACKING WILDERNESS CHARACTERISTICS (NOT RECOMMENDED AS WSA)

AREA DELETED FROM ORIGINAL INVENTORY UNIT DUE TO ROAD IDENTIFICATION

AREA ADDED DUE TO ROAD IDENTIFICATION

PRIVATE OR STATE INHOLDINGS 
The 8,000 acre Timber Ridge Unit (MT-066-258) is located in southeastern Blaine County. It is approximately 50 miles south of Harlem and 12 miles north of the Missouri River.

The unit's broken topography consists of numerous ridgetops which descend to tributaries that feed Suction Creek. The western half has sparse vegetation and a badland appearance. The eastern half is less dissected and has more vegetative cover. Prairie grasses and low growing forbs combine with scattered patches of pine, juniper, and fir. The pockets of tall growing vegetation and the area's diverse topography provide some visual screening. It shelters from sight the very few impacts that lie in the unit and preserves the areas's natural appearance. It does not, however, provide sufficient screening to provide outstanding opportunities for solitude. Hunting is the predominant recreational activity but is not considered outstanding. Animal concentrations are not exceptional and surrounding areas offer similar or better experiences.

\section{FINAL DECISION ANALYSIS}

Summary of Public Comments:

No public comments containing specific information about the unit were received.

Final Decision and Rationale:

The area will not be studied for wilderness. The unit provides neither outstanding opportunities for solitude nor primitive and unconfined types of recreation. 


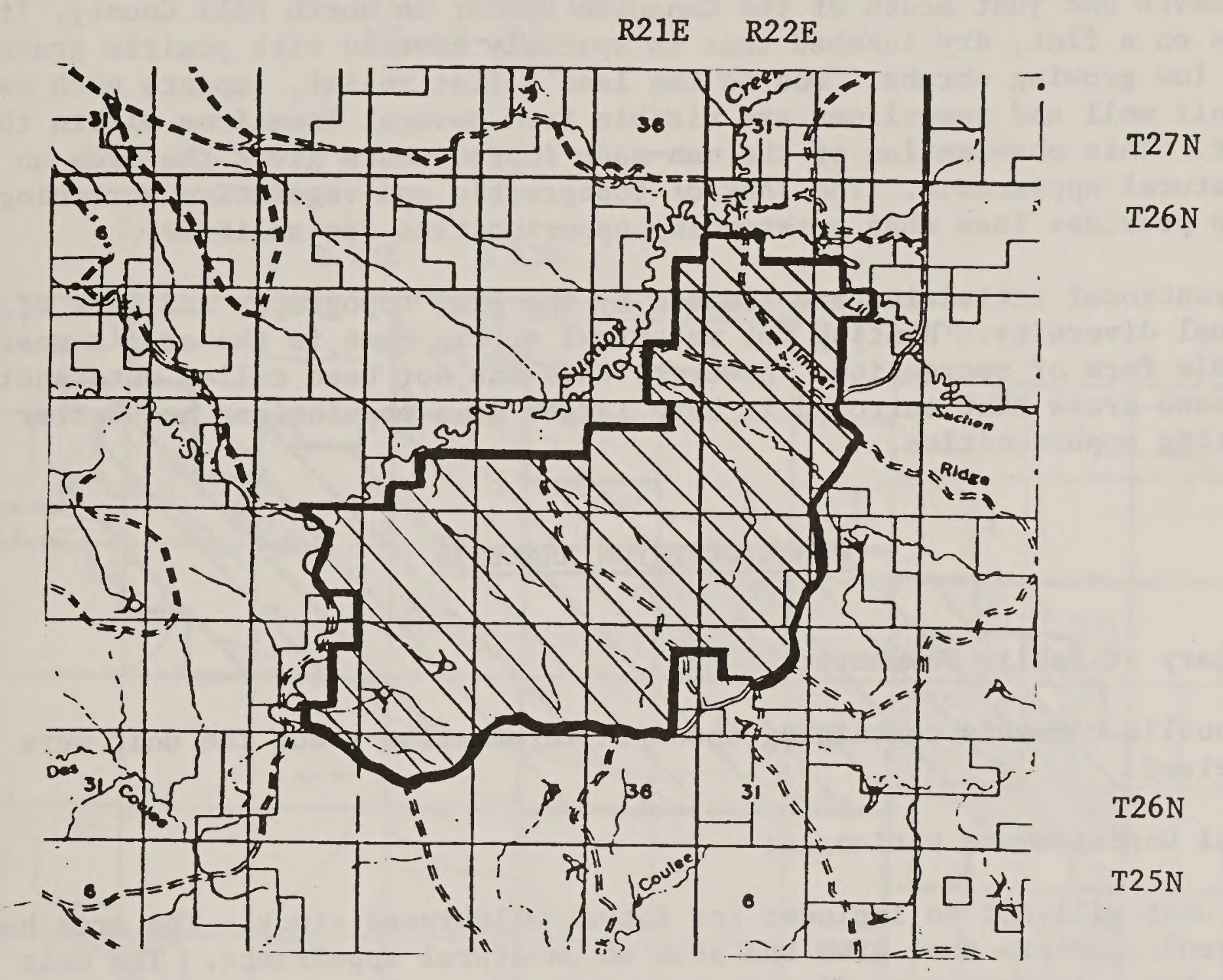

LEGEND

SCALE $1: 126,720$

$\frac{1}{2}$ inch $=1$ mile
DU UNIT OR PORTION OF UNIT LACKING WILDERNESS CHARACTERISTICS (NOT RECOMMENDED AS WSA)

AREA DELETED FROM ORIGINAL INVENTORY UNIT DUE TO ROAD IDENTIFICATION

AREA ADDED DUE TO ROAD IDENTIFICATION PRIVATE OR STATE INHOLDINGS 
UNIT NO.: $\quad$ MT-066-261

UNIT NAME: Wildhorse Lake

\section{WILDERNESS CHARACTERISTICS NARRATIVE SUMMARY}

The 11,453 acre Wildhorse Lake Unit (MT-066-261) is 40 miles north of Havre and just south of the Canadian border in north Hill County. It lies on a flat, dry lakebed that is sparsely covered with prairie grasses and low growing shrubs. Due to the land's flat relief, impacts such as an oil well and powerlines are visible from several locations within the unit. This observation of the man-made improvements gives the area an unnatural appearance. The lack of topographic and vegetative screening also provides less than outstanding opportunities for solitude.

Recreational activities are limited by the flat topography and lack of visual diversity. Hunting for waterfowl or big game is the area's most viable form of recreation. However, this has not been called outstanding because areas that surround it have larger game populations and better hunting opportunities.

\section{FINAL DECISION ANALYSIS}

Summary of Public Comments:

No public comments containing specific information about the unit were received.

Final Decision and Rationale:

The unit will not be included for future wilderness study. The area has numerous impacts that give the area an unnatural appearance. The unit also has neither outstanding opportunities for solitude nor a primitive and unconfined type of recreation because of the flat terrain and lack of ecological diversity. 
UNIT NO.: $\quad$ MT-066-264

UNIT NAME: Woody Island

Coulee

\section{WILDERNESS CHARACTERISTICS NARRATIVE SUMMARY}

The 23,035 acre Woody Island Coulee Unit (MT-066-264) is 6 miles north of Turner along the Canadian border in north Blaine County. It is situated among rolling hills of glacial till covered with prairie grass and low growing shrubs.

The unit has many reservoirs, windmills, and vehicular ways dispersed throughout it. The topography cannot sufficiently screen these improvements from view to insure a natural appearance. The topography and vegetation also do not provide enough protection to avoid the sight, sounds, and evidence of other people in the unit.

Recreational activities are limited by the lack of visual and ecological diversity. Hunting for waterfowl or big game is the areas most viable form of recreation. However, this is not outstanding because areas that surround it have as large or larger game populations and better hunting opportunities.

\section{FINAL DECISION ANALYSIS}

Summary of Public Comments:

No public comments containing specific information about the unit were received.

Final Decision and Rationale:

The unit will not be included for future wilderness study. The area has numerous impacts that give the area an unnatural appearance. The area also lacks outstanding opportunities for either solitude or a primitive and unconfined type of recreation. 

R. $23 \mathrm{E}$.
R. $24 \mathrm{E}$.

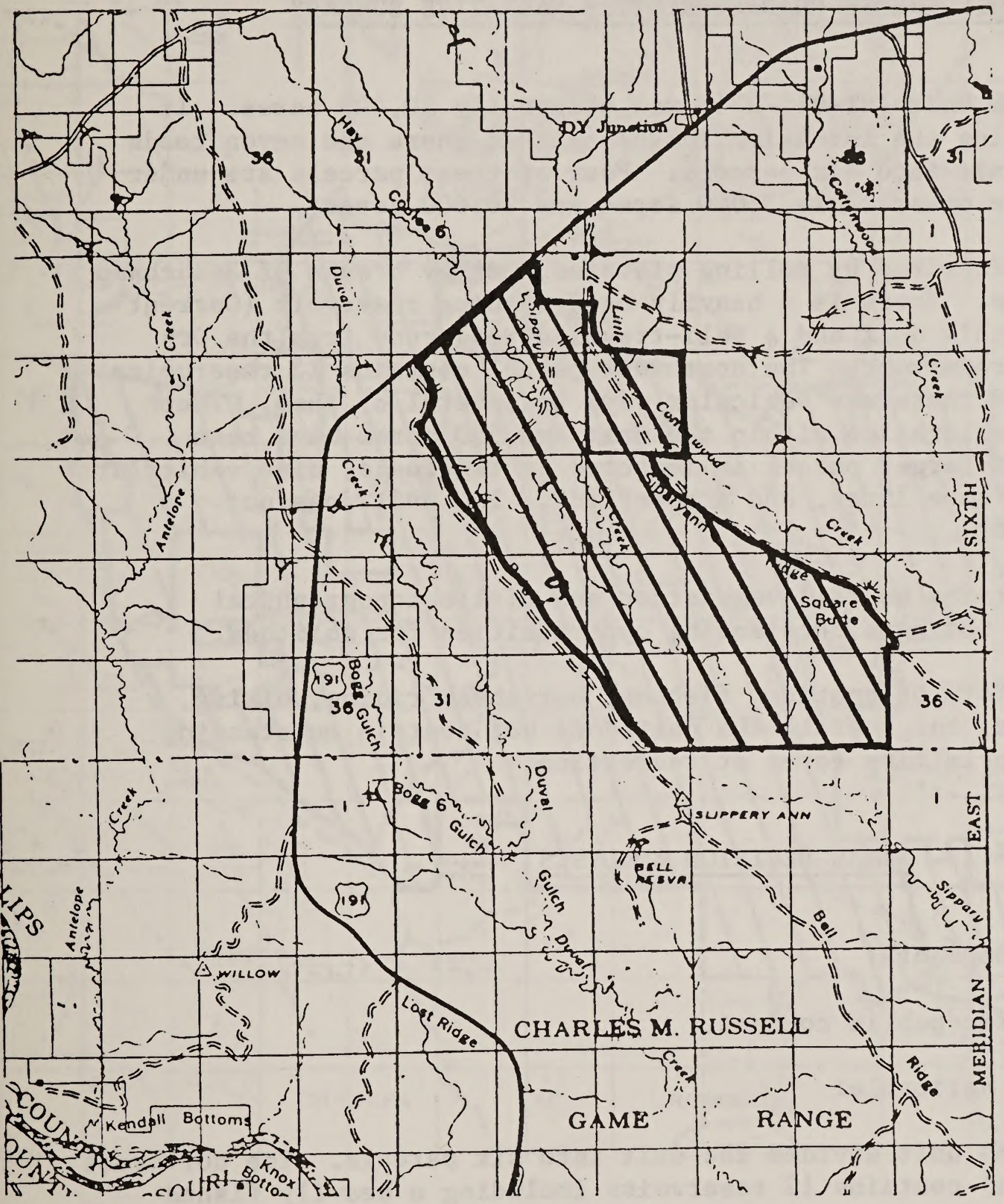

T. $23 \mathrm{~N}$.

SCALE $1: 126,720$

$\frac{1}{2}$ inch $=1 \mathrm{mile}$
MIIV
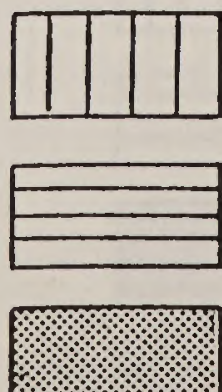

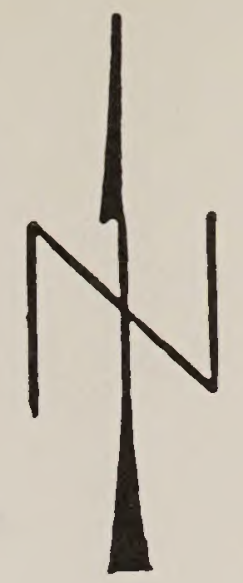

\section{s inch $=1$ mile}

\section{LEGEND}

UNIT OR PORTION OF UNIT LACKING WILDERNESS CHARACTERISTICS (NOT RECOMMENDED AS WSA)

AREA DELETED FROM ORIGINAL INVENTORY UNIT DUE TO ROAD IDENTIFICATION

AREA ADDED DUE TO ROAD IDENTIFICATION

PRIVATE OR STATE INHOLDINGS
\end{abstract}


UNIT NO.: $\quad$ MT-065-274

UNIT NAME: Beauchamp Creek

\section{WILDERNESS CHARACTERISTICS NARRATIVE SUMMARY}

The Beauchamp Creek Unit (MT-065-274) was originally 30,400 acres. It was determined during the intensive inventory that there are seven roads which divide the unit into six parcels. Four of these parcels are under 5,000 acres and the other 2 are 7,000 acres and 20,600 acres.

This unit is characterized by rolling plateaus, cut by breaks of Beauchamp and Dry Fork Creeks. There is a heavily used fishing reservoir (Current Reservoir) within this unit and a wel1-traveled road runs from the Dry Fork Road to this reservoir. The northwest parcel contains 12 reservoirs besides Current and there are vehicular ways to several of them. There has been mineral exploration within the unit and 550 acres have been chisel-plowed. The larger parcel is impacted by two roads, nine vehicular ways, State land, fence lines, and a powerline. The unit does not appear to be natural.

Since the unit contains no tall vegetation and little topographical screening, it does not have outstanding opportunities for solitude.

Recreation in the form of hunting, fishing, horseback riding, hiking, etc., are available, but overall the unit does not contain outstanding opportunities for primitive forms of recreation.

\section{FINAL DECISION ANALYSIS}

Summary of Public Comments:

There was no specific public comment.

Final Decision and Rationale:

The roads within the unit divided the unit into six parcels. The northwest parcel (7,000 acres) contains 12 reservoirs including a heavily fished reservoir, and there are vehicular ways to many of the reservoirs. Five hundred and fifty acres have been chisel-plowed. The large parce1, 20,600 acres, contains 2 roads, 9 vehicular ways, and a powerline. These intrusions significantly detract from the naturalness of both parcels. Neither unit contains enough vegetation or topographical screening to provide outstanding opportunities for solitude of unconfined recreation. This unit will not be studied for wilderness. 


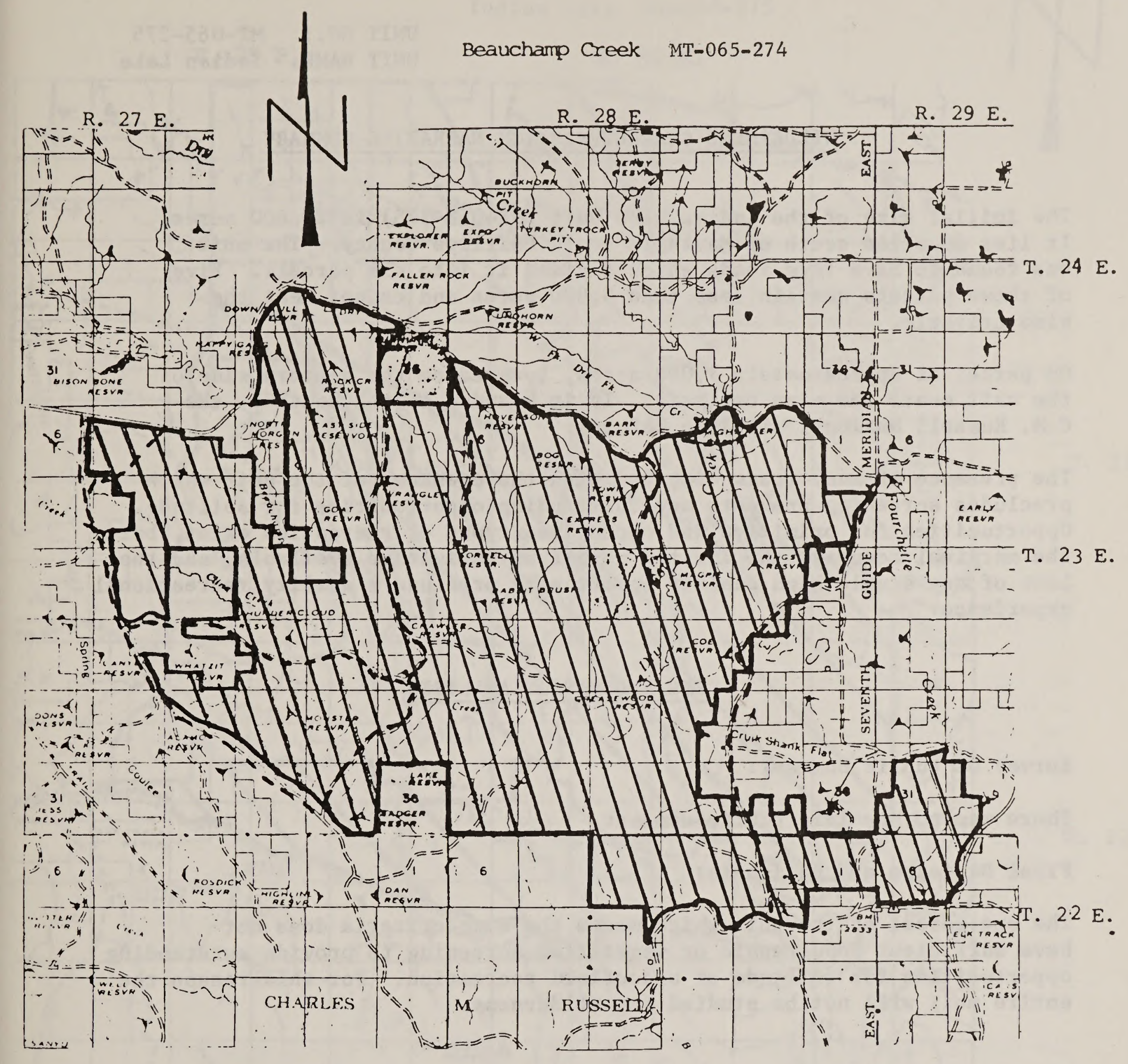

LEGEND

SCALE $1: 126,720$

$\frac{1}{2}$ inch $=1 \mathrm{mile}$

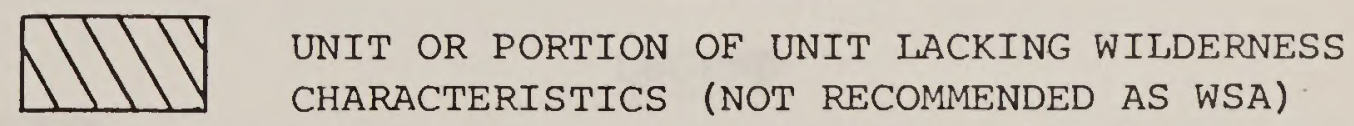

AREA DELETED FROM ORIGINAL INVENTORY UNIT DUE TO ROAD IDENTIFICATION

\section{AREA ADDED DUE TO ROAD IDENTIFICATION}

PRIVATE OR STATE INHOLDINGS 
UNIT NO.: $\quad$ MT-065-275

UNIT NAME: Indian Lake

\section{WILDERNESS CHARACTERISTICS NARRATIVE SUMMARY}

The initial size of the Indian Lake Unit (MT-065-275) is 20,600 acres. It lies 60 miles south of Malta in south Phillips County. The unit was found to have five roads which divided it into six parcels. Five of those parcels contain less than 5,000 acres and cannot meet the size criteria.

On parcel of approximately 7,000 acres, located on the eastern side of the unit meets the size criteria. It is bounded to the south by the C.M. Russell National Wildlife Refuge.

The presence of many roads combined with the openness of the unit which precludes screening prevents any outstanding opportunities for solitude. Opportunities for primitive and unconfined types of recreation exist, but the marginal scenery, the limited number of activities available, and the lack of any single high quality opportunity preclude a quality recreational experience.

\section{FINAL DECISION ANALYSIS}

Survey of Public Comment:

There was no specific public comment.

Final Decision and Rationale:

The one parcel of the unit which meets the size criteria does not have sufficient topographic or vegetative screening to provide outstanding opportunities for solitude or unconfined recreation. For this reason the entire unit will not be studied for wilderness. 
Ind1an Lake MT-065-275

R. $29 \mathrm{E}$.

R. $30 \mathrm{E}$.

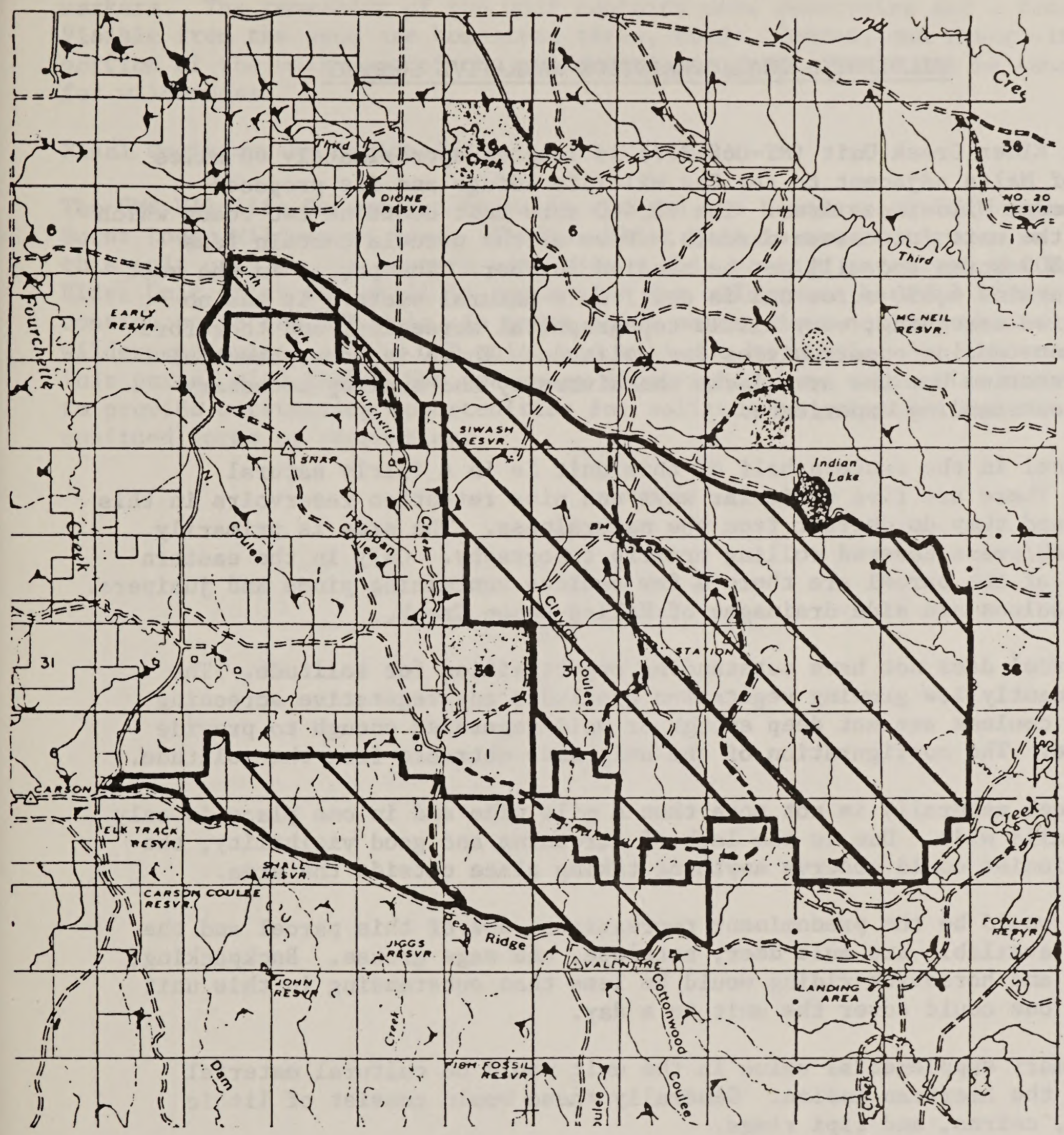

T. $23 \mathrm{~N}$.

T. $22 \mathrm{~N}$.

\section{I.EGEND}

SCALE $1: 126,720$

$\frac{1}{2}$ inch $=1 \mathrm{mile}$
WU UNIT OR PORTION OF UNIT LACKING WILDERNESS CHARACTERISTICS (NOT RECOMMENDED AS WSA)

AREA DELETED FROM ORIGINAL INVENTORY UNIT DUE TO ROAD IDENTIFICATION

AREA ADDED DUE TO ROAD IDENTIFICATION

PRIVATE OR STATE INHOLDINGS 
UNIT NO.: MT-068-277

UNIT NAME: Box Elder Creek

\section{WILDERNESS CHARACTERISTICS NARRATIVE SUMMARY}

The Box Elder Creek Unit (MT-068-277) is located approximately 60 miles south of Malta adjacent to the CMR Wildlife Refuge and its proposed Burnt Lodge Wilderness Area. The 19,440 acre unit contains two roads which divide the unit into seven parcels. Five of the parcels contain less than 5,000 acres and will not be studied further. The parcel in the west half contains 6,890 acres and is still in a natural state. It has no vegetative screening, very little topographical screening, and therefore lacks outstanding opportunities for solitude. There is some potential for recreation but the area lacks the diversity and quality necessary for an outstanding experience.

The parcel in the eastern half of this unit is in a fairly natural state. There are five vehicular ways and nine retention reservoirs in this parcel and they do detract from the naturalness. The area is primarily sagebrush/grass covered rolling prairie topography. Only in the eastern portion of the parcel are there a few coulees containing pines and junipers. These coulees are side drainages of Killed Woman Creek.

This parcel does not have outstanding opportunities for solitude. The predominantly low growing vegetation precludes any vegetative screening and the coulees are not deep enough or well vegetated enough to provide solitude. The configuration of the unit also detracts from the solitude.

The parcel generally is not more than a mile wide and in one place is only $\frac{1}{4}$ of a mile wide. Due to the lack of screening and good visibility, the recreationist could observe anything taking place outside the area.

Hunting would be the predominant recreational use of this parcel and the species available are mule deer, antelope, and sage grouse. Backpacking, hiking, and horseback riding would be less than outstanding in this unit because one could cover the unit in a day.

The primary supplemental value in the unit would be cultural material left by the American Indian. Generally these would consist of lithic scatter, cairns, and tipi rings.

\section{FINAL DECISION ANALYSIS}

Summary of Public Comments:

One comment stated that the vehicular way located in Sections $23-24$ should meet the definition of a road. This road leads to private property located adjacent to Killed Woman Creek. The southeastern portion of the unit adjacent 
to another proposed WSA, does exhibit naturalness even though it contains a reservoir and numerous Charles M. Russell National Wildlife boundary markers. The remainder of the unit contains more reservoirs and a fence. Visible from the area are homestead sites, roads, fences, and reservoirs. The portion of the unit west of the aforementioned creek should not be considered for wilderness.

Final Decision and Rationale:

The CMR Wildlife Refuge has recently changed the boundary of its proposed Burnt Lodge Wilderness Area. The Box Elder Unit is now contiguous to this unit only on its eastern most side. This eastern parcel of the Box Elder Unit which was still in contention for wilderness because it was contiguous to the CMR Unit, is under 5,000 acres, does not add to the wilderness values of the CMR unit, and will not be studied for wilderness. This parcel also lacked the necessary topographical or vegetative screening to provide outstanding opportunities for solitude or primitive and unconfined forms of recreation. 


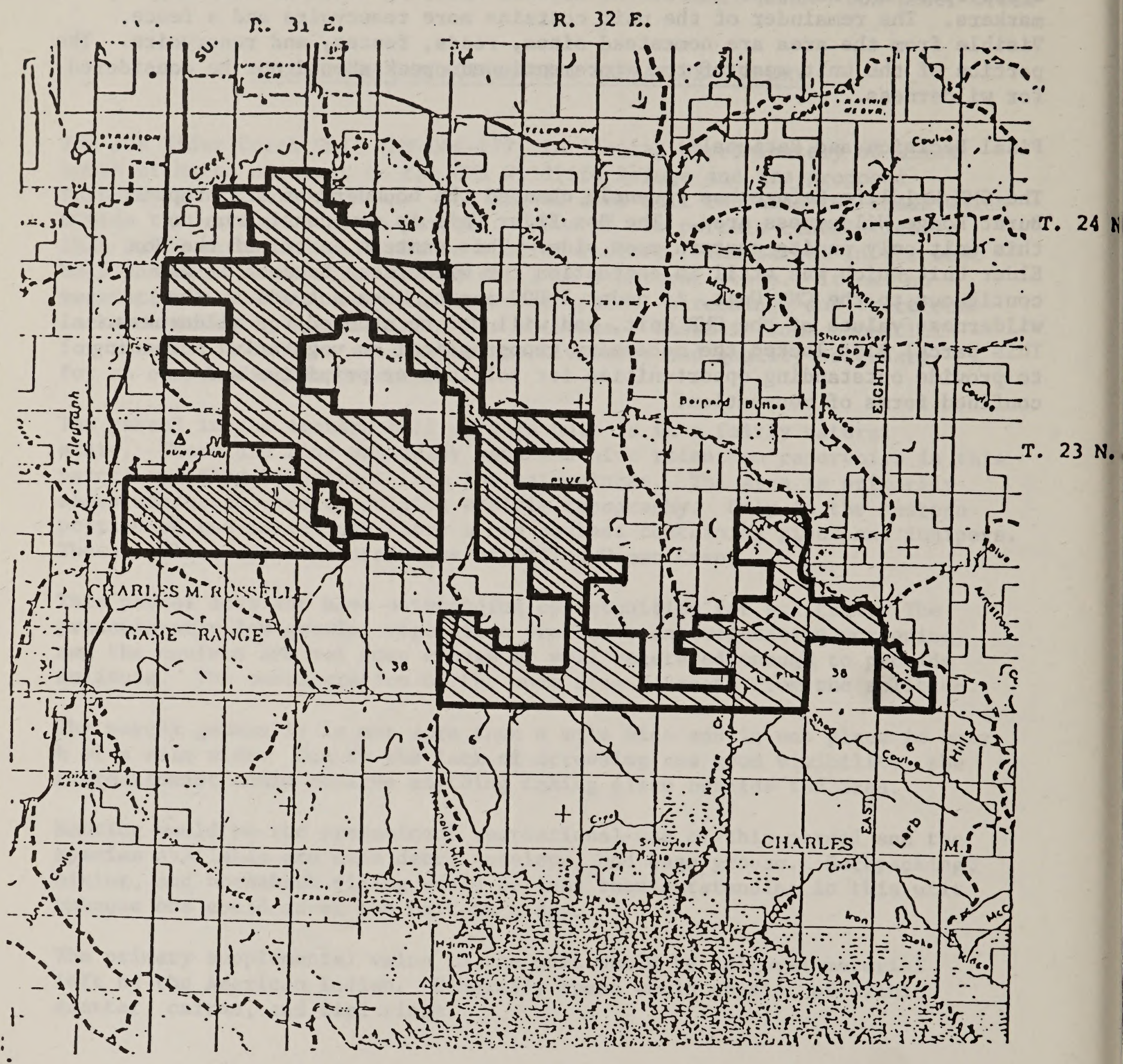

LEGEND

SCALE 1:126,720

is inch $=1$ mile
MIIV
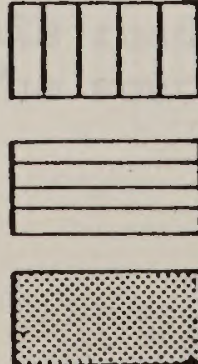

UNIT OR PORTION OF UNIT LACKING WILDERNESS CHARACTERISTICS (NOT RECOMMENDED AS WSA)

AREA DELETED FROM ORIGINAL INVENTORY UNIT DUE TO ROAD IDENTIFICATION

AREA ADDED DUE TO ROAD IDENTIFICATION

PRIVATE OR STATE INHOLDINGS 


\section{WILDERNESS CHARACTERISTICS NARRATIVE SUMMARY}

The initial size of the Dry Fork Creek Unit (MT-065-280) was 16,000 acres. It is 45 miles south of Malta in south Phillips County. The unit has a road that bisects it into two separate parcels. The eastern parcel has 8,700 acres and the western parcel contains 7,300 acres.

Both parcels have numerous impacts such as reservoirs and vehicular ways that impair their apparent naturalness. The unit's lack of size and visual screening prevents any outstanding opportunities for solitude. Primitive and unconfined types of recreation exist but their lack of diversity and uniqueness in relation to surrounding areas make them less than outstanding.

\section{FINAL DECISION ANALYSIS}

Summary of Public Comments:

There was no specific public comment.

Final Decision and Rationale:

The reservoirs and vehicular ways within both parcels detract somewhat from the naturalness. This unit lacks good vegetative or topographical screening and thus has no outstanding opportunities for solitude or primitive or unconfined recreation. This unit will not be studied for wilderness. 


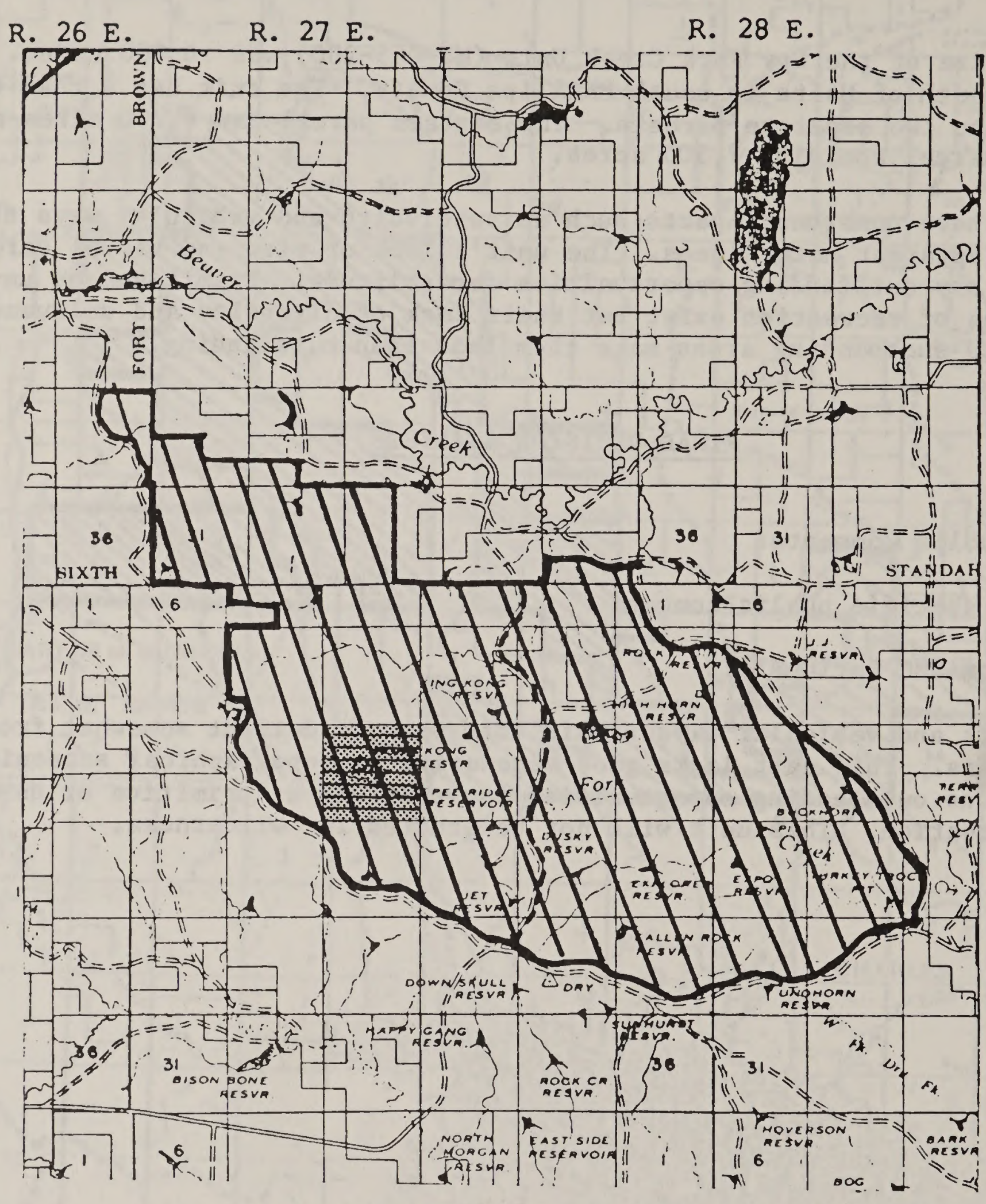

T. $25 \mathrm{~N}$.

T. $24 \mathrm{~N}$.

\section{LEGEND}

SCALE $1: 126,720$ $\frac{1}{2}$ inch $=1$ mile
MIIV
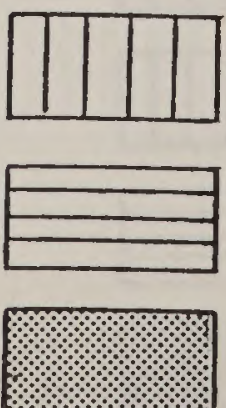

UNIT OR PORTION OF UNIT LACKING WILDERNESS CHARACTERISTICS (NOT RECOMMENDED AS WSA)

AREA DELETED FROM ORIGINAL INVENTORY UNIT DUE TO ROAD IDENTIFICATION

AREA ADDED DUE TO ROAD IDENTIFICATION

PRIVATE OR STATE INHOLDINGS 
UNIT NO.: : MT-065-282

UNIT NAME: Third Creek

\section{WILDERNESS CHARACTERISTICS NARRATIVE SUMMARY}

The 31,860 acre Third Creek Unit (MT-065-282) is approximately 70 miles south of Malta and 5 miles north of the C.M. Russell National Wildlife Refuge. Five roads divide it into five parcels with three of the parcels having less than 5,000 acres. The two remaining parcels contain 11,500 acres and 13,500 acres.

The two large parcels have numerous impacts that have altered the apparent naturalness. They both possess very little topographic relief and have no vegetative screening to provide seclusion for a potential user. This landform also contributes to a lack of recreational diversity which limits opportunities for a primitive and unconfined type of recreation.

\section{FINAL DECISION ANALYSIS}

Summary of Public Comment:

There was no specific public comment.

Final Decision and Rationale:

The two parcels which meet the size criteria do not contain sufficient topographical or vegetative screening to provide outstanding opportunities for solitude. Primitive recreation opportunities are not outstanding. This unit will not be studied for wilderness. 


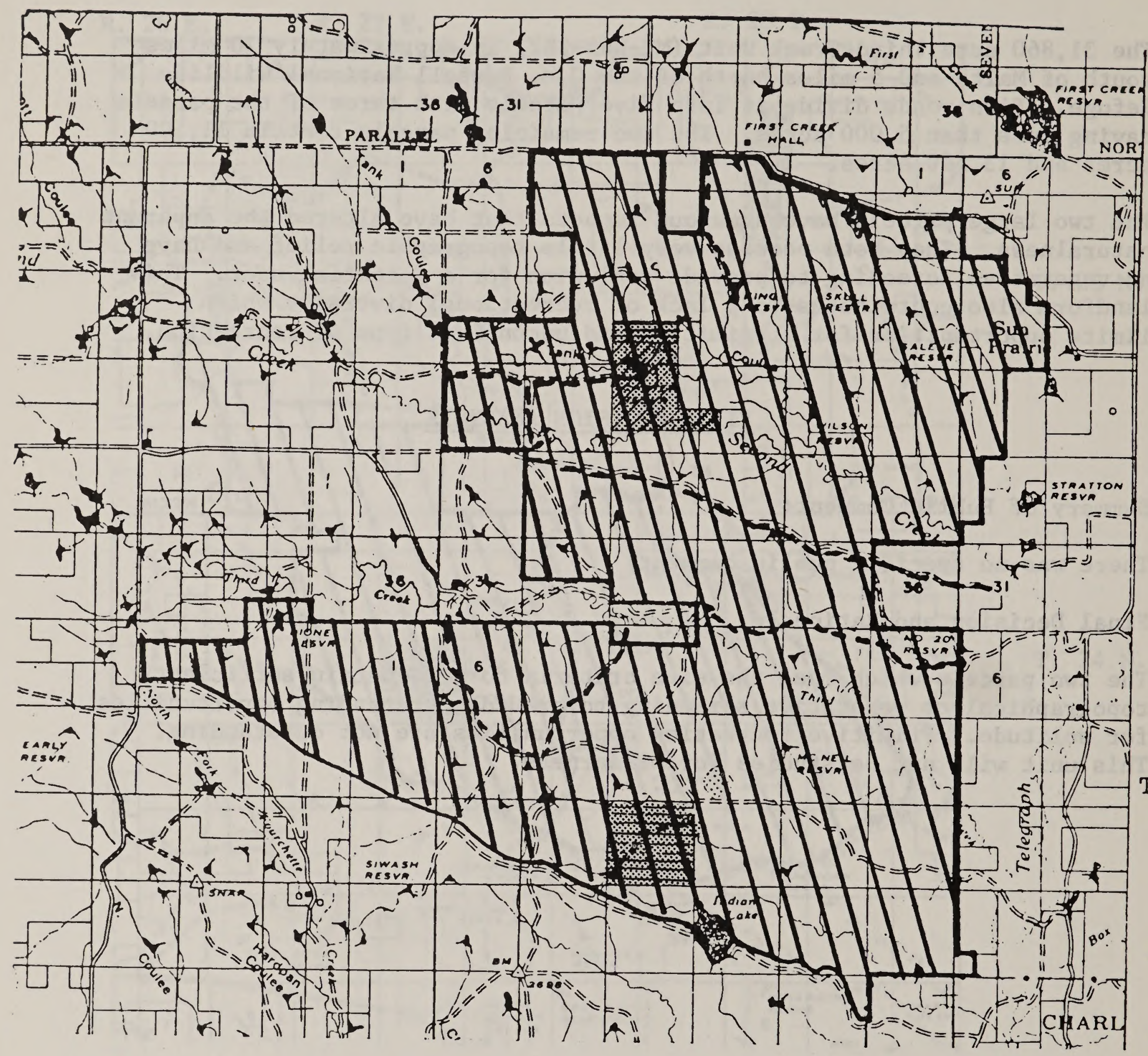

T. $24 \mathrm{~N}$.

SCALE $1: 126,720$

$\frac{1}{2}$ inch $=1 \mathrm{mile}$

\section{LEGEND}

MIIV UNIT OR PORTION OF UNIT LACKING WILDERNESS CHARACTERISTICS (NOT RECOMMENDED AS WSA)

AREA DELETED FROM ORIGINAL INVENTORY UNIT DUE TO ROAD IDENTIFICATION

AREA ADDED DUE TO ROAD IDENTIFICATION

PRIVATE OR STATE INHOLDINGS 
UNIT NO.: $\quad$ MT-065-286

UNIT NAME: Little Rockies

\section{WILDERNESS CHARACTERISTICS NARRATIVE SUMMARY}

The Little Rockies Unit (MT-065-286) is located in the northwestern portion of the Little Rocky Mountains managed by the BLM. The unit is mountainous terrain covered by ponderosa pine, Douglas fir, lodgepole pine, and deciduous shrubs. The unit contains approximately 6,900 acres and includes four separate parcels of patented land.

There are four roads and numerous old mining digs throughout the unit as well as tree thinning areas, all of which detract from the naturalness in their vicinity. Overall the unit does have a good deal of naturalness, aside from the intrusions mentioned.

Adjacent to the southeastern and southwestern boundaries of the unit are gold mines. These mines are generally working 24 hours a day. The blasting from the mining can be heard throughout the unit and as far away as Camp Creek Campground. The mining is done with D8, D9 and D10 caterpillar tractors, large haul trucks, and scrapers whose sounds filter into much of the unit. The mining activity can be seen from any of the peaks within the unit and at night the lights can be seen from within the unit. In fact the lights can be seen for 50 miles or more. Roads form the border on the east and south and the traffic on these roads can be heard from within the unit, how far depending on the immediate topography. Recognizing the fact that the mining takes place outside the unit, nevertheless, it is of such magnitude that it effectively destroys the solitude in most of the unit.

Opportunities for primitive and unconfined recreation exist within the unit, however, they are not outstanding. Hiking is available on old logging and fire trails within the unit. Much of the unit is heavy timber, some of it so dense that it would be impossible to walk through. There are very few open parks within the unit and this would create problems for those who wished to photograph or observe wildlife. Hunting for mule deer, whitetail deer, and mountain grouse is available within the unit, but because the area is so heavily timbered, it is not considered outstanding.

Supplemental values include an old lime kiln and historic mining digs.

\section{FINAL DECISION ANALYSIS}

Summary of Public Comment:

One comment received stated that intrusions within this unit could be easily rehabilitated. The unit has scenic value, excellent hiking, and opportunities for photography and wildlife observations. This unit should be included in the wilderness system. 
A second comment stated that the unit should not be designated as a wilderness area because of the visual impacts. The large scale disruptive visual activity and daily blasting would destroy the solitude. The unit also contains mining claims, buildings, fences, roads, logging trails, private property, and a study area for university geology students. If the unit becomes a wilderness area it would effect the existing recreation and the economy of the area.

Final Decision and Rationale:

The Little Rockies Unit will not be studied for wilderness. Although it does have some of the qualities necessary for wilderness study, the unit is overwhelmed by the sight and sounds of the large mining complex adjacent to its boundaries. The unit is small $(6,900$ acres) and it would be difficult for one to get far enough from the mining to be out of its sphere of influence. Recreation activities are not considered outstanding. 
R. $24 \mathrm{E}$.

R. 25 E.

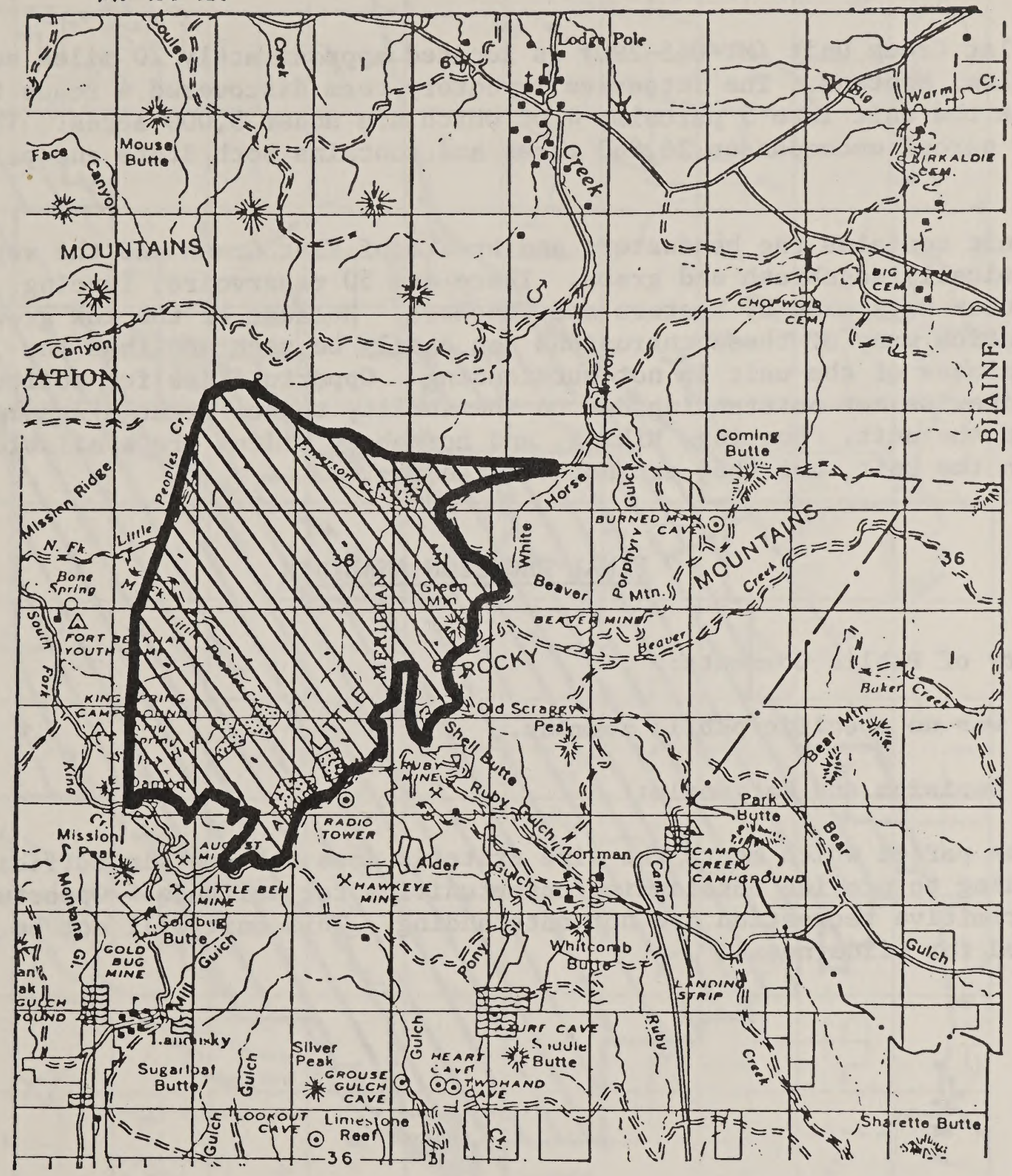

T. $26 \mathrm{~N}$.

T. $25 \mathrm{~N}$.

\section{LEGEND}

SCALE $1: 126,720$ inch $=1 \mathrm{mile}$
MIIV
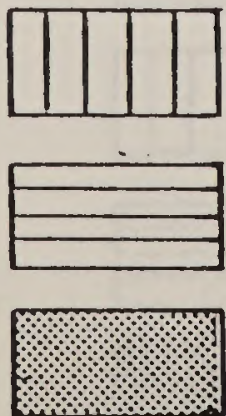

UNIT OR PORTION OF UNIT LACKING WILDERNESS CHARACTERISTICS (NOT RECOMMENDED AS WSA)

AREA DELETED FROM ORIGINAL INVENTORY UNIT DUE TO ROAD IDENTIFICATION

AREA ADDED DUE TO ROAD IDENTIFICATION
PRIVATE OR STATE INHOLDINGS


UNIT NO.: $\quad$ MT-065-290

UNIT NAME: Flat Creek

\section{WILDERNESS CHARACTERISTICS NARRATIVE SUMMARY}

The Flat Creek Unit (MT-065-290) is located approximately 20 miles south of Malta, Montana. The intensive inventory team discovered 4 roads that divide the unit into 5 parcels, 4 of which are under 5,000 acres. The fifth parcel encompasses 26,860 acres and contains both State and private land.

The unit contains the headwaters and breaks of Flat Creek and the vegetation is basically sagebrush and grass. There are 50 reservoirs, fencing, and vehicular ways made by hunters and ranchers. Because of the low growing vegetation many of these intrusions can easily be seen and thus the naturalness of the unit is not outstanding. Opportunities for solitude are likewise not outstanding due to the ability to see great distances within the unit. Hunting, hiking, and horseback riding are available within the unit, but they are not outstanding.

\section{FINAL DECISION ANALYSIS}

Summary of Public Comments:

There was no specific public comment.

Final Decision and Rationale:

The one parcel which meets the size criteria does not contain sufficient screening to provide outstanding opportunities for solitude. Opportunities for primitive recreation are not outstanding. This unit will not be studied for wilderness. 
R. $30 \mathrm{E}$.

R. $31 \mathrm{E}$.

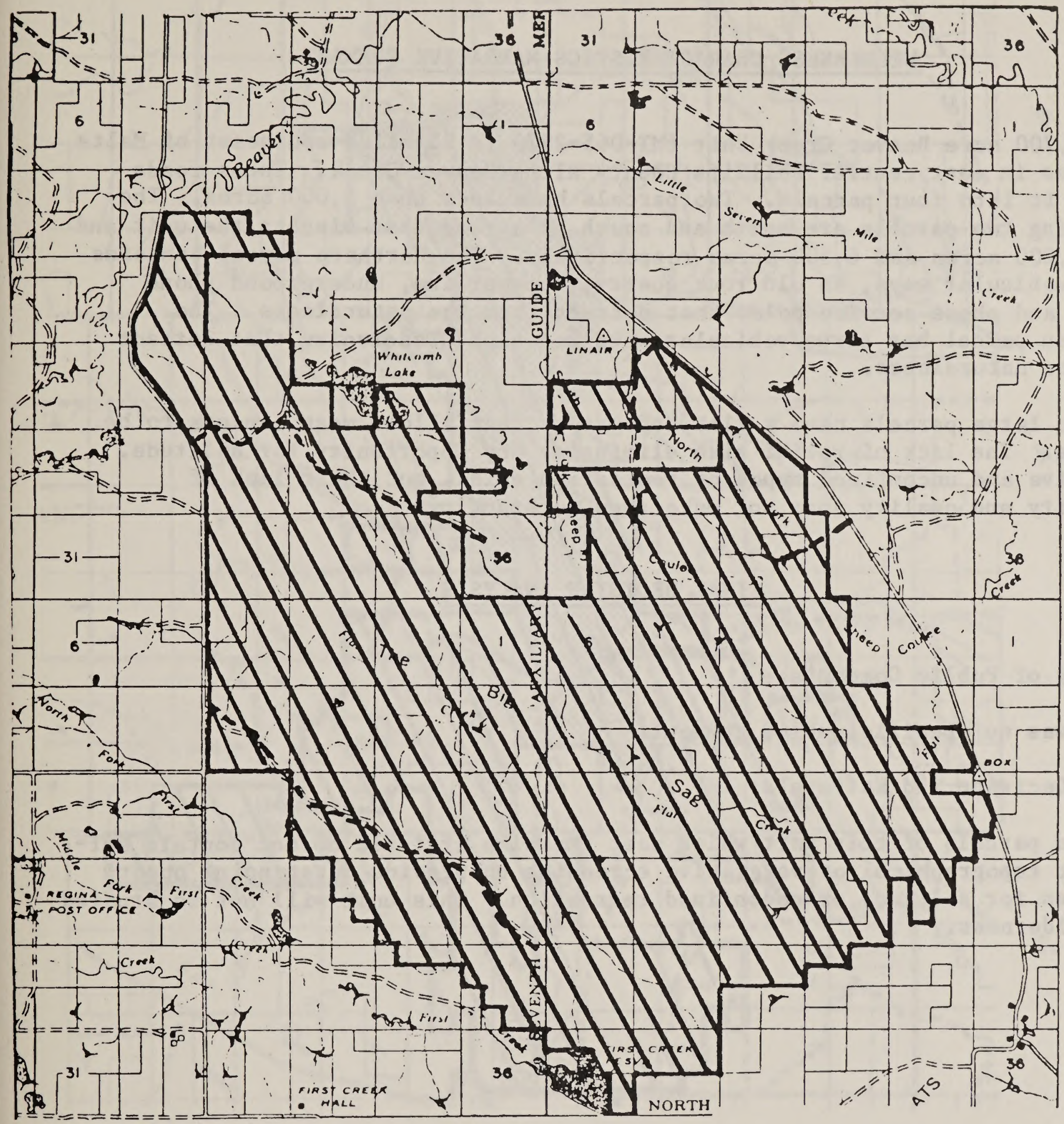

T. $26 \mathrm{~N}$.

T. $25 \mathrm{~N}$.

\section{LEGEND}

SCALE $1: 126,720$

$\frac{1}{2}$ inch $=1$ mile
MIIV

UNIT OR PORTION OF UNIT LACKING WILDERNESS CHARACTERISTICS (NOT RECOMMENDED AS WSA)

AREA DELETED FROM ORIGINAL INVENTORY UNIT DUE TO ROAD IDENTIFICATION

AREA ADDED DUE TO ROAD IDENTIFICATION

PRIVATE OR STATE INHOLDINGS 
UNIT NO.: $\quad$ MT-065-297

UNIT NAME: Beaver Creek

\section{WILDERNESS CHARACTERISTICS NARRATIVE SUMMARY}

The 19,700 acre Beaver Creek Unit (MT-065-297) is 25 miles southeast of Malta and lies in east central Phillips County along Beaver Creek. Three roads divide it into four parcels. Two parcels have less than 5,000 acres. The remaining two parcels are north and south of a road that bisects the unit and have 8,200 acres and 6,500 acres respectively. The northern parcel contains eight vehicular ways, an old rock quarry, a powerline, underground phone lines, and phone service poles that detract from the naturalness. The southern parcel has three vehicular ways and eight reservoirs that detract from the naturalness.

The two large parcels have a flat topography that allows most impacts to be visible. The lack of relief also eliminates any opportunity for solitude. Primitive and unconfined types of recreation exist, but their lack of diversity and quality does not make them outstanding.

\section{FINAL DECISION ANALYSIS}

Summary of Public Comments:

There was no specific public comment.

Final Decision and Rationale:

The two parcels of this unit which meet the size criteria do not contain sufficient topographical or vegetative screening to provide outstanding opportunities for solitude or unconfined recreation. This unit will not be studied for wilderness. 

R. $31 \mathrm{E}$.
R. $32 \mathrm{E}$.
R. $33 \mathrm{E}$.

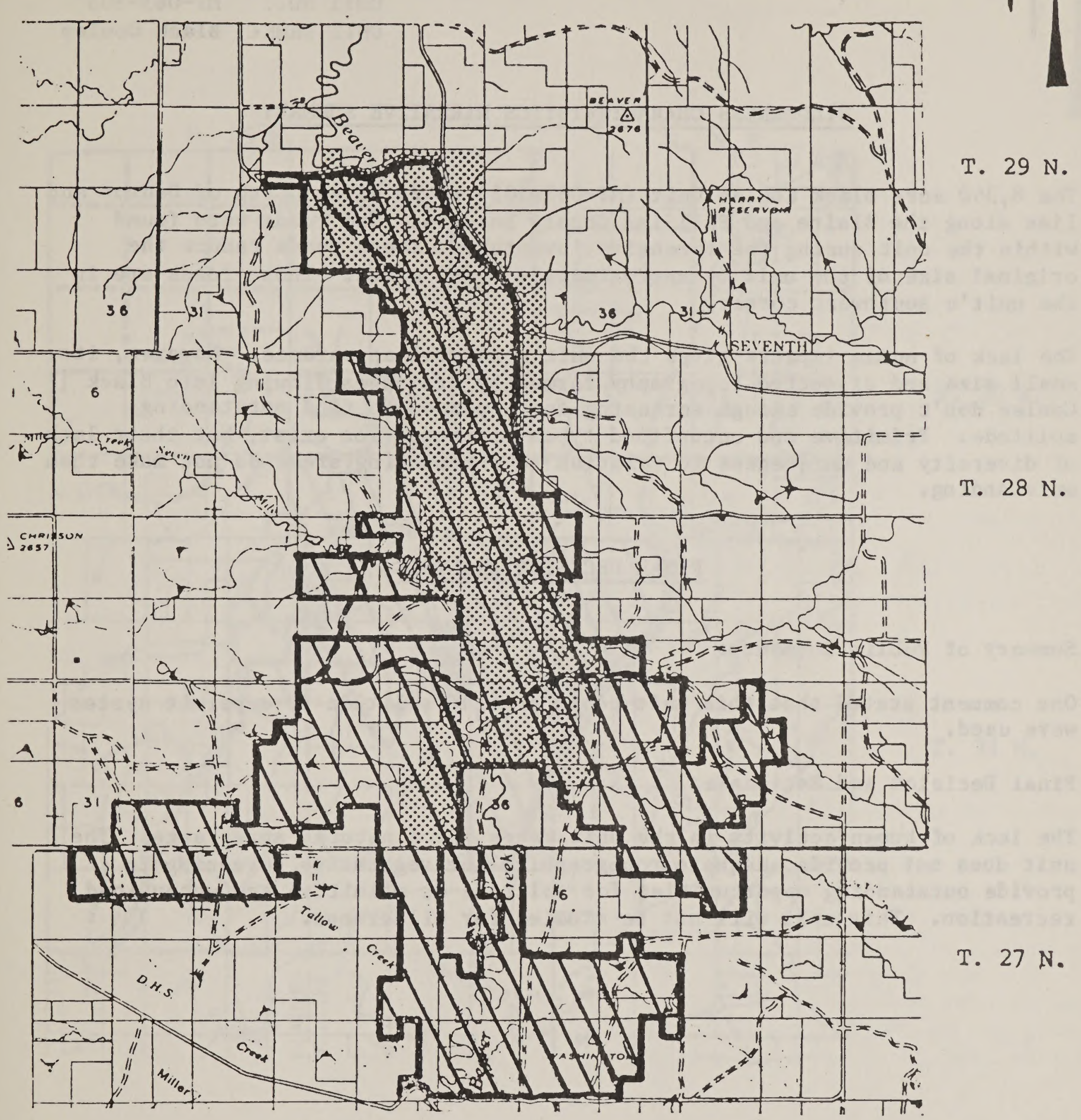

LEGEND

SCALE 1:126,720

$\frac{1}{2}$ inch $=1 \mathrm{mile}$
1D UNIT OR PORTION OF UNIT LACKING WILDERNESS CHARACTERISTICS (NOT RECOMMENDED AS WSA)

AREA DELETED FROM ORIGINAL INVENTORY UNIT DUE TO ROAD IDENTIFICATION

AREA ADDED DUE TO ROAD IDENTIFICATION

RECLAMATION OR POWER SITE WITHDRAWAL 
UNIT NO.: $\quad$ MT-065-303

UNIT NAME: Black Coulee

\section{WILDERNESS CHARACTERISTICS NARRATIVE SUMMARY}

The 8,360 acre Black Coulee Unit (MT-065-303) is 25 miles north of Dodson and lies along the Blaine and Phillips County borders. Two roads were found within the unit during the intensive inventory. These roads reduce the original size of the unit by approximately 1,000 acres. Those roads are in the unit's southwest corner.

The lack of human impacts gives the unit a natural appearance. However, its small size and dissected topography formed by drainages flowing into Black Coulee don't provide enough screening for a person to find outstanding solitude. Primitive and unconfined types of recreation exist, but their lack of diversity and uniqueness in relation to surrounding areas do not make them outstanding.

\section{FINAL DECISION ANALYSIS}

Summary of Public Comments:

One comment stated that this unit could provide solitude if a permit system were used.

Final Decision and Rationale:

The lack of human activity in the unit makes for a natural appearance. The unit does not provide adequate topographical or vegetative screening to provide outstanding opportunities for solitude or primitive and unconfined recreation. This unit will not be studied for wilderness. 


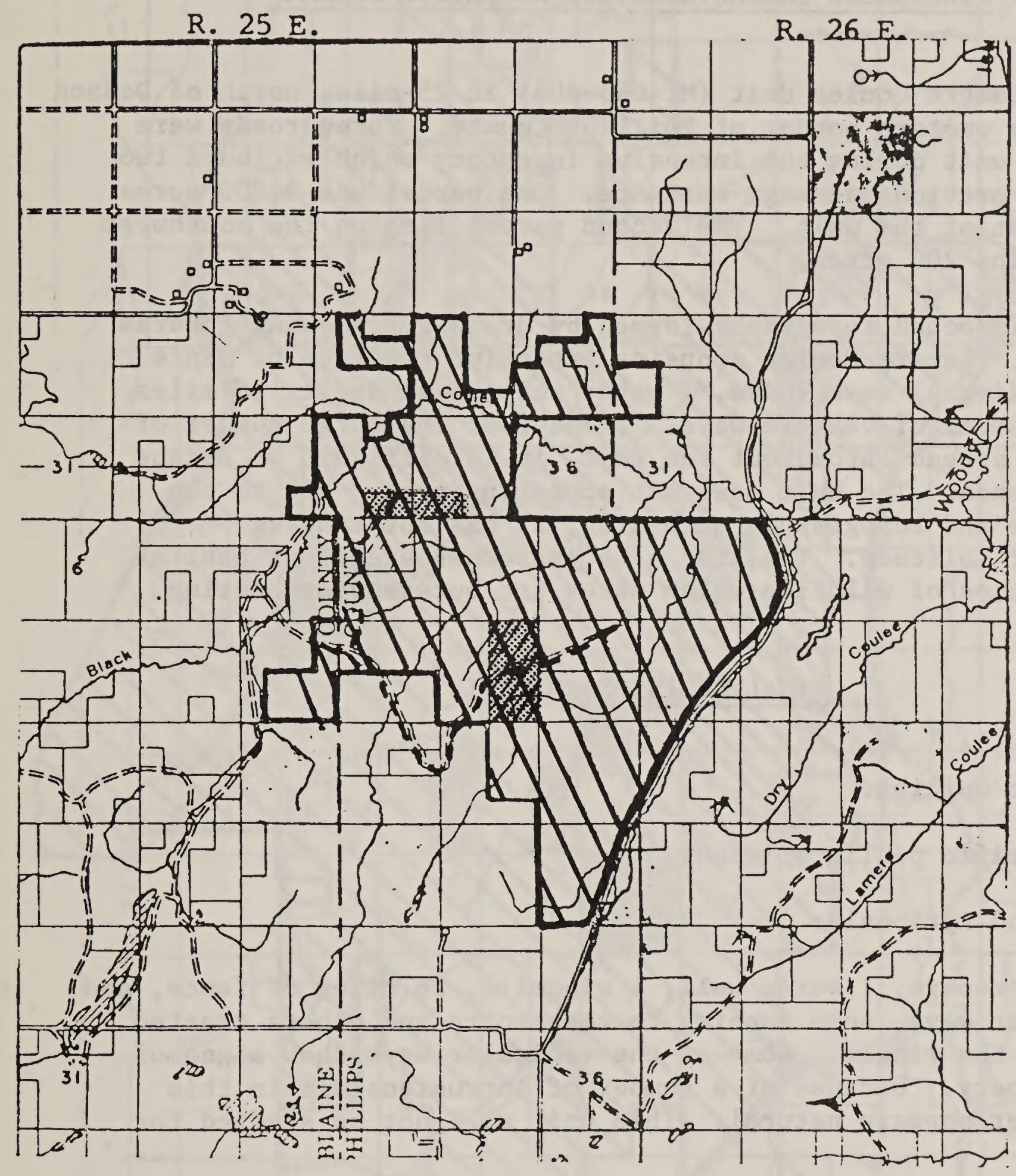

T. $35 \mathrm{~N}$.

T. $34 \mathrm{~N}$.

LEGEND

SCALE $1: 126,720$

$\frac{1}{2}$ inch $=1$ mile

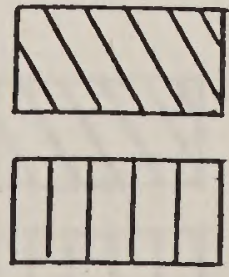

UNIT OR PORTION OF UNIT LACKING WILDERNESS CHARACTERISTICS (NOT RECOMMENDED AS WSA)

AREA DELETED FROM ORIGINAL INVENTORY UNIT DUE TO ROAD IDENTIFICATION

AREA ADDED DUE TO ROAD IDENTIFICATION

PRIVATE OR STATE INHOLDINGS 
UNIT NO.: $\quad$ MT-065-304

UNIT NAME: Lamere Coulee

\section{WILDERNESS CHARACTERISTICS NARRATIVE SUMMARY}

The 33, 800 acre Lamere Coulee Unit (MT-065-304) is 25 miles north of Dodson and lies near the western border of Phillips County. Three roads were found within the unit during the intensive inventory which excluded two parcels from the previous acreage estimate. One parcel has 3,200 acres and lies northwest of the unit. The second parcel lies on the southwest corner and contains 200 acres.

The unit has a dissected topography formed by drainages flowing towards Cottonwood Creek. Lamere Coulee contains extensive evidence of man's activities including 47 reservoirs, 1 water well, 1 windmill, 26 miles of fence and a number of vehicle ways. Because of the large number of evidences of man spread throughout the unit, it is difficult to escape from human influence. The unit does not appear natural. Due to the unit's large size and topographic screening, it has outstanding opportunities for solitude. The area also possesses excellent habitat for numerous species of wildlife which makes for outstanding hunting.

\section{FINAL DECISION ANALYSIS}

Summary of Public Opinion:

There was no specific public opinion.

Final Decision and Rationale:

There are 47 reservoirs, 1 water well, 1 windmill, 26 miles of fence, and numerous vehicular ways, some running to reservoirs and others created by hunters along the ridges. Some of the vehicular ways show signs of blading by machinery. Because of a number of intrusions within this unit, it no longer appears natural. This unit will not be studied for wilderness. 


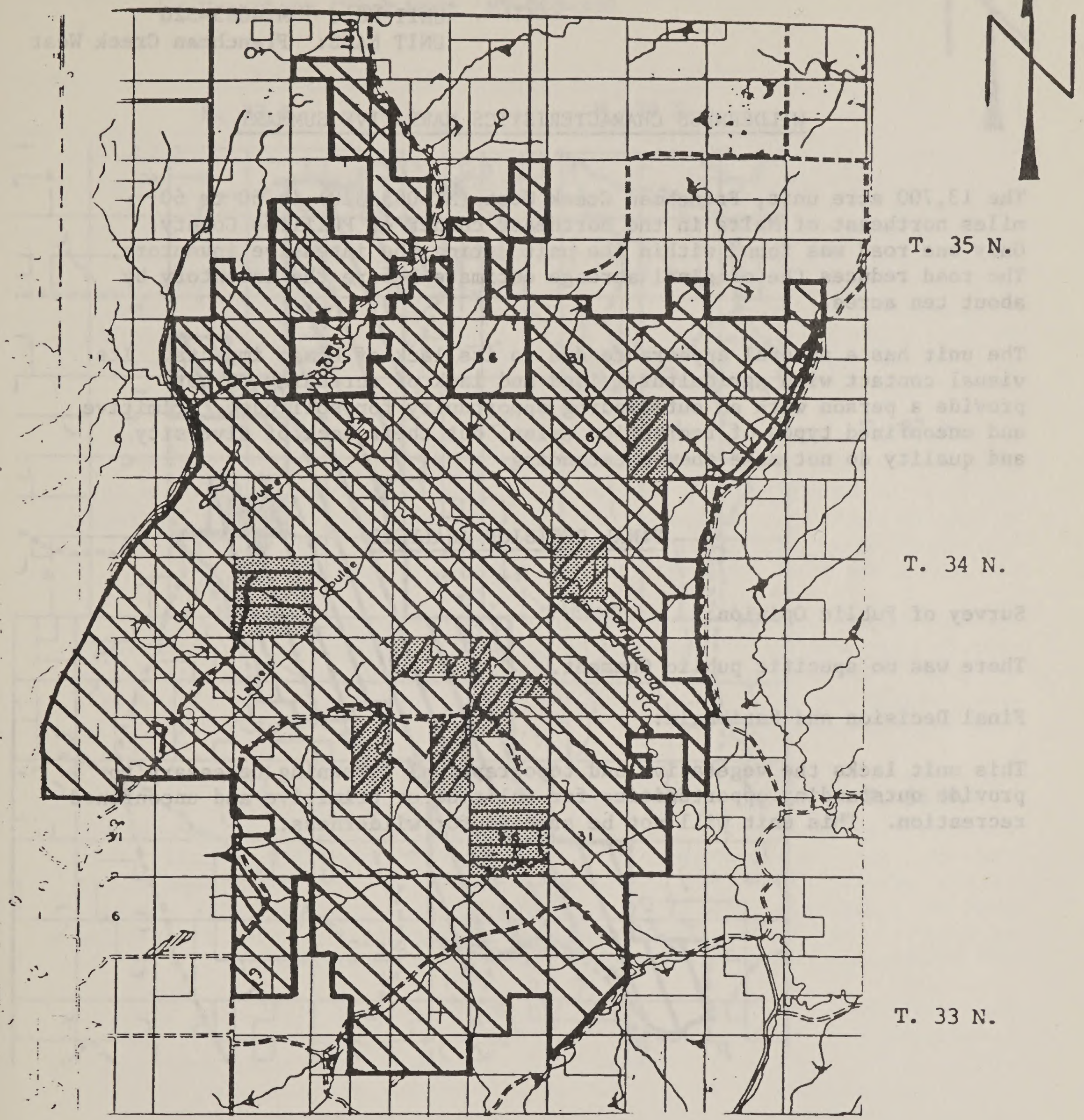

\section{LEGEND}

SCALE $1: 126,720$

$\frac{1}{2}$ inch $=1 \mathrm{mile}$
WU UNIT OR PORTION OF UNIT LACKING WILDERNESS CHARACTERISTICS (NOT RECOMMENDED AS WSA)

AREA DELETED FROM ORIGINAL INVENTORY UNIT DUE TO ROAD IDENTIFICATION

AREA ADDED DUE TO ROAD IDENTIFICATION

PRIVATE OR STATE INHOLDINGS 
UNIT NO.: MT-065-320

UNIT NAME: Frenchman Creek West

\section{WILDERNESS CHARACTERISTICS NARRATIVE SUMMARY}

The 13,700 acre unit, Frenchman Creek West (MT-065-320) is 50 to 60 miles northeast of Malta in the northeast corner of Phillips County. Only one road was found within the unit during the intensive inventory. The road reduces the original acreage estimate before the inventory by about ten acres.

The unit has a natural appearance due to its lack of human impacts. Its visual contact with agricultural land and lack of screening do not provide a person with an outstanding opportunity for solitude. Primitive and unconfined types of recreation exist, but their lack of diversity and quality do not make them outstanding.

\section{FINAL DECISION ANALYSIS}

Survey of Public Opinion:

There was no specific public Comment.

Final Decision and Rationale:

This unit lacks the vegetative and topographical screening necessary to provide outstanding opportunities for solitude or primitive and unconfined recreation. This unit will not be studied for wilderness. 
Frenchman Creek West MT-065-320

R. $33 \mathrm{E}$.

R. 34 E.

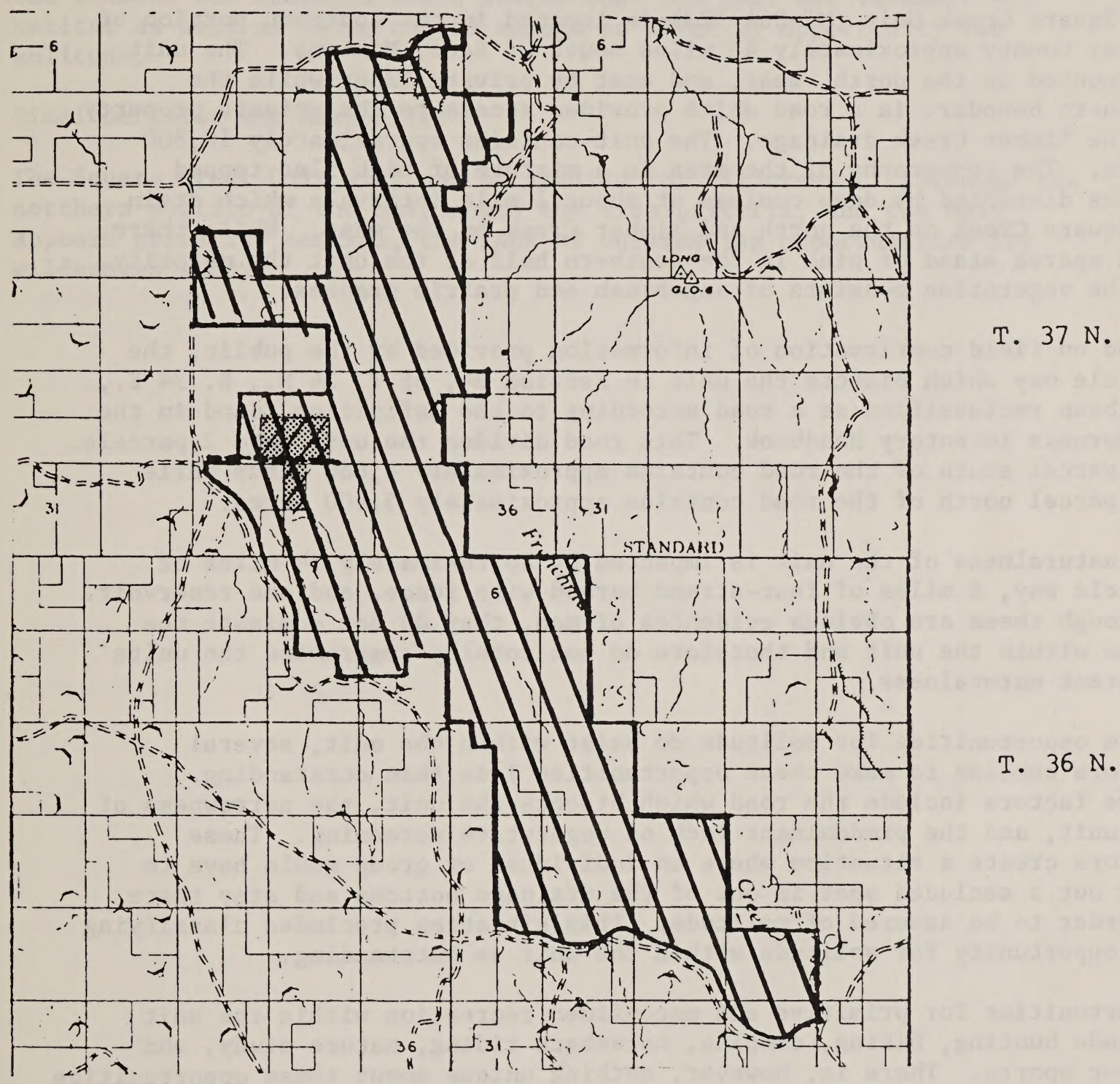

LEGEND

SCALE $1: 126,720$

$\frac{1}{2}$ inch $=1 \mathrm{mile}$

TIV UNIT OR PORTION OF UNIT LACKING WILDERNESS CHARACTERISTICS (NOT RECOMMENDED AS WSA)

AREA DELETED FROM ORIGINAL INVENTORY UNIT DUE TO ROAD IDENTIFICATION

AREA ADDED DUE TO ROAD IDENTIFICATION

PRIVATE OR STATE INHOLDINGS 
UNIT NO.: $\quad$ MT-064-323

UNIT NAME: Square Creek

\section{WILDERNESS CHARACTERISTICS NARRATIVE SUMMARY}

The Square Creek Unit (MT-064-323) is located in the southern portion of Valley County approximately 45 miles south of Saco, Montana. The unit is bounded on the north, west, and east by private lands while the southern boundary is a road which provides access to the private property in the Timber Creek drainage. The unit contains approximately 10,800 acres. The topography of the area is a mixture of high flat topped ridges dissected by deep coulees at about 1 mile intervals which drain to Square Creek on the north and Timber Creek on the west. While there is a sparse stand of pine in the southern half of the unit the majority of the vegetation consists of sagebrush and prairie grasses.

Based on field confirmation of information provided by the public, the vehicle way which bisects the unit in Section 34, of T. 24 N., R. 34 E., has been reclassified as a road according to the definition found in the Wilderness Inventory Handbook. This road divides the unit into 2 parcels. The parcel south of the road contains approximately 4,860 acres while the parcel north of the road contains approximately 5,600 acres.

The naturalness of the unit is impacted by approximately $5 \frac{1}{2}$ miles of vehicle way, 6 miles of four-strand barbed wire fence, and one reservoir. Although these are obvious evidences of man, they do not dominate the scene within the unit and therefore do not totally compromise the units' apparent naturalness.

While opportunities for solitude do exist within the unit, several factors combine to make these opportunities less than outstanding. These factors include the road which bisects the unit, the narrowness of the unit, and the predominant lack of vegetative screening. These factors create a situation where an individual or group would have to seek out a secluded spot in one of the drainage bottoms and stay there in order to be assured of solitude. This situation precludes classifying the opportunity for solitude within the unit as outstanding.

Opportunities for primitive and unconfined recreation within the unit include hunting, hiking, camping, horseback riding, nature study, and winter sports. There is, however, nothing unique about these opportunities either individually or in combination when viewed in the context of the region. Therefore, the opportunities for primitive and unconfined recreation are not considered outstanding.

Supplemental values within the unit include its importance as a crucial elk range, and the presence of several large rock cairns which may be of some historical or archeological value. 
Summary of Public Comments:

One comment was received which stated that the unit was valuable elk habitat as well as being rugged enough to offer an opportunity for solitude.

Final Decision and Rationale:

The Square Creek Unit will not be studied for wilderness. Although the northern portion of the unit meets the size criteria, and the unit appears primarily natural, the lack of outstanding opportunities for wilderness study. 
SQUARE CREEK

MT-064-323

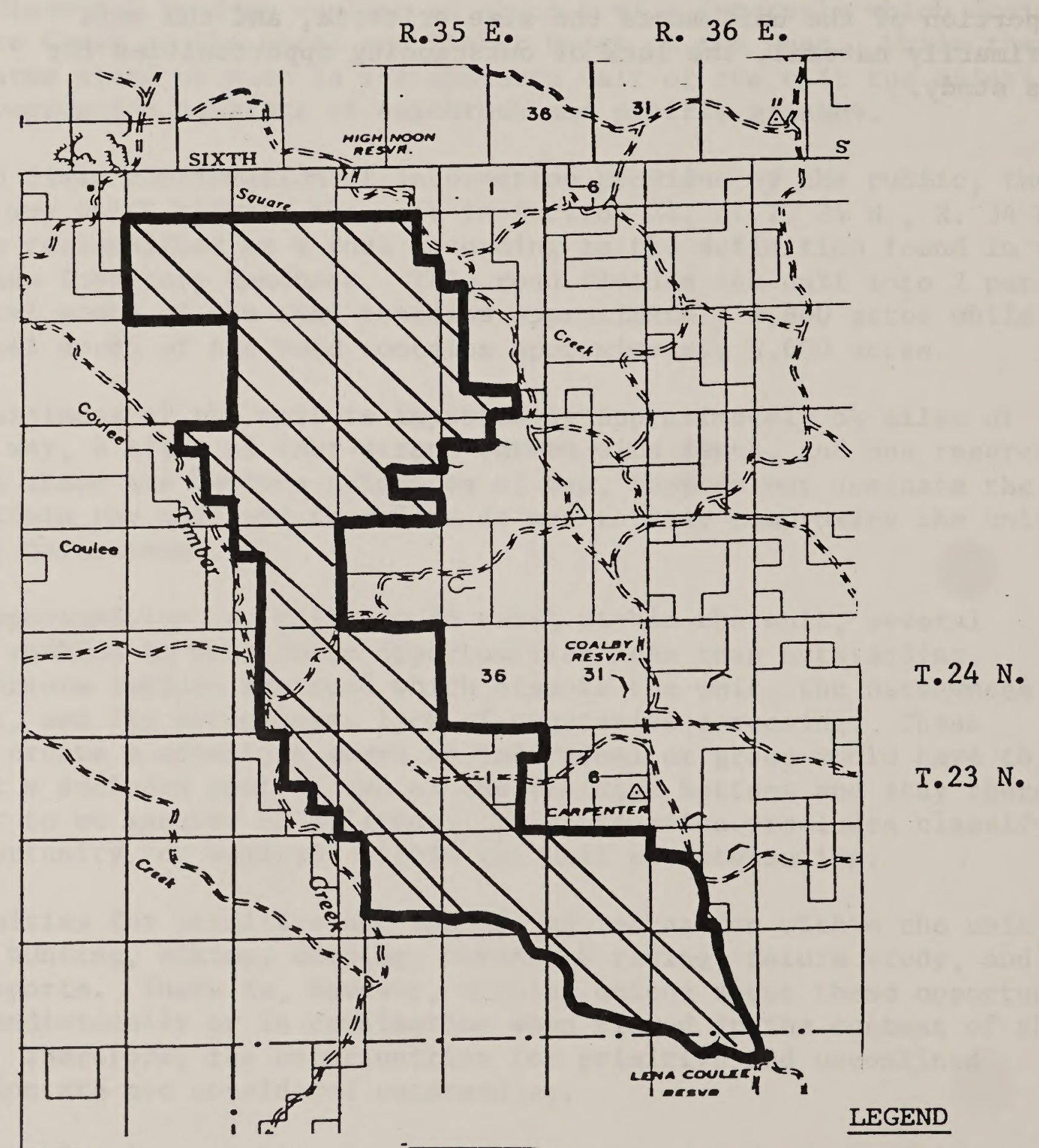

TIV UNIT OR PORTION OF UNIT LACKING WILDERNES: CHARACTERISTICS (NOT RECOMMENDED AS WSA)

AREA DELETED FROM ORIGINAL INVENTORY UNIT DUE TO ROAD IDENTIFICATION

SCALE $1: 126,720$ inch $=1$ mile

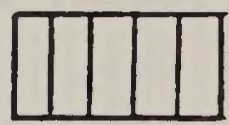

AREA ADDED DUE TO ROAD IDENTIFICATION

PRIVATE OR STATE INHOLDINGS 
UNIT NO.: $\quad$ MT-064-325

UNIT NAME: Wagon Coulee

Tack-on

\section{WILDERNESS CHARACTERISTICS NARRATIVE SUMMARY}

Wagon Coulee Tack-on Unit (MT-064-325) is an area of approximately 560 acres located some 65 miles southwest of Glasgow, Montana. This is a narrow strip of land bounded on one side by a county road (Harper Ridge Road) and on the other by private cropland.

Though it is basically natural, there is no topographic or vegetational screening, making solitude opportunities very limited. The area is too small to offer any recreational opportunities by itself. Hunting is the only recreation which might incidentally occur.

No significant supplemental values are known. Approximately 1 mile of this unit contacts Charles M. Russell Game Range proposed wilderness area on its southern boundary. There is, however, no evidence to suggest that the management of this area would have any effect on the quality of the CMR unit. They are not similar in character.

\section{FINAL DECISION ANALYSIS}

Summary of Public Comments:

One person felt that even though the unit borders the Charles M. Russell Game Range wilderness proposal, it does not have qualities that add to the game range proposal.

Final Decision and Rationale:

The unit will not be studied for wilderness. It lacks topographic and vegetative screening making solitude opportunities limited. It is also too small for any outstanding recreational activities. 
WAGON COULEE TACK-ON

MT-064-325

R 35E R 36E

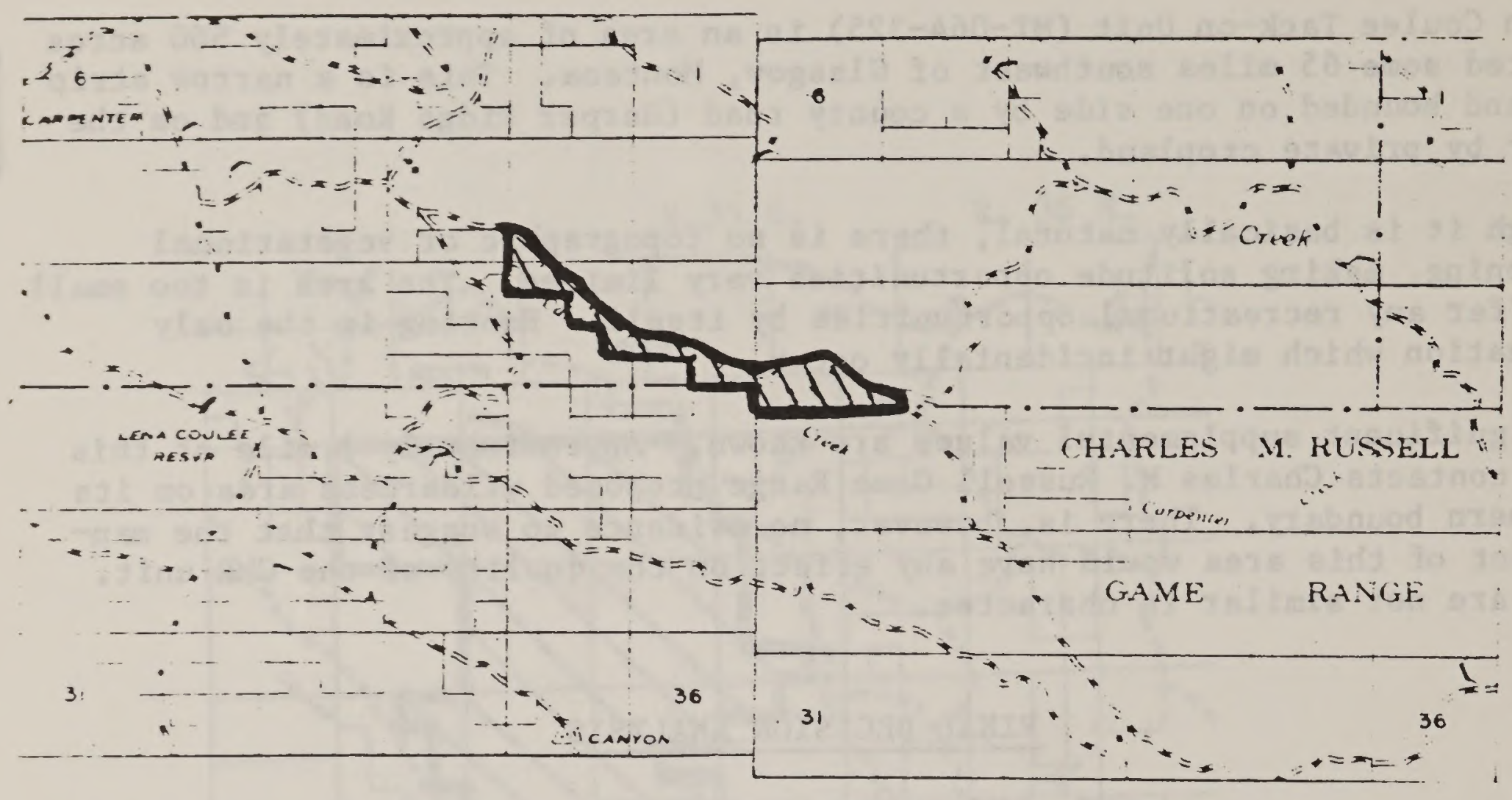

T 23N

SCALE $1: 126,720$ inch $=1 \mathrm{mile}$

\section{IEGEND}

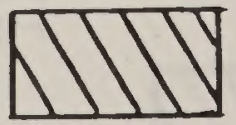

UNIT OR PORTION OF UNIT IACKING WILDERNESS CHARACTERISTICS (NOT RECOMMENDED AS WSA)

AREA DELETED FROM ORIGINAL INVENTORY UNIT DUE TO ROAD IDENTIFICATION

AREA ADDED DUE TO ROAD IDENTIFICATION

PRIVATE OR STATE INHOLDINGS 
UNIT NO.: $\quad$ MT-064-326

UNIT NAME: Carpenter Creek

\section{WILDERNESS CHARACTERISTICS NARRATIVE SUMMARY}

Carpenter Creek Unit (MT-064-326) is an area of approximately 10,000 acres. It is located 60 miles southwest of Glasgow, Montana. The irregular boundary is provided by a combination of county road, private property, and Charles $M$. Russell Game Range property.

While fairly rugged mountains flank the north and south, most of the central portion is a flat, open drainage. The absence of both large vegetation and significant topographic relief severely limit the opportunities for solitude. Both elk and deer are available to hunt, but neither offers outstanding recreational opportunities.

No significant supplemental values were noted.

\section{FINAL DECISION ANALYSIS}

Summary of Public Comments:

No substantive public comments.

Final Decision and Rationale:

The unit will not be studied for wilderness. Due to the flat topography, the area lacks opportunities for solitude. The best recreational activity is hunting, but it is not outstanding. 
CARPENTER CREEK

$M T-064-326$

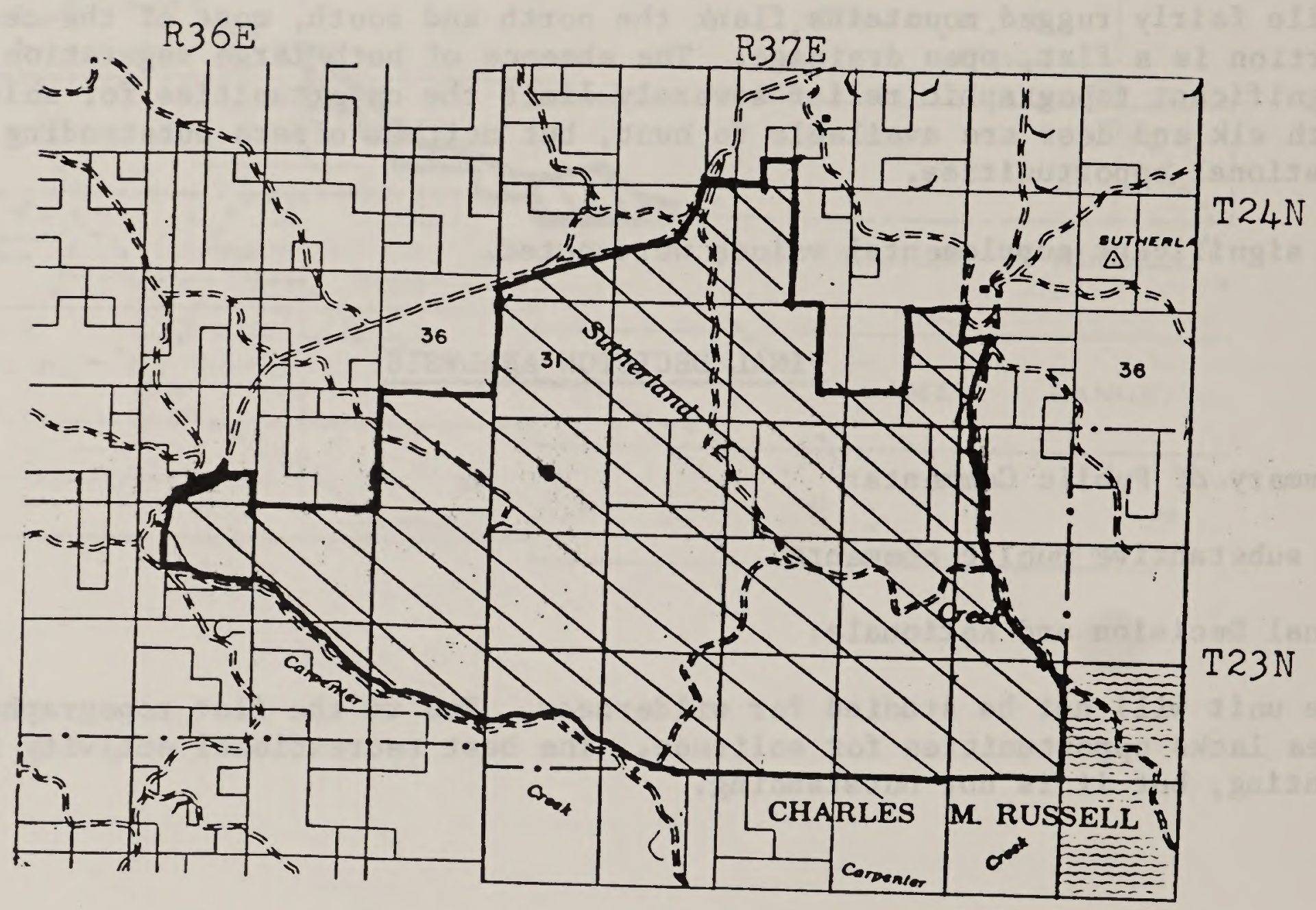

SCALE $1: 126,720$

is inch $=1 \mathrm{mile}$

\section{LEGEND}

MIV UNIT OR PORTION OF UNIT LACKING WILDERNESS CHARACTERISTICS (NOT RECOMMENDED AS WSA)

AREA DELETED FROM ORIGINAL INVENTORY UNIT DUE TO ROAD IDENTIFICATION

AREA ADDED DUE TO ROAD IDENTIFICATION

PRIVATE OR STATE INHOLDINGS 


\section{WILDERNESS CHARACTERISTICS NARRATIVE SUMMARY}

Duck Creek Unit (MT-064-328) is an area of approximately 6,400 acres. It is located some 60 miles south of Glasgow, Montana. Private property bounds three sides while Charles M. Russell Game Range bounds the south.

The area is composed of two deep, rugged canyons which join near the southern boundary. There are only scattered upright shrubs, mostly juniper.

The unit is not recommended for wilderness study status. Even though it is substantially natural, the very small canyons offer little opportunity for solitude. The canyon walls are steep but the way in which they face each other makes visibility good over the whole valley floor.

There are good opportunities for deer and elk hunting, however, it is not superior to the surrounding area and is not outstanding.

There were no supplemental values noted.

\section{FINAL DECISION ANALYSIS}

\section{Summary of Public Comments:}

A person felt the unit could provide an opportunity for solitude providing use was restricted to a permit system.

\section{Final Decision and Rationale:}

The unit will not be studied for wilderness. Even though the area is apparently natural, it lacks outstanding opportunities for solitude or a primitive and unconfined type of recreation. 


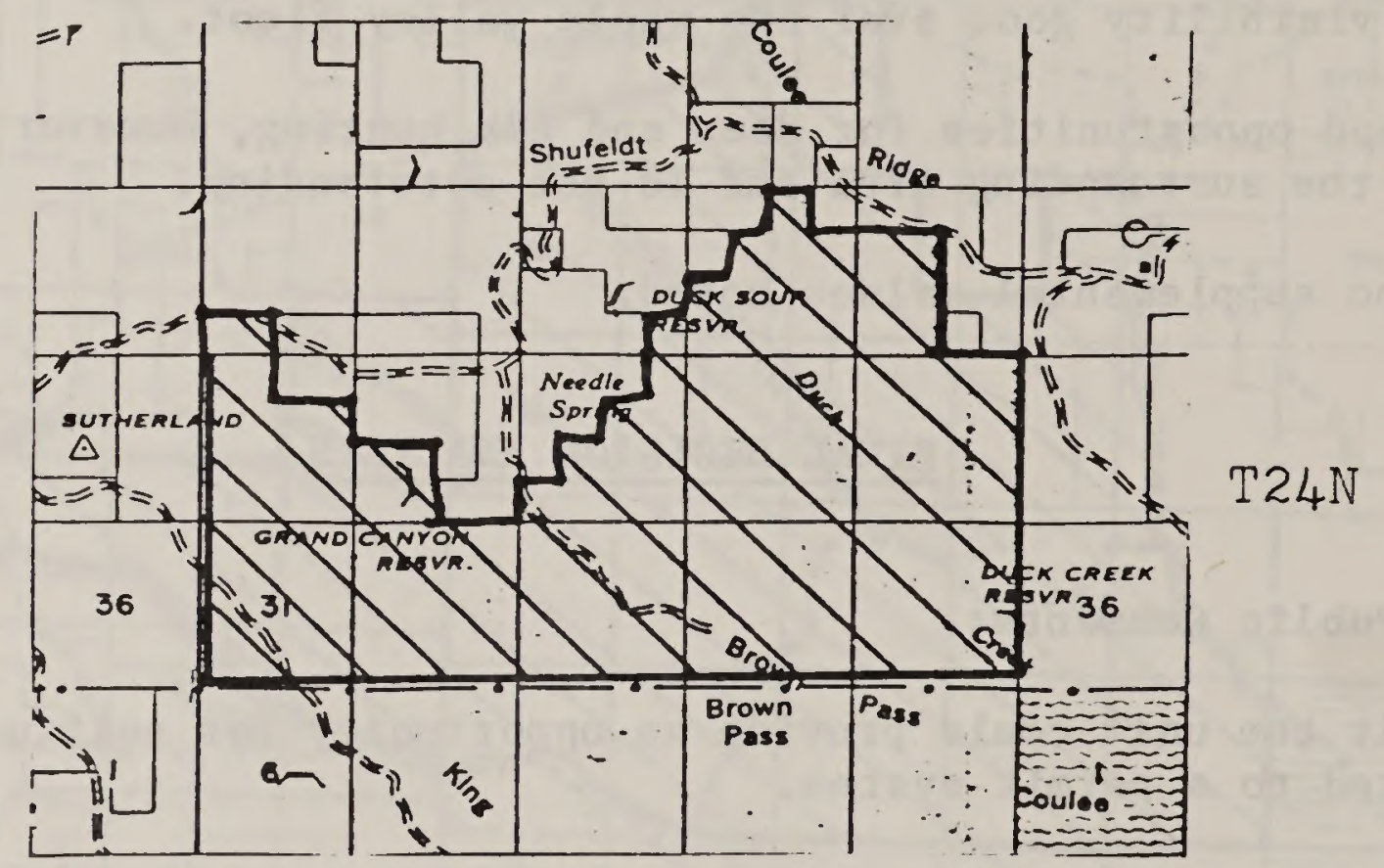
CHARACTERISTICS (NOT RECOMMENDED AS WSA)

AREA DELETED FROM ORIGINAL INVENTORY UNIT DUE TO ROAD IDENTIFICATION

AREA ADDED DUE TO ROAD IDENTIFICATION

PRIVATE OR STATE INHOLDINGS 


\section{WILDERNESS CHARACTERISTICS NARRATIVE SUMMARY}

Gumbo Plateau Unit (MT-064-329) is approximately 18,200 acres of land and is located 40 miles south of Saco, Montana. There are some small mountains in the southeast $\frac{1}{4}$, however, the remainder of the unit is flat and featureless. There are a very few upright junipers in the southeast, the remainder is grassland, with $30 \%$ sagebrush.

While it is large enough and natural, the very flat open terrain offers limited opportunity for solitude. The recreational opportunities are fairly well limited to hunting which is less than outstanding.

There are some cairns which may have archeological value, although they are not inventoried at present. No other supplemental values are known.

\section{FINAL DECISION ANALYSIS}

Summary of Public Comments:

A person felt the unit could provide an opportunity for solitude providing use was restricted to a permit system.

Final Decision and Rationale:

The unit is not considered suitable for future wilderness study. Even though the unit is natural, the area's flat terrain and the lack of topographic diversity provide neither an outstanding opportunity for solitude nor a primitive and unconfined type of recreation. 


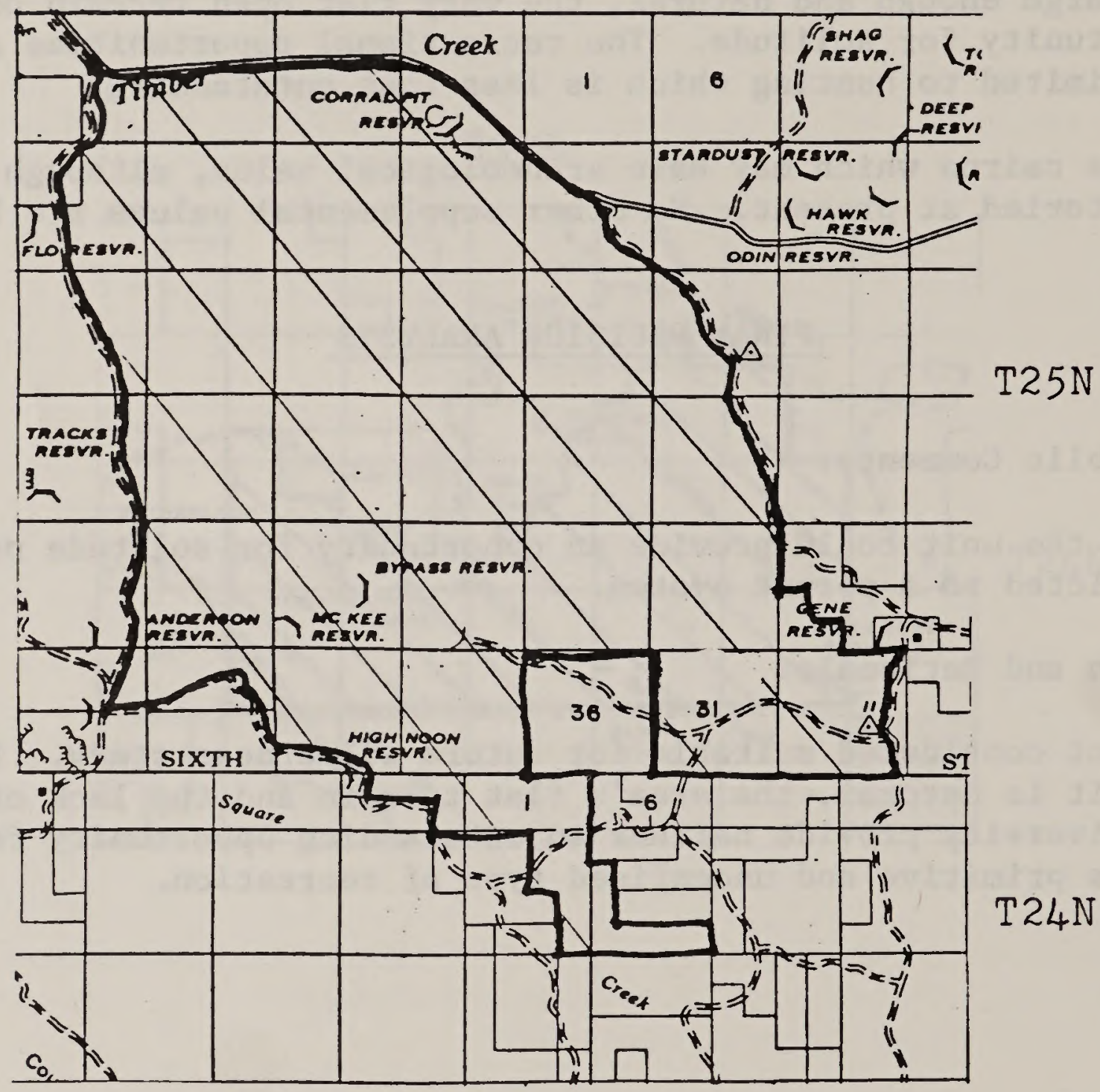

\section{IEGEND}

SCALE $1: 126,720$ DIV UNIT OR PORTION OF UNIT LACKING WILDERNESS

inch $=1$ mile

AREA DELETED FROM ORIGINAL INVENTORY UNIT DUE TO ROAD IDENTIFICATION

AREA ADDED DUE TO ROAD IDENTIFICATION

PRIVATE OR STATE INHOLDINGS 
UNIT NO.: $\quad$ MT-064-330

UNIT NAME: Caravan

\section{WILDERNESS CHARACTERISTICS NARRATIVE SUMMARY}

The Caravan Unit (MT-064-330) is located in Valley County, approximately 40 miles south of Saco, Montana. The unit contains approximately 5,580 acres of generally rolling terrain dissected by 2 shallow drainages. The vegetation in the unit consists of prairie grasses and horizontal juniper with stands of cottonwood and willow in the upper reaches of the drainages. The north, west, and south boundaries of the unit are county roads while the east adjoins the Marsh Hawk Hills BLM Inventory Unit.

The unit retains an apparently natural appearance in spite of the one large reservoir, five miles of vehicular ways, and several old road cuts from a previous alignment of the county road which forms the western boundary of the unit.

While opportunities for solitude exist within the unit they are restricted to the drainages and, therefore, cannot be called outstanding. Opportunities for primitive and unconfined types of recreation such as hiking, backpacking, and winter sports exist in the area but they are not unique and are constrained by the small size of the unit. Therefore, they are not considered outstanding.

Several rock cairns of uncertain origin are the only supplemental values identified within the unit.

\section{FINAL DECISION ANALYSIS}

Summary of Public Comments:

Two public comments were received which specifically addressed this unit. One commenter felt that the lack of man-made structures gave this unit a natural appearance and the terrain provided outstanding opportunities for solitude, hunting, and photography. The other commenter felt that the terrain and manmade structures gave the unit an unnatural appearance and would not provide outstanding opportunities for solitude or recreation.

Final Decision and Rationale:

This unit will not be studied for wilderness suitability. While it retains a natural appearance, the generally open terrain, small size, and lack of vegetative screening do not provide an outstanding opportunity for solitude. The opportunities for hiking, backpacking, and winter sports are not unique or outstanding. 


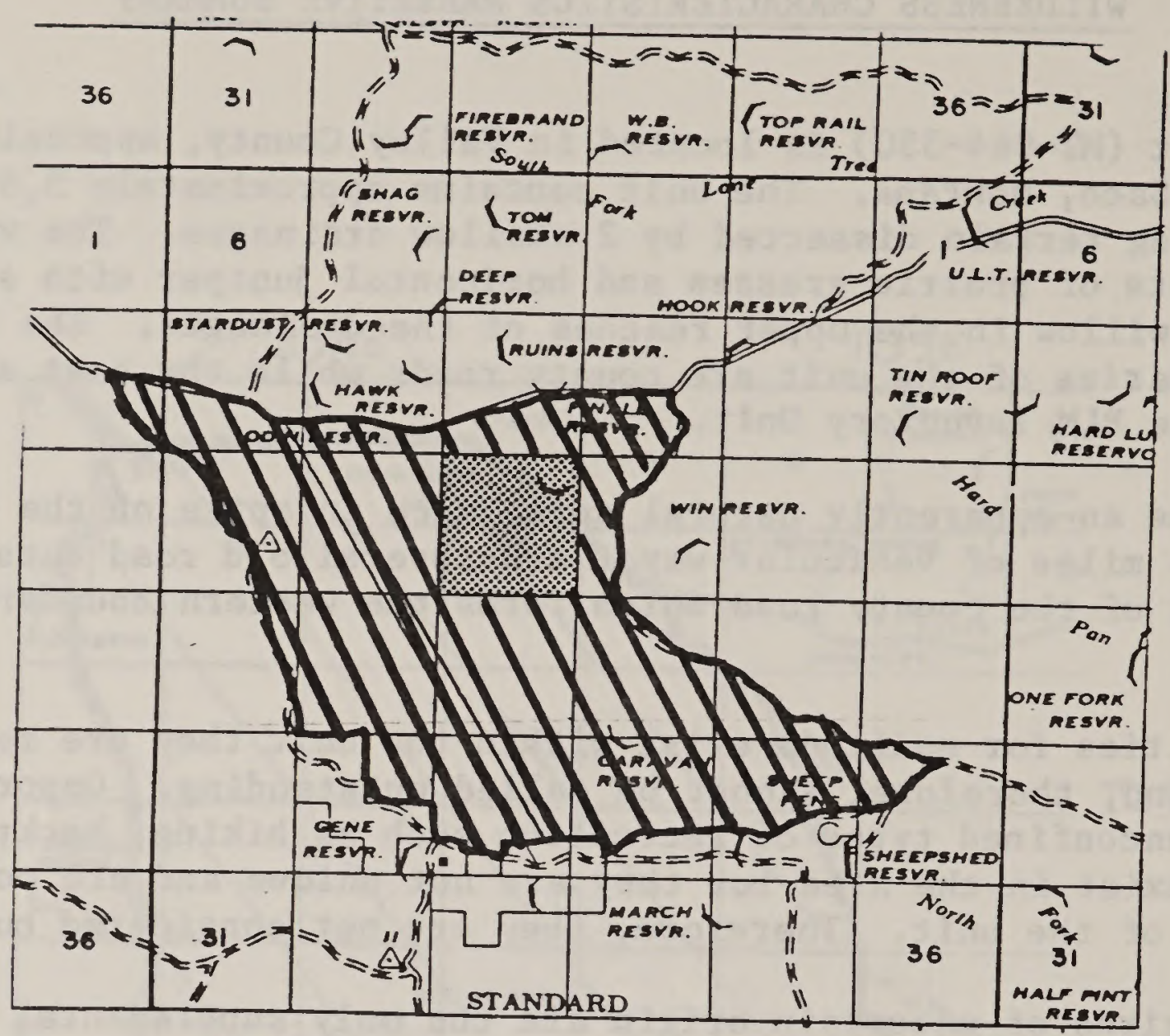

SCALE $1: 126,720$ is inch $=1$ mile

\section{IEGEND}
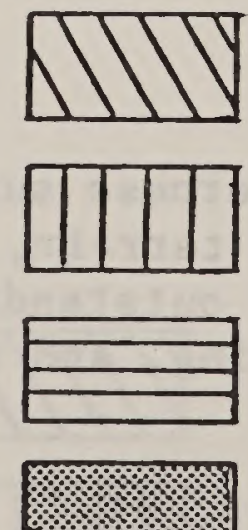
UNIT NO.: MT-064-331

UNIT NAME: South Fork

Willow Creek

\section{WILDERNESS CHARACTERISTICS NARRATIVE SUMMARY}

South Fork Willow Creek Unit (MT-064-331) is an area of approximately 10,840 acres. It is located 50 miles southwest of Glasgow, Montana. The irregular boundary is provided by a combination of private property and county roads.

The numerous reservoirs, and vehicle ways in this rather small, illshaped area make it less than natural in appearance. It is also so open and poorly shaped, opportunities for solitude are less than outstanding. Hunting, which is the only good recreational opportunity is also less than outstanding.

This unit has numerous rock cairns on top of several plateaus. These may have some supplemental value. They are uninventoried for archeological values at present.

\section{FINAL DECISION ANALYSIS}

Summary of Public Comments:

No substantive public comments were received.

Final Decision and Rationale:

The unit will not be studied for wilderness. The area is so severely impacted and open, that it lacks a natural appearance. It also neither provides an outstanding opportunity for solitude nor a primitive and unconfined type of recreation. 
SOUTH FORK WILLOW CREEK

MT $-064-331$

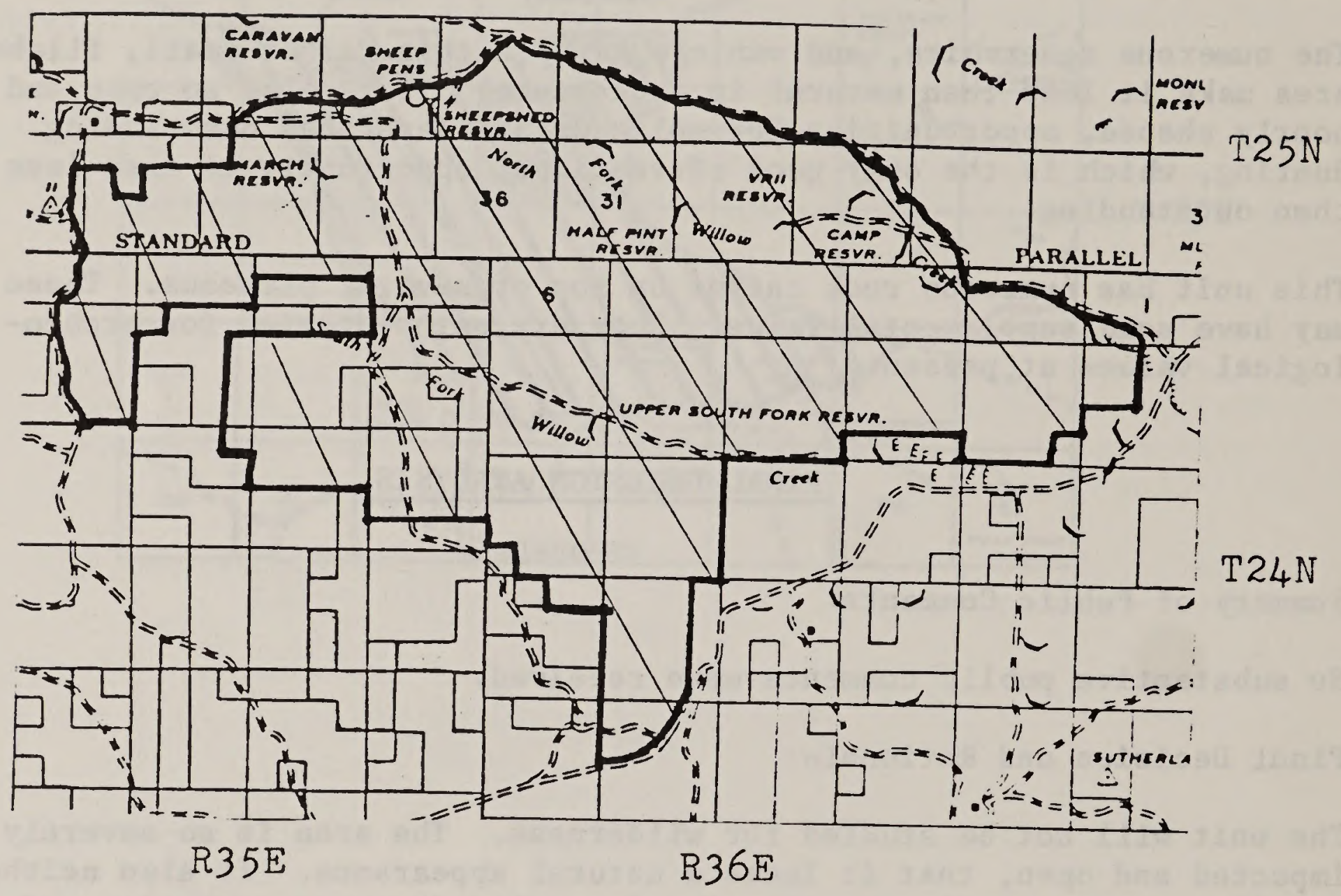

SCALE $1: 126,720$

$\frac{1}{2}$ inch $=1 \mathrm{mile}$

\section{LEGEND}

MIIV
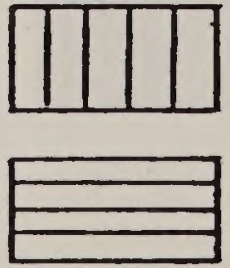

UNIT OR PORTION OF UNIT LACKING WILDERNESS CHARACTERISTICS (NOT RECOMMENDED AS WSA)

AREA DELETED FROM ORIGINAL INVENTORY UNIT DUE TO ROAD IDENTIFICATION

AREA ADDED DUE TO ROAD IDENTIFICATION

PRIVATE OR STATE INHOLDINGS 
UNIT NO.: MT-064-336

UNIT NAME: Marsh Hawk Hills

\section{WILDERNESS CHARACTERISTICS NARRATIVE SUMMARY}

The Marsh Hawk Hills Unit (MT-064-336) is located in Valley County, approximately 35 miles southwest of Glasgow, Montana. The unit is bounded on the north, east, and south by county roads while on the west it is contiguous with the Caravan BLM Wilderness Inventory Unit. This unit contains approximately 78,340 acres of gently rolling hills vegetated with sagebrush, prairie grasses, and isolated stands of cottonwood and willows.

Evidences of man's activity exist within the unit. These include approximately 45 reservoirs and a network of vehicle ways which top most of the main ridges within the unit. Because of the large size of the unit, these man-made features do not dominate the scene and allow the retention of a natural appearance.

Opportunities for solitude exist within the unit by virtue of its size. However, the nature of the topography and the lack of screening vegetation would limit this experience to only a few parties at a time; therefore, these opportunities are not considered outstanding. While a person could hunt, hike, camp, or ride horseback within the unit, these opportunities are not considered outstanding because of the lack of diversity within the unit. The only supplemental values known to exist within the unit are a few archeological sites.

\section{FINAL DECISION AND ANALYSIS}

\section{Summary of Public Comments:}

Only one public comment was received which specifically addressed this unit. The comment stated that the unit has been used for the past nine years for grazing purposes by a group of ranchers. The grazing unit was established in cooperation with several Federal agencies including the BLM. By setting up the grazing unit, additional fences and water development had to be constructed with vehicular roads traversing the area. These improvements affect the naturalness of the unit. The area has a flat, treeless type of terrain; thus vegetative and topographic screening would be limited.

Final Decision and Rationale:

The Marsh Hawk Hills Unit will not be studied for wilderness suitability. Although the unit retains a natural appearance, the openness of the terrain, lack of vegetative screening, and lack of diversity do not provide outstanding opportunities for solitude or primitive recreation. 
UNIT NO.: $\quad$ MT-064-337

UNIT NAME: Grant Coulee

\section{WILDERNESS CHARACTERISTICS NARRATIVE SUMMARY}

Grant Coulee Unit (MT-064-337) is an area of approximately 66,980 acres. It is located 18 miles south of Saco, Montana. The vast majority of this boundary is provided by county roads.

Though in a very natural condition, the lack of topographic, or vegetational screening does not provide solitude of notable quality. The recreational opportunities are limited to hunting, which is not outstanding.

There were no significant supplemental values noted in the area.

\section{FINAL DECISION ANALYSIS}

Summary of Public Comments:

No substantive public comments were received.

Final Decision and Rationale:

The unit is not considered suitable for future wilderness study. Although the area appears natural, the lack of topographic diversity allows for neither an outstanding opportunity for solitude nor a primitive and unconfined type of recreation. 


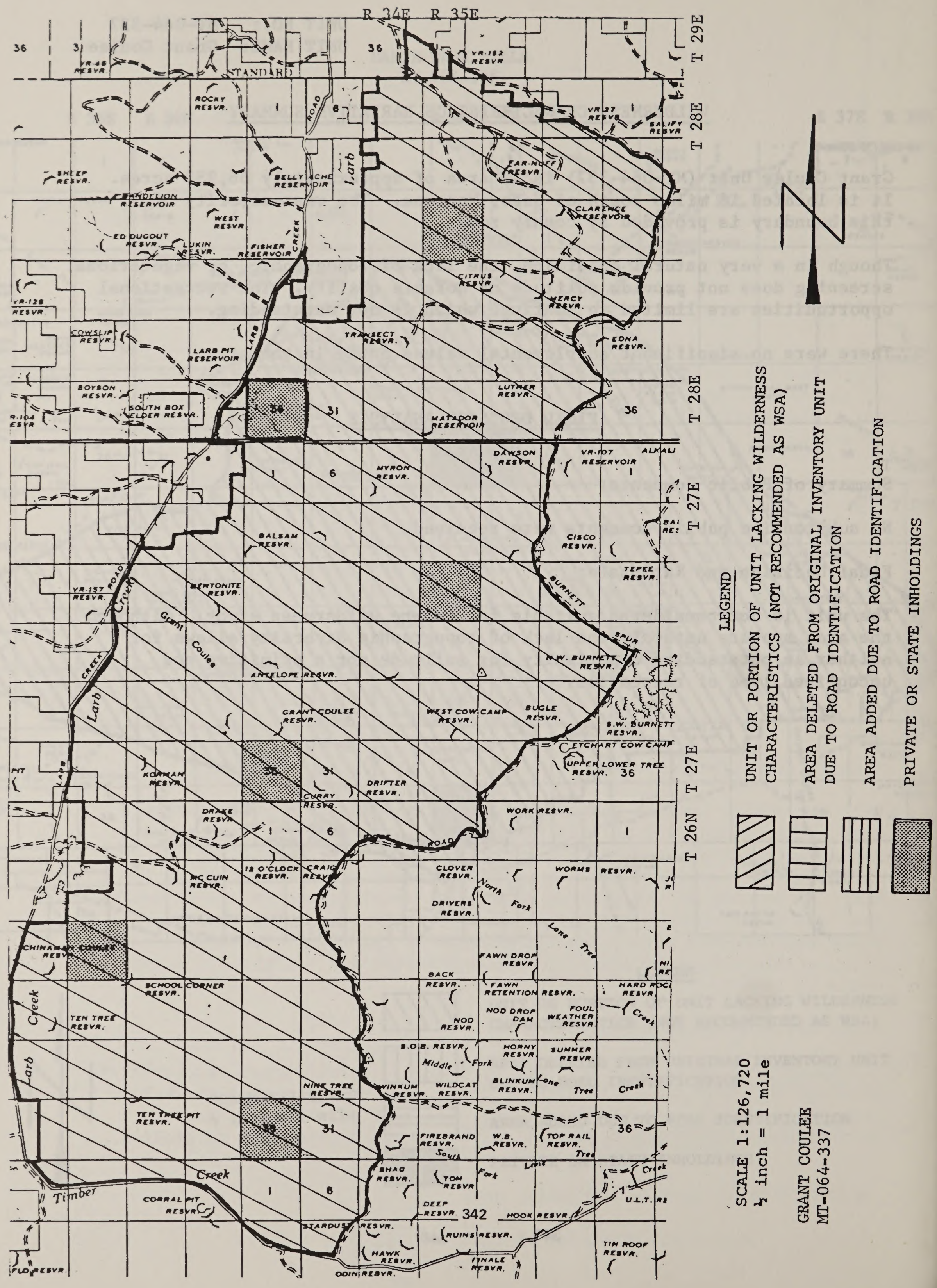


UNIT NO.: $\quad$ MT-064-338

UNIT NAME: Pearson Coulee

\section{WILDERNESS CHARACTERISTICS NARRATIVE SUMMARY}

Pearson Coulee Unit (MT-064-338) is approximately 23,840 acres. It is located 20 miles southwest of Glasgow, Montana. The entire boundary is provided by county roads.

While the area is large enough and basically natural, opportunities for solitude are only moderate at best. The area is very open with little to no vegetation of any size. The only recreation opportunities of note relate to hunting and these are not outstanding.

Only minor supplemental values were identified. These were some tipi rings.

\section{FINAL DECISION ANALYSIS}

Summary of Public Comments:

No substantive public comments were received.

Final Decision and Rationale:

The unit is not considered suitable for future wilderness study. Although the area appears natural, the lack of topographic diversity allows for neither an outstanding opportunity for solitude nor a primitive and unconfined type of recreation. 


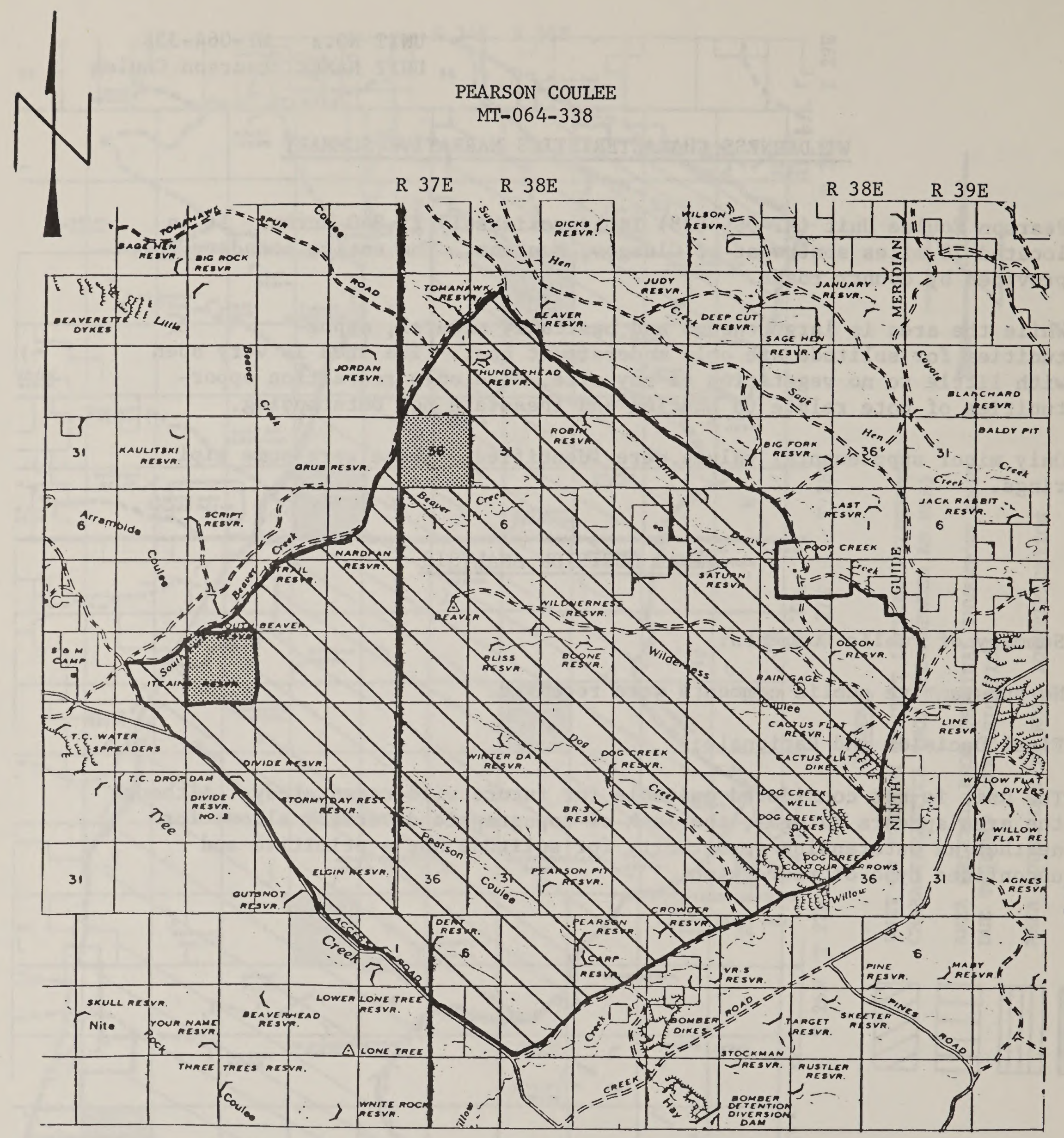

T $27 \mathrm{~N}$

T $26 \mathrm{~N}$

T $26 \mathrm{~N}$

T $25 \mathrm{~N}$

LEGEND

SCALE $1: 126,720$

$\frac{1}{2}$ inch $=1$ mile
WU UNIT OR PORTION OF UNIT IAACKING WILDERNESS CHARACTERISTICS (NOT RECOMMENDED AS WSA)

AREA DELETED FROM ORIGINAL INVENTORY UNIT DUE TO ROAD IDENTIFICATION

AREA ADDED DUE TO ROAD IDENTIFICATION PRIVATE OR STATE INHOLDINGS 
UNIT NO.: MT-064-340

UNIT NAME: Hurricane

\section{WILDERNESS CHARACTERISTICS NARRATIVE SUMMARY}

Hurricane Unit (MT-064-340) is an area of approximately 6,680 acres. It is located some 25 miles southwest of Glasgow, Montana. It is totally bounded by county roads.

The naturalness of this unit is seriously compromised by mining claims, vehicle ways, reservoirs, and a small amount of active bentonite mining. The opportunities for solitude are also seriously limited. The bentonite processing plant, with its haul road, railroad, and several active mining sites, just outside this unit boundary, makes serious impacts. No real solitude at any location in this unit is possible. The only recreational opportunities are those associated with hunting which are not outstanding.

No significant supplemental values were noted during the field inventory.

\section{FINAL DECISION ANALYSIS}

Summary of Public Comments:

No substantive public comments were received.

Final Decision and Rationale:

The unit is not considered suitable for future wilderness study. The impacts associated with mining claims makes the unit apparently unnatural. They also limit a person's opportunity to find solitude. Opportunities for a primitive and unconfined recreation are not outstanding due to the lack of ecological diversity. 


\section{HURRICANE}

MT-064-340

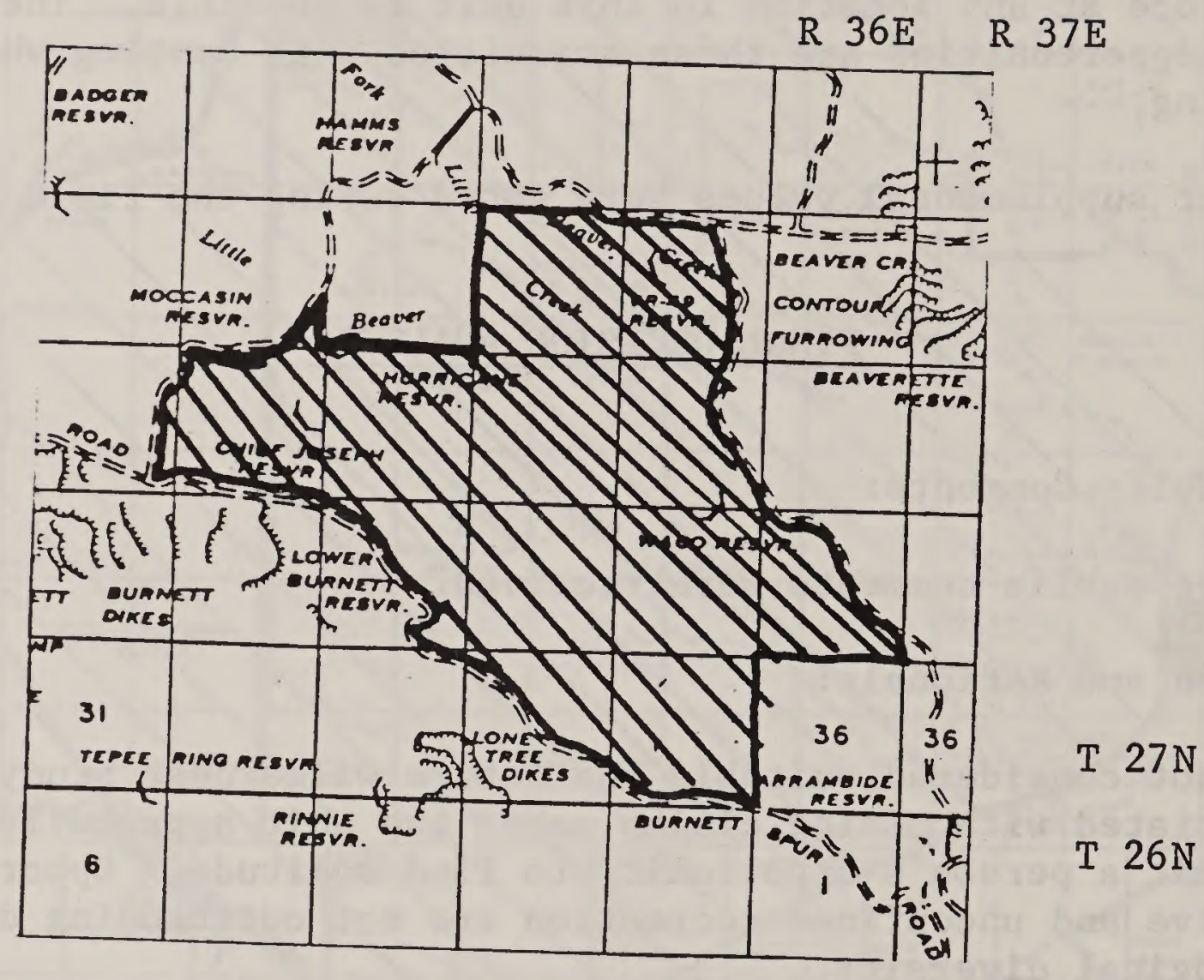

SCALE $1: 126,720$

$\frac{1}{2}$ inch $=1$ mile

\section{LEGEND}
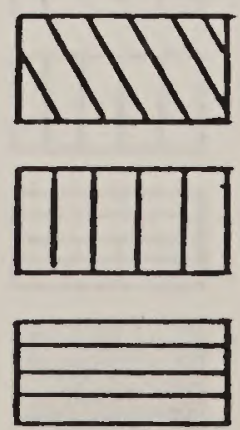

$\%$
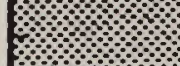

UNIT OR PORTION OF UNIT LACKING WILDERNESS CHARACTERISTICS (NOT RECOMMENDED AS WSA)

AREA DELETED FROM ORIGINAL INVENTORY UNIT DUE TO ROAD IDENTIFICATION

AREA ADDED DUE TO ROAD IDENTIFICATION

PRIVATE OR STATE INHOLDINGS 
UNIT NO.: MT-064-342

UNIT NAME: Coyote Creek

\section{WILDERNESS CHARACTERISTICS NARRATIVE SUMMARY}

Coyote Creek Unit (MT-064-342) is an area of 22,430 acres. The unit is located some 12 miles south of Glasgow, Montana. The boundary in the west is provided by county roads while in the east private property marks the border of the unit. This is an irregular unit with two separate sections, joined by a small strip in the south.

While Coyote Creek is in a near natural state, there is a significant lack of vegetation, and topographic screening making solitude far less than outstanding. The units lack of diversity also precludes outstanding opportunities for primitive and unconfined recreation.

There were some minor supplemental values, such as tipi rings, and critical watershed.

\section{FINAL DECISION ANALYSIS}

Summary of Public Comments:

No substantive public comments were received.

Final Decision and Rationale:

The unit will not be studied for wilderness. Although the area appears natural, it's flat topography and lack of ecological diversity allows for neither an outstanding opportunity for solitude nor a primitive and unconfined type of recreation. 
COYOTE CREEK

MT-064-342

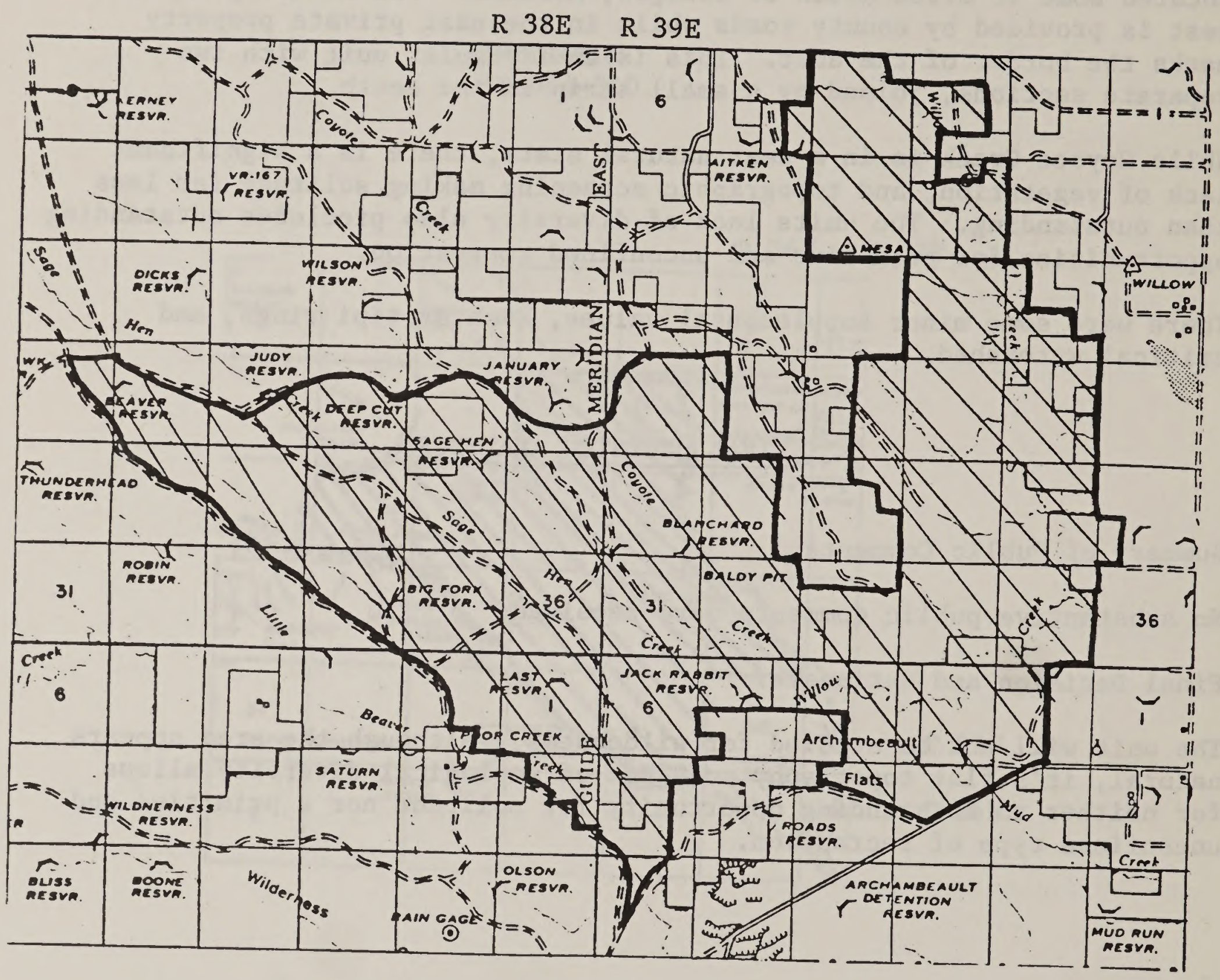

T $27 \mathrm{~N}$

T $26 \mathrm{~N}$

LEGEND

SCALE $1: 126,720$

th inch $=1$ mile
MIIV
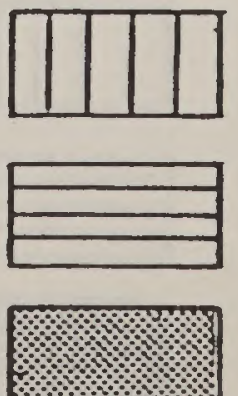

PRIVATE OR STATE INHOLDINGS DUE TO ROAD IDENTIFICATION
UNIT OR PORTION OF UNIT LACKING WILDERNESS CHARACTERISTICS (NOT RECOMMENDED AS WSA)

AREA DELETED FROM ORIGINAL INVENTORY UNIT

AREA ADDED DUE TO ROAD IDENTIFICATION 
UNIT NO.: MT-064-343

UNIT NAME: Moss Coulee

\section{WILDERNESS CHARACTERISTICS NARRATIVE SUMMARY}

Moss Coulee Unit (MT-064-343) is an area of approximately 14,920 acres. The unit is located 25 miles south of Saco, Montana. Private land and county roads make up all of the unit's irregular boundary.

The unit appears natural with only minor vehicle ways and small reservoirs existing as impacts. However, there are numerous noticeable offsite intrusions and a total lack of vegetational or topographic screening making the area's solitude potential far less than outstanding. Hunting is the only notable recreational opportunity, and is only average for the surrounding area.

There were no significant supplemental values inventoried.

\section{FINAL DECISION ANALYSIS}

Summary of Public Comments:

No substantive public comments were received.

Final Decision and Rationale:

The unit is not considered suitable for future wilderness study. Although the area appears natural, its flat topography and lack of ecological diversity allows for neither an outstanding opportunity for solitude nor a primitive and unconfined type of recreation. 


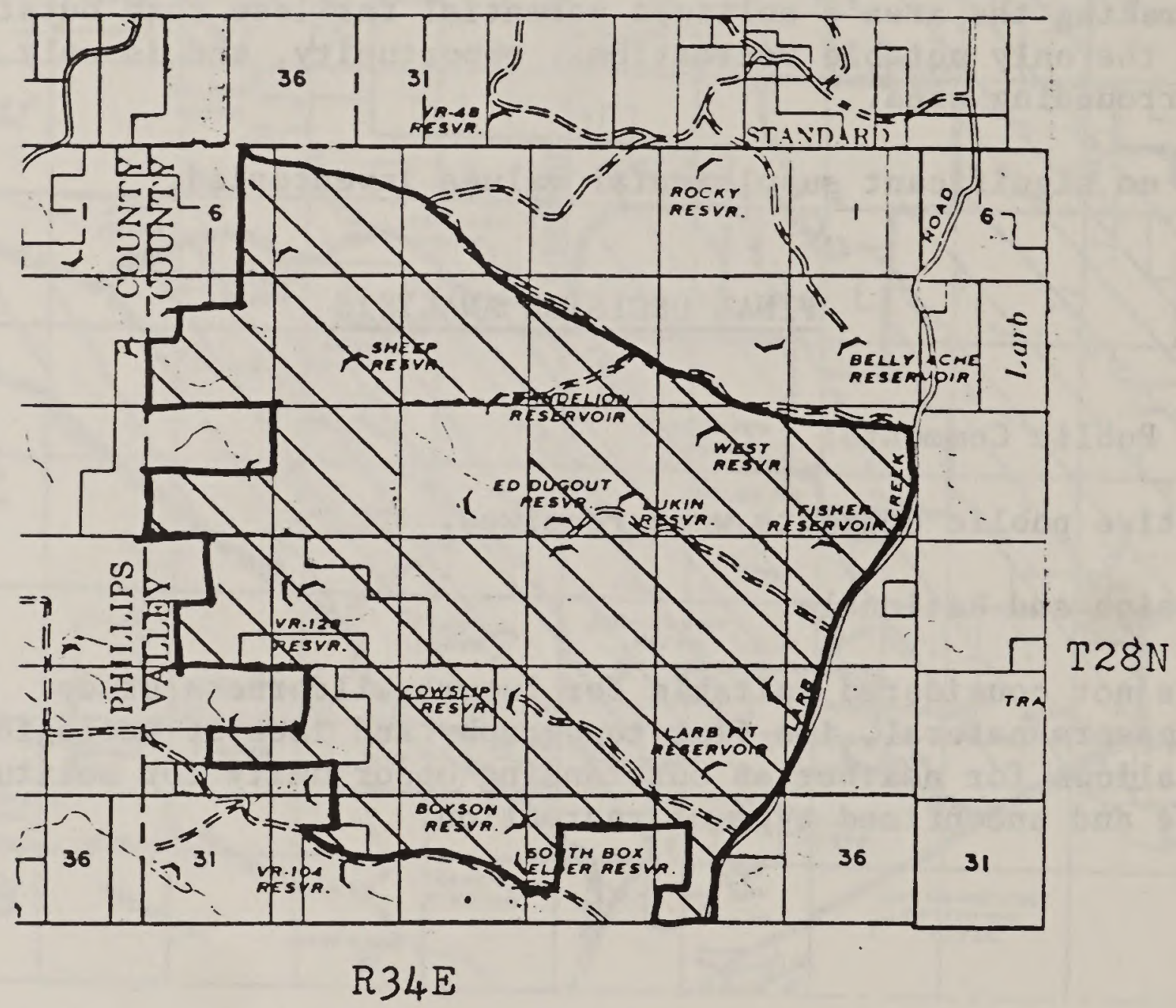

SCALE $1: 126,720$

is inch $=1$ mile
LEGEND

NIV UNIT OR PORTION OF UNIT LACKING WILDERNES: CHARACTERISTICS (NOT RECOMMENDED AS WSA)

AREA DELETED FROM ORIGINAL INVENTORY UNIT DUE TO ROAD IDENTIFICATION

AREA ADDED DUE TO ROAD IDENTIFICATION

PRIVATE OR STATE INHOLDINGS 
UNIT NO.: $\quad$ MT-064-346

UNIT NAME: Sage Hen

\section{WILDERNESS CHARACTERISTICS NARRATIVE SUMMARY}

Sage Hen Unit (MT-064-346) is an area of 7,540 acres. The unit is located 12 miles southwest of Glasgow, Montana. Two county roads and one BLM maintained road provide this unit's boundary.

This unit with a $60 \%$ stand of sagebrush, and no other upright shrubs, is in a basically natural condition. It is however too open and exposed to offer any good opportunities for solitude. There are numerous species of game animals available to hunt, which makes hunting above average, but still not outstanding. No supplemental values were noted.

\section{FINAL DECISION ANALYSIS}

Summary of Public Comments:

No substantive public comments were received.

Final Decision and Rationale:

The unit will not be studied for wilderness although the area appears natural, it's lack of screening and ecological diversity allows for neither an outstanding opportunity for solitude nor a primitive and unconfined type of recreation. 
SAGE HEN

MT-064-346

R $38 \mathrm{E}$

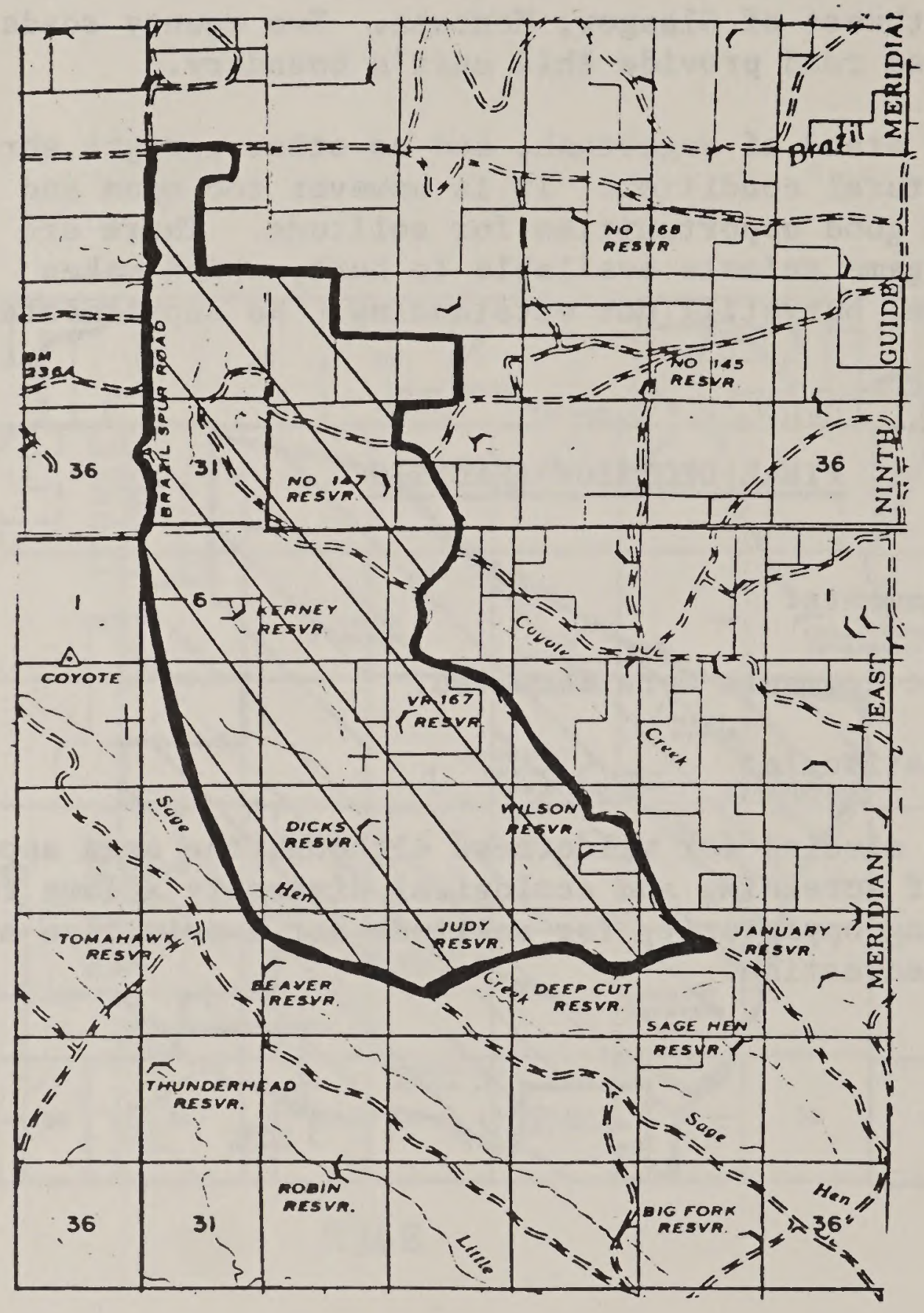

T $28 \mathrm{~N}$

T $27 \mathrm{~N}$

T $27 \mathrm{~N}$

LEGEND

SCALE $1: 126,720$

$\frac{1}{2}$ inch $=1$ mile
MIIV
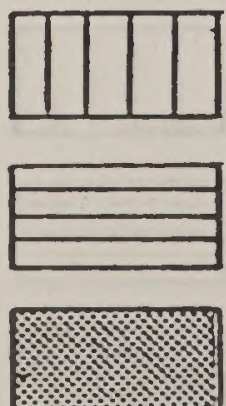

UNIT OR PORTION OF UNIT LACKING WILDERNESS CHARACTERISTICS (NOT RECOMMENDED AS WSA)

AREA DELETED FROM ORIGINAL INVENTORY UNIT DUE TO ROAD IDENTIFICATION

AREA ADDED DUE TO ROAD IDENTIFICATION

PRIVATE OR STATE INHOLDINGS 


$\begin{array}{ll}\text { UNIT NO.: } & \text { MT-064-347 } \\ & \text { MT-064-348 } \\ & \text { MT-064-350 } \\ & \text { MT-064-352 } \\ \text { UNIT NAME: } & \text { 7th Parallel } \\ & \text { North Fork Brazil Creek } \\ & \text { South Fork Antelope Creek } \\ & \text { Antelope Creek }\end{array}$

\section{WILDERNESS CHARACTERISTICS NARRATIVE SUMMARY}

The 7th Parallel (MT-064-347), North Fork Brazil Creek (MT-064-348), South Fork Antelope Creek (MT-064-350), and Antelope Creek (MT-064-352), are located 12 to 20 miles south of Highway 非, between Glasgow and Saco, Montana. These units will be considered jointly because of their high degree of similarity and geographic proximity.

While all of these units are of adequate size, none of them are in a truly natural condition. The two major impacts are vehicle ways and tracts of land which show signs of having been farmed in the past.

The extremely flat, featureless character of these units severely limits the opportunities for solitude. Various offsite impacts also limit the feeling of aloneness in these units.

The only recreational opportunity of note is hunting. This is significant but not outstanding.

There were no supplemental values of significance detected.

\section{FINAL DECISION ANALYSIS}

Summary of Public Comments:

No substantive public comments were received.

Fina1 Decision and Rationale:

None of the units will be studied for wilderness. Although the areas appear natural, their lack of screening and ecological diversity allow for neither an outstanding opportunity for solitude nor a primitive and unconfined type of recreation. 


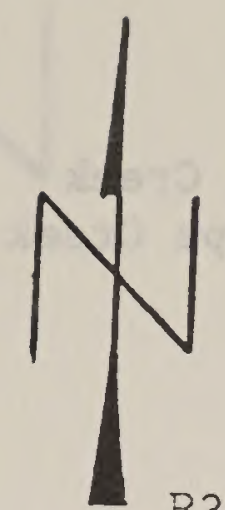

7th PARALLEL - MT-064-347

NORTH FORK BRAZIL CR. - MTT-064-348

SOUTH FORK ANTELOPE CR. - MT-064-350

ANTELOPE CR. - MT-064-352

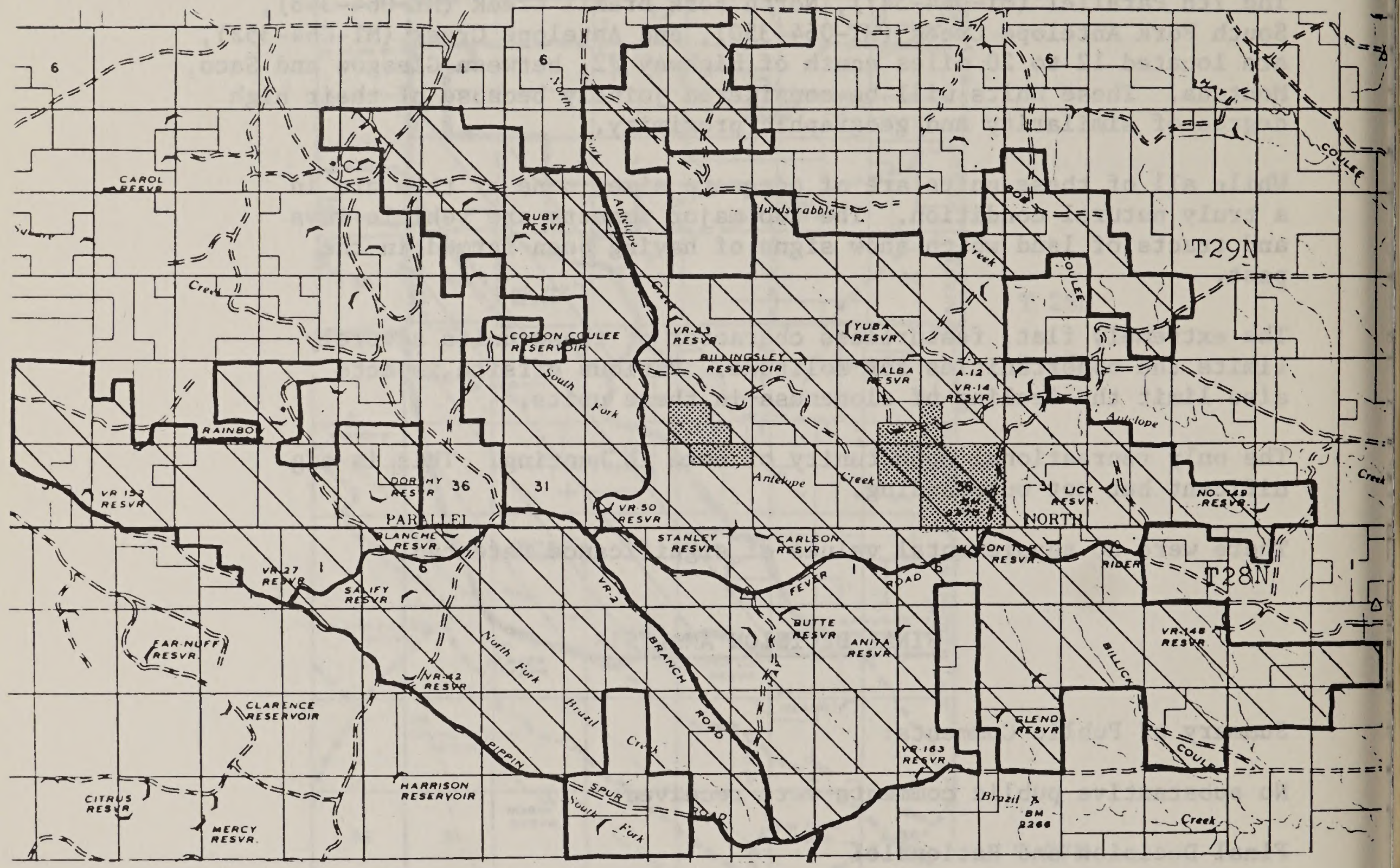

SCALE $1: 126,720$

anch $=1$ mile
MIIV
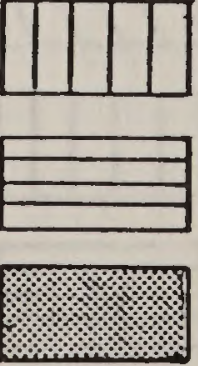

\section{LEGEND}

UNIT OR PORTION OF UNIT LACKING WILDERNESS CHARACTERISTICS (NOT RECOMMENDED AS WSA)

AREA DELETED FROM ORIGINAL INVENTORY UNIT DUE TO ROAD IDENTIFICATION

AREA ADDED DUE TO ROAD IDENTIFICATION

PRTVATE OR STATE INHOLDINGS 
UNIT NO.: MT-064-357

UNIT NAME: Willow Creek

\section{WILDERNESS CHARACTERISTICS NARRATIVE SUMMARY}

Willow Creek Unit (MT-064-357) is an area of 39,040 acres. It is 1ocated 14 miles west of Opheim, Montana.

The unit is noticeably less than natural. There are numerous vehicle ways, reservoirs, and large tracts of land which show some signs of having been farmed. Solitude is also less than outstanding. The unit is comprised of a series of plateaus with gentle drainages, all of which exhibit too little relief to have outstanding screening.

The only recreational opportunities notable are those which would be related to hunting. The hunting opportunity is not outstanding even though it is significant.

Numerous tipi rings, and several old homestead sites make up the only notable supplemental values.

\section{FINAL DECISION ANALYSIS}

Summary of Public Comments:

No substantive public comments were received.

Final Decision and Rationale:

The unit will not be studied for wilderness. The area appears unnatural due to numerous vehicle ways and reservoirs. It also lacks sufficient screening and ecological diversity to allow outstanding opportunities for solitude or a primitive and unconfined type of recreation. 


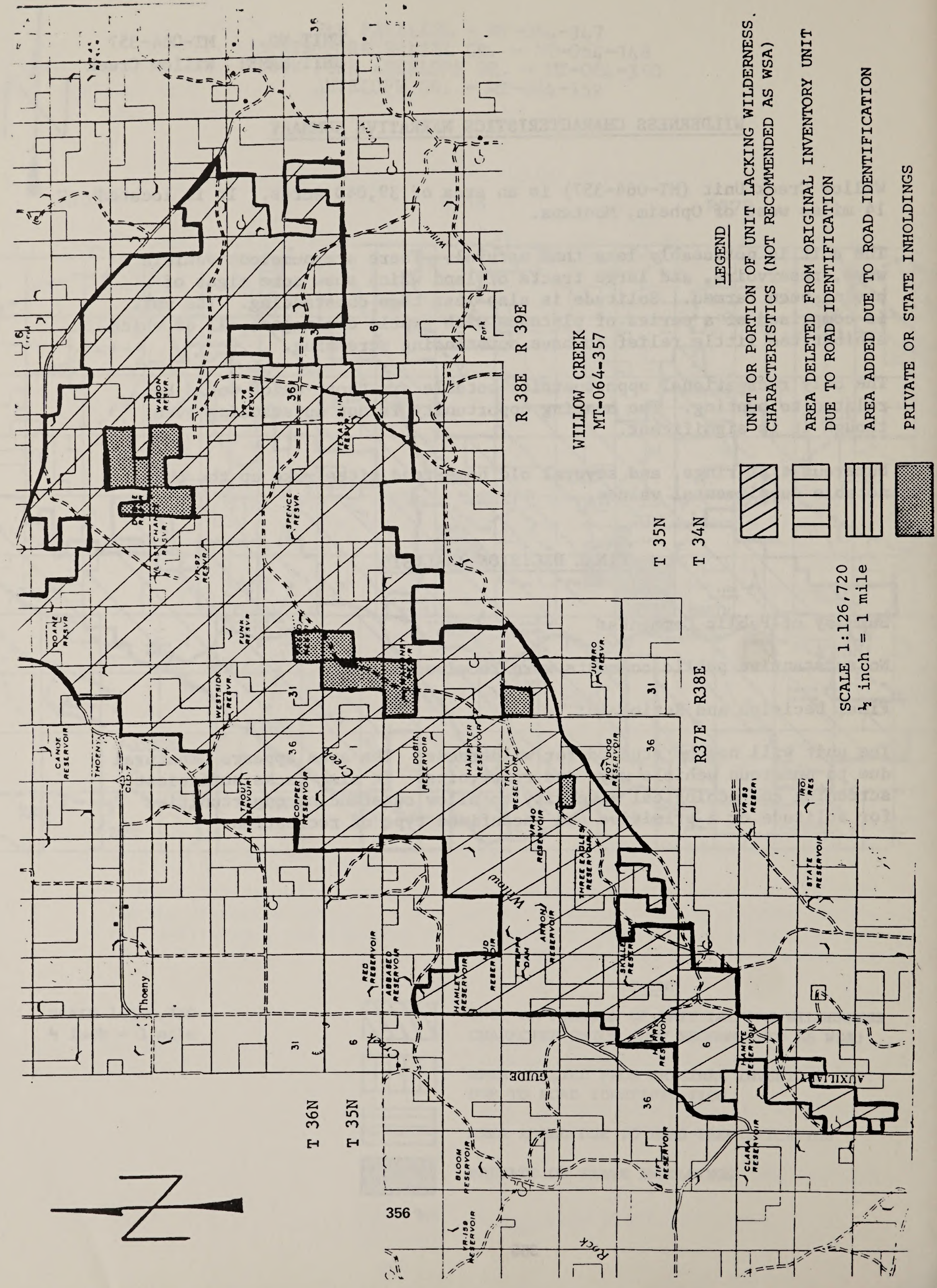


UNIT NO.: $\quad$ MT-064-358

UNIT NAME: Crow Creek

\section{WILDERNESS CHARACTERISTICS NARRATIVE SUMMARY}

Crow Creek Unit (MT-064-358) is an area of 7,054 acres. It is located 27 miles north of Hinsdale, Montana. The boundary is entirely provided by county roads and private property.

This unit does not have the minimum wilderness characteristics. Even though the unit is only slightly less than natural, the unit is so small, flat, and void of upright shrubs, that no solitude exists.

Limited hunting opportunities represent the only recreational potentials. These are not outstanding.

Tipi ring, and homestead sites represent the only supplemental values whatsoever.

\section{FINAL DECISION ANALYSIS}

\section{Summary of Public Comments:}

No substantive public comments were received.

Final Decision and Rationale:

The unit will not be studied for wilderness. The area has a flat terrain that lacks an ecological diversity. This topography allows for neither an outstanding opportunity for solitude nor a primitive and unconfined type of recreation. 


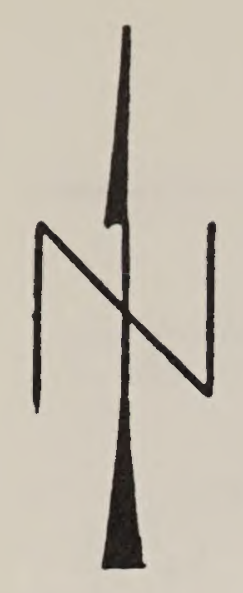

CROW CREEK

MT $-064-358$

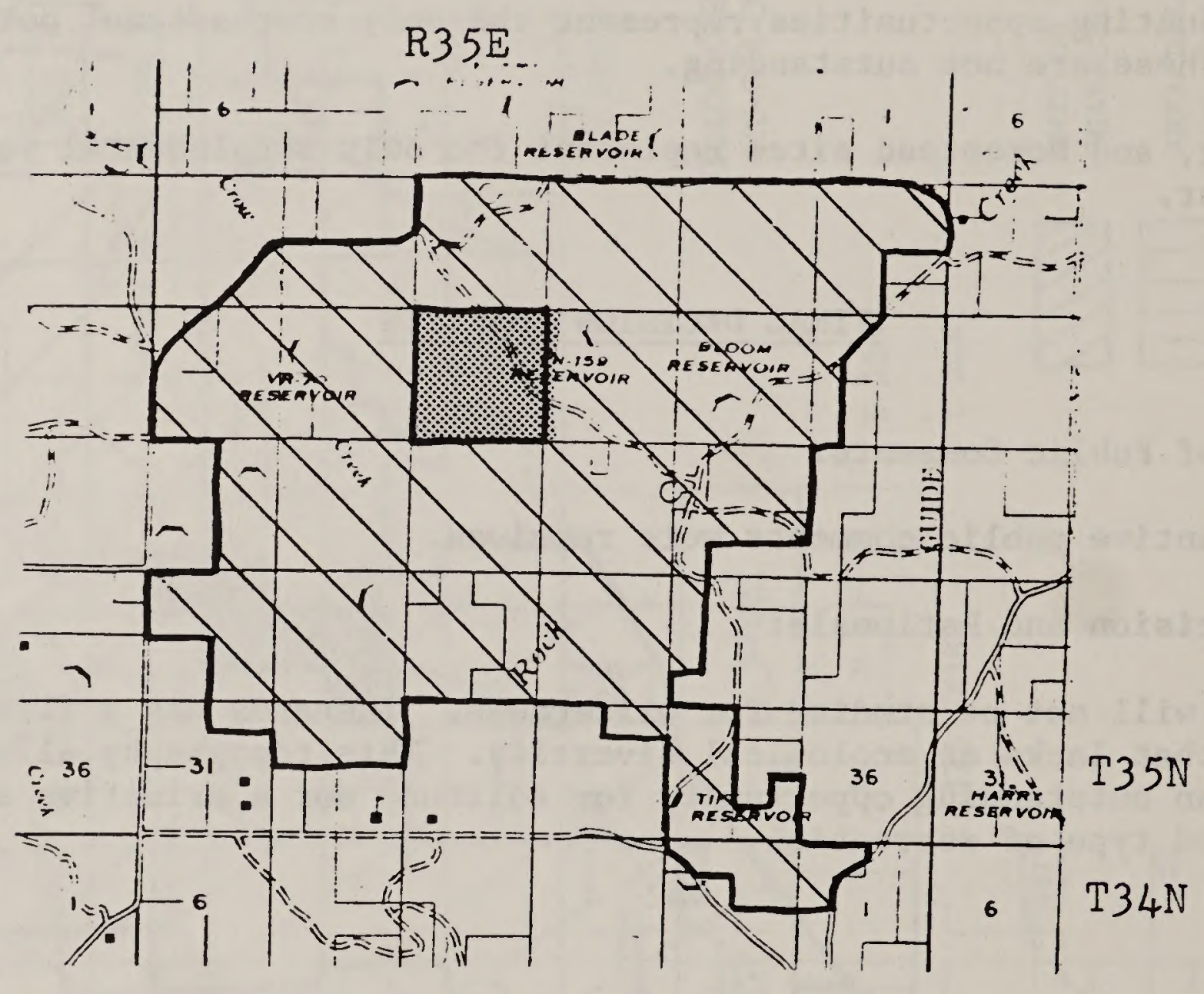

SCAIE $1: 126,720$

$\frac{1}{2}$ inch $=1 \mathrm{mile}$
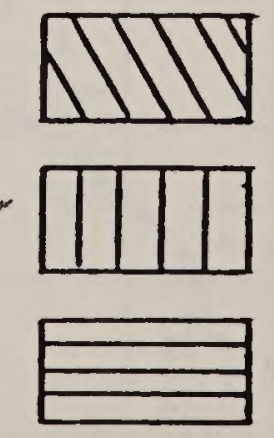

\%
IEGEND

UNIT OR PORTION OF UNIT LACKING WILDERNES CHARACTERISTICS (NOT RECOMMENDED AS WSA)

AREA DELETED FROM ORIGINAL INVENTORY UNIT DUE TO ROAD IDENTIFICATION

AREA ADDED DUE TO ROAD IDENTIFICATION

PRIVATE OR STATE INHOLDINGS 
UNIT NO.: $\quad$ MT-064-359

UNIT NAME: Frenchman Creek East

\section{WILDERNESS CHARACTERISTICS NARRATIVE SUMMARY}

The Frenchman Creek East Unit (MT-064-359) is located in the northeastern corner of Phillips County and the northwestern corner of Valley County. Its eastern, southern, and northern boundaries are roads and its western boundary is the private land along Frenchman Creek. The unit contains approximately 19,444 acres of land.

The unit has been divided by roads into three separate segments. The original proposal was to drop Segment $C$ of this unit and retain Segments $A$ and $B$ for further study. Parts A and B adjoin each other separated only by a road. The western boundary of segment $A$ is the private land along Frenchman Creek.

In general Segments $A$ and $B$ have outstanding naturalness while Segment $C$ with its numerous obvious reservoirs and 25 miles of vehicular ways, does not.

After a field review to confirm public comment, none of the segments were found to have outstanding opportunities for solitude or primitive and unconfined recreation. The roads and the creek which separate the three segments have divided them into long, thin areas. The widest portion of Segment A is 4 miles and most of the segment is 3 miles or less. Within some of the well timbered coulees of Segment A the solitude could be outstanding, but one would have to remain within the timber. Anyone hiking near the western border could observe the farming activity that takes place along Frenchman Creek.

Segment $B$ has a more acute problem than A concerning solitude. The widest portion of this segment is only $2 \frac{1}{2}$ miles and the majority of the unit is 2 miles wide or less. From the plateau in the eastern portion of the unit, several ranches and cultivated fields can be seen. Some of the canyons are deep enough to provide solitude but the narrowness of the unit would constantly force separate groups in contact with each other.

Segment C contains rolling untimbered hills which offer little solitude. Visibility is generally over 2 miles and this is nearly all the way across the unit.

The Frenchman Creek area has been rated as one of the outstanding hunting areas in the Phillips Resource Area for pheasants, sharp-tailed grouse, whitetail deer, mule deer, and antelope. However, it is Frenchman Creek and the private land along this creek which provides much of the habitat for wildlife. There are very few whitetail deer found within the unit and no pheasants. Mule deer and sharptailed grouse can be found in all three segments. Antelope would be found generally in Segment C but they may occasionally wander into the other two segments. 
All three segments contain supplemental values which consist of tipi rings and lithic scatter. There are no other known supplemental values.

\section{FINAL DECISION ANALYSIS}

Summary of Public Comments:

All of the comments received described manmade impacts. Individuals commenting stated that the unit contains several parcels of private property, irregular boundaries, numerous fences, roads, old homesteads, previously plowed fields, rock piles, buildings, abandoned machinery and pits. The area does not have heavy stands of timber nor does it have outstanding opportunities for hunting. The area should be kept open for oil and gas exploration, fire control, and other multiple use options.

Final Decision and Rationale:

The Frenchman Creek East Unit will not be studied for potential addition to the National Wilderness System. None of the three segments contain outstanding opportunities for solitude or primitive and unconfined recreation due to the configuration of the segments and the great visibility from the open ridgetops found throughout the area. 

R. $33 E$.
FRENCHHMAN CREEK MT-064-359
R. $34 \mathrm{E}$.
A. $35 \mathrm{E}$.

(i)

$-\sqrt{15}$

[it

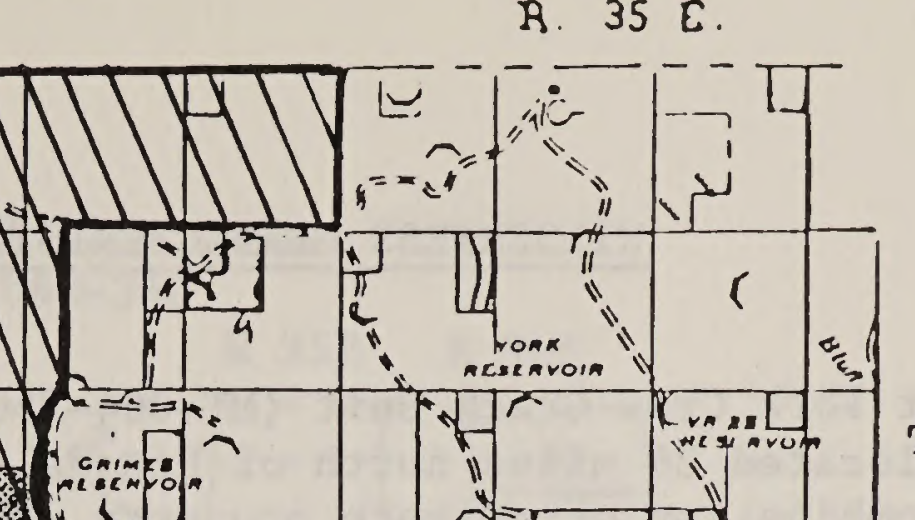

T. $37 \mathrm{~N}$.

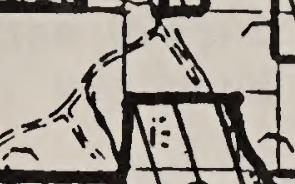

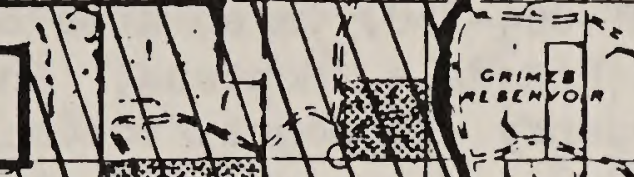

$+1$

cing

7 i.

化 5 f f

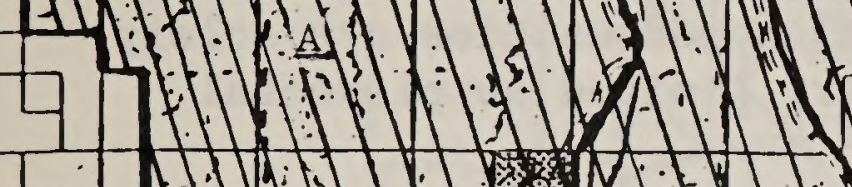

36 (1)

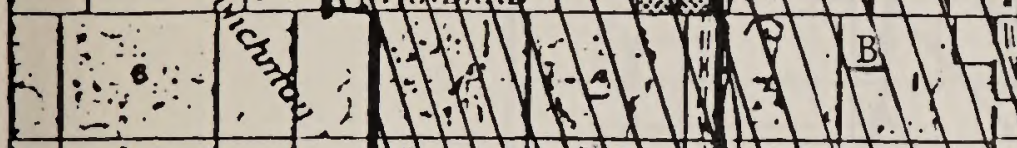

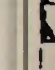

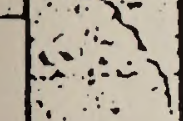

(1)

$=$

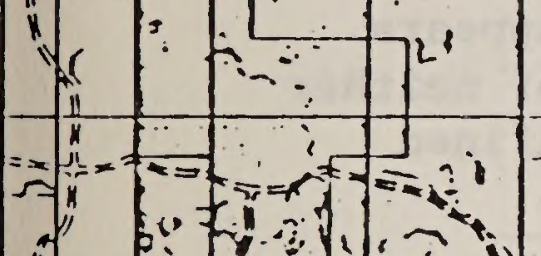

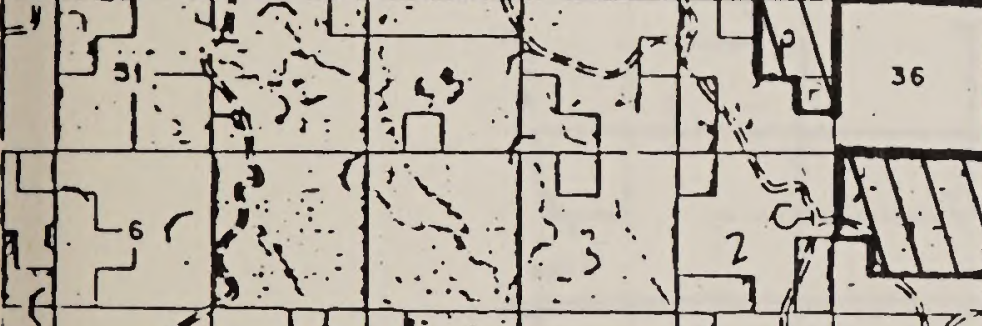

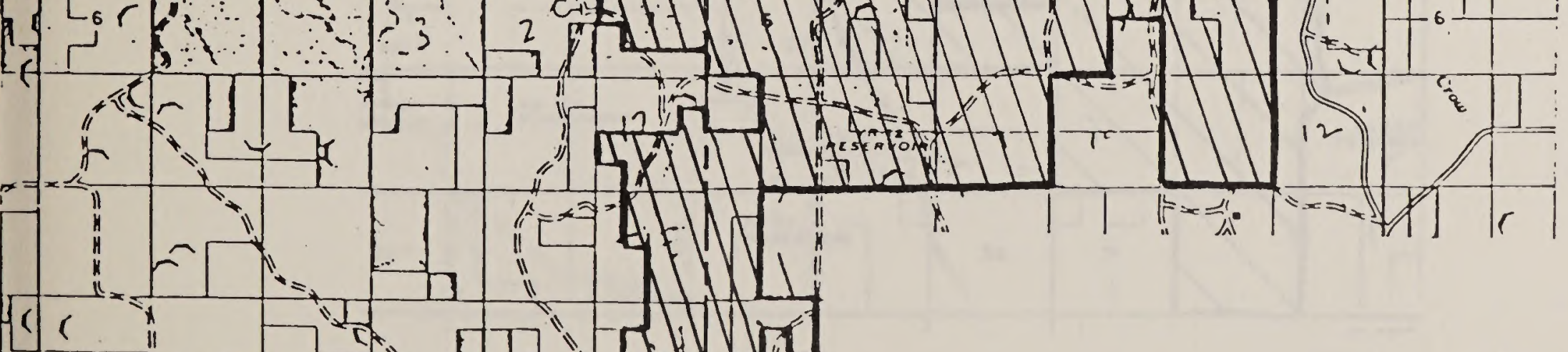
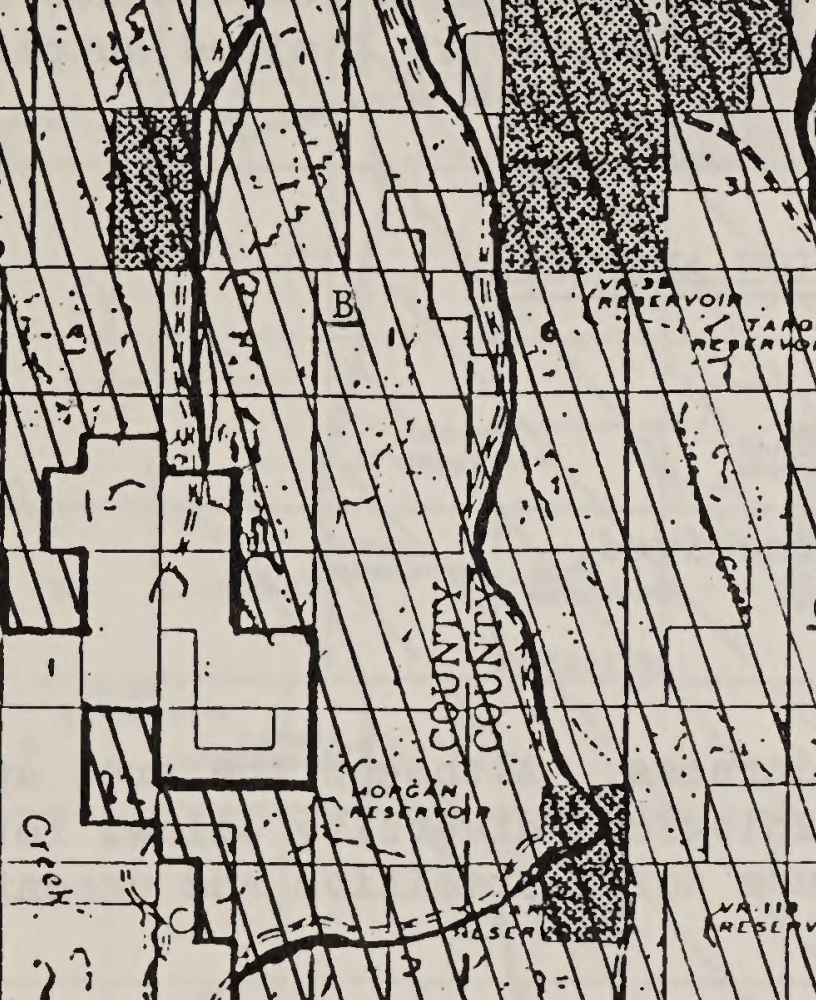

ㅊ..…

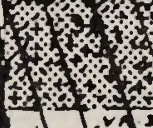

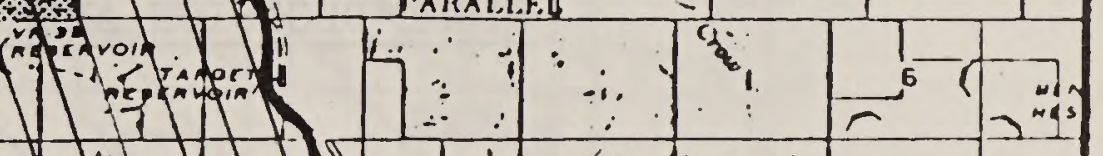

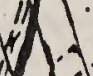

4 - 1 -

av $A 1$.

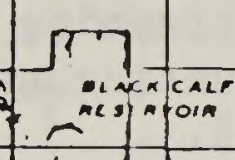

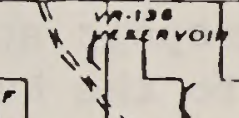

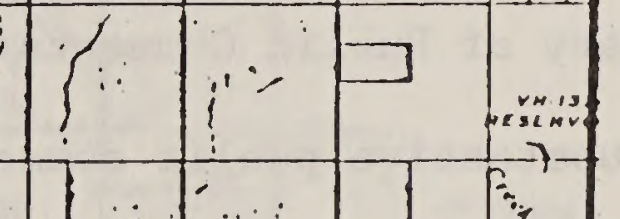

LEGEND

T. $35 \mathrm{~N}$.

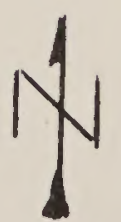

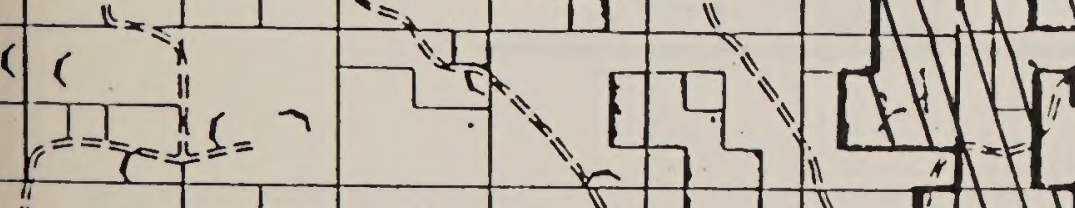

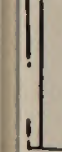

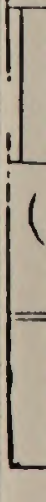

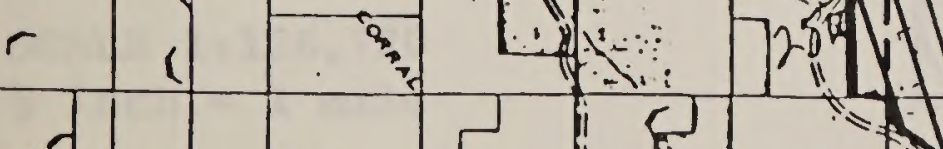

$\left\{\begin{array}{l}7 \\ \hline 3 \\ 3\end{array}\right.$

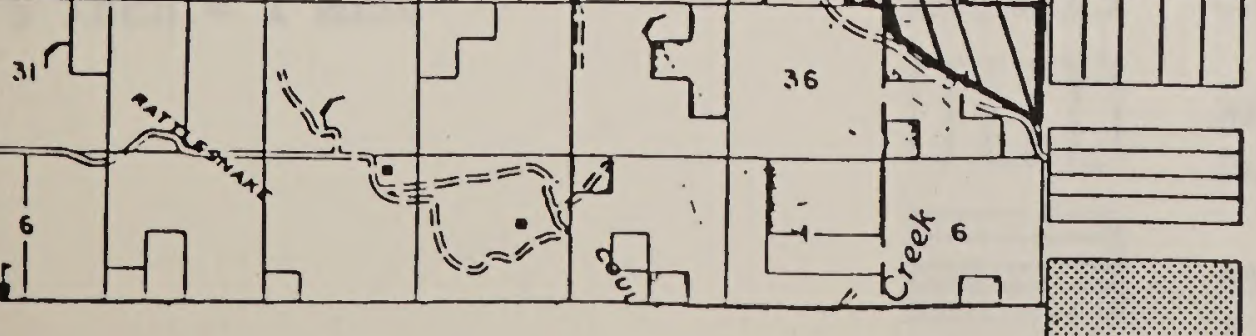

UNIT OR PORTION OF UNIT LACKING WILDERNESS CHARACTERISTICS (NOT RECOMMENDED AS WSA)

AREA DELETED FROM ORIGINAL INVENTORY UNIT DUE TO ROAD IDENTIFICATION

AREA ADDED DUE TO ROAD IDENTIFICATION

PRIVATE OR STATE INHOLDINGS 
UNIT NO.: $\quad$ MT-064-360

UNIT NAME: East Fork Crow Creek

\section{WILDERNESS CHARACTERISTICS NARRATIVE SUMMARY}

East Fork Crow Creek Unit (MT-064-360) is an area of 24,940 acres. It is located 36 miles north of Hinsdale, Montana. The boundary is provided by a combination of private property and county roads.

The unit has a typical rolling prairie land that is basically natural. There are however, only limited opportunities for solitude. No vegetational, or topographic screening exists. The recreational opportunities are solely limited to the hunting associated activities. Very limited supplemental values were noted.

\section{FINAL DECISION ANALYSIS}

Summary of Public Comments:

No substantive public comments were received.

Final Decision and Rationale:

The unit will not be studied for wilderness. Although the area appears natural, its lack of screening and ecological diversity allows for neither an outstanding opportunity for solitude nor a primitive and unconfined type of recreation. 
EAST FORK CROW CREEK

MT-064-360

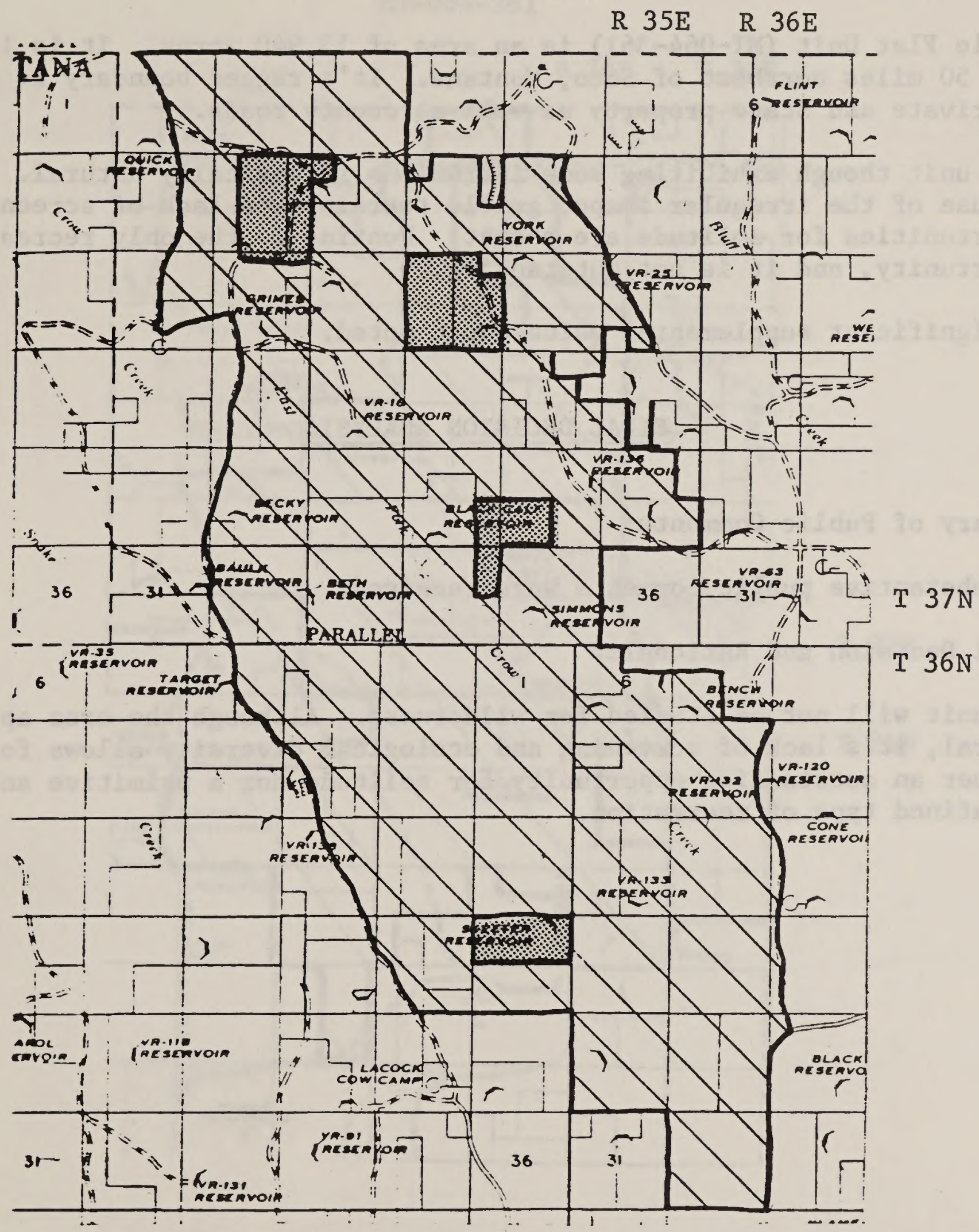

LEGEND

SCALE $1: 126,720$

$\frac{1}{2}$ inch $=1$ mile
WU UNIT OR PORTION OF UNIT LACKING WILDERNESS CHARACTERISTICS (NOT RECOMMENDED AS WSA)

AREA DELETED FROM ORIGINAL INVENTORY UNIT DUE TO ROAD IDENTIFICATION

AREA ADDED DUE TO ROAD IDENTIFICATION

PRIVATE OR STATE INHOLDINGS 


\section{WILDERNESS CHARACTERISTICS NARRATIVE SUMMARY}

Little Flat Unit (MT-064-361) is an area of 13,940 acres. It is located some 50 miles northest of Saco, Montana. It's ragged boundary is provided by private and State property as well as county roads.

This unit though exhibiting some intrusions is basically natural. However, because of the irregular shape, gentle terrain, and lack of screening, opportunities for solitude are absent. Hunting is the only recreational opportunity, and it is not outstanding.

No significant supplemental values were noted.

\section{FINAL DECISION ANALYSIS}

Summary of Public Comments:

No substantive public comments were received.

Final Decision and Rationale:

The unit will not be studied for wilderness. Although the area appears natural, it's lack of screening and ecological diversity allows for neither an outstanding opportunity for solitude nor a primitive and unconfined type of recreation. 


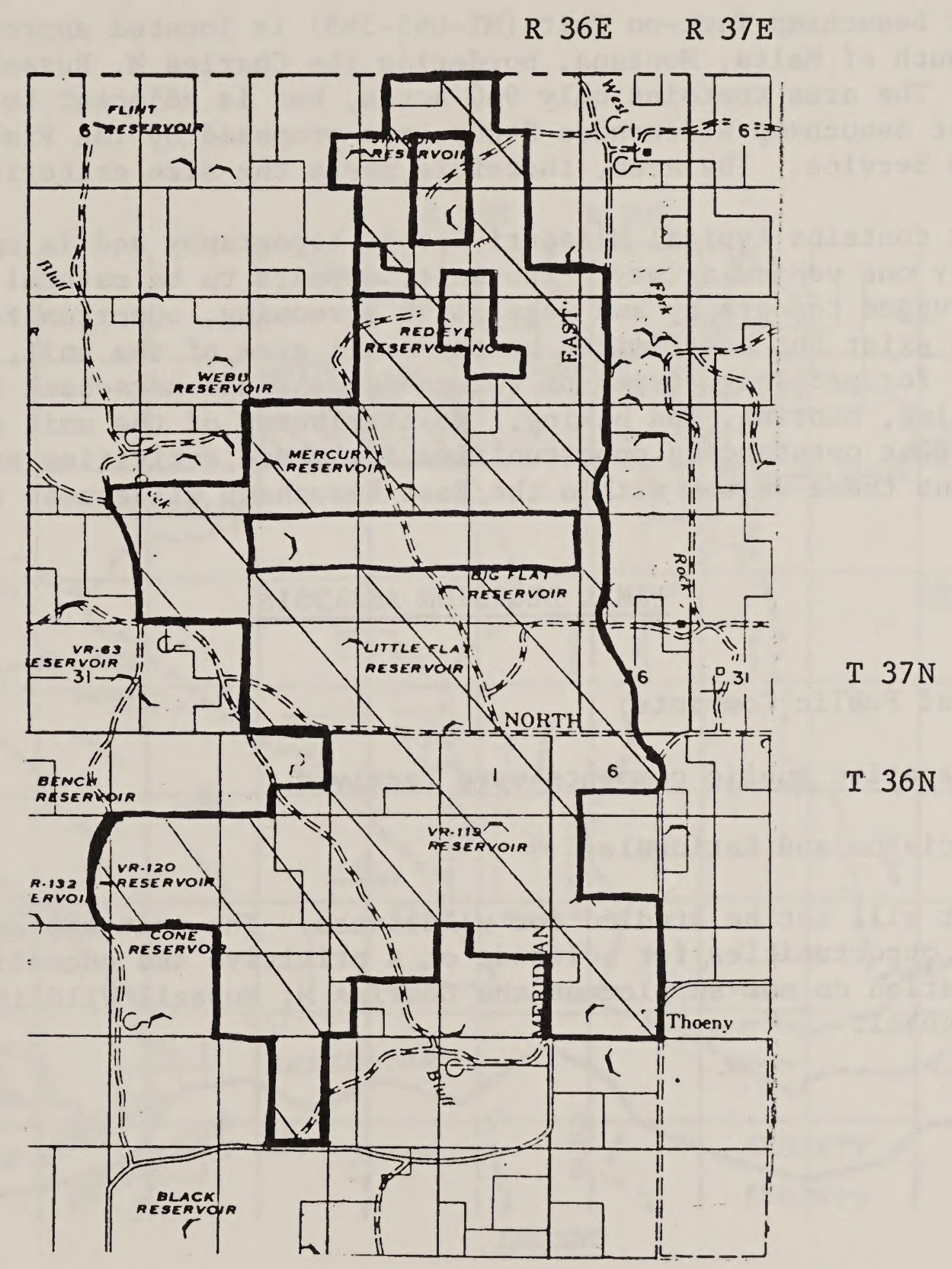

LEGEND

SCALE $1: 126,720$

inch $=1$ mile
MIIV
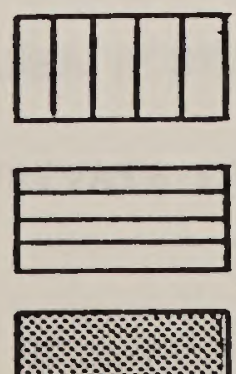

UNIT OR PORTION OF UNIT LACKING WILDERNESS CHARACTERISTICS (NOT RECOMMENDED AS WSA)

AREA DELETED FROM ORIGINAL INVENTORY UNIT DUE TO ROAD IDENTIFICATION

AREA ADDED DUE TO ROAD IDENTIFICATION

PRIVATE OR STATE INHOLDINGS 
UNIT NO.: MT-065-365

UNIT NAME: East Beauchamp

Tack-on

\section{WILDERNESS CHARACTERISTICS NARRATIVE SUMMARY}

The East Beauchamp Tack-on Unit (MT-065-365) is located approximately 50 miles south of Malta, Montana, bordering the Charles M. Russell Wildlife Refuge. The area contains only 960 acres, but is adjacent to the 5,264 acre East Beauchamp Wilderness Study area proposed by the Fish and Wildlife Service. The area, therefore meets the size criteria.

The unit contains typical Missouri Breaks topography and is only intruded by one vehicular way. The unit, appears to be natural. Because of the rugged topography and vegetative screening, opportunities for solitude exist but are limited by the small size of the unit. Opportunities for primitive types of recreation include horseback riding, backpacking, hunting, and hiking. No attributes of the unit are of such quality that outstanding opportunities for these activities exist or supplement these values within the East Beauchamp wilderness study area.

\section{FINAL DECISION ANALYSIS}

Summary of Public Comments:

No substanative public comments were received.

Final Decision and Rationale:

This unit will not be studied for wilderness. The unit appears natural. However, opportunities for solitude or a primitive and unconfined type of recreation do not supplement the Charles M. Russell Wildlife Wilderness proposal. 


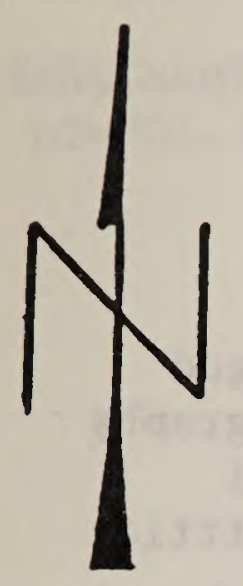

EAST BEAUCHAMP TACK $-\mathrm{ON}$ MT-065-365

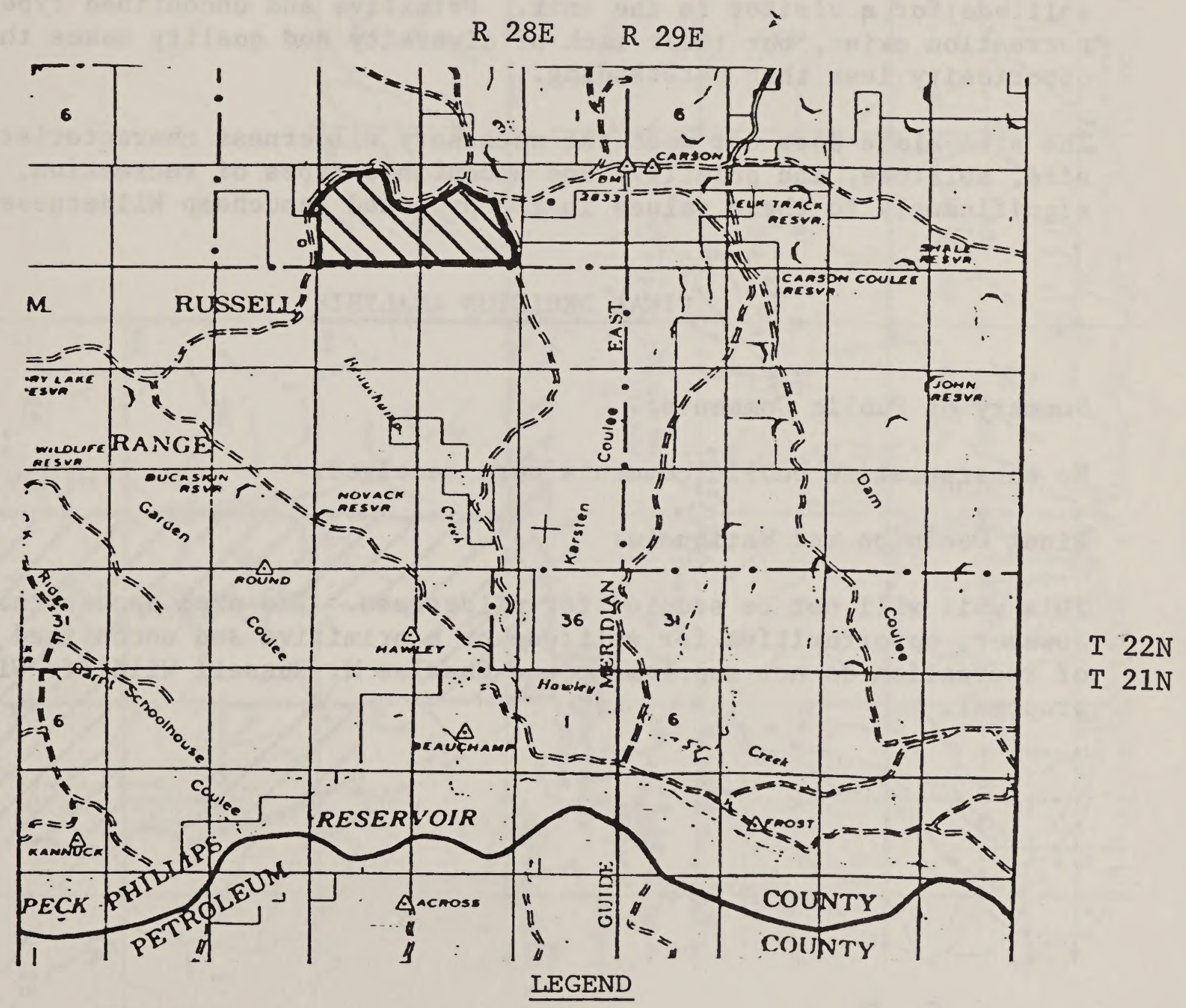

SCALE $1: 126,720$

$\frac{1}{2}$ inch $=1$ mile
UNIT OR PORTION OF UNIT IACKING WILDERNESS CHARACTERISTICS (NOT RECOMMENDED AS WSA)

AREA DELETED FROM ORIGINAL INVENTORY UNIT DUE TO ROAD IDENTIFICATION

AREA ADDED DUE TO ROAD IDENTIFICATION

PRIVATE OR STATE INHOLDINGS 
UNIT NO.: $\quad$ MT-060-366

UNIT NAME: Beachamp Tack-on

\section{WILDERNESS CHARACTERISTIC NARRATIVE SUMMARY}

The 2,680 acre Beachamp Tack-on Unit (MT-060-366) is 60 miles south of Malta and lies adjacent to the proposed Beauchamp Wilderness Area managed by the U.S. Fish and Wildlife Service. The tack-on has a rolling topography formed by drainages that flow to the Missouri River. There are minimal amounts of tall growing vegetation. The lack of screening, provides little solitude for a visitor in the unit. Primitive and unconfined types of recreation exist, but their lack of diversity and quality makes the recreation opportunity less than outstanding.

The area alone does not meet the necessary wilderness characteristics for size, solitude, and primitive and unconfined types of recreation, nor add significantly to these values in the proposed Beauchamp Wilderness Area.

\section{FINAL DECISION ANALYSIS}

Summary of Public Comments:

No substantative public comments were received.

Final Decision and Rationale:

This unit will not be studied for wilderness. The area appears natural. However, opportunities for solitude or a primitive and unconfined type of recreation do not supplement the Charles $M$. Russell Wildlife Wilderness proposal. 


\section{BLM Library}

Denver Federal Center

Bldg. 50, OC-521

P.O. Box 25047

Denver, CO 80225 

